\title{
Renewable energy tax incentives and WTO law: irreconcilably incompatible? : an examination of the WTO-consistency of direct corporate tax incentives for the development of renewable energy
}

Citation for published version (APA):

Ni Ghiollarnath, C. (2011). Renewable energy tax incentives and WTO law: irreconcilably incompatible? : an examination of the WTO-consistency of direct corporate tax incentives for the development of renewable energy. [Doctoral Thesis, Maastricht University]. Wolf Legal Publishers. https://doi.org/10.26481/dis.20110114cn

Document status and date:

Published: 01/01/2011

DOI:

$10.26481 /$ dis.20110114cn

Document Version:

Publisher's PDF, also known as Version of record

Please check the document version of this publication:

- A submitted manuscript is the version of the article upon submission and before peer-review. There can be important differences between the submitted version and the official published version of record. People interested in the research are advised to contact the author for the final version of the publication, or visit the DOI to the publisher's website.

- The final author version and the galley proof are versions of the publication after peer review.

- The final published version features the final layout of the paper including the volume, issue and page numbers.

Link to publication

\footnotetext{
General rights rights.

- You may freely distribute the URL identifying the publication in the public portal. please follow below link for the End User Agreement:

www.umlib.nl/taverne-license

Take down policy

If you believe that this document breaches copyright please contact us at:

repository@maastrichtuniversity.nl

providing details and we will investigate your claim.
}

Copyright and moral rights for the publications made accessible in the public portal are retained by the authors and/or other copyright owners and it is a condition of accessing publications that users recognise and abide by the legal requirements associated with these

- Users may download and print one copy of any publication from the public portal for the purpose of private study or research.

- You may not further distribute the material or use it for any profit-making activity or commercial gain

If the publication is distributed under the terms of Article 25fa of the Dutch Copyright Act, indicated by the "Taverne" license above

Download date: 26 Apr. 2023 
Renewable Energy Tax Incentives and WTO Law:

Irreconcilably Incompatible?

An Examination of the WTO-Consistency of Direct Corporate Tax Incentives for the Development of Renewable Energy 
Renewable Energy Tax Incentives and WTO Law: Irreconcilably Incompatible?

An Examination of the WTO-Consistency of Direct Corporate Tax

Incentives for the Development of Renewable Energy

Carol Ni Ghiollarnáth

ISBN: 978-90-5850-606-1

NUR-code: 826

Wolf Legal Publishers

POB 31051

6503 CB Nijmegen

www.wolfpublishers.nl

Layout by Marina Jodogne. 


\section{Renewable Energy Tax Incentives and WTO Law: Irreconcilably Incompatible?}

An Examination of the WTO-Consistency of Direct Corporate Tax Incentives for the Development of Renewable Energy

\section{DISSERTATION}

to obtain the degree of Doctor

at the Maastricht University,

on the authority of the Rector Magnificus,

Prof. dr. G.P.M.F. Mols

in accordance with the decision of the Board of Deans,

to be defended in public

on Friday the $14^{\text {th }}$ of January 2011, at 14.00 hours

by

Carol Ní Ghiollarnáth 


\section{Supervisors}

Prof. dr. Raymond Luja

Prof. dr. Peter Van den Bossche LL.M.

\section{Assessment Committee}

Prof. dr. R.G. Prokisch (Chairman)

Prof. dr. M.G.W.M. Peeters

Prof. dr. M. Rodi, University of Greifswald 
Do mo mbáthair agus i gcuimbne m'athar.

For my family: the big ones and the little ones who won't be little for long.

Maireann na daoine ar scáil a chéile. 



\section{Acknowledgements}

The publication of this book brings to a close an ambition that was ignited while studying for exams for my bachelor degree in N.U.I. Galway with my friend and paranymph Lisa, back in 2002. The defence of this thesis and the publication of this book are testimony to the idea that the first step in achieving our goals is first to plant the seed.

My sincere thanks go to all those who have contributed to my Maastricht story. Although I will not be able to mention everyone who has touched my life in this time there are a few who must be mentioned.

My supervisors Prof. Raymond Luja and Prof. Peter Van den Bossche have supported my thesis from its very first draft in the form of a proposal to the book as it is today. I want to thank Raymond for being as reliable and steadfast a $\mathrm{PhD}$ supervisor can be. Our never-failing regular up-date meetings supported my research and writing progress greatly. With the help of his interest, contact and support I can proudly say that I set out my plan in 2005 and that it unfolded like the days of the month of our electronic calendars. My PhD schedule ran with clockwork precision from research plan to the submission of the manuscript because of the solid support from Raymond. I want to thank Peter especially for the tough training he put me through which started even before my master programme began in 2003 and since then he has pushed me to strive for the high standards that he sets by his example. The world of international trade law was opened up to me by Peter and his passion and enthusiasm for this area of law was contagious. I wish to thank for the detailed comments that he made on my manuscript and for examining in particular the WTO chapters with a fine-tooth comb.

Prof. Rainer Prokisch and Prof. Ellen Vos deserve a special mention as it is because of them that I came to start to work as a PhD researcher in Maastricht University in the first place. I would like to thank the members of my Assessment Committee, Prof. Rainer Prokisch, Prof. Marjan Peeters and Prof. Michael Rodi for taking the time to read my manuscript and for giving me comments to help improve my book.

A very special 'thanks (for your patience)' goes to my paranymphs, Marcel and Lisa. You, in particular, along with Jona, have borne the brunt of my difficult $\mathrm{PhD}$ times and have been essential to my sanity especially over the last year. Thanks for always having been there to listen and distract me from the dreary moments. Lisa gets an additional big 'thank you' for completely editing my thesis. I could not have wished for a more professional job. Marcel equally gets an additional big 'bedankt for translating my conclusions and summary into Dutch. This was a task I certainly didn't expect to be so swiftly resolved! You can both be sure that if you need someone to hold your book on your day, or any other day, I'll be there for you. Finally regarding 'getting the book ready', I want to thank Marina Jodogne for her flexibility and professionalism in taking care of the layout of the book.

An important word of appreciation goes to the rich group of friends that became my Maastricht family in the last seven years. Being the international bunch (plus a few Dutchies) we rely on each other for the family support that is far away. You know 
who you are and you have made my life in Maastricht a rich and merry one: Anna, Anke, Bram, Eliza, Joakim, Jos, Kees, Marcel, Mariolina, Mélanie, Michal, Mieke, Nadja, Nikos, Roland, Ruta, and Taisce. It is only a pity that many of you have by now moved away.

The home-connection, despite the time and distance, are always on the end of the line: Lisa, Deirdre and Caroline. I always feel that if I were to come back to Galway we would just pick up where we left off seven years ago - although some of us now with partners and kids in tow.

My biggest 'shout-out' goes to my family which has grown considerably since I arrived in Maastricht. It used to be big - Mam, two brothers, Kevin and Pádhraic, two sisters, Susan and Lisa, their wives, husbands, and partners, Clare, Caroline, Frankie, Thomas and Aidan but by now it is even bigger: eight nieces and nephews Caoimhe, Clara, Olivia, Patrick, Lucy, Róisin, Lily, and Thomas (but I wouldn't stop counting yet!). By now my family has grown to include my partner Jona, our two beautiful sons Ira and Eli and Jona's family. It is because of you, all of you, that I have looked forward to the day of my $\mathrm{PhD}$ defence - an excuse to get you all together and to celebrate how special you all are to me. 'Maireann na daoine ar scáil a chéile', to be translated as - 'we live in each other's shadows', or 'no man is an island'.

Jona has been my steady rock for the last few years and I am grateful he came into my life when he did. Our 'road trip' began about the same time as my $\mathrm{PhD}$ journey. Thank you for making my life about a whole lot more than this book. Hopefully now that it is finished we will have even more road trips to discover the world together.

My mother deserves a special and separate paragraph, and really a book just for her (one that would be slightly more entertaining to read). In Irish there is a saying: 'Mol an páiste agus molann tú an mbáthair' to be translated as 'praise the child and you praise the mother'. With this in mind, I want to dedicate this book to my mother and remind her that our achievements, and whatever we her five children contribute to this world, are her achievements by right. Thank you Mam for all you have given me and all of us.

The manuscript of this book was completed in April 2010. Consequently, later developments, including the Panel Report in EC and certain Member States - Large Civil Aircraft dispute, have not been taken into account in this analysis.

Maastricht, 17 August 2010 


\section{Table of Contents}

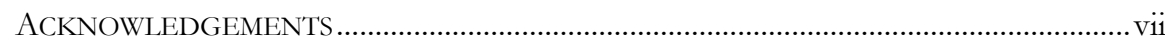

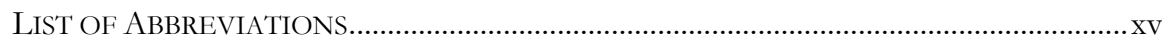

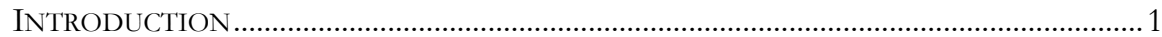

\section{PART I: KYOTO PROTOCOL FRAMEWORK}

CHAPTER 1 : THE KYOTO PROTOCOL TO THE UNFCCC................................................... 7

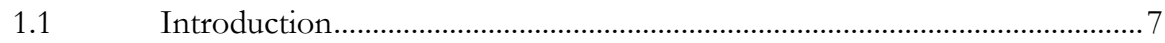

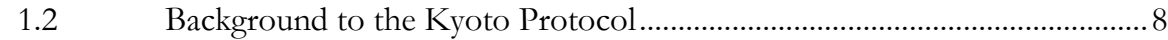

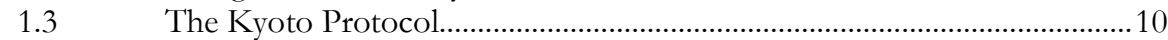

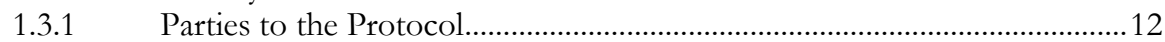

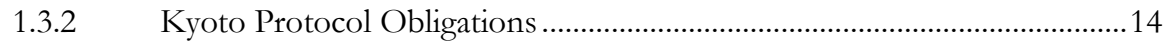

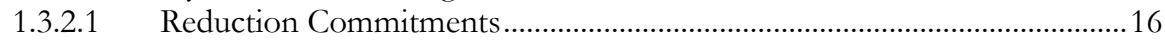

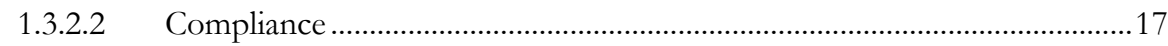

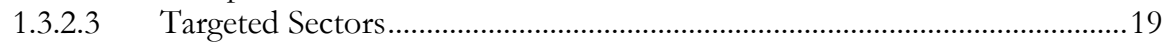

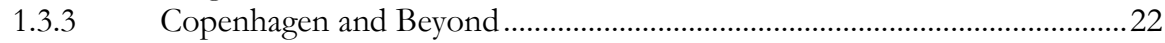

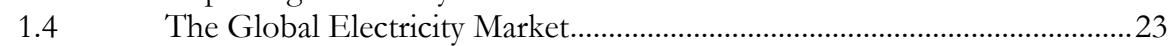

1.4.1 Public Good Nature of Electricity................................................................24

1.4.2 Liberalisation of the Electricity Market.........................................................25

1.4.3 Electricity Liberalisation and the Kyoto Protocol .......................................27

1.4.3.1 Development of Renewable Energy .............................................................2

1.4.3.2 Elimination of Market Imperfections ............................................................2. 28

1.4.3.3 No Adverse International Trade Affects ......................................................28

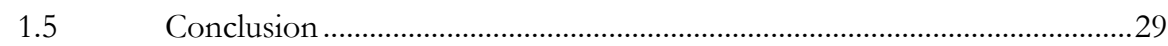

Chapter 2 : Pro-Kyoto Protocol TAX Treatment …………………....................... 31

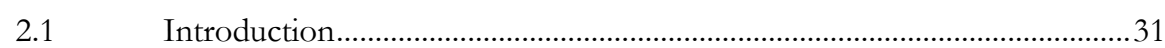

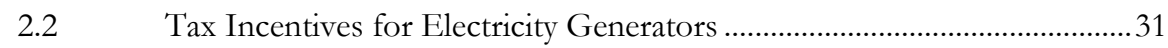

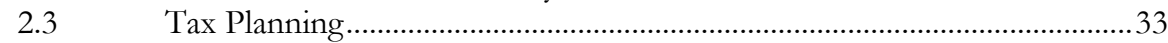

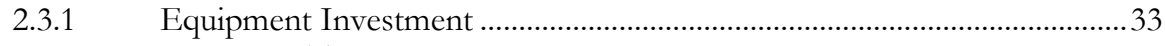

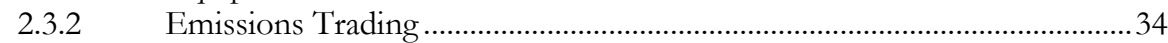

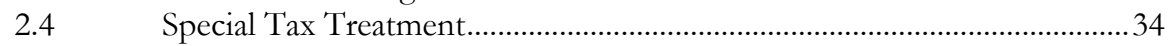

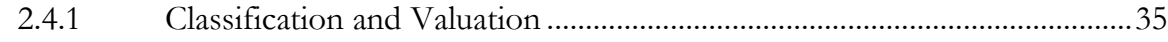

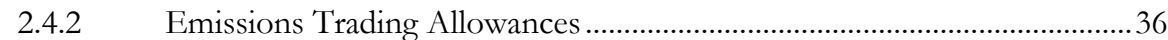

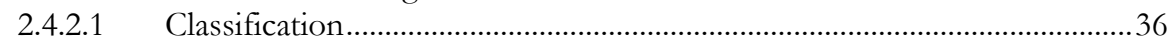

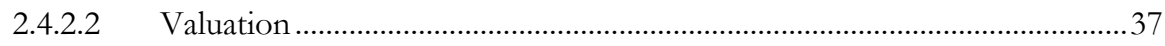

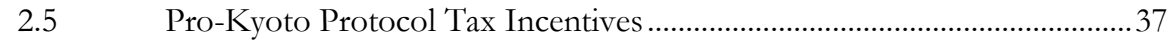

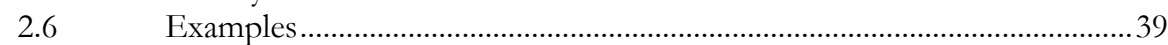

2.7 International Trade Impacts of Tax Incentives .............................................40

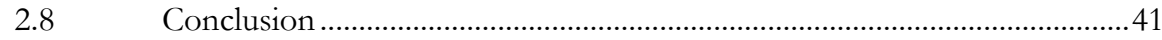




\section{PART II: EUROPEAN REGULATORY FRAMEWORK}

CHAPTER 3 : EU FrAMEWORK - TAX AID FOR RENEWABLE ENERGY ........................ 45

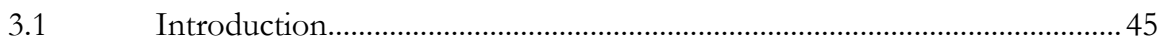

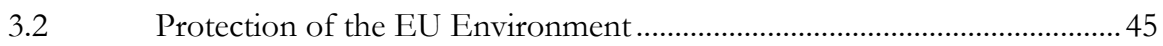

3.2.1 European Taxation and Environmental Protection..................................... 48

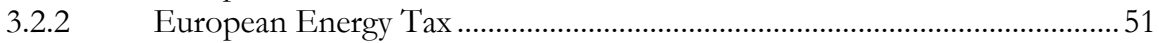

3.2.3 Development of Renewable Energy Resources ............................................ 51

3.2.3.1 Directive on the Promotion of the Use of Energy from Renewable

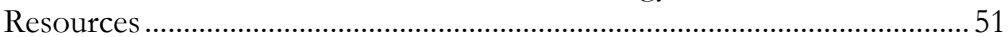

3.2.3.2 EU Support of National Tax Incentives for Renewable Energy .................. 53

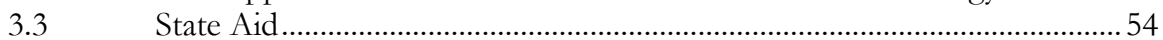

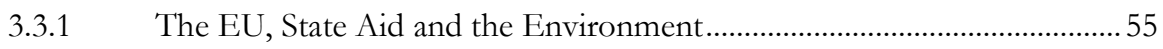

3.3.1.1 2001 Community Guidelines on State Aid for Environmental

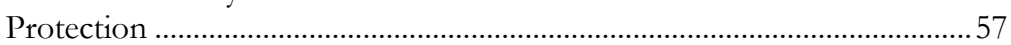

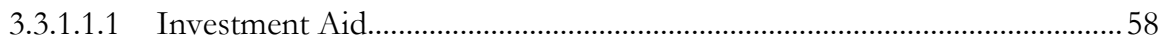

3.3.1.1.2 Operating Aid......................................................................................... 59

3.3.1.1.3 Operating Aid in the Form of Environmental Tax Exemptions/

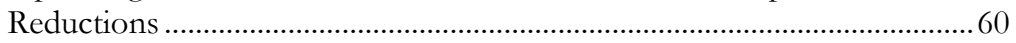

3.3.1.2 Review of the Community Guidelines on State Aid for Environmental

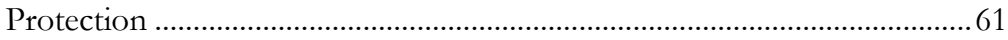

3.3.1.3 2008 Community Guidelines on State Aid for Environmental

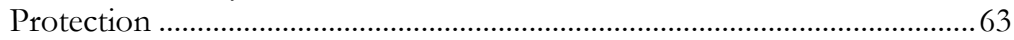

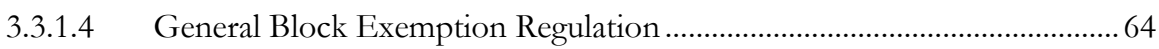

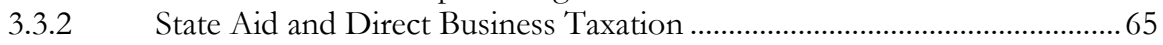

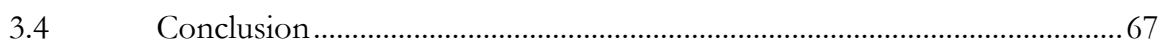

PART III: TAX SUBSIDIES APPLIED IN THE CASE STUDY COUNTRIES. DESCRIPTIVE OUTLINE OF CASE STUDY TAX INCENTIVES

Chapter 4 : TAX SubSidies Applied In EU Member STATES ...................................... 73

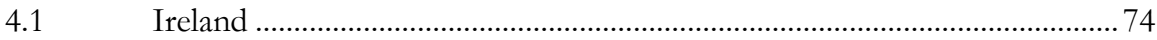

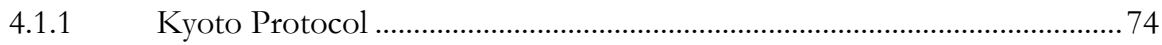

4.1.2 Investment Tax Incentive for Renewable Energy .......................................... 75

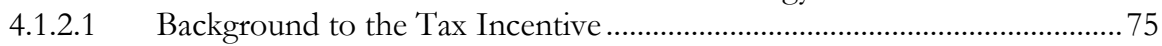

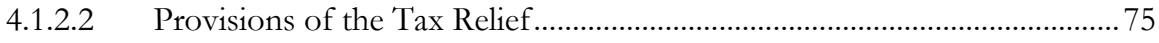

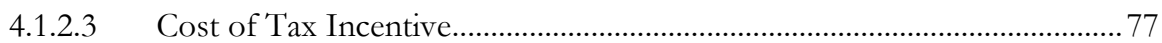

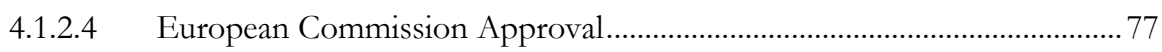

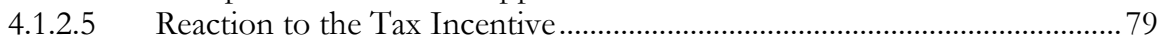

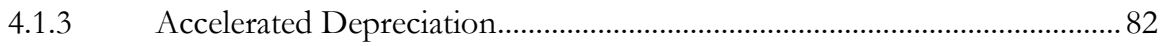

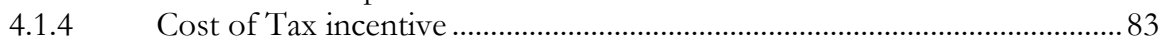

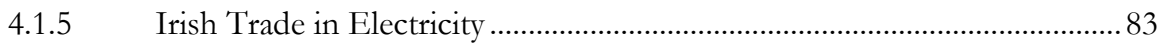

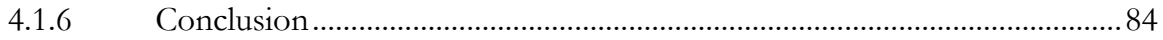

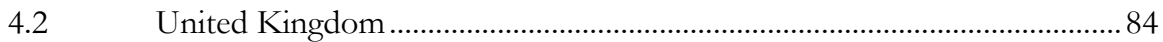

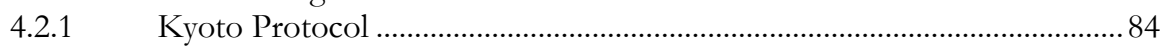

4.2.2 Tax Incentives for Renewable Energy ............................................................ 85 


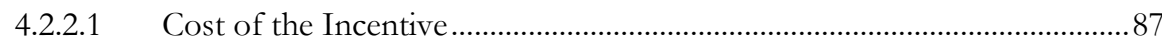

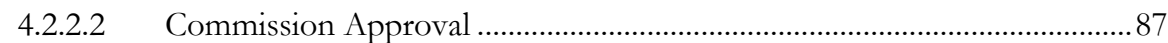

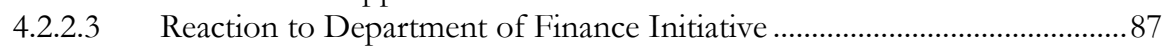

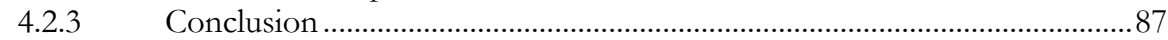

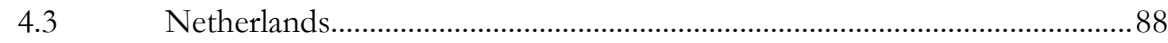

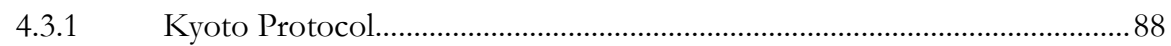

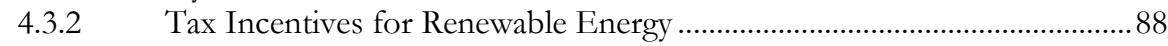

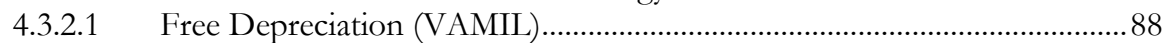

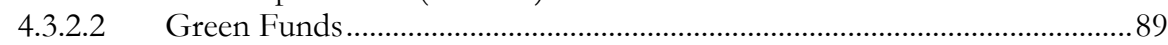

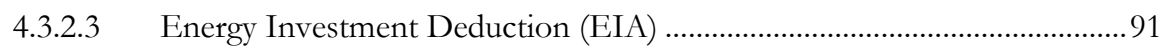

4.3.2.4 Environmental Investment Deduction (MIA) ...............................................93

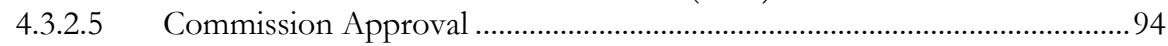

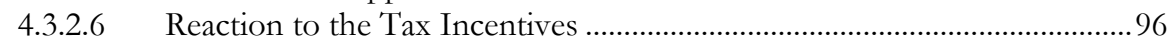

4.3.2.7 Cost of the Incentives .................................................................................. 97

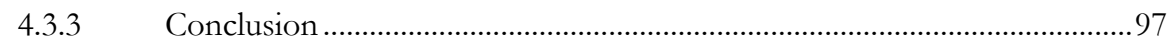

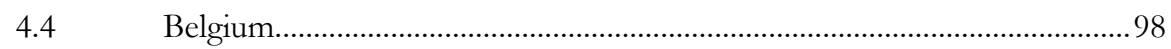

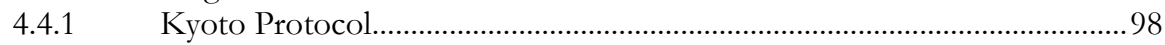

4.4.2 Tax Incentives for Renewable Energy …………............................................99

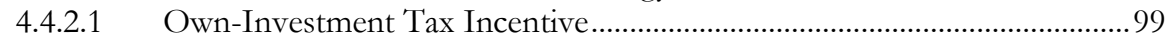

4.4.2.2 Reaction to the Investment Tax Incentive ..................................................100

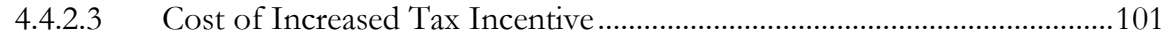

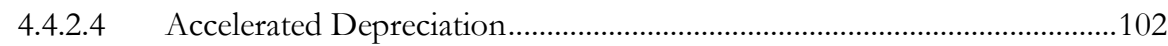

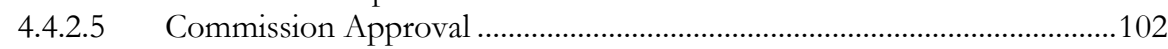

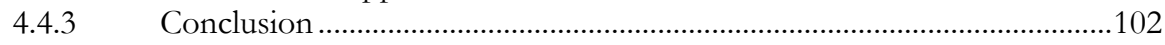

4.5 Comparison of Ireland, Belgium, UK and the Netherlands ......................103

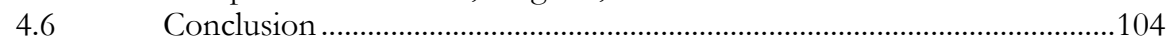

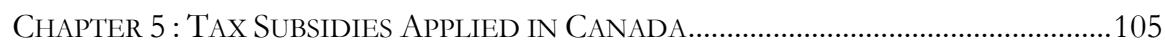

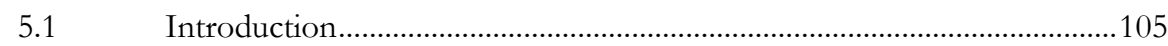

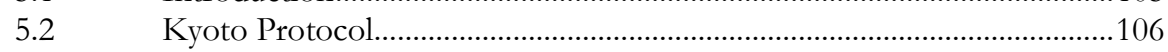

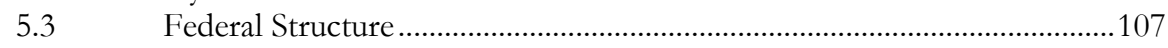

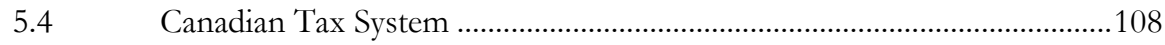

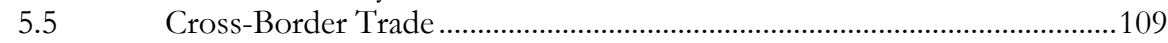

5.6 Renewable Energy Development ...........................................................111

5.7 Federal Tax Incentives for Renewable Energy ...........................................111

5.7.1 Capital Cost Allowance Class 43.1 ................................................................111

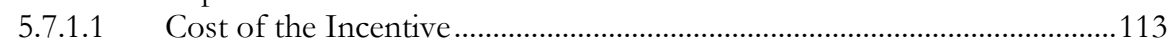

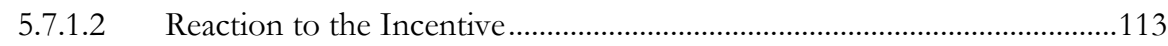

5.7.2 Canadian Renewable and Conservation Expense (CRCE) ........................114

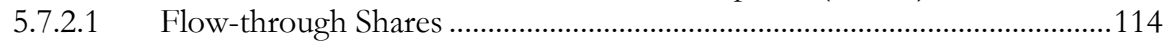

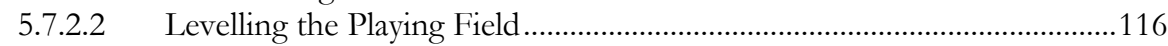

5.7.2.3 Cost of the Incentive .................................................................................117

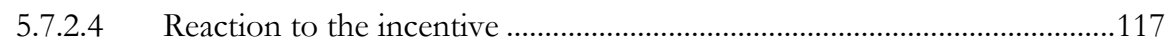

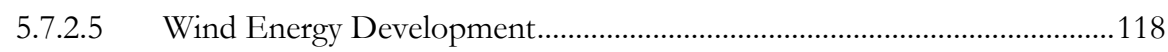

5.8 Provincial Tax incentives for Renewable Energy ......................................118

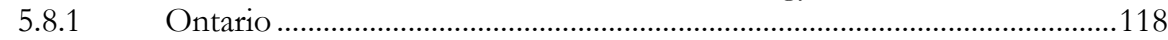

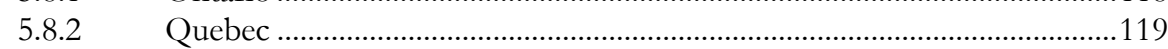

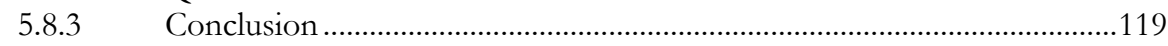


CHAPTER 6 : TAX SUbSIDIES APPLIED IN NEW ZEALAND ...........................................121

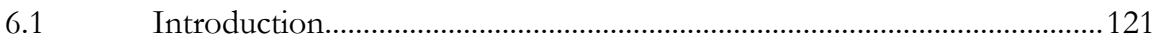

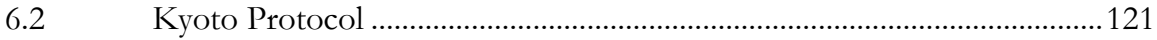

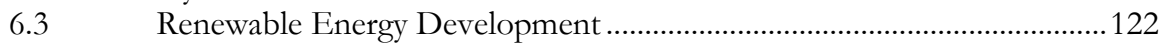

6.4 Subsidy in the Form of Carbon Credits.......................................................124

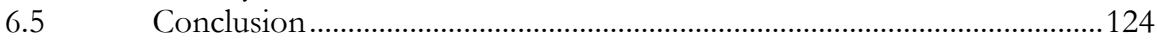

\section{PART IV: WTO IMPLICATIONS OF CASE STUDY TAX INCENTIVES}

\begin{tabular}{|c|c|}
\hline .1 & Introduction.. \\
\hline 2 & 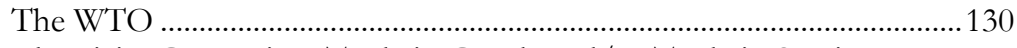 \\
\hline 3 & Electricity Generation: Trade in Goods and/or Trade in Services...........131 \\
\hline 4 & The GATT 1994, Non-Discrimination and Tax Incentives .......................136 \\
\hline 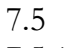 & 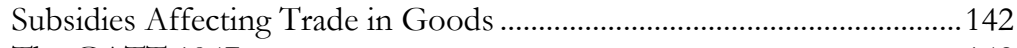 \\
\hline .5 .1 & The GATT 1947 ............................. \\
\hline 5.2 & Tokyo Round Subsidies Code.. \\
\hline 5.3 & 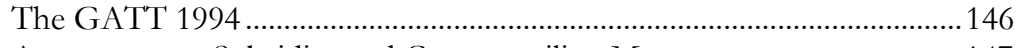 \\
\hline 5.4 & Agreement on Subsidies and Countervailing Measures...............................147 \\
\hline 6 & Conclusion ............... \\
\hline
\end{tabular}

Chapter 8 : CASE STUdy TAX InCENTIVES' Consistency WiTH THE SCM

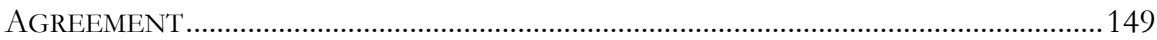

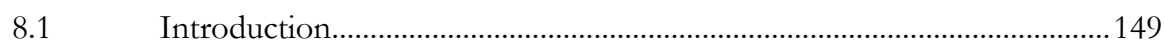

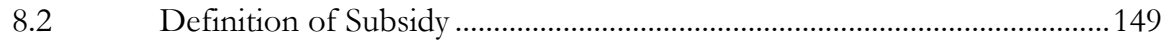

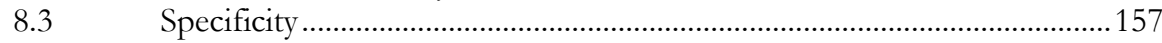

8.4 Case Studies - Accelerated Depreciation Incentive ....................................159

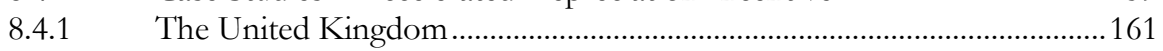

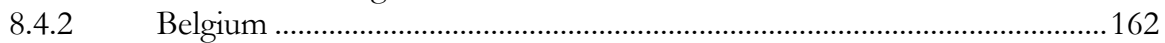

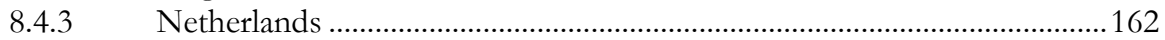

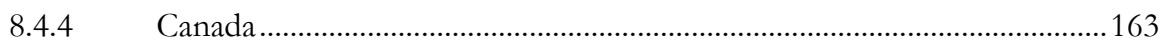

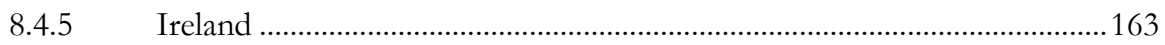

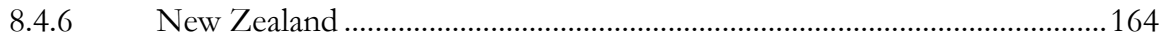

8.5 Accelerated Depreciation Incentive - a Subsidy?...........................................164

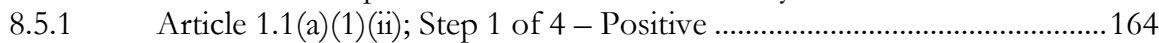

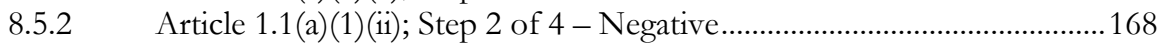

8.5.3 Article 1.1(a)(1)(i); Step 3 of 4 - Positive Again! ........................................... 169

8.5.4 Article 1.1(a)(1)(i); Step 4 of 4 - Negative After All?...................................171

8.6 Accelerated Depreciation Incentive - a Specific Subsidy? ..........................174

8.6.1 De Jure Specificity ..................................................................................178

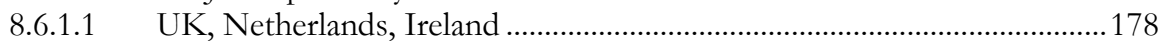

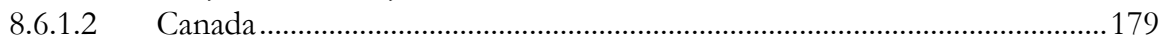

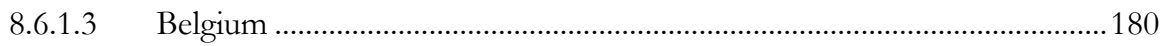

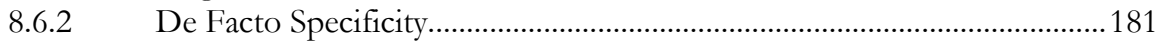

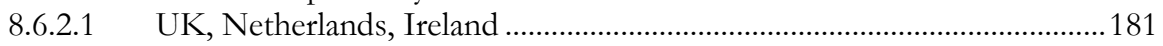

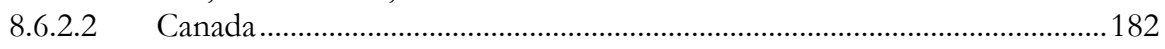

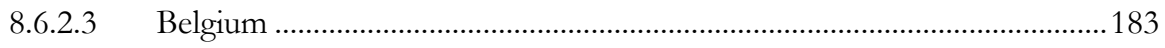


8.7 Accelerated Depreciation Conclusion.......................................................184

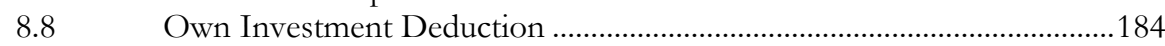

8.8.1 Own Investment Deduction - a Subsidy? .....................................................185

8.8.2 Own Investment Deduction - a Specific Subsidy? .......................................186

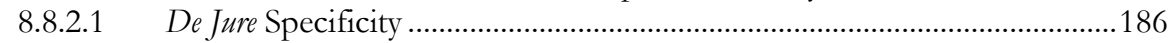

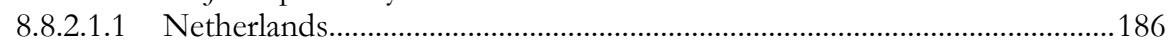

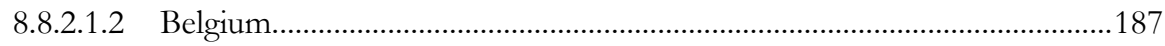

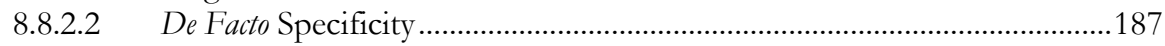

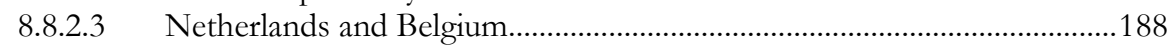

8.8.3 Own Investment Deduction Conclusion.....................................................188

8.9 Third-Party Project Investment Deduction..................................................188

8.9.1 Third-Party-Project Investment Deduction - a Measure Related to Trade in Goods?..............................................................................................189

8.9.2 Third-Party-Project Investment Deduction - a Subsidy?............................190

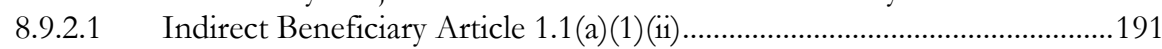

8.9.2.2 Indirect Beneficiary Article 1.1(a)(1)(iv).....................................................195

8.9.2.2.1 Indirect Beneficiary Article 1.1(a)(1)(iv) Financial Contribution...............197

8.9.2.2.2 Indirect Beneficiary Article 1.1(a)(1)(iv) Benefit.........................................198

8.9.2.2.3 Mandatory Versus Discretionary Conferral of a Benefit .............................202

8.9.3 Third-Party-Project Investment Deduction - A Specific Subsidy?..........207

8.9.3.1 Specific to Investors (Ireland, Netherlands, Canada)? .................................208

8.9.3.2 Specific to Investment Funds? ..................................................................208

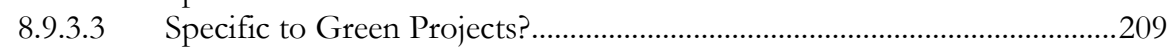

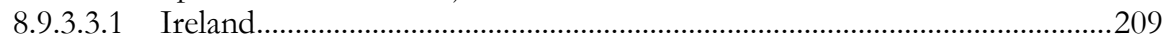

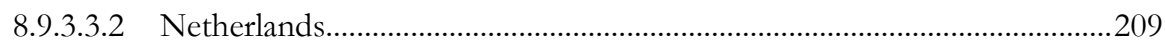

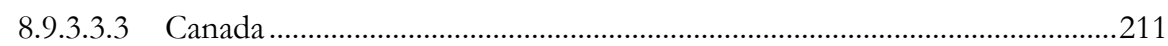

8.9.4 Third-Party-Project Investment Deduction - Conclusion.........................212

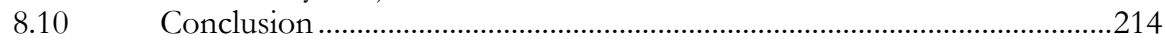

CHAPTER 9 : CASE STUdy SPECIFIC SUBSIDIES WTO-CONSISTENT?...........................215

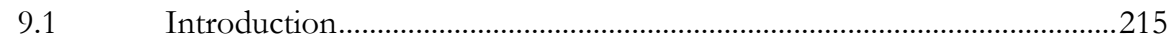

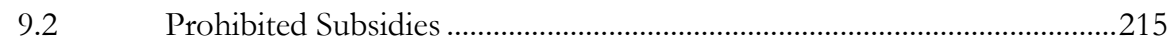

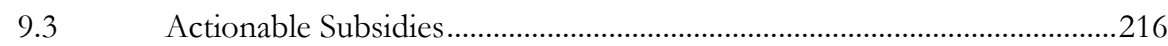

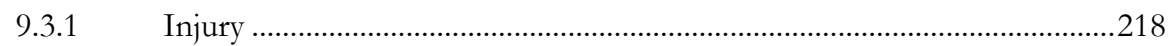

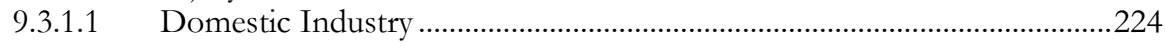

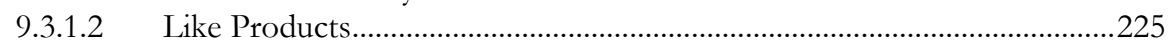

9.3.2 Nullification or Impairment .................................................................226

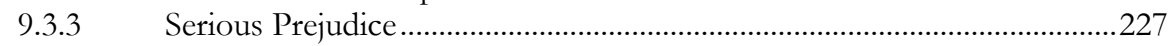

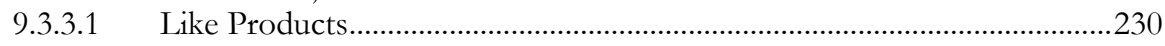

9.3.3.2 (Non-product related) Processes and Production Methods ........................2234

9.4 Adverse Effects on Electricity Market......................................................2238

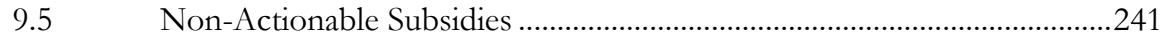

9.6 The SCM Agreement and the Environment ...............................................2. 241

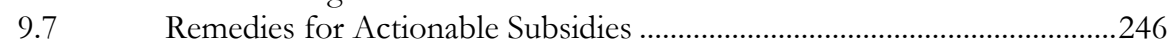

9.8 EU Subsidising Member: Member State or Commission Competence ..248

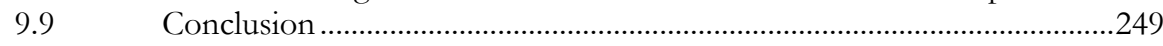




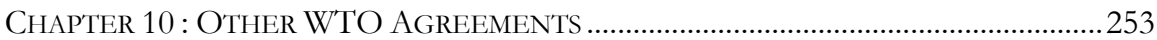

10.1 Subsidies Affecting Trade in Goods .........................................................253

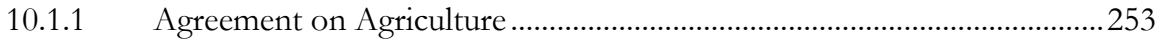

10.1.2 Indirect Agricultural Subsidy …..................................................................253

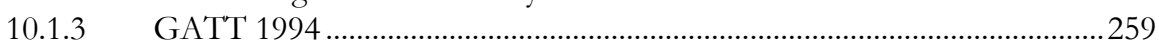

10.1.4 Article XX of the GATT 1994 and the SCM Agreement .........................259

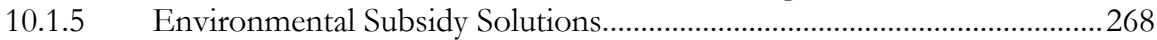

10.1.6 Article 3 of the TRIMs and the SCM Agreement .....................................22

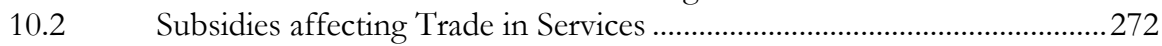

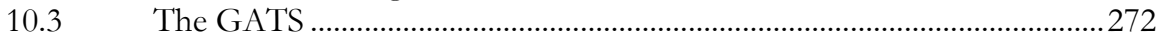

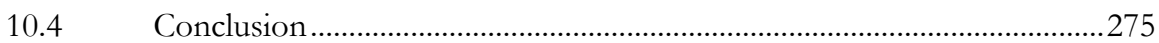

\section{PART V: CONCLUSIONS AND SUMMARY}

CHAPTER 11 : CONCLUSIONS AND SUMMARY

11.1 Kyoto Protocol: Not the Catalyst for the Environmental Tax

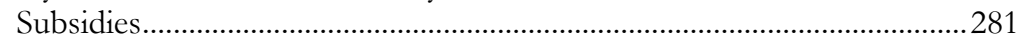

11.2 EU Positive Legal Environment for Environmental Tax Incentives .......282

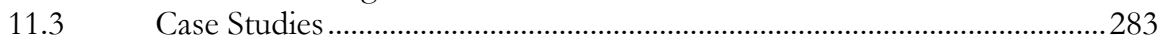

11.4 Subsidy Test for Tax Incentives ...................................................................2 284

11.5 Case Study Tax Incentives - Specific Subsidies within the Meaning

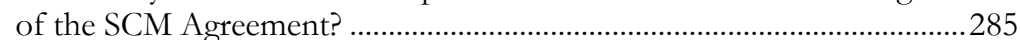

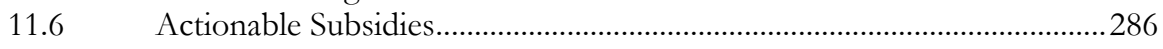

11.7 Positive Environmental Externalities..............................................................2.28

11.8 Environmental Solutions in the SCM Agreement.......................................28

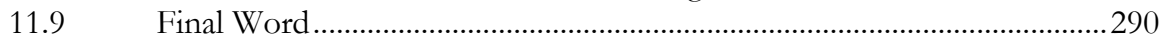

CHAPTER 12 SAMENVATTING EN CONCLUSIES .............................................................229

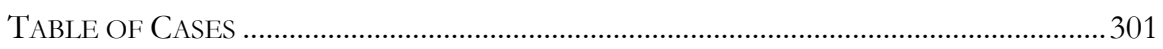

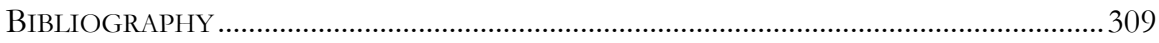

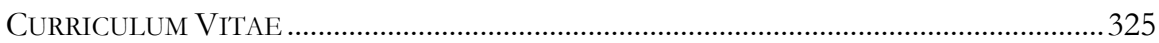




\section{List of Abbreviations}

\begin{tabular}{|c|c|}
\hline A & Accelerated \\
\hline AER & Alternative Energy Requirement \\
\hline ASCM & Agreement on Subsidies and Countervailing Measures \\
\hline $\mathrm{BE}$ & Belgium \\
\hline CA & Canada \\
\hline CCA & Capital Cost Allowance \\
\hline CCAB-I & Consultative Committee of Accountancy Bodies, Ireland \\
\hline ССРC & Canadian Controlled Private Corporation \\
\hline CEE & Canadian Exploration Expense \\
\hline CISG & Contracts for the International Sale of Goods \\
\hline CHP & Combined Heat and Power \\
\hline CRCE & Canadian Renewable and Conservation Expense \\
\hline DG & Directorate-General \\
\hline $\mathrm{DH}$ & District heating \\
\hline DRAM & Dynamic Random Access Memory \\
\hline DSU & Dispute Settlement Understanding \\
\hline $\mathrm{EC}$ & European Community \\
\hline ECJ & European Court of Justice \\
\hline EEC & European Economic Community \\
\hline EIA & Energie-investeringsaftrek (Energy Investment Deduction) \\
\hline $\mathrm{EU}$ & European Union \\
\hline ETCL & Energy Technology Criteria List \\
\hline ETPL & Energy Technology Product List \\
\hline FSC & Foreign Sales Corporation \\
\hline G & General \\
\hline GATT & General Agreement on Tariffs and Trade \\
\hline GATS & General Agreement on Trade in Services \\
\hline HS & Harmonised Commodity Description and Coding System \\
\hline I & Investment deduction \\
\hline IE & Ireland \\
\hline IPCC & Intergovernmental Panel on Climate Change \\
\hline MEA & Multilateral Environmental Agreement \\
\hline MIA & $\begin{array}{l}\text { Milieu-investeringsaftrek (Environmental Investment } \\
\text { Deduction) }\end{array}$ \\
\hline MW & Megawatt \\
\hline NL & The Netherlands \\
\hline NPV & Net Present Value \\
\hline OECD & $\begin{array}{l}\text { Organisation for Economic Co-operation and } \\
\text { Development }\end{array}$ \\
\hline OJ & Official Journal \\
\hline PPM & Processes and Production Methods \\
\hline SCM & Subsidies and Countervailing Measures \\
\hline SME & Small and medium-sized enterprise \\
\hline SPS & Sanitary and Phytosanitary \\
\hline $\mathrm{T}$ & Time \\
\hline TBT & Technical Barriers to Trade \\
\hline TCA & Tax Collection Agreement \\
\hline
\end{tabular}


TD

TEC

TEU

TFEU

TRIMs

TRIPs

UK

UN

UNEP

UNFCCC

US

USA

VAMIL

VROM

WIB

WMO

WTO
Teachta Dála (Deputy to the Dáil)

Treaty establishing the European Community

Treaty on European Union

Treaty on the Functioning of the European Union

Trade-Related Investment Measures

Trade-Related Aspects of Intellectual Property Rights

United Kingdom

United Nations

United Nations Environment Programme

United Nations Framework Convention on Climate

Change

United States

United States of America

Willekeurige Afschrijving Milieu-investeringen (voluntary

depreciation on environmental investment

Ministerie van Volkshuisvesting, Ruimtelijke Ordening en

Milieubeheer (Ministry of Housing, Spatial Planning and the Environment)

Wet op de Inkomstenbelasting (Income Tax Code)

World Meteorological Organization

World Trade Organization 


\section{Introduction}

Environmental, tax and trade policies are often developed and implemented independently of each other. However, the intertwining and overlap between these policies, as well as their interdependence, may give rise to tensions and conflict. Tax measures in pursuit of environmental protection may be inconsistent with international trade policy objectives and international trade law obligations. International trade law may not provide sufficient 'wriggle-room' for States to pursue tax measures for environmental protection within the limits of the WTO Agreements. This thesis examines the tenuous relationship between environmental protection, tax and trade.

At the outset of the research for this thesis, the Kyoto Protocol was an appropriate context within which to examine these intertwining issues of environmental protection, tax and trade. The Kyoto Protocol was ratified just prior to the commencement of the research for this thesis and called for efforts in the development of national measures to support the increased use of renewable energy resources. The Kyoto Protocol required ratifying States to implement national measures in pursuit of the Kyoto Protocol objectives in a manner which minimises adverse effects on international trade. The Kyoto Protocol also addressed tax measures by specifically addressing the reduction of and withdrawal of tax incentives provided to greenhouse gas-emitting sectors. Rather than examine the trade effects of the withdrawal of environmentally harmful subsidies, this thesis concentrates on the introduction of comparable tax incentives in pursuit of the goal of developing and increasing the use of renewable resources. The application of comparable incentive measures for the development of renewable energy could potentially address the creation of a level playing field between renewable energy resources and previously subsidised greenhouse gas-emitting energy resources.

Direct tax incentives for the development of renewable energy are the measures of choice for this examination. At the time the Kyoto Protocol was ratified, and even still today, discourse addressing tax policies for environmental protection concentrates on indirect tax measures (for example carbon taxes or energy taxes). Therefore, it was appropriate for the purpose of innovative research, to direct the focus of the research for this thesis rather to direct tax incentives as a tool for fulfilling the Kyoto Protocol goal of developing renewable energy.

The Kyoto Protocol and national tax law apply not in a vacuum, but side by side with an existing body of international law. Conflict arises when, in pursuit of objectives of one international agreement, (in this case by introducing national direct tax incentives), a State infringes its obligations under another body of law. In this thesis the tensions between and the conflicts deriving from the pursuit of the Kyoto Protocol aim of developing renewable energy resources by recourse to national tax policy with international trade law obligations are investigated.

Subsidies in the form of tax incentives are and have been a popular policy choice of governments in providing financial support and for this reason are explicitly mentioned in the Kyoto Protocol. Although tax incentives provided to renewable energy resources can have positive results in light of Kyoto Protocol obligations, the 
provision of such incentives is not without restrictions. Providing tax incentives to the electricity generation industry, be it in support of existing greenhouse gasemitting sectors or to promote the development of renewable energy resources, creates tensions with other international law obligations. It is not within the scope of this research to determine the effectiveness of the role tax incentives play in achieving Kyoto Protocol objectives, but rather to investigate the consistency of those measures with international trade law. This research examines whether direct tax incentives are currently in place to play a role in changing the balance of fuel inputs in the electricity generation sector and whether those tax incentives are WTOconsistent.

International trade law regulates the provision of subsidies related to the trade of goods in the General Agreement on Tariffs and Trade 1994 (hereinafter the 'GATT 1994'), in the Agreement on Subsidies and Countervailing Measures (hereinafter the 'SCM Agreement') and - to the extent trade in agricultural products are concerned - the Agreement on Agriculture. The rules on the provision of subsidies related to trade in services are set out in the General Agreement in Trade in Services (hereinafter the GATS). The Kyoto Protocol-ratifying States, which are also Members of the WTO, are obliged to ensure that Kyoto Protocol policies, including tax incentives, are consistent with the WTO Agreements. The Kyoto Protocol recognises that the obligations it imposes may have external effects which result in inconsistencies with other spheres of law. The Kyoto Protocol therefore requires that ratifying States implement policies so as to minimise adverse effects, including effects on international trade.

Not all WTO Members have ratified the Kyoto Protocol and thus not all WTO Members have binding reduction commitments ensuing from the Kyoto Protocol. The United States, for example, a WTO Member and Annex I country, having signed the Kyoto Protocol in 1998 did not subsequently ratify it. Therefore, the United States is not subject to the same obligations with respect to greenhouse gas emission reductions as the ratifying States; for example the Member States of the EU, Canada, or New Zealand. This heightens the tensions between the use of tax incentives in the pursuit of Kyoto Protocol obligations and the potential for those measures to be challenged as being WTO-inconsistent. International trade disputes arising from the provision of tax incentives by Kyoto Protocol-ratifying States are liable to be brought by non-Kyoto Protocol-ratifying States before WTO panels and the Appellate Body. Non-Kyoto Protocol-ratifying States importing subsidised renewable electricity from Kyoto Protocol-ratifying States may allege that the subsidies are inconsistent with the provisions of the WTO Agreements, in particular the SCM Agreement.

At present there is no environmental exception or justification embodied in the SCM Agreement to provide a safety net for environmentally motivated subsidies. Without an exception being available to justify environmental subsidies, these measures are in particular danger of being deemed WTO-inconsistent. The lack of an environmental safety net available to environmentally-motivated subsidies within the WTO legal regime is a serious lacuna which will be addressed in detail in this thesis.

Part I of this thesis provides a general, historical and legal framework of the Kyoto Protocol, from which point the examination of the development of pro-Kyoto Protocol policy in the case study countries departs. To this end, Chapter 1 introduces 
the Kyoto Protocol, its history and objectives, paying particular attention to the electricity generation industry and its development. Chapter 2 addresses the types of tax incentives which may be provided to the electricity generation industry in pursuit of the Kyoto Protocol objective of developing renewable energy resources.

Part II of this thesis, as a prelude to the investigation of the tax incentives for the development of renewable energy in the EU case study countries, addresses the EU regulatory framework within which these policies are developed, in particular EU State aid regulation.

Part III specifically examines the tax incentives actually provided to (renewable energy) electricity generators in the case study countries. This section provides an examination of the background to, and the development of, the tax incentives addressing renewable energy generation, as well as the overlap of these measures with the Kyoto Protocol reduction commitments. In the EU case study countries, the compatibility of the tax incentives for the development of renewable energy in place in the case study countries with EU State aid rules is also explored.

As case study countries, four EU Member States: Ireland, the United Kingdom, Belgium and the Netherlands, as well as two non-EU countries: Canada and New Zealand were chosen. The choice of case study countries was motivated by the starting point of this thesis - the national obligations arising out of the ratification of the Kyoto Protocol. For this reason the choice of case study countries was limited to countries that were Annex I countries subject to the legal obligation to reduce carbon emissions and which had (at that time) ratified the Kyoto Protocol. The choice was also limited by language constraints (English, French and Dutch). From these considerations the following EU Member States: Ireland, the United Kingdom, Belgium and the Netherlands, were chosen. Considering that the focus of the research was to rest on the examination of the consistency of the tax incentives with WTO rules on subsidies, it was decided that the determining factor (in addition to language constraints) in the choice of non-EU case study countries would rest on the neighbouring countries and trading partners of the most important non-Kyoto Protocol-ratifying States, the USA and Australia; namely Canada and New Zealand. The choice of case study countries also provided a broad geographical coverage, comprising three continents from Europe, to North America and Oceania.

Part IV examines the WTO legal framework, which provides rules on subsidies, and analyses the WTO-consistency of the case study tax incentives to answer the question whether these tax incentives are indeed WTO-consistent or not. In this part the lack of an environmental safety net in the SCM Agreement creates tension between environmental protection through environmental subsidies and the WTO rules on subsidies.

Finally, Part V summarises the main findings, provides conclusions and proffers proposals for change. 

Part I: Kyoto Protocol Framework 



\section{Chapter 1 : The Kyoto Protocol to the UNFCCC}

\subsection{INTRODUCTION}

Climate change is a natural phenomenon of changing atmospheric conditions on the planet over time. Global warming, a specific phenomenon of climate change induced by human action rather than natural processes, poses a significant threat to the future of the planet. Being a manmade problem, manmade solutions are sought to solve, or at least slow down, the hazardous effects of climate change on the planet.

Global warming, often generally described as 'climate change', refers to a gradual rise in the temperature of the earth's surface caused by an increase of greenhouse gases emitted into the atmosphere. An ever-growing industrialised world is a leading cause of the change to the global climate. The continuous burning of fossil fuels to power this industrialisation, and the greenhouse gases resulting from this fuel consumption, are the primary factors of climate change. Greenhouse gases, although in natural quantities necessary for life on earth, cause an increase in the overall temperature of the planet when quantities become excessive. Greenhouse gases are important in the atmosphere as a balance of carbon dioxide is essential so that the surface of the earth can remain at a temperature suitable to sustain life. ${ }^{1}$ However, as the balance of these greenhouse gases changes, due to an increase in industrialisation, there is a gradual heating of the earth's surface, also called climate change.

Some of the problems posed by climate change, and the gradual increase of the earth's temperature, include changing climatic zones, ${ }^{2}$ melting icecaps resulting in higher water levels - in time perhaps submersing seaside developments in water and the extinction of certain plants and animals not equipped to cope with the change in conditions. An overall change in temperature also requires changes to agricultural practices, which, in turn, affects the food chain. The extent of the hazards posed by climate change, although not absolutely certain, are not insignificant and therefore solutions have been and are still being sought. Despite an ever-existing level of uncertainty, there is international consensus that climate change is a real problem. ${ }^{3}$

As the emissions of greenhouse gases, which cause the temperature change on the earth's surface and thus climate change, are not limited only to affecting the territory of their emitting country, but rather indiscriminately spread over borders, transboundary action is required to tackle such a global problem. ${ }^{4}$ An improved atmosphere in the future resulting in less negative externalities from the growth of industrialisation and therefore an increase in social welfare will create a somewhat fictitious public good, namely an atmosphere free from the threat of climate change. ${ }^{5}$ Since public goods are non-excludable, the inherent benefits of an improved atmosphere shall be enjoyed by inactive countries to the same extent as countries having taken measures to combat climate change. It is for this reason that this trans-

Cameron 2000, p. 4.

Ibid.

Ibid.

Ibid., p. 17.

Woerdman 2002, p. 8. 
boundary problem should be tackled by as many countries as possible in order to avoid the free-rider problem and have the costs of achieving a cleaner atmosphere justly distributed. ${ }^{6}$ The cost of reversing, stopping or at least slowing down the effects of climate change are so extensive, to the level of being indeterminable, that not only one or even a few States must undertake this duty and responsibility on behalf of the planet, but action should be undertaken by all affected.

Climate change is now one of the major concerns regarding environmental protection being addressed at the international round table. International agreements concerning environmental protection have been gradually developed on a multilateral basis recognising the importance of the trans-boundary nature of environmental problems. This progress in international law has resulted in a multilateral environmental agreement specifically addressing the problem of climate change - the Kyoto Protocol to the United Nations Framework Convention on Climate Change.

As far back as 1972, protection of the environment became an issue to be addressed specifically within the United Nations (hereinafter UN). ${ }^{7}$ As a result of the UN Conference on the Human Environment in Stockholm in 1972, in which it was recommended that a UN Environmental Organisation be created, the United Nations Environment Programme (hereinafter UNEP) was later established by the UN General Assembly and the international commitment to the protection of the environment commenced. ${ }^{8}$

Within the UNEP, the specific issue of climate change was not initially targeted. Rather, in reaction to the discovery of the hole in the ozone layer in Antarctica in 1985, the most pressing concern relating to the environment was identified as the depletion of the ozone layer and was thus the primary concern. ${ }^{9}$ In that same year, the Vienna Convention on the Protection of the Ozone Layer was signed and an international agreement was made to make efforts to protect the environment by reducing the detrimental effects of human activities on the ozone layer. ${ }^{10}$ Furthermore, in September 1987, the Montreal Protocol was agreed upon in which schedules of commitments to reduce emissions of substances depleting the ozone layer were set. ${ }^{11}$

\section{Ibid.}

See also: Bradbrook 2001, p. 56.

See: $\quad<$ http://www.unep.org/Documents.Multilingual $/$ default.asp?documentid= 97\&l=en>; <http://www.unep.org/Documents.Multilingual/Default.asp? Document $\mathrm{ID}=43 \&$ ArticleID $=3301 \& \mathrm{l}=\mathrm{en}>$; $\quad<\mathrm{http}: / /$ www.unep.org/Documents.Multilingual/ Default.asp?7\&ArticleID=1493\&l=en>; last visited 23 November 2009.

9 <http://ozone.unep.org/Publications/MP_Handbook/>; last visited 23 November 2009.

10 <http://ozone.unep.org/Publications/VC_Handbook/index.shtml>; last visited 23 November 2009.

11 <http://ozone.unep.org/Publications/MP_Handbook/>; last visited 23 November 2009. 
Realising that the dangers posed to the environment run deeper than merely addressing the depletion of the ozone layer, a broader problem of climate change was also recognised in the late 1980s. In 1988, the Intergovernmental Panel on Climate Change (hereinafter IPCC) was established by the World Meteorological Organization (hereinafter WMO) and the UNEP. ${ }^{12}$ This Panel consisted of a group of international experts charged with investigating the effects of climate change on the environment and providing regular reports on the status of knowledge on climate change. ${ }^{13}$ In 1990, the IPCC produced its first report outlining the scientific, technical and socio-economic issues related to climate change. Due to this report, an initiative within the General Assembly of the UN established an International Negotiating Committee for a UN Framework Convention on Climate Change, resulting in the United Nations Framework Convention on Climate Change (hereinafter UNFCCC) being adopted in May 1992, at the 'Earth Summit' in Rio de Janeiro. It was subsequently open for signature at the UN Headquarters in New York. ${ }^{14}$ This Convention set out, in broad terms, the efforts to be made internationally to combat climate change. The UNFCCC, as is clear from its title, is a framework convention. Negotiations resulting in the finalisation of the Convention were so difficult that the only feasible option was to follow the model of the Montreal Protocol in its development. ${ }^{15} \mathrm{It}$ is therefore the case that the Convention, far from prescribing specific or targeted requirements or obligations, rather provides broad and general guidelines.

Despite some actions taken in the 1970s and again with the UNFCCC in the 1990s, and despite the explicit agreement in Article 4 of the UNFCCC by the signatories to adopt national measures to achieve greenhouse gas emissions equal to 1990 levels within ten years, no real efforts were made. ${ }^{16}$ Only Germany and the UK took some action at that time. However, this action would perhaps have come about regardless of the UNFCCC since it could be argued that developments and changes were mainly due to the collapse of the coal industry in the UK and the integration of the former East and West Germany and the subsequent cleaning of operations previously allowed in the East. ${ }^{17}$ In fact, between 1990 and 1995 there was an overall increase in carbon dioxide emissions of $12 \%$. This increase was mainly due to the vast industrial development of 30\% experienced in the Asia Pacific region and Japan. ${ }^{18}$ Therefore, it became clear after some time that the UNFCCC was not the ultimate step along the path of combating climate change in a real way. Without legally binding obligations, the intentions of the parties were not becoming a reality.

\footnotetext{
$12<$ http://www.unep.org/Documents.Multilingual/Default.asp?DocumentID=43\& ArticleID=206\&l=en>; <http://www.ipcc.ch/ >; last visited 23 November 2009. $<$ http://www.ipcc.ch/>; last visited 23 November 2009.

$<$ http://unfccc.int/resource/docs/convkp/conveng.pdf; > $<$ http://unfccc.int/ essential_background/convention/status_of_ratification/items/2631.php>; $<$ http://unfccc.int/files/essential_background/convention/status_of_ratification/app lication/pdf/unfccc_ratification_20091016.pdf>; last visited 23 November 2009. Richardson 1998, p. 250. Bradbrook 2001, p. 56. Ibid., p. 56. Richardson 1998, p. 251.
} 
The greatest legislative leap after the adoption of the UNFCCC was the negotiation of the Kyoto Protocol: a protocol to the UNFCCC. The UNFCCC, having been seen as a set of overall broad obligations, was set to be improved by the negotiation of the Kyoto Protocol. ${ }^{19}$ The second report of the IPCC in 1995 claimed that, based on scientific evidence, it was clear that there is a 'discernable human influence on global climate'. ${ }^{20}$ It was time to increase the stakes if this momentum of 'human influence' was to be curbed. In December 1997, over 160 nations negotiated for over 11 days addressing the broad objectives of the UNFCCC and aiming to translate those objectives into a legally binding international agreement. ${ }^{21}$ The result was the Kyoto Protocol.

In order for the Kyoto Protocol to come into force and its legally binding effect to be of any consequence, ratification by a threshold of 55 countries representing $55 \%$ of the total carbon dioxide emissions in 1990 was required. This threshold was reached in February 2005, following the ratification of the Protocol by Russia in November 2004. The failure of the USA and Australia (at that time) to ratify the Protocol did not prevent its conclusion despite fears of this occurring. ${ }^{22}$ It was uncertain that without ratification by the USA, since it has the highest global levels of greenhouse gas emissions in the world, that successful implementation of the Kyoto Protocol would be possible. ${ }^{23}$ The failure of the USA to ratify the Protocol, and the subsequent success of ratification of the Protocol despite this, is somewhat ironic since the USA was the first developed country to ratify the UNFCCC in $1992 .{ }^{24}$ Seven years of heated negotiations finally saw the Kyoto Protocol come into force, creating legally binding obligations for its ratifying States to reduce their greenhouse gas emissions below 1990 levels by 2012 .

\subsection{THE KYoto PROTOCOL}

The Kyoto Protocol is an international treaty on climate change which is the result of seven years of negotiation between 162 countries. The Kyoto Protocol is a legally binding instrument which makes it a landmark international environmental agreement. Legally binding commitments by the ratifying States to reduce their levels of greenhouse gas emissions are set in the Kyoto Protocol and to be complied with by 2012. The Kyoto Protocol addresses all the greenhouse gases that were not targeted by the Montreal Protocol. ${ }^{25}$ In terms of climate change, this is important as the gases targeted here ${ }^{26}$ have particular radiative effects and remain in the atmosphere for a considerable time and have detrimental effects on the global climate resulting in greatly increased temperatures. ${ }^{27}$

Ibid., p. 250.

IPCC Second Assessment Report 1995; Cameron 2000, p. 3.

See Woerdman 2002.

Cameron 2000, p. 11.

Ibid., p. 11.

Ibid.

Richardson 1998, p. 253.

Annex A 6 gases.

Richardson 1998, p. 253. 
The Kyoto Protocol, being a Protocol to the UNFCCC, was originally adopted on 11 December 1997 and was open to signature of all the parties to that Convention in the UN Headquarters in New York between 16 March 1998 to 15 March 1999, at which point 84 countries had signed the Protocol: subject to ratification, acceptance, approval or accession. This signature, subject to ratification, acceptance, approval or accession, signifies that the Parties only agreed to be committed to the treaty-making process rather than being, at this stage, bound by its contents. ${ }^{28}$ Furthermore, the possibility to become a party to the Protocol was not limited to those countries that had signed by 15 March, 1999. Accession was possible at anytime.

Since the Kyoto Protocol was subject to ratification, acceptance, approval or accession, the legal obligations of the parties were not activated by mere signature of the Protocol but required further action. Ratification of the Protocol creates a legal obligation of the ratifying country to be bound by the terms of the Treaty. ${ }^{29}$ Acceptance and approval are terms that also bind the parties to the legal obligations created by the Protocol. ${ }^{30}$ The difference in terms used may be due to the need or lack thereof of a party to the Protocol, under national constitutional law, to have the Protocol ratified by its head of State. Finally, accession to the Protocol, also creating legal obligations for the parties, may generally only occur after the Treaty has already come into force. ${ }^{31}$

Despite this additional obligation of ratification, acceptance, approval or accession, after the signing of the Protocol, a further threshold was imposed before the Kyoto Protocol would could into force. Article 25 of the Kyoto Protocol specifies that the Protocol will only come into force:

... on the ninetieth day after the date on which not less than 55 Parties to the Convention, incorporating Parties included in Annex I which accounted in total for at least 55 per cent of the total carbon dioxide emissions for 1990 of the Parties included in Annex I, have deposited their instruments of ratification, acceptance, approval or accession.

Two elements were to be achieved to fulfil this threshold. First, a minimum of 55 States were required to undertake the obligation to be bound by the legal requirements created by the Kyoto Protocol, and second, this minimum number of States had to include Annex I States, being developed nations, which were responsible for $55 \%$ of the carbon dioxide emissions of the base year, 1990. This threshold took from December 1997, the adoption of the Protocol, until February 2005 to be achieved.

$<$ http://untreaty.un.org/English/guide.asp\#glossary>; last visited 23 November 2009. $<$ http://untreaty.un.org/English/guide.asp\#glossary>; last visited 23 November 2009. Articles 2(1)(b), 14(1) and 16 of the Vienna Convention on the Law of Treaties 1969. Articles 2(1)(b) and 14(2) of the Vienna Convention on the Law of Treaties 1969. Articles 2(1)(b) and 15 of the Vienna Convention on the Law of Treaties 1969. This was the case after the ratification by Russia when the threshold level of ratifications had been reached to allow the Treaty to come into force. After this date however, many developing States acceded to the Treaty. 
Fulfilling the requirements of the second element of the threshold was politically difficult since it required cooperation by the most polluting and most developed nations. Failure by the USA and Australia, two of the most developed countries, which have the highest carbon dioxide emissions levels in the world, to ratify (accept, approve, accede to) the Protocol (at that time) held up the process significantly. Finally, in March 2004, Russia ratified the Protocol bringing the number of ratifying countries to $130,{ }^{32}$ and more importantly, finally reaching the threshold level of developed countries accounting for $55 \%$ of carbon dioxide emissions in $1990 .{ }^{33}$ At present, a total of 189 States have ratified (accepted, approved, acceded to) the Kyoto Protocol, finally also including Australia. ${ }^{34}$

\subsubsection{Parties to the Protocol}

The Parties to the Kyoto Protocol are divided into two groups, Annex I countries and non-Annex I countries. This distinction derives from the UNFCCC and takes account of the level of industrial development of each of the signatory countries. Article 3(10) UNFCCC states that Annex I countries should take the lead in combating climate change. ${ }^{35}$ This is important since the level of carbon dioxide emissions of each country directly correlates to the level of industrial development, currently and historically. It was agreed that developed countries are largely responsible for the majority of greenhouse gas emissions currently and also from a historical point of view. ${ }^{36}$ Therefore, the legal obligations created by the Kyoto Protocol correspond to the responsibility for the carbon dioxide emissions over time. The obligations to be fulfilled by each State differ depending on their level of industrial development. Annex I countries are those industrialised countries legallybound to limit or reduce their greenhouse gas emissions to the targets set in the Kyoto Protocol. Conversely, non-Annex I countries are not currently required to reduce their greenhouse gas emissions. ${ }^{37}$ It is therefore clear that, in examining measures and policies being pursued by countries aiming to fulfil their Kyoto Protocol obligations, and, in general, the efforts being made to combat climate

3233 of which were Annex I countries. Liechtenstein ratified on 3 December 2004.

33 At that time, the Annex I countries that signed the Protocol but failed to ratify it were: Australia, Croatia, Monaco, and the United States of America. Non-Annex I countries not having ratified are: Kazakhstan and Zambia. Status of Ratification: <http://unfccc.int/files/essential_background/kyoto_protocol/application/pdf/kpsta ts.pdf $>$; last visited 23 November 2009.

Although the number of ratifying countries has increased dramatically only four of the countries having ratified after Russia are Annex I countries, namely Australia, Croatia, Liechtenstein, and Monaco. Last updated August 2009. On 12 December 2004 Australia acceded to the Kyoto Protocol. <http://unfccc.int/files/kyoto_ protocol/status_of_ratification/application/pdf/kp_ratification_20090826corr.pdf >; last visited 23 November 2009.

35 Richardson 1998 , p. 250.

36 Ibid., p. 251; Decision 1//CP.1 (UN Doc.FCCC/CP/1995/7/Add.1).

37 This was the major bone of contention for the USA to become bound by the Protocol. Since, by the momentum of its industrial development, China threatens to be a major competitor and thus also polluter over the commitment period (to 2012), the USA did not agree that developing States or States undergoing transition to market economy should be exempt from fulfilling reduction commitments. USA is the largest greenhouse gas emitter with China being in second place. See Woerdman 2002, p. 594. 
change, the examination ultimately deals with the actions pursued by the 38 Annex I countries having ratified the Protocol.

The 38 countries that have ratified the Kyoto Protocol and that are also Annex I countries include the European Union, ${ }^{38}$ and also in an individual capacity, 25 of the 27 Member States of the European Union, Australia, Belarus, Canada, Croatia, Iceland, Japan, Liechtenstein, Monaco, New Zealand, Norway, Russia, Switzerland and the Ukraine. ${ }^{39}$ It is interesting to note that Member States of the European Union make up over two-thirds of the Annex I countries. In this way, it is also significant that the cooperation to combat climate change in a trans-boundary or international manner does not stop with concluding an international agreement but, in addition, smaller joint agreements, bi-lateral or also multilateral, are important in making a difference to the potential hazards posed by climate change.

The European Union and 25 Member States of the European Union, ${ }^{40}$ being Annex I countries and having individually ratified the Kyoto Protocol and set reduction commitments to be achieved by 2012, agreed to act jointly to achieve these commitments. ${ }^{41}$ In agreeing to act jointly to achieve the levels set in the Kyoto Protocol, an individual reduction commitment is set for each Member State and it is the aggregate result of these reductions that is taken into account when establishing whether the levels agreed upon in the Protocol have been exceeded. This joint action is also provided for by the independent ratification of the Protocol by the European Union as a regional body. ${ }^{42}$ The ratification by the Member States individually, along with a separate ratification by the European Union, may seem to create a more complex obligation at first sight; but it is intended to make compliance and achieving the Kyoto targets more efficient. ${ }^{43}$ Joint action allows individual States to independently pursue climate change strategies and also to cooperate with other

25 of the 27 Member States of the EU are Annex I countries and subject to the reduction commitments in the Kyoto Protocol. Cyrus and Malta are considered to be non-Annex I countries and although they have ratified the Kyoto Protocol, they are not subject to reduction commitments. However, since the European Community has also ratified the Protocol, Cyprus and Malta derive obligations with respect to climate change by virtue of their status as Member States of the European Union. Although the European Community had the competence to ratify the Kyoto Protocol, following the adoption of the Treaty on the Functioning of the European Union, European Union competence and not Community competence is the correct formal term for competence. Therefore, European Union competence will be referred to in place of the Community in the rest of this thesis.

39 Amendment to Annex B Kyoto Protocol, last accessed August 2009. Available at: $<$ http://unfccc.int/files/na/application/pdf/kp_annex_b_ratification_status_2009082 5.pdf $>$; last visited 23 November 2009.

$4025 \mathrm{Member}$ States of the EU are Annex I parties and have ratified the Kyoto Protocol in their own name, Cyrus and Malta are considered to be non-Annex I countries. The European Community (now to be referred to as the European Union) is also party to the Protocol. See also Amendment to Annex B Kyoto Protocol, last accessed August 2009. Available at: <http://unfccc.int/files/na/application/pdf/kp_annex_b_ ratification_status_20090825.pdf >; last visited 23 November 2009.

41 Article 3(1) Kyoto Protocol.

42 Cameron 2000, p. 12.

43 Ibid. 
States with similar levels of industrialisation for a more efficient and even stronger impact.

Although the European Union undertakes a responsibility in ensuring that the Kyoto Protocol obligations are fulfilled, action by the European Union is to be seen as complementary to action by the individual Member States. ${ }^{44}$ With respect to action at the European Union level, much has already been done with regard to the Kyoto Protocol obligations in setting up systems to aid action by the Member States. For example, a European Union emission trading market has been established and attempts were made to introduce an EU-wide energy tax. Despite these EU-level efforts, however, the development of renewable energy resources and in particular pro-Kyoto Protocol policies has been largely left up to the Member States. ${ }^{45}$ For example, the Kyoto Protocol suggests the use of flexible instruments in pursuit of Kyoto obligations, upon which the European Union has established new procedures; however, these flexible instruments are intended to only supplement other action at a national level. ${ }^{46}$ Thus, it is important to review the measures implemented by the ratifying Annex I parties to the Protocol individually, despite their joint implementation agreements.

\subsubsection{Kyoto Protocol Obligations}

The over-arching aim of the Kyoto Protocol is to enhance the protection of the environment through curbing the damaging effects of carbon dioxide emissions and other greenhouse gases on the climate. The increase in use and dependence on fossil fuels in an ever more industrialised world, coupled with the growing demand for energy, has led to an unprecedented increase of emissions of dangerous greenhouse gases into the atmosphere. Article 2 of the Kyoto Protocol addresses the obligation of Kyoto Protocol-ratifying States to achieve sustainable development in climate change. Article 2 addresses the overall aims of the Protocol stating that in order to achieve the reduced levels of greenhouse gases in the atmosphere that, inter alia, the following strategies should be put in place:

(iv) Research on, and promotion, development and increased use of, new and renewable forms of energy, of carbon dioxide sequestration technologies and of advanced and innovative environmentally sound technologies;

(v) Progressive reduction or phasing out of market imperfections, tax incentives, tax and duty exemptions and subsidies in all greenhouse gas-emitting sectors that run counter to the objective of the Convention and application of market instruments; [emphasis added $]^{47}$

It is clear from these broad guidelines given in the Kyoto Protocol that renewable energy development strategies should be developed from two points of view. First, emphasis is placed on the important role the development of renewable energy technologies have to play in reducing the greenhouse gas emissions in the

Ibid., p. 13.

Ibid.

Woerdman 2002, p. 3; Articles 6.1d, 12.3b and 17 Kyoto Protocol.

Article 2(1) Kyoto Protocol. 
atmosphere. Second, in order to create a place on the international energy markets for those renewable technologies, a level playing field must be established. The preferential treatment provided in the past and continuing to be provided at present to greenhouse gas-emitting sectors, such as national oil, gas, and coal industries, by tax incentives, tax and duty exemptions, must be eliminated in order for the new competitor, renewable resources, to be able to compete on the energy market. However, elimination of such market imperfections is still insufficient to create a level playing field for renewable technologies when a realistic view is taken of the research and development and investment costs associated with the establishment of a new technology and industry. In this way these two obligations may be interlinked. The reduction of market imperfections in greenhouse gas-emitting sectors may give the financial means as well as the inspiration for new policies and measures - proKyoto Protocol measures - for the development of renewable energy resources.

Thus, the establishment of a level playing field between renewable and nonrenewable energy resources and the real phasing-out of existing market imperfections may be viewed in two ways. First, irrespective of the obligation in the Kyoto Protocol to remove market imperfections applying to the greenhouse gas-emitting industries, equal financial measures (tax incentives) may be justifiably provided to nongreenhouse gas-emitting sectors (renewable energy technologies) - thereby placing both sectors on a equal footing in bare financial terms. However, this method in no way takes account of the long history of financial support provided to greenhouse gas-emitting sectors which has allowed such sectors to gain and maintain the market position currently enjoyed to the exclusion of the renewable energy sector. A second way in which a somewhat more equitable equal footing could potentially be achieved is proffered. The increase in revenue derived from phasing out financial support to greenhouse gas-emitting sectors could be redirected (earmarked) to the renewable energy sector. In addition, extra financial support may be provided for capital investment and research and development, to account for the historical disadvantage that renewable energy industries experience in the energy market.

In order to create a real and credible place on the market for renewable technologies, not only capital investment and research and development financial support could be contemplated, but also the possibility of extending such financial support to assistance with operating costs; thereby furthermore equalising the market position between greenhouse gas-emitting sectors and renewable energy resources.

Despite the major objective of the Kyoto Protocol being the limitation and reduction of emissions of greenhouse gases, Article 2(3) goes on to state that such objectives should be pursued with a view to reducing to a minimum not only the negative effects of climate change, but also that in reducing the negative effects of climate change, the potential negative effects of pro-Kyoto Protocol actions on international trade should also be minimised.

3. The Parties included in Annex I shall strive to implement policies and measures under this Article in such a way as to minimize adverse effects, including the adverse effects 
of climate change, effects on international trade, and social, environmental and economic impacts on other Parties, especially developing country Parties... [emphasis added] ${ }^{48}$

The obligations of the Kyoto Protocol are indeed primarily the reduction of greenhouse gases in the atmosphere in order to reduce the negative effects of climate change, however, the Kyoto Protocol points to more specific obligations such as the elimination of market imperfections in relation to greenhouse gas-emitting sectors, the development of renewable energy technologies and ensuring that international trade does not suffer negative effects as a result of the pro-Kyoto Protocol actions.

\subsubsection{Reduction Commitments}

The broad aims of the Kyoto Protocol become legally binding obligations when translated into the Parties' individual commitments. The ratification of the Kyoto Protocol brought the legally binding obligations of greenhouse gas reductions into force. ${ }^{49}$ By virtue of Article 3 of the Kyoto Protocol, parties agree to reduce their emissions of certain greenhouse gases listed in Annex A to the Protocol between 2008 and 2012 to the levels they have agreed to set out in Annex B to the Protocol:

1. The Parties included in Annex I shall, individually or jointly, ensure that their aggregate anthropogenic carbon dioxide equivalent emissions of the greenhouse gases listed in Annex A do not exceed their assigned amounts, calculated pursuant to their quantified emission limitation and reduction commitments inscribed in Annex B and in accordance with the provisions of this Article, with a view to reducing their overall emissions of such gases by at least 5 per cent below 1990 levels in the commitment period 2008 to 2012.50

The reduction commitment is set out as a level of greenhouse gas emissions stated as a percentage of the level of the base year, 1990. Article 3(1) of the Kyoto Protocol requires that a minimum reduction of $5 \%$ from 1990 levels should be achieved by 2012. In the case of the European Union, the target level of greenhouse gases is set at $92 \%$ of the 1990 emission levels, thus a joint reduction commitment of $8 \%$. This aggregate commitment is made up of many different levels for individual Member States. For example, as set out in the Kyoto Protocol Status of Ratifications document, Germany has a commitment to reduce its emission levels by $7.4 \%$ from 1990 levels, whereas Luxembourg has to reduce by a level of $0.1 \%$ and Latvia and Ireland by $0.2 \%$. Of all Annex I countries, Russia has by far the highest reduction commitment, at $17.4 \%$, which corresponds to achieving emissions levels equal to $100 \%$ of levels recorded in $1990,{ }^{51}$ while Japan is next in line with $8.5 \%$ reductions

$48 \quad$ Article 2(3) Kyoto Protocol.

49 Richardson 1998, p. 249.

$50 \quad$ Article 3(1) Kyoto Protocol.

51 Despite the requirement in Article 3(1) of a minimum reduction of 5\% from 1990 levels, Article 3(5) goes on to provide an exception for Annex I countries going through transition to a market economy. For those countries, a different base year (other than 1990) could be negotiated, or a different target other than less $5 \%$ set to which the reduction commitments would refer. The commitments listed in Annex B to the Kyoto Protocol take account of this difference and translate the relevant commitments to their 1990 base year equivalent levels. For example Hungary uses 1985-86 as a base year, Poland uses 1988, and Bulgaria 1989. 
necessary. Article 3(2) applies a preliminary timeframe for actions to be taken by ratifying parties in fulfilling the requirement to reduce emissions.

2. Each Party included in Annex I shall, by 2005, have made demonstrable progress in achieving its commitments under this Protocol. ${ }^{52}$

It is clear that although reductions are to be made between 2008 and 2012, for this to be a realistic achievement, action must be taken many years in advance. All Annex I Parties were required to have made clear efforts in achieving these reduction commitments by 2005 .

\subsubsection{Compliance}

Legally binding obligations have been created by the ratification (acceptance, approval, accession) of the parties to the Kyoto Protocol. It is important, therefore, to address the issue of compliance and potential non-compliance with these legally binding obligations. Each Annex I country is obliged to limit their greenhouse gas emissions to a set target by 2012. However, the extent of the implications of the legal obligations of the Kyoto Protocol are vague. It has been called the 'bottleneck of the Kyoto Protocol'.53 Having legally binding provisions dealing with compliance, or rather real consequences for non-compliance is important to make the objectives set out in the Kyoto Protocol achievable and realistic. Without compliance mechanisms, the risk of sub-optimal results and inefficiency are prominent. ${ }^{54}$ Without clearly stated rules dealing with incompliance, the weight of the 'legally binding' nature of the Protocol is no longer significant. It is widely agreed that soft law or informal agreements on compliance are of no real value in this sphere. ${ }^{55}$

It is clear that monitoring and reporting form important parts of the Kyoto Protocol compliance obligations. ${ }^{56}$ These compliance procedures take the procedures developed in the UNFCCC and extend them. ${ }^{57}$ Reporting obligations are more extensive under the Kyoto Protocol. Annual inventories and accounts evidencing the levels of greenhouse gas emissions must be reported in addition to an obligation for parties to the Protocol to report to the Secretariat ${ }^{58}$ on an ad hoc basis on its national efforts in achieving the Kyoto Protocol obligations. ${ }^{59}$ A Compliance Committee was established which is viewed as the enforcement branch of the Secretariat. This Compliance Committee must receive action plans from the parties indicating the proposed measures and indicating the time frame in which the measures are to be

Russia, on the other hand, is required to achieve greenhouse gas emission levels equal to levels in 1990. Russia currently has levels of greenhouse gas emissions at $30 \%$ below 1990, levels that leave some room for Russia's industrial development between now and 2012.

52 Article 3(2) Kyoto Protocol.

53 Woerdman 2002, p. 145.

54 Ibid.

55 Ibid.

56 Richardson 1998, p. 256

$57 \quad$ Ibid., p. 257.

58 The Secretariat established under Article 8 of the UNFCCC acts as the secretariat for Kyoto Protocol reporting purposes. Article 14 Kyoto Protocol.

59 Richardson 1998, p. 257. 
implemented. ${ }^{60}$ Also, should a party not comply, that party loses the right to trade in emissions subject to Article 17.61 It is hoped that some suggested implementation mechanisms of the Kyoto Protocol will make compliance a less problematic issue. ${ }^{62}$ The compulsory publication of emissions data is also hoped to have a positive effect on compliance. ${ }^{63}$

It is considered that new provisions addressing incompliance could be developed in the years following the Kyoto Protocol ratification by mutual agreement of the ratifying parties. ${ }^{64}$ However, this possible development of potential sanctions for incompliance requires amendments to be made to the Protocol by the parties. Bearing in mind the difficulties with which negotiations took place in developing the Kyoto Protocol in the first place and the subsequent ratification, pursuing the development of compliance mechanisms which would be agreed upon by all ratifying States could be considered a wasted activity as the time-frame for compliance (or non-compliance) is less than the time it took to reach ratification. ${ }^{65}$

The reporting obligations to which the ratifying parties are subject are intended to make it possible for a special expert review group within the secretariat to detect potential instances of incompliance. ${ }^{66}$ This in itself is rather problematic. The extent to which a country may be liable for its inaction or incorrect action with respect to its Kyoto Protocol obligations is thus not based on independent review or assessment of action/inaction but rather based on a review of (potentially) biased reports provided by the potentially incompliant ratifying party. It is clear that the Kyoto Protocol is especially lacking when addressing the issue of compliance. ${ }^{67} \mathrm{It}$ is also clear that there are no real compliance mechanisms provided for in the Kyoto Protocol dealing with the general obligations enshrined in the Protocol for example the requirement to phase out market imperfections to greenhouse gas-emitting industries, or the development of renewable energy technologies, or the even more general requirement not to adversely affect international trade. However, the problem of lack of compliance provisions runs even deeper and creates a problem at an even more fundamental level. No sanctions or other provisions are in place to date to deal with potential incompliance with the basic quantitative reduction commitments required to be fulfilled by 2012. The 'legally binding' character of the Kyoto Protocol is thus put into question.

The phrase 'legally binding obligations' is repeatedly attached to the Kyoto Protocol and hailed as one of the breakthroughs in the development of international agreements dealing with environmental concerns. It is important to see what this actually means in practice. The actual legal implications of the Protocol are unclear. It remains unclear who is charged with enforcing the Protocol and how it should be

Woerdman 2002, p. 145.

Ibid.

Richardson 1998, p. 257.

Woerdman 2002, p. 147.

Richardson 1998, p. 257.

Ibid., p. 258; Article 18.

Ibid., p. 257; see Article 8.

Ibid., p. 258. 
enforced and when it should have effect. ${ }^{68}$ Whether the only legally binding aspect of the Kyoto Protocol is indeed the requirement of the fulfilment of the quantitative reduction commitments or whether the more general requirements as laid down in the Protocol and as discussed above (phasing out market imperfections, developing renewable energy technologies, minimal adverse international trade effects), were also intended to carry legally binding weight is ambiguous.

Despite the lack of Kyoto Protocol provisions dealing with compliance and the uncertainty surrounding the actual legal status of the Kyoto Protocol obligations, both specific and general, what is abundantly clear is that no independent body exists with Kyoto Protocol compliance as its clear and sole mandate. In this case, it is probable that potential Kyoto Protocol incompliance may be battled out in other international fora.

As the majority of Kyoto Protocol-ratifying countries are also WTO members and the WTO has, since 1994, a reliable and well-established dispute settlement system, it is not inconceivable that, should incompliance with the Kyoto Protocol obligations occur and the same action (inaction) be subject to the mandate of the WTO Dispute Settlement Mechanism, that this would be the appropriate forum in which action would be taken. ${ }^{69}$ The potential for this occurring may be drawn also from the provisions of the Kyoto protocol itself to:

minimize adverse effects, including the adverse... effects on international trade... [emphasis added $]^{70}$

In Part IV, the potential inconsistency of the case study tax incentives for renewable energy generation with the WTO Agreements, despite their being tax incentives which may contribute to the fulfilment of Kyoto Protocol obligations, will be examined in detail. Thereby it will be demonstrated to what extent Kyoto Protocolratifying Annex I countries have indeed minimised adverse effects on international trade while developing the renewable energy tax policies.

\subsubsection{Targeted Sectors}

The Kyoto Protocol not only lists the greenhouse gases to be targeted by the ratifying States, ${ }^{71}$ but also stipulates which sectors should be primarily targeted. Article 10 of the Kyoto Protocol refers to the energy, transport and industry sectors. ${ }^{72}$ Included in the category of industry sector is agriculture, forestry and waste management. ${ }^{73} \mathrm{In}$ addition, Annex A to the Kyoto Protocol also clearly lists the relevant sectors at which reduction commitment policies should be aimed. The first sector or source category mentioned is energy, followed by fuel combustion, energy industries and so

Cameron 2000, p. 1.

Schram Stokke 2004, p. 339-357.

Article 2(3) Kyoto Protocol.

See Annex A Kyoto Protocol. Carbon Dioxide, Methane, Nitrous oxide, Hydrofluorocarbons, perfluorocarbons, sulpher hexafluoride.

Article 10(b)(i) Kyoto Protocol.

Ibid. 
on. ${ }^{74}$ The energy sector is a primary target in the pursuit of policies aimed at hindering the hazardous effects of climate change. Energy production is the cause of more than $50 \%$ of 'anthropogenic carbon emissions' ${ }^{75}$ A high percentage of greenhouse gases come from energy intensive industry, thereby indirectly coming from the energy production sector. ${ }^{76}$ In the EU, the energy sector accounts for $80 \%$ of the EU's carbon dioxide emissions and is also responsible for $26 \%$ of its methane emissions. ${ }^{77}$

Energy resources such as coal, oil and gas account for the majority of production of greenhouse gases. This dependence on non-renewable energy resources can be changed, bringing about a major reduction in the related carbon dioxide emissions. ${ }^{78}$ This change can be seen in a positive or negative light. Change in the structure of the energy sector can create new opportunities for new categories of energy but may have detrimental effects on the coal, oil and gas sectors including financial uncertainty and high costs resulting from Kyoto Protocol obligations. ${ }^{79}$ In addition, by targeting the energy sector and changing the balance of industry inputs, the reliance on outside supplies is also affected. By switching to renewable energy resources, the issue of energy security may also be addressed..$^{80}$

Energy use is mainly by industrial, residential and commercial operations and can be subdivided into three sectors, namely: electricity, transport and heating. Electricity generation accounts for approximately $45 \%$ of the use of energy resources (transport $30 \%$, heating $25 \%$ ), and is therefore a major cause of increasing greenhouse gas emissions. Electricity generation is the source of $41 \%$ of world carbon dioxide

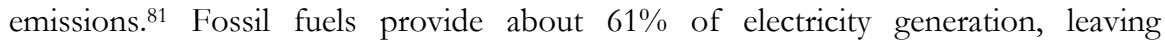
renewable energy responsible for the generation of only about $17 \%$ of electricity. ${ }^{82}$ The electricity sector also covers all the three main user areas: industrial, residential and commercial. Furthermore, the demands for electricity from all of the user areas only increase as the industrialised world continues to grow.

As addressed above, an important sector targeted by the Kyoto Protocol is the energy sector, which includes the electricity industry. The burden created by the Kyoto Protocol falls on the electricity generation sector, in particular those electricity generation companies (being the majority) that depend on coal, gas and oil and are therefore set to endure costly compliance procedures. This is particularly true when

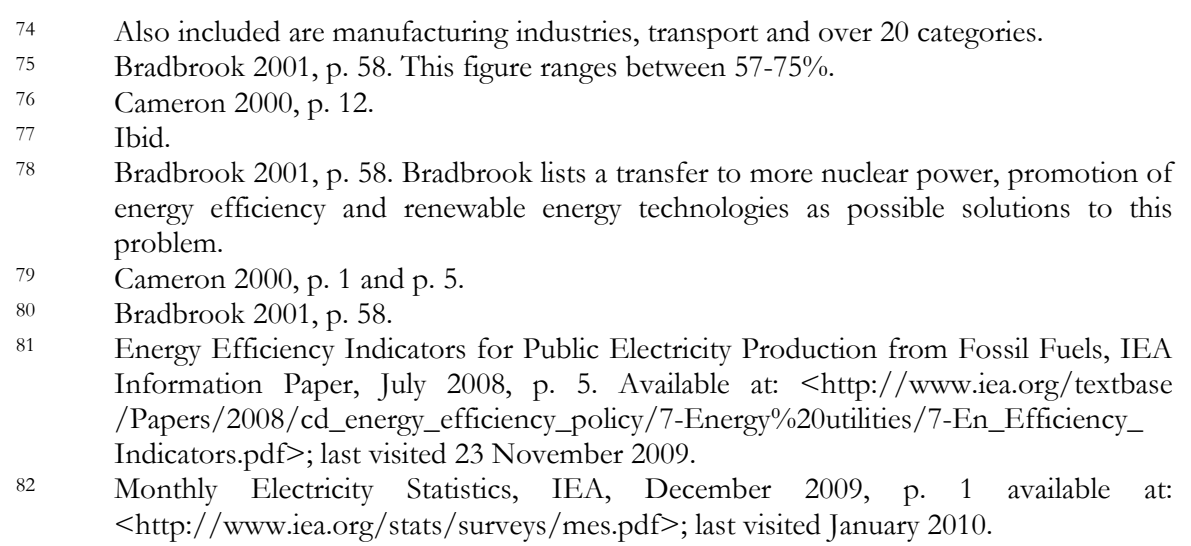


the Kyoto obligations of phasing out tax incentives provided to greenhouse gasemitting industries, and the development of renewable energy are taken seriously. The electricity generation industry, traditionally being a greenhouse gas-emitting industry receiving much financial support, is therefore a significant player in ensuring compliance with the Kyoto Protocol obligations. However, despite the current reliance of the electricity generation sector on fossil fuels and financial support, change is indeed possible. The UK provides a good example, having switched from coal-fired electricity generation to the less polluting natural gas as a first step and, in addition, providing possibilities for the development of some renewable energy resources. ${ }^{83}$ Electricity generation is an area in which it is feasible to change the balance of dependence from non-renewable energy to renewable and for the obligations enshrined in the Kyoto Protocol to have real and effective results.

In addition, the energy sector, and in particular with respect to electricity generation, is especially interesting to examine in light of Kyoto Protocol obligations since the conflict between the goals of creating a liberalised electricity market and the reduction of greenhouse gas emissions is not insignificant. ${ }^{84}$ Great efforts have been made in the past decade to liberalise the electricity market; however it has been suggested that there is indeed a link between the deregulation of electricity markets and the subsequent increase in carbon dioxide emission levels..$^{85}$

Finally, the importance of targeting the energy sector in the name of achieving Kyoto Protocol objectives has not been underestimated by certain authors. It has even been suggested that the Kyoto Protocol does not adequately address this sector. Bradbrook considers the energy sector to be so important with respect to climate change that he recommends that a separate international treaty be concluded targeting greenhouse gas emissions specifically in the energy sector. He points to the fact that the link between environmental law, and in particular the relation to climate change and energy issues, has not yet been addressed efficiently. ${ }^{86} \mathrm{He}$ sees energy production to be the underlying cause of climate change and suggests that it should be tackled directly, targeting both production and consumption. ${ }^{87}$

Although the claim that the energy sector is an important culprit in climate change is indeed a valid one, as is also argued above, the negotiation and development of a new and separate international multilateral treaty addressing the energy sector specifically, would be excessively administratively burdensome. The link between energy and climate change has clearly not been entirely ignored. The Kyoto Protocol addresses the energy sector as one of the primary targets for action with respect to fulfilling the greenhouse gas reduction commitments. ${ }^{88}$ Indeed, claims that the way in which the obligations are set out in the Kyoto Protocol are 'too terse and vague' to be sufficient ${ }^{89}$ hold some truth. However, the negotiation of a new treaty in response to the imperfections of the Kyoto Protocol does not seem to be a viable solution. On

Cameron 2000, p. 5.

Ibid., p. 13.

Ibid.

Bradbrook 2001, p. 55 and p. 57.

Ibid., p. 57.

Annex A Kyoto Protocol.

Bradbrook 2001, p. 60. 
the other hand, with the long awaited ratification of the Kyoto Protocol having become a reality, a more viable option with regard to targeting the energy sector in a real way in reducing the negative effects of climate change is to take the Kyoto Protocol seriously. By ensuring action with respect to the above outlined Kyoto Protocol obligations, both the more general and specific obligations, along with ensuring compliance within the targeted sectors, the result can be to have real and effective implementation of climate change policies and a real change to the energy sector.

\subsubsection{Copenhagen and Beyond}

It has been stated that the conclusion of an international agreement at the United Nations Climate Change Conference - Copenhagen 2009 is essential in combating climate change. According to Yvo de Boer, the Executive Secretary of the UN Framework Convention on Climate Change: 'a climate deal in Copenhagen ... is an unequivocal requirement to stop climate change from slipping out of control...' Despite the weight of the expectations relating to the conclusion of an agreement in Copenhagen, no legally-binding agreement ensued and rather a political Accord, agreed upon only by a proportion of participating countries, was concluded..$^{0}$

The agreements reached within the Accord ${ }^{91}$ includes a request for Annex I countries to establish new reduction commitments by 31 January 2010, intended to be the follow-up to the Kyoto Protocol reduction commitments. Non-Annex I countries are required to identify nationally appropriate mitigation measures by 31 January 2010. Annex I countries committed to providing $\$ 30$ billion of funding over three years to developing countries to support their mitigation efforts. Furthermore, developed countries committed to providing $\$ 100$ billion per year by 2020 to fund mitigation efforts. Finally, the Accord established a High Level Panel to address revenue sources and in particular to address the development of the Copenhagen Green Climate Fund as a fund source for mitigation and adaptation efforts. ${ }^{92}$

In particular, it will be interesting to examine the commitments made by 31 January 2010 and whether these commitments indeed extend and increase reduction commitments beyond the expiry Kyoto Protocol commitment period in 2012. The lack of willingness to come to an agreement on new commitments in Copenhagen is somewhat an indicator of the lack of success of the initial Kyoto Protocol commitments.

A point of hope is that the negotiations specifically addressed financial support of mitigation and adaptation, in particular how to generate new, additional and predictable financial resources and technology. ${ }^{93}$ The importance of start-up

90 Fowler 2009, available at <http://www.law.uoregon.edu/academics/docs/first_S10/ copenhagen.pdf $>$.

$91 \quad$ Copenhagen Accord, 18 December 2009.

92 Fowler 2009, available at <http://www.law.uoregon.edu/academics/docs/first_S10/ copenhagen.pdf $>$.

93 UNFCCC, Fact sheet: 'Copenhagen Why is a deal so important?', September 2009, available at: <http://unfccc.int/files/press/application/pdf/fact_sheet_copenhagen_ 
financing has also been recognised. ${ }^{94}$ Although technology, financing and capacity building from developed countries to support developing countries mitigation efforts are obligations already originating from the Framework Convention on Climate Change $^{95}$ and were furthered by their inclusion in the Kyoto Protocol, ${ }^{96}$ to date it seems that compliance with these provisions has been unlikely. ${ }^{97}$ The commitments in the Copenhagen Accord relating to financial aid from the developed countries to the developing countries, as well as the establishment of the Copenhagen Green Climate Fund, are positive outcomes of the Copenhagen negotiations.

Although the Copenhagen negotiations did not result in a new Kyoto Protocol, legally binding and with new and greater reduction commitments, it is perhaps a more realistic result. The political agreement, or Accord, which also includes the intention to make reduction commitments by 31 January 2010, as opposed to having a legally binding protocol recognises the 'failure' of the legally binding nature of the Kyoto Protocol. The much-hailed legally binding nature of the Kyoto Protocol, in practice, did not amount to much. Lack of compliance with the commitments in the Kyoto Protocol only amounted to a 'slap on the wrist' for the non-compliant countries. Therefore, that the Copenhagen negotiations resulted in a system of commitments which will instead rely on national governance to monitor and assure compliance with the commitments is a much more realistic result.

\subsection{The Global Electricity MARKET}

The Kyoto Protocol calls for efforts to be made in the energy sector to achieve emission reduction targets. The energy sector accounts for over $50 \%$ of anthropogenic carbon dioxide emissions. $45 \%$ of this world energy use is dedicated to electricity generation. In electricity generation almost $61 \%$ of inputs are fossil fuels. Renewable energy inputs to electricity generation account for only about $17 \%$ of total inputs..$^{98}$ It is thus clear that in addressing the requirements of the Kyoto Protocol, the electricity generation industry is of great significance.

The electricity sector is an interesting case as it has undergone significant changes in the last decade. Previously an industry characterised by the operation of national monopolies providing what has long been considered to be a public good, the electricity industry has undergone significant changes in recent times opening up the market to competition and liberalising trade in electricity. This section addresses the developments in the electricity sector with respect to electricity generation. Electricity generation is of particular importance with respect to the Kyoto Protocol obligations as it is at this level that distinctions between renewable or non-renewable inputs are made. It will be shown that although the liberalisation of the electricity sector has

deal.pdf>, p. 3; last visited 23 November 2009. Apparently, up to $\$ 250$ billion will be necessary per annum to adapt and mitigate climate change.

Ibid.

Article 4(3), 4(5) and 4(7) of the FCCC.

Article 10 Kyoto Protocol.

Rajamani 2008, p. 934.

Monthly Electricity Statistics, IEA, December 2009, p. 1 available at: <http://www.iea.org/stats/surveys/mes.pdf>; last visited January 2010. 
indeed been a positive step in relation to making Kyoto Protocol objectives more possible, it has not yet eliminated State interference in electricity generation.

\subsubsection{Public Good Nature of Electricity}

In the past, the electricity sector was made up of large national monopolies devoid of competition on a national or international level. The provision of electricity was a responsibility assumed by national governments. Access to electricity was seen as a basic need which should be guaranteed by the State. States are required for reasons of equity to ensure that, despite ability to pay, each citizen has secure access to electricity at a fair price. The most vulnerable groups in society are to be protected by the State and provision of a necessary standard of living should be ensured by the State. Electricity is one such good which is deemed necessary in developed States in order to have a minimum standard of living.

The electricity sector has been considered to be a 'natural monopoly' due to certain characteristics of electricity which categorises it as a public good. ${ }^{99}$ The cost of supplying each unit of electricity, whether to detached rural areas with only one household, or to highly populated urban areas should not influence the price charged to each household under the equity principle. Each household, regardless of their dwelling place should incur the same per unit cost for electricity. ${ }^{100}$ It was considered that this business could not be a commercially viable one. ${ }^{101}$ Based on principles of equity and ability to pay, the electricity sector was in the hands of national governments. In addition, for reasons of security of supply, especially in the post-war era, it was essential that the electricity sector was government-controlled.

However, from the 1990s deregulation of many highly regulated sectors was occurring globally. The underlying belief motivating the move towards trade liberalisation was a desire for more competitive industries, more efficiency and commercially viable operations. Further motives for trade in electricity and a beginning point of departure for a liberalised market was the desire for countries to reduce their need for large reserves of electricity in order to be able to meet needs at peak times. This desire for inter-State trade was a starting-point for the current trend to increase trade in electricity. ${ }^{102}$

At present, in the post-liberalisation stage of the history of the global electricity market, the natural monopoly characteristic has not been eliminated completely. The security of electricity supply, along with the equitable treatment of consumers and reasonable pricing of public goods are still important aspects affecting the electricity industry. However, since not all elements of the electricity industry affect or influence the equitable provision of this public good, the particular tasks which are free of this responsibility are therefore open to operating in a fully competitive, liberalised market.

See further Steiner 2000.

Zarrilli 2004, p. 259.

Wälde and Gunst 2004, p. 184.

Ibid., p. 121. 
Even prior to liberalisation, the electricity sector could be divided into four separate tasks: generation, transmission, distribution and supply. These four elements were generally all comprised of separate parts of vertically integrated national monopolies. Since some tasks in the electricity chain were more clearly connected with the provision of a public good, or ensuring security of supply, some elements were clearly 'natural monopolies'. However, the whole chain, from generation to supply was treated as a natural monopoly. The trend was for national governments to assume the responsibility of all the levels of the electricity sector: generation, transmission, distribution and supply. It is now clear, in the post liberalisation stage, which elements of the electricity chain are in fact significantly connected to provision of public goods and security of supply and which are in fact commercially viable operations open to competition.

\subsubsection{Liberalisation of the Electricity Market}

As introduced above, the electricity industry, both pre- and post-liberalisation can be naturally divided into four levels: electricity generation, transmission, distribution and supply. Certain levels of the electricity industry are more naturally disposed to liberalisation than others. The peculiar nature of electricity and the importance of the supply of electricity in our society are important factors in determining to what level each task in the electricity chain (generation, transmission, distribution and supply) has been liberalised. One of the first steps in liberalising the electricity market was the opening up of different levels of the electricity sector to third parties in generation, transmission, distribution or supply. ${ }^{103}$

Electricity generation, or the production of electricity, is a process by which a primary energy resource is transformed into a secondary energy resource. ${ }^{104}$ Primary energy resources are those which require no further process to be considered energy. Electricity on the other hand is a secondary energy resource, as a process of transformation is required. This transformation, depending on the inputs, creates either primary electricity or secondary electricity. ${ }^{105}$ Primary electricity is produced from renewable energy resources; the process involved in harnessing this natural resource for transformation. Secondary electricity is produced from the combustion of mainly non-renewable energy resources although there is the possibility of combustion of renewable resources - such as waste products. ${ }^{106}$ As mentioned earlier, only $17 \%$ of inputs to electricity generation are producing primary electricity.

Electricity transmission involves the transportation of generated electricity from electricity generators to a national electricity grid. Transmission also involves managing voltage and frequency of inputs from dispersed generators within the grid. ${ }^{107}$ Electricity distribution involves the transport of electricity from the national

\footnotetext{
$103 \quad$ Ibid

$104 \quad$ Zarrilli 2004, p. 239. This classification of generation as a process whereby a primary good is transformed into a secondary good is relevant for the classification of electricity generation as the production of a good or the supply of a service.

105 Ibid., p. 238: Geothermal, solar, tide, wave, and wind power.

106 Oil, gas, coal and waste.

$107 \quad$ Lakatos 2004, fn 2.
} 
grid to consumers - both individual and industrial. ${ }^{108}$ Distribution systems are also responsible for transforming the high voltage electrical power of the grid to lower voltage levels in substations making it suitable for final consumer purposes. ${ }^{109}$ The supply of electricity is the final level in the electricity chain involving the sale of electricity to consumers at the household and industrial level. This includes the management and administration of electricity metres, invoicing, and general consumer contact. ${ }^{110}$

Reducing or eliminating regulation which creates or maintains State monopoly powers in the electricity sector is not sufficient to open the market to competition. ${ }^{111}$ For real competition and a liberalised market the vertically integrated monopolies have to be dismantled. The process of untying the four levels in the electricity sector is termed the unbundling of the electricity monopolies. ${ }^{112}$ Having seen how the tasks in the electricity sector are divided, and bearing in mind the social policy relevant to the provision of electricity equitably and a stable supply of electricity, it can be deduced that various levels of the electricity sector have been liberalised to different extents, with respect to the public service requirements. The operation of the national grid is essential in determining the levels of electricity available for use in a State. It is also clear that the operation of the distribution networks are essential in ensuring that all citizens in a State, regardless of their location (populated urban developments or dispersed rural developments), have equal access to electricity. For competition in the electricity sector and liberalisation of the electricity market, the generation and supply levels should at least be severed from the natural monopolies of transmission and distribution and opened to competition. ${ }^{113}$ In Europe the liberalisation of generation and supply were primarily addressed by the First Electricity Directive in 1996. ${ }^{114}$ The liberalisation of the electricity market in this way also came about in an unbalanced manner in which transmission and distribution have remained 'natural monopolies' to a large extent, whereas generation and supply have been liberalised. ${ }^{115}$

The move towards a liberalised electricity market has many advantages. Primarily the opening of markets to independent generators and suppliers makes price competition possible and directly influences the efficiency of operations. The more efficient and price competitive a national electricity market is, the more successfully that national market will compete on an international scale. With improvements to electricity technologies and infrastructure, international trade in electricity is now possible both on the supply and demand side. Advantage may be taken of this new system allowing for minimum need for reserve capacity and most efficient utilisation of time zone differences for peak demand.

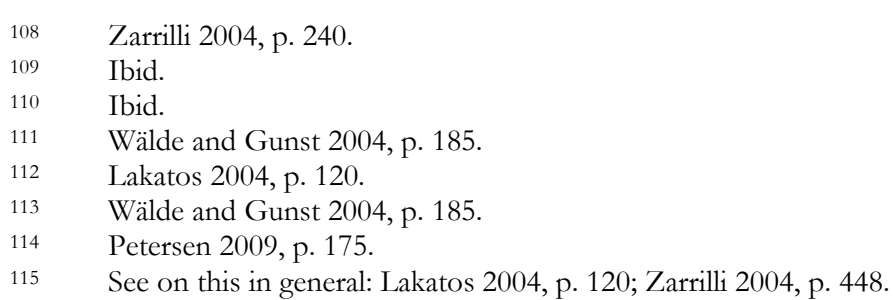




\subsubsection{Electricity Liberalisation and the Kyoto Protocol}

The electricity industry has been 'unbundled', allowing for different levels of liberalisation to the four levels of the electricity industry, namely: generation, transmission, distribution and supply. This research is primarily concerned with electricity generation, as this is the level at which energy resources, as inputs in the electricity sector, may be distinguished - between renewable and non-renewable energy resources. As discussed above, the Kyoto Protocol requires that, in addressing the emission reductions which each ratifying party has committed itself to, development of renewable energy technologies is also targeted. As also mentioned above, considering the current balance of inputs into electricity generation (fossil fuels: $61 \%$; renewable energy: $17 \%$ ) a significant change is necessary in this sector for Kyoto Protocol obligations to be met. Once electricity has been produced and moves on to the level of transmission, distribution and supply, it is difficult to distinguish between electricity produced from different generators or different inputs. ${ }^{116}$ Therefore, in addressing the above-mentioned requirements of the Kyoto Protocol, electricity generation is significant and is the level in the electricity chain at issue here.

\subsubsection{Development of Renewable Energy}

The liberalisation of electricity generation, which provides access to national grids for competing electricity generators, makes it possible for new independent operators to the come onto the market. These new electricity generators, having access to national grids are in a position to locate where it is most economically viable in terms of access to particular inputs and also in terms of having access to national transmission services as well as cross-border infrastructure. ${ }^{117} \mathrm{New}$ technology in electricity generation makes it now possible to generate electricity on a small-scale basis from small-scale fuel cells. ${ }^{118}$ These small-scale operations are argued to be more costefficient and set up more quickly to be in an operational state than traditional large scale power plants which were designed with the view that one (or few) generator provides electricity for a whole State - within a monopoly structure.

This development is especially interesting bearing the Kyoto Protocol obligations in mind. Renewable energy technologies that harness renewable energy resources, such as wind, solar, tidal etc. are all technologies characterised by the operation of smallscale operations located in the geographic area most suited to that energy source. The liberalisation of electricity generation has made it possible for new operators interested in developing renewable energy generation cells to access the national grid and to compete in an open and competitive market. It may be said, therefore, that the trend of liberalisation in the global electricity market is a positive development with

116 See Zarrilli 2004, fn 14. Also see ECJ: C-213/96, Outokumpu Oy, [1998] ECR I-1777, a Finnish case in which tracking the origin of electricity was also at issue. There was a Finnish tax system which favoured renewable energy, however, the method of production of the electricity could not be established when the electricity had already entered into the national grid. Foreign producers of renewable electricity were subject to a higher tax rate than the producers of like renewable electricity in Finland and thus were discriminated against. See also Fernández Armenteros 2005, p. 236.

117 Zarrilli 2004, p. 235.

118 Ibid., p. 248. 
respect to the potential for renewable energy creating a place for itself in the energy market. The decoupling of national monopolies has made it possible for new actors to come onto the market. ${ }^{119}$

\subsubsection{Elimination of Market Imperfections}

The Kyoto Protocol calls for market imperfections in greenhouse gas-emitting sectors to be eliminated. Such market imperfections include tax incentives, tax and duty exemptions and subsidies. ${ }^{120}$ The mere displacement of electricity generation away from political influence and the corruption ${ }^{121}$ associated with State controlled monopolies and general anti-competitive behaviour characteristic of monopolies, creates an environment in which not only economic benefits may be passed on to the consumer but also in which market imperfections may be detected and eliminated. ${ }^{122}$ In the hands of private operators, obligations to produce transparent accounts and be answerable to shareholders makes efficiency an important goal, and hidden subsidies, hopefully, a thing of the past. However, as this thesis will illustrate, explicit subsidies are perhaps the thing of the present as well as the future.

\subsubsection{No Adverse International Trade Affects}

The Kyoto Protocol calls for efforts to be made to ensure that adverse effects on international trade are minimised. International trade in electricity is preconditioned by the liberalisation of the electricity markets, as well as being a goal of the same market liberalisation. This trade in electricity is to be seen both from the generation and supply perspectives. International trade in electricity is possible now in an open market. Liberalisation has made it possible not only for various electricity generators to compete for access to the national grid, it is also a possibility for electricity generators to compete for access to the national grids of other States, or even to establish electricity generation companies in other States. In addition, competition on the supply side of the electricity sector means that administration and management of supply of electricity from national distribution systems to consumers is carried out by competing 'electricity companies' - also with the possibility for consumers to access electricity supply from across the border.

Electricity generation and supply have been liberalised to different levels across the world allowing for trade in electricity to now be a reality not only on a national and regional level but also at an international level. Previously, infrastructure did not allow such trade and trade in electricity was a non-issue with respect to international trade. It is only in this new environment of a liberalised electricity market that there could be possible ramifications for international trade with respect to electricity generation and the trade of such electricity.

\footnotetext{
$119 \quad$ Faure, Gupta and Nentjes 2003, p. 206.

120 Article 2(1) Kyoto Protocol.

121 Wälde and Gunst 2004, p. 182. According to Transparency International, the energy sector has one of the highest incidences of 'grand corruption'. Ibid.
} 
The Kyoto Protocol establishes legally binding obligations for 38 developed (Annex I) countries to reduce greenhouse gas emissions to 5\% below 1990 levels by 2012. In addition, the Kyoto Protocol requires these ratifying States to develop, inter alia, renewable energy technologies and to ensure that international trade is not adversely affected.

The Kyoto Protocol lists the greenhouse gases which must be targeted and also the sectors which are most important with respect to reducing the negative effects of climate change. The energy sector plays a significant role here, being responsible for over $50 \%$ of carbon emissions deriving from human activity. $45 \%$ of energy production is consumed for electricity generation. At present, almost $61 \%$ of world electricity is generated from greenhouse gas-emitting fossil fuels coal, oil and gas while only about $17 \%$ is generated from renewable resources. It is thus clear that in order to fulfil the requirements of the Kyoto Protocol, the balance of inputs to electricity generation must be changed and the current support of greenhouse gasemitting industries must be eliminated in order for the development of renewable energy resources to be possible. In the past decade, there have been many changes to the electricity generation sector, opening this industry to competition and potential international trade, and to a certain extent these changes have laid the groundwork for fulfilling Kyoto Protocol obligations.

The last decade has seen the liberalisation of electricity monopolies on a national, regional and international level. ${ }^{123}$ Increased national welfare is deemed to be a result of the liberalisation process allowing for competition and, following on from that, improved consumer products and service along with positive effects on security of supply. ${ }^{124}$ Efficient trade in electricity at national, regional and international levels improves security of supply as pressure on markets at peak times may be reduced and this also reduces the need for reserve supplies on a national level. In this respect, advantage of time differences across time zones may be manipulated. ${ }^{125}$ Improvements to consumer prices are a distinctive feature of liberalised markets as private markets are deemed to operate more efficiently. ${ }^{126}$

It is also the case, from the perspective of fulfilling Kyoto Protocol obligations, that the liberalisation of the electricity sector has been an important development. A liberalised electricity generation sector allows new entrants into the market, making the development of renewable energy technologies more feasible. Due to the liberalisation of electricity markets, it is now more important than ever that the international trade implications of actions taken within the electricity generation sector do not hinder international trade.

Finally, since the Kyoto Protocol does not address the issue of potential incompliance with its 'legally binding obligations', great uncertainty surrounds the

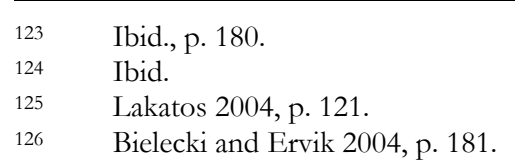


implications of ratifying States failing to fulfil the Kyoto Protocol requirements addressed above. Since most of the parties bound by the obligations of the Kyoto Protocol are also WTO Members, and in addition since there is explicit reference in the Kyoto Protocol to parties minimising adverse international trade effects, the potential overlap between the Kyoto Protocol mandate and the mandate of the WTO must be addressed. The existence of the Dispute Settlement System of the WTO, and the lack of such a body with a similar mandate with respect to obligations deriving from the Kyoto Protocol, leads to an important potential link between the Kyoto Protocol and the WTO. In this research, the examination of this link will focus on the WTO-consistency of pro-Kyoto Protocol national direct corporate tax incentives for the development of renewable energy electricity. Such measures, despite their being pro-Kyoto Protocol and essentially environmental subsidies, are at risk of being the subject of WTO disputes to the extent the subsidies are specific and cause (or threaten to cause) adverse effects to the interests of other WTO members. 


\section{Chapter 2 : Pro-Kyoto Protocol Tax Treatment}

\section{$2.1 \quad$ INTRODUCTION}

Article 2(3) of the Kyoto Protocol requires market imperfections in greenhouse gasemitting sectors to be eliminated and renewable energy technologies to be developed. Market imperfections are listed as tax incentives, tax and duty exemptions and subsidies. Although market imperfections provided to greenhouse gas-emitting sectors should be eliminated, it is the case that market imperfections such as tax incentives, tax and duty exemptions and subsidies have been called upon for the development of renewable energy technologies. This chapter aims to outline the special tax treatment which constitutes tax incentives. The aim of this dissertation is not to determine the effectiveness or efficiency of tax incentives in the pursuit of Kyoto Protocol objectives, but rather to explore the de facto application of Kyoto Protocol tax incentives in the electricity generation sector and the consistency of that de facto application with WTO rules.

\subsection{TAX INCENTIVES FOR ELECTRICITY GENERATORS}

Tax incentives take the form of differential tax treatment away from the norm in order to provoke certain behaviour - to develop an industry or to influence/alter existing industry. All tax incentives are funded from the public purse. Subsidies in the form of tax incentives are a common financial support available to electricity sector operators. $^{1}$

Since the electricity market has only been liberalised in the last decade, it is fair to say that State involvement in electricity generation, although lessened to a great extent, has not been eliminated entirely. In fact, liberalisation is not a process which is completed overnight and therefore market imperfections, which were available to electricity generators when operated by national monopolies, are often still in place as a result of incomplete unbundling or imperfect separation of tasks. ${ }^{2}$ These now revitalised companies are still the recipients of subsidies which have not (yet) been rescinded or extended to the new independent entrants to the market. Existence of such unevenly distributed market imperfections would be extremely damaging to the market position of new entrants. ${ }^{3}$

When addressing tax incentives provided to electricity generators, it is important to consider that public service obligations accrue to electricity generators to provide secure, good quality electricity at reasonable prices. The extra costs associated with fulfilling public service obligations are often deemed to be compensated by virtue of preferential tax treatment provided to those companies. As public service obligations may accrue only to particular electricity generators to the exclusion of others,

Zarrilli 2004, p. 258.

Lakatos 2004, p. 131

Ibid., p. 132. 
preferential tax treatment may tend to over-compensate certain operators (previously State monopolies) to the detriment of the other (new) operators on the market. ${ }^{4}$

Bradbrook, in favour of financial support being offered to companies fulfilling public service obligations, suggests that public service duties should go hand in hand with financial incentives so that companies seriously comply with their public service obligations. ${ }^{5}$ However, it is indeed questionable whether it is justifiable to provide financial incentives to any company to give motives to such companies to fulfil the duties which are required of them by law - those of providing public services. Problems may arise with respect to the provision of tax incentives when they are provided on a discriminatory basis, either within a State or across borders, between previously monopolistic industries and new market entrants. Under international trade law, tax incentives should not create trade-distorting effects or constitute unfair competition practices.

Subsidies are competition-distorting regardless of the motives behind their application - support of a domestic industry or development of environmentally friendly processes. Despite this, due to the lack of trade, and therefore also competition, in the past, market distortion was not an important issue affecting the electricity sector. Now, this is no longer the case. Tax incentives form an important part of subsidies provided to electricity generators and constitute potential tradedistorting measures.

Tax incentives may take the form of applying differential corporate tax rates to electricity generators depending on the inputs used. For instance, in order to maintain employment and commercial activity in a certain region, reduced tax rates may be applied to companies that use a minimum percentage of local inputs in generation. ${ }^{6}$ On the other hand, lower tax levels may be applied to companies that take significant measures in reducing the environmental damage caused by its electricity generation. Investment incentives, tax exemptions, tax reductions and refunds to influence electricity generators to use renewable energy resources all constitute tax incentives. ${ }^{7}$ Although some justifications for differential tax treatment may be proffered, tax discrimination resulting in national revenue foregone may constitute unfair subsidisation and significant market distortions. ${ }^{8}$

Having depended on academic literature for the above assumptions, it will be interesting to discover, in Part IV, to what extent these assumptions are confirmed by actual practice in the case study countries. Will it indeed be shown that the tax incentives provided to electricity generators are provided in a discriminatory manner creating international trade implications? Will it be discovered that the tax incentives were indeed motivated by the ratification by the subsidising countries of the Kyoto Protocol?

Ibid., p. 145.

Bradbrook 1997, p. 333.

Ibid.

Del Rio and Gual 2004, p. 219-234; Lakatos 2004, p. 140.

Lakatos 2004, p. 127. 
As taxation principles, tax rates and accounting practices differ from State to State, so too do the myriad of tax incentives made available. The unpredictable nature in which governments favour particular behaviour and aim to influence industries to pursue a particular course of action differs not only from State to State, but from industry to industry, between policies pursued and between governments in power and ministers in office. The unpredictability of the application of tax incentives, and the potential for measures to change annually with each new tax bill makes tax planning extremely important for companies aiming to maximise profitability.

Efforts made in pursuit of Kyoto Protocol obligations have a significant economic impact and have important tax consequences. ${ }^{9}$ On the one hand, it is in a company's interest to be aware of the tax consequences of possible actions it may take and to pursue the most economically viable path - being the actions which reduce the tax liability of the company to the lowest levels. Tax planning forms a very significant element of any business and is certainly not to be disregarded in relation to fulfilling Kyoto Protocol objectives. On the other hand, it is for governments to maximise the national welfare and in the interest of equity and the fulfilment of the ability-to-pay principle, to tax profitable industries and indeed to have more profitable industries bear a higher tax burden. Here, in relation to electricity generation industries, the tax treatment of income and expenditure with regard to efforts taken in pursuit of Kyoto Protocol obligations are of importance. ${ }^{10}$ Electricity industries should be taxed according to a State's normal income tax principles and should be subject to normal rates of taxation as other industries.

Electricity generators may approach the attainment of Kyoto Protocol obligations in a number of ways. In the following sections, actions which may be taken by electricity generators in pursuit of Kyoto Protocol objectives, but which may also trigger special tax treatment are addressed. The potential actions to be taken by an electricity generation company in reducing its emissions may involve investments, assets acquisition/disposal and trading in the emissions allowances/credits markets. ${ }^{11}$

\subsubsection{Equipment Investment}

The impact of electricity generation on the environment may be lessened by ensuring that the equipment used for electricity generation is of high quality and incorporates the latest in environmentally friendly technologies. In this sense, in pursuit of Kyoto Protocol objectives, an electricity generation company may opt for three different strategies. First, it can change the equipment in use in the company for less polluting equipment or carry out maintenance and repair on existing equipment to make the operation of that equipment more environmentally friendly. To renew or change equipment used in electricity generation, substantial investment is required.

Stevens and Pon 2002, p. 1.

Ibid., p. 2.

Ibid., p. 5. 
Another strategy involves the development of new renewable energy technologies. For this, extensive capital investments are necessary to acquire the technology to commence operation. Prior to a decision of a company to develop new renewable energy technologies, investment in research is necessary. This research provides the background to the future implementation of cleaner technologies. This step also creates excessive additional expenditure. Actions taken with Kyoto Protocol objectives in mind, such as research in and development of renewable energy technologies, maintenance or renewal of existing plant and equipment are all important investment decisions that have important financial consequences. The cost of these investments could, in absence of governmental tax incentives, be prohibitive.

As well as having financial consequences, such decisions also have tax consequences. Disposal and acquisition of assets, or changes to existing equipment affects the taxable income of a company. The tax consequences rest on the determination of whether the expenditure/investment in question is a capital expenditure or a current expenditure. This determination has a bearing on the tax treatment of the transaction. It is by creating special rules related to such investments that tax incentives are created for the burden of costs related to environmentally friendly investments to be lightened. The special tax treatment will be dealt with in more detail in following sections.

\subsubsection{Emission Trading}

Although emission trading is indeed an important policy in fulfilling Kyoto Protocol objectives, an in-depth treatment of emission trading is outside the scope of this research. This section intends to only briefly highlight the potential tax implications of emission trading.

As well as investing in new technologies and equipment, a company may choose to partake in the newly developed emission trading market in pursuit of its Kyoto Protocol obligations. This decision has tax consequences. Depending on whether emission rights are acquired for free or have an acquisition cost greatly affects the taxation of that company. Where no acquisition cost is in question, the accounting decision whether, and if so at what value, such emissions allowances are to be valued are important elements to be considered in relation to the decision whether to partake in the market. The decision to sell excess credits or to carry them over to future years also has tax consequences. Once again, special tax rules developed in relation to the trade in emissions allowances constitute tax incentives and aim at enticing companies to partake in the market for the environmental benefits attached.

\subsection{SPECIAL Tax TreatMent}

Taxation of enterprises must comply with the general principles of income taxation. A corporation's taxable liability is calculated based on its income reported in the company financial accounts for the financial year. The corporate tax rate, which differs from country to country, is then applied to the level of income for the taxable liability to be determined. 
It is clear that, as with all industries, the calculation of taxable liability of electricity generation companies is a complex one concerning classification, valuation and timing issues. Here it is illustrated that, in certain circumstances, there is a deviation from the normal principles of income tax rules and preferential treatment is given to companies for a myriad of reasons. The preferential treatment, in the form of tax incentives, affects in one way or another classification, valuation or timing issues, in order to reduce the income tax liability of the industry in question and to influence behaviour of the said industry in pursuit of environmental policy objectives. This will be further elaborated below.

\subsubsection{Classification and Valuation}

Important classification and valuation issues arise with respect to determining corporate tax liability. The determination and classification of capital versus current income and capital versus current deductible expenditure have significant effects in calculating taxable liability. For example, where expenditure is considered to be current expenditure it is fully deductible in the year the expense occurs, thereby reducing taxable liability in that same year. However, when an expense is capitalised, a value is attributed to increase the level of fixed assets in the annual accounts and the value of the asset is not immediately deductible as with current expenditure, but rather may be 'written off' (depreciated) over the deemed life-span of the asset.

Capital assets are considered to have a lasting benefit for the company. In this case, there are certain annual tax allowances (deductions) available in relation to the acquisition expenditure related to that asset. Capital assets are reduced by a depreciation rate. This rate reduces the value of that asset in the companies' accounts by a fixed percentage annually over the deemed life of the asset. The reduction in this value leads to an overall reduced taxable income for the company. Higher levels of depreciation reduce the book value of assets and in turn reduce the calculated profit levels reducing tax liability. With respect to depreciation rates, special rates are often provided by States for the acquisition of, or improvements to, assets which are 'environmentally friendly'.12 A provision allowing accelerated depreciation is a provision reducing taxable liability, and results in revenue foregone from the public purse. Such tax incentives aim to influence companies to incur the cost of acquiring the asset and the reward provided for environmentally friendly action is an initial reduced tax liability. ${ }^{13}$

A further method of providing an incentive for companies to invest in environmental conservation is the conversion of a capital expense into a current expense for tax purposes. Rather than the normal situation where the expense would be capitalised, (since the asset has a lasting value) and a depreciation rate be applied to its value over the deemed life span of the asset, as a 'fictional' current expense, the full amount relating to the acquisition may deducted at $100 \%$ in the year of acquisition. In

12 See ibid., p. 6. For example, in Canada certain assets, which are deemed to be in a class of equipment that benefits the environment, are deductible at up to $100 \%$ of the unclaimed balance per year.

13 Accelerated depreciation will be dealt with later in more depth for the analysis of the consistency of the case study accelerated depreciation provisions with the SCM Agreement. See section 8.4, Case Studies - Accelerated Depreciation Incentive, p. 159. 
addition, tax credits may also be provided for such current and capital expenditure; all reducing the taxable income of the company. ${ }^{14}$

\subsubsection{Emission Trading Allowances}

Emission trading could be a risky business. Since it is a completely new market, it is not clear to-date what the economic consequences will be. In addition, there is much uncertainty as to the accounting treatment, and therefore also the tax treatment of transactions involving emissions allowances. Despite economic, accounting and taxation consequences being unclear, some potential problems can already be highlighted which relate also to valuation, classification and timing.

It has already been determined by ECJ case law that the conferral of emission allowances by governments does not constitute conferral of a subsidy, in itself. However, since the tax treatment of the same allowances has not yet been addressed, the potential for special tax treatment to constitute subsidies (State aid) may not be ruled out. ${ }^{15}$ Only in the UK has the question been raised as to the potential tax consequences of attaining emission allowances. ${ }^{16} \mathrm{It}$ is predicted that the tax treatment of these assets will follow the accounting principles which apply to the valuation of such assets. Once again, little insight can be drawn from this statement to date, since such accounting principles as they should apply to emission trading have not been clarified. The accounting principles when developed should determine, also for tax purposes, the timing attached to the value of the asset or expenditure - when it is deemed to be acquired or the expense incurred. ${ }^{17}$ It is only at this point that it could be determined whether special valuation, classification or timing rules pertain to emission trading and then whether these special rules constitute subsidies.

\subsubsection{Classification}

With respect to the tax treatment of emission allowances, it is also important to first determine whether allowances should be treated as capital or current assets. The tax treatment of current and capital assets, as addressed above, furthermore differs in that gains on sale of capital assets are subject to capital gains tax, while gains on the sale of current assets create a corporate tax liability. Since capital tax is usually at a lower rate than corporate taxes, the classification of this asset as capital or current is important in determining tax liability. First, it must be determined whether the purchase/sale of emission allowances/credits may be considered to be an intrinsic element of the activity carried out in the electricity generation company; second it must be answered whether the transaction concerning the emissions allowances was of a trading nature of itself (independent of electricity production business); or it should be determined whether this trading constitutes an irregular occurrence - an 'odd transaction'. ${ }^{18}$

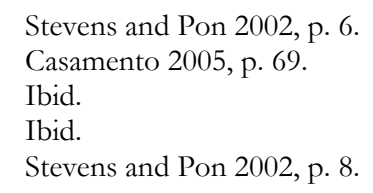




\subsubsection{Valuation}

Problems arise in determining the value to attach to the purchase of emission allowances as they are new market commodities which are often provided to companies at zero cost by the government. Irrespective of there being no real acquisition cost of the emission allowances, they do indeed attract a market value. The treatment of such assets in the financial accounts of a company has a bearing on the taxable liability. For instance where the acquisition cost (here zero) would be taken, no tax liability would ensue as the level of fixed assets would not be altered. However, a more equitable solution could be imagined that a 'fair market value' should be attributed to such assets. The valuation attached to such assets may operate as an incentive tool for companies to be active in this market, without their tax liability being negatively affected.

This fictional acquisition value also becomes important when the asset is sold later. The acquisition cost is deducted from the sale value in order to determine the taxable profit, the capital gain, and once again a fictional acquisition cost makes the determination of this gain rather flexible and open to manipulation for incentive creation. The normal tax treatment would be to tax the gain in full taking account of the zero acquisition cost.

Although the valuation treatment of emission trading is an indeed interesting one for tax treatment purposes, emission trading remains an area which could not be sufficiently dealt with within this research and reference to it aims only to highlight the existence of tax implications following from the treatment of acquisitions and disposals of emissions allowances.

\subsection{Pro-Kyoto Protocol TAx InCENTIVES}

In order for renewable energy technologies to have a chance to penetrate the electricity generation market governments have put tax incentives in place. ${ }^{19}$ Tax incentives are argued to be a flexible instrument for governments to achieve their desired policy objectives, in this case the development of renewable energy resources. Governments are in a position to make tax incentives available for the time deemed necessary to create a viable market position for renewable energy and once this is achieved, financial support may be retracted. ${ }^{20}$ Thus, a minimum of action required of governments in order for renewable energy to have a chance is for equal treatment to be provided to renewable energy as is and was provided to non-renewable energy.

It should be remembered that this research does not propose to answer (the much debated and already addressed) question of the efficiency of tax incentives versus other methods of governmental support. This research takes it as a given that efficient or not, governments pursue tax policy in pursuit of Kyoto Protocol objectives.

\footnotetext{
$19 \quad$ Bradbrook 1997, p. 313-337.

$20 \quad$ Ibid.
} 
Special tax treatment provided as an incentive for taking measures which aim to fulfil the Kyoto Protocol objectives may have more than one point of departure. Indeed there is justification for the creation of new incentive mechanisms which operate to provide financing possibilities to new projects aiming to develop renewable energy. However, yet another justification for further financing exists. A level playing field could be created between fossil fuels and renewable resources by extending equal financial support to renewable energy as is enjoyed currently and historically by nonrenewable energy resources. As such, justification for two types of pro-Kyoto Protocol tax incentive may be advocated. This argument could also be framed in making a distinction between initial investment and operating cost support.

However, before addressing these two avenues, on incentives in general, Bradbrook raises an interesting question which is fundamental to the debate on the provision of tax incentives by States for the development of renewable energy. He asks:

Why would a manufacturer of renewable energy or energy conservation products trade in a country where there is no adequate taxation incentives under the local tax laws, especially where differing and more favourable tax treatment is given to non-renewable resources?21

Bradbrook goes on to elaborate that in the area of the development of renewable energy technologies, private capital investment does not exist without a preferential legal regime in place, making the development of such industry more attractive. The reaction of governments to the Kyoto Protocol in creating an attractive scheme for renewable energy resources is not a new one. Such schemes have for a long time been made available to gas and oil industries without the protection of the environment justification. ${ }^{22}$ Not only have such schemes been in place for fossil fuels, such schemes, were they to be compared to schemes now in place for renewable technologies, would show that support of renewable energy pales in contrast to support of fossil fuel industries. ${ }^{23}$ The initial capital investment costs are often the initial insurmountable stumbling block that potential investors face when considering the option of introducing renewable energy resources, for example investment in wind turbines or photovoltaic cells or hydroelectric technology. ${ }^{24}$ In addition to these extravagant capital costs, a renewable energy developer also has the difficult considerations of finding an appropriate site for the development, and getting permits for the site. ${ }^{25}$ Thus, arguments for providing incentives for the investment in and development of new technologies existed in the past for nonrenewable energy resources and should in the same way be provided now for the development of renewable energy resources.

The competition between renewable energy resources, coal and oil and gas is not on a level playing field. Provision of financial support to greenhouse gas-emitting sectors creates a barrier to entry to the energy market for new renewable energy technologies.

Ibid., p. 314.

Ibid., p. 315.

Ibid.

Ottinger and Jayne 2001-2002, p. 38.

Milne 2005, p. 215-241. 
The Kyoto Protocol calls for such financial support to be rescinded. ${ }^{26}$ Were this requirement to be fulfilled, the revenue recaptured by the removal of tax subsidies provided to greenhouse gas-emitting electricity generators could be earmarked for the development of renewable energy electricity generation. ${ }^{27}$ Since fossil fuels are the greatest cause of greenhouse gas emissions and pollution, reduction of subsidisation in this area can not only make these energy resources more open to fair competition in the energy market but may also make more State revenue available to be transferred to the promotion of renewable energy resources. ${ }^{28}$

In addition to the argument that financial support of renewable energy is necessary to provide a level playing field between it and non-renewable energy, there exists a further, perhaps more significant justification. Environmental protection is a public objective, one which may justifiably be financed by the public purse. ${ }^{29}$

The return on investment in renewable energy technologies is not only to be achieved over an extensive time frame but is also not only reaped by the investors. Indeed future profits provide a return on investment for investors, however, in addition to this and perhaps more importantly, benefits are to be reaped by society in general through achieving a cleaner environment in which future generations may survive. There is a public good aspect to the development of renewable energy technologies and the resultant environmental benefits. The reduction of greenhouse gas emissions is a non-excludable benefit. ${ }^{30}$ The burden of investment in renewable energy technologies should therefore not only fall onto the shoulders of individual investors but considering the public good nature of the benefits to be reaped from such investment, should also fall on public finances and be supported through State resources.

Financial support is seen as necessary for renewable energy resources to be able to compete on the electricity market. ${ }^{31}$ The requirement of the Kyoto Protocol to increase use of renewable energy will undoubtedly result in an expansion of financial aid provided to this sector. ${ }^{32}$ The aim of such tax support would naturally be put in place in order to allow new renewable energy technologies to penetrate the existing market. $^{33}$

\subsection{EXAMPLES}

Bradbrook gives examples of tax incentives which, in his opinion, should be provided for the development of renewable energy. These include investment allowances, income tax deductions for expenses related to the development of environmentally friendly activities, for instance allowing for accelerated depreciation in relation to

26 Article 2(3) Kyoto Protocol calls for market imperfections to greenhouse gas-emitting sectors to be rescinded.

Ottinger and Jayne 2001-2002, p. 41.

Ibid., p. 20.

Bradbrook 1997, p. 313-337.

Woerdman 2002, p. 8.

Hancher 2004, p. 288.

Ibid.

Ibid., p. 289. 
assets related to renewable energy resources or tax credits and rebates for costs incurred in investing in, installing and maintaining assets for energy conservation. ${ }^{34}$ Again, the extent to which this academic assumption is supported in practice will be illustrated by the case study countries in Part III.

\subsection{INTERNATIONAL TRADE IMPACTS OF TAX INCENTIVES}

The liberalisation of the electricity market has not eliminated State intervention in the finances of electricity generation companies. Tax incentives are available which affect the financial position of such companies. In addition, the liberalisation of the electricity market means that there is now a real potential for differential tax treatment to distort competition on a national level and also across borders. Although, in light of Kyoto Protocol obligations, environmental policies play an important role in developing tax treatment, tax incentives aiming to influence companies to perform well with respect to protection of the environment may also distort competition or even constitute protectionist policies, favouring national over imported goods. ${ }^{35}$ The environmental protection justification of tax incentives may not be sufficient to allow such policies to discriminate between various electricity generators, whether between national operators or operators competing across borders.

The provision of tax incentives can be seen as putting limits on the extent of market liberalisation in the electricity sector. However, as discussed above, such limits to liberalisation could potentially be justified by the necessity of fulfilling certain public interests such as the protection of the environment. Another public interest which may justify the provision of tax incentives is the fulfilment of public service obligations. $^{36}$ Despite this public service justification however, once again, tax incentives must be provided in a transparent and equitable manner. There should be no unfair, protectionist, or discriminating elements attaching to the incentives which may call the true objective of those incentives into question. Bradbrook, in favour of tax incentives in this area, suggests that in addition to legislative public service obligations imposed on companies, such duties should go hand in hand with financial incentives for companies to seriously comply with this obligation. ${ }^{37}$ In support of this it is also clear that private corporations have commercial viability as a 'bottom line' and therefore even environmental objectives will be pursued to the extent that they are also a positive force in the overall commercial success of the company. If the environmentally friendly strategy is 'good for business' then it is a strategy which will be pursued. ${ }^{38}$

A difficulty occurs in relation to the provision of tax incentives for producing electricity from renewable energy resources since it is the nature of electricity that once it is produced and part of a pool, it is impossible to distinguish electricity produced from renewable energy and that produced from non-renewable energy. ${ }^{39} \mathrm{~A}$

Bradbrook 1997, p. 325 and p. 332.

Wälde and Gunst 2004, p. 206.

Klom 1997, p. 20.

Bradbrook 1997, p. 333.

Lucas 1996, p. 70.

Hancher 2004, p. 197. 
striking example of differential tax treatment based on origin of inputs to electricity generation was the European Court of Justice case Outokumpu $O y,{ }^{40}$ in which different tax rates were applied to different types of electricity generation, preferential rates being applied to locally produced electricity from renewable resources. ${ }^{41}$ However, the dispute at issue in this case was the fact that imported electricity also produced from renewable energy resources, did not benefit from the reduced tax rates and rather was subject to the same rates as Finnish electricity generated from nonrenewable energy resources. ${ }^{42}$ Finally, the Court held that the Finnish government, in order to avoid infringing the principles of non-discrimination, should afford foreign electricity generators the opportunity to provide proof that the electricity they produced was indeed produced from renewable energy resources and thus also benefit from the favourable tax treatment. ${ }^{43}$

Discriminatory tax treatment of electricity generators related to the origin of the goods in question was not permitted despite the environmental protection nature of the tax incentive. Such measures must be provided to all operators on the market irrespective of origin. The problem in relation to the provision of tax incentives to the electricity generation sector, to entice use of renewable energy resources occurs when such support measures are applied in a discriminating manner and not provided to all similarly situated actors on the market. ${ }^{44}$

The international trade implications of the actual tax incentives for renewable energy electricity generators, discovered in the case study countries in Part III, will be examined in detail in Part IV.

\subsection{CONCLUSION}

Rules for tax liability differ from State to State and depend on a complex range of issues. The application of tax incentives is an important element in determining tax liability. Special tax treatment, including special tax incentives for environmentally friendly policies, or maintenance of a locally important industry (eg. coal mining) play an important role in tax planning by companies. In view of Kyoto Protocol obligations, tax incentives can be an important policy tool in achieving the development of renewable energy technology.

Although it is recognised that subsidisation is not a healthy option as a long-term solution since market distortions resulting from such incentives create anticompetitive market structures. As discussed above, on the one hand, tax incentives

40 ECJ C-213/96, Outokumpu Oy, [1998] ECR I-1777, a Finnish case in which tracking the origin of electricity was also at issue. The Finnish tax system favoured renewable energy, however the method of production of the electricity could not be established when the electricity had already entered into the national grid. Foreign producers of renewable electricity were subject to a higher tax rate than the like producers of renewable electricity in Finland and thus were discriminated against. See also Fernández Armenteros 2005, p. 236.

Hancher 2004, p. 297.

Ibid.

Ibid.

Ibid., p. 288. 
provided at the initial investment phase are necessary, in particular with respect to the development of renewable energy technologies and creating a level playing field in the energy sector allowing for the penetration of renewable energy into the market. ${ }^{45}$

The potential for discriminatory treatment in the provision of tax incentives in a now liberalised electricity market open to competition has become a real issue. All tax incentives provided to electricity generators, whether located in the national territory or across borders must be provided without preferential treatment for certain generators. International trade in electricity is now possible and therefore international trade implications for trade distorting practices in the electricity sector have become a new legal complication in the provision of tax subsidies. National governments must now be aware of the potential trade distorting effects of the tax incentives provided to electricity generating industries, irrespective of the motivation for those incentives. 
Part II: European Regulatory Framework 



\section{Chapter 3 : EU Framework - Tax Aid for Renewable Energy}

\section{$3.1 \quad$ INTRODUCTION}

Before examining the case study tax incentives for renewable energy electricity generation and thereafter examining the consistency of these incentives with international trade rules, since four of the six case study countries are EU Member States, it is important to outline the legal framework within which these Member States have developed their environmental tax policy. In this respect, this chapter, which acts as a prelude to the case study examination of Part III, will provide the EU legal framework which deals with, inter alia, internal and external trade and competition issues and protection of the environment.

The European Union, having signed the Kyoto Protocol on the 29 April 1998 and approved it on the 31 May 2002, is under the legal obligation to reduce the aggregate level of greenhouse gas emissions in its Member States to $92 \%$ of the 1990 levels by 2012. ${ }^{1}$ Development of renewable energy is one of the objectives to be pursued in line with the Kyoto Protocol. In this regard, the EU has set a target level of renewable energy of $20 \%$ of total energy production, which it intends the Member States to reach by 2020 .

At the Member State level, Kyoto Protocol-ratifying countries pursue many policies to fulfil the Kyoto Protocol objectives, including the development of renewable energy through the use of direct tax incentives. Within the EU, direct tax incentives or tax subsidies, although developed at the national level, are not only subject to the national legal regime but must also be in line with EU law. All such measures employed by a Member State, whether in pursuit of Kyoto Protocol objectives or not, are bound by the general EU legal regime, in particular provisions dealing with internal trade in the EU, environmental protection, taxation policy and also of particular importance here, State aid rules.

The following section explores the position of direct tax incentives for the development of renewable energy electricity generation in the EU legal framework including environmental policy, tax policy and finally the State aid rules. The examination of this legal framework aims to highlight that direct tax incentives for renewable energy, although to be developed and applied by the Member States and not yet an area of harmonised EU law, indeed do have extensive support both within the general EU legal framework, and in particular in the legal framework dealing with State aid. Furthermore, by the end of this research, this EU legal framework may be juxtaposed with the WTO legal framework with the result that inspiration for an adequate approach to environmental subsidies may be imported from one legal framework to the other.

\subsection{PROTECTION OF THE EU ENVIRONMENT}

From 1957 until 1972, protection of the environment was not a primary objective for the European Economic Community. In the Treaty Establishing the European

$1 \quad$ See Annex B Kyoto Protocol. 
Economic Community [EEC Treaty], there was no explicit objective of environmental protection. The only related provision referred to 'the protection of the health and life of humans, animals and plants'. Article 36 TFEU, (ex Article 36 EEC; ex Article 30 TEC) ${ }^{2}$ allowed Member States to derogate from obligations pertaining to internal trade in so far as they were justified by this objective. Thus, as long as an environmental objective could be framed as protecting the health and life of humans and animals it was possible for an environmental protection measure, infringing free trade rules, to be justified.

In 1972, the Member States called for further action regarding protection of the environment. The First Environmental Action Programme was published. This programme introduced the 'precautionary principle', and the 'polluter-pays-principle' in to the EEC legal regime, along with the concept of incorporating environmental considerations into other policies, the integration principle. ${ }^{3}$ This impetus led to an expansion of the environmental regulations. ${ }^{4}$

At this time, the legal basis used for the new environmental regulations, since there was no legal basis yet specific to environmental protection, was one of two. Either Article 115 TFEU, requiring the approximation of laws of the Member States to eliminate certain impediments to the common market or Article 352 TFEU which calls for the implementation of measures which attribute to the functioning of the common market.

Over time it was recognised that resorting to such general legal bases for the development of EU environmental law was not sufficient and a more explicit legal base should be introduced. In 1986, the Single European Act introduced a new Title which dealt explicitly with the environment. The then Article 130r-t is now embodied in Article 114 TFEU paragraphs 3, 4 and 5. This new Environment Title enabled the Commission to propose legislation addressing environmental protection and such proposals would be based on the principles that preventive action is to be taken, that environmental damage should be rectified at the source and that the polluter should pay. From this time, a high level of environmental protection was introduced as an EU objective by the introduction of the principle that 'environmental protection requirements shall be a component of the Community's other policies'.

Although much progress was made by the Single European Act in establishing an explicit legal base for action in environmental protection, as always, there was still room for improvement and development. In 1992, the Maastricht Treaty further expanded the environmental objectives of the EU. Article 191 TFEU, Title XX, states that a common policy dealing with the environment should have as its objective, the preservation, protection and improvement of the quality of the environment, the protection of human health, rational use of natural resources and promotion of international regimes dealing with environmental hazards. The

2 Hereinafter, reference will only be made to the current article numbering according to the Treaty on the Functioning of the European Union. In addition, the European Union, or EU, will be referred to in place of the Community.

Collins 2001-2002, p. 185-214.

4 See in general on the history of the development of environmental issues into the EU law regime: De Búrca and Craig 2003 and Macrory, Havercroft and Purdy 2004. 
Maastricht Treaty added to the objectives introduced in the Single European Act Environment Title the objective to 'aim at a high level of protection', and be based on the 'precautionary principle'. Although the Environment Title calls for a high level of environmental protection as a base, it is ensured by Article 191 TFEU that this EU standard be considered to be just that, a minimum level. Member States are free to introduce environmental measures which go beyond the EU standards.

The Maastricht Treaty introduced environmental protection into the core objectives by adding to Article $2 \mathrm{EC}$ that in achieving sustainable and non-inflationary growth, respect for the environment should be maintained. In addition, the decision-making procedure under the Environment Title was amended to allow environmental measures to be decided upon with qualified majority voting in the Council. Article 2 EC was not taken over word-for-word into the Treaty on the Functioning of the European Union and instead the former wording of Article $2 \mathrm{EC}$, along with Articles 3 and 13 EC and Articles 2 and 6 TEU, provided a basis upon which Articles 2(1a) and 3(2) TFEU were elaborated adding to the objectives of the European Union. ${ }^{5}$ That is to say that the objectives of the European Union were elaborated to now include the objectives of the EC.

The inclusion of environmental protection in Article 2 EC in the Maastricht Treaty in 1992 was good news for EU environmental policy in general, however, with regard to the possibilities for EU environmental tax measures, the situation had not changed at all. The exception to the new qualified majority voting procedure for environmental measures related to measures (inter alia) of a tax nature. EU environmental tax measures continued to be subject to the unanimity requirement.

In light of this change in decision making procedure in general environmental matters, the subsidiarity principle was also amended, requiring the EU to take action only in areas which are not better resolved by the Member States. ${ }^{6}$ Therefore, although it is clear that the EU is competent in environmental protection issues, the competence is not exclusive. Subject to the subsidiarity principle, protection of the environment is a shared competence of the EU and the Member States. ${ }^{7}$ It is also clear that where environmental tax questions are at issue, the subsidiarity principle holds even more weight. Not only should the EU only take action where the issue is not better dealt with at the national level, but in order to do so, the 27 Member States must agree unanimously that this is the case.

Furthermore, in 1997, the Treaty of Amsterdam extended the importance of the protection of the environment objective by introducing another principle, first introduced in the First Environmental Programme - the integration principle, that the protection of the environment should be incorporated into all policies of the

\footnotetext{
5 Other than the new numbering and renaming of procedures and institutions, the TFEU did not provide for any major alterations to the status of European environmental law and policy. See Vedder 2010.

6 Article 3 TEC.

7 Borgsmidt 1999, p. 228-240.
} 
EU. ${ }^{8}$ Relevant areas include, for example, energy policy and tax policy which from that point should incorporate environmental protection into all policy considerations.

The TFEU, which came into force on 1 December 2009 has contributed further to the positive legal setting for environmental protection as well as the development of renewable energy in the European Union. This Treaty has reinforced the importance of the combating climate change and, of particular relevance for this study, the development of renewable energy. The objective of providing for sustainable development and a high level of protection and improvement of the quality of the environment is an explicit objective of the European Union enshrined in Article 3 TFEU. ${ }^{9}$ This objective also extends to a commitment in Article 21.2 TFEU to adopt iinternational measures to preserve and improve the quality of the environment and the sustainable management of global natural resources'. The Environment Title, as introduced in the SEA and expanded upon by the Maastricht Treaty emphasises the EU's commitment to worldwide environmental protection and explicitly refers to the goal of combating climate change.

A most important development made by the TFEU is the introduction of the new Energy Title. Article 194, Title XXI, explicitly addresses the EU's energy policy. This Article calls for European energy policy to be enacted with regard to 'the need to preserve and improve the environment' and reiterates the goal of the EU to promote energy efficiency and energy savings, and of particular importance here, the continued development of new and renewable sources of energy. This new Energy Title brings the overlapping fields of energy policy and environmental protection together and highlights the important role the development of renewable energy may play in that overlap.

Although in 1957, environmental protection was not at the top of the list of priorities in the EEC, at present and over fifty years later, there is an Environment Title and an Energy Title which call for the protection of the environment to be a common thread running through all of the policies of the EU and in which the importance of the goals of combating climate change and the pursuit of the development of renewable energy technologies play are underlined. Environmental protection is now an important objective of the EU. The loophole in the EU proactive environmental policy, however, is the development of EU environmental tax policy. Tax measures for environmental protection remain entirely in the hands of the Member States with any EU action being subject to unanimity.

\subsubsection{European Taxation and Environmental Protection}

As discussed above, within environmental policy, environmental tax policy mainly remains at the Member State level. In this regard, considering that tax policy remains an area of EU law in which the subsidiarity principle is of particular importance, it is worthwhile to take a brief look at EU tax policy in order to establish whether environmental tax incentives have a place in EU tax policy, and if so what this position is.

Collins 2001-2002, p. 185-214.

Ibid., p. 3 and p. 4. 
In the EU legal regime, taxation is a complex and difficult issue. First and foremost, the basic distinction between direct and indirect taxation plays an important role in the EU regime. Direct taxation is tax levied on income of natural or legal persons whereas indirect tax is tax levied on sales/consumption. EU tax policy is entirely concerned with the latter - tax on products. Direct taxation policy, being one of the last strongholds of the principle of subsidiarity, is not (yet) developed at the EU level. Despite this, it is appropriate to sketch the tax framework of the European Union, if only to illustrate the lack of provisions pertaining to direct taxation.

Taxation is dealt with in Article 30 and Article 110-113 TFEU. Article 30 prohibits customs duties of a tax nature applied to imports or exports while Article 110 TFEU allows Member States, through an internal system of taxation, to charge import taxes on products as long as such taxes are applied in a non-discriminatory fashion. ${ }^{10}$ Similar imported products and domestic products must be subject to the same level of taxation. Also, national products may not be protected by the national taxation system by discriminately taxing competing, or potentially competing products, from other Member States. Article 111 TFEU deals with export subsidies provided through the general taxation system of a Member State. Any refund of national taxes to exporters should not be in excess of the internal tax paid on the exported products.

The decision-making procedures relating to tax policy impose high hurdles to be jumped between the phase of the Commission introducing a proposal for an EU tax measure and the actual adoption and implementation of such a measure into the Member States' legal regimes. In relation to tax measures at the EU level, the decision procedure is laid down in Article 113 (of Chapter 2, dealing in general with tax provisions) and Article 192 TFEU.

\title{
Article 113 TFEU states:
}

\begin{abstract}
The Council shall, acting unanimously in accordance with a special legislative procedure and after consulting the European Parliament and the Economic and Social Committee, adopt provisions for the harmonisation of legislation concerning turnover taxes, excise duties and other forms of indirect taxation to the extent that such harmonisation is necessary to ensure the establishment and functioning of the internal market and to avoid distortion of competition. [emphasis added]
\end{abstract}

Although the high hurdles have been cleared for some EU tax policy to be developed, as seen in Article 113 TFEU, it is only in the realm of indirect taxation and only where it is essential for the effective functioning of the internal market.

As touched upon in the previous section, tax matters are also referred to in the Environment Chapter. Article 192(2) TFEU states:

By way of derogation from the decision-making procedure provided for in paragraph 1 and without prejudice to Article 114, the Council, acting unanimously in accordance with a special legislative procedure and after consulting the European Parliament, the Economic and Social Committee and the Committee of the Regions, shall adopt: (a) provisions primarily of a tax nature... [emphasis added] 
Article 192 TFEU falls under the general Title dealing with the environment, making it clear that tax measures to deal with environmental policies should be expected. However, any tax measures to be developed with a view to further European harmonisation or in pursuit of environmental goals at the European level would only be promulgated when all the Member States are unanimous. This provision refers only to 'provisions primarily of a tax nature' and does not distinguish between direct and indirect taxation measures. Thus, in the environmental arena, it is not impossible that EU action could indeed take the form of direct tax measures (as well as indirect tax measures) for environmental protection, with the condition of unanimity attached. Due to this stringent decision-making procedure, the harmonisation of taxation, or the adoption of EU level taxation measures in general was, and still is, hindered by the unanimity requirement. ${ }^{11}$

In the new Energy Title introduced in the TFEU, Title XXI, Article 194 similarly addresses tax measures pursued in light of the objectives of, inter alia, promoting the development of renewable energy. Article 194(3) states:

By way of derogation from paragraph 2, the Council, acting in accordance with a special legislative procedure, shall unanimously and after consulting the European Parliament, establish the measures referred to therein when they are primarily of a fiscal nature. [emphasis added]

As is the case with tax measures addressing environmental policies, tax measures pursuing the goals laid out in the Energy Title, such as the development of renewable energy, are also subject to the unanimity requirement. Once again, it is to be recognised that due to this stringent decision-making procedure, the adoption of EU level tax measures for the development of renewable energy, or in pursuit of other goals as per the Energy Title, is conditioned by the unanimity requirement.

Although much progress has been made since the 1970s to make protection of the environment and the development of renewable energy legitimate explicit objectives of the EU, where tax measures are pursued to this end, the situation has not changed significantly. Environmental tax measures as well as more specific tax measures for the development of renewable energy can be promulgated at the EU level with sufficient legal base; however, to be adopted they must jump the difficult hurdle of unanimity. Since EU tax policy deals only with indirect taxation, this hurdle is likely to be first jumped for an indirect tax measure. And indeed this has been the case. The development of the EU minimum energy tax (indirect tax) will be addressed in the next section.

To conclude, it is clear that despite treaty provisions making it legally possible to introduce $\mathrm{EU}$ direct tax measures for the protection of the environment, due to the unanimity requirement it is likely that this area will remain in the hands of the Member States in the foreseeable future, both from an environmental law, energy law and tax law perspective.

$11 \quad$ Franco and Herrera 2005, p. 181. 


\subsubsection{European Energy Tax}

As discussed above, provisions are made in the EU legal regime for taxation measures, direct or indirect, for environmental protection to be developed at the European level subject to the requirement of unanimity. Although this is a requirement which hinders development of such measures at the EU level, and rather leaves this type of policy in the hands of the Member States, the Commission has been 'successful' in introducing one such measure, the European Energy Tax. ${ }^{12}$ This measure took over ten years to clear the unanimity hurdle, but it finally did.

However, this research is concerned with direct corporate tax incentives for the development of renewable energy and although there has been extensive harmonisation of indirect tax measures (in general) at the European level, there is no harmonisation of direct tax measures. Considering that the introduction of EU-wide indirect tax measures with environmental protection motivation, an area in which the EU indeed does have much experience, was extremely difficult, it is clear that any such development addressing direct taxation would be close to impossible. The unanimity requirement ensures that any developments are won with difficulty. It is thus clear that there is no EU-wide action to be expected in the realm of direct tax incentives for the development of renewable energy. Thus, the investigation into the Member State direct tax incentives for the development of renewable energy, which is carried out in Chapters 4 to 6 , becomes even more important in view of the lack of action at the EU level.

\subsubsection{Development of Renewable Energy Resources}

Although development of renewable energy, with tax incentives, is mainly a Member State matter, the EU has provided a broad framework of encouragement for Member State action. These initiatives are explored in this section, with a view to highlighting the recognition of the EU of the role that tax incentives, and in particular direct tax incentives, play in this policy objective.

\subsubsection{Directive on the Promotion of the Use of Energy from Renewable} Resources

In 2001 Directive $2001 / 77$ on the promotion of electricity from renewable energy was adopted. ${ }^{13}$ In the Preamble to this Directive, it was recognised that although renewable energy is favourable for environmental protection and sustainable

12 Council Directive 2003/96/EC of 27 October 2003 restructuring the Community framework for the taxation of energy products and electricity amended by Council Directive 2004/74/EC of 29 April 2004 amending Directive 2003/96/EC as regards the possibility for certain Member States to apply, in respect of energy products and electricity, temporary exemptions or reductions in the levels of taxation and Council Directive 2004/75/EC of 29 April 2004 amending Directive 2003/96/EC as regards the possibility for Cyprus to apply, in respect of energy products and electricity, temporary exemptions or reductions in the levels of taxation.

13 Directive 2001/77/EC of the European Parliament and of the Council of 27 September 2001 on the promotion of electricity produced from renewable energy sources in the internal electricity market. 
development, as well as security of energy supply and fulfilling Kyoto Protocol objectives, this energy source is under-exploited in the EU. ${ }^{14}$ The general objective of this Directive was environmental protection, in particular in light of Kyoto Protocol obligations. ${ }^{15}$ It was recognised in this Directive that the development of renewable energy resources has an important role to play in complying with the EU obligations under the Kyoto Protocol and thus the Directive set a collective target of $20 \%$ of electricity to be from renewable energy by $2010 .{ }^{16}$ To achieve this collective target the Directive set national indicative targets for the consumption of electricity from renewable resources. ${ }^{17}$ The Kyoto Protocol played a significant role in the development of renewable energy policy since 1997 by setting binding targets for the period from 2008 to $2012 . .^{18}$

Directive 2001/77 on the promotion of electricity from renewable energy was replaced by Directive 2009/28 on the promotion of the use of energy from renewable resources. ${ }^{19}$ Directive 2009/28 sets a mandatory target level of renewable energy production to be achieved by each Member State by 2020, going far beyond the binding reduction commitment period set in the Kyoto Protocol, 2008-2010. Directive 2001/77 had established indicative targets and only until $2010 .^{20}$

A mandatory target of $20 \%$ is set by Directive $2009 / 28$ for the share of EU renewable energy production, to be achieved by Member States by fulfilling their mandatory national targets. ${ }^{21}$ While the $2001 / 77$ Directive focused on the production of electricity from renewable energy resources, ${ }^{22}$ the new Directive establishes production targets for renewable energy in electricity, heating and cooling and transport to be achieved by 2020 . The measures undertaken to achieve these targets

Directive 2001/77/EC, Preamble para. (1).

15 Commission Staff Working Document Annex to the Communication from the Commission The Support for electricity from renewable energy sources, Impact Assessment, SEC(2005) 1571.

16 Del Rio and Gual 2004, p. 219-234; Johnston et al. 2008, p. 126. Directive 2001/77/EC, Preamble para. (2).

17 Article 3 of Directive 2001/77/EC provides for indicative targets stating that Member States should 'take appropriate steps... in proportion to the objective to be attained'. $\operatorname{COM}(97) 599$ final, p. 4.

Directive 2009/28/EC on the promotion of the use of energy from renewable resources and amending and subsequently repealing Directives 2001/77/EC and 2003/30/EC, OJ L140/16, 5, June 2009. See also Mitchell and Tran 2009, available at: $<$ http://scholarship.law.georgetown.edu/fwps_papers/119/>, last visited 23 November 2009. In this paper Mitchell and Tran analyse the consistency of this Directive with the National Treatment obligation, the Most Favoured Nation obligation, and the Technical Barriers to Trade Agreement as well as the possibility for any such inconsistencies to fall within the Article XX of the GATT 1994 exception. Directive 2001/77/EC; See also Del Rio and Gual 2004, p. 219-234. Directive 2001/77 defined renewable energy resources as being energy produced from wind, solar, geothermal, wave, tidal, hydropower, biomass, landfill gas, sewage treatment plant gas and biogases. Directive 2009/28 added aerothermal, changed wave, tidal and hydropower to hydrothermal and ocean energy, and eliminated sewage treatment plant gas. See Article 2(a) of Directive 2009/28/EC. Article 3 of Directive 2009/28/EC. Del Rio and Gual 2004, p. 219-234; Johnston et al. 2008, p. 126. 
are chosen by each Member State in accordance with the conditions in that country and the national action plans. ${ }^{23}$

The Renewable Energy Directive provides for support mechanisms to allow renewable energy electricity (and heating and cooling energy) to enter the market. Included amongst these mechanisms is investment aid, tax exemptions or reductions, tax refunds, renewable energy obligation support schemes including those using green certificates, and direct price support schemes including feed-in tariffs and premium payments as well as a guarantee of origin scheme. ${ }^{24}$

The Directive also promotes public financial support of renewable energy with State aid measures. The Directive refers to the Community Guidelines on State Aid for Environmental Protection stating that it is recognised that national mechanisms supporting renewable energy continue to be necessary. ${ }^{25}$ Directive 2001/77 also referred to the Community Guidelines on State Aid for Environmental Protection stating that since such Guidelines have been issued by the Commission, 'national support mechanisms' to fulfil the goals of this Directive are permitted, in so far as they are in line with the Guidelines. ${ }^{26}$

The Renewable Energy Directive does not assume that EU measures are sufficient to achieve Kyoto Protocol objectives, or the $20 \%$ renewable energy target. As mentioned above, additional support measures to be pursued by the Member States are also listed: investment aid, tax exemptions, reductions and refunds. These measures, according to the Commission in the Preamble to Directive 2001/77, should be used in a way that gains and maintains the confidence of potential investors in renewable energy. ${ }^{27}$ Thus, although the Renewable Energy Directive does not prescribe the pursuit of tax incentives for the development of renewable energy, by their inclusion in the list of support mechanisms, the use of these measures is certainly encouraged.

\subsubsection{EU Support of National Tax Incentives for Renewable Energy}

In a 2005 Commission Communication on the support of electricity from renewable energy resources ${ }^{28}$ referred to tax measures as a 'good secondary instrument'. ${ }^{29}$ The Commission suggested that in order to optimise the measures used at the national level, Member States should, inter alia, make better use of tax exemptions and reductions for renewable energy products as provided for in the Energy Tax Directive. ${ }^{30}$

\footnotetext{
23 Article 4 of Directive 2009/28/EC.

Article 3(3) (a) in conjunction with Article 2(k) of Directive 2009/28/EC.

Fn 1 to Annex 1 of Directive 2009/28/EC.

Delvaux 2003, p. 107.

Directive 2001/77/EC, Preamble para. (14).

Communication from the Commission, The support of electricity from renewable energy sources, $\mathrm{COM}(2005) 627$ final.

29 Commission Staff Working Document Annex to the Communication from the Commission The Support for electricity from renewable energy sources, Impact Assessment, SEC(2005) 1571, p. 19.

$30 \quad \operatorname{COM}(2005) 627$ final, p. 16.
} 
The European Parliament, also in support of general tax incentives for renewable energy development, in a Resolution on the share of renewable energy in the EU and proposals for concrete actions, suggested that tax incentives are 'generally an effective way to promote renewable energies'. The European Parliament suggests that the Commission abolish any obstacles that hinder Member States from using measures such as tax cuts.

However, where tax exemptions are intended to be incentives for the use of renewable energy, the Commission considers that the exemptions are only effective in countries that have high levels of tax from which to be exempted. ${ }^{31}$ With respect to corporate tax rates in the EU the range is from 12.5\% in Ireland to 33\% in Belgium in 2009. ${ }^{32}$ Thus, it should be noted that according to the Commission, should direct tax incentives be implemented by the Member States for the development of renewable energy resources, these incentives would be effective only in the countries at the higher end of the corporate tax rate, for example in Belgium $(33 \%)$, the UK $(28 \%)$ or the Netherlands $(25.5 \%)$ but not so much in Ireland $(12.5 \%)$ ! Again, in Chapters 4 to 6 which investigate the direct tax incentives in the case study countries, this comparison of tax rates will be significant.

\subsection{STATE AID}

Despite the lack of EU level tax incentives for renewable energy, there is at least EU support for such measures implemented by the Member States. However, regardless of the numerous words of support, potential tax incentives must also comply with EU law. Of particular relevance to tax incentives are the detailed EU rules regulating the conditions under which aid - financial aid in the form of tax incentives - may be lawfully granted.

Article 107 TFEU defines incompatible State aid as aid, granted by a Member State which distorts or threatens to distort competition in the internal market by treating certain undertakings or the production of certain goods favourably. Article 107(1) stipulates that any aid (advantage) granted by a Member State or through State resources, in any form, which distorts or threatens to distort competition by favouring certain enterprises, shall, to the extent that it has trade effects between Member States, be incompatible with the internal market. Thus, the conditions to be fulfilled are: favourable treatment provided by the State or through state resources to a specific enterprise with the result that it affects trade between Member States. ${ }^{33}$

Article 107 TFEU also lists situations in which aid granted is not considered to be incompatible with the common market as well as situations in which the aid may be considered to be compatible aid. Such situations include 'aid to promote the execution of an important project of common European interest', ${ }^{34}$ and 'aid to facilitate the development of certain economic activities' ${ }^{35}$ the latter exception also

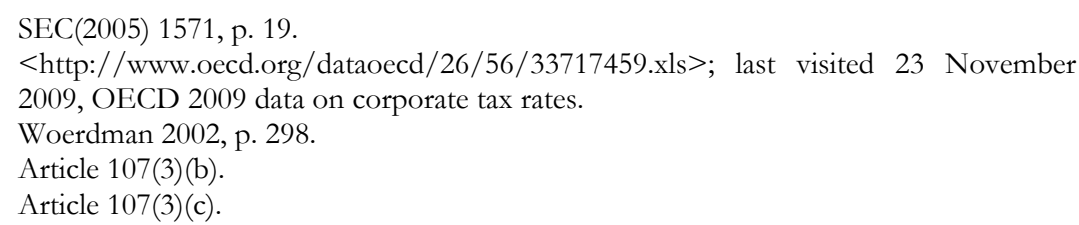


being subject to the condition that such aid does not adversely affect trading conditions where this would be contrary to the common interest. These two definitions of permissible aid cover situations of aid for environmental protection. In the situation where an important EU interest is at issue, further conditions must be fulfilled: the necessity test, the specificity test, it must be qualitatively important and must make a clear contribution to the common interest.

State aid within the EU regime is considered to be an advantage, such as a lower tax burden, conferred on a company, which is granted through State resources. To qualifiy as State aid, a measure should have an effect on the internal trade in the EU and should be applied in a selective manner. It has been noted by the Commission, however, that selectivity is not only determined by virtue of the fact that only a few companies access the financial support. Borgsmidt gives the example of investment aid for environmental investments in which she states that if an investment tax incentive is only used by those companies which make the investments, this does not necessarily indicate that a State aid is involved. ${ }^{36}$

When a Member State wishes to implement a measure that may be State aid, it is under obligation to notify that aid to the Commission, which then investigates and makes a decision on the compatibility of the aid with the State aid rules. The procedure under which Member States are obliged to notify new State aid or amendments to existing aid is laid out in Article 108 TFEU, in which it is stated that 'the Commission shall, in cooperation with Member States, keep under constant review all systems of aid existing in those States.' If a Member State fails to notify an aid measure, the Commission may nevertheless investigate that aid as 'unnotified aid' and decide on its compatibility with the State aid rules. Only after the Commission has made a decision that the aid is compatible aid can the Member State implement the measure. Where the Commission decides that a measure in incompatible aid which has already been implemented, it may recover the said aid.

With respect to the Member State tax incentives for the development of renewable energy, this power of the Commission will be revisited in Chapter 4, which examines the EU case study countries. The Commission decisions as to the compatibility of the measures in place in the case study countries with State aid rules will be elaborated on. The following section will deal with the status of environmental aid within EU State aid rules in general.

\subsubsection{The EU, State Aid and the Environment}

In this section, although primarily concerned with EU State aid rules, what is of particular relevance is environmental State aid. In addition to the rules on State aid as laid down in these Articles of the Treaty on the Functioning of the European Union, other provisions of the same Treaty are of relevance in this respect. In Part One of the Treaty on the Functioning of the European Union which deals with the Principles of the Treaty, Article 11 TFEU states that environmental protection must

Borgsmidt 1999, p. 228-240. Commission Notice on the Application of State aid Rules to Measures Relating to Direct Business Taxation, OJ C 384 of 10 December 1998, p. 3-9. 
be considered while all other policy areas of the EU are being developed (integration principle). The aim for sustainable development in the area of environmental protection is emphasised.

Article 11 TFEU is indeed an important starting point for incorporation of environmental protection considerations into the examination of State aid rules. Furthermore, since the ratification of the Kyoto Protocol, the European Union is under an international legal obligation to comply with the environmental protection objectives committed to by ratifying the Protocol. The Commission was aware, in the years leading up to the coming into force of the Kyoto Protocol, of the growing importance of climate change policies in international fora and recognised the potential conflict in objectives with EU law. The Eighth Survey on State aid in the European Union recognised that tax subsidisation of greenhouse gas reductions fell within the objectives of the Kyoto Protocol and is to be recognised as a category of State aid for environmental protection. ${ }^{37}$

Within the European Commission, DG Competition is responsible for the review of compatibility of State aid with the common market. Although, in that respect, DG Competition was responsible for the elaboration of the rules on State aid in environmental protection, the field of environmental protection belongs to the dossier of DG Environment. DG Environment is responsible for overviewing and prescribing the environmental policies put in place (and to be put in place) by the Member States in pursuit of Kyoto Protocol obligations. Furthermore, pro-Kyoto Protocol policies are to be pursued within DG Energy and Transport since energy is the primary sector targeted by the Kyoto Protocol.

The potential tension between DG Environment and DG Energy and Transport, and national Member State measures in pursuit of Kyoto Protocol obligations was solved as early as 1985. At the Conference of Permanent Government Representatives a Declaration was made in which it was clearly stated that in EU action aimed at environmental protection, the principle of subsidiarity is of utmost importance since national natural resource policies shall take precedence. The environmental protection measures pursued by the Member States, although supported by DG Environment or DG Energy and Transport and being national policies taking precedence over EU action, may nevertheless constitute State aid. The examination of the compatibility of these measures with EU State aid rules is the role of DG Competition.

As discussed above, environmental concerns crept into the EU mandate slowly from 1974 in the form of communications from the Commission intended as guidelines. ${ }^{38}$ The development of Guidelines on State Aid for Environmental Protection was very gradual. ${ }^{39}$ The following section addresses the treatment of renewable energy and tax

37 Eighth Survey on State Aid in the European Union, $\operatorname{COM}(2000)$ 205(01), 11 April 2000, Point 32.

38 See letter from the Commission to the Member States S/74/30807 from 7 November 1974 with the Communication from the Commission to the Member States of 6 November 1974 in annex; Delvaux 2003, p. 105. Ibid. 
incentives in the 2001 Community Guidelines on State Aid for Environmental Protection.

\subsubsection{2001 Community Guidelines on State Aid for Environmental Protection}

In view of the requirement for environmental protection to be taken into account when policing the compatibility of State aid with the common market, the Commission developed Community Guidelines on State Aid for Environmental Protection in 1994. ${ }^{40}$ These Guidelines remained intact until 2001 when they were reviewed and the need for updated Guidelines was recognised..$^{41}$ As stated in the introduction to the new 2001 Community Guidelines on State Aid for Environmental Protection, development in the area of environmental protection, in particular with regard to the adoption of the Kyoto Protocol, led to a need to re-evaluate the Guidelines at this time. In light of the Kyoto Protocol, the Member States, along with other international players, more frequently use State aid as an instrument in pursuit of objectives of environmental protection, and this aid is granted in particular to the energy sector. The Member States are encouraged to do so considering the absence of EU action in fulfilling the Kyoto Protocol obligations. ${ }^{42}$

Another reason for the importance of the new Guidelines at this particular time, according to the Introduction, is the tendency of Member States to now implement State aid in forms which were not common under the previous Guidelines, in particular State aid as tax subsidisation (tax reductions and exemptions). In addition, operating aid was beginning to be more frequently provided whereas in the past the focus was generally on investment aid. New Guidelines were necessary to take account of the change in response of Member States to environmental protection initiatives, and in particular in response to Kyoto Protocol obligations. There is explicit mention in the Guidelines of the use of State aid in energy production, especially renewable energy and sustainable development. ${ }^{43}$ The Guidelines highlight situations in which State aid is not prohibited, developing on Article 107(3) TFEU such as: subsidies being a remedy to a serious disturbance in a member State's economy, or State aid facilitating the development of certain economic activities or areas. ${ }^{44}$

As a departure from the previous attitude to State aid, where the Guidelines on State Aid for Environmental Protection aimed to clarify the requirements to be fulfilled for aid to be compatible with EU law without encouraging the proliferation of such aid, the 2001 Guidelines clearly encourage Member States to actively pursue this policy choice and, even more dramatic a development, to experiment with new incarnations of State aid. ${ }^{45}$ This political development, according to Fernández Armenteros, should not be underestimated. ${ }^{46}$ This encouragement is clearly seen in Part F of the Guidelines where the Commission identifies State aid as a means which may be

40 Community Guidelines on State Aid for Environmental Protection, [1994] OJ C 72/3. Community Guidelines on State Aid for Environmental Protection, [2001] OJ C 37/3. Community Guidelines 2001, Point 70.

Woerdman 2002, p. 297 and Community Guidelines 2001.

Ibid., p. 301.

Fernández Armenteros 2005.

Ibid. 
employed in complying with Kyoto Protocol obligations. However, since adoption of measures in the post Kyoto Protocol ratification phase was still in an early stage, the Commission did not put itself in a position to lay down the conditions, or provide a specific category or list of such measures exempted from State aid rules. ${ }^{47}$

The aim of the 2001 Commission Guidelines was to provide a clearer picture to policy makers in the Member States concerning the compatibility with EU law of their State aid measures aiming to improve environmental protection. The requirement of Article 11 TFEU to incorporate environmental protection concerns into other policy areas of the EU is by no means a carte blanche for Member State governments to apply State aid as they wish with the justification of environmental protection, despite the encouraging attitude of the Commission. Within the limits of the relevant treaty articles and the Community Guidelines on State Aid for Environmental Protection, the Commission maintains the power of overseer of all State aid measures and, regardless of environmental justifications, may strike a measure down should it fail to fulfil three conditions. The first of these conditions is that the aid should not distort (or threaten to distort) competition in the common market, second, the measure should fulfil the 'polluter pays principle'48 and third, the measure should take the sustainable development requirement of Article 11 TFEU into account.

State aid pursued by Member States must be for the purpose of environmental protection, provide for the costs of pollution to be borne by the polluter, ${ }^{49}$ and ensure a certain level of sustainable development to fall within the category of permitted aid within the meaning of the Community Guidelines and therefore, also within the meaning of Article 107 TFEU. The Community Guidelines specify three types of aid which may be deemed compatible: investment aid, ${ }^{50}$ aid to SMEs for advisory/consultancy services in the environmental field ${ }^{51}$ and operating aid..$^{52}$

\subsection{Investment Aid}

In 2001, significant changes were made to the EU regime, allowing for investment aid in pursuit of environmental protection objectives. In the past, provisions were made for aid provided to existing entities to be allowed to facilitate the adaptation to new environmental requirements imposed by EU law. ${ }^{53}$ This type of aid was no longer permitted under the 2001 Guidelines. Justification for this is also provided in the Guidelines where it stated that the EU standards constitute ordinary law and thus no encouragement 'to obey the law' is necessary. ${ }^{54}$ An exception to this was the

\footnotetext{
$47 \quad$ Ibid., p. 224.

48 The Polluter pays principle determines that all costs of the production of a product should be reflected in the price of the product. This includes internalising in the price of the product the cost to the environment is caused by its production. Polluter pays principle: Community Guidelines 2001, para. 6. This Principle first appeared in the Single European Act Article 174(2).

Community Guidelines 2001, Part E, Point 1.

Community Guidelines 2001, Part E, Point 2.

Community Guidelines 2001, Part E, Point 3.

Community Guidelines 1994.

Community Guidelines 2001, Point 21.
} 
provision for SMEs, in which case the 15\% subsidisation of adaptation costs was permitted over a three-year period from the time the EU standards had come into force. ${ }^{55}$

Although investment aid facilitating adaptation to minimum EU environmental requirements was, in general, no longer permitted by the 2001 Guidelines, the Commission nevertheless aimed to encourage Member States to pursue higher standards than the minimum standards imposed by EU law. By permitting investment aid in cases where higher standards then the EU minimum level were pursued or where no EU standard was yet in place, an incentive was to be given for such investment. ${ }^{56}$ The provisions of the Guidelines dealing with this encouragement of higher standards was quite revolutionary, stating that where it can be shown to be necessary, levels of up to $100 \%$ investment aid are permitted to promote renewable energy resources. ${ }^{57}$

It is clear from the Commission's attitude to permitting investment aid that it is willing to pull out the stops where Member States wish to take radical action in pursuit of environmental protection through the development of new renewable energy solutions. It is no surprise that the threshold of innovation required for aid to be permitted to be increasing steadily as the compulsory environmental standards at the EU level also increase. It is indeed clear that if renewable resources are to become competitive, provisions for allowing some forms of subsidisation is necessary. ${ }^{58}$

\subsection{Operating Aid}

A further impressive development in 2001 to the Commission's attitude to permitted aid was the extension of the categories and concepts of operating aid from merely exemption from environmental taxes and aid concerning waste management. The new regime under the 2001 Guidelines provided for three distinct situations of operating aid, which normally would have constituted incompatible aid under the general rules. This development occurred as a reaction to the de facto situation in the Member States where new forms of operating aid were appearing.

Since renewable energy resources are at a comparative disadvantage to traditional energy resources (fossil fuels), ${ }^{59}$ the Commission deemed operating aid for renewable energy resources compatible aid. The aid may take the form of equalising the difference between the production ${ }^{60}$ costs of renewable energy and the market price of that energy. Many Member States have implemented new mechanisms which

$55 \quad$ Community Guidelines 2001, Point 28.

$56 \quad$ Community Guidelines 2001, Points 20 and 29.

$57 \quad$ Community Guidelines 2001, Point 31.

58 Renewable costs 3 times conventional to produce. Faure, Gupta and Nentjes 2003, p. 201.

59 High investment costs, unable to compete with the already subsidised and the firm market position of fossil fuels: government subsidies on fossil fuel produced energy keeps the costs of this energy artificially low. Ibid., p. 200.

60 Renewable energy has higher production costs than fossil fuel produced energy. This also results from the fact that external costs - such as costs to the environment - are not internalised into the cost of production of non-renewable energy. Ibid., p. 200. 
support the production of renewable energy by creating a compulsory market for renewable energy through market instruments such as green certificate systems. Although such aid must be seen to be necessary and not provide excess compensation to the renewable energy producers, it may be allowed for up to 10 years. The third type of operating aid which may be provided to new producers of renewable energy is based on the avoided environmental costs which would have been incurred by society had the energy been produced otherwise. In other words, this is a type of reward provided to renewable energy producers for causing neither damage to the environment nor cost to society, like other energy producers.

\subsection{Operating Aid in the Form of Environmental Tax Exemptions/ Reductions}

As addressed earlier, the 1994 Guidelines also provided for operating aid schemes, namely exemption from or reduction of tax burden. ${ }^{61}$ Despite the rules on this form of State aid already being in place, the 2001 Guidelines did not neglect to also address them, and does so in a more detailed fashion. Such State aid had been endorsed by the Commission - CO2 tax exemptions applied in the Netherlands, Denmark, Finland and Sweden. ${ }^{62}$ However, the exemptions and reductions in taxes relate only to environmental taxes. Exemptions from or reductions of other taxes are not covered by the 2001 Guidelines, thereby remaining potentially incompatible State aid under the general rules, should such aid be granted.

With respect to investment and operating aid in the form of tax exemptions, they may be granted only for a maximum of ten years. Furthermore, with respect to future tax exemptions, the Commission declared that it would be flexible in determining whether State aid exists or not. ${ }^{63}$

There are two cases in which a reduction to or exemption from a tax which has as its purpose environmental protection may be State aid which is deemed compatible with the Common Market. The first is where such a tax is a new tax that is not of a type which has been implemented at the European Union level, or alternatively goes beyond the requirements of the harmonised EU tax. Such exemption/reduction may be justified for a period of ten years if they come about after an environmental agreement is negotiated and concluded by the Member States and are also monitored by the Member States (which includes providing for penalties in cases of failure to fulfil the terms of the agreement). The Commission maintains the power to review such agreements.

The second case in which exemption from or reduction of environmental taxes is justified is where the environmental taxes have EU action as their origin. The Commission provides that in situations where Member States exempt companies

Delvaux 2003, p. 109.

Woerdman 2002, p. 302.

Community Guidelines 2001. 
from tax levels which are higher than the minimum imposed under EU law, these excess amounts may be permitted State aid according to the Guidelines. ${ }^{64}$

\subsubsection{Review of the Community Guidelines on State Aid for Environmental Protection}

In 2005, the Member States of the European Communities reacted to a Commission questionnaire on the review of the 2001 Community Guidelines on State Aid for Environmental Protection. An interesting revelation in the responses was in relation to the development of a Block Exemption Regulation for environmental aid. There was strong support for the introduction of such a block exemption, with the UK suggesting, among other areas, that support for renewable energy should be included. ${ }^{65}$ The idea of the block exemption was to create a more simplified approval system for Member State aid schemes, where they fall within the Guidelines. Ireland was also of the opinion that the procedures were too cumbersome and thus a disincentive for introducing new State aid. The Member States considered that the State aid rules were underused due to their complexity. Belgium also followed suit, calling for a simplification of the rules. ${ }^{66}$ The Netherlands was also in favour of a block exemption for State aid for renewable energy. ${ }^{67}$

Another general remark was that the level of aid allowed might not have been enough to incentivise action in the environmental sector. The UK considered that the minimum aid necessary to incentivise environmental action was not always enough to justify a new project. ${ }^{68}$ The UK was also of the opinion that using fixed percentages to determine whether the amount of aid is allowed was not flexible enough. Ireland was also of this opinion. According to Ireland, the allowed aid intensities were not sufficient to encourage real action by companies in environmental protection. ${ }^{69}$ Ireland stated that it had not made use of the Guidelines for this reason. It also stated that an increase to permitted aid could be justified by the Kyoto Protocol obligations.

64 The Demand side of providing electricity suppliers/producers with a tax rebate or reduction in environmental taxes is the same type of subsidy provided to purchasers of green electricity. Faure, Gupta and Nentjes 2003, p. 212.

65 UK response, available at: < http://ec.europa.eu/competition/state_aid/reform/ comments_environmental_protection_revision/38229_en.pdf >; last visited, 24 November 2009, p. 7.

66 Belgium response, available at: < http://ec.europa.eu/competition/state_aid/reform/ comments_environmental_protection_revision/38464_nl.pdf and $<\mathrm{http}: / /$ ec.europa. eu/competition/state_aid/reform/comments_environmental_protection_revision/387 47_fr.pdf $>$; last visited 24 November 2009, p. 2.

67 Netherlands response, available at: <http://ec.europa.eu/competition/state_aid/ reform/comments_environmental_protection_revision/38137_nl.pdf $>$; last visited 24 November 2009, p. 4.

68 UK Response, available at:

$<$ http://ec.europa.eu/competition/state_aid/reform/comments_environmental_prote ction_revision/38229_en.pdf >; last visited, 24 November 2009, p. 9.

69 Ireland Response, available at: < http://ec.europa.eu/competition/state_aid/reform/ comments_environmental_protection_revision/38753_en.pdf $>$; last visited 24 November 2009, p. 2. 
Belgium opened its response with a general statement that Belgium wished to remind that the State aid rules are restrictive, considering the EU objectives regarding renewable energy. In its response, Belgium maintained its concern for the application of State aid rules with respect to the development of renewable energy, and the fulfilment of Kyoto Protocol objectives. ${ }^{70}$ Furthermore, Belgium was of the opinion that the percentage rates of allowed aid should be increased for innovative technology relating to renewable energy resources in order to compensate for the risk associated with launching such technologies onto the market. ${ }^{71}$ The Netherlands went into detail to show that the levels of permitted aid do not compensate the net cost to the company to take the environmental action. From this perspective the Netherlands emphasised the indirect benefit of the environmental action to the general community and not just to the company receiving payment. The Netherlands emphasised that at the permitted levels of aid companies were not being given incentives to take environmental action as there was no commercial advantage of doing so since the State aid only served to compensate the cost. In addition, extra risks associated with introducing innovative technology were not included in the calculation of the aid allowed. ${ }^{72}$ The Netherlands considered $100 \%$ permitted State aid for renewable energy an adequate level.

A special section of the review was devoted to tax reduction/exemptions. Here the UK considered that rules in this area should be more flexible and temporary tax measures should be allowed, to compensate for temporary loss of competitiveness from for example, the introduction of a new climate change levy. This flexibility is necessary according to the UK bearing in mind that tax matters are annually changing and extensive changes often come about with changes of government. It is interesting that Ireland's response to the questions relating to taxation was: 'We have no experience to draw from here'. ${ }^{73}$

Another point of interest raised by the UK, and further touched upon in the next section, 'State aid and direct business taxation', is that nowhere in the 2001 Guidelines was there reference to recipients of aid, or beneficiaries, other than to

70 Belgium response, available at: < http://ec.europa.eu/competition/state_aid/reform/ comments_environmental_protection_revision/38464_nl.pdf $>$ and $<$ http://ec. europa.eu/competition/state_aid/reform/comments_environmental_protection_revisi on/38747_fr.pdf>; last visited 24 November 2009, p. 2.

71 Belgium response, available at: < http://ec.europa.eu/competition/state_aid/reform/ comments_environmental_protection_revision/38464_nl.pdf $>$ and $<$ http://ec. europa.eu/competition/state_aid/reform/comments_environmental_protection_revisi on/38747_fr.pdf $>$; last visited 24 November 2009, p. 3.

72 Netherlands response, available at: <http://ec.europa.eu/competition/state_aid/ reform/comments_environmental_protection_revision/38137_nl.pdf>; last visited 24 November 2009, p. 6.

73 Ireland Response, available at: <http://ec.europa.eu/competition/state_aid/ reform/comments_environmental_protection_revision/38753_en.pdf $>$; last visited 24 November 2009, p. 5. 
direct recipients/beneficiaries. The UK proposed that in future editions of the Guidelines this be amended. ${ }^{74}$

As will be shown in the next section, in 2008 the Commission took the comments of the Member States seriously and introduced a new set of Guidelines with extended aid levels, in particular for the development of renewable energy, and also introduced a General Block Exemption Regulation for, inter alia, environmental aid. This being the case, a proliferation of aid for environmental protection may be expected, and not least in the form of tax incentives for renewable energy.

\subsubsection{2008 Community Guidelines on State Aid for Environmental Protection}

In January 2008, the European Commission adopted new Guidelines on State Aid for Environmental Protection, ${ }^{75}$ following a general review of all State aid policy commenced in the State aid Action Plan in 2005. ${ }^{76}$ This overhaul was designed to simplify State aid rules so that the Member States could pursue environmental policies by introducing environmental aid without an excessive administrative burden attached, in particular in straightforward cases with which the Commission has much experience. $^{77}$

Upon receipt of suggestions for reform of the Guidelines in 2006, as discussed in the previous section, it was unclear whether the Commission would take the comments of the Member States seriously and indeed introduce simplified approval procedures, extended aid levels and a block exemption approval regulation. Some two years later based on the comments of the Member States, the new 2008 Community Guidelines on State Aid for Environmental Protection were adopted.

The changes introduced in the new 2008 Guidelines are in line with the Member States' comments resulting from the consultation process. A simplified general balancing test is to be used in determining compatibility of all aid with the State aid rules. In addition to this general test, the Guidelines categorise twelve different types of aid and address the applicable aid intensity for each category as well as the additional conditions to be fulfilled by compatible aid. The categories include, inter alia: aid for renewable energy resources; aid for environmental studies; aid for energy saving; aid for cogeneration and aid for district heating (DH); and aid in the form of tax reductions of or exemptions from environmental taxes.

\footnotetext{
74 UK response, available at: <http://ec.europa.eu/competition/state_aid/reform/ comments_environmental_protection_revision/38229_en.pdf>; last visited, 24 November 2009, p. 10.

75 On 23 January 2008, the Commission adopted the new Community Guidelines on State Aid for Environmental Protection [2008] OJ C 82/01, available at: $<$ http://ec.europa.eu/comm/competition/state_aid/reform/environmental_guideline s_.

76 State aid Action Plan: Less and better targeted State aid, a roadmap for state aid reform 2005-2009, COM (2005) 107 final.

Ní Ghiollarnáth 2009.
} 
The suggestions of the Member States to include special provisions for aid for renewable energy were taken seriously. ${ }^{78}$ Furthermore, the aid intensities for renewable energy were increased to the extent that up to $100 \%$ aid might be provided!79 This level of aid is thus to make it more feasible to make real environmental changes and progressive renewable energy development through the use of State aid policy.

\subsubsection{General Block Exemption Regulation}

The suggestions by the Member States to create a system of Block Exemption for particular types of aid with which the Commission has much experience, and thereby reduce the administrative burden on the Member States, were taken on board. The Commission introduced a General Block Exemption Regulation ${ }^{80}$ setting out simplified rules not only for environmental State aid but also for regional aid, SME investment aid, aid for consultancy and SME participation in fairs, aid in the form of risk capital, aid for research and development, training aid and aid for disadvantaged and disabled workers. ${ }^{81}$

Environmental State aid falls under Section 4 of Block Exemption Regulation further simplifying the obligations of the Member States. Section 4, Articles 18 to 25 cover eight forms of environmental State aid covered by the Exemption Regulation:

- Investment aid enabling undertakings to go beyond Community standards for environmental protection or to increase the level of environmental protection in the absence of Community standards;

- Aid for the acquisition of new transport vehicles which go beyond Community standards or which increase the level of environmental protection in the absence of Community standards;

- Aid for early adaptation to future Community standards for SMEs;

- Environmental investment aid for energy saving measures;

- Environmental investment aid for high-efficiency cogeneration;

- Environmental investment aid for the promotion of energy from renewable energy sources;

- Aid for environmental studies;

- Aid in the form of reductions in environmental taxes.

State aid for the promotion of energy from renewable energy resources is included in this list. This development provides that environmental investment aid, for the development of renewable energy, is no longer subject to a notification obligation up

78 Community Guidelines 2008, Sections 1.5.6 and 3.1.6.

79 Community Guidelines 2008, Section 3.1.6, Point 104.

80 Commission Regulation (EC) No. 800/2008 of 6 August 2008 declaring certain categories of aid compatible with the common market in application of Articles 87 and 88 of the Treaty (General block exemption Regulation) [2008] OJ L 214/3, adopted August 2008.

81 See in general: Deiverova and Nyssens 2009, p. 27-38; and Berghofer 2009, p. 323-336. 
to an aid intensity of $45 \%{ }^{82}$ and Member States are relatively free to introduce such measures with greater ease and speed. ${ }^{83}$

A Member State introducing a new State aid measure with a view to increasing environmental protection and developing renewable energy has a new set of simplified rules to abide by. Although, as will be examined in Chapter 4 , none of the case study tax incentives were introduced after the adoption of the General Block Exemption Regulation, the introduction of new aid for the development of renewable energy resources in the future, it will definitely be relevant and important in Member States' decisions to introduce new aid for the development of renewable energy resources in the future.

It is heartening to see that the consultation process undertaken by the Commission in updating its policy guidelines was more than window dressing and that the comments of the experts, the Member States and the interested third parties led to some positive development in a relatively short time. It is hoped that the introduction of the new Guidelines and the Block Exemption Regulation that the transparency and accessibility of State aid rules will lead to a healthy proliferation of environmental State aid, including direct tax incentives for renewable energy development, resulting in real action combating climate change. These changes, although addressing all forms of aid but indeed encompassing tax incentives, make the future for tax incentives for the development of renewable a brighter one within the EU.

\subsubsection{State Aid and Direct Business Taxation}

Although, at the European level, extensive rules have been established in relation to State aid, and of particular relevance here, State aid for environmental protection, the majority of State aid schemes approved by the Commission to date in this field have related only to indirect taxation measures. Of particular interest in this respect have been the exemptions from energy taxes (indirect tax on energy products) applied to energy intensive industry and low carbon emitting sectors by many Member States. However, since this research focuses on direct tax incentives for the development of renewable energy, it is interesting to note the lack of EU involvement in this area.

It is widely recognised that direct taxation issues are not at the fore of EU taxation policy. However, this does not render the potential discussions fruitless. In this regard, the Commission has, in a follow up to the Code of Conduct for Business Taxation $^{84}$ - a voluntary Code dealing with direct taxation issues from an EU perspective - published a Notice on the application of State aid rules to measures relating to direct business taxation. ${ }^{85}$

\footnotetext{
82 General Block Exemption Regulation, Section 4, Article 23.

Deiverova and Nyssens 2009, p. 34.

Resolution of the Council of representatives of the governments of the Member States, meeting with the Council of 1 December 1997, on a Code of Conduct for business taxation, OJEC, No. C2 of 6 January 1998.

85 Commission Notice on the application of the State aid rules to measures relating to direct business taxation, 98/C 384/03 of 10 December 1998.
} 
In order to be considered State aid, direct business taxation measures must, as is the case with any State aid measure, fulfil the general criteria. Namely an advantage is conferred by the State, which affects competition and trade between the Member States and constitutes a specific or selective measure. The 1998 Notice of the Commission aims only to clarify the application of State aid rules to direct tax measures. It does not in any way make available a new set of State aid rules specifically for this form of measure.

State aid in the form of tax measures poses an additional difficulty with respect to the condition of specificity. Where a tax measure is potentially applicable to all economic actors in a Member State, it is a general tax system measure and not State aid. However, where such a measure is only available to a certain sector of economic actors or particular products, it may indeed, having fulfilled the rest of the conditions be considered State aid. ${ }^{86}$ Thus, any deviation from the general system of taxation, to the advantage of one firm or a group of firms may constitute State aid. It should be borne in mind that only measures, which are part of the general system of taxation and applicable to the whole territory of the Member State, definitely do not fulfil the specificity criteria. Where a measure deviates from the general system of taxation, a justification that the measure is necessary for the proper functioning of the general tax system may save it from the State aid rules.

It is recognised by the Commission Notice that aid, whatever its form, including direct tax measures, may distort trade within the internal market. The Notice aims to highlight the potential of certain tax schemes in the Member States to fall within the State aid rules, and be harmful to competition.

In addition to outlining the criteria for a measure to be considered State aid, the Notice lists the situations where, as long as the measure is not specific, measures falling within the definition are accepted. Within this list are measures which pursue 'general economic policy objectives through a reduction of the tax burden related to certain production costs - such as environmental protection. ${ }^{87}$ The Notice goes on to clarify that even though in certain circumstances, direct tax measures in pursuit of environmental policy objectives are more beneficial to some firms than others, that 'does not necessarily mean that they are caught by the competition rules governing State aid'. ${ }^{88}$ A poignant example is given whereby the Commission states that, where environmental incentives are put in place, the fact that they only benefit those companies that undertake the environmental investment does not necessarily mean that the measure constitutes State aid. Such measures must be in proportion to, and targeted at, the aims sought'. ${ }^{89}$

As with aid granted in other forms, aid in the form of relief from direct taxation is subject to the same notification requirements. Aid schemes should be notified in advance and should not be implemented prior to Commission approval. ${ }^{90}$

Case 173/73, Italy v. Commission, 1972, ECR 709.

Commission Notice, para. 13.

Commission Notice, para. 14.

Commission Notice, para. 33.

Commission Notice, para. 34. 
In 2004, the Commission published a report on the implementation of the above Notice. In this report, a clearer picture is given of the type of taxation methods used in the Member States which could be affected by the State aid rules. In the report, the complexity of this area of State aid becomes apparent. In the use of pricing methods in transfer pricing for example - cost-plus method - advantages may be conferred on the companies in question. From this one example it is clear that it is the economic reality of the taxation of companies that creates a State aid issue, as opposed to the particular tax arrangement. It is the effect of the tax rules rather than the intention behind the tax rule that is the determining factor in whether it is State aid or not. However, despite paying adequate attention to such technically difficult State aid, the report also pays tribute to the more traditional forms of State aid - clear and simple tax exemptions or tax deductions.

One of the more significant clarifications of this report is the recognition that the recipients of aid, or the beneficiaries of aid, 'are not necessarily confined to the firms subject to a special tax measure. Rather account must be taken of the actual effects of the aid, with a view to classing as aid recipients all firms which have actually benefited from it'.

\subsection{CONCLUSION}

In the EU a clear and strong legal framework, which provides motivation and support to the Member States in their pro-Kyoto Protocol policy-making, is in place. There is a clear growth in the importance of the development of renewable energy within the EU and Member States are obliged to strive for a target of $20 \%$ share of renewable energy by 2020. Tax incentives are recognised as policies which Member States pursue in fulfilling this renewable energy target as well as the Kyoto Protocol reduction commitments.

Further support of these tax incentives for the development of renewable energy in the EU is found by the development of special State aid rules governing environmental aid and a General Block Exemption for certain environmental aid. The approach of the EU will be seen to be quite remarkable and innovative when the analysis of the WTO analysis is undertaken in Chapters 7-10.

The Community Guidelines on State Aid for Environmental Protection as well as the new General Block Exemption Regulation provide Member States with a legal environment within which aid for the development of renewable energy is not only compatible with the EC Treaty, such aid is openly encouraged. Furthermore, the proliferation of Communications, Directives and Regulations addressing the development of renewable energy and recognising the need for aid in order for this sector to flourish and compete with conventional energy serves to further the cause for incentives for renewable energy.

The following chapters will examine the actual tax incentives for the development of renewable in place in the case study countries. Since four of these case study countries are Member States of the EU (the Netherlands, Belgium, Ireland and the United Kingdom), the tax incentives will also be examined with respect to the State 
aid rules. This will potentially create a point of tension once the mirror analysis is carried out with respect to the WTO subsidy disciplines.

The Environmental State aid Guidelines provide for clear circumstances in which subsidies may be provided for the purpose of environmental protection, and the Block Exemption Regulation provides for situations in which aid for renewable energy need not even be notified to the Commission! Although indeed the direct tax incentives for renewable energy should be developed and implemented by the Member States, clear support is provided by the EU in making it legally possible to do so. 
Part III: Tax Subsidies Applied in the Case Study Countries

Descriptive Outline of Case Study Tax Incentives 



\section{Introduction}

The case study countries examined include six countries, namely Ireland, the United Kingdom, Belgium and the Netherlands, Canada and New Zealand. The choice of case study countries was motivated by the starting point of this thesis - the national obligations arising out of the ratification of the Kyoto Protocol. For this reason the choice of case study countries was limited to countries having (at that time) ratified the Kyoto Protocol and only countries being Annex I countries subject to the legal obligation to reduce carbon emissions. The choice of case study countries was also limited by language constraints (English, French and Dutch). From these considerations the EU Member States: Ireland, the United Kingdom, Belgium and the Netherlands were chosen.

Outside the EU the only Annex I countries having ratified the Kyoto Protocol at the time this research was undertaken were Canada, New Zealand, Iceland, Japan, the Russian Federation, the Ukraine and Norway. Considering the focus of the research was to rest on the examination of the consistency of the tax incentives with WTO rules on subsidies, the Ukraine was eliminated as it was not yet a WTO Member as was the Russian Federation which is still not a WTO Member. Finally, it was decided that the last determining factor in the choice of non-EU case study country would rest on the neighbouring countries, and trading partners of the most important nonKyoto Protocol-ratifying States, the USA and Australia, namely Canada and New Zealand.

The choice of case studies also provided a broad geographical coverage, covering three continents from Europe to North America and Oceania. 



\section{Chapter 4 : Tax Subsidies Applied in EU Member States}

Although both at the international and EU level, new systems to reduce greenhouse gas emissions have been developed in pursuit of Kyoto Protocol objectives, such as tendering systems, feed-in tariffs and green certificates, more traditional policy choices have also been introduced such as tax incentives. Although most countries use at least one of the above-mentioned mechanisms, they are more often than not used in conjunction with tax measures. ${ }^{1}$ Indeed it was argued that in the past, tax policy was the 'most used new environmental policy instrument in the Member States'. ${ }^{2}$

Although not new anymore, it will be seen that tax policy still plays an important role. As discussed in Chapter 1, the measures pursued by Kyoto Protocol-ratifying States to reduce their emission levels are to be national measures. This is particularly the case with respect to tax measures as any EU level efforts to address Kyoto Protocol goals which encompass the use of tax measures are subject to the stringent unanimity decision making. Any EU level efforts aiming at coordinating the Member State use of tax measures, even for environmental goals, would be too grand an attack on national sovereignty to find any conclusion.

The direct tax incentives applied by the Member States of the European Union for the promotion of renewable energy resources will be examined in this chapter. Four case study countries have been chosen: Ireland, the UK, the Netherlands and Belgium. In addition to the direct tax incentives addressed in the case study countries, all of the case study countries have also implemented renewable purchase obligations, green certificate systems, national climate strategies and action plans and emission trading.

The aim of this research is not to give an overview of all pro-Kyoto Protocol policies in use in the case study countries, but rather to examine the compatibility of direct (corporate) tax incentives for renewable energy with international trade law rules on subsidies. Therefore, the examination in this section will be limited to an exploration of the direct tax incentives that effect the development of renewable energy resources in place in Ireland, the United Kingdom, the Netherlands and Belgium,.

It is important to note that in this research the tax incentives considered are positive incentives, as in, they entice companies to take certain action which leads to improving environmental protection, in particular in relation to the development of renewable energy. This distinction is made as dis-incentives such as energy taxes (also used to pursue Kyoto Protocol goals) are not within the scope of this research. Extensive research has and is being carried out in relation to carbon taxes and climate change levies, and thus in order to cover a new and innovative question only positive direct tax incentives are addressed here.

Del Rio and Gual 2004, p. 221.

Deketelaere 1999, p. 188. 
The aim of this section is to investigate the direct tax incentives for renewable energy in Ireland and their role in Ireland's strategy to attain the goals of the Kyoto Protocol. This section aims to outline the direct tax incentives in place as well as the background to those measures. The consistency of the tax incentives with international trade law will be examined in detail in Part IV.

Ireland has had a history of spectacular successes in generating very large levels of investment with tax incentives. ${ }^{3}$

For this reason, in addressing tax incentives for investment in renewable energy in the EU, it is not inappropriate to commence the study with an examination of such investment incentives pursued in Ireland. ${ }^{4}$ This 'spectacular success' will then later be compared to the relative success of the other three case study countries.

\subsubsection{Kyoto Protocol}

As a Member of the European Union, Ireland signed the Kyoto Protocol on 29 April 1998 and ratified the Protocol on 31 May 2002. As indicated in Chapter 1, the Protocol came into force for all States that had ratified the Protocol on the 16 February 2005. Ireland has a greenhouse gas emission reduction commitment equal to $13 \%$ above the 1990 recorded level to be attained by $2012 .{ }^{5}$ Ireland is under an obligation to reduce its emissions jointly with the other Member States of the European Union to achieve an aggregate emissions level of $92 \%$ of the EU-wide 1990 level. ${ }^{6}$ In addition, Ireland should have increased the share of renewable energy in its energy supply by 2010 to $13.2 \%$ from a level of $2.9 \%{ }^{7}$ and attained a level of $16 \%$ by $2020 .^{8}$

In the development of environmental strategy in Ireland, or pro-Kyoto Protocol tax measures, there is no definite 'Kyoto Protocol' line of action. There was no appreciable spurt of new measures following the signing or ratification of the Kyoto Protocol. Rather developments which may be considered in line with the motives of the Kyoto Protocol came about somewhat independently of the ratification of the

3 Economic Analysis of RES-E Support Mechanisms, Report prepared for Sustainable Energy Ireland, Vienna, 2004, p. 7.

$4 \quad$ For a general overview of measures in EU Member States for the development of renewable energy resources, see Altener programme, Final Reports of the Ener-Iure Project, available at: <http://eneriure.jrc.ec.europa.eu/analysis.htm\#Final\% 20reports\%20and\%20tables>, last visited 24 November 2009.

$5<$ http://europa.eu/rapid/pressReleasesAction.do?reference=MEMO/05/49\&format $=$ HTML\&aged $=0 \&$ language $=\mathrm{EN} \&$ guiLanguage $=$ en $>$; last visited 23 November 2009 . The reduction commitment of the EU as a whole is 8\% below 1990 levels. Ireland's individual commitment is to reduce to $13 \%$ above its 1990 level.

6 Annex B Kyoto Protocol.

7 Directive 2001/77/EC; the current share is the 2006 figure provided by Europe's Energy Portal, available at: <http://www.energy.eu/\#renewable>, last visited 23 November 2009.

$8 \quad$ Annex I to Directive 2009/28/EC. 
Kyoto Protocol. A coherent Kyoto policy drive is not evident, but more a random retrospective mention of Ireland's Kyoto Protocol obligations essentially as an expost justification for the measures already in place. Egan states that ' $[$ Kyoto] is a key driving force behind a push for greater use of renewable forms of energy such as Wind Power'. ' Indeed, as the text of the Kyoto Protocol explicitly calls for the development of renewable energy technologies, this should hopefully be the case. However, as far as tax incentives for renewable energy in Ireland are concerned, the 'key driving force' for the tax incentive was only ratified four years after the implementation of the tax incentive.

\subsubsection{Investment Tax Incentive for Renewable Energy}

The investment tax incentive is an initiative for bolstering renewable energy and was initiated in 1998, a month before the Kyoto Protocol was signed. ${ }^{10}$ This tax incentive targeted the set up and running costs of renewable energy projects. It provided an incentivised injection of equity for project developers to get the project off the ground. A tax incentive for investment in renewable energy projects was introduced into the Finance Act in Ireland in 1998.

\subsubsection{Background to the Tax Incentive}

As early as December 1996, the issue of introducing tax incentives for the promotion of renewable energy was addressed in the Dáil. ${ }^{11}$ Prior to the signing of the Kyoto Protocol, when asked his views on tax incentives for investors in renewable energy, the Minister of State at the Department of Transport, Energy and Communications (now renamed the Minister for Communications, Energy and Natural Resources), stated that tax incentives were being explored by his department for the development of renewable energy resources. ${ }^{12}$ At the time the incentive available to developers was the general 'business expansion scheme'. The then Minister for Finance Mr. Charlie McCreevey (European Commissioner, DG Internal Market and Services until 2010) duly complied with the stated initiative and introduced a tax incentive to promote renewable energy resources in Ireland.

\subsubsection{Provisions of the Tax Relief}

Section 62 of the Finance Act 1998 introduced tax relief aimed at potential corporate investors, allowing a company or partnership to invest up to $€ 12.7$ million per annum in renewable energy projects and avail of a tax deduction up to the amount of the investment. The aim of the incentive is to entice corporate investors to enable startup renewable energy companies to undertake the project. ${ }^{13}$ The tax incentive created

Egan 2002, p. 373-377.

The tax incentive programme is an incentive secondary to the AER programme, a renewables purchase obligation. The tax incentive purports to support the building and development of renewable energy generating plants. Select Committee on Public Enterprise and Transport; Dáil Reports 26 June 2001, p. 11.

'Dáil is the Irish term for 'Parliament'.

Dáil Éireann - Volume 473 - 17 December 1996.

Finance Act 1998, Section 486B 'relevant investment'. 
a potential tax deduction from taxable profits of the amount of the investment up to $€ 12.7$ million. The total profit of the company is reduced by the amount of the investment in the renewable energy project, and where this amount exceeds the total profit of the company, the loss is carried forward to the subsequent accounting periods.

Some conditions apply in order for an investor in renewable energy projects to avail of the tax relief. The company carrying out the renewable energy project must be incorporated and solely resident in Ireland and 'exists solely for the purposes of undertaking a qualifying energy project'. ${ }^{14}$ There is no such residence requirement of the investing company, although, obviously in order for the tax relief to be of any relevance, the investing company must be subject to Irish corporate taxation, and thus must indeed carry out corporate activities in Ireland. ${ }^{15}$

The investment must be in new ordinary shares. Thus, purchase of already existing shares is not covered. The investment must be directly in the company that carries out the renewable project in question. The renewable energy project must be in developing wind, solar, hydro or biomass power and the project must also be approved as a qualifying project by the Minister for Public Enterprise. The funds generated by the sale of the new shares in the renewable energy project must be used on the development of the project within two years of the issuance of the shares.

One renewable energy project may benefit from the scheme for an amount of up to the lower of $€ 9.525$ million or, $50 \%$ of the capital expenditure of the project, which does not include the purchase of land, in sale of new ordinary shares to investors availing of the tax relief. ${ }^{16}$ Thus, one project may benefit indirectly from the tax relief, only once, up to a maximum of $€ 9.525$ million. On the other hand, the investing company may avail directly of the tax incentive every year with up to a maximum of $€ 12.7$ million reduction from taxable profits. Taking the maximum corporate tax rate of $25 \%,{ }^{17}$ an investment of $€ 12.7$ million in renewable projects could reduce the tax liability of a company by $€ 3.175$ million. However, if a trading company is in question, subject to a $12.5 \%$ corporate income tax rate, this would result in a tax saving of $€ 1.586$ million. The new ordinary shares must be held by the corporate investor for a minimum of five years in order for the tax relief to be valid. This provision aims to ensure that such investments are made for bona fide commercial reasons and the primary purpose is not tax avoidance.

Should a company wish to profit from this tax relief in full, it could do so only by, for example, investing $€ 9.525 \mathrm{~m}$ in one project and a further $€ 3.175 \mathrm{~m}$ in another/other projects. ${ }^{18}$ In any case, no one renewable energy project can gain more than $€ 9.525 \mathrm{~m}$ from the sale of new ordinary shares benefiting from the tax incentive. Related

Finance Act 1998, Section 486B 'qualifying company'.

Duggan 2002, p. 586.

Judge, Bradley and Scully 1998.

This rate applies to rental income and to investment income. Judge, Bradley and Scully 1998, p. 263. 
companies' aggregated investments are apportioned between the relevant investments by each company so that the benefits of the tax relief are divided equitably. ${ }^{19}$

This tax incentive was originally intended to apply from 18 March 1999 until 17 March 2002. ${ }^{20}$ However, the period was subsequently extended until 31 December $2004^{21}$ by the Finance Act 2002 and again until 31 December $2006^{22}$ by the Finance Act 2004. ${ }^{23}$ The Finance Act 2007 extended the application of this tax incentive until 2011. ${ }^{24}$ Although the Minister of Finance retracted after this extension, the support for renewable energy through the tax system remained untouched. In 2004, two weeks into his new office, the new Minister for Finance, Mr Brian Cowen, reiterated that 'Taxation can play a part in attaining environment objectives'. ${ }^{25}$ It is interesting to note that there was very little academic discussion surrounding this tax incentive. Although the new incentive was introduced into the Finance Act 1998, a leading series of commentaries on the Finance Acts failed to discuss the relief until the 20002001 Edition. $^{26}$

\subsubsection{Cost of Tax Incentive}

In May 2001 the Minister for Finance was asked to outline the 'success or otherwise' of the renewable energy investment incentive scheme. According to the Minister, between 18 March 1998 and May 2001, six companies had directly benefited from the tax incentive, having invested a total of $€ 19.5$ million in qualifying renewable energy projects. The tax cost of this tax incentive was a total of $€ 5.08$ million in that period. ${ }^{27}$

\subsubsection{European Commission Approval}

New tax incentives, being State aid, have to be notified to the European Commission in order to allow the Commission to determine whether the aid was in line with EU State aid rules. ${ }^{28}$ The Commission adopted its Decision not to raise any objections to the investment tax incentive in January 1999. ${ }^{29}$ The aid was classified as tax relief for corporate equity investment in renewable energy projects with the objective of promoting investment in renewable energy production. The Commission also

19 Related companies are holding companies and subsidiaries.

20 Finance Act 1998, Section 486B: "qualifying period" means the period beginning on the commencement date and ending on the day before the third anniversary of that date'. This Section came into force on 18 March 1999.

Dáil Éireann - Volume 557 - 12 November, 2002, p. 113.

Dáil Éireann - Volume 584 - 5 May 2004, p. 87.

Finance Act 2004, Section 39. See also Redmond and Thornton 2004, p. 129 and Finance Act 2002, Section 43 amendment of Section 486B of Principal Act.

Finance Act 2007, Section 51.

Dáil Éireann - Volume 590 - 14 October 2004, p. 5.

Duggan 2000.

Dáil Éireann - Volume 535 - 1 May 2001, p. 269.

See section 3.3 State Aid, p. 54.

Authorisation for State aid pursuant to Articles 87 and 88 of the EC Treaty - Cases where the Commission raises no objections, 1999/C 151/04, State aid decision N353/98. 
indicated the intensity of the aid at $16 \%,{ }^{30}$ at a cost of $€ 6.5$ million foregone revenue and lasting for three years.

At the end of the three-year period, in January 2002, (following an extension of the qualifying period until 31 December $2004^{31}$ by the Finance Act 2002,32 and again until 31 December $2006{ }^{33}$ by the Finance Act 2004), ${ }^{34}$ permission for the extension of the aid was requested to the Commission.

Ireland notified the extension of the aid in September 2003, requesting approval for extension until 31 December 2006. ${ }^{35}$ The Commission once again decided not to raise objections. In this decision by the Commission, and by virtue of the four requests for additional information by the Commission to make an informed decision on the compatibility of this aid with the State aid rules, the aid was described and assessed in detail.

The objectives of the aid were further identified as:

removing an impediment arising among equity investors in new projects of electricity generation produced from renewable energy resources...

The aim was, in short, to promote investment in renewable energy projects. The outcome of this aid was to be the development of new electricity generation plants operating on renewable energy.

The decision of the Commission not to raise objections also clarified that not only is the aid available to corporate investors in renewable energy projects but also applies to the developers of the projects. This clarifies that investors in renewable projects which they themselves develop may also avail of the tax credit. There is no extra 'at arm's length' requirement. The Decision also highlights that although the direct tax benefit goes to the corporate investors in renewable projects, regardless of the nature of their primary corporate activities, the final, albeit indirect, beneficiaries are the renewable energy projects by providing an otherwise unavailable source of equity allowing the projects to develop and grow.

Since the Commission considered that the aid is provided to investors on a nondiscriminatory basis, it is 'a general measure which cannot favour certain undertakings at the level of investors'. The Commission also argues that since the benefit is passed on to the renewable energy project developers, this furthermore illustrates that the measure is general. However, the generality of the measure, as claimed by the Commission, and also the lack of discrimination over frontiers, only addresses the direct beneficiaries. The indirect beneficiaries are neglected in this sense. It is

$30 \quad$ According to Point 32 of the Community Guidelines on State Aid for Environmental Protection, the maximum aid intensity is $40 \%$ of the eligible costs.

Dáil Éireann - Volume 557 - 12 November 2002, p. 113.

Finance Act 2002, Section 43 amendment of Section 486B of Principal Act.

Dáil Éireann - Volume 584 - 5 May 2004, p. 87.

Finance Act 2004, Section 39.

State aid decision N447/2003 - Ireland Tax relief for corporate equity investment in renewable energy projects, C (2004) 3288. 
doubtful that, had the indirect benefit to the project developers been the examined, the measure would still be deemed to be general in nature and undiscriminating.

In its decision, the Commission decided that the tax relief is indeed State aid according to Article 87(1) of the EC Treaty (now Article 107(1) TFEU) since an economic advantage is granted and State revenue is foregone. Although the aid bolsters the competitive position of the beneficiaries, and may thus distort trade, the aid complies with the State aid rules contained in Article 107(3)(c) and Article 108(3) TFEU and the Community Guidelines on State Aid for Environmental Protection and was thus found to be compatible with EU State aid rules and no objection was raised by the Commission.

Indeed, the development of renewable energy resources is an objective of the European Communities, and as long as the measures used to reach this goal do not infringe EU law, they should be applauded. The Community Guidelines on State Aid for Environmental Protection highlights that such measures are not only priorities but long-term objectives which should be encouraged. ${ }^{36}$

\subsubsection{Reaction to the Tax Incentive}

This measure, introduced by the Department of Finance, perhaps as a result of a nudge from the Department of Transport, Energy and Communications, ${ }^{37}$ was met with only support in the parliamentary process. No questions were raised relating to the new tax incentive introduced in the Finance Bill 1998, neither in the Dáil nor the Seanad, ${ }^{38}$ and only one comment was made. Deputy Avril Doyle TD of the Seanad stated: 39

I applaud the Minister's support for renewable energy projects. Everyone is in favour of developments in this area. It may be a little and it is certainly late but we need to implement these as quickly as possible.

Although the introduction of the tax incentive in the Finance Act 1998 raised no questions in Parliament, some curiosity was raised during its application. Questions were raised relating to tax incentives for individuals investing in renewable energy and the Minister for Finance gave clarification on the tax incentives provided to corporate investors - namely the Section 62 tax relief. The Minister took the opportunity to publicise the aim of the provision, to:

[facilitate] growth of electricity generation capacity using these alternative sources of energy. The aim of this measure is aimed at protecting the environment and reducing $\mathrm{CO}_{2}$ and other greenhouse gas emissions. ${ }^{40}$

\footnotetext{
36 Community Guidelines on State Aid for Environmental Protection 2001/C 37/03; Egan 2002, p. 376.

37 Dáil Éireann - Volume 473 - 17 December 1996.

38 Houses of Parliament; 'Seanad' is the Irish term for 'Senate'.

39 Seanad Éireann, Volume 154, 24 March 1998; <http://historical-debates. oireachtas.ie/S/0154/S.0154.199803240006.html>; last visited 23 November 2009.

Dáil Éireann - Volume 500 - 23 February 1999, p. 283.
} 
Again in 2000, the Minister for Finance was afforded the opportunity to clarify that although intended for companies only, the provision in the 1998 Finance Act could also apply to limited partnerships. ${ }^{41}$

In a paper presented at the $11^{\text {th }}$ Annual International Sustainable Development Research Conference in Helsinki, it was claimed that the introduction of the tax incentive for renewable energy investment in Ireland in 1998 'sent an important signal of support from the Department of Finance'. ${ }^{42}$ However, this paper also indicated that as the rate of corporate tax has reduced since the introduction of the tax incentive to a mere $12.5 \%$ for trading profits, 'the benefits associated with this scheme have diminished'. ${ }^{43}$

Furthermore in general discussions relating to investment incentives in Ireland, and also to developments in the Finance Act of 2002, in which the first extension of the tax incentive is incorporated, no mention was made of the 'important signal' given by the Department of Finance in 1998. In his article in the International Tax Review, Gary O’ Mahony synopsises some positive developments in the Finance Bill 2002. In conclusion, he states that 'Ireland continues to be an extremely attractive location for mobile international investment', however, the extension of the renewable energy tax incentive plays no role in O'Mahony's discussion. ${ }^{44}$ Instead he pays attention to the attractive incentives for investment in Ireland due to the $12.5 \%$ corporation tax rate available to certain sectors. ${ }^{45}$ Furthermore, discussion of extending the $12.5 \%$ rate to a new sector was also mentioned, shipping, whereas no such discussion surrounded the development of renewable energy activities. ${ }^{46}$

In 2005, the Department of Finance launched a public consultation process to review tax reliefs and exemptions. The Minister instigated this review to improve the equity of the tax system taking into account the social and economic benefit of reliefs, ${ }^{47}$ Furthermore, the Minister aimed to evaluate the effect of all relevant incentive reliefs. ${ }^{48}$ After a public call for opinions of interested parties, the Department of Finance received 88 responses with varying views on the extensive range of tax exemptions and reliefs available through the Finance Act. Of these replies, only one mentioned the tax relief available for investment in renewable energy projects introduced in the 1998 Finance Act - The Green Party. ${ }^{49}$ The Green Party did not object to the tax incentive available for investment in renewable energy resources, although the party is not, generally speaking, in favour of tax exemptions available to top-earners in

$41 \quad$ Dáil Éireann - Volume 517 - 6 April 2000, p. 92.

42 Ó 'Gallachóir, Bazilian and McKeogh 2005, p. 20. However, it also indicated that as the rate of corporate tax has reduced since its introduction to a mere $12.5 \%$, 'the benefits associated with this scheme have diminished'.

$43 \quad$ Ibid., p. 20.

$44 \quad$ O'Connor and Forde 2003; O'Mahony 2002; O'Mahony 2001.

45 Financing activities, distribution and professional services, headquarter activities, software, intellectual property exploitation, e-commerce/e-business.

O’Mahony 2001.

Murphy 2005, p. 40-41.

Ibid.

$<$ http://www.finance.gov.ie/viewdoc.asp?DocID=3176\&CatID=50\&StartDate=1+ January $+2006 \& \mathrm{~m}=\mathrm{p}>$; last visited 23 November 2009. 
Ireland. ${ }^{50}$ In particular, the Green Party objected to tax incentives which do not have broad social, economic or environmental purpose. However, with respect to tax relief for investors in renewable energy projects, the Green Party called upon the Department of Finance to extend and introduce further tax incentives in this area. In the 88 responses to the public consultation, there were many calls for the abolition of certain tax incentives, but also many interested parties stressed the need for the continuance of others. No objection to the investment incentive for renewable energy was recorded.

On December 7 2005, the official results of the tax incentives and relief review were published by the Department of Finance. In the 948 pages of the three Volumes of Reports, the tax incentive for investment in renewable energy resources is not mentioned. ${ }^{51}$ An article written by Mark Redmond, Chief Executive of the Irish Taxation Institute in support of tax incentives in general and those in a position to avail of them may shed some light on a possible justification for the lack of interest in this tax incentive. Mr. Redmond writes that persons availing of tax incentives make a valuable contribution to the State. ${ }^{52}$ Even though tax incentives constitute revenue foregone for the State, the investment the lost revenue relates to is much higher in value. An example is given of an investment of $€ 10,000$ typically resulting in an individual reduction in tax bill of $€ 4,200$. Since the aim of tax incentives is to develop a particular sector, the aim is fulfilled when investment in the sector is made, and thus a contribution to the goals of the State is made. ${ }^{53}$ Once again, the tax incentive for renewable energy relates only to companies and partnerships and not individuals, and different tax rates and rules apply for corporate taxation, but the issue of exploitation of the tax system remains the same. Is it therefore that the contribution considered to be made by investors in renewable energy, improving the environment and prolonging the lifespan of humanity, does indeed outweigh the cost to the revenue, poses no problem to the government or public in general and thus does not even merit discussion during a general review of all relevant incentives. ${ }^{54}$

Despite all of these resounding positive reactions to Ireland's investment tax incentive for the development of renewable energy there was indeed some criticism. There are concerns that the tax incentive is not of a high enough monetary value to entice investors to take the risk in such a new sector as wind energy. Since the tax liability which is relieved is only $12.5 \%$ of the invested amount (or even the previous non-trading income rate of $25 \%$ ), the resultant savings were perhaps not significant enough. ${ }^{55}$ Also, irrespective of the level or relief, the Consultative Committee of Accountancy Bodies, Ireland (CCAB-I) is of the opinion that investment decisions in

50 The letter from the Green Party stated that 29 out of the 115 top earners in Ireland paid no tax in 2001 - a cost of $€ 42$ million.

$<$ http:/ $/$ www.finance.gov.ie $/$ viewdoc.asp?DocID $=3749 \&$ CatID $=45 \&$ StartDate $=01+$ January $+2006 \& m=>$; last visited 23 November 2009.

Redmond 2004, p. 443-444.

Ibid.

Murphy 2005, p. 40-41.

Egan 2002, p. 374; Economic Analysis of RES-E Support Mechanisms prepared for Sustainable Energy Ireland, the authors, when discussing corporate investment tax credits, were of the opinion that in Ireland such a provision would not be interesting considering the low levels of corporate tax. 
general are not taken because of tax incentives. ${ }^{56}$ Rather it is the return on investment that drives investment decisions. ${ }^{57}$ With respect to wind energy investments it was expected in 1998 that the return on investment in this sector would be ten to fifteen per cent. ${ }^{58}$ The second consideration for investment according to the CCAB-I is the level of risk attached to the investment and the last factor is the existence of a tax incentive. ${ }^{59}$ However, others are of the opinion following the introduction of the incentive that the incentive is 'deserving of closer attention' since this incentive appears to be one of the few areas in which tax breaks are being offered to investors. ${ }^{60}$ An example of one such investor, Managing Partner of BDO Simpson Xavier stated that: 'wind energy projects represent one of the few remaining tax breaks for high net worth individuals' ${ }^{61}$ However, there is one catch to this very positive feedback - the tax incentive is not available for individuals, only companies or partnerships. Nonetheless there are mixed feelings as to the interest in and effectiveness of this incentive.

The question must be addressed whether it is the low lost revenue cost that results in passive satisfaction coupled with apathy in relation to this particular tax incentive. Is the revenue foregone of only $€ 6$ million not enough to be bothered about?

\subsubsection{Accelerated Depreciation}

In 2008, a new capital allowance provision was introduced into the Taxes Consolidation Act 1997 by the Finance Act $2008^{62}$ and Finance (No.2) Act 2008. ${ }^{63}$ A new Section 285A was included introducing accelerated depreciation of $100 \%$ of the cost of listed assets in year one. The Department of Communications Energy and Natural Resources has the task of establishing the lists of eligible assets. The provision came into force on 9 October 2008 when the first list was published. The list was then subsequently updated in $2009 .{ }^{64}$

In November 2008, the Finance (No.2) Act 2008 extended the scope of the capital allowance provision by extending the categories of technology to which the provision

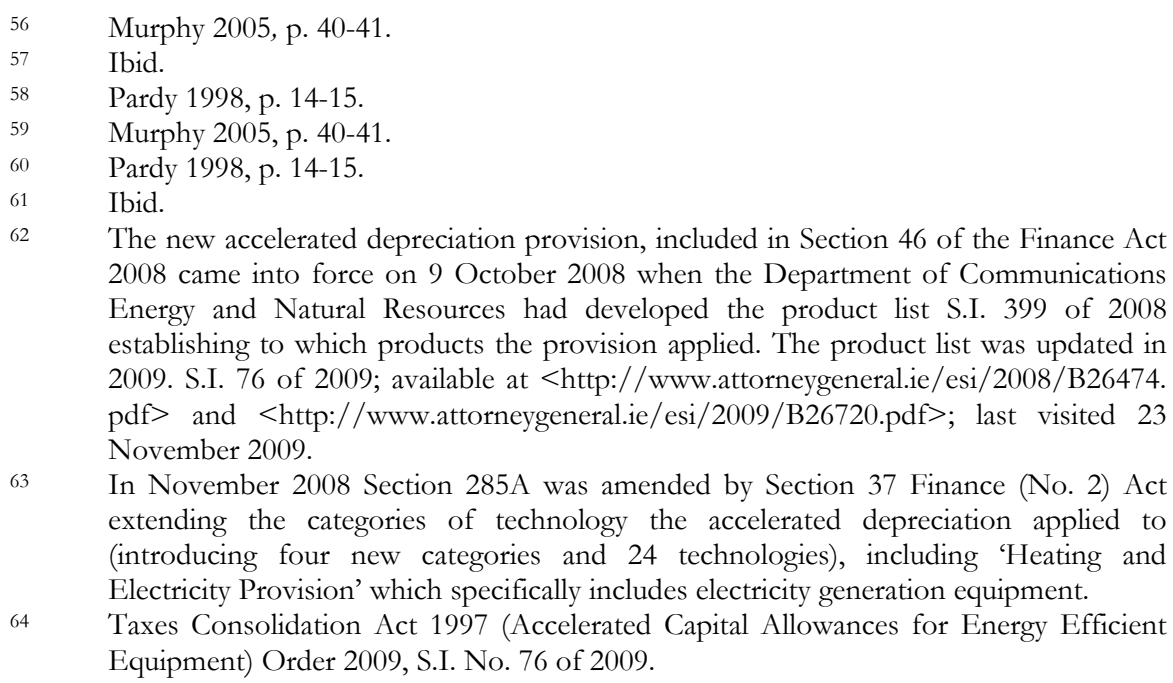
2008 came into force on 9 October 2008 when the Department of Communications Energy and Natural Resources had developed the product list S.I. 399 of 2008 establishing to which products the provision applied. The product list was updated in 2009. S.I. 76 of 2009; available at <http://www.attorneygeneral.ie/esi/2008/B26474. pdf> and <http://www.attorneygeneral.ie/esi/2009/B26720.pdf>; last visited 23 November 2009.

63 In November 2008 Section 285A was amended by Section 37 Finance (No. 2) Act extending the categories of technology the accelerated depreciation applied to (introducing four new categories and 24 technologies), including 'Heating and Electricity Provision' which specifically includes electricity generation equipment.

Taxes Consolidation Act 1997 (Accelerated Capital Allowances for Energy Efficient Equipment) Order 2009, S.I. No. 76 of 2009. 
applies and explicitly including 'Heating and Electricity Provision' which specifically includes electricity generation equipment. The specific electricity generation technology to which it refers includes the following: co-generation, wind turbines, stationary fuel cell power systems, and photovoltaic systems. The product-specific list has not yet been fully established for the four new categories of technology and it is currently being developed after manufacturers were requested to submit their specific products for inclusion on the list. ${ }^{65}$ Only companies may avail of the accelerated capital allowance scheme and only on new assets which are used in their trade and which the company owns. Leased equipment does not qualify.

This tax incentive allows companies which invest in the listed products to write off $100 \%$ of the cost of the investment in the year of purchase. The aim of this new tax incentive is to give financial support to companies investing in energy efficient equipment, including renewable energy equipment, which in turn reduces energy costs and reduces carbon emissions. The accelerated capital allowance scheme will first be in place for a trial period of three years.

\subsubsection{Cost of Tax incentive}

The cost of this change is estimated to be $€ 1$ million in 2009 and $€ 5$ million in a full year. ${ }^{66}$

\subsubsection{Irish Trade in Electricity}

As Ireland is an island, the question may arise as to the relevance of trade in electricity where an island is concerned. Ireland has cross-border trade in electricity with the United Kingdom through Northern Ireland. Also, a recent development will see a submarine electricity link between Ireland and Wales. Planning permission was granted in September 2009 for 110 miles of electricity cable under the Irish Sea. The advantages of cross-border trade allow both countries to benefit from the differences in their peak usage to result in an overall capacity need. ${ }^{67}$

65 The only heating and electricity products listed at the time of writing were Eoltec SAS wind turbines, three photovoltaic products from REC Solar AS and three photovoltaic products from Schott Solar EG. As this is not the final completed list no great conclusions can yet be drawn from the limited list, however, were the list to remain this limited, there would be no doubt that the tax incentive would be de facto specific to a few enterprises (albeit indirectly), namely Eoltec SAS, REC Solar AS and Schott Solar EG. However, since these are not national enterprises there is no question of domestic protectionism.

66 <http://www.budget.gov.ie/Budgets/2009/Summary.aspx\#_Toc211585088>; last visited 23 November 2009.

67 Renewable Energy News, 30 September 2009, available at: $<$ http://www.renewablepowernews.com/archives/25>, last visited on 23 November 2009. 


\subsubsection{Conclusion}

There are two tax incentives for the development of renewable energy in Ireland, namely the investment tax incentive and the accelerated capital allowance for energy saving assets.

The role of tax incentives in Ireland's pro-Kyoto Protocol effort is not clear. It is apparent that there are two tax incentives in place to support the development of renewable energy, however, there is no clear link made between the policy choices to introduce these tax incentives and the attainment of the Kyoto Protocol objectives. Although the development of renewable energy inevitably addresses the Kyoto Protocol goals, the Kyoto Protocol was only mentioned ex-post as a justification for the introduction of the investment tax incentive.

The failure of the Commission to examine the investment tax incentive for indirect subsidies leaves the question open whether these direct tax incentives could also result in subsidies to indirect beneficiaries. This will be examined in Part IV, which will examine the WTO-consistency of both the direct and indirect subsidies.

\subsection{UNITED KINGDOM}

This section investigates tax incentives for renewable energy in the United Kingdom and their role in the UK's strategy to attain the goals of the Kyoto Protocol. This section aims to outline the tax incentives in place, the background to those measures and the interaction of those incentives with the general Kyoto Protocol action plan. The consistency of the tax incentives with international trade law will be examined in detail in Part IV.

\subsubsection{Kyoto Protocol}

The United Kingdom (of Great Britain and Northern Ireland) signed the Kyoto Protocol on 29 April 1998 and ratified the Protocol on 31 May 2002. As indicated in Chapter 1, the Protocol came into force for all States having ratified the Protocol on the 16 February 2005. The United Kingdom has a greenhouse gas emission reduction commitment equal to $12.5 \%$ below the 1990 recorded level to be attained by $2012 .{ }^{68}$ The UK is under an obligation to reduce its emissions jointly with the other Member States of the European Union to achieve an aggregate emissions level of $92 \%$ of the EU-wide 1990 level. ${ }^{69}$ Also, the UK should achieve a level of renewable energy electricity consumption of $10 \%$ of total electricity consumption by $2010^{70}$ and a

68 The reduction commitment of the EC as a whole is 8\% below 1990 levels. The UK's individual commitment is to reduce to $12.5 \%$ below its 1990 level. $<$ http://europa.eu/rapid/pressReleasesAction.do?reference=MEMO/05/49\&format $=$ HTML\&aged $=0 \&$ language $=$ EN\&guiLanguage $=$ en $>$; last visited 23 November 2009 . Annex B Kyoto Protocol. Directive 2001/77/EC. 
target level of $15 \%$ by $2020 .^{71}$ This is a significant increase from its share of $1.2 \%$ in $2006 .{ }^{72}$

\subsubsection{Tax Incentives for Renewable Energy}

In 1997 with the change of government in the UK, the intention to use taxation to attain environmental policy objectives was paraded, however little became of this in the ten years following. ${ }^{73}$ The tendency in the UK is to shy away from tax incentives in preference of direct subsidies. However, in the Policy Background of the tax incentive to be discussed below, it is clear that the UK has an ambitious national emission reduction target of $20 \%$ to achieve by 2010 and tax incentives do play a role. ${ }^{74}$

The direct tax environmental incentive scheme put in place in the UK is a capital allowance for energy saving investments. ${ }^{75}$ This provision came into force on 1 April 2001. According to Her Majesty's Revenue Service, the Capital Allowance scheme is a 'part of the Climate Change Levy Programme, [and] it's designed to help the UK reach its Kyoto target of reducing carbon emissions by $20 \%{ }^{\prime}{ }^{76}$ The form of tax incentive at play here is an accelerated tax relief, operating in the same fashion as a provision for accelerated depreciation of assets. The equipment invested in can be written off in full in the year of acquisition. This has the result of lowering the taxable profit of that company for that year. Without the incentive, the company would write off the asset over a number of years. ${ }^{77}$ Thus, the effect of the incentive is to reduce the tax liability in the first year, but the tax liability is subsequently higher in the following years than it would have been without the incentive.

The capital allowance scheme is available for energy saving equipment which is listed on a list published by the Department of the Environment, Food and Rural Affairs. Like in the other case study countries, the investments must be in new, unused assets. ${ }^{78}$ The list has been updated and amended several times, expanding the assets to which it applies. ${ }^{79}$ For example, in 2009 the list was updated by introducing a new qualified technology, uninterruptable power supplies, as well as two sub-technologies, air to water heat pumps and close control air conditioning systems. At the same time three sub-technologies were cancelled from the list: air source, which comprises single duct and packaged double duct heat pumps; ground source: brine to air heat

\footnotetext{
$71 \quad$ Annex I to Directive 2009/28/EC.

72 Europe's Energy Portal available at <http://www.energy.eu/\#renewable $>$; last visited 23 November 2009.

73 Essers, Flutsch and Ultee 2000, p. 69.

74 The Capital Allowances (Energy-saving Plant and Machinery) (Amendment) Order 2006 No. 2233.

75 Finance Act 2001 Sections $65 \& 66$ of Schedules $17 \& 18$ and expanded by Finance Act 2002 amending Capital Allowances Act 2001.

76 <http://www.eca.gov.uk/etl/about/>; last visited 24 November 2009.

77 The normal depreciation rate relating to plant and machinery is $25 \%$ for ordinary spending and $6 \%$ for assets with a normal life-span of over 25 years.

Schedule 17 Finance Act 2001.

April 2001 first published list, amended every year.
} 
pumps and water source: packaged heat pumps. ${ }^{80}$ Some assets are also subject to the requirement of having a certificate of energy-efficiency provided by the Secretary of State for Environment, Food and Rural Affairs. Included in this list of eligible plant and machinery are combined heat and power systems and solar thermal systems. Wind energy equipment does not come within the list.

Where the asset is subsequently leased, the asset will not qualify for the tax incentive since $2002 .^{81}$ The exception to this lease rule is where the asset becomes a fixed part of the buildings - a fixture.

In general, the incentive is available to all companies, without restriction. Also, no restrictions are attached to the origin of the equipment invested in. However, for the purpose of this research one important restriction stands out. Combined heat and power systems acquired by electricity generating companies are not eligible for the tax deduction. The motivation behind this restriction is the fulfilment of the nonspecificity requirement of the EU State aid rules. If the measure were available to electricity generating companies, it could become de facto more beneficial to one specific sector of companies - electricity generators. ${ }^{82}$ The UK provided this exception in light of a similar occurrence in Germany where the de facto benefit to electricity generators from subsidised CHP systems was deemed to be State aid. ${ }^{83}$ Thus, although this incentive is indeed a direct tax incentive, it is not a particularly powerful incentive for the development of renewable energy.

It should be remembered, however, that despite this, the UK has opted (like Germany) for capital grant systems rather than tax incentives to bolster the development of renewable energy. ${ }^{84}$

Not only are there no specific tax breaks related to the development of renewable energy resources, this sector is at a specific disadvantage when compared to tax breaks available for some fossil fuel sectors. For example, when offshore oil and gas is compared to offshore wind-farms, a clear tax disadvantage is experienced by the more environmentally friendly energy resource. Offshore oil and gas operations in the process of decommissioning may report the costs of this decommissioning for

BN11 - Enhanced Capital Allowances for Energy Saving and Water Efficien (Environmentally Beneficial) Technologies, available at <http://www.hmrc.gov.uk/ budget2009/bn11.pdf., visited on 24 November 2009. Section 46(2) Capital Allowances Act 2001 and 62 Finance Act 2002 and Section 81, Schedule 9, para. 11 Finance Act 2006.

SG(2001) 286845, State aid decision N797/2000.

State aid decision N555/2000.

See for this the Capital Grants System for Renewable Technologies - Commission Approval. This aid was to be granted to electricity generators opting for renewable energy inputs. The scheme was open to companies in Great Britain (England, Wales and Scotland). The aid was to be available for a period of 10 years, until 2010. There was a specified budget for the capital grants of $100 \mathrm{~m}$ pounds. SMEs may apply for $40 \%$ aid intensity according to this scheme. In 2002 the aid was increased the budget of this aid to 140 million pounds, increased the aid intensity for SMEs to $50 \%$ and also extended the application of the aid to the whole of the United Kingdom (including Northern Ireland) Again, in 2003 the budget was increased to $183 \mathrm{~m}$ pounds, a $30.7 \%$ increase in aid. 
the determination of the taxable profits and these costs may be used against the profits of the year of decommissioning and the preceding three years. This provision has an important effect on the taxable liability of the said company. On the other hand, should a wind-farm be in the process of 'decommissioning', there is no carryback provision available to reduce the tax liability of that company or any tax breaks available for that matter. In the UK, in this respect, renewable energy technologies are not favoured by the tax system. Rather, provisions are still in place which provide advantages to fossil fuel producers. ${ }^{85}$

\subsubsection{Cost of the Incentive}

The cost of the Capital Allowances scheme was estimated to be 100 million pounds sterling in 2001 and 140 in the following year. ${ }^{86}$ Again, it should be noted that this budget is not useful for the generation of electricity since electricity generation companies are explicitly excluded from its application.

\subsubsection{Commission Approval}

The Capital Allowances scheme was notified to the Commission in $2000 .{ }^{87}$ It is important with respect to the State aid rules that the incentive was available to all companies, without restriction, except electricity generation companies to whom the aid may have been considered specific. The Commission decided that this aid did not constitute State aid and thus was allowable.

\subsubsection{Reaction to Department of Finance Initiative}

The reaction to the support given to renewable energy in the UK has not been entirely positive. In 2005, the Auditor General in the Renewable Energy Report considered that the support offered was more than necessary for the development of wind farms despite there being no explicit tax incentive available for renewable energy. ${ }^{88}$ The Renewable Energy Report also takes into account the exemption from the climate change levy - the energy tax. However, as previously stated this research is in particular concerned with positive incentives as opposed to exemptions from disincentives (energy taxes).

\subsubsection{Conclusion}

In the UK, the majority of attention to climate change issues is absorbed by discussions relating to the climate change levy and the exemptions therefrom. The one direct tax incentive for investment in renewable energy gains little attention. Furthermore, there is even a specific cut-out in this incentive, making it inapplicable to electricity generating companies. It should be recognised that the UK has

Renewable Energy Association, Evidence to the EAC enquiry on Pre-Budget 2005. SG(2001) 286845, State aid decision N797/2000.

Ibid.

Etherington 2006, available at <http://www.sswfag.org.uk/docs/Wind\%20power\%20 subsidy $\% 20$ in $\% 20$ the $\% 20$ UK.doc $>$; Renewable Energy Report, Controller and Auditor General, HC 210 Session 2004-2005, 11 February 2005. 
adamantly denied the use of tax incentives in this field and has instead pursued other policy methods such as the granting of direct subsidies.

\subsection{NETHERLANDS}

\subsubsection{Kyoto Protocol}

The Netherlands has a greenhouse gas emission reduction commitment equal to $6 \%$ below the 1990 recorded level to be attained by $2012 .{ }^{89}$ In addition to this, under the EU Renewables Directive, the Netherlands had a 9\% renewable energy target to be reached by $2010^{90}$ and a target of $17 \%$ to reach by $2020 .{ }^{91}$ The renewable share in 2006 was $2.7 \% .{ }^{92}$

\subsubsection{Tax Incentives for Renewable Energy}

In the Netherlands, direct tax incentives for environmental protection are not a postKyoto Protocol drive. The first incentive was introduced as early as 1964 even prior to the environment becoming a policy objective in its own right in the EU.93 Tax support for renewables has been maintained since 1964 with, in particular, new life being poured into tax incentives from 1991. ${ }^{94}$ This support has continued until the present day with four separate schemes possible and with extensive budgets available. The European Commission has approved these incentives primarily due to their environmental objective. However, this European Commission approval says nothing about the potentially trade distorting nature of the incentives at the international level. The WTO consistency of these measures will be examined in Part IV. In the following sections, the four direct tax incentives will be examined in turn.

\subsubsection{Free Depreciation (VAMIL)}

The first environmental tax incentive in the Netherlands, already introduced in 1964, provides for environmentally friendly capital assets to be written off early, thus giving the business a direct financial advantage - lower corporate or personal income tax. ${ }^{95}$

89

The reduction commitment of the EC as a whole is $8 \%$ below 1990 levels. The Netherlands's individual commitment is to reduce to $6 \%$ below its 1990 level. De Leeuw and Van Ierland 2000.

Bruggeman 2005.

Annex I to Directive 2009/28/EC.

Europe's Energy Portal, available at: <http://www.energy.eu/\#renewable>.

It should be borne in mind that this research looks specifically at positive incentives for development of renewable energy, thus leaving energy taxes and emission trading schemes outside its scope. Vast amounts of research has been and is being carried out in this field. For some discussion on this topic please see inter alia: Chapman 2003, p. 29-51; De Vries and Ouwehand 2004, p. 1899-1906; De Waard and Zom 2000, p. 369376; Gassler 1997, p. 1632-1639; Kamminga 1996, p. 53-61; Zwemmer 1998, p. 17571758. Herreveld 1998, p. 1715-1716: 'Staatssecretaris Vermeend heeft het gebruik van taxe stimulantia nieuw leven ingeblazen'. 'De machtige arm van Vermeend reikt ver'. rticle 10(3) and Article 26 WIB 1964 (512). See De Waard and Zom 2000, p. 372. See also Faure and Ubachs 2005. 
This provision, currently Article 3.31 of the Personal Income Tax Act 2001 was first introduced in the Personal Income Tax Act 1964. The idea behind the incentive was to speed up technological development and to spread the use of environmentally friendly techniques - thereby reducing 'negative effects of human activity on the environment'. 96 The incentive allows capital assets purchased or produced which contribute to the protection of the environment (and are listed) to be depreciated at the discretion of the investor. ${ }^{97}$ In this sense, it is not required that the system of depreciation reflect the real life-span of the product.

This provision was reformulated in 1991 on the instigation of a private Bill by two Members of Parliament - Vermeend and Melkert - and is still in operation. ${ }^{98}$ The investments to which the accelerated depreciation provision applies ${ }^{99}$ are laid out in the VAMIL ${ }^{100}$ list (the environmental list). ${ }^{101}$ The List, with 450 different investment possibilities, was developed and maintained by the Ministry of Public Housing, Spatial Planning and Environmental Management along with the Ministry of Finance and the Ministry of Economic Affairs. The investment must be made in assets which are not in common use in the Netherlands and are in use for the first time and are used for the protection of the environment in the Netherlands. ${ }^{102}$

Over time, the VAMIL scheme has been altered and improved, extending the list of assets to which it applies. The latest of these amendments took place in June 2009. ${ }^{103}$

In its first seven years of operation, the free depreciation scheme applied to some $€ 1.6$ billion worth of investments made in the Netherlands. ${ }^{104}$ The annual budget for this incentive is $€ 79$ million in 2009. ${ }^{105}$

\subsubsection{Green Funds}

In 1995, a second investment scheme was introduced for private investors in, inter alia, renewable energy. 106 This provision also stemmed from a private Bill from Members of Parliament Vermeend, Melkert and Van der Vaart. ${ }^{107}$ The scheme involves private investors transferring their investment funds to 'green banks' at a low interest rate, with which the banks provide cheaper loans $(1-2 \%$ below market

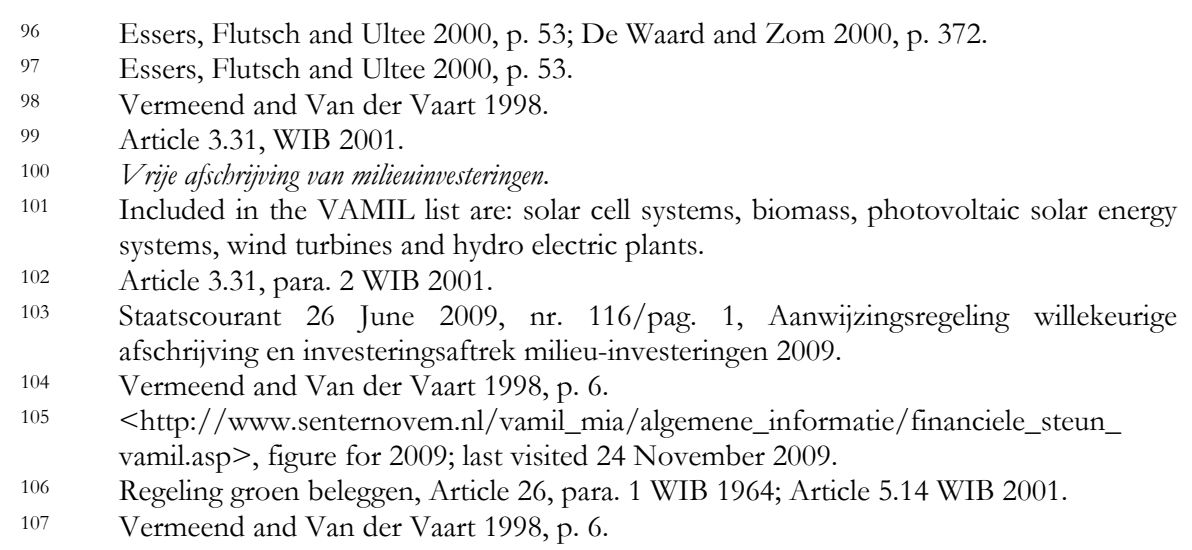


rates) to eligible green project developers. ${ }^{108} 70 \%$ of the investment funds received by the banks under the Green Funds scheme must be used to finance qualifying green projects. ${ }^{109}$

Until 2001, investors were exempt from tax on interest related to green projects and also did not have any tax liability deriving from the receipt of dividends relating to the investment in the Green Funds. ${ }^{110}$ Now, a similar result is also achieved in that tax on savings and dividends related to the green investments is limited. A maximum of $€ 55,145$ 'green capital' per investor is exempted from Dutch income tax (an effective levy of $1.2 \%$ of the amount normally deemed due as taxable capital income). ${ }^{111}$

The eligible green projects include, for example, forestation projects, sustainable energy projects and environmental technology. ${ }^{112}$ Included in the list of eligible investments are 'projects in the field of sustainable energy'. ${ }^{113}$ The conditions attached to this incentive are also that the investment must be in new assets situated in the Netherlands for the purpose of carrying out the green project in the Netherlands. ${ }^{114}$ Furthermore, the capital of the project should be at least $€ 22,689$ and the benefit of the project to the environment should be immediate. ${ }^{115}$

Private investments have amounted to approximately $€ 6.8$ billion since $1995 .{ }^{116} \mathrm{~A}$ cut-off amount of tax expenditure is designated for this scheme annually. ${ }^{117}$ Like the

To be an eligible green project, and therefore be entitled to borrow the green funds at preferential rates, the borrower must obtain a green certificate from the Ministry of Housing, Spatial Planning and the Environment VROM.

109 Essers, Flutsch and Ultee 2000, p. 61.

110 See The Netherlands Country Report, Altener Programme, Ener-Iure Project Phase III, p. 8, available at: <http://eneriure.jrc.ec.europa.eu/Reports/NLD\%20gen.pdf>, last visited 24 November 2009.

111 SenterNovem: Jaarbericht Groen Beleggen 2009 met jaarcijfers 2008, p. 3 available at: <http://www.senternovem.nl/mmfiles/GBJaarcijfers20081_tcm24-307369.pdf>, last visited 24 November 2009. $€ 55,145$ is the amount for 2009.

112 De Waard and Zom 2000, p. 372.

113 This sector includes inter alia wind, solar, geothermal, and hydro energy. In 2005 investments included 54 wind energy projects. Wind projects made up the largest part of the funding at $20.3 \%$. The avoided $\mathrm{CO}_{2}$ emissions attributed to these 54 projects is 257,800 tonnes. Since its inception, there are 928 renewable energy projects established through Green Funds; 928 out of 4,499 of all the other categories. The Green Projects Financing Scheme Annual Report 2005.

114 Vermeend and Van der Vaart 1998, p. 61. See also SenterNovem: Green Funds Scheme:

$<$ http://www.senternovem.nl/greenfundsscheme/finance/the_green_certificate.asp>. Although the main rule is that the project be carried out in the Netherlands, it is also possible to carry out such a green project in the Netherlands Antilles and/or Aruba and claim the tax benefits. The 'Vader Piet' windpark in Aruba is an example of the result of this scheme.

115 See SenterNovem: Green Funds Scheme: <http://www.senternovem.nl/green fundsscheme/finance/the_green_certificate.asp $>$.

116 SenterNovem: Jaarbericht Groen Beleggen 2009 met jaarcijfers 2008, p. 3 available at: <http://www.senternovem.nl/mmfiles/GBJaarcijfers20081_tcm24-307369.pdf>, last visited 24 November 2009. 
other tax incentives, the Green Funds scheme can be used concurrently with the above discussed VAMIL and EIA and MIA which are yet to be discussed below.

In relation to this investment scheme, it is relevant to examine not only the benefit of the tax scheme to the investors, but to investigate the indirect benefit of the scheme to renewable energy developers. Although the scheme does not provide the tax incentive directly to project developers, they benefit from the scheme by attaining bank loans at reduced levels $-1-2 \%$ below market rates. Part IV will examine the extent to which such an indirect incentive falls within the SCM Agreement definition of subsidy.

\subsubsection{Energy Investment Deduction (EIA)}

The third environmental tax incentive ${ }^{118}$ was introduced in 1997 providing investors with a deduction of $44 \%{ }^{119}$ of the cost of an investment in energy efficient assets and renewable energy projects from taxable profits. ${ }^{120}$ The incentive was introduced in Article 3.42 of the Income Tax Code to stimulate investments in energy saving business assets. ${ }^{121}$ Although this incentive somewhat overlaps and applies concurrently with the existing general investment deduction, it increased the threshold value of investments and the deduction percentages are also higher than those of the general investment incentive. ${ }^{122}$ This incentive could be used in addition to the free depreciation incentive (VAMIL). However, it should be noted that both the EIA and the MIA (discussed below) cannot be used in relation to the same asset. One must be chosen over the other. Also, the EIA scheme is more profitable than the MIA scheme. Only new equipment included on the Energy List, developed and maintained by the Ministry of Economic Affairs and the Ministry of Public Housing and Spatial Planning and Environmental Management, is eligible for the tax incentive. ${ }^{123}$

Application for eligibility for the MIA scheme must be made within three months of the acquisition of the asset. Included in the Energy List are:

- 'Technical facilities to limit the use of primary energy (crude oil, coal, natural gas etc.) by making considerably more use $(>30 \%)$ of solar energy, hydro power or biomass';

- Cogeneration plants;

- Solar collector system;

117 Vermeend and Van der Vaart 1998, p. 55.

118 Energie-investeringsaftrek; Bruggeman 2005.

119 Faure and Ubachs 2005; <http://www.senternovem.nl/mmfiles/EIA\%20 Energielijst \%202009\%20-\%20versie\%209jan09_tcm24-290261.pdf>.

$120 \quad$ See De Waard and Zom 2000, p. 372.

121 Energie-investeringsaftrek See Article 11, para. 1, b WIB1964.

122 Prinsen 1998, p. 212. In 1997 this investment threshold was $€ 22.7 \mathrm{~m}(\mathrm{f50m})$ and in 1998 already $€ 90.5 \mathrm{~m}(\mathrm{f} 200 \mathrm{~m})$ whereas for the general investment deduction this limit was a mere $\mathrm{f} 545,000$. For example an investment of $€ 219,500$ (f485,000) was subject to an investment deduction of $40 \%$, according to Prinsen - a considerable tax saving. See also Essers, Flutsch and Ultee 2000, p. 53. Faure and Ubachs 2005. 
- Thermal recovery system;

- Photovoltaic solar energy system;

- Wind turbine;

- Biomass gasification plant;

- Biomass combustion plant with heat (and power) usage;

- Hydroelectric power plant.

There is also a condition that the said investment should be brought into use with three years from the $1^{\text {st }}$ of January of the year of purchase. This rule also applies to the general investment deduction and was introduced in 1964.124 Although the investment threshold and the percentages were changed with respect to the energy investment deduction, the time limit for usage was not changed. ${ }^{125}$ The implications of this particular rule are not completely logical. An asset thus purchased in December would have to be brought into use with two years and one month as opposed to three years due to the calendar year rule. ${ }^{126}$ Prinsen proposes that a more realistic approach would be for the three-year time limit to commence from the day of purchase of the asset as opposed to the $1^{\text {st }}$ of January, in addition to suggesting that this period should be extended to five years. Furthermore, in order to obtain the investment deduction, a request must be made to the tax administration within three months of acquisition of the asset. ${ }^{127}$

The investment deduction is only available for assets purchased for use in the Netherlands. Essers highlights the potential problem of this requirement at the EU level with the example that purchase of such an asset by a Dutch parent company would not be eligible for the tax deduction where the asset is used by a subsidiary in another Member State. This could conflict with the freedom of establishment embodied in Article 49 to 54 TFEU. ${ }^{128}$

The cost of this incentive was $31.5 \%$ (the tax rate) of the $44 \%$, leaving net revenue foregone of $13 \%$ of total investments made. The range of investments to which the deductions apply is between a minimum of $€ 2,200$ and maximum of $€ 113$ million $^{129}$ per annum per investor (tax entity). The cost of the individual asset must be at least $€ 450$.

In its first year, investments worth $€ 272$ million benefited from the incentive. ${ }^{130}$ In its twelve and a half years this incentive scheme was responsible for business investing $€ 10$ billion in energy saving assets. ${ }^{131}$ Finally, in 2009 , the total value of the tax break will equal $€ 145$ million, $€ 6$ million more than in 2008 . ${ }^{132}$

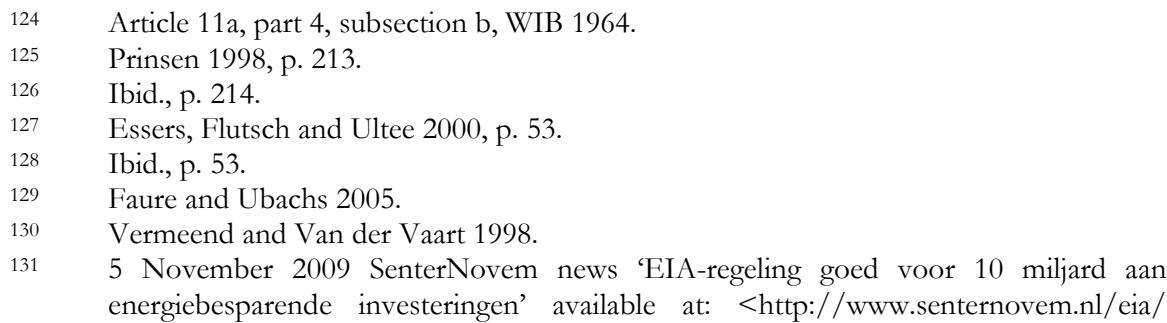




\subsubsection{Environmental Investment Deduction (MIA)}

The MIA ${ }^{133}$ incentive was introduced in the Netherlands in 2000, following approval from the Commission. This provision is in Article 3.42a of the Income Tax Code. This investment deduction, like the energy investment deduction, allows a percentage of the invested amount in listed products to be deducted from taxable profits of enterprises. Included in the Environmental List are up to 400 energy-saving tangible assets. The assets are such that investment in these assets goes beyond the required national environmental standards. The deductible percentage relates to the extra cost associated with the acquisition of the environmentally friendly asset.

The Environmental List is divided into Categories, to which a different deduction percentage is applicable. On its introduction, there were two Categories with deductions of $30 \%$ and $15 \%$. However, now, the List contains three Categories with rates of $60 \%,{ }^{134} 50 \%$, and $35 \% .135$ The $60 \%$ and $50 \%$ rates are applied to assets which are of particular interest for the protection of the Dutch environment, and the $35 \%$ relates often to production-related investments which, although not vital are interesting for the Dutch environment. ${ }^{136}$ Costs for environmental consultation related to potential environmental investments were also deductible under the $60 \%$, $50 \%$ or $55 \%$ category for SMEs. The percentage used depended on the asset on which the advice/consultation was given. A minimum investment amount means that the asset must at least cost $€ 450$ and the total of investments must come to $€ 2200 .{ }^{137}$ The deduction had to be used with the 12 months after the advice was received or the asset obtained. The anti-abuse provision requires the assets to be held for a minimum of five years.

As was discussed in relation to the other case study countries, there is a possibility to benefit from the tax incentive when leasing the listed assets. The decision to purchase or lease, and if to lease which form of lease to choose has implications on whether or not the tax incentive applies. ${ }^{138}$ The tax incentives in the Netherlands benefit the economic owner of the environmentally friendly assets. ${ }^{139}$ Thus, a distinction must be

nieuws/eiaregeling_goed_voor_10_miljard_aan_energiebesparende_investeringen.asp $>$, last visited 24 November 2009.

'Voorwaarden voor energie-investeringsaftrek verruimd', available at: <http://www.vrom.nl/pagina.html?id=38452>, last visited on 24 November 2009.

133 Milieu-investeringsaftrek.

134 This category was introduced in 2000 and relates to assets mainly used in the agriculture sector.

135 In 2010 , the percentages were increased from $40 \%, 30 \%$ and $15 \%$ to $60 \%, 50 \%$ and $35 \%$ respectively.

136 The code of the asset in the List determines whether it will be eligible for the MIA or not. If the asset code begins with $\mathrm{B}$ or $\mathrm{E}$ the deduction is $35 \%$. With code starting with A or D $50 \%$ is deductible and codes starting with $\mathrm{F}$ or $\mathrm{G}$ have a $60 \%$ deduction. Article 3.42a(3) WIB.

Green Projects Financing Scheme Annual Report 2005, p. 16.

In the case of a lessor retaining economic ownership of environmentally friendly assets, Bruins Slot considers that an extra tax subsidy is being offered by the Inland Revenue. By virtue of the tax incentive received by the lessor, the lease price should then be reduced, also reducing the income gained by the lessor and resulting in revenue 
made between operational and financial leases. ${ }^{140}$ Essentially the conclusion of a financial lease allows the lessor to benefit from the tax subsidy.

This investment scheme is applicable alongside the VAMIL scheme (free depreciation) as long as the application of both does not provide aid to a higher level than permitted by the State aid rules but as discussed above, either the MIA or the EIA must be chosen as both do not apply concurrently. The current budget allowed for MIA investment deductions in 2009 is a maximum of $€ 89$ million. ${ }^{141}$ The budget has consistently been increased, by applications for approval from the Commission from the $€ 18$ million which was allowed in 1999.

\subsubsection{Commission Approval ${ }^{142}$}

There is no record of Commission approval in relation to the EIA scheme. VAMIL, MIA and the Green Funds scheme have, however, been investigated. In fact, the EIA scheme was never notified to the Commission since the Dutch authorities considered that it does not fall with the requirements for notification of Article 107(1) TFEU. The Commission mentioned the EIA scheme in its Q7 Windpark decision ${ }^{143}$ describing it as a direct financial incentive for corporations which invest in energy saving business assets and sustainable energy. Also the Commission clarified that the Dutch authorities considered that the EIA scheme is not State aid since it is general in nature, which fits into the Commission notice on the application of the State aid rules to measures relating to direct business taxation ${ }^{144}$ and since the measure is available to all corporations on an equal basis, and upon objective criteria. The Commission furthermore did not examine the measure under the 'unnotified aid' procedure. It can therefore be taken that, as the Dutch authorities, the Commission accepted the EIA scheme as not being State aid under the meaning of Article 107(1) TFEU.

foregone by the Inland Revenue. The taxable profit is lower with the adjusted lease price by virtue of the tax incentive. Bruins Slot 1998, p. 669-670.

140 With an operational lease both the legal and economic ownership remain with the lessor and the tax incentives correspond to the lessor regardless of who employs the environmentally friendly asset. In the case of a financial lease however, the legal ownership remains with the lessor while the economic ownership transfers to the lessee - thereby also transferring the rights to the tax incentives to the lessee. However, Bruins Slot discusses this issue from the perspective of providing those companies, which would normally conclude financial leases, but by virtue of their being an organisation no subject to taxation, could not benefit from the above tax incentives otherwise. In such cases Bruins Slot advises to construct rather an operational lease leaving the economic ownership, and therefore the tax incentives, in the hands of the lessee and deriving the indirect benefit from the tax incentives in the form of lower lease prices. Ibid. <http://www.senternovem.nl/vamil_mia/algemene_informatie/financiele_steun_ vamil.asp >, last visited 24 November 2009 . 71.

143 State aid decision N266/2003, p. 2.

144 Commission Notice on the application of the State aid rules to measures relating to direct business taxation, 98/C 384/03 of 10 December 1998. 
The VAMIL scheme came under approval of the Commission in both in 1994 and 2003. In 1994, the VAMIL scheme - a scheme for the free depreciation of environmentally friendly assets - was approved in general. ${ }^{145}$ In 2003, the Netherlands applied to the Commission for approval for State aid for the development of an offshore wind farm - Windpark Q7 and the use of the tax aid VAMIL scheme in relation to this project, allowing the investor to depreciate the assets in full in the year of purchase. The initial investment cost of the Q7 project was estimated at $€ 275 \mathrm{~m}$. ${ }^{146}$ A budget of $€ 16.5 \mathrm{~m}$ is provided for the VAMIL scheme. In the framework of this deduction an estimation of $€ 49.8 \mathrm{~m}$ was budgeted for the Windpark Q7.

According to the Dutch authorities, this investment deduction does not fall within the scope of the State aid rules, since it is a scheme available to all business in the Netherlands and objective criteria are applied. For this reason the Dutch authorities did not notify this scheme to the Commission.

The Commission stated that the proposed aid was financed by the State in the form of loss of tax revenue. However the Commission also reminded that support of renewable energy is a priority of the EU. After carrying out an extremely complex calculation of the benefits provided by the aid to Windpark Q7, the Commission decided not to raise any objections to the said aid.

In 1999, the Netherlands notified the European Commission of a fiscal State aid measure with the motivation of protection of the environment: the environmental investment deduction (MIA). ${ }^{147}$ The aid intensity of this measure was considered to be $18 \%$ and to be available for an unlimited period of time. The Commission approved the proposed State aid. The measure was considered to constitute State aid but was compatible with the State aid rules and in line with the Community Guidelines.

In 2001, the MIA tax incentive was amended with the introduction of the new Category (III) with a deduction percentage of $40 \%$ for extra costs. ${ }^{148}$ Again the Commission approved this extra aid. ${ }^{149}$ In 2001, this tax incentive was once again sent to the Commission for approval. ${ }^{150}$ A tax deduction for environmental advice was introduced. A budget of $€ 907,560.43$ was indicated for this new category of deduction. This change was approved by the Commission as compatible State aid.

In 2005, the same incentive was examined by the Commission. ${ }^{151}$ This time a budget increase was in question from $€ 46$ million (the amount allowed in 2004) to $€ 83$ million. Again the Commission approved. Another approval of the Commission ${ }^{152}$ in

\footnotetext{
145 State aid decision N262/94.

146 Based on prices in 2002.

147 State aid decision N247/99 and State aid decision N648/1999.

$148 \quad$ State aid decision N79/2001.

149 The commission deemed this aid measure to be compatible aid and approved the aid by a decision not to raise objections.

$150 \quad$ State aid decision N634/2001.

$151 \quad$ State aid decision NN24/2005.

152 State aid decision N643/2005.
} 
2005 gave the green light to budgets for the MIA scheme of up to $€ 123$ million in one year.

The Green Funds scheme was not notified by the Netherlands to the Commission. However, following what the Commission termed as 'informal contacts', the State aid examination in relation to this aid did take place under the unnotified aid procedure. ${ }^{153}$ The Commission approved the aid and declared it compatible with the State aid rules and the Community Guidelines. Again in October 2009 the Commission examined the Green Funds scheme and again decided not to raise any objections. However, the public version of this document was not yet available at the time of writing and the content of this decision is yet to be revealed. However despite this, it is clear that the Commission has decided that the Green Funds scheme is in line with EU State aid rules. This decision applies to the period between 2009 and 2014 while the State aid decision NN41/2005 applied to the period 1994 to 2011. This is so since as stated in the State aid decision NN41/2005, the Netherlands committed to discontinuing the scheme after 2011 without having approval from the Commission. ${ }^{154}$

\subsubsection{Reaction to the Tax Incentives}

As in the UK, the discussions relating to the acceptability of tax incentives for environmental protection tends to focus on energy taxes and exemptions therefrom provided to generators and consumers. ${ }^{155}$ There is little reaction to the direct tax incentives. Of the debate that has taken place however, an important issue relating to tax support of renewables refers to the lack of Dutch capacity to fulfil the levels of demand for such electricity. Because of this lack of capacity, the tax support for consumption of renewable energy falls inevitably into the hands of foreign green electricity generators. It is understandable that this 'tax leakage'156 cannot be considered to be justified tax expenditure in the Netherlands. The liberalisation of the electricity market was effective in the Netherlands, and green electricity is outsourced at a high rate.

It has been stated that the VAMIL scheme 'seems to be stimulating' investments in capital which contributes to the environment ${ }^{157}$ and that, despite some criticism, this scheme is indeed popular. ${ }^{158}$ However, potential problems related to this tax incentive scheme have been highlighted by Essers. He considers that due to these restrictions to the eligibility of capital assets for the VAMIL scheme, 'the impact of this provision is rather limited'. ${ }^{159}$ Further problems highlighted relate to potential restrictions on the freedom of establishment in the European Union. Since VAMIL is in place only for capital assets that affect the protection of the environment in the

153 State aid decision NN41/2005.

$154 \quad$ State aid decision NN41/2005, para. 12.

155 For a discussion on the use of energy taxes in the Netherlands and in particular the application of energy taxes to renewable energy sources see: Ubachs 2004, p. 150-154.

156 Cramer 2005.

157 Essers, Flutsch and Ultee 2000, p. 54; see also, General Auditor's Office, 18 March 1999, Tweede Kamer 1998-1999, 26.452, nrs. 1-2.

158 Ibid

159 Essers, Flutsch and Ultee 2000, p. 53. 
Netherlands, the provision does not apply to assets held in other Member States. ${ }^{160}$ For example, if a parent company invests in assets for use by its subsidiary in another Member State, since these assets therefore do not affect the protection of the environment in the Netherlands, they are not eligible for the VAMIL scheme. If it had been a purely domestic situation this would not be the case. This leads to the question whether the TFEU provisions on the freedom of establishment do not preclude the Netherlands from making this a requirement and thereby potentially restricting the freedom of establishment. ${ }^{161}$

The reaction to the Green Funds scheme has also been positive. Vermeend cites the project as being 'a resounding success' which 'brought new players on to the field for the environmental team, bank managers in search of green projects'. ${ }^{162}$ In all, the Green Funds scheme has proven to be very popular and very successful with 234,000 investors taking part representing over 5,000 green projects by 2009 with a total of over $€ 6.8$ billion in investments. ${ }^{163}$

Ubachs considers the MIA and EIA to be rather limited incentive schemes due to their strict conditions to qualify - only new listed assets qualify. ${ }^{164}$

\subsubsection{Cost of the Incentives}

From the estimation of the annual costs of each tax incentive programme discussed above, it can be estimated that over $€ 300$ million is budgeted for direct tax incentives for renewable energy and energy efficiency in the Netherlands. By only counting the 2009 budget for VAMIL, $€ 79$ million, MIA, $€ 89$ million and $€ 145$ million for EIA over $€ 300$ million is already reached without even counting the Green Funds scheme. This is substantial tax expenditure in one country when compared to the equivalent in the other countries.

\subsubsection{Conclusion}

In the Netherlands, much use has been made by the government of direct tax incentives for environmental protection. However, due to the main attention being focused globally on indirect taxation, there has even discussions about the 'Greying of Dutch Taxes' since the indirect tax incentives for green energy were retracted by the government. Since all the attention on tax incentives surrounds indirect taxes, little credit is given to the government for maintaining some of the most successful and wide ranging collection of direct tax incentives for environmental protection. Once again, since these incentives having been initiated as early as 1964, it cannot be said to be a direct result of the Kyoto Protocol ratification but rather an independent policy objective pursued with fervour by the Dutch government. The evidence that the Netherlands has so many notifications of aid to the Commission, which are in turn

\footnotetext{
160 'Bescherming van het Nederlandse milieu'.

$161 \quad$ Essers, Flutsch and Ultee 2000, p. 54.

162 Bruggeman 2005; Vermeend and Van der Vaart 1998.

163 Essers, Flutsch and Ultee 2000, p. 61. For these updated figures based on 2008 data see: Jaarbericht Groen Beleggen 2009 met jaarcijfers 2008, p. 3. Ubachs 2004, p. 153.
} 
approved, highlighting increases in budget for the said tax incentives gives hope that indeed the investment in renewable energy resources can be encouraged.

\subsection{BELGIUM}

This section investigates tax incentives for renewable energy in Belgium and their role in Belgium's strategy to attain the goals of the Kyoto Protocol. This section aims to outline the tax incentives in place, the background to those measures and the interaction of those incentives with the general Kyoto Protocol action plan. The consistency of the tax incentives with international trade law will be examined in detail in Part IV.

\subsubsection{Kyoto Protocol}

Along with the other EC Member States, Belgium also signed the Kyoto Protocol on 29 April 1998 and ratified the Protocol on 31 May 2002. Belgium has a greenhouse gas emission reduction commitment equal to $7.5 \%$ below the 1990 recorded level to be attained by $2012 .{ }^{165}$ Belgium is under an obligation to reduce its emissions jointly with the other Member States of the European Union to achieve an aggregate emissions level of $92 \%$ of the EU-wide 1990 level. ${ }^{166}$

In Belgium, nuclear energy makes up $60 \%$ of electricity generation. Energy imports are very important in Belgium and account for most of the remaining electricity supply. ${ }^{167}$ Only $2.6 \%$ of Belgium's electricity supply is derived from renewable energy resources of which the main players are combined heat and power plants. ${ }^{168}$ It is thus clear that without a significant support structure of renewables in Belgium, the target level of $6 \%$ of consumed electricity to be from renewable energy by 2010 will be very difficult to achieve ${ }^{169}$ without even considering the target of $13 \%$ to be achieved by 2020. ${ }^{170}$ Although Belgium has ratified the Kyoto Protocol, the legislative action seems to have been mainly focused on implementing European-level legislation with 'little in the way of concrete planning' with respect to the ratification of the Kyoto Protocol. ${ }^{171}$

\footnotetext{
165 The reduction commitment of the EU as a whole is $8 \%$ below 1990 levels. Belgium's individual commitment is to reduce to $7.5 \%$ below its 1990 level.

$<$ http://europa.eu/rapid/pressReleasesAction.do?reference=MEMO/05/49\&format $=$ HTML\&aged $=0$ \&language $=$ EN\&guiLanguage $=$ en $>$; last visited 24 November 2009 . Annex B Kyoto Protocol.

Renewable Energy Policy Review Belgium May 2004, European Renewable Energy Council, p. 3.

O'Brien, Carey, Hoj and Woergoetter 2001. 2.6\% is the figure for 2006 provided by Europe's Energy Portal available at: <http://www.energy.eu/\#renewable>. Directive 2001/77/EC.

Annex I to Directive 2009/28/EC.

O'Brien, Carey, Hoj and Woergoetter 2001.
} 


\subsubsection{Tax Incentives for Renewable Energy ${ }^{172}$}

A difficulty for Belgium in developing tax policy specific to encouraging renewable energy development is that the responsibility for development of renewable energy strategy is in the hands of the regional governments, whereas all tax policy is determined at the federal level. ${ }^{173}$ Regions may introduce tax measures for renewable energy development only to the extent that such measures have not been put in place at the federal level. ${ }^{174}$ Despite this difficulty, the use of tax incentives was heralded in the Plan Fédéral de Développement Durable (The Federal Plan for Sustainable Development) as a way to influence production methods and consumer trends towards sustainable development. ${ }^{175}$ In Belgium, it is also recognised that the use of tax incentives in this area, in particular to encourage industrial investment in sustainable energy, is a favourable measure by the government to safeguard Belgium's competitive position. ${ }^{176}$

\subsubsection{Own-Investment Tax Incentive}

In 1992, ${ }^{177}$ the Company Tax Code introduced a tax incentive for energy efficient assets, including renewable energy equipment in Belgium. ${ }^{178} \mathrm{~A}$ deduction from taxable income of $13.5 \%$ of the cost of the investment in assets for sustainable energy was allowed until 2001 when the deduction percentage was raised to $14.5 \% .{ }^{179}$ This has increased to $15.5 \%$ for $2010 .{ }^{180}$ This is $10 \%$ higher than the general investment deduction available for all assets irrespective of their environmental impact. ${ }^{181}$ The asset should contribute to combating the negative effects on the environment caused by manufacturing processes or be energy-saving assets. ${ }^{182}$ The condition for eligibility for the tax relief is that the provincial government has certified the investment asset. In order for the tax incentive to apply, the Walloon, Flemish or Brussels Regional administration must also provide the investor with a certificate of authenticity.

172 It should be borne in mind that this research looks specifically at positive incentives for development of renewable energy, thus leaving energy taxes and emissions trading schemes outside its scope. Vast amounts of research has been and is being carried our in this field. For some discussion on this topic please see inter alia: Deketelaere 1994; Paredis 2000, p. 409-418.

173 See Parliamentary Debate, 8 June 2004, Minister Fientje Moerman on renewable energy; See also Essers, Flutsch and Ultee 2000, p. 1.

O’Brien, Carey, Hoj and Woergoetter 2001.

175 Réduction d'impôt pour investissements économiseurs d'énergie dans les enterprises, $<$ www.Minfin.fgov.be>.

Ibid.

Article 69, 2 WIB; Royal Decree 10 April 1992 on Company Tax; Deketelaere 1994.

See The Belgium Country Report, Altener Programme, Ener-Iure Project Phase III, p. 4, available at: <http://eneriure.jrc.ec.europa.eu/Reports/BEL\%20fin.pdf>, last visited 24 November 2009

179 Avis relatif à la déduction pour investissement, nr. 1992-04-10/71 (2001).

180 <http:// fiscus.fgov.be/interfaoifnl/investeringsaftrek/Bericht-aj2010.pdf>; last visited 24 November 2009.

181 Essers, Flutsch and Ultee 2000, p. 76.

$182 \quad$ Ibid., p. 8. 
Industrial, commercial or agricultural companies are eligible for the deduction whether operated by physical or legal persons. Those of the 'liberal professions' are also entitled to the deduction. The majority shares ${ }^{183}$ and thus majority vote of the company concerned must be held by one or more physical persons. ${ }^{184}$ The deduction applies to newly-purchased depreciable ${ }^{185}$ tangible or intangible fixed assets. The particular projects which are subject to the tax reduction are ordinary investments in patents, investments in environmental research and development, energy saving investments, and investments in reusing waste. The list in Annex II of the Royal Decree lists the investments that are eligible. It is required that the investments result in more efficient use of energy, improving energy use in industrial processes, saving energy in industry. Included in the ways to make energy use more efficient, the list includes assets for energy generation from renewable energy resources. ${ }^{186}$ Thus, although this tax incentive is not exclusively aimed at the development of renewable energy, it is included. The asset should last at least for the duration of the accounting period in question and the incentive concerns investments in assets used exclusively in a professional activity in Belgium. ${ }^{187}$

The investment is not eligible for the tax deduction in the case that the investment is rented to a third person unless that third person is a physical person renting the asset to carry out an independent professional activity. However, case law furthermore clarified that the tax exemption would still apply where no professional activity is being carried out, but rather when the asset was in private use. Thus, leased assets also are eligible for the tax deduction.

\subsubsection{Reaction to the Investment Tax Incentive}

Although, the level of tax incentive available is $15.5 \%$ of the cost of the asset, this level has been considered to be insufficient to really encourage investments in energy saving equipment. ${ }^{188}$ The Legislative Proposal of 28 April 2004 called for an increase in the percentage of the deductible amount from $13.5 \%$ to $23.5 \%$ for the promotion of research and development of new environmentally friendly products and technologies, as well as energy saving in industry. ${ }^{189}$ This call for an increase in incentive level was considered to be justifiable, since it pursued the goal of sustainable development. The authors of this proposal stated that tax incentives remain some of the most effective methods of encouraging citizens to change behaviour. Deketelaere was also of the opinion, in relation to Belgium, and in general, that the percentage of aid allowed is not high enough and this is a real

183 'Majority shares' refers to more than $50 \%$ of the shares.

184 <http://koba.minfin.fgov.be/commande/pdf/Broch_investeringsaftrek_2008.pdf>; last visited 24 November 2009

185 The assets should be depreciable in 3 years or more. See < http://koba.minfin.fgov. be/commande/pdf/Broch_investeringsaftrek_2008.pdf $>$; last visited 24 November 2009. <http://koba.minfin.fgov.be/commande/pdf/Broch_investeringsaftrek_2008.pdf>; last visited 24 November 2009. Articles 68-77, 201 and 204, WIB 1992; Articles 47-49 Royal Decree; Article 123, Law Programme, 2 August 2002; Article 69 WIB. Legislative Proposal, on the alteration of Article 69 WIB 1992, 28 April 2004, Doc 51, $1060 / 001$.

$189 \quad$ Article 69 WIB, para. 1, part 3. 
disadvantage for the development of environmentally friendly investments. ${ }^{190}$ For this reason it is doubted that investment deductions are a decisive factor for companies when making their investment decisions. ${ }^{191}$

It can be questioned once again whether the limitation of the tax incentives to assets located in Belgium constitutes a restriction on the freedom of establishment as discussed in the Dutch case study. However, Essers considers that it is 'reasonable ... to restrict Belgian tax incentives to businesses and organisations that have activities on Belgian territory'. ${ }^{192}$ It is argued that in providing authorisation for the tax incentive to companies the same standards are applied to both Belgian and foreign entities and therefore no conflict arises with competition within the EU.193

\subsubsection{Cost of Increased Tax Incentive}

In January 2006, the Court of Auditors ${ }^{194}$ gave its opinion on this Legislative Proposal for alteration to Article 60 of the Income Tax Code to increase the tax base deduction by $23.5 \%$ of the cost of the acquired asset. The Court of Auditors was required to establish the loss in revenue which would ensue by the increase of the deduction percentage to $23.5 \%$ for two categories of investments. In order to do this, the Court relied on the income tax figures from 2004 until June 2005. In these figures account is taken of the possibility of a tri-annual tax return which is provided for in Article 354 of the Income Tax Code 1992. Therefore, it must be borne in mind that the figures used give a quasi-realistic result, amounting to on average $92.6 \%$ of the total taxable income. Nevertheless, based on these figures, according to the Court, the total loss of revenue, with an increased deduction of $23.5 \%$, would amount to $€ 10,502,759.06$ (hereinafter $€ 10.5$ million). In addition, this $€ 10.5$ million reduction in revenue does not take account of the potential increase in investments, due to the increase in deduction percentage which would equally result in revenue loss. Furthermore, this result also takes no account of the fact that, where a tax loss is in question, the investment deduction can be carried forward without limits. With respect to this the Court presented further figures. An increase in reported investments of $€ 6,265,135.34$ would thus occur. Taking an average corporate income tax rate of $33.37 \%$, this increase would result in an additional loss of revenue of just over $€ 2$ million.

The decision of the Court of Auditors was thus an estimation of a loss of revenue of an increased $€ 10.5$ million, were conditions to remain unchanged. This is the only information available in relation to the cost of the investment incentive in Belgium. That if the incentive were raised by $10 \%$ an additional loss of revenue of $€ 10.5$ million would ensue. A very rough estimation therefore of the current cost of this tax incentive to the Inland Revenue would be $€ 6$ million. ${ }^{195}$

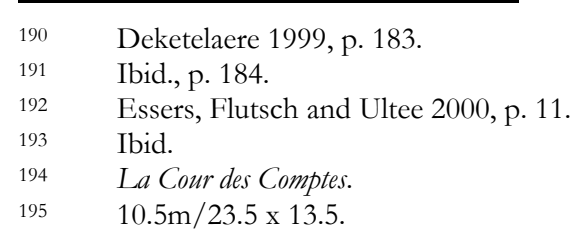




\subsubsection{Accelerated Depreciation}

In Belgium, the general system of taxation provides for linear depreciation and in some cases, in agreement with the tax authority, double declining balance depreciation where this method better reflects the true depreciation of the asset over its useful life. ${ }^{196}$ Double declining balance depreciation allows a maximum of double the linear amount and limited to $40 \%$ of the acquisition cost of the asset. This double amount is only allowed until the depreciation deduction is equal to that allowed under the straight-line method, after which the straight-line method must be employed. The rates of depreciation are not set by legislation, but rather an accepted practice has been developed over time by companies in agreement with the tax authorities. Tax practitioners, relying on this developed practice, then provide guidelines for companies on what rates of depreciation are accepted by the tax authorities. ${ }^{197}$ For example, up to $20 \%$ depreciation is allowed for machinery and equipment.

Although the Belgian Tax Code neither provides general depreciation rates, nor accelerated depreciation rates, the accepted practice of the tax authorities has developed a reasonable expectation of companies to have accelerated depreciation applied to energy saving assets. ${ }^{198}$ The rate accepted in the past has been $33.3 \%$ over three years. Compared to the generally accepted practice related to ordinary (not energy saving) equipment, this is clearly a derogation. The useful life is reduced from five to three years.

\subsubsection{Commission Approval}

It is interesting to note in the case of Belgium that other than Commission approval for exemptions from energy taxes, and tax incentives for domestic incentives for energy efficiency, there is no post-1994 State aid decision on a direct tax incentive for environmental protection. Thus there is no Commission approval for any of the tax incentives discussed above.

\subsubsection{Conclusion}

Once again, despite there being a pro-Kyoto Protocol strategy in place in Belgium, the role of tax incentives in this strategy is questionable. Firstly, the tax incentive in place was introduced in 1992, ten years before the ratification of the Kyoto Protocol. The national action plans for climate change were published after this. Belgium

\footnotetext{
196 Article 64 WIB. This method allows for greater reductions in value of the asset in the first years of holding the asset.

197 <ttp://www.deloitte.com/assets/Dcom-Belgium/Local\%20Assets/Documents/ FINAL_BelgiumTaxBusGuide_lowres.pdf >; last visited 24 November 2009. See for instance this explanation of the depreciation treatment of assets in Belgium in the Belgian edition of an online series by Deloitte, Touche, Tohmatsu providing information on tax regimes in various countries, 'International Tax and Business Guide, Belgium', February 2008, p. 21.

198 This practice is neither documented in any legislation nor in publically available guidelines from the tax authorities.
} 
suffers a particular problem in the development of a cohesive pro-Kyoto Protocol plan where the development of tax incentives is concerned. The competence for tax matters is with the federal government, whereas competence for development of proKyoto Protocol measures (other than tax measures) is in the hands of the regional governments.

\subsection{COMPARISON OF IRELAND, BELGIUM, UK AND THE NETHERLANDS}

As stated in the introduction to this chapter, the lack of a common framework for the introduction of direct tax incentives for the development of renewable energy resources results in a random mix of measures chosen by Member States to reduce greenhouse gases. As seen from the case studies, direct tax incentives are used in all four countries. However, different tax incentives are used in each country, to different extents, incentivising different actions and with different budgets.

One common denominator for all the direct tax incentives investigated here is that they are not a direct part of a real pro-Kyoto Protocol drive. Most of the measures were introduced many years prior to the ratification of the Kyoto Protocol, some as early as forty years before! Furthermore, most of the measures were also introduced prior to the many EU legislation and policy papers which claim to encourage the use of tax incentives for the protection of the environment and in particular the fulfilment of the Kyoto Protocol objectives. It could therefore be concluded that, with respect to tax incentives, the Kyoto Protocol was not a major consideration in deciding upon the implementation of the measures whose objectives, or at least the measures implemented to pursue those objectives, would have anyway been put in place (or were already in place). As far as direct tax incentives are concerned this argument can indeed be made. However, it is not for this research to address this complex issue, but rather highlight that either the national tax authorities of the EU Member States had already long had on their Kyoto Protocol hats, or that simply, irrespective of the Kyoto Protocol, the Member States were intent on environmental protection through taxation in any case.

In Ireland two clear renewable energy investment incentives are available, a third party investment project incentive and accelerated depreciation. In Belgium, a general energy saving investment incentive, which includes investment in renewable energy and accelerated depreciation provisions are in place, while in the UK only a limited renewable energy capital allowance scheme exists. In the Netherlands, an accelerated depreciation scheme, an energy investment scheme, an environmental investment scheme, and the Green Funds scheme. In Ireland and Belgium the revenue foregone is estimated at under $€ 1$ million and $€ 6$ million respectively - peanuts compared to the budgets in the UK and the Netherlands of $€ 210$ million and over $€ 300$ million. Taking into account the overall budget size of the countries or the population size, these amounts do not measure up. ${ }^{199}$ Also, it should be noted, that as far as tax measures are concerned, both direct and indirect taxes, the above-mentioned incentives get little attention in the UK and the Netherlands. In these countries, it is the Climate Change Levy and the Energy Tax and the exemptions to these taxes that

199 Ireland may only have a population of 4 million but that of the UK and the Netherlands is only 58 million and 16 million respectively. 
are discussed at length in view of the Kyoto Protocol objectives. Ireland on the other hand, with as little as $€ 1$ million tax revenue foregone in tax measures for renewable energy has not even implemented a separate carbon tax. Belgium, is equally interesting. Since the European Commission had not had any State aid investigations concerning Belgium since 1994 with regard to environmental direct tax issues the value of the tax forgone is clearly within the State aid limits as no notification was necessary and also no investigation by the Commission was carried out.

The next question to be addressed is whether these differences between the case study countries' application of direct tax incentives for renewable energy create competition differences for the renewable energy generators, and whether these differences distort trade. Indeed, the State aid rules aim to prevent trade distortion from the application of State aid by the Member States, however, an exception is in place for environmental State aid. This is not necessarily true for the trade-distortion investigation within the WTO Agreements.

\subsection{CONCLUSION}

Although, through examination of the tax incentives against EU State aid rules satisfied the Commission that either no trade distortions were at hand, or otherwise such distortions could be justified by the environmental protection motivation, the same is not necessarily true where international trade is in question. To examine the compliance of the direct corporate tax incentives for the development of renewable energy in the EU Member States with international trade rules, it is relevant to look to the national level measures and examine them against the WTO rules in particular, since no European common framework is in place in this area. The lack of an environmental exception in the WTO subsidy rules, and the existence of such an exception in the EU rules, leaves open the clear possibility that EU Member State national tax incentives may be incompliant with WTO rules. For this reason, it is important to look beyond the EU provisions relating to the Kyoto Protocol - such as emission trading and the EU Energy Tax, to national measures, and investigate WTO compliance. The tax incentives elaborated in this section will be examined against WTO subsidy rules in Part IV. 


\section{Chapter 5 : Tax Subsidies Applied in Canada}

\section{$5.1 \quad$ INTRODUCTION}

This chapter investigates direct corporate tax incentives for renewable energy in Canada and their role in Canada's strategy to attain the goals of the Kyoto Protocol. This chapter aims to outline the tax incentives in place, the background to those measures and the interaction of those incentives with the general Kyoto Protocol action plan. The consistency of the tax incentives with international trade law will be examined in detail in Part IV.

With regard to the natural resource sector, Canada is very different from the case studies explored to date. Canada is rich in natural resources, both non-renewable and renewable. Hydro-electricity in Canada is traditionally a main player in the resource sector, unlike in European jurisdictions. In Canada (since 1990) this share has been $60 \% .^{1}$ The other players in the energy scene in Canada are of course fossil fuels and nuclear power together accounting for the remaining $40 \% .^{2}$ Unlike most of the EU Member States, natural resources generating electricity in Canada are sourced in Canada, making security of supply a less pressing issue. The fact that Canada is a major oil and gas producer creates problems in establishing a secure pro-Kyoto Protocol regime involving ambitious targets for renewables. Again, the lack of pressing concern relating to security of supply, as in the EU, creates this setting. It is this national oil and gas capacity that has resulted in a federal carbon tax being, to date, out of the question in Canada. ${ }^{3}$ It has even been suggested that melting ice caps in the northern hemisphere would create potential benefits for Canada making a huge span of land accessible and the potential for further discoveries of natural resources possible.

The energy industry in Canada is also peculiar compared to the previously examined case studies. Energy resources, energy demand and energy production varies to a great extent from one province to another. ${ }^{4}$ It is for this reason that a trans-Canadian view is not representative of all provinces. For example in Quebec, hydro power provides $96 \%$ of all power generated in this province, making fossil fuel consumption less of an issue for electricity production. ${ }^{5}$ This is also the case for Newfoundland and Labrador, Manitoba, British Colombia, and Yukon. The provinces in which a switch from fossil fuels to renewable energy would be more significant are Saskatchewan, Nova Scotia, and Alberta, since it is in these provinces that $75 \%$ to $90 \%$ of power is generated by fossil fuels. ${ }^{6}$ The remaining provinces, Ontario, New

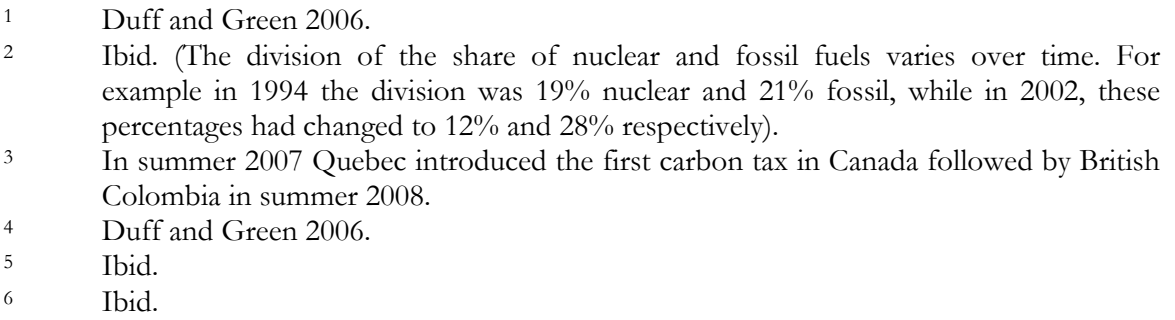
example in 1994 the division was 19\% nuclear and 21\% fossil, while in 2002, these percentages had changed to $12 \%$ and $28 \%$ respectively).

3 In summer 2007 Quebec introduced the first carbon tax in Canada followed by British Colombia in summer 2008.

Duff and Green 2006.

Ibid.

Ibid. 
Brunswick and the Northwest Territories have a less extreme energy mix with somewhat of a balance between renewables and fossil fuels. ${ }^{7}$

Supply and demand differ greatly from one province to another. Ontario has a history of extremely high demand, thereby creating strain on the available resources. ${ }^{8}$ Prince Edward Island mainly depends on electricity sourced from neighbouring provinces.

\subsection{KYOTO PROTOCOL}

Canada signed the Kyoto Protocol on 29 April 1998 and ratified the Protocol on 17 December 2002. As indicated in Chapter 1, the Protocol came into force for all States having ratified the Protocol on the 16 February 2005. Canada has a greenhouse gas emission reduction commitment equal to $6 \%$ below the 1990 recorded level to be attained by $2012 .{ }^{9}$ As far as electricity is concerned, there is a goal that $7 \%$ of all electricity production in Canada would be sourced from low-impact renewable resources by 2010 and increasing to $15 \%$ by $2020 .{ }^{10}$ Although the Kyoto Protocol was not yet signed or ratified by Canada, its goals were in the minds of the federal policy makers and action began in this respect as early as $1996 .{ }^{11}$

When examining the Kyoto Protocol in Canada, it is essential that the political development and context be viewed carefully. The federal-provincial government interaction and tension is of particular importance. The Kyoto Protocol was signed by the Canadian federal government, which has the competence to conclude international agreements such as the Kyoto Protocol, without the express agreement of the provinces despite the implementation burdens thereby imposed on the provinces. It is sure that not all the provinces were in agreement with this political decision as the ratification was met with much tension. The competitive relationship between Canada and the US was a major factor in the lack of momentum surrounding the acceptance of the Protocol. The payback by the federal government, or consideration for the implementation obligation of the provinces was to provide a budget from the federal level to the provincial level. A Kyoto budget was established of between Can $\$ 8$ and 10 billion with some of this budget being filtered down to the

\section{Ibid.}

Ibid. Ontario has the highest energy consumption level of all provinces in Canada with a history of power black outs and brown outs at its peak consumption time in the high summer.

$9 \quad$ Duff 2003, p. 2063-2118.

$1038^{\text {th }}$ Parliament, Standing Committee on Finance, Wednesday 19 October 2005, $<$ http://cmte.parl.gc.ca/cmte/CommitteePublication.aspx?COM=8977\&SourceId=13 3199\&SwitchLanguage $=1>$; last visited 24 November 2009.

11 Standing Committee on Environment and Sustainable Development, Monday, 17 November 1997, Ms Anne Park, <http://cmte.parl.gc.ca/cmte/Committee Publication.aspx? COM=110\&SourceId $=49630 \&$ SwitchLanguage $=1>$; last visited 24 November 2009. 
provincial level for projects, such as the creation of an east-west power grid. ${ }^{12}$ How much of this pie tax incentives represent is yet to be discovered. ${ }^{13}$

A Climate Change Action Plan ${ }^{14}$ was established by the federal government outlining the measures which would aim to fulfil the Kyoto obligations. This plan was a general 'target' plan, stipulating the emission reduction targets to be achieved. Although tax policy is mentioned as one policy measure with a role in achieving Kyoto Protocol goals, the specific tax policies are not enumerated. ${ }^{15}$ In the Action Plan, no example of a direct corporate tax incentive is mentioned. ${ }^{16}$ Indeed as Duff highlights, and contrary to the case in many of the EU case study countries, Canada did not address a potential introduction of a carbon tax in relation to addressing Kyoto Protocol goals. ${ }^{17}$ The federal government in this document pointed to the use of public spending, voluntary agreements and public information programmes for the achievement of Kyoto goals. It is clear that the role of tax measures was not seriously considered in respect of the Kyoto Protocol. ${ }^{18}$ However, despite this lack of recognition for the potential role of tax incentives in environmental protection at this point in Canadian political history, there are and were at that time such tax incentives already in place in Canada.

\subsection{FEDERAL STRUCTURE}

The federal structure in Canada is important, since competence for environmental protection $^{19}$ and taxation are shared competences of the federal and provincial governments, while energy matters ${ }^{20}$ are generally the competence of the provinces. ${ }^{21}$ The provinces have competence in relation to the regulation of electricity generation, transmission and distribution. ${ }^{22}$ The federal responsibility for electricity regulation is directly related to federally-owned electricity production sites as well as being the over-seer of inter-provincial trade of electricity, and the (federal) taxation of the

\footnotetext{
$12 \quad$ McKeever 2005, p. 217-226.

13 Ibid.

14 The Climate Change Action Plan for Canada was released in November 2002 one month prior the ratification of the Kyoto Protocol by Canada. See <http://www.ec.gc.ca/media_archive/press/2002/021121_n_e.htm>, last visited 24 November 2009.

15 Duff 2003, p. 2063-2118. Canada, Climate Change Action Plan for Canada, Ottawa: Public Works and Government Services, 2002, p. 15.

Only the excise tax exemption for ethanol is addressed.

Duff 2003, p. 2067.

Ibid.

Environmental competence is de facto a shared competence despite specific reference to this in the Constitution Act 1967. Hawke 2002, p. 185-196.

20 Duff and Green 2006. The provinces have competence for electricity regulation due to the inseverable link with electricity regulation and land ownership. The provinces often own the land related to the energy generation resources.

21 Sections 30, 31, 92 and 93 of the Constitution Act on the other hand expressly confer exclusive competence on the provinces for the exploration for, development, conservation and management of non-renewable natural resources and sites and facilities for the generation and production of electrical energy. Ibid.; Hawke 2002, p. 185-196.

22 Duff and Green 2006.
} 
sector. ${ }^{23}$ As far as environmental regulation is concerned, this shared competence is managed in some respect by virtue of many 'cooperation' clauses in the relevant environmental acts, in which the federal level and the provinces are required to cooperate in environmental protection issues. ${ }^{24}$ Although as Hawke puts it: "[t]he delicate process of disentangling federal from provincial competence has arisen in many cases before the court', ${ }^{25}$ the delicate overlap of competence relating to federal and provincial governments in this area where environmental law, energy policy and taxation all intertwine has not yet resulted in more than disgruntlement at all levels and in each section of policy making. In general, it is considered that the federal provincial 'cooperation' results in an 'unnecessarily complex' system of regulation. ${ }^{26}$

In environmental law and policy there is a Canadian Council of Ministers of the Environment which attempts to oversee a comprehensive Canadian environmental law by promoting the ever-important cooperation. It is made up of the Ministers of the Environment from the 14 provinces and the federal government. ${ }^{27}$ This Council was successful in adopting an accord which introduced some environmental law principles such as the polluter pays principle, the precautionary principle and the preventative principle. ${ }^{28}$ Hawke reflects that considering that the Canadian Council of Ministers of the Environment is a voluntary body, it relies on political influence in its success as opposed to any particular legal authority. ${ }^{29}$ Although according to various policy officials of both the provincial and federal levels of government there is informal cooperation between the levels, and between various departments where, for example, environmental, energy and tax policy come together, there is no formal structure for this interaction.

\section{4}

\section{CANADIAN TAX SYSTEM}

The Canadian system of corporate taxation differs to that of the other case study countries in that jurisdiction to tax corporate income is not exclusive to the federal government. The Canadian Constitution ${ }^{30}$ provides for unlimited taxing rights for the federal government, ${ }^{31}$ while limiting the taxing powers of the provincial governments to direct $\operatorname{taxes}^{32}-\operatorname{tax}$ on income of residents and income earned in that province. ${ }^{33}$

23 Ibid

24 Hawke 2002, p. 185-196. This cooperation between federal and provincial government, called for in example the Canadian Environmental Assessment Act 1992 and the Canadian Environmental Protection Act 1999, aim to 'promote uniformity and harmonisation' and 'to ensure that federal regulation is complementary and does not duplicate control', p. 186.

Ibid., p. 190.

Ibid., p. 195

Ibid., p. 190.

Canada-Wide Accord on Environmental Harmonization adopted in 1998. Quebec did not approve.

Hawke 2002, p. 196.

Constitution Act, 1867 (U.K.), 30 \& 31 Vict., c. 3.

Subsection 91(3).

Subsection 91(2). The revenue raised by the provincial government is intended for provincial expenses.

33 For a brief overview of Canadian Income Taxation see Ault and Arnold 2004, p. $23-36$. See in more detail: Duff, Alarie, Brooks and Philipps 2006; see also: Krishna 2006. 
The administration of the two levels of taxes is carried out by the federal government. The tax base (taxable income) of provincial corporate tax is levied on the tax base established by the Federal Income Tax Act (definition of taxable income $)^{34}$ and the collection of provincial income tax is also carried out by the federal government at the same time as federal income tax under a Tax Collection Agreement. ${ }^{35}$

Corporate income is allocated to permanent establishments for the purpose of determining provincial corporate tax liability. ${ }^{36}$ It is the aggregate of the federal and provincial corporate tax rates which determines the total corporate rate to which a company is subject. For example, in 2009 the federal corporate income tax rate was $19 \% 0^{37}$ (after 10\% abatement, 9\% M\&P reduction ${ }^{38}$ and/or $9 \%$ rate reduction) ${ }^{39}$ and the relative corporate (general active business) income tax rate in Ontario is $14 \%$. In 2009 the aggregate corporate income tax is thus $33 \%$.

This will become more interesting through examination of the tax incentives in place both at the federal level as well as the provincial level. Canada demonstrates an interesting divergence from the experiences in the other case studies. Although Belgium also operates a federal system of government, income tax rights are the exclusive tax jurisdiction of the federal government whereas renewable energy development is in the hands of the regions. In Canada, this is not the case.

\subsection{CROSS-BORder TRADE}

The opening of the electricity market was expected to create many cross-border trade opportunities in North America. ${ }^{40}$ As Kramer and Sumner predicted:

As competition becomes more widespread in North America electric power markets, industry players... will be scrutinizing each other's markets for economic opportunities and sophisticated consumers will be looking across the border for lower cost sources of electric power. ${ }^{41}$

Each province may choose to levy provincial income tax based on the Federal tax payable or the Federal taxable income.

Quebec constitutes an exception to this rule, using its own tax base and collecting its own provincial individual and corporate income tax. Due to the lack of a TCA with Quebec, residents of Quebec receive a $16.5 \%$ abatement of Federal income tax. In addition, Alberta and Ontario collect their own corporate income tax, while their individual income tax is collected by the federal government.

S.124 Income Tax Regulation, C.R.C., c. 945, s. 400. Krishna 2006.

For general active business income $>\$ 400,000$ CAN earned by Canadian controlled private corporations (CCPCs).

This deduction is available for corporations manufacturing or producing goods in Canada.

16.5\% abatement for Québec; <http://www.kpmg.ca/en/services/tax/documents/ FPT_2008_09.pdf>; last visited 24 November 2009.

Kramer and Sumner 1999, p. 81.

Ibid. 
Canada is a primary supplier of electricity to the US. Cross border trade is not a thing of the future for Canada, but is already a reality. ${ }^{42}$ It is estimated that reciprocal trade in electricity between the US and Canada would be worth in the region of $\$ 23$ and $\$ 32.5$ billion. ${ }^{43}$ Between $9 \%$ and $10 \%$ of electricity produced in Canada annually is exported to the US. ${ }^{44}$ There are of course comparable imports from the US to fulfil, for example Ontario summer peak demand.

Although there is no trans-Canadian electricity transmission system, ${ }^{45}$ there are indeed US-Canada transmission systems facilitating cross-border trade of electricity. There are two transmission facilities providing the infrastructure for this trade: the Western Interconnection connecting the provinces and States west of the Rockies and the Eastern Interconnection connecting the eastern US States with the exception of Texas, with British Colombia and Alberta. ${ }^{46}$ Most US - Canada electricity trade is between Ontario, Quebec, and New Brunswick with New York and New England on the Eastern transmission system. ${ }^{47}$

For the functional operation of these interconnection systems, there is much intergovernmental cooperation to ensure reliability of supply on both sides of the border. This trade in electricity is not so much a question of competition as of cooperation. Furthermore, the per unit electricity price does not so much play a role in determining the frequency of trade, but rather supply and demand. For example, the import of electricity to Ontario from the US in the peak summer times has often been at extremely high per unit prices. ${ }^{48}$ Trade occurs not at those times the price is at a preferential rate across the border, but rather when demand exceeds supply in either of the various states and provinces of the US and Canada. In these circumstances the importing country is in a vulnerable position, and price is nonnegotiable. It was highlighted by a representative of the Ontario Ministry of Energy that the diplomatic relationships between its Ministry and that of the corresponding US State Ministries are extremely good. They depend on each other for supply and maintaining a reliable electricity supply. ${ }^{49}$ Apparently it is often quoted that the top three issues as Minister of Energy are supply, supply, supply'. ${ }^{50}$ It is this cross-border trade and positive inter-governmental relationships which aid in securing that reliable supply.

It has been claimed that having focused on generation issues in North America, transmission problems have been neglected prior to, and during the opening of the electricity market despite the fact that without such a transmission system, there is no

42 Sanderson 1995, p. 1-13.

$43 \quad$ Ibid.

$44 \quad$ Duff and Green 2006.

45 Ibid. The lack of this trans-Canadian transmission system means that there can be no Canadian electricity market as such. This affects the definition of national market in WTO terms. The national market would then be divided into several (separated) national markets.

Kramer and Sumner 1999, p. 82.

Duff and Green 2006.

Ibid.

Interview with Senior Policy Advisor, Office of Energy Supply and Conservation, Ontario Ministry of Energy, July 2007.

McKeever 2005, p. 219. 
North American electricity market. ${ }^{51}$ However, from another perspective it is considered that generation is rather the problematic link in the chain of maintaining a reliable electricity supply. ${ }^{52} \mathrm{It}$ is clear however, that one entirely depends on the other.

Accessible power generators are limited to those regions in which an existing transmission system is available. In this case the reliability of supply is dependent on the generators currently linked to the transmission system. This makes the reliability of the supply of electricity rely on the capacity of those generators to fulfil demand. On the other hand where a more abstract point of view is taken, and potential new transmission systems would be available, the pool of generators would increase, and the reliability of supply would thereby become less vulnerable. Thus, by solving the transmission problem the reliability of the generation situation could also be solved by including more new (renewable) generators. Transmission systems are cost prohibitive in many cases - the reason the trans-Canadian transmission system has yet to become a concrete plan. Indeed the Canadian Climate Change Action Plan calls for a reduction of the trade barriers to provincial trade in electricity through further inter provincial government cooperation. ${ }^{53}$

\subsection{RENEWABLE ENERGY DEVELOPMENT}

The tax policies in place in Canada at the federal level may be said to be, to some extent, a response to the Kyoto Protocol ratification by the federal government, however, the influence of renewable energy lobbyists should also not be underestimated. ${ }^{54}$

\subsection{FEDERAL TAX INCENTIVES FOR RENEWABLE ENERGY55}

Since 1996, the objective of the Canadian government, with respect to renewable energy, has been to, at least, level the playing field between it and fossil fuels. ${ }^{56}$

\subsubsection{Capital Cost Allowance Class 43.1}

The Capital Cost Allowance Class 43.1 incentive provides for a system of accelerated depreciation for certain energy efficient assets, including renewable energy equipment, of $30 \%$ on a declining balance. ${ }^{57}$ It was introduced in the 1994 budget to give industry an incentive to invest in eligible assets in order to encourage electricity generation from environmentally friendly resources. ${ }^{58}$ Prior to the introduction of

\footnotetext{
$51 \quad$ Manning 2005, p. 230.

$52 \quad$ McKeever 2005, p. 217-226.

53 Climate Change Action Plan, p. 35, Duff 2003, p. 2113.

54 Sereda 2000, p. 105-122.

55 Clement, Lehman, Hamrin and Wiser 2005, available at: <http://www.resourcesolutions.org/lib/librarypdfs/IntPolicy-Renewable_Tax_Incentives.pdf>.

56 Standing Committee on Environment and Sustainable Development, Monday, November 17, 1997, Ms Anne Park,

$<$ http://cmte.parl.gc.ca/cmte/CommitteePublication.aspx?COM=110\&SourceId=496 30\&SwitchLanguage $=1>$; last visited 24 November 2009 .

$57 \quad$ Duff and Green 2006.

$58 \quad 38^{\text {th }}$ Parliament, $1^{\text {st }}$ Session, Thursday April 14, 2005
} 
this new Class in the 1994 budget, renewable energy investments were also indeed subject to accelerated depreciation, under Classes $1,2,8$, or 34 , at $4 \%, 6 \%, 20 \%$, or $50 \%$ respectively. ${ }^{59}$ For example, in 1986 wind energy assets were included in Class 34 therefore being eligible for $50 \%$ depreciation on a straight line basis. ${ }^{60}$

Class 43.1 addresses, in particular, electricity generating and heat generating equipment and includes renewable energy assets such as solar, wind, hydroelectric, heat recovery and cogeneration systems. Normally the equipment should be new, however, it is possible under certain circumstances to avail of the CCA for used equipment. ${ }^{61}$ The equipment should be situated in Canada ${ }^{62}$ and used for gaining income in a business setting. The provision also applies to lessors as long as the equipment is used by the leasee for business purpose in Canada. ${ }^{63}$

The level of depreciation was increased from 30\% to $50 \%$ by the 2005 budget for certain assets listed in Class 43.1, creating a new Class 43.2. The assets subject to the $50 \%$ depreciation include assets for renewable energy generation, as long as the asset is purchased on or after February 23, 2005 until 2012. This alteration is foreseen to be available until 2012 - coinciding with the end of the first commitment phase of the Kyoto Protocol - at which a review of the measure is to be undertaken. In fact, this Class is being regularly reviewed by the government. In 2007 there is a proposal to extend Class 43.2 to wave and tidal energy effective from March 19, 2007. ${ }^{64}$ The inclusion of this new technology, for which the potential is not yet known, is to give a signal to generate interest for potential developers. The assets covered were previously extended to include geothermal energy equipment, fuel-cell-generating equipment and equipment which converts biomass into bio-oil. ${ }^{65}$ Indeed geo-thermal was introduced in 1994, however, still by 2007 there was no geothermal plant in Canada (which makes use of the incentive). ${ }^{66}$

Although originally this provision of accelerated depreciation was a general tax policy, it now includes language referring to the environment and climate change issues. The measures are clearly not derived from federal pro-Kyoto Protocol action even if they may now indeed be seen as contributing instruments. ${ }^{67}$ Since climate change is a hot

<http://www2.parl.gc.ca/HousePublications/Publication.aspx?DocId=1767856\&Lan guage $=\mathrm{E} \&$ Mode $=1 \&$ Parl $=3 \& S e s=1>$; last visited 24 November 2009 .

Sereda 2000, p. 105-122.

Duff and Green 2006.

If the equipment has been previously used it should be equipment which was eligible under Class 34 or 43.1 depreciation by the previous owner and the property is no more than 5 years old. There should have only been one previous owner and the property remained at the same site in Canada. The property should have been used for the generation of electricity.

Income Tax Regulations Schedule II Class 43.1 (b)(i).

Ibid., (b)(ii).

Budget Plan 2007 - Annex 5.

Duff 2003, p. 2104.

Results of interview with Senior Policy Official, Canada Revenue Agency. Ibid. 
political topic, a tax incentive which contributes to combating climate change (potentially) is nice politically. ${ }^{68}$

It is worth noting that the accelerated depreciation provision is only useful to companies in a profit making situation. ${ }^{69}$ Flow-through share options are not available for accelerated depreciation deductions.

\subsubsection{Cost of the Incentive}

In general the renewable resources industry is a small one, and the tax expenditure related to this industry is therefore also small. ${ }^{70}$ The estimated tax cost of this measure is $\$ 25$ million per annum between $2008-2010$. $^{71}$

\subsubsection{Reaction to the Incentive}

Calls for further enhancements of this incentive scheme claimed that the ratification of the Kyoto Protocol makes greenhouse gas reductions 'much more significant' and equipment subject to Class 43.1 'goes a long way to helping that goal'.72

Industry certainly applauded the increase of depreciation rate from $30 \%$ to $50 \%$ for renewable generation equipment. For example Canadian Hydro was of the opinion that it will have a significant positive impact on the development of renewable resources in western Canada and across the country'. ${ }^{73}$

Some reactions to the incentive consider it to be 'limited in scope'. For example a 'very small percentage of the total capital required for a wind farm is eligible'. ${ }^{74}$ Also the fact that the CCA is not eligible to be part of a flow-through share agreement is a further criticism of the measure. ${ }^{75}$ Since accelerated depreciation deductions are only useful to companies with a profit-making situation, the extension of these deductions to shareholders through a flow-through share agreement would make the measure more relevant for start up (loss-making) companies. This is particularly relevant in the renewable energy sector since the opening of the electricity market is still relatively

\footnotetext{
$68 \quad$ Ibid.

Ibid.

Ibid.

Industry Canada, available at: <http://www.ic.gc.ca/eic/site/fte-fte.nsf/eng/ 00004.tml >. Last visited 24 Nov 2009.

72 37th Parliament, $2^{\text {nd }}$ Session, Standing Committee on Finance, Evidence, Thursday 6 November 2003, <http://www2.parl.gc.ca/HousePublications/Publication.aspx?DocId=1169619\&Lan guage $=\mathrm{E} \&$ Mode $=1 \&$ Parl $=37 \&$ Ses $=2>$; last visited 24 November 2009 .

$73 \quad 38^{\text {th }}$ Parliament, $1^{\text {st }}$ Session, Standing Committee on Environment and Sustainable Development, Evidence, Tuesday 22 March 2005, <http://www2.parl.gc.ca/ HousePublications $/$ Publication.aspx?DocId=1707948\&Language=E\&Mode $=1 \&$ Parl $=$ $38 \&$ Ses $=1>$; last visited 24 November 2009.

$74 \quad$ Standing Committee on Finance, Thursday May 31, 2001, Ms Marlie Burtt:

<http://cmte.parl.gc.ca/cmte/CommitteePublication.aspx?COM=215\&SourceId=551

$24 \&$ SwitchLanguage $=1>$; last visited 24 November 2009.

75 Result from interview with Deloitte, Toronto representative.
} 
recent, a large representation of these companies are, or recently were, start up companies.

\subsubsection{Canadian Renewable and Conservation Expense (CRCE)}

The Canadian Renewable and Conservation Expense (CRCE) was introduced to equalise the position between renewable energy and fossil fuels in Canada and to entice investment in new renewable energy projects. ${ }^{76}$ Historically, fossil fuels had been subject to a special taxation initiative, the Canadian Exploration Expense (CEE), which made exploration costs related to fossil fuel exploration fully deductible in the year they were incurred. In 1996 the CRCE initiative was introduced relating to start-up expenses of renewable projects and allowing particular expenses to be deducted in full in that year. ${ }^{77}$ The implementing regulations, however, were only adopted in 2000 . The regulations still covered expenses dating from $1996 .{ }^{78}$ The first condition of this incentive is that $50 \%$ of the capital cost of the renewable project in question is eligible for the Capital Cost Allowance from Class 43.1. ${ }^{79}$ The CRCE itself then provides for a deduction of intangible costs related to setting up a green project. Costs included may be feasibility studies, valuation and approval costs, test costs, and site preparation costs. Eligible costs are 100\% deductible at once or over several years with the carry forward provision. ${ }^{80}$ Expenses should be related to arm's length enterprises. In 1997 the incentive was amended to include the cost of installing test wind turbines. This provision was also to apply to expenses dating from 1996. ${ }^{81}$ Although this incentive was introduced specifically for renewable energy development, it in fact only serves to equalise the treatment between fossil fuels and renewable energy resources. No additional development incentive is in place here.

In 2002 the CRCE was adapted to make it broader as far as testing costs were concerned, with the amendment that costs related to more than one wind turbine test could be deducted. This amendment was largely a result of successful lobbying by the wind industry. ${ }^{82}$ The second enhancement was to allow flow-through shareholders to take advantage of the CRCE rather than the energy project developers. Flow-through share provisions are examined in the next section.

\subsubsection{Flow-through Shares}

At the same time as the introduction of the CRCE deduction in relation to renewable energy projects, the flow-through shares provision, traditionally in place for the oil and gas industry, was extended to the renewable energy sector. ${ }^{83}$ This provision was originally introduced to aid start up oil and gas operations in Canada by allowing the operation to pass on its expenses to its shareholders. The rationale was that during the initial years of the operation the company is loss-making thereby making the tax

Duff 2003, p. 2063-2118; Sereda 2000, p. 105-122.

Tax incentives, Government of Canada, 6 August 1998. Sereda 2000, p. 105-122.

Duff and Green 2006.

Sereda 2000, p. 119.

The carry forward provision applies indefinitely.

Duff and Green 2006.

Ibid.

Sereda 2000, p. 105-122. 
deductible expenses like CRCE of no value. By passing on these expenses to its investors, both the operation and shareholders were in a beneficial position and the operation was in a position to attract investors. ${ }^{84}$ The CRCE is considered to be equivalent to the CEE (Canadian Exploration Expense) and therefore puts the renewable energy sector on the same footing as non-renewable energy companies.

Whether the flow-through share system is in operation in respect of mining and petroleum exploration, or renewable energy resources, the theory of the 'equity-based financing mechanism' is the same. ${ }^{85}$ The flow-through share mechanism was first introduced in respect of mining and petroleum companies in $1954 .{ }^{86}$ It proved to be an interesting financing mechanism for such companies. Jog et. al clarify that, between 1987 and 1991, of Can $\$ 2.5$ billion raised equity for mining exploration, 60\% related to the purchase and sale of flow-through shares. ${ }^{87}$ In the same study the conclusion was reached that this equity raising mechanism 'can be cost-effective' for the resource companies and 'provide significant encouragement to exploration'. 88 Furthermore, the authors go as far as to expect that the flow-through share agreements may even be beneficial to profit making (tax-paying) resource companies. On the other side, the conclusions of the same report are less positive in relation to the cost-effectiveness of flow-through shares for investors. This depends in particular on the pricing of the flow-through shares and the premium charged for the tax benefits. ${ }^{89}$

Flow-through shares are especially useful for start up energy companies which do not yet pay corporate income tax (do not yet make a profit). Thus, the relevant deductions would not apply nor provide any benefit. With the flow-through shares the tax incentives may be used by the investors in the energy projects.

The flow-through share capacity of tax deductions is the most important element for start-up companies. At the moment the amount of deductions which can flow through is not significant enough to constitute a real incentive. It amounts approximately to $10 \%$ of total costs. ${ }^{90}$ In the same way, the accelerated depreciation scheme is not particularly useful for start-ups as although the deductions can indeed be carried forward, they may not flow-through. Having an increasing loss carry forward annually does not increase financing options in the beginning - the main concern for start-ups. ${ }^{91}$

The conditions relating to implementing the flow-through share option is that the company is a 'principal business corporation', being a corporation whose primary activity is a combination of several specific activities which, since the introduction of the CRCE, includes generation of energy with equipment within CCA Class 43.1 and

Ibid., p. 120.

Jog, Lenjosek and McKenzie 1996, p. 1016-1051.

Ibid., p. 1018.

Ibid., p. 1019

Ibid., p. 1050

Ibid., p. 1051.

Result from interview with Deloitte, Toronto representative. Ibid. 
projects in which at least $50 \%$ of the capital involved falls within the scope of Class 43.1. ${ }^{2}$

In the year prior to claiming the CRCE deduction, the energy project developer may pass those costs and thereby the CRCE initiative to flow-through shareholders. ${ }^{93} \mathrm{An}$ exploration company enters into an agreement with its investors for the sale/purchase of flow-through shares. The investor, by virtue of these shares, receives equity interest in the resource company and in addition the use of the tax deductions related to the exploration expenses of the resource company (the CCE or CRCE). The resource company (in a loss-making position and in any case unable to use the CCE or the CRCE yet) sells these flow-through shares for the normal equity price plus a premium relating to the tax value of the CCE (CRCE) deductions. ${ }^{94}$ The flow-through share initiative was primarily intended to make the available tax deduction useful to a loss-making enterprise (an enterprise in the developing stages) and at the same time create an incentive for investors to create extra financing opportunities for such start-up companies.

The introduction of the CRCE and flow-through share options aimed to improve 'access to financing in the early stages of operations when they have little or no income to utilise the income tax deductions related to these expenses'. ${ }^{95}$

\subsubsection{Levelling the Playing Field}

The development of the CRCE (and its flow-through provisions) tax incentive was initiated in response to a call from various lobbyists and in particular the Task Force on Economic Instruments and Disincentives to Sound Environmental Practices to remove the inequalities existing between renewable and non-renewable resources of energy. Indeed it was the preparation and publication of the Report: The Level Playing Field that initiated developments in the 1996 Budget to the benefit of renewable energy resources. ${ }^{96}$ Canada, with is rich source of oil and gas, historically had in place various tax incentives for the promotion and development of this sector. However, until the 1990s, no corresponding support for other fuel resources was in place. In 1996, the Ministry of Finance in association with Natural Resources Canada published a document addressing this issue: The Level Playing Field, The Tax Treatment of Competing Energy Investments. ${ }^{97}$ The message was:

92 Subsection 66(15) of the Income Tax Act; Sereda 2000, p. 105-122.

93 Basically the flow-through share agreement has to be completed before expenses are incurred.

$94 \quad$ Jog, Lenjosek and McKenzie 1996, p. 1018.

95 Duff and Green 2006. Canada, Department of Finance, Budget 1996: Budget Plan Including Supplementary Information and Notices of Ways and Means Motions, 6 March 1996, at 171, available at <www.fin.gc.ca/budget96/bp/bp96e.pdf>; last visited 24 November 2009.

96 See Preamble to The Level Playing Field: The Tax Treatment of Competing Energy Investments, (1996).

97 Ibid. 
The challenge is to ensure that the tax system conveys the appropriate signals for investment decisions across non-renewable, renewable energy and energy efficiency options.

The report called for a more equal treatment of various energy resources. This involved a recommendation of extending certain beneficial tax provisions, available to the fossil fuel sector for many years, to renewable energy resources.

It is important to note that in creating a certain 'level playing field' between renewables and non-renewables in Canada by extending these tax provisions, the environmental consequences of this extension was not examined. ${ }^{98}$ The investors' perspective was the point of examination. Although a decent level of tax support was indicated for renewables, it was recognised that where a start-up renewable energy company is not in a position to make use of special tax deductions (due to not yet being in a profit making position) the tax support is significantly lower than expected. ${ }^{99}$ The 1996 report stated that the support variations between renewable energy and other energy were not excessive despite there not being a level playing field. The 1996 budget aimed to further correct this. In addition, general tax exemptions and deferrals from progressive tax systems are inclined to be regressive: conferring a more substantial benefit relative to the extent of profits. ${ }^{100}$ Thus, without correction for this vertical inequity, the incentives will continue to be of little value to start-up companies which do not yet have profit-making capacity.

\subsubsection{Cost of the Incentive}

The tax expenditure related to this incentive is not available.

\subsubsection{Reaction to the incentive $\mathrm{e}^{101}$}

The CRCE scheme and in particular the possibility of having this incentive passed on to shareholders with the flow-through share mechanism was considered to be a step in improving international competitiveness of the Canadian resource sector, in particular relative to the U.S'. ${ }^{102}$ One concern about the introduction of this measure was that the benefit would go to foreign investors rather than Canadian investors. ${ }^{103}$

\footnotetext{
$98 \quad$ Executive Summary Ibid.

$99 \quad$ Ibid.

$100 \quad$ Duff 2003, p. 2080.

101 March 2003 Department of Finance technical paper: Improving the Income Taxation of the resources sector in Canada.

<http://canadagazette.gc.ca/archives/p1/2006/2006-09-30/html/reg1-eng.html>; last visited 24 November 2009.

$10237^{\text {th }}$ Parliament, $2^{\text {nd }}$ Session, Wednesday 24 September 2003, $<$ http://www2.parl.gc.ca/HousePublications/Publication.aspx?DocId=1063525\&Lan guage $=\mathrm{E} \&$ Mode $=1 \& \operatorname{Parl}=37 \&$ Ses $=2>$; last visited 24 November 2009. Second reading of the Bill C-48 on the Income Tax Act (natural resources). Ibid.
} 


\subsubsection{Wind Energy Development}

It is interesting to see the development of wind energy in Canada in the aftermath of the changes to the Income Tax Act in the late 1990s to include the CRCE and in particular the inclusions of up to two test wind turbines within these expenses. This increase did indeed improve the take-up level of the CRCE deduction as it made it possible to have real trials. Since these costs also could be flowed through, it increased the financial value of setting up flow-though shares. There was a more significant tax deduction to pass on and therefore the administrative costs of setting up the flow through shares was somewhat overcome. ${ }^{104}$

There was a significant increase in the share of wind energy of the total energy pie from 1998. In 1998, wind energy capacity was 25MW. ${ }^{105}$ From 1999 to 2002, this capacity increased by over $36 \%$ annually. The opening of the electricity markets was by far one of the most significant factors for this development. Previously there was little room for private developers to make use of the incentives. ${ }^{106}$ The second most significant factor was the introduction of the production incentive in 2001. By 2002 the forthcoming wind capacity had increased to $3000 \mathrm{MW} .{ }^{107}$ Although this increase in capacity was rather unstable during this time, from 2003, growth has been relatively steady. ${ }^{108}$ In 2009 the current installed wind capacity was 289 MW. ${ }^{109}$

Of course, also to be counted into the equation is the general reduction in the set-up cost of wind farms. ${ }^{110}$ The purchase price for example of turbines has decreased, as well as the production capacity of each turbine having increased. ${ }^{111}$ Further influencing factors, besides tax measures, in Canada have been feed-in tariffs, and procurement policies. ${ }^{112}$

\subsubsection{Ontario}

Ontario also has a direct corporate tax incentive for renewable energy generation. It was introduced in 2002, with a life-span of 10 years. The provision exempts income from renewable energy resources from corporate tax for a duration of 10 years. ${ }^{113} \mathrm{~A}$

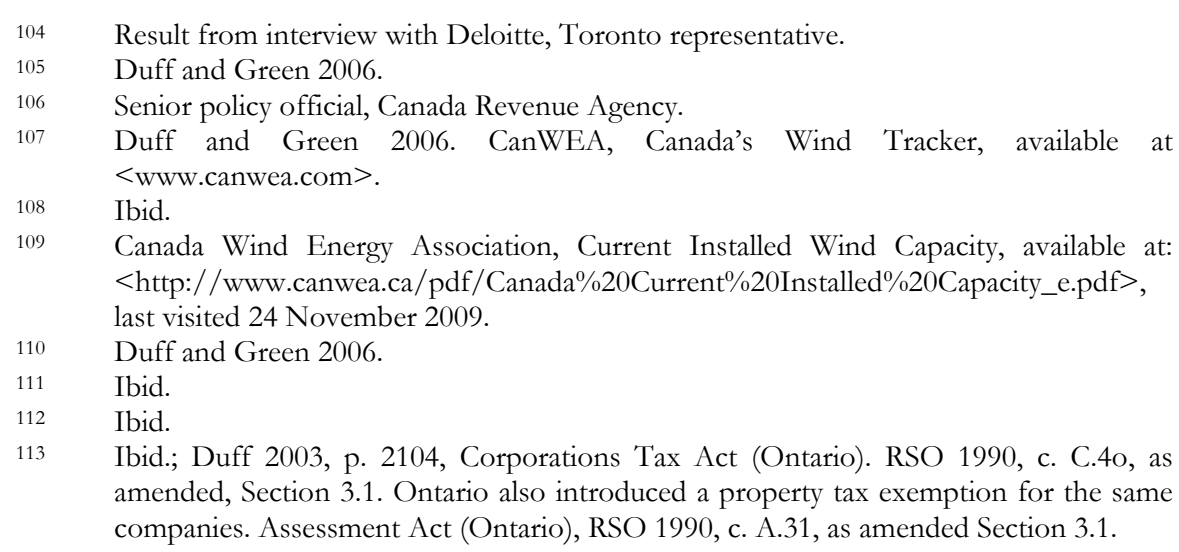


property tax exemption and a 100\% corporate tax deduction and capital tax exemption for new assets used in generating renewable electricity and a 100\% corporate income tax exemption for self-generation equipment were also announced. These incentives were short lived however, as with the change of government in 2003, all were cancelled. ${ }^{114}$

\subsubsection{Quebec}

In Quebec, in 2001 the flow-through share scheme was replaced by a $40 \%$ payroll tax credit applying to wind energy equipment manufacturers or wind energy generators in certain areas of Quebec. ${ }^{115}$

\subsubsection{Conclusion}

The result of an interview carried out with a Senior Policy Officer in Canada Revenue Agency left the impression that the introduction of tax incentives for renewable energy discussed above, gave the government an opportunity to communicate investment signals to investors and developers. The financial significance of these measures is not entirely clear, nor is the significance of these measures in increasing the share of renewable energy in the market. A tax incentive, being published in the widely read and scrutinized annual budget gives the government a political platform upon which it may be seen to be doing 'good' - supporting renewable energy. There is less concern, it would seem, with regard to the actual effect of the said measures.

It is this 'educational and transformative function'116 of tax incentives supporting renewable energy which Duff and Green put forward as a rationale for such subsidies. It is a legitimate aim of tax incentives to change behaviour by altering the price differential between green and grey energy. It is hoped by such financial signals that attitudes towards environmentally friendly and harmful products and processes will change and environmentally preferential behaviour follows.

The effectiveness and efficiency of the tax incentives in place in Canada is an open question. ${ }^{117}$ To date, no such examination has been undertaken by the Canadian federal government. Indeed, it was considered by a Senior Policy Officer in the Canadian Revenue Agency to be a study that would be very useful and interesting; however, the resources have not been available to date to undertake such a study. Even in the 1996 Level Playing Field Report it is expressly stated that the report does not in any way address the environmental effectiveness of these measures. ${ }^{118}$ Without further information regarding the effectiveness of the tax incentives, or even the tax

\footnotetext{
114 Duff and Green 2006; Green 2006b.

115 Ibid.

Duff 2003, p. 2079

Ibid., p. 2105.

The Level Playing Field: The Tax Treatment of Competing Energy Investments, (1996).
} 
expenditure related to these measures, it may be only concluded that they are in attempt to reflect environmental 'value judgements' into the budget. ${ }^{119}$

As to the level of influence of the Kyoto Protocol in the introduction of direct tax incentives for the development of renewable energy generation in Canada, it is clear that although the incentives may be pursuing climate change goals, it is not in response to the Kyoto Protocol that they have been introduced.

The potential for developing a strong renewable energy electricity market in Canada, supported by tax incentives, for export to the US exists. However, without further development of transmission lines, and stronger financing and investment incentives (such as flow-through shares) for start-up companies, the current situation of tradeon-demand will remain. As a unique country with spectacular existing renewable energy capacity, not only is self-sufficiency a possibility, but also fulfilling Kyoto Protocol obligations may be accomplished with the help of strong renewable energy development.

$119 \quad$ Green 2006a, p. 377-414. 


\section{Chapter 6 : Tax Subsidies Applied in New Zealand}

\section{$6.1 \quad$ INTRODUCTION}

New Zealand has a unique approach to the Kyoto Protocol and energy strategy. Also in the fortunate position of being 'well endowed' with renewable natural resources, ${ }^{1}$ New Zealand is traditionally considered to be a 'pioneer of environmental standards"2 and is considered to be 'clean and green'. ${ }^{3}$ However, its Kyoto Protocol approach leaves this reputation somewhat in question. Although renewable energy has an important role in New Zealand, with wind energy growing at exponential rates annually, tax incentives have played no role in this development. Some authors see this lack of environmental tax reform as creating a 'mismatch' between the reality and New Zealand's reputation. ${ }^{4}$ Not only is the role of tax incentives non-existent, as well as general economic instruments, but the role of the Kyoto Protocol in driving this development in New Zealand is also questioned.

\subsection{KYOTO PROTOCOL}

New Zealand ratified the Kyoto Protocol on 19 December 2002.5 The reduction commitment agreed to by New Zealand is exactly the emission levels recorded in 1990.6 This reduction represents an actual reduction of about $40 \%$ of current levels. The Kyoto Protocol policy plan of the New Zealand government was enshrined in the Climate Change Response Act 2002. ${ }^{7}$ This Act primarily enabled the government to partake in international emission trading schemes.

New Zealand is a country dominated by its agriculture industry with its economy largely dependent on agricultural exports. ${ }^{8}$ It is therefore this industry that is also held primarily responsible for the emission of harmful greenhouse gases. ${ }^{9}$ Over $30 \%$ of emissions in New Zealand are due to agriculture. ${ }^{10}$ New Zealand is home to only 4 million people but 40 million sheep and 9 million cattle all producing methane and contributing to New Zealand's climate change problem. Although agriculture is considered to be a main culprit, recent significant increases in emissions levels are now also due in particular to increases in emissions in transport. ${ }^{11}$

As far as Kyoto Protocol policy is concerned, there has been no implementation of tax measures to reduce emissions in New Zealand. A significant aspect of this failure

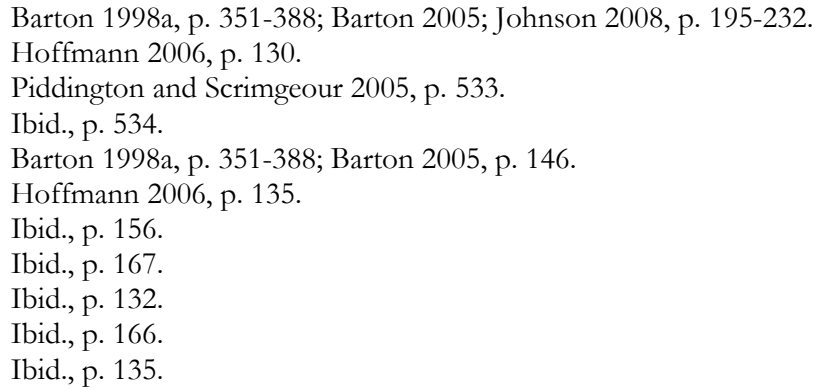


is a reliance on the development of carbon sinks ${ }^{12}$ in order to achieve target levels of emissions, rather than reductions in emissions themselves. One such failed reduction policy was the carbon charge which was to be introduced in $2007 .{ }^{13}$ It was intended to use the revenue raised from such a 'tax' to reduce general business tax and to provide subsidies for renewable energy strategies. ${ }^{14}$ By 2005, however, the New Zealand government had decided to reject this carbon tax plan.

Indeed in respect of allocation of resource permits in New Zealand, the Kyoto Protocol plays a notional role: Section 104(1)(c) of the Resource Management Act requires that decision-makers involved in granting resource consent take $\mathrm{New}$ Zealand's Kyoto Protocol commitment into account. ${ }^{15}$

The New Zealand government has yet to implement a coherent active Kyoto Protocol policy plan and is said to be reviewing the climate change strategy. ${ }^{16}$

\subsection{RENEWABLE ENERGy DEVELOPMENT}

New Zealand is in the proud position of generating the majority of its electricity from renewable energy resources. ${ }^{17}$ Also, New Zealand is ranked third highest in the level of renewable primary energy supply among all OECD countries. ${ }^{18}$ Hydro-electricity plays an important role providing $54.9 \%$ of electricity generated. ${ }^{19}$ Geothermal energy contributes $7.7 \%$ while wind contributes only $2.2 \%$ having increased by $50 \%$ between 2006 and $2007 .{ }^{20}$ Coal and gas have a relatively minor role accounting for $6.9 \%$ and $26.4 \%$ respectively. ${ }^{21} \mathrm{It}$ is for this reason (as well as the dominance of agriculture in New Zealand) that greenhouse gas emissions related to electricity generation represent a meagre $8 \%$ of total emissions. ${ }^{22}$ Furthermore, New Zealand has ambitions to achieve a renewable energy electricity level of $90 \%$ by 2025.23

Although tax incentives have not been pursued to this end, the legal climate has become more favourable for renewable energy development. However, it should be noted that new measures in use in other case study countries such as renewable

12 The Carbon Sink Initiative was set up to provide incentives for reforestation in order to fulfil Kyoto Protocol objectives. Ibid. p. 157 New Zealand negotiated fervently in the Kyoto Protocol negotiations for a 'net approach' to be taken in which carbon sinks would be counted to offset carbon emissions. The net value of the carbon sinks in New Zealand was expected to turn the Kyoto Protocol into an international trading opportunity. Parr 2000, p. 60; Gillespie 1997, p. 50.

Hoffmann 2006, p. 146; Piddington and Scrimgeour 2005, p. 537.

Hoffmann 2006, p. 146.

Fisher 2005, p. 330.

Hoffmann 2006, p. 158.

Ibid., p. 147; Johnson 2008, p. 195-232.

Johnson 2008, p. 211.

Ibid., p. 207.

Ibid., p. 211.

Hoffmann 2006, p. 129-168; Johnson 2008, p.1 66; Sagemuller 2006, p. 169.

Hoffmann 2006, p. 147.

Speech by the then Prime Minister Helen Clarke, 'Launch of Emissions Trading Scheme', 20 September 2007, available at: <http://www.beehive.govt.nz/ node/30691>, last visited 24 November 2009. Johnson 2008, p. 195-232. 
purchase obligations and green certificates are also not in place in New Zealand. ${ }^{24}$ In 2000, an Energy Policy Framework was introduced in which the objective of making a transition from fossil fuels to renewable energy resources was communicated. 25 Again in 2000 this was reiterated in the Energy Efficiency and Conservation Act. The National Energy Efficiency and Conservation Strategy in 2001 set a (an indicative, non-mandatory) target for renewable energy to be achieved by $2012 .{ }^{26}$ In 2004 , the Resource Management Act was amended to explicitly incorporate objectives of development of renewable energy. ${ }^{27}$ Again in 2005 this Act was amended allowing the national government the possibility to influence local authority decisions relating to renewable energy development, where previously this was exclusively a local authority matter. It is expected that this change will entice local authorities to particularly favour renewable energy project. ${ }^{28}$

Traditionally, New Zealand has followed a non-interventionist governance approach, ${ }^{29}$ allowing the market to regulate. However, following a change in government in 1999 and the subsequent ratification of the Kyoto Protocol, a more proactive approach has come about giving 'modest encouragement' to renewables through the regulatory system. ${ }^{30}$ However, as seen from above, this 'modest encouragement' takes the form, to some extent, of political and legal rhetoric. In particular, tax policy plays no role in backing up this rhetoric.

New Zealand is said to have a climate particularly suitable for wind energy development, ${ }^{31}$ however, at present wind energy accounts for only $2 \%$ of electricity supply. ${ }^{32}$ Despite this low share of the energy pie, the growth rate of wind energy in New Zealand is the highest to be found worldwide. ${ }^{33}$ As in many other countries, development of wind energy has been a relatively recent occurrence, the first commercial wind farm-commencing operation in 1996. ${ }^{34}$ This recent rapid growth rate in wind energy in New Zealand should not be viewed through a Kyoto Protocol telescope. A second issue was also prevalent in the New Zealand political climate in recent years, which also affected a move towards a differentiation in energy resources from the traditionally dominant source - hydro electricity. Extremely dry winters in 2001 and 2003 caused reduced energy supply from the much-relied on hydro plants. This was followed by a critical review of issue of security of supply ${ }^{35}$ and a resultant slow shift towards wind energy developments.

Barton 2005, p. 144.

Ibid.

Ibid., p. 145.

Fisher 2005, p. 311; Barton 1998a, p. 351-388; Barton 2005, p. 149.

Barton 1998a, p. 351-388; Barton 2005, p. 150.

Barton 2005, p. 141; Piddington and Scrimgeour 2005, p. 540.

Barton 2005, p. 141.

Fisher 2005, p. 308; Barton 1998a, p. 351-388; Barton 2005, p. 142.

Sagemuller 2006, p. 168.

Ibid., p. 165.

Fisher 2005, p. 308.

Barton 2005, p. 150; Piddington and Scrimgeour 2005, p. 536. 
As is the case in Canada, the development of certain renewable energy sites is often impeded by the balancing of rights of project developers and indigenous peoples. ${ }^{36}$

\subsection{SUBSIDY IN THE FORM OF CARBON CREDITS}

New Zealand has no tax incentives in place for the development of renewable energy. The only incentive introduced was a subsidy in the form of tradable carbon credits to industries which have guaranteed minimum carbon emissions savings of 10,000 tonnes of CO2 between 2008 and 2012.37 The recipient of the carbon credits should be able to show that it would not otherwise be able to commence its energy operations without the subsidy. The subsidy, in the form of carbon credits, constitutes a form of future monetary value as the credits are intended for trade on the international market.

Furthermore, of all the tax subsidies (and in this case carbon credit subsidy) examined in all case study countries, this is the only subsidy scheme whose application is $100 \%$ dependent on the Kyoto Protocol commitment. Had the Kyoto Protocol not come into force in 2005, this measure would not have been pursued or implemented. ${ }^{38}$ The projects that were successful in gaining the subsidy (carbon permits to be sold on the international carbon market) included wind farms, hydro projects, landfill sites and bio-energy projects. ${ }^{39}$

The only use of the tax system to incentivise renewables was introduced in the form of an excise tax exemption, limited in time to two years, for ethanol used for blending for gasoline. ${ }^{40}$ However, as this research is concerned with direct corporate tax incentives for the development of renewable energy, this indirect tax exemption does not fall within its scope.

\subsection{CONCLUSION}

The lack of a role for tax policy in New Zealand in addressing climate change, in addition to the general policy reaction to the Kyoto Protocol, has been considered to be 'between the sublime and the ridiculous'. ${ }^{41}$ It is clear from a preliminary comparison of the case study countries examined that general policy addressing renewables is greatly lacking in New Zealand. Not only is tax policy, both direct and indirect, of no significance in attaining Kyoto Protocol goals, or in developing renewable energy potential, but also non-tax related policies are also neglected. For example, there has been no implementation of green certificate schemes or renewable purchase obligations. To date there seems to be a general reliance on the hopefully successful operation of the international trade in carbon credits, and existing and new

$36 \quad$ Piddington and Scrimgeour 2005, p. 533.

$37 \quad$ Fisher 2005, p. 318; 'Government offers carrots for green energy projects', New Zealand Herald, 1 April 2004.

38 'Government offers carrots for green energy projects', New Zealand Herald, 1 April 2004.

Barton 1998b, p. 187-208; Barton 2005, p. 147.

Barton 1998b, p. 187-208; Barton 2005, p. 143.

Gillespie 1997, p. 43. 
carbon sinks in New Zealand to offset the current and increasing levels of greenhouse gas emissions.

It should be noted, however, that despite the lack of a role of tax policy in New Zealand in developing renewable energy, and the traditional market approach prominent in New Zealand politics until the late 1990s, electricity generation is relatively an innocent party with respect to greenhouse gas emissions. Despite the lack of tax incentives, there is an exponential growth of wind energy and renewables in general are the dominant energy resource. However, the continuance of tax incentives for the exploration of gas and oil leaves a bitter taste considering that the exploration, set-up and development of renewable energy sites are not receiving the same financial backing. ${ }^{42}$

Perhaps it is fair to say that, considering that agriculture and transport are the sectors account for the greatest share of greenhouse gas emissions, and thus the potential for New Zealand to achieve (or otherwise) its Kyoto Protocol targets, the lack of tax policy in general and tax incentives in particular is a justified reflection of the political and environmental reality in New Zealand.

42 New Zealand Herald, Tax Breaks Continue for Offshore Energy Explorers, 14 May 2005, available at: <http://www.nzherald.co.nz/business/news/article.cfm?c_id= 3\&objectid $=10572121>$, last visited 24 November 2009 . 

Part IV: WTO Implications of Case Study Tax Incentives 



\section{Chapter 7 : Tax Subsidies on Renewable Electricity Regulated by the WTO}

As addressed in Part I to III of this thesis, fulfilling the Kyoto Protocol objective to develop renewable energy technologies and in general promoting the development of renewable energy, to a large extent, involves the provision of various tax incentives. Having examined the particular tax incentives in place to this end in the case study countries in Chapters 4-6, this part will address the WTO consistency of the those tax incentives. This chapter will provide an outline of the treatment of subsidies on electricity generation in WTO law, while Chapter 8 will specifically examine the requirements of Article 1 and 2 of the SCM Agreement and the case study tax incentives, to show to what extent they are covered by the definition of subsidy in the SCM Agreement. To the extent that the case study subsidies are covered by the SCM Agreement, Chapter 9 will examine the causes of adverse effects of subsidisation. Finally, Chapter 10 addresses other WTO Agreements and their potential relevance for the tax incentives at issue.

\subsection{INTRODUCTION}

Lodefalk and Storey recognise that:

Through subsidies, climate friendly technologies and consumption of renewable forms of energy can be promoted. Pursuant to climate change commitments, countries use subsidies to provide incentives for green electricity production... ${ }^{1}$

According to Zhang:

The subsidies question in relation to Kyoto implementation may be one of the most intricate and difficult issues facing the world trading system. ${ }^{2}$

These points of view form the starting point of Part IV of this thesis. Although environmental subsidies are positive measures from a Kyoto Protocol perspective, these measures are by no means problem-free from a WTO law perspective. The previous chapters have established the need of the case study countries, as Kyoto Protocol signatories, to embark on renewable energy development strategies. This chapter examines, in particular in relation to tax subsidies for renewable energy development, why this particular subsidies question is indeed so intricate and difficult.

The provision of tax incentives is limited by international trade law. It is recognised that although Members of the WTO are free to choose their tax systems and tax measures:

...certain WTO rules do have implications for specific tax practices of Members. In the area of subsidies, it is clear from Article 1 of the ASCM itself that tax measures of a WTO Member may give rise to subsidies subject to the disciplines of the ASCM. ${ }^{3}$

Lodefalk and Storey 2005, p. 26.

Zhang 2005, p. 25. 
International trade law regulates the provision of subsidies by WTO Members in order to ensure that the objectives of free trade are protected and a level playing field is maintained. National policy measures, such as tax incentives, providing for the development of renewable electricity fall within the scope of WTO rules on subsidies and as such should be examined for consistency therewith. Tax incentives, even when motivated by environmental objectives, must comply with WTO rules on the provision of subsidies since there is a risk that even where environmental protection subsidies are at issue the SCM Agreement may restrict WTO Member's use of this policy measure. ${ }^{4}$

As explained in section Liberalisation of the Electricity Market, international trade issues are now becoming relevant with respect to the electricity sector. In the past, without open competition in this sector, trade in electricity was not an issue of concern in international trade. This is no longer the case. Cross-border trade in electricity has been facilitated by the liberalisation of the electricity market and the development of cross-border electricity infrastructure. These developments increase the potential for international trade disputes relating to trade in electricity and the importance of this emerging issue should not be underestimated. ${ }^{5}$ Consequently, negotiations in the context of the Doha Development Round address the trade implications of trade in the energy. This chapter will also address this emerging issue by examining the WTO disciplines with which national policies, aimed at the development of renewable electricity, should be consistent.

\subsection{THE WTO}

Since 1947, the aims of liberalised global trade have been pursued by GATT Contracting Parties and these aims were solidified in 1994 with the conclusion of the Marrakesh Agreement Establishing the World Trade Organization (hereinafter the WTO Agreement) and its entry into force on 1 January 1995. The WTO Agreement extended the scope of international trade law beyond the General Agreement on Tariffs and Trade 1947 , regulating trade in goods, by the introduction of new agreements related to trade in goods and trade in services as well as intellectual property rights. The WTO Agreement comprises (13) multilateral agreements on trade in goods, ${ }^{6}$ the General Agreement on Trade in Services and the Agreement on Trade-Related Aspects of Intellectual Property Rights.

Panel Report, US - FSC, para. 7.122. Bentley 2000, p. 102.

Lodefalk and Storey 2005, p. 23-44; Van Hoorn 2009, p. 51-76.

Energy has become something of a 'hot topic' in the WTO. Energy-related issues are showing up in no less than six subjects within the Work Programme of the Doha Development Round, namely: services, agriculture, subsidies, environment, market access (non-agriculture) and trade facilitation. Van Hoorn 2009, p. 62, fn. 103; Gibbs 2003, p. 4.

General Agreement on Trade in Goods 1994, Agreement on Agriculture, Agreement on the Application of Sanitary and Phytosanitary Measures, Agreement on Textiles and Clothing, Agreement on Technical Barriers to Trade, Agreement on Trade-Related Investment Measures, Antidumping Agreement, Customs Valuation Agreement, Agreement on Preshipment Inspection, Agreement on Rules of Origin, Agreement on Import Licensing Procedures, Agreement on Subsidies and Countervailing Measures, Agreement on Safeguards. 
The 'business' of the WTO is trade relations. Article II of the WTO Agreement states that the WTO provides 'the common institutional framework for the conduct of trade relations among its Members.... ${ }^{7}$ The WTO Members, currently 153, ${ }^{8}$ agree to limit their freedom in determining national trade policy in the name of international trade liberalisation. The reach of these limits has been evolving steadily in the last fifteen years. ${ }^{9}$

Despite the primary objective of the WTO being to facilitate free trade, the importance of other objectives was not neglected in the WTO Agreement. In the Preamble, the WTO Members recognise the global objectives of raising standards of living, providing optimal use of the world's resources, as well as the protection and preservation of the environment. ${ }^{10}$ Thus, prior to examining the consistency of environmentally motivated tax incentives with the WTO Agreement in detail, it is important to highlight the over-arching aims the WTO Members had in mind when concluding the WTO Agreement. From the Preamble, it is clear that environmental issues can be WTO issues and vice versa. ${ }^{11}$

The extent of this overlap between environmental objectives and international trade objectives, with respect to tax subsidies, and the implications of this overlap for compliance with the WTO Agreement will be highlighted later. First, a general overview of the subsidies disciplines within the WTO Agreement is pertinent.

As indicated above, the WTO disciplines are divided into three categories, namely, the multilateral agreements on trade in goods and the General Agreement on Trade in Services and the Agreement on Trade-Related Aspects of Intellectual Property Rights. In relation to the disciplining of subsidies in international trade law, the General Agreement on Tariffs and Trade 1994 (hereinafter the GATT 1994), the Agreement on Subsidies and Countervailing Measures (hereinafter the SCM Agreement), the Agreement on Agriculture and the General Agreement on Trade in Services (hereinafter the GATS) are of particular importance. In the subsequent sections, the above agreements will be outlined as a foundation for the examination of the consistency of the case study tax incentives with the WTO agreements regulating subsidies.

\subsection{ElECtricity GENERATION: TRADE IN GOODS AND/OR TRADE IN SERVICES}

In order to determine which WTO agreements are to be examined with respect to tax incentives provided for the generation of renewable electricity, it is important to establish whether the incentives provided to electricity generators affect trade in goods or trade in services. There are differences in the rules dealing with subsidies affecting trade in goods and rules dealing with subsidies affecting trade in services and therefore this delineation is important.

Article II:1 of the WTO Agreement.

As of 23 July 2008.

Woerdman 2002, p. 264.

WTO Agreement, Preamble, first paragraph.

Schram Stokke 2004, p. 339-357. 
There has been no electricity-related WTO dispute before WTO panels or the Appellate Body to date in which the categorisation of electricity as a good or service could be tested. In a potential WTO dispute related to the generation of electricity, the complainant and respondent would take advantage of the lack of a clear definition and classification of electricity in WTO law to construct their arguments. The respondent would aim to convince a panel that electricity generation should be deemed to be a service and therefore that the GATS applies. To the extent that no sector specific GATS commitments have been made by the respondent, the contested subsidies would be subject to a very lenient treatment under the GATS compared to the subsidy disciplining under the SCM Agreement and/or the Agreement on Agriculture. The complainant would on the contrary aim to convince a panel that the generation of electricity should be classified as the production of a good, affecting trade in goods (and also affecting trade in services) and therefore be covered by the multilateral agreements on trade in goods, including the SCM Agreement and the Agreement on Agriculture (and also the GATS).

In this thesis, the relevant measure (tax incentive) is applied to electricity generation, therefore the question first is whether the 'electricity' which is being generated and traded is, itself, considered to be a good or service. After determining whether the measure is applied to a good or a service, the question will also be addressed whether the measure affects trade in goods and/or trade in services.

What is covered by the terms 'good' and 'service' is not defined in the multilateral agreements on trade in goods or in the GATS. Whether electricity is a good or a service is still a matter of debate. ${ }^{12}$ Therefore, the next section will call on other international agreements, economic classifications, as well as international customs classification lists including Harmonised Commodity Description and Coding System and the Services Sectoral Classification List to find some answers to the question whether electricity is a good or a service.

The categorisation of electricity as a good or service has only come to the fore in recent times since its relevance in relation to international trade law is a direct result of the liberalisation efforts in the preceding years. In the past, international trade in electricity was not an issue as the infrastructure, political-will and cross-border electricity trading companies were not yet a reality. This is no longer the case in the wake of extensive liberalisation efforts worldwide. ${ }^{13}$ Electricity is now internationally traded and thus, from a WTO-perspective, the question whether electricity is a good or service now begs an answer.

The liberalisation of the electricity sector separated the four levels of the electricity chain into four distinct functions: generation, transmission, distribution and supply. From this separation it becomes more apparent that a distinction can be made between each of the levels of the electricity chain addressing whether that level concerns the production of a good or the supply of a service. Essentially it will be argued in the following paragraphs that although transmission, distribution and supply may indeed be services, the generation of electricity is the production of a

12 Wang and Liu 2006, p. 30.

13 See section 1.4 The Global Electricity Market, p. 23 where the liberalisation of the electricity sector is discussed in more detail. 
good. In order for the links in the electricity chain to have something to transmit, distribute or supply, it must first be produced. ${ }^{14}$ It is this production of the good electricity by generation that feeds into the transmission, distribution and supply services.

The generation of electricity (the production of a good - electricity) can be simply compared to the production of other energy goods. The fact that electricity is intangible, incorporeal and cannot be stored should not lead to confusion. ${ }^{15}$ The production of oil is obviously the production of a good. Oil is tangible, storable and transportable. Oil, after its production, also goes on to be distributed and supplied. Oil is also the subject of service providers. The 'oil' chain can also (like electricity) be divided into sectors. The oil is first produced, then transported and then distributed and supplied. The transporters are service providers although the service they provide is the transport of a good. The distributors are also service providers and suppliers equally - wholesale and retail stores. The production of oil remains the production of a good, while the transport, distribution and supply of oil concern services related to the good. As with the production of oil, the production of (or generation of electricity is a production process which results in a good and the production (service) of that good is incorporated into the value of the good produced'. ${ }^{16}$ This is the same for electricity. The generation of electricity is the production of a (an intangible, non-storable) good. As mentioned earlier - in order for the electricity chain to have something to transmit distribute and supply, the something must be produced. Once the good 'electricity' is produced, it then becomes the object of service suppliers.

14 If something is produced, there is a natural presumption that the production results in a good. However, this is not always the case. The ordinary meaning of 'produce' is: to bring something into existence. Indeed, services are also 'produced'. Article XXVIII(b) of the GATS supports this by providing that the "supply of a service" includes the production, distribution, marketing, sale and delivery of a service' (emphasis added). Here one can think of audiovisual services where television programmes are 'produced' and go on to be distributed and traded etc. A perhaps arbitrary system of classification has resulted in cinema movies being considered to be goods, while television films (and general television content) are classified as services. The ambiguity of classification in the audiovisual sector is akin to the ambiguity of classification in the energy sector. This issue also arose in Cbina - Publications and Audiovisual Products in which the Appellate Body was called upon to interpret the phrase 'sound recording distribution services' to establish whether this covered both distribution of sound recordings both in a tangible physical form and also in an intangible electronic form. The Appellate Body also referred to Article XXIII(b) of the GATS for a context within which to interpret the phrase and in light of the inclusion of the word 'distribution' in the definition of 'supply of a service' the Appellate Body held that it could not follow that 'sound recording distribution services' would be limited to the distribution of sound recordings in physical from. Appellate Body Report, China - Publications and Audiovisual Products, paras. 373-380.

15 Although indeed it is physically possible to store electrical energy in batteries and to convert electrical energy into other forms of energy to be converted back into electricity at a later time, it is a very costly exercise and thus the mass-storage of electricity is not feasible to the extent that electricity could be generally described as storable.

$16 \quad$ Wang and Liu 2006, p. 31. 
From an economic perspective, economic activities can be divided into three sectors: primary, secondary and tertiary. Essentially primary and secondary activities are concerned with goods and tertiary with services. Primary activity concerns the exploitation of natural resources. Secondary activity is concerned with the transformation of natural resources from the primary sector into tradable goods (commodification). The tertiary sector deals with services. In this respect, and from an economic perspective, electricity generation (be it from renewable or nonrenewable resources) falls within the secondary sector - the transformation of natural resources into tradable goods - electricity. Electricity generation is the production of electricity from primary energy goods (coal, oil, gas, and renewable resources) and the transformation of these goods into a secondary energy good (electricity). The transformation is the production process and the end result is the production of a good: electricity. In fact, it should be noted that contracts for trade in electricity do not differ from contracts for trade in other commodities. ${ }^{17}$ It is therefore clear that from an economic perspective, electricity generation is the production of a good and that electricity is thus a good.

Further support for the classification of the generation of electricity as the production of a good can be found in other international agreements. The United Nations Convention on Contracts for the International Sale of Goods (CISG, 1980) explicitly excludes electricity from the coverage of the Convention. ${ }^{18}$ Although excluded, the explicit mention of electricity in the ambit of 'sale of goods' identifies electricity indeed as a good. Had electricity been considered to be a service, the mention of electricity in relation to the 'sale of goods' would have been moot. The North American Free Trade Agreement (1989), regulating trade between the USA, Canada and Mexico has a specific section dealing with cross border trade in energy. ${ }^{19}$ Here electricity is also included as a good. Furthermore the Energy Charter Treaty (1994) also includes electricity as a good. ${ }^{20}$

Further arguments for the classification of electricity as a good can be found by reference to the Harmonised Commodity Description and Coding System. Only goods are classified in the Harmonised Commodity Description and Coding System. Services are excluded. Electricity, or 'electrical energy' to be precise, is listed with Mineral Products in Chapter 27, HS 2716. ${ }^{21}$ However, this is an optional heading, indicating that not all Members were in agreement with the classification of electrical energy as a good when, in 1983, the Harmonised Commodity Description and Coding System was established. In their national tariffs, the EC, USA, Japan and Canada have all classified 'electrical energy' under the optional heading in Chapter 27 HS. Also, following the structure of the Harmonised Commodity Description and Coding System, the EC classifies 'electrical energy' as a good in Chapter 27 of the

$17 \quad$ Albath 2004, p. 92.

18 Article 1 United Nations Convention on the Sale of Goods.

$19 \quad$ Article 602 paragraph 2(h) North American Free Trade Agreement.

2053 countries have signed and ratified the Energy Charter Treaty. See list of Members as of 08 May 2007 available at: <http://www.encharter.org/index.php?id=61\#c229>; last visited 24 November 2009. Annex EM to the Energy Charter Treaty indicates that electricity is a good.

21 Some WTO Members have scheduled import duties on electrical energy under this optional heading of the Schedules of Concessions of the GATT 1994. Lakatos 2004. 
Common Customs Tariff. Furthermore, in its case law, the ECJ has also treated electricity as a good. ${ }^{22}$

Reference can also be made to the Services Sectoral Classification List (the W/120 List), ${ }^{23}$ the Services version of the HS System, for insight into the classification of electricity as a good or a service. The W/120 List is void of almost any mention of energy services. ${ }^{24}$ It does not include electricity - rather it only includes services incidental to the distribution of energy..$^{25}$ The production of electricity being a most important aspect of the electricity chain, without which there would be nothing to distribute, can never be incidental ${ }^{26}$ to its distribution. Therefore, the electricity chain, including all activities up to the point of distribution, cannot be considered to be a service. ${ }^{27}$ The fact that no Member has included electricity generation in the Services Sectoral Classification List, ${ }^{28}$ or has made specific commitments related to electricity generation, also rebuts this weak argument which relies only on the physical (or the lack of) physical characteristics of electricity.

In spite of the above arguments for classifying electricity generation as the production of a good, there are also proponents of its classification as a service. However, these arguments, in my view, are less founded. They rely on the characteristics of goods as being tangible, storable and transportable and of services being intangible, non-storable and non-transportable. Obviously electricity is neither tangible nor storable. ${ }^{29}$ Although it is recognised that in most cases these properties of goods (tangible versus intangible, storable versus non-storable, transportable versus non-transportable) provide a simple distinction between most goods and services, they cannot be relied upon for the classification of all goods and services as some situations are not so clear-cut. Indeed there are goods that are intangible, ${ }^{30}$ and goods that are non-storable and even non-transportable, however, all three characteristics together are usually the characteristics of services. Despite the fact that characteristics of electricity are also characteristics of services, the reliance on the (lack of) physical characteristics of electricity - incorporeal and intangible - and the

22 C-6/64 Flaminio Costa v. ENEL [1964] ECR 585, C-393/92 Almelo [1994] ECR I-1477; C-91/79 Commission v. Italy [1980] ECR 1099.

23 Services Sectoral Classification List, MTN.GNS/W/120.

$24 \quad$ Wang and Liu 2006, p. 31-32. In the Doha development round, the energy sector is one in which some Members want to make specific GATS commitments.

25 Ibid., p. 31-32; Meggiolaro and Vergano 2005, p. 102; Delimatsis 2009, p. 451.

26 The ordinary meaning of incidental is: 'occurring as a minor part or an inevitable accompaniment or by chance'.

See also Wang and Liu 2006, p. 30-33.

Services Sectoral Classification List, MTN.GNS/W/120.

Although indeed it is physically possible to store electrical energy in batteries and to convert electrical energy into other forms of energy to be converted back into electricity at a later time, it is a very costly exercise and thus the mass-storage of electricity is not feasible to the extent that electricity could be generally described as storable.

30 The classification of electronic transmissions is also subject to debate. Digitalised information, such as software, music or text is neither fixed nor tangible. Although this digitalised information can be stored on a hard drive or on paper upon delivery, its value is in its intangible non-permanent form: the digital form. Despite this there are proponents of its classification as a good. See: Hernández-López 2001, p. 564. 
fact that electricity cannot be stored but is consumed as it is produced is not sufficient to support the classification of electricity as a service.

In conclusion, considering that electricity generation is at issue in this thesis and based on the arguments above, I submit that the generation of electricity should be classified as the production of a good. ${ }^{31}$ Thus, tax incentives for the generation of electricity by WTO Members, being applied to a good and thus also affecting trade in goods, should be examined for consistency with the multilateral agreements on trade in goods, in particular here, the GATT 1994, the SCM Agreement, and where the measure affects trade in agricultural products (or where an agricultural product is deemed to be indirectly subsidised by virtue of subsidies on the input electricity) also the Agreement on Agriculture.

Although classifying electricity as a good indicates that tax incentives provided for the production of this good affect trade in goods, this does not preclude the possibility that the same measures (applied to the good electricity) also affect trade in services. Therefore, to the extent that the tax subsidies may also affect trade in services (the transmission, distribution and supply of the good electricity) the GATS rules on subsidies will also be addressed. ${ }^{32}$ For this reason, although it was argued above that electricity should be categorised as a good, it is still possible that subsidies applied to the production of a good affect trade in services. Therefore, this thesis will address both the multilateral agreements on trade in goods as well as the GATS in examining the WTO-consistency of the tax incentives in the case study countries.

Prior to addressing the specific WTO rules dealing explicitly with subsidies, the rules on non-discrimination will first be addressed in the following section.

\subsection{THE GATT 1994, NON-DisCRIMINATION AND TAX INCENTIVES}

In this section the inter-relationship of direct tax measures as subsidies with the Most-Favoured-Nation obligation and the National Treatment obligation in the GATT 1994 will be addressed. The purpose of this exercise is to clarify why an indepth examination of these measures for their consistency with Articles I and III of the GATT is not necessary and thus also not carried out in the rest of this thesis.

Upon analysis of the wording of Articles I and III of the GATT it is clear that, with respect to taxes, these Articles apply specifically to indirect tax measures. This interpretation eliminates a challenge of the direct tax incentives of the case study countries for consistency with these provisions of the GATT 1994. ${ }^{33}$

$31 \quad$ Wang and Liu 2006, p. 32. The authors, although explaining the need for energy services to be included in the GATS, also make a distinction between electricity generation as the production of a good and the transmission and supply of electricity as energy services.

32 See section 10.3 The GATS, p. 272.

33 Other pro-Kyoto Protocol measures have been examined for GATT-consistency by academic authors. See for example: Mitchell and Tran 2009, available at: $<$ http://scholarship.law.georgetown.edu/fwps_papers/119/>, last visited 24 November 2009. 
Article I:1 of the GATT reads:

With respect to customs duties and charges of any kind imposed on or in connection with importation or exportation or imposed on the international transfer of payments for imports or exports, and with respect to the method of levying such duties and charges, and with respect to all rules and formalities in connection with importation and exportation, and with respect to all matters referred to in paragraphs 2 and 4 of Article III, any advantage, favour, privilege or immunity granted by any contracting party to any product originating in or destined for any other country shall be accorded immediately and unconditionally to the like product originating in or destined for the territories or all other contracting parties. [emphasis added]

Essentially, any advantage extended by a WTO Member to any country must be extended by that Member to all other Members immediately and unconditionally. The Most-Favoured-Nation obligation is concerned with requiring Members to afford the same treatment (in this case tax treatment) to products originating in two other Members. The tax treatment of domestic products is irrelevant. Therefore, the national tax treatment of domestic renewable energy generators is irrelevant where the Most-Favoured-Nation obligation is concerned. Since the tax incentives do not afford any special treatment to any other Members, it is clear upon an initial examination of the Most-Favoured-Nation obligation, with respect to direct corporate tax incentives, that there is no violation of this obligation.

The National Treatment obligation of Article III:2 of the GATT 1994 requires that Members neither use taxes to protect domestic production by taxing products originating in another Member, in excess of the tax imposed on the like domestic product, nor to apply internal taxes or charges to imported or domestic products in a way so as to afford protection to domestic production. The aim of the National Treatment obligation is to eliminate protectionist measures in the form of internal tax and regulatory measures by providing equality of competitive competitions between imported and domestic products. ${ }^{34}$ Furthermore, Article III:4 also requires Members to accord treatment no less favourable to imported products than the treatment afforded to the like domestic products. The requirement of 'treatment no less favourable' applies to laws, regulations and requirements which affect, inter alia, the internal sale of products. Therefore, this provision also covers tax provisions. ${ }^{35}$

Article III:2 states:

... products of the territory of any contracting party imported into the territory or any other contracting party shall not be subject, directly or indirectly, to internal charges of any kind in excess of those applied directly or indirectly to like domestic products ... [emphasis added]

34 Panel Report, Japan Alcoholic Beverages II, para. 6.33; Appellate Body Report, US - FSC (Article 21.5 - EC), para. 204.

35 Panel Report, Dominican Republic - Import and Sale of Cigarettes, paras. 7.170-7.171. In this dispute, the Panel confirmed that the requirement to affix a 'tax stamp' to packets of cigarettes at the time of production or importation in order for those cigarettes to be permitted (by the tax inspector) to enter the market was an internal regulation affecting the internal sale and offering for sale of cigarettes on the Dominican Republic domestic market and thus was a measure within the meaning of Article III:4 of the GATT 1994. 
According to Jackson:

[T] he interpretation was made several times that income taxes did not fall within the language of Article III, paragraph 2, because that language "is concerned solely with internal taxes on goods". 36

Although Jackson's statement leads to an expectation that the case study direct corporate tax incentives are not covered under Article III:2 of the GATT 1994, there is a more explicit exclusion of these measures from the National Treatment obligation provided for in Article III:8 of the GATT 1994. Subsidies provided to domestic producers are explicitly excluded from the National Treatment obligation.

Article III:8(b) states:

The provisions of this Article shall not prevent the payment of subsidies exclusively to domestic producers...

This provision was examined by the Appellate Body in Canada Periodicals in which it was clarified that subsidies conferred on producers which are funded by government revenue are saved from inconsistency with Article III of the GATT 1994. By referring to the drafting history ${ }^{37}$ of the sub-paragraph in which it was stated that Article III:8(b) could not be 'construed to sanction the exemption of domestic products from internal taxes imposed on like imported products or the remission of such taxes' the Appellate Body made clear that the sub-paragraph did not include subsidies conferred on products. ${ }^{38}$ [emphasis added] This only underlines the conclusion that direct tax subsidies are not subject to challenge under Article III of the GATT 1994 since by their nature they can only be conferred on producers and not on products.

This position was upheld by the Panel in Indonesia - Autos in which Indonesia's indirect tax subsidy was challenged for consistency with Article III and Indonesia claimed that these measures were exempt from challenge subject to Article III:8(b). The words of the Panel go a long way to explaining the purpose of Article III:8(b).

We consider that the purpose of Article III:8(b) is to confirm that subsidies to producers do not violate Article III, so long as they do not have any component that introduces discrimination between imported and domestic products. In our view the wording 'payment of subsidies exclusively to domestic producers' exists so as to ensure that only subsidies provided to producers, and not tax or other forms of discrimination on products, be considered subsidies for the purpose of Article III:8(b) of GATT. 39

$36 \quad$ Jackson 1969, p. 297.

37 Interim Commission for the International Trade Organization, Reports of the Committees and Principal Sub-Committees: ICITO I/8, Geneva, September 1948, p. 66.

38 Appellate Body Report, Canada - Periodicals, p. 33-34.

39 Panel Report, Indonesia - Autos, paras. 14.43. 
This case provides important clarification with respect to the different treatment of direct tax incentives versus indirect tax incentives within the WTO. Although indirect tax incentives could be found to be inconsistent with Article III:2 of the GATT, direct corporate tax incentives conferred on producers are exempted from the National Treatment obligation. This is so, since according to Article III:8(b), as explained above, subsidies to producers do not violate Article III:2, since Article III:2 concerns indirect taxes and subsidies to producers would be in the form of direct tax concessions. By providing corporate direct tax breaks to domestic producers without extending equivalent tax treatment to foreign economic processes (so as not to tax foreign processes in excess of domestic processes), ${ }^{40}$ foreign economic processes would first have to be subject to taxation in the granting Member. Since, in a territorial system of taxation, foreign economic processes are not subject to tax in the first place, the extension of domestic direct tax incentives to foreign producers could not in fact even practically be implemented.

In the case study countries, the eligibility for the tax incentives rests on the basic system of taxation, being either the worldwide or the territorial system of taxation. The Appellate Body in US - FSC, (although this case also concerned an alleged inconsistency with Article 3.1(a) and (b) of the SCM Agreement and Article 3.3 of the Agreement on Agriculture and not Article III of the GATT 1994), ${ }^{41}$ confirmed the right of Members to choose their tax system. By choosing worldwide or territorial taxation, Members were considered free to thereby subject foreign economic process to domestic direct taxation or not. ${ }^{42}$

Since foreign economic processes are not taxed in the case study countries, those foreign economic processes are also not eligible for carve-outs from those domestic direct tax rules, namely the tax incentives. In the territorial system of taxation, a country asserts taxation rights only on entities in or activities carried out in that country's territory. Countries with a territorial system of taxation do not engage in extra-territorial taxation of entities or activities. Only those corporate entities, which are resident for tax purposes in the granting country, can avail of a subsidy when it is in the form of a direct tax incentive. In view of this, it is common sense that direct corporate tax incentives are not subject to the National Treatment obligation as it is formulated in Article III:2 of the GAT'T 1994.43

Although indeed Article III:2 does not require a Member to extend equivalent tax treatment to foreign products, the requirement to not tax foreign products in excess of like domestic products can, for the purposes of finding an appropriate equivalent wording suitable for direct taxation, be formulated in this way. Therefore, this formulation is intended for illustration purposes.

Panel Report, US - FSC, para. 8.1.

Panel Report, US - FSC, para. 7.122.

Although there have been GATT disputes in which direct corporate tax measures were contested, and panels were faced with measures originating in the operation of the territorial or worldwide tax system, the contested measures were not contested for consistency with Article III of the GATT 1947 but rather with Article XVI:4 of the GATT 1947. These cases were called the Income Tax Practices disputes in which the US contested income tax provisions in Belgium, the Netherlands and France and the DISC dispute in which the EC contested income tax provisions in the US. All of the measures were deemed to be export subsidies within the meaning of Article XVI:4 of 
However straightforward the exclusion of direct corporate tax incentives from the National Treatment obligation of Article III:2 of the GATT 1994 is, it is possible that such measures may nevertheless be inconsistent with Article III:4 of the GATT 1994, since this provision does not call for the elimination of taxation in excess, but rather a more broad requirement of treatment no less favourable. As stated succinctly by the Panel in Indonesia - Autos:

...subsidies granted in respect of direct taxes are generally not covered by Article III:2, but may infringe Article III:4 to the extent that they are linked to other conditions which favour the use, purchase, etc. of domestic products... ${ }^{44}$

\section{Article III:4 states:}

The products of the territory of any contracting party imported into the territory of any other contracting party shall be accorded treatment no less favourable than that accorded to like products of national origin in respect of all laws, regulations and requirements affecting their internal sale, offering for sale, purchase, transportation, distribution or use...

Direct tax incentives may have indirect effects on the treatment of products. Daly states that there is equivalence between the flows of products and their factors of production and thus direct taxes on the factors of production or indirect taxes on the products can have equivalent effects. ${ }^{45}$ In addition to the different forms of taxation potentially having equivalent effects, they also both affect products - directly in the case of indirect taxes and indirectly in the case of direct taxes. Although Article III:8(b) seems to exclude direct tax subsidies conferred on producers from being found to be inconsistent with the National Treatment obligation, it is worth examining whether the indirect effects of these subsidies on the treatment of products could indeed be inconsistent with Article III:4 of the GATT 1994. Essentially, the laws enacting the subsidies could be found to be inconsistent with Article III:4 of the GATT 1994 if the effects of those laws or regulations result in treatment less favourable for like imported products.

Although the case of subsidies provided to domestic producers is explicitly covered by Article III:8(b), the Panel in US - FSC addressed the obligations arising from Article III of the GATT $1994 .{ }^{46}$ While confirming the right of Members to choose their tax system, the Panel also recapitulated that tax measures may have implications for the consistency of a Member's measures with other WTO obligations including, inter alia, Article III of the GATT 1994 and cited the Appellate Body Report, JapanAlcoholic Beverages II:

the GATT 1947. No statement was made on the potential consistency of the measures with the National Treatment obligation. GATT Panel Report, US - DISC, para. 74; GATT Panel Report, France - Income Tax, para. 53; GATT Panel Report, Belgium Income Tax, para. 40; GATT Panel Report, Netherlands - Income Tax, para. 40.

44 Panel Report, Indonesia - Autos, para. 14.38. The Panel in US - FSC (Article 21.5 EC II) also quoted this passage, see para. 8.156.

45 Daly 2005 , p. 4 , fn. 10.

46 In this dispute the consistency of a US tax measure with Article 3.1(a) of the SCM Agreement and Article 3.3 of the Agreement on Agriculture was contested, and not Article III of the GATT 1994, Panel Report, US - FSC, para. 8.1. 
Members of the WTO are free to pursue their own domestic policy goals through internal taxation or regulation so long as they do not do so in a way that violates Article III or any of the other commitments they have made in the WTO Agreement (emphasis added). ${ }^{47}$ [emphasis in original]

In US - FSC (Article 21.5 EC II), the US income tax measure was contested for consistency with Article III:4 of the GATT 1994. The Panel clarified that the tax subsidies at issue in the FSC dispute, although they were direct tax subsidies, were not excluded from the application of the National Treatment obligation. ${ }^{48}$ As stated by the Panel:

If measures conditioning access to income tax advantages in respect of certain products were excluded from the scope of Article III:4, a wide range of tradedistortive measures with enormous economic and commercial implications would, in effect, be given a safe haven, while measures not linked to income tax advantages and perhaps associated with a lesser extent of trade distortion would be subject to the disciplines of Article III:4. ... Article III:4 of the GAT'T 1994 applies to measures conditioning access to income tax advantages in respect of certain products. ${ }^{49}$

In the FSC dispute, the contested income tax measure contained conditions to determine eligibility for the subsidy which included that 'not more than $50 \%$ of the fair market value of qualifying property be attributable to articles produced or direct labour performed outside the United States'.50 This requirement determined which corporate entities were entitled to the income tax concession and essentially excluded producers using imported products (for more than 50\%) from the subsidy. The Panel stated that these conditions altered the conditions of competition between imported and domestic products and resulted in the internal use of imported products being affected and less favourable treatment being afforded to imported products than that of the like domestic products as per Article III:4 of the GATT 1994. ${ }^{51}$

Although it is clear that subsidies may, in addition to being contested for consistency with the SCM Agreement, also be inconsistent with the National Treatment obligation. In the case of direct tax subsidies, this will only be so to the extent that the conditions governing eligibility for the direct tax incentive discriminate between like imported and domestic products, as was the case in US - FSC. With respect to the case study direct tax incentives, 'the laws, regulations and requirements' do not make eligibility for the tax incentive conditional upon factors which change the competitive relationship between imported and domestic products related to the generation of electricity. There is a fundamental difference between the FSC challenged subsidy and those at issue in this thesis. Prohibited subsidies were challenged in the US -

$47 \quad$ Panel Report, US - FSC, fn. 686.

48 Panel Report, US - FSC (Article 21.5 EC II), paras. 8.144. There have also been other disputes in which the consistency of tax measures with Article III:4 of the GATT was contested, however, these tax measures were indirect tax measures unlike the direct income tax measure in the US - FSC dispute. See for example, Panel Report, Dominican Republic - Import and Sale of Cigarettes, paras. 7.156-7.212.

Panel Report, US - FSC (Article 21.5 EC II), paras. 8.142-8.143.

Appellate Body Report, US - FSC (Article 21.5 - EC), para. 197.

Panel Report, US - FSC (Article 21.5 EC II), paras. 8.148-149; Appellate Body Report, US - FSC (Article 21.5 - EC), para. 222. 
FSC dispute, ${ }^{52}$ while in the case study countries only potentially actionable subsidies are at issue. None of the tax incentives in the case study countries are export subsidies or import substitution subsidies and are thus to be differentiated from those in the US - FSC dispute. ${ }^{53}$

Article III:8(b) of the GATT 1994 recognises the inherent differences in the operation of direct versus indirect taxes by explicitly excluding direct tax subsidies from the National Treatment obligation. As explained above, the very nature of direct taxes in a territorial system of taxation precludes the extension of National Treatment to foreign economic processes.

Article III:8(b) of the GATT 1994 allows direct tax subsidies to be provided to producers, but not under conditions that discriminate between imported and domestic like products. This is essential in respect of the tax incentives in place in the case study countries. They are direct tax subsidies, funded by government revenue foregone and which do not have any conditions attached which discriminate between domestic or imported products, ${ }^{54}$ and thus are not inconsistent with Article III:2 or III:4 of the GATT 1994.

Prior to examining the national tax incentives in detail against the provisions of WTO agreements explicitly addressing subsidies, the following section offers some background to the treatment of subsidies in international trade law over time.

\subsection{Subsidies AfFECTING Trade in GoOds}

With the conclusion of the WTO Agreement and the establishment of the WTO in 1995, the issue of subsidies came to the fore and international trade rules to discipline potentially trade distorting effects of subsidies were developed within the SCM Agreement and the Agreement on Agriculture. Prior to 1995, however, international trade law was not void of reference to subsidies.

\subsubsection{The GATT 1947}

Article XVI of the GAT'T 1947 provided rules on subsidies to be complied with by the Contracting Parties, while Article VI provided limits to the situations in which a Contracting Party could apply countervailing duties on products of another Contracting Party which accorded subsidies to its industries. The term 'subsidy' was

52 In US - FSC, although the FSC scheme was challenged as constituting both prohibited export subsidies as well as prohibited import substitution subsidies, the Panel, having ruled that the FSC exemptions were indeed prohibited export subsidies within the meaning of Article 3.1(b) of the SCM Agreement, did not deem a further examination of Article 3.1(b) of the SCM Agreement to be necessary or appropriate. Panel Report, US FSC, para. 7.132.

53 See later discussion on the obligations under the SCM Agreement in section 8.2 Definition of Subsidy, p. 149.

54 An example of such a condition would be an income tax reduction for renewable energy projects which use nationally produced wind turbines. This is not the case in any of the case study countries. Such discrimination by direct tax measures was also referred to by Slemrod and Avi-Yonah 2001, p. 536. 
nowhere defined in this Agreement, and the Contracting Parties were only required to notify each other of subsidies in place that affect international trade. ${ }^{55}$ Under Article XVI:1 of the GATT 1947, where such notified subsidies were deemed to 'cause [or threaten to cause] serious prejudice to the interests of any other Contracting Party' the only requirement was for the parties in question to 'discuss... the possibility of limiting the subsidisation' [emphasis added]. ${ }^{56}$

\subsubsection{Tokyo Round Subsidies Code}

In 1979 there was some development in international trade law dealing with subsidies by the adoption by some of the GAT'T Contracting Parties (twenty-four) of the Tokyo Round Subsidies Code. ${ }^{57}$ This Subsidies Code was essentially a clarification on Articles VI, XVI and XXIII of the GATT 1947 and was so named: 'Agreement on Interpretation and Application of Articles VI, XVI and XXIII of the General Agreement. ${ }^{58}$ In the Annex to this Subsidies Code, an Illustrative List of Export Subsidies was introduced, which for the first time gave some clarification on the definition of 'export subsidy'.

This Illustrative List of Export Subsidies in the Tokyo Round Subsidies Code later formed the basis of the Illustrative List of Export Subsidies in the SCM Agreement. Furthermore since at that time there was no clear subsidy definition in international trade law, the Illustrative List of Export Subsidies in the Tokyo Round Subsidies Code also provided a base-line for what could definitely be considered to be included in such a definition. Having been a mould for the Illustrative List of Export Subsidies in the SCM Agreement, the Illustrative List of the Tokyo Round Subsidies Code does not lack some weight. Rather than concluding that, now having a definition of a subsidy in WTO law, the Tokyo Illustrative List should be disregarded for the purpose of defining a subsidy, the Panel in US - FSC instead warned that reference to the Tokyo Round Subsidies Code Illustrative List of Export Subsidies in interpreting the now existing definition of subsidies should be done with caution. ${ }^{59}$ Although there are some differences between the Tokyo Round Subsidies Code Illustrative List of Export Subsidies and the SCM Agreement Illustrative List of Export Subsidies, reference to the older list may indeed be useful as long as such a reference is done with caution.

Of particular relevance for the purposes of this thesis which concerns direct tax incentives is that it was the Tokyo Round Subsidies Code which first explicitly included direct tax measures within the ambit of subsidies in international trade law and also

\footnotetext{
55 Article XVI:1 of the GATT 1947.

56 Article XVI:3 of the GATT 1947.

57 GATT Analytical Index Guide to GATT Law and Practice, Updated 6 $6^{\text {th }}$ Edition (1995), p. 1147-1150.

BISD 26/S/56.

59 Panel Report, US - FSC, para. 7.80. See also Vermulst and Graafsma 2002. Although there are some differences between the Tokyo Illustrative List and the SCM Agreement list of export subsidies, those differences do not include the introduction of new types of export subsidies not covered by the Tokyo list. Rather, the amendments assist in the interpretation of the list as it was in the Tokyo list. For example, paragraph (d) is altered in the SCM Agreement list by a clarification that export subsidies are also at issue when products are indirectly provided (not delivered as was in the Tokyo list) by the government as long as the provision of the goods is through a government-mandated scheme.
} 
provided a relevant definition of what was to be covered by direct taxes. In the Illustrative List, subsidies affecting direct taxes (rather than just indirect taxes on products) first appear. Paragraph ' $\mathrm{e}$ ' and ' $\mathrm{f}$ of the Illustrative List include the following measures relating to direct taxation as export subsidies: ${ }^{60}$

(e) The full or partial exemption, remission, or deferral specifically related to exports, of direct taxes ${ }^{61}$ or social welfare charges paid or payable by industrial or commercial enterprises. ${ }^{62}$

(f) The allowance of special deductions directly related to exports or export performance, over and above those granted in respect to production for domestic consumption, in the calculation of the base on which direct taxes are charged.

In footnote 1 to the provision introducing a definition of a direct tax export subsidy in the Tokyo Code, direct taxes are defined as:

taxes on wages, profits, interest, rents, royalties, and all other forms of income, and taxes on the ownership of real property. ${ }^{63}$

The Illustrative List of Export Subsidies recognises that, especially with respect to direct taxation, a web of international law exists in the form of international bilateral tax treaties. Footnote 2 provides that:

Paragraph (e) is not intended to limit a signatory from taking measures to avoid the double taxation of foreign source income earned by its enterprises or the enterprises of another signatory ...

It is clear that, especially with respect to direct tax measures, the new provisions dealing with subsidies within the Tokyo Round Subsidies Code did not intend to overlap with efforts taken within bilateral tax treaties aiming at eliminating double taxation.

However, despite this, also in footnote 2 , the possibility of direct tax subsidies being incompatible with Article XVI of the GATT 1947 was indeed foreseen. Footnote 2 reads:

... Where measures incompatible with the provisions of paragraph (e) exist, and where major practical difficulties stand in the way of the signatory concerned bringing such measures promptly into conformity with the Agreement, the signatory concerned shall, without prejudice to the rights of other signatories under the General Agreement or this Agreement, examine methods of bringing these measures into conformity within a reasonable period of time. ${ }^{64}$

From this provision it is clear that as early as 1979, the remedy foreseen for direct tax (export) subsidies which cause injury to other Contracting Parties was for the

Bentley 2000, p. 83.

Footnote in original, Footnote 1 in the Annex to the Tokyo Round Subsidies Code.

Footnote in original, Footnote 2 in the Annex to the Tokyo Round Subsidies Code.

Text of Footnote 1 in Annex to the Tokyo Round Subsidies Code.

Text of Footnote 2 in the Annex to the Tokyo Round Subsidies Code. 
measure at issue to be promptly brought into conformity with the GATT 1947. Should this not be immediately feasible, the party in question was to 'examine' ways in which this could be achieved 'within a reasonable period of time'. ${ }^{5}$

Although by the conclusion of the Tokyo Round Subsidies Code, some clarification on subsidies, and particularly relevant for this study - direct tax subsidies - in international trade law was provided, this was clearly not yet sufficient. Although the Tokyo Subsidies Code lacked a comprehensive definition of 'subsidy', the development of, and detail provided in the Code and in particular enlightening examples provided in its Illustrative List, may be seen to be the catalyst for the explosion of subsidies disputes brought before GATT panels in the period between the late 1970s and the early 1990s. ${ }^{66}$ Prior to 1979 , only two GATT panel decisions were adopted relating to subsidies ${ }^{67}$ whereas, in 1981 alone, five subsidies disputes were brought before GATT panels - four of the five being direct tax subsidy cases. ${ }^{68}$ The significance of this should not be underestimated as the foundations for future international trade law dealing with subsidies were laid in this early period by the foresight of the twenty-four forerunning Contracting Parties signatory to the Tokyo Subsidies Code.

It must be admitted, however, that despite some groundwork being carried out in the Tokyo Round, during the Uruguay Round, the negotiating parties took on board the subsidies issue and were equal to the task, producing in the end the SCM Agreement. With this Agreement, the clarification of the law with respect to subsidies, which was initially sought by the signatories of the Tokyo Round Subsidies Code in 1979, was finally brought to fruition in 1995 with the incorporation of the new SCM Agreement comprising 32 Articles and 7 Annexes (including Annex I - an Illustrative List of Export Subsidies) into the body of international trade law - into the WTO Agreement.

65 Footnote 2 in Annex I of the Tokyo Round Subsidies Code. An example of such a circumstance is provided. In this connection the European Economic Community has declared that Ireland intends to withdraw by 1 January 1981 its system of preferential tax measures related to exports, provided for under the Corporation Tax Act of 1976, whilst continuing nevertheless to honour legally binding commitments entered into during the lifetime of this system'.

66 Van den Bossche 2008, p. 559. Here, Van den Bossche raises the point that, due to the lack of clarification provided by the Tokyo Round Subsidies Code, and lack of clear rules in general throughout the 1970s and 1980s, a host of subsidies disputes ensued. Considering especially the initial thrust with which the cases commenced in 1981, and the predominance of tax subsidies cases, I respectfully submit that the Tokyo Round Subsidies Code should not be underestimated for the clarification it did bring especially with respect to tax issues. It could be said that the Tokyo Round Subsidies Code furthermore added to the legal certainty or positive expectations of the complainants in the cases between 1979 and 1994. The Tokyo Round Subsidies Code included in black and white that both direct and indirect tax measures could be considered to be covered by the GATT 1947 subsidy provisions.

67 GATT Working Party Report, Australia - Ammonium Sulphate and GATT Panel Report, France - Wheat Exports.

68 GATT Panel Report, US - CVD (India); GATT Panel Report, US - DISC; GATT Panel Report, France - Income Tax; GATT Panel Report, Belgium - Income Tax, GATT Panel Report, Netherlands - Income Tax. 


\subsubsection{The GATT 1994}

At present the WTO rules dealing with subsidies and countervailing measures are enshrined in Articles XVI and VI of the GAT'T 1994 and in the SCM Agreement of Annex 1A to the WTO Agreement.

Articles XVI and VI of the GATT 1994 are identical to Articles XVI and VI of the GATT 1947 discussed above. ${ }^{69}$ Although the SCM Agreement was developed in the same time-frame as the 'Understandings' 70 on the various Articles of the GATT 1947, the SCM Agreement was a new multilateral agreement on trade in goods which provided 'a broad package of new export subsidy disciplines that "go well beyond merely applying and interpreting Articles VI, XVI and XXIII of the GATT 1947". ${ }^{71}$ The development of a new multilateral agreement on trade in goods dealing explicitly with subsidies eliminated the need for an 'Understanding on Article VT' or 'Understanding on Article XVT of the GATT 1994.

At this point it is important to note the 'General Interpretative Note to Annex $1 A$ ' of the WTO Agreement which states:

In the event of conflict between a provision of the General Agreement on Tariffs and Trade 1994 and a provision of another agreement in Annex 1A to the Agreement Establishing the World Trade Organization..., the provision of the other agreement shall prevail to the extent of the conflict.

From this provision, it is clear that the intention of the WTO Members was to ensure that in the event that provisions of the GATT 1994, which are in this instance identical to those of the GATT 1947, would conflict with provisions of the new agreements, the latter would prevail. With respect to the GATT 1994 and the SCM Agreement, the SCM Agreement would prevail ensuring that the developments envisaged by the negotiations of Uruguay Round would indeed come to fruition.

In this respect no further attention will be paid to Article VI and XVI of the GATT 1994, and rather focus will be turned to the SCM Agreement. As stated by the Appellate Body in US - FSC:

Whether or not a measure is an export subsidy under Article XVI:4 of the GATT 1947 provides no guidance in determining whether that measure is a prohibited export subsidy under Article 3.1(a) of the ASCM. ${ }^{72}$

Thus, considering the text of Article XVI of the GATT 1947 and the GATT 1994 are identical, a conclusion can be drawn here that in examining the consistency of a subsidy with WTO law, panels and the Appellate Body deems the SCM Agreement to be the more specific and relevant agreement.

See section 7.5.1 The GATT 1947, p. 142.

70 For example: Understanding on the interpretation of Article II:1(b) of the General Agreement on Tariffs and Trade 1994.

$71 \quad$ Appellate Body Report, US - FSC, para. 117.

72 Ibid. 


\subsubsection{Agreement on Subsidies and Countervailing Measures}

First and foremost, the aim of the SCM Agreement is to curb national governments' freedom in providing subsidies that may have a distorting impact on international trade. Furthermore, the SCM Agreement provides for situations in which retaliatory measures - countervailing measures - may be taken against WTO Members for subsidies that have a negative impact on trade. ${ }^{73}$ It has been accepted that governments use subsidies to pursue national goals, other than trade goals, and although such goals, for example the protection of the environment, may be justified, the trade effects of the subsidies may provoke an examination of the consistency of those subsidies with international trade law. In fact, in the preamble to the Tokyo Round Subsidies Code ${ }^{74}$ states the following:

Recognizing that subsidies are used by governments to promote important objectives of national policy,

Recognizing also that subsidies may have harmful effects on trade and production,... ${ }^{75}$

Thus, although it may be recognised that tax subsidies provided to electricity generators, in pursuit of environmental objectives, may be justifiable from an environmental perspective, they may also have negative international trade implications. ${ }^{76}$ Since electricity is an industrial good, the provisions of the SCM Agreement apply to these incentives to the extent that they are specific subsidies within the meaning of Article 1 and 2 of the SCM Agreement. And as there is no explicit exclusion of environmental subsidies from the provisions of the SCM Agreement, ${ }^{77}$ the tax incentives are nevertheless subject to the provisions of the SCM Agreement. This is a potential concern in particular in light of government environmental policies including 'tax concessions, rebates and write-offs'. ${ }^{78}$

As discussed in Chapter 2, in particular in relation to the electricity generation sector, renewable energy resources have a weak market position, being a relatively new development compared to the fossil fuel inputs. Due to the high level of capital investment needed in the early stages of development and the difficulty of competing with already subsidised non-renewable energy resources, ${ }^{79}$ the provision of subsidies,

Ya Qin 2004, p. 865.

Note that the SCM Agreement does not have a preamble.

Preamble to the Tokyo Round Subsidies Code.

Ya Qin 2004, p. 865.

Herman 2007, p. 50.

Ibid., p. 51.

See section 2.5 Pro-Kyoto Protocol Tax Incentives, p. 37. See also, Cottier, Malumfaschi et al. 2009, p. 11, available at: <http://www.nccr-trade.org/ images/stories/projects/ip6/IP6_synthesis_report_with\%20biblio.pdf > last visited 24 November 2009. In this paper, suggestions for reform are made for Energy within the WTO. One suggestion aimed at subsidies provided to fossil fuels is to create within the WTO a subsidy-watch committee as a subsidiary of the Committee on Subsidies and Countervailing Measures in accordance with Article 24.2 of the SCM Agreement. The paper additionally suggests that Member's subsidy reform related to harmful subsidies to fossil fuels would be integrated into the Member's WTO Commitments. See p. 12. 
especially for the development of renewable resources, has been essential. ${ }^{80}$ The provision of subsidies only becomes contentious in WTO terms where the subsidies are not provided in a manner consistent with the WTO rules. This is the case where the subsidies fall within the SCM Agreement definition of 'subsidy', and are export subsidies, import substitution subsidies (both of which are deemed to be specific) or otherwise are specific subsidies which create adverse effects to the interests of other WTO Members. ${ }^{81}$ The first step of examining national subsidy policies for SCM Agreement-consistency is to determine whether the measure in question falls within the definition of a subsidy in the SCM Agreement. The next chapter will deal in detail with the definition of subsidy within the SCM Agreement.

\subsection{CONCLUSION}

This chapter provided an introduction to the treatment of subsidies, and in particular direct tax subsidises within the WTO. The treatment of electricity within the WTO system was addressed specifically in this chapter since a WTO analysis is impossible before first delineating whether the measure at issue affects trade in goods and/or trade in services. The consistency of the case study tax incentives was examined against the non-discrimination obligations of the GATT 1994. The special provisions on subsidies, in the past and their evolution were introduced.

By addressing the particular treatment of direct tax subsidies in the WTO, this chapter clarified the differentiation of treatment of direct tax incentives versus indirect tax incentives. Although indirect tax incentives could be found to be inconsistent with Article III:2 of the GATT, direct corporate tax incentives conferred on producers are exempted from the National Treatment obligation. This is so, since according to Article III:8(b) subsidies to producers do not violate Article III:2 since Article III: 2 concerns indirect taxes and subsidies to producers would be in the form of direct tax concessions. In fact, the extension of domestic direct tax incentives to foreign producers could not even practically be implemented within a territorial taxation system. Despite this conclusion, however, it should be borne in mind that the laws or regulations providing for the domestic direct tax incentives could be found to be inconsistent with Article III:4 of the GATT 1994 if the effects of those laws or regulations result in treatment less favourable for like imported products.

Chapter 8 will examine the tax incentives in place in the case study countries to establish whether they are subsidies within the meaning of Article 1 of the SCM Agreement and specific within the meaning of Article 2 of the SCM Agreement. 


\section{Chapter 8 : Case Study Tax Incentives' Consistency with the SCM Agreement}

\subsection{INTRODUCTION}

This chapter assesses whether the particular tax incentives found to be in place in the case study countries are covered by the SCM Agreement. First, the definition of 'subsidy' and 'specificity' in the SCM Agreement will be outlined. Then it will be examined whether the tax incentives in place in the case study countries can indeed be considered subsidies and whether they are specific within the meaning of Article 1 and 2 of the SCM Agreement.

Since the tax incentives in the case study countries comprise three categories of measures: accelerated depreciation, own-investment deduction and third-partyproject investment deduction, the measures will be dealt with in this way and in this order. In each section there will be an introduction (a reminder) of the type of tax incentive in question as well as an overview of the case study countries employing the measure and the conditions attached to that application.

\subsection{DEFINITION OF SUBSIDY}

Understanding the definition of subsidy under WTO law is essential to understanding whether, if at all, the measures examined in the case studies would be subject to the disciplines of the SCM Agreement. As discussed above, until the introduction of the SCM Agreement and the establishment of the WTO and the WTO Agreement, there was no definition of subsidy in the law governing subsidies which is the predecessor of the SCM Agreement - namely Articles VI and XVI of the GATT (1947 and 1994) and the Tokyo Round Subsidies Code. Finally a definition of subsidy was explicitly provided in the SCM Agreement. The Panel in US - FSC stated that the development of this definition is generally considered to represent one of the most important achievements of the Uruguay Round in the area of subsidy disciplines'. ${ }^{1}$ Article 1.1 of the SCM Agreement defines which measures by Members constitute subsidies falling within the mandate of the WTO.

Article 1.1 of the SCM Agreement provides that:

(a)(1) there is a financial contribution by a government or any public body within the territory of a Member (referred to in this Agreement as "government"), i.e. where:

(i) a government practice involves a direct transfer of funds (e.g. grants, loans, and equity infusion), potential direct transfers of funds or liabilities (e.g. loan guarantees);

\footnotetext{
Panel Report, US - FSC, para. 7.80. See also Vermulst and Graafsma 2002.
} 

(e.g. tax incentives such as tax credits) ${ }^{2}$

a government provides goods or services other than general infrastructure, or purchases goods;

(iv) a government makes payments to a funding mechanism, or entrusts or directs a private body to carry out one or more of the type of functions illustrated in (i) to (iii) above which would normally be vested in the government and the practice, in no real sense, differs from practices normally followed by governments;

or

(a)(2) there is any form of income or price support in the sense of Article XVI of GATT 1994;

and

(b) a benefit is thereby conferred.

This definition can be sub-divided into three parts. There should be a (1) financial contribution; (2) provided by the government; (3) which confers a benefit. As is clear from parts $i$ to iv of the definition, there are many forms of financial contribution which may be conferred upon a beneficiary by the government. However, in this study only one of these forms is of primary importance for the tax incentives explored in the case studies - direct tax incentives for the development of renewable energy electricity generation - that of Article 1.1 (a) (1) (ii). ${ }^{3}$

As discovered in the case studies, the financial contributions in question are in particular: accelerated depreciation provisions leading to a reduced corporate tax liability, increased current deductions related to investments in assets also reducing corporate tax liability and thirdly increased current deductions related to investments in third party projects again reducing corporate tax liability.

The definition of a subsidy, which includes the positive requirement of a financial contribution, does not preclude this financial contribution from consisting of

2 Footnote in original, Footnote 1 in Article 1.1(ii) of SCM Agreement reads: In accordance with the provisions of Article XVI of GATT 1994 (Note to Article XVI) and the provisions of Annexes I through III of this Agreement, the exemption of an exported product from duties or taxes borne by the like product when destined for domestic consumption, or the remission of such duties or taxes in amounts not in excess of those which have accrued, shall not be deemed to be a subsidy'.

3 Although in this research Article 1.1(a)(1)(ii) is the most relevant provision of this Article to be examined as the financial contributions explicitly concern tax measures, in Chapter 8 Article 1.1(a)(1)(i) will also be examined in relation to the accelerated depreciation provisions as it is possible that the benefit ensuing from these measures could also be classified as tax deferral. Furthermore, Article 1.1(a)(1)(iv) will also be addressed in examining the consistency of the Dutch Green Funds and Irish investment incentive with the SCM Agreement. 
inaction or omission by the government rather than action or an act. ${ }^{4}$ In the case at hand this financial contribution relates to the non-collection of taxes.

The next section will therefore, within the three-pronged subsidy test (financial, contribution, by government, conferring a benefit), concentrate on the financial contributions falling within the definition:

government revenue that is otherwise due is foregone or not collected (e.g. tax incentives such as tax credits); 5

It has repeatedly been underlined by the Appellate Body that 'financial contribution' and 'benefit' are two distinct and separate legal elements in the subsidy test, a combination of which make up the definition of subsidy. I proffer that a finding of the existence of a financial contribution within the meaning of Article 1.1 (a) (1) (ii) ${ }^{6}$ leads directly to an immediate finding of the existence of a benefit. As put by Rubini:

Although financial contribution and benefit are different requirements and should, in principle, be interpreted according to their own criteria, they can certainly represent part of the relevant context of each other. ${ }^{7}$

In order to make this argument I will now address the findings of panels and the Appellate Body determining that 'financial contribution' and 'benefit' must be examined separately so that it can be highlighted that in the case of financial contributions in Article 1.1 (a) (1) (ii), in practice, these elements of the test are examined concurrently. The following section should illustrate that with regard to financial contributions in Article 1.1 (a) (1) (ii), the rulings of panels and the Appellate Body do not preclude testing for 'financial contribution' and 'benefit' together.

The negotiating history of Article 1 SCM Agreement sheds some light on the requirement developed by panels and the Appellate Body that the two elements of the subsidy test should be de-coupled. The importance of the two elements of this definition (financial contribution and benefit) reflects the fact that initially different WTO members hoped for different coverage of measures by the SCM Agreement. Finally, the agreement by the Members on the inclusion of 'financial contribution' was intended to curb an overly broad coverage of the SCM Agreement of all measures by a government that conferred a benefit. The 'financial contribution' element ring fences the application of the SCM Agreement only to a certain group of measures by a government that confers benefit. Visually this can be illustrated below. Subsidies which are financial contributions conferring a benefit are in this case a subset of subsidies which confer a benefit. This view is further supported by the Panel in US -

Panel Report, US - Softwood Lumber III, para. 7.24.

Footnote 1 in Article 1.1(ii) of SCM Agreement.

See for example, Appellate Body Report, Brazil - Airraft, para. 157; Appellate Body Report, Canada - Aircraft, para. 156; Panel Report, US - Export Restraints, para. 8.20; Panel Report, Canada - Aircraft Credits and Guarantees, para. 7.396.

Rubini 2009, p. 261. 
Export Restraints which stated that: 'the drafters foreclosed the possibility of the treatment of any government action that resulted in a benefit as a subsidy'. ${ }^{8}$

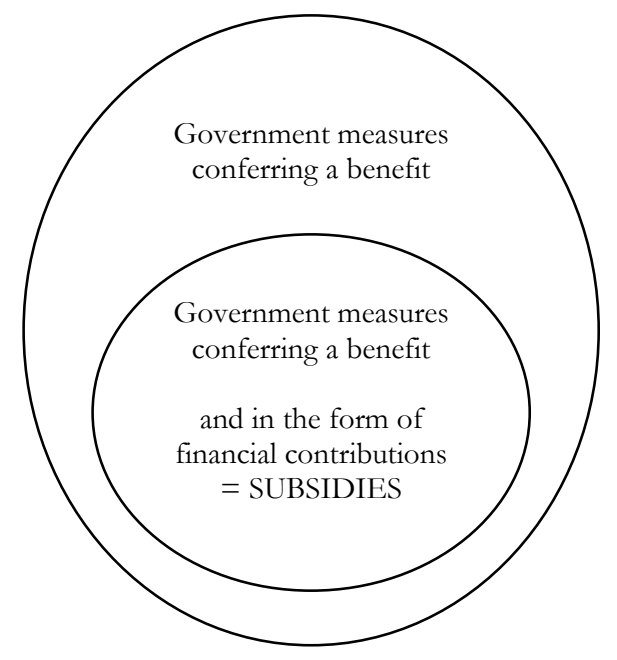

The Appellate Body all but reprimanded the Panel for its finding in Brazil - Aircraft that there was 'no direct transfer of funds' by reason that there was no benefit conferred. The Appellate Body stated that the Panel made a 'mistake' by importing 'the notion of "benefit" into the definition of a financial contribution'? This explanation of the requirement by the Appellate Body in Brazil - Aircraft that the elements 'financial contribution' and 'benefit' should be separated is essentially requiring that the examination of the existence of one of the listed 'financial contributions' should not be neglected and the Panel should not rely solely on the existence of a benefit to inform the existence of a financial contribution.

Although the figure above represents the reasoning of the Appellate Body in BrazilAircraft it does not represent the later reasoning by the Panel in Canada - Aircraft Credits and Guarantees which also called for 'financial contribution' and 'benefit' to be examined separately.

In Canada - Aircraft Credits and Guarantees the Panel stated that to establish the existence of a benefit, it is not sufficient to establish that there has been a financial contribution. ${ }^{10}$ The following figure better represents this reasoning.

Panel Report, US - Export Restraints, para. 8.38.

Appellate Body Report, Braqil - Aircraft, para. 157.

Panel Report, Canada - Airrraft Credits and Guarantees, para. 7.396. 


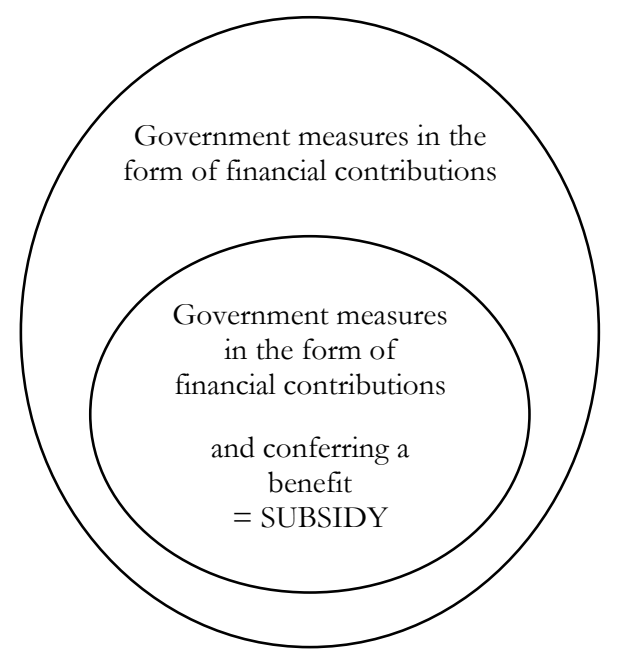

And where the reasoning in both disputes is taken together, the following figure demonstrates the inter-relationship of financial contribution and benefit.

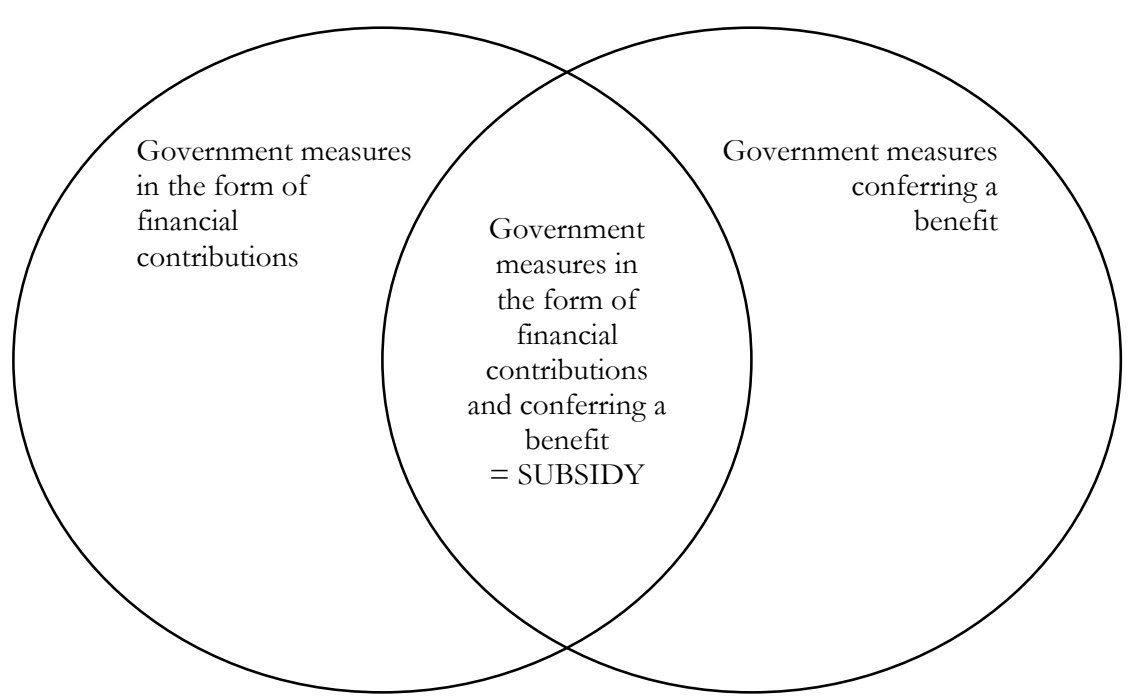

Again, the Panel referred to the existence of two elements within Article 1 of the SCM Agreement. In this case the measure at issue was a loan guarantee. The Panel explained that if Brazil's submission, that the existence of a financial contribution necessarily proves the existence of a benefit, were to be accepted, all loan guarantees would be deemed to be subsidies. In the opinion of the Panel, this would be contrary to the consideration in Article 14(c) dealing with 'benefit' for the purpose of calculating countervailing duties. According to this Article, not all loan guarantees confer a benefit and thus not all loan guarantees are subsidies. Article 14(c) uses a 
comparison to establish benefit. The distinction between loan guarantees conferring a benefit and loan guarantees not conferring a benefit is made by a comparison with a relevant 'normative benchmark' - the comparable amount available in a commercial loan guarantee. This comparison is essential in the determination of a benefit. This reference to Article 14(c) is intended to underline and highlight the importance of examining 'benefit' from Article 1.1(b) separate from and in addition to Article 1.1(a)(1)(i).

This underlining, by reference to Article 14(c), of a necessary comparison to be established under Article 1.1(b) was also highlighted in Canada - Aircraft. The Panel made clear that 'benefit' under Article 1.1(b) requires a comparison. 'There can be no "benefit" to the recipient unless the financial contribution makes the recipient "better off" than it would otherwise have been, absent the contribution'.11 Thus it is clear that while in these disputes the separate and additional examination of benefit, comprising of a comparison analysis was deemed essential by panels and the Appellate Body, this does not necessarily hold true for cases which address a financial contribution under Article 1.1(a)(1)(ii). The separate and additional examination of benefit conferred by financial contributions within the meaning of Article 1.1(a)(1)(ii), in practice, is not necessary since the answer to the benefit question is obvious from the financial contribution examination.

The wording of this Article 1.1(a)(1)(ii) differs significantly from the wording used in Article 1.1(a)(1)(i), (iii) and (iv). The requirement of a making comparison between the effects of the government measure (financial contribution) with the 'normative benchmark' to determine whether there is a benefit - the Article 1.1(b) test - is already built-in to Article 1.1(a)(1)(ii). ${ }^{12}$ All other categories of financial contribution lack a built-in benchmark comparison requirement and rely on the separate examination of a benefit under Article 1.1(b).

Article 1.1(a)(1)(ii) reads:

government revenue that is otherwise due is foregone or not collected (e.g. tax incentives such as tax credits) $;^{13}$

In the wording of Article 1.1(a)(1)(ii), the foregoing or non-collection of government revenue is compared with the normative benchmark, which is the government revenue that is otherwise due. This comparison establishes concurrently whether there is a financial contribution and whether that financial contribution confers a benefit. Where revenue is foregone which was otherwise due, this logically leads to a result that less revenue was collected and the financial contributions automatically

$1 \quad$ Appellate Body Report, Canada - Aircraft, para. 157.

12 Rubini 2009, p. 263. See also Panel Report, US - FSC, para. 7.103 and Panel Report, US - FSC (Article 21.5 EC II), para. 8.46.

$13 \quad$ Footnote 1 in Article 1.1(ii) of SCM Agreement. 
makes the beneficiary better off. ${ }^{14}$ That is to say, by virtue of the wording in Article 1.1(a)(1)(ii), Article 1.1(b) is also addressed..$^{15}$

This was also evident from the only WTO dispute that examined a measure under Article 1.1(a)(1)(ii), US - FSC, in which the Panel formally addressed Article 1.1(b) separately from Article 1.1(a), but it is clear from the 1.1(b) analysis that the benefit criteria had already been examined in detail by default in the Article 1.1(a)(1)(ii) analysis. ${ }^{16}$ In the words of the Panel:

In our view, the financial contribution clearly confers a benefit, in as much as both FSCs and their parents need not pay certain taxes that would otherwise be due. ${ }^{17}$

The special nature of a tax incentive, as a financial contribution, logically infers that the 'benefit conferred' 'by the government' in practice is addressed at the same time. The three separate parts of the definition of a (tax) subsidy are inextricably intertwined to the extent that by answering one condition (the first), it automatically provides the answer to the other two.

If it is established that a tax incentive is in place which constitutes 'revenue foregone that is otherwise due' and thereby a financial contribution exists, this financial contribution is automatically, by definition, forgone from the government purse. Taxes (revenue) may only be collected by the government. This notion follows the famous call by revolutionaries at the Boston Tea Party in 1776 that there should be no taxation without representation. The flip-side of this is that taxation should only be implemented by the representation. Taxes are applied and collected only by the elected government. Therefore the non-collection of taxes can also only be by the government. The 'government' in this case can also cover municipal, provincial and local governments charging and collecting (and not collecting) taxes. It remains however a measure which can only be provided by the government, and this part of the definition may therefore be assumed. Thus by determining the existence of a financial contribution in the form of 'revenue foregone that is otherwise due' the first two steps of the 'subsidy test' are fulfilled: financial contribution by the government.

Following on to the third element of the subsidy test - whether a benefit is thereby conferred. If it is established that a tax incentive is in place which constitutes 'revenue forgone that is otherwise due', by definition provided by the government, then it automatically is to be assumed that this 'revenue forgone otherwise due' confers a benefit. The fact that the revenue was 'otherwise due', presumes that it is not paid by

14 Rubini 2009, p. 262. See also footnote 5, p. 263.

15 As put by Wolf 2006, p. 102, ‘... the most difficult hurdle is classifying the... action as a financial contribution... The strongest argument is to classify the ... action as a financial contribution lies under the foregoing of government revenue that is otherwise due. If that hurdle is overcome, it is relatively easy to demonstrate that a benefit is thereby conferred... When a benefit is obvious, the issue often receives little attention from the parties in a dispute and in Panel reports and Appellate Body reports'.

Panel Report US - FSC, para. 7.103.

Once the Panel established that there was revenue foregone that was otherwise due, the respondent that the contested measure thereby conferred a benefit. Panel Report, US - FSC, para. 8.47. Wolf 2006, p. 102. 
the beneficiary in this instance and thus provides for an automatic benefit - a lower tax liability.

In the following paragraphs, the subsidy analysis which will be carried out for the case study direct tax incentives will be introduced by an examination of the first 'financial contribution' prong.

This financial contribution test has two elements: government revenue is foregone and government revenue would otherwise be due. Since these two elements form two sides of one coin, in the WTO jurisprudence, it has been impossible to consider one part without the other. Reference to one serves to provide the context of the other. It is useful to now highlight some of the important findings of panels and the Appellate Body on the interpretation of Article 1.1(A)(1)(ii) SCM Agreement. ${ }^{18}$

The only WTO case in which Article 1.1(A)(1)(ii) SCM Agreement has been considered and its interpretation 'clarified' is the US - FSC case. In this case, unlike in Indonesia Autos ${ }^{19}$ it was first clarified by the Panel whether the measure at issue was indeed a subsidy within the meaning of Article 1.1(A)(1)(ii) SCM Agreement.

The Panel in US - FSC clarified the definition of subsidy in Article 1.1(A)(1)(ii) SCM Agreement ${ }^{20}$ by elaborating on the terms of this definition. Revenue due but foregone is deemed to be a financial contribution by a government. In Canada - Autos, the Panel defined the term 'revenue' as 'the annual income of a government or State, from all sources, out of which public expenses are met'. ${ }^{21}$ The Panel in US - FSC defined 'due' to mean 'that is owing or payable, as a debt'. ${ }^{22}$ Also as is the situation in the first indent of Article 1.1, the revenue foregone should be forgone from the government purse. 'Foregone' is defined as 'not collected'.

First it must be determined whether taxes were originally due to be paid to the government and then whether there has been a situation in which these taxes were not collected by virtue of governmental action. The Panel in US - FSC established that in order to determine whether taxes were originally due, the general tax regime of the government in question should be examined.

In order to illustrate such a situation fulfilling the conditions of Article 1.1(a)(1)(ii) the Panel in US - FSC gave an example of such a subsidy from a previous case

Although in Panel Report, Indonesia - Autos, para. 14.115, a case which also concerned measures falling within Article 1.1(A)(1)(ii) ASCM, the Panel was not called to interpret 'revenue foregone which is otherwise due' as the parties to the case (EC, Japan, US, Indonesia) agreed that duty and sales tax exemptions represented revenue foregone within the meaning of Article 1.1(A)(1)(ii) and that these exemptions conferred a benefit within the meaning of Article 1.1(b). This is the first WTO case in which this form of financial contribution was at issue. However, the Panel in this case was not in a position to lay the groundwork for the interpretation of this provision and instead this provision was thoroughly investigated by panels and Appellate Bodies in the only other WTO case dealing with 'revenue foregone which is otherwise due': US - FSC. Ibid.

Panel Report, US - FSC, para. 7.42.

Panel Report, Canada - Autos, para. 10.159.

Panel Report, US - FSC, para. 7.42. 
Indonesia - Autos. This case involved tax and duty exemptions. The test was to establish that in the normal tax regime of the country more taxes would be normally due, were it not for the special exemptions applied. The normal tax regime is the reference benchmark. The Panel held that there was no requirement of international law that the taxes be imposed, but rather only the national tax regime was relevant. ${ }^{23}$ Thus the Panel also expanded on the meaning of 'otherwise due' to indicate a situation in which a 'but for' (were it not for) test could be applied. Thus, 'but for' the contested measure - the tax incentive, tax credit, or exemption, as the case may be - revenue would accrue to the government of the territory. Were it not for the tax incentive, the corporation in question would be subject to a higher tax liability. ${ }^{24}$

The Appellate Body accepted the Panel's application of a 'but for' test in this case to determine whether or not revenue otherwise due was at issue. The Appellate Body considered the Panel's reasoning to provide 'a sound basis for comparison'. However, the Appellate Body cautioned against using such a test in place of following the wording of the SCM Agreement to the letter. ${ }^{25}$ Since the 'but for' test does not offer a solid normative benchmark against which the measures has to be tested it is inherently instable. ${ }^{26}$ A concern of the Appellate Body in this respect was the possibility for easy circumvention of this test by Members intent on providing special tax treatment to certain corporations. ${ }^{27}$ Thus, although accepting the 'but for' test in this case, the Appellate Body cautioned against it being the ultimate test in detecting all circumstances of 'revenue otherwise due'.

Following on from the general introduction of tax subsidies, it is clear that such measures as those applied in the case study countries potentially fall within the definition of Article 1.1(a)(1)(ii) of the SCM Agreement and therefore subject to further review under this agreement. Article 1.2 of the SCM Agreement goes on to state that:

A subsidy as defined in paragraph 1 shall be subject to the provisions of part II or shall be subject to the provisions of part III or $\mathrm{V}$ only if such a subsidy is specific in accordance with the provisions of Article 2 .

Where it is determined that the measures at issue fall within the Article 1 definition of subsidy, the provisions of Article 2 must be examined. ${ }^{28}$

\subsection{SPECIFICITY}

For a subsidy to be further examined under Part II (prohibited subsidies) or III (actionable subsidies) of the SCM Agreement it must be de jure or de facto specific to 'an enterprise or industry or group of enterprises or industries' located in the jurisdiction

Panel Report, US - FSC, para. 7.44.

Panel Report, US - FSC, para. 7.45. See also Rubini 2009, p. 265.

Benitah 2001, p. 189.

Appellate Body Report, US - FSC, para. 90. See also Rubini 2009, p. 265.

Appellate Body Report, US - FSC, para. 91; A situation where no general rule exists which would be applied 'but for' the measure in question.

28 Subsidies within the definition of Article 1 SCM Agreement must be specific within the meaning of Article 2 to be further examinable under the SCM Agreement. Panel Report, Indonesia - Autos, para. 14.155. 
of the state granting the subsidy in question, as provided by Article 2 of the SCM Agreement. ${ }^{29}$ Although the SCM Agreement indicates factors which, together, provide a tool with which to determine specificity, it is not a precise definition. Specificity must be examined on a case-by-case basis. ${ }^{30}$ Should the following conditions be fulfilled, the subsidy may be deemed to be specific:

1) access to subsidy is limited to certain enterprises by the granting authority; ${ }^{31}$

2) neutral and objective criteria or conditions, which are economic in nature and horizontal in application and strictly followed, determine eligibility for the subsidy; ${ }^{32}$

3) a subsidy is effectively only accessed by a limited number of enterprises; the amounts of subsidy provided are allocated disproportionately or dubious discretion is exercised by the granting authority in deciding on recipients. ${ }^{33}$

Further aspects to be taken into account in determining whether a subsidy is specific include information on applications for the subsidy and reasons for refusals/ approvals, the economic activities for which the granting authority has responsibility and the duration of the provision of the subsidy. ${ }^{34}$

Article 2.2 of the SCM Agreement states that a subsidy will be deemed to be specific where the common factor for granting the subsidy is the geographic location of the enterprises involved, when that geographic location is a designated region within the jurisdiction of the granting Member. In order to show that a measure falls within the requirements of Article 2 and is thus specific, the complainant is required to provide positive evidence of the measure falling within the Article 2.1 determination of specificity. ${ }^{35}$

However, Article 2.3 SCM Agreement states clearly that, with respect to export subsidies (prohibited subsidies under Article 3), specificity is deemed to exist without further examination. Therefore, where the conditions of Article 3 are fulfilled, the conditions of Article 2 are also deemed to be fulfilled without the requirement to provide positive evidence of specificity under Article 2.

Article 2.2 SCM Agreement provides an exception to a measure being considered a specific subsidy within the meaning of this Agreement. Article 2.2, second sentence, states that where a generally applicable tax rate is introduced or altered by the relevant body having authority to do so, this measure is not to be considered a

29 As put by Benitah, selective subsidies can be seen to distort 'the optimal allocation of resources by the market in a national economy' in favour of the specific enterprise/sector on which the subsidy is conferred. In a situation where the subsidy is generally available, no such distortion would occur. Thus the extent of the market distortion caused by the subsidy is directly related to how specific or general the subsidy is in SCM Agreement terms. Benitah 2001, p. 273.

Panel Report, US - Upland Cotton, para. 7.1142.

Article 2.1 (a) SCM Agreement.

Article 2.1(b) SCM Agreement.

Article 2.1(c) SCM Agreement.

Article 2.1 SCM Agreement.

Article 2.4 SCM Agreement. 
specific subsidy. ${ }^{36}$ Although the terms 'generally applicable' allude to a lack of specificity, it is interesting that this sentence was included in Article 2. Any generally applicable measure, by nature, cannot be a specific subsidy since being generally applicable it does not benefit one group of industries more than another. However, this clarification can serve as a reminder that generally applicable tax rates and generally applicable changes to tax rates comprise the general system of taxation and thus are not a deviation from the normative benchmark, but rather constitute the normative benchmark.

In the WTO context, there are very few disputes which examine the specificity (de facto or de jure) of contested subsidies. This is particularly the case since it is only relevant to specifically address specificity if a subsidy is potentially actionable but not a prohibited subsidy as prohibited subsidies are deemed to be specific according to Article 2.3.37

Having outlined the form of tax incentives which are covered by Article 1.1, the definition of a subsidy, and highlighting the requirement of positive evidence that the measure is also specific according to Article 2.1,38 the particular tax incentives applied in the case study countries will be examined for consistency with Article 1 and 2 of the SCM Agreement in the next chapter.

The SCM Agreement divides subsidies into three categories according to their degree of harmful effects on international trade, namely: prohibited subsidies, actionable subsidies and non-actionable subsidies. Since export subsidies have the most extensive negative effects on international trade, they are prohibited by the SCM Agreement. Subsidies may be considered to be actionable subsidies and may be found to be inconsistent with the SCM Agreement if they are provided to a specific enterprise or industry and causes adverse effects to the interests of another WTO Member. Until 1999, there was also a category of non-actionable subsidies being subsidies which were permitted by the WTO which has since lapsed. In the following section the SCM Agreement rules will be addressed in this order: prohibited subsidies, actionable subsidies and non-actionable subsidies. The effects of the subsidies in place in the case study countries as well as the requirements of Part III of the SCM Agreement addressing prohibited subsidies and Part IV if the SCM Agreement addressing actionable subsidies are dealt with in Chapter 9.

\subsection{CASE STUDIES - ACCELERATED DEPRECIATION INCENTIVE}

Prior to examining the WTO-consistency of the accelerated depreciation provisions, it is appropriate to introduce the concept of depreciation in general and then accelerated depreciation in particular.

Article 2.2 SCM Agreement.

See also Panel Report, Indonesia - Autos, para. 14.155.

Unless it is first shown that it is in fact an export subsidy and thus automatically considered to be specific. 
The general system of taxation reflects a country's concept of 'ability to pay'39 and thus establishes a country's definition of taxable income and revenue due. The general system of taxation permits certain special tax deductions to the extent that they reflect the ability to pay of the tax payer and thus are taken into account in determining the revenue due from that tax payer. From a commercial perspective, the ability to pay and thus the taxable income is the revenue raised from carrying out a commercial activity less the costs incurred in raising that revenue. Therefore, general systems of taxation provide for depreciation rules.

Depreciation is a cost-recovery method that allows for a percentage of the cost of an exhaustible asset to be recovered (deducted) over a period of years, representing the useful life of the asset. For example, if an asset has a useful life of fifteen years, a percentage of the cost of the asset will be deducted every year for fifteen years. The percentage of the deduction depends on the method of depreciation used: inter alia, straight line, sum of years. The determination of the method and useful life of an asset is provided for by legislation in some systems and is at the discretion of the company (in agreement with the tax administration) in others. Administrative feasibility is often chosen over accurate determinations of useful life value. Thus, depreciation rules are generally applicable tax rules and form part of the general system of taxation.

Accelerated depreciation was historically introduced as one method by which governments aimed to stimulate investment by industry. ${ }^{40}$ The aim was to provide a financial ( $\operatorname{tax}$ ) incentive for industry to invest in assets in which they would not otherwise. Accelerated depreciation, as suggested by its name, is a deviation from the general depreciation rules and thus, a deviation from the 'general system of taxation' - which includes general depreciation. Accelerated depreciation deems the period over which the asset is written-off to be shorter than the useful life of the asset. A simple example: plant and machinery, having a useful life normally determined to be fifteen years, is allowed full cost-recovery of the asset in year one. For the purposes of depreciation, the useful life of the asset is reduced from fifteen years to one year and the accelerated depreciation deduction is equal to $100 \%$ of the cost of the asset in year one. Essentially, such an accelerated depreciation scheme converts a capital cost into a current expense. The incentive amount is the financial advantage derived from the difference between the deduction allowed under the general depreciation rule and the deduction allowed under the accelerated depreciation rule. ${ }^{41}$

A brief overview of the accelerated depreciation provisions in place in the case study countries is now appropriate prior to their examination against the SCM Agreement provisions. Also, in order to demonstrate that the special depreciation rules are tax expenditures in the form of tax incentives, the general rules of depreciation will also

39 In public finance the ability to pay principle practically has unanimous support as the equity benchmark for corporate income tax design. See for instance Thorndike and Ventry 2002. See also, Andrews 1972, p. 309, and Brooks 2004, p. 255. Margalioth 2007, p. 509. For example, in the US, Accelerated depreciation was introduced in 1954 with the intention of stimulating investment. discussed in detail in sections 8.5.3 Article 1.1(a)(1)(i); Step 3 of 4 - Positive Again!, p. 169 and section 8.5.4 Article 1.1(a)(1)(i); Step 4 of 4 - Negative After All?, p. 171. 
be provided. The general rule forms part of the general system of taxation and therefore is not tax expenditure. ${ }^{42}$

\subsubsection{The United Kingdom}

In the UK, depreciation is provided for in the Capital Allowances Act 2001. The general depreciation rule in the UK for plant and machinery provides an annual write-down of $25 \%$ of qualifying assets. ${ }^{43}$ This translates into a depreciation period of four years.

Accelerated depreciation (enhanced capital allowance) is provided for certain assets, including energy-saving plant and machinery. Assets meeting the Energy Technology Criteria List (ETCL) and being listed on the Energy Technology Product List (ETPL) qualify for accelerated depreciation. ${ }^{44}$ In addition, assets meeting the Energy Technology Criteria List (ETCL), not listed on the Energy Technology Product List (ETPL), but instead having been positively certified also qualify for accelerated depreciation. The accelerated depreciation provision applicable to these assets allows a $100 \%$ write-off in year one.

In this example, the fact that the accelerated deprecation provision derogates from the general system of taxation is clear. The tax expenditure amount is equal to the difference of deduction of $100 \%$ in one year compared to $25 \%$ over four years.

It is important to note, however, that the application of such accelerated depreciation provisions with respect to the generation of renewable energy is conditional upon the inclusion of renewable electricity technology in the Ministerial List of qualifying assets. The Energy Technology Product List does not include any specific assets relevant for the production of electricity. However, combined heat and power $(\mathrm{CHP})^{45}$ is included in the Energy Technology Criteria List (ETCL) and thus CHP equipment, subject to energy-efficiency certification, will be eligible for accelerated depreciation. This is to ensure that the tax support only goes to 'good quality' CHP.46 For this reason, no specific CHP equipment is listed and rather the certification will take the latest developments in technology into account in determining the energy efficiency of the CHP-related equipment.

42 See for example Luja 2003, p. 8. Luja provides a clarification on the meaning of tax expenditure.

43 Long-life assets 6\%. Capital Allowances Act 2001, Chapter 5, s 56.

44 Ministerial list.

45 CHP (combined heat and power) refers to the production electricity and heat simultaneously. In conventional electricity generation plants heat is created as a byproduct. With CHP, this heat is captured for industrial or domestic heating. Similarly, a CHP installation used to heat a greenhouse produces excess electricity which can be sold on to the grid. CHP installations which use renewable inputs such as wood fire, waste wood, oil from animal or plant products, gas from landfills or gas from algae ponds are more energy efficient than conventional CHP from oil, gas and coal and thus included in the renewable energy technologies category. 
In examining the UK accelerated depreciation scheme, related to renewable energy generation, only certified CHP equipment is covered.

\subsubsection{Belgium}

In Belgium, the general system of taxation provides for linear depreciation and in some cases, in agreement with the tax authority, double declining balance depreciation where this method better reflects the true depreciation of the asset over its useful life. ${ }^{47}$ Double declining balance depreciation allows a maximum deduction of double the amount allowed under the linear method. The amount of the deduction under the double declining balance method is limited to $40 \%$ of the acquisition cost of the asset and is only allowed until such a time as the depreciation deduction is equal to that allowed under the straight-line method, after which the straight-line method must be employed. The rates of depreciation are not set by legislation but, rather, an accepted practice has been developed over time by companies in agreement with the tax authorities. Tax practitioners, relying on this developed practice, then provide guidelines for companies on what rates of depreciation are accepted by the tax authorities. ${ }^{48}$ For example, up to $20 \%$ depreciation is allowed for machinery and equipment.

Although the Belgian Tax Code neither provides general depreciation rates, nor accelerated depreciation rates, the accepted practice of the tax authorities has developed a reasonable expectation of companies to have accelerated depreciation applied to energy saving assets. ${ }^{49}$ The rate accepted in the past has been $33.3 \%$ over three years. Compared to the generally accepted practice related to ordinary (not energy saving) equipment, this is clearly a derogation. The useful life is reduced from five to three years.

The Belgian case study will be interesting in particular in the WTO-consistency examination when it comes to evaluating the existence of de facto specific subsidies rather than de jure specific subsidies since there is no legislation establishing neither the general rule nor the derogation there from.

\subsubsection{Netherlands}

In the Netherlands the normal depreciation is represented by the 'useful life' and historical value of the asset and the choice of method is flexible. It should however

47 Article 64 WIB. This method allows for greater reductions in value of the asset in the first years of holding the asset.

48 <http://www.deloitte.com/assets/Dcom-Belgium/Local\%20Assets/Documents/ FINAL_BelgiumTaxBusGuide_lowres.pdf >; last visited 24 November 2009. See for instance this explanation of the depreciation treatment of assets in Belgium in the Belgian edition of an online series by Deloitte, Touche, Tohmatsu providing information on tax regimes in various countries, 'International Tax and Business Guide, Belgium', March 2008, p. 21.

49 This practice is neither documented in any legislation nor in publically available guidelines from the tax authorities. 
represent 'good business practice'. Since 2007, the minimum depreciation period for normal business assets is five years $(20 \%) .{ }^{50}$

A special depreciation regime exists in the Netherlands for environmental assets. The depreciation method and useful life of assets can be determined by the investor. ${ }^{51}$ This freedom extends to also allowing a $100 \%$ write-off in year one. However, the accelerated depreciation provision applies only to assets listed on the ministerial Environment List. ${ }^{52}$ As fixed capital assets never have a useful life of one year (if so it would be a current expense rather than a capital asset), it is clear that the VAMIL scheme is a deviation from the general system of taxation which requires a minimum write-off period of at least five years. ${ }^{53}$

\subsubsection{Canada}

In Canada, depreciation rates are set out in detail in the Schedules of the Income Tax Regulations. The normal depreciation rate for commercial electrical generating equipment is in Class 17 and is eight per cent on a declining balance basis with only half of the rate allowed in year one. ${ }^{54}$

Accelerated depreciation is provided for renewable electricity generating in Schedule II, Class 43.1 and 43.2 of the Income Tax Regulations. A 30\% or 50\% (depending on the assets in question) write-off on a declining balance basis is available for assets listed here. These assets refer to electricity generating assets used in various renewable energy technologies. ${ }^{55}$

\subsubsection{Ireland}

In Ireland the normal depreciation regime for machinery and equipment allows a write-off of $12.5 \%$ per annum over eight years. A new accelerated depreciation provision was introduced in the Finance Act 2008 for a provisional period of three

WIB 3.30(2); applies to assets other than goodwill and real estate.

WIB 3.31. This means that the investor can apply accelerated depreciation or delayed depreciation at his or her discretion. In this research, the focus is on accelerated depreciation.

<http://download.belastingdienst.nl/belastingdienst/docs/milieulijst_2008_ml0281z 81fd.pdf $>$; last visited 24 November 2009.

Naturally, if an asset has a useful life span of more than one year and less than five it could be written off over that period rather than applying a five-year write off.

Income Tax Regulations, Schedule II, Class 1 4\% was increase to $8 \%$ by the 2001 Budget. $\quad<$ http://www.parl.gc.ca/information/library/PRBpubs/prb0606-e.htm\# appendixa>; last visited 24 November 2009.

Class 33 provides for $10 \%$ depreciation where the electricity is generated with petroleum, natural gas or related hydrocarbons, coal, coal gas, coke, lignite or peat but the consumption of the fossil fuels in relation to the electricity generation creates a maximum of 7,000 British Thermal Units per kilowatt-hour of electrical energy produced. This is also a form of accelerated depreciation with an environmental goal less carbon emission from fossil fuel consumption.

Heat recovery, combined heat and power, solar, hydro, thermal waste, fuel cell, photovoltaic, wind turbine. 
years. ${ }^{56}$ This provision allows $100 \%$ capital write-off in year one. Like in the Netherlands, this converts the capital cost into a current expenditure. Also, like in the Netherlands, the eligible assets are determined by the Department of Communications Energy and Natural Resources and maintained by Sustainable Energy Ireland. ${ }^{57}$ Although the specific product-list has not yet been fully established for the four new categories of technology, including 'heat and electricity provision', the broad category of electricity generation technology is indeed known. ${ }^{58}$ Cogeneration, wind turbines, stationary fuel cell power systems, and photovoltaic systems equipment may be subject to $100 \%$ accelerated depreciation rate.

\subsubsection{New Zealand}

New Zealand does not have an accelerated depreciation provision for energy saving technology.

\subsection{ACCELERATED DEPRECIATION INCENTIVE - A SUBSIDY?}

The first step in examining the WTO-consistency of the above accelerated depreciation provisions is to determine whether they are subsidies within the meaning of the SCM Agreement and in particular within the meaning of Article 1.1(a)(1)(ii) SCM Agreement - a financial contribution consisting of revenue foregone otherwise due, by the government and conferring a benefit. The Panel Report and Appellate Body Report in the US - FSC dispute will be considered since this is the only WTO dispute which examined this type of financial contribution. The questions to be answered are:

- Is there a financial contribution; provided by the government; which confers a benefit?

\subsubsection{Article 1.1(a)(1)(ii); Step 1 of 4 - Positive}

As argued in the previous chapter, where tax subsidies are at issue, the three elements of the subsidy test (financial contribution; provided by the government; which confers a benefit), from a practical point of view, are answered concurrently as tax

$56 \quad$ Finance (No. 2) Act 2008, Section 37, amending Taxes Consolidation Act 1997 by extending Section 285A with subsection 8A. The Finance Act 2008 introduced the accelerated depreciation provision and the Finance (No. 2) Act amended the categories of technology to which the provision applies and included 'Heating and Electricity Provision' which specifically includes electricity generation equipment.

57 Taxes Consolidation Act 1997 (Accelerated Capital Allowances for Energy Efficient Equipment) Order 2009, S.I. No. 76 of 2009.

58 The only heating and electricity products listed at the time of writing were Eoltec SAS wind turbines, three photovoltaic products from REC Solar AS and three photovoltaic products from Schott Solar EG. As this is not the final completed list no great conclusions can yet be drawn from the limited list, however, were the list to remain this limited, there would be no doubt that the tax incentive would be de facto specific to a few enterprises (albeit indirectly), namely Eoltec SAS, REC Solar AS and Schott Solar EG. However, since these are not national enterprises there is no question of domestic protectionism. 
subsidies can only be provided by the government and the resulting reduction in tax liability automatically confers a benefit since it increases the after-tax profit of the company receiving the tax subsidy. Thus, the main question to be answered is whether the accelerated depreciation provision creates a situation where:

- government revenue, which is otherwise due, is foregone or not collected?

In order to answer this question the following question may serve as guidance:

- But for the accelerated depreciation scheme, would the electricity generation company be subject to a higher tax liability and therefore would more government revenue be otherwise due?

Although the Panel in US - FSC did not require panels to identify the general tax regime and then to identify exceptions from the general rule, instead it required a comparison between domestic 'legitimately comparable income' to determine whether taxes were originally due to the government. ${ }^{59}$ A comparison is necessary between 'revenues due under the contested measure and those that would be due in some other situation and that the basis of the comparison must be the tax rules applied by the Member in question'. ${ }^{60}$

Whether one calls the benchmark for comparison the 'tax rules applied by the member in question' or the member's general tax regime, the result is the same. In this case, the revenue due under the contested measure is the revenue due while applying accelerated depreciation (A). This should be compared to the revenue due in 'some other situation' being the general tax rules in the country applying the contested measure, namely the general depreciation rule $(\mathrm{G})$. After determining that taxes were originally due to the government, by reference to the general system of taxation, it then must be determined whether there was non-collection of these taxes by virtue of government action (or inaction). Where the tax due under the general rule is greater than the tax due under the special rule (accelerated depreciation), this initially appears to be the case. But for the accelerated depreciation provision, more revenue would have been collected (during the years the accelerated depreciation provisions apply).

A numerical comparison for all the case study countries is provided below and represents what I would like to term the 'Step 1 Calculation'.

UK(G) Income (100) - deductions (including depreciation: asset (10) $\times 25 \%$ ) = taxable income $\mathrm{x}$ tax rate $(20 \%)=$ tax due $100-2.5=97.5 \times 20 \%=19.5$ (available for 4 years)

UK(A) Income (100) - deductions (including depreciation: asset (10) $\times 100 \%$ ) $=$ taxable income $\mathrm{x}$ tax rate $(20 \%)=$ tax due.

$100-10=90 \times 20 \%=18$ (available in one year)

UK(G) $19.5>\mathrm{UK}(\mathrm{A}) 18$

59 Appellate Body Report, US - FSC (Article 21.5 - EC), paras. 8.17-8.19.

60 Panel Report, US - FSC, para. 8.17. 
Value of revenue foregone: 1.5 (for 1 year)

BE(G) Income (100) - deductions (including depreciation: asset (10) $\times 20 \%$ ) $=$ taxable income $\mathrm{x}$ tax rate $(20 \%)=$ tax due

$100-2=98 \times 20 \%=19.6$ (available for 5 years)

BE(A) Income (100) - deductions (including depreciation: asset (10) $\times 33.3 \%$ ) $=$ taxable income $\mathrm{x}$ tax rate $(20 \%)=$ tax due.

$100-3.33=96.66 \times 20 \%=19.33$ (available for 3 years)

$\mathrm{BE}(\mathrm{G}) 19.6>\mathrm{BE}(\mathrm{A}) 19.33$

Value of revenue foregone 0.27 (for 3 years) $\{$ total $0.27 \times 3=.81\}$

$\mathbf{N L}(\mathbf{G})$ Income (100) - deductions (including depreciation: asset (10) $\times 20 \%$ ) $=$ taxable income $\mathrm{x}$ tax rate $(20 \%)=$ tax due $100-2=98 \times 20 \%=19.6$ (available for 5 years)

NL(A) Income (100) - deductions (including depreciation: asset (10) x 100\%) = taxable income $\mathrm{x}$ tax rate $(20 \%)=$ tax due.

$100-10=90 \times 20 \%=18$ (available for 1 year)

\section{NL(G) $19.6>\mathrm{NL}(\mathrm{A}) 18$}

Value of revenue foregone: 1.6 (for 1 year)

CA(G) Income (100) - deductions (including depreciation: asset (10) x 8\%) = taxable income $\mathrm{x}$ tax rate $(20 \%)=$ tax due $100-0.8=99.2 \times 20 \%=19.84$ (available for 12.5 years)

CA(A) Income (100) - deductions (including depreciation: asset (10) $\times 30 \%$ ) = taxable income $\mathrm{x}$ tax rate $(20 \%)=$ tax due. $100-3=97 \times 20 \%=19.4$ (available for 4 years)

\section{CA(G) $19.84>$ CA(A) 19.4}

Value of revenue foregone: 0.44 (for 4 years) \{total $0.44 \times 4=1.76$ \}

IE(G) Income (100) - deductions (including depreciation: asset (10) $\times 12.5 \%$ ) = taxable income $\mathrm{x}$ tax rate $(20 \%)=$ tax due $100-1.25=98.75 \times 20 \%=19.75$ (available for 8 years)

IE(A) Income (100) - deductions (including depreciation: asset (10) $\times 100 \%$ ) $=$ taxable income $\mathrm{x}$ tax rate $(20 \%)=$ tax due. $100-10=90 \times 20 \%=18$ (available for 1 year)

IE(G) $19.75>$ IE(A) 18

Value of revenue foregone: 1.75 (for 1 year) 
In all the case studies it is clear to see that a general rule of taxation is easily identifiable against which the special rule can be compared. It is also clear to establish that in all cases, in this 'Step 1 Calculation', the tax due is reduced by virtue of the accelerated depreciation measure and thus confers a benefit in that year (those years).

Although in the US - FSC case, the Panel considered the 'non-collection' of taxes, accelerated depreciation does not directly provide for the 'non-collection' of taxes. Rather, accelerated depreciation provides for a greater reduction from the normal tax liability - compared to the reduction provided for by the general system of taxes. This, in essence, results in the same - 'non-collection' of the difference between the reductions, as illustrated above.

This is easier to examine using the 'but for' test used by the Panel in FSC. Despite the reservation attached to the 'but for' test by the Appellate Body, since it may 'not work in other cases', ${ }^{61}$ it did agree with its use in the FSC dispute since it was 'not difficult to establish in what way the foreign-source income of an FSC would be taxed 'but for' the contested measure'. ${ }^{2}$ Where an alternative measure exists in the tax system of the member in question, the 'but for' test is appropriate. Since with respect to the above accelerated depreciation provisions, there is clearly an alternative $\operatorname{tax}$ measure available in absence of the accelerated depreciation (the general depreciation rate) the 'but for' test is an adequate and sound legal standard for comparison. ${ }^{63}$

The 'but for' test informs the 'otherwise due' component of Article 1.1(a)(1)(ii) SCM Agreement. Were it not for the accelerated depreciation provision (more) revenue would accrue to the government. This is clearly the case with straightforward measures such as accelerated depreciation. But for the accelerated depreciation provision, the general depreciation provision would be applied and would result in a higher tax liability.

As explained above, the Appellate Body confirmed the Panel's application of a 'but for' test although it cautioned against it being the ultimate test in detecting all circumstances of 'revenue otherwise due'. The 'but for' test may only be useful for straightforward measures. More complicated tax measures may not be adequately examinable with this test and a more sophisticated test would then be necessary. Despite this caution, it may be accepted that accelerated depreciation measures are indeed straightforward and can be adequately examined using the 'but for' test. Accelerated depreciation is not a measure which lacks a comparable situation in the general system of taxation or more specifically the domestic tax treatment of 'legitimately comparable income' is easily established.

Using this year-by-year method of calculation, the accelerated depreciation is a subsidy according to Article 1.1(a)(1)(ii) SCM Agreement. But for the accelerated depreciation provision (a government action), (more) revenue would accrue to the government and thus (more) revenue would be otherwise due.

Appellate Body Report, US - FSC (Article 21.5 - EC), paras. 91-92.

Appellate Body Report, US - FSC, para. 91.

Ibid. 
In all the case studies examined above, increased write-off percentages and decreased writeoff periods result in a lower tax liability than would result from the general depreciation rates and periods. Revenue otherwise due is foregone (by the government) and thus by being foregone confers a benefit on the tax-payer. These accelerated depreciation provisions are thus subsidies according to Article 1.1(a)(1)(ii) SCM Agreement.

\subsubsection{Article 1.1(a)(1)(ii); Step 2 of 4 - Negative}

Although when examining the tax effect of the accelerated depreciation provision for one year only, the result explained above is clear, (there is a reduced tax liability in the years the accelerated depreciation provision applies), the measure should not be examined in isolation for those years only. As put forward by Benitah, the amount of the subsidy is the difference between the tax due under the accelerated depreciation scheme and the tax due under the normal depreciation regime during the investigation period. ${ }^{64}$ Although this suggests that a period longer than one year should be used to calculate the potential benefit, I submit that this calculation does not take into account the tax effects of the period (possibly after the investigation period) which relates to the depreciation until the asset's useful life has expired. This, in my opinion, would also lead to an artificial calculation of the alleged benefit.

In the general depreciation regime, the tax effects of depreciation span the usual lifetime of the asset in question. Thus, a comparison should at least take this full period into account. I call this the 'Step 2 Calculation'. The calculation below shows the total tax effect (based on the tax liability established in the case calculations above).

$64 \quad$ Benitah 2001, p. 397. 


\begin{tabular}{|l|c|c|c|c|c|c|c|c|c|c|}
\hline & \multicolumn{2}{|c|}{ UK } & \multicolumn{2}{c|}{ BE } & \multicolumn{2}{c|}{ NL } & \multicolumn{3}{c|}{ CA } & \multicolumn{2}{c|}{ IE } \\
\hline & $G$ & $A$ & $G$ & $A$ & $G$ & $A$ & $G$ & $A$ & $G$ & $A$ \\
\hline Year 1 & 19.5 & 18 & 19.6 & 19.33 & 19.6 & 18 & 19.84 & 19.4 & 19.75 & 18 \\
\hline Year 2 & 19.5 & 20 & 19.6 & 19.33 & 19.6 & 20 & 19.84 & 19.4 & 19.75 & 20 \\
\hline Year 3 & 19.5 & 20 & 19.6 & 19.33 & 19.6 & 20 & 19.84 & 19.4 & 19.75 & 20 \\
\hline Year 4 & 19.5 & 20 & 19.6 & 20 & 19.6 & 20 & 19.84 & 19.4 & 19.75 & 20 \\
\hline Year 5 & & & 19.6 & 20 & 19.6 & 20 & 19.84 & 20 & 19.75 & 20 \\
\hline Year 6 & & & & & & & 19.84 & 20 & 19.75 & 20 \\
\hline Year 7 & & & & & & & 19.84 & 20 & 19.75 & 20 \\
\hline Year 8 & & & & & & & 19.84 & 20 & 19.75 & 20 \\
\hline Year 9 & & & & & & & 19.84 & 20 & & \\
\hline Year 10 & & & & & & & 19.84 & 20 & & \\
\hline Year 11 & & & & & & & 19.84 & 20 & & \\
\hline Year 12 & & & & & & & 19.84 & 20 & & \\
\hline Year 13(.5) & & & & & & & 9.92 & 10 & & \\
\hline & $\mathbf{7 8}$ & $\mathbf{7 8}$ & $\mathbf{9 8}$ & $\mathbf{9 8}$ & $\mathbf{9 8}$ & $\mathbf{9 8}$ & $\mathbf{2 4 8}$ & $\mathbf{2 4 8}$ & $\mathbf{1 5 8}$ & $\mathbf{1 5 8}$ \\
\hline
\end{tabular}

As illustrated by the table above, and assuming that all other things are equal, when the general depreciation scheme is compared to the accelerated depreciation scheme over the time-span reflecting the useful life of the asset, there is no reduction in tax liability. Ceteris paribus, there is thus no revenue foregone. The increase in tax due (or rather the decrease in deprecation deductions) in the subsequent years following the application of the accelerated depreciation provision eliminates the benefit received in the first year(s). This calculation method can lead to only one conclusion, none of the accelerated depreciation provisions fall within the definition of a subsidy under Article 1.1(a)(1)(ii) since there is no revenue which was due but is foregone from the government purse. Although in the year the accelerated depreciation provision is applied there is indeed a 'non-collection' of taxes, as also considered by the Panel in the US - FSC case, in the form of a greater reduction from the normal tax liability compared to the reduction provided for by the general system of taxes - this noncollection of taxes is only temporary and the tax revenue temporarily foregone is later recouped in the following years.

\subsubsection{Article 1.1(a)(1)(i); Step 3 of 4 - Positive Again!}

The conclusion from the section above that, in fact, over time there is no revenue foregone and thus the measure does not fall within the definition of subsidy under Article 1.1(a)(1)(ii) does not preclude this measure from indeed being a subsidy according to the SCM Agreement since accelerated depreciation provides a temporal tax benefit. The net present value of the tax liability over time differs. The net present value of the ensuing tax liability (over the life span of the asset) is lower under the 
application of the accelerated depreciation provision than under the general depreciation provision. The difference in the net present value under the accelerated versus general depreciation scheme constitutes a benefit.

In this examination, a financial contribution in the form of foregone revenue otherwise due is not at issue. Therefore, the examination must now consider whether the measure could be deemed a subsidy under one of the other forms of subsidy listed in Article 1.1(a)(1). Also, in contrast to the foregoing examination, for the other forms of subsidy it is essential to mention that since no foregone revenue otherwise due is at issue, there can be no assumption of benefit and the conferral of a benefit must be explicitly examined.

First an explanation of the measure will be given. Taking the UK as an example, the difference in the net present value of the tax liability in the general depreciation scheme and the accelerated depreciation schemes will be illustrated below. The discount rate (interest rate) taken is $4 \%$ reflecting the interest of no-risk investments such as government bonds.

\section{UK}

G A

$\begin{array}{lll}\text { Year 1 } & 19.5 & 18 \\ \text { Year 2 } & 19.5 & 20 \\ \text { Year 3 } & 19.5 & 20 \\ \text { Year 4 } & 19.5 & 20\end{array}$

Since the net present value of the total tax liability over the lifespan of the asset subject to the depreciation scheme is lower in the case of the accelerated depreciation provision than in the case of the general depreciation scheme, there is indeed a potential subsidy in question. This is the 'Step 3 Calculation'.

The total tax effect of accelerated depreciation versus normal depreciation is a tax deferral in the first year(s). However, this tax deferral results in another potential benefit, in addition to the straight-forward year-by-year benefit of an initial reduction in tax liability. Although the tax reduction will be recouped by the tax administration 
in later years, the advantage of not having to pay the tax now could be classified as a subsidy as the funds do not have to be sourced in that first year to finance the (higher) tax debt.

This deferral results in a subsidy in the form of accrued savings interest, where that tax liability would have been financed by equity or where that liability would have been financed by debt, the benefit is in the form of saved loan interest which would have been charged in order to finance the tax debt immediately. ${ }^{65}$

The appropriate classification of this potential subsidy, therefore, would be a government loan in the form of a tax deferral. To determine whether this tax deferral is indeed a subsidy according to Article 1 SCM Agreement it should be examined within the definition of Article 1.1(a)(1)(i): 'a government practice involves a direct transfer of funds (e.g. grants, loans and equity infusion), potential direct transfers of funds or liabilities (e.g. loan guarantees)'.66 Also, it should be illustrated (as above) that a benefit is conferred (for example a lower net present value of the tax liability when the accelerated depreciation provision is applied compared to the general depreciation scheme).

In this situation, where there is a tax deferral by virtue of the accelerated depreciation scheme, the tax authority is the creditor. In a normal commercial setting, this deferral would be subject to an interest charge. In the case of tax deferral as a result of accelerated depreciation, no interest is charged. As long as this government loan is not accompanied by interest payments, a benefit may be shown to exist. Part $\mathrm{V}$ of the SCM Agreement provides guidance on the valuation of the benefit provided by virtue of a government loan. Where a loan is provided at less cost to a firm than would be available to that firm under normal commercial conditions (for example at a lower interest rate or without interest) then the difference between these two amounts is the amount of benefit provided by the subsidy. ${ }^{67}$

It could thus be argued that this tax deferral constitutes a direct transfer of funds in the form of a government loan consistent with the definition of subsidy in Article 1.1(a)(1)(i) of the SCM Agreement which confers a benefit in accordance with Article 1.1(b).

\subsubsection{Article 1.1(a)(1)(i); Step 4 of 4 - Negative After All?}

Unlike in other WTO disputes concerning measures within this definition of subsidy where the respondents did not contest that the measure at issue constituted a subsidy

65 See Luja 2003, p. 32-34. With respect to government loans constituting subsidies, the Panel in Korea - Commercial Vessels also clarified that interest reductions and interest deferral also constituted a financial contribution within the meaning of Article 1 SCM Agreement. Panel Report, Korea - Commercial Vessels, para. 7.31. See also Van den Bossche 2008, p. 563.

66 Article 1.1(a)(1)(i) SCM Agreement.

$67 \quad$ Article 14(b) SCM Agreement. 
under Article 1.1(a)(1)(i), ${ }^{68}$ in this case concerning accelerated depreciation, there is sufficient evidence that there are parties that would indeed contest this classification.

There are objections to using the net present value in depreciation calculations, rather than the straightforward year-by-year method set out above. The objections are based on the following: (1) the net present value is speculative and depends on the same tax conditions being in place for the whole depreciation period and considering annual tax changes, this is not certain; (2) there is no guarantee that the reduced tax liability provided by the accelerated depreciation will indeed be recouped in the following years as the firm may no longer be active, or the asset in question may have been disposed of or replaced. ${ }^{69}$

In particular, the US approach of relying on the year-by-year method would indicate that the US would not readily accept that the net present value differences lead to the provision of a government loan in the form of a tax deferral. ${ }^{70}$ Furthermore, as Luja explains, taking the net value approach for accelerated depreciation runs into problems, highlighted by the calculation of countervailing duties in Article 19.2 of the SCM Agreement. ${ }^{71}$ The 'face value' of the subsidy would not include the temporal benefit provided by the difference of net present value of the tax liability under the accelerated depreciation scheme rather than the general depreciation scheme. Since this 'face value' should represent the 'full amount of the subsidy or less' as required by Article 19.2, this would not include the interest.

I submit that following the method proposed and followed by the US (the Step 1 Calculation) and argued by the US commentators, ${ }^{72}$ namely excluding the interest benefit completely, excludes accelerated depreciation provisions from possible inconsistency with the SCM Agreement. I am of the opinion that this method results in potential subsidies falling outside the scope of the SCM Agreement only due to the choice of calculation method. If a temporal benefit is not recognised as being a countervailable benefit and rather the year-by-year calculation method of benefit is preferred this leads to a self-cancelling situation.

If the only accepted method of calculation is the year-by-year method, and the normal situation is taken as the point of departure rather than the exceptions (where the firms are no longer in operation or the assets have been replaced eliminating the possibility for the reduced tax liability to be recouped in later years), then the examination is limited to Article 1.1(a)(1)(ii) to the exclusion of Article 1.1(a)(1)(i). Being limited to revenue foregone which was otherwise due, in a situation where the

68 Federal Register Vol. 63, No. 227, 25 November 1998, p. 65375-65376 available through search at: <http://www.gpoaccess.gov/fr/retrieve.html>; last visited 27 April 2010.

70 Ibid

$71 \quad$ Luja 2003, p. 176.

72 Federal Register Vol. 63, No.227, 25 November 1998, p. 65375-65376 available through search at: <http://www.gpoaccess.gov/fr/retrieve.html>; last visited 27 April 2010. 
lost tax revenue is anyway recouped in later years, the revenue is obviously no longer foregone and thus it would be a self-cancelling examination of the potential subsidy.

Although accelerated depreciation has never been examined by WTO panels or the Appellate Body as a measure falling within Article 1.1(a)(1)(i), in 1999 the Informal Group of Experts on Calculation Issues Related to Annex IV of the Agreement on Subsidies and Countervailing Measures examined accelerated depreciation to determine a suitable calculation of the benefit provided, albeit without coming to consensus on its treatment. ${ }^{73}$ The group discussed three calculation (classification) options. ${ }^{74}$

Of the three approaches debated by the group, the first takes a year-by-year examination, such as the first step taken above, ${ }^{75}$ where the difference between the normal and accelerated depreciation represents revenue foregone. However, the group rather referred to this difference as an annual 'grant' rather than 'revenue foregone'. Also, this classification of the benefit in terms of a grant does not address the fact that there will be an increase in tax liability in subsequent years following the application of the accelerated depreciation provision. It is therefore also not a comprehensive solution to testing the full extent of the nature of the subsidy in question or an adequate reflection of the tax effect of a measure which spans over several years.

The second method is illustrated by Figure $\mathrm{X}$ above, where the net present value of the tax liability is calculated (Step 3 Calculation). Since the cost to the government is considered to be this difference in the net present value, this could indeed be construed as revenue due but forgone. The subsidy exists since the net present value of the tax due over the whole depreciation period is less than the net present value of the tax otherwise due under the normal depreciation scheme.

The third method approaches the difference in net present value from a different perspective. It was discussed that the difference in tax liability over time could be deemed to be a tax deferral and, thus, a form of government loan, not subject to interest charges. Thus the group considered that accelerated depreciation also has an element of a deferred government loan, and the benefit provided by that subsidy would be the amount of interest that the government 'should have' charged for that loan.

However plausible any of the three methods of calculation, and considering the SCM Agreement implications of applying one method or the other (for example - the yearby-year method possibly falling within the subsidy definition of Article 1.1(a)(1)(ii) and the net present value method falling within Article 1.1(a)(1)(i)), the group could not come to consensus, leaving the matter still open to debate until such time as WTO panels and the Appellate Body would deem one method a more appropriate a representation of the existence of a subsidy (or not) over another.

\footnotetext{
73 Luja 2003, p. 174; WTO documents G/SCM/W/415/Rev.2/Supp.1, circulated 1 October 1999, paras. 15-16 and G/SCM/W/415/Rev.2, circulated 15 May 1998, paras. 52 and $96-98$

74 Ibid., p. 175.

75 See section 8.5.1, Article 1.1(a)(1)(ii); Step 1 of 4 - Positive, p. 164.
} 
From the above, it should at least remain clear that with the several possibilities of interpreting the financial implications of accelerated depreciation, these measures may indeed be deemed to be subsidies under Article 1.1(a)(1)(ii) of the SCM Agreement. ${ }^{76}$ The determination of what form the subsidy takes becomes more important and relevant with respect to the determination of the benefit the subsidy confers.

Thus, also considering the lack of consensus by the group, the possibility remains that the difference in net value of the tax liability under the accelerated depreciation provision compared to the general depreciation scheme, would not be deemed to be government loan in the form of a tax deferral and also not conferring a benefit as such since any such determination would be only speculative and the actual affects (costs and benefits) of the depreciation scheme could only be determined after the depreciation period is over. ${ }^{77}$ Although the possibility remains, I submit that limiting consideration of accelerated depreciation to a year-by year calculation (Step 1 Calculation) is addressing the measure in a blinkered fashion. The true financial effects of the measure should be considered for the determination of a subsidy conferring a benefit, which, in this case, includes the time value of the deferred tax liability. Thus, on a case-by-case basis, the year-by-year calculation of the benefit should be undertaken (to cover situations where the revenue foregone is not fully recouped) in addition to a calculation of the temporal benefit, thereby engaging with both Article 1.1(a)(1)(ii) and Article 1.1(a)(1)(i).

\subsection{ACCELERATEd Depreciation InCENTIVE - A SpeCific SubSidy?}

Having determined that the accelerated depreciation provisions in the case studies could indeed be deemed to be subsidies according to Article 1.1(a)(1)(ii) of the SCM Agreement, they should also be specific within the meaning of Article 2 SCM Agreement in order to be examined further for compliance with the SCM Agreement provisions.

Whether or not the accelerated depreciation measure is a specific subsidy or not depends on the de jure and de facto reach of the measures. Essentially, it is the effect of the measure on the competitive relationship between enterprises, industries and sectors that determines whether the measure is applied in a specific or general manner. It will of course be examined whether any of the measures in the case study countries are de jure or de facto specific to the electricity generation sector and furthermore, whether the energy intensive industry could be deemed to be a specific group of enterprises and thus whether measures specific to that industry would be specific within the meaning of Article 2 SCM Agreement.

The question is whether the accelerated depreciation provision is de jure or de facto specific to 'an enterprise or industry or group of enterprises or industries'. In order to answer this question the provisions of Article 2 SCM Agreement, should be addressed

76 As explained above, the accelerated depreciation would only be deemed to be a subsidy under Article 1.1(a)(1)(ii) to the extent that the 'Step 1 Calculation' would be used in isolation since it is only by this method that the recouping of the revenue foregone in the years following the application of the accelerated depreciation scheme would be neglected.

$77 \quad$ Luja 2003, p. 175. 
in order. First Article 2.1(a) states that a subsidy will be specific if access to the subsidy is explicitly limited to certain enterprises. This is also the case where the subsidy is limited to certain enterprises located in a particular geographic region. ${ }^{78}$ Thus, Article 2.1(a) relates to a situation in which a subsidy exists. Conversely, Article 2.1(b) addresses a situation in which a subsidy does not exist. Thus having answered 2.1(a) in the negative, Article 2.1(b) should be answered in the positive. Article 2.1(b) states that where for eligibility for a subsidy is determined by objective criteria or conditions, which are economic in nature, horizontal in application and applied strictly and automatically, and are 'clearly spelled out in law', that subsidy will not be specific. Article 2.1(c) addresses de facto specificity and will be examined later.

To find out whether the accelerated depreciation provisions are de jure specific, the conditions for eligibility for the tax subsidy should be examined. However, prior to doing so it is pertinent to address the question whether energy intensive industry would be deemed to be a specific industry in the first place. This discussion will serve to answer the specificity question of the case studies more readily since the incentives are, in general, provided to the energy intensive industry rather than to electricity generators.

Whether energy intensive industry is a specific industry has yet to be examined by WTO panels and the Appellate Body. Therefore, until such time as this happens, reference to other disputes in which panels and the Appellate Body have addressed the definition of a specific industry will serve to shed light on this question.

According to the Panel in US - Upland Cotton, the concept of 'industry' may 'modulate according to the particular circumstances in a given case'. Apparently this modulating concept of industry may provide a range of results from a broad interpretation of specificity to a narrow one and this discretion of the Panel is not susceptible to rigid quantitative definition'. ${ }^{79}$ Based on this starting point in which panels and the Appellate Body have the discretion to evaluate on a case-by-case basis, here I can only speculate as to the outcome of these tentative issues.

Would a measure available to all energy intensive industries be deemed to be provided to a specific group of industries within the meaning of Article 2 SCM Agreement? It has to be submitted, first and foremost, that specificity has to be seen in relation to the products produced by the industries in question, although the products produced do not necessarily have to be the same products. In US - Softwood Lumber IV, the Panel examined the definition of industry in Article 2. The Panel reminded that there is no definition of industry in the SCM Agreement, nor a set requirement that a group of enterprises comprising an industry should produce 'certain similar products'. ${ }^{80}$ The Panel considered a specific industry to be broader than enterprises producing the same (or similar) goods or end products. ${ }^{81}$ It seems the Panel was more comfortable to delineate what does not define an industry rather than providing a clear-cut definition of industry. However, the Panel did state that 'specificity under Article $2 \mathrm{SCM}$ is to be determined at the enterprise or industry

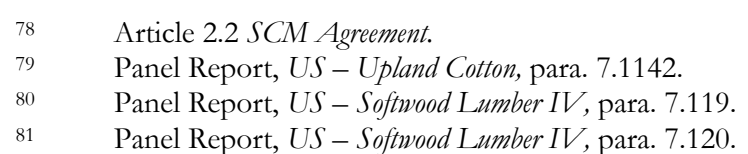


level, not at the product level'.82 It is useful to examine US - Softwood Lumber IV in more detail.

In US - Softwood Lumber IV, the industry in question was the wood-product manufacturing industry. This included manufacturers of a broad range of (related) products, for example pulp, paper, lumber, plywood, chips, sawdust and remanufactured wood products such as furring, strips, crating, and industrial cut stock. The common denominator of these products is the fact that they are all produced from the input - softwood lumber. However, the Panel rejected Canada's argument for a product-based specificity test and instead examined specificity at the industry level. ${ }^{83}$ The question was thus whether the subsidy was specific to the softwood lumber industry. This broad definition of industry opens the way for, for example, the energy intensive sector, as a whole, to be considered one industry even though the range of end-products produced is very broad and diverse and generally unrelated. Indeed the products produced by the energy intensive sector have a common denominator - their high proportion of use of energy as an input. In US Softwood Lumber IV, it also did not preclude the Panel from considering the softwood lumber sector to be a specific group of industries even though the subsidy was also available to other industries outside of this industry. ${ }^{84}$

Despite this acknowledgement of a broad interpretation of industry in the SCM Agreement, and although it is not end-product based, the determination of a specific group of industries is still related to 'types of products produced' and therefore I submit that it is still not broad enough for 'energy intensive industry' to be considered to be one industry which, when in receipt of a subsidy, would be in receipt of a specific subsidy. ${ }^{85}$ This is so from an examination of what industries are covered by the term 'energy intensive industry' which includes producers of food,

82 Panel Report, US - Softwood Lumber IV, para. 7.121.

83 Gagné and Roch 2008, p. 554.

84 Ibid., p. 554; The Panel in US - Softwood Lumber IV, agreed with the US determination that the stumpage programme constituted a specific subsidy. See also Davidson, Bergsma, Backes and Van den Bossche 1999, p. 81-82. In this report, Van den Bossche examined a Dutch subsidy benefitting sustainably-produced processed and unprocessed wood products in light of the Panel Report in US - Softwood Lumber IV with the conclusion that these producers and/or importers would be considered to be a specific group of enterprises within the meaning of Article 2 of the SCM Agreement. This opinion is at odds with that of Wolf 2006, p. 105. Wolf argues that since a broad interpretation of industry was determined in the Softwood Lumber dispute, including the lumber industry, pulp and paper mills and remanufacturers of lumber merchandise were considered all as one industry, the same would be true of the energy intensive industry. She argues this since the fact that the energy intensive industry produces a range of different end products would not save it from being one industry as was the case in Softwood Lumber. Although this, I agree, is true, to say that the fact that the group of enterprises produce different end products will not save the group from being considered one industry, differs from saying that the fact that the group of enterprises produce different end products and are also thus one industry, since they are all recipients of the subsidy and are all energy intensive enterprises. Rather, there must be a product-related common denominator which relates the enterprises to each other. In the case of energy intensive enterprises, this is not the case. 
bulk chemicals, refining, glass, cement, steel, and aluminium. ${ }^{86}$ To distinguish this case from US - Softwood Lumber IV, although there is a common denominator (high energy use) as there was in that case (soft-wood lumber), this common denominator has no connection whatsoever to the 'types of products produced'. To consider energy intensive industry to be a specific industry would be tantamount to considering all commercial product-manufacturing industry to be a specific industry, thus eliminating even the possibility for general measures. Given not only the range of end-products but also the sheer range of product sectors covered by 'energy intensive industry', it is more likely that a measure which is available to and availed of by the energy intensive industry will be a general measure rather than a specific one.

This argumentation does not preclude the possibility of measures being designed in a way to be specific to an industry within the energy intensive industries - for example the energy sector or even more specific, the renewable energy sector. In this sense, in examining the case study measures, this spectrum of specificity could be borne in mind.

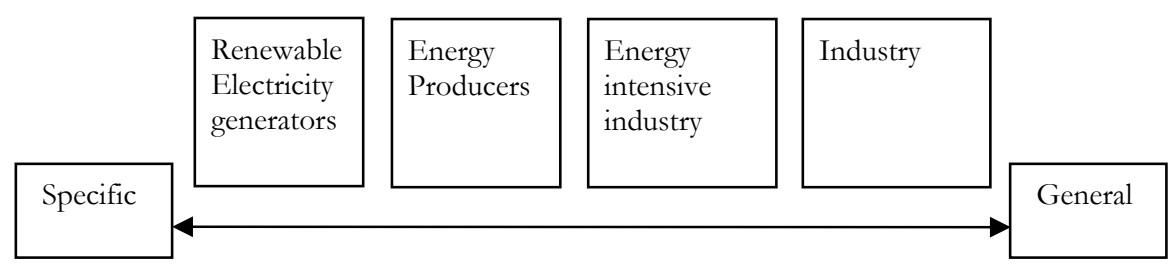

In the case of environmental tax incentives provided to the electricity generation sector, it is very likely, since in fact there are very few actors in this sector, that subsidies provided here may indeed be at least de facto if not de jure specific. ${ }^{87}$ An example proffered by Zhang is that, where a criterion of energy efficiency or energy intensity is applied to establish eligibility for a subsidy, this subsidy could therefore be considered to be specific. ${ }^{88}$ The subsidies need only to be provided to a few energy intensive sectors to be considered specific. However, even if it is possible to show that the government in question designed the subsidy to be available across the board, if it can then be shown that, in fact, the subsidies are availed of only by a certain group of companies, it will be considered de facto specific. ${ }^{89}$

As submitted by Zhang, this issue may become more relevant with regard to emission reduction strategies pursued by Kyoto Protocol-ratifying countries. Where emission reduction strategies include providing subsidies to environmentally friendly

\footnotetext{
86 <http://www.eia.doe.gov/oiaf/aeo/otheranalysis/neim.html>; last visited 24 November 2009.

87 Assunção and Zhang 2002, p. 3; Zhang 2005, p. 26.

88 Ibid., p. 4

89 Specificity is determined on a case-by-case basis.
} 
producers, the conditions for eligibility for such subsidies may become a contentious issue in light of WTO obligations set out in the SCM Agreement. ${ }^{90}$

\subsubsection{De Jure Specificity}

The accelerated depreciation provisions apply to the purchase of designated equipment. In the UK, the Netherlands and Ireland, the condition determining the applicability of the incentive is whether the purchased asset is a listed one or not and is situated in the country providing the tax incentive. In these countries, the role of the purchaser - be it a renewable energy generation station or a shop - is irrelevant. In Ireland the asset should be acquired between 2008 and 2011. In Canada, the accelerated depreciation provision is applied to equipment listed in the Income Tax Act that is acquired or purchased for the purpose of gaining or producing income from a business situated in Canada between 2005 and 2012. In all cases the equipment subject to the accelerated depreciation should be new and unused. In the case of Belgium the accelerated depreciation will be applied in agreement with the tax authorities. The application of the accelerated depreciation is neither based in the legislation nor is it documented.

These conditions will now be examined in detail to determine whether they are specific to an enterprise or group of enterprises within the countries applying the measures.

\subsubsection{UK, Netherlands, Ireland}

In the first three case studies, the UK, the Netherlands and Ireland, the measures are not de jure specific since all businesses are eligible to have access to the incentive. The only condition is to invest in a listed asset - a condition that is economic in nature and horizontal in application. The tax subsidy applies across the board to all economic actors. With regard to this particular incentive, a shop, an office, as well as an electricity generation plant may avail of the accelerated depreciation provision.

Furthermore, the assets covered in the lists are diverse. The assets listed are suitable for use by diverse sectors of the economy. ${ }^{91}$ Despite the broad range of eligible products, an argument can be made that, although diverse, all these products have one common denominator - that they are of more value to energy intensive industry. ${ }^{92}$ However, I submit that this is not a question of de jure specificity but rather may be better examined under de facto specificity. The legislation for these three case study measures is broad enough that all sectors of the economy can invest in a listed asset and avail of the tax subsidy. The measures are thus not specific subsidies within the meaning of Article 2.1(a) and (b) of the SCM Agreement. There is also no

\footnotetext{
$90 \quad$ Assunção and Zhang 2002, p. 1.

91 This concerns the establishment of objective criteria which do not favour certain enterprises over others. The UK includes not only energy assets but also cars and water related assets. The Netherlands includes 450 assets while Ireland includes 7 broad classes.

$92 \quad$ See Zhang 2005.
} 
geographic criteria attached to the provisions meaning that the measures are also not specific subsidies under Article 2.2 of the SCM Agreement.

Thus, following the analysis of the case study measures against the meaning of specificity under Article 2.1(a) of the SCM Agreement, all three case study measures have not been found to be de facto specific subsidies. ${ }^{93}$ The legislation providing the accelerated depreciation provision does not explicitly limit access to the subsidy to certain enterprises.

Furthermore, following the analysis of the case study measures against the meaning of specificity in Article 2.1(b) of the SCM Agreement, it was found that the conditions for eligibility (the purchase of a listed asset) are objective, meaning neutral and economic in nature and horizontal in application and thus the measures are not specific subsidies.

The accelerated depreciation measures in the UK, the Netherlands and Ireland are not specific subsidies under Article 2.2 SCM Agreement.

\subsubsection{Canada}

Although like in the other case studies, Canada has a list of the type of equipment covered in Class 43.1 and 43.2, and subject to the accelerated depreciation provision. In this case the legislation explicitly limits access to the subsidy to certain enterprises. ${ }^{94}$ The company availing of the accelerated depreciation provision must acquire the electricity generation asset for the purpose of gaining or producing income. ${ }^{95}$ A narrow interpretation of this phrase in the legislation: 'is acquired by the taxpayer for use by the taxpayer for the purpose of gaining or producing income from a business situated in Canada' may lead to the conclusion that this accelerated depreciation provision is available only for commercial renewable electricity generators whose primary business activity is generating renewable electricity by use of the renewable energy equipment listed in the Schedule. In fact, the Canadian Schedule 43.1 and 43.2 capital cost allowance is only available for electricity (and heat combined) generation equipment and furthermore is only available to commercial generators. The answer to Article 2.1(a) thus may be interpreted to be positive. In further support of this interpretation Article 2.1(b) sheds more light by being answered in the negative.

Although in this case it is shown that conditioning eligibility upon the purchase of certain listed assets did not result in the tax incentive being considered to be specific, this does not preclude that such a method of conditioning eligibility could, in other situations, be found to be specific. If a system of listing eligible assets is used selectivity may still be triggered. In order for such a list to be selective, however, the list may be restricted to certain types of assets, or may be only used in certain types of industries. See the Canadian case study for more on such an example of selectivity, section 5.7.1 Capital Cost Allowance Class 43.1, p. 111.

94 Article 2.1(a).

95 Class 43.1(b)(ii)(A). 
The criteria for eligibility for the accelerated depreciation should be objective and not favour certain enterprises over others. ${ }^{96}$ In order for such a list not to favour certain enterprises over others it should include equipment for use in most sectors of the economy. As seen above, there is a requirement for the purchaser to use the equipment for the purpose of gaining or producing income. This criteria would not necessarily limit the subsidy unless the equipment referred to is limited and relevant for use only by a certain group of enterprises. This is the case for the Canadian list as it includes a very limited selection of energy efficient equipment - namely renewable electrical generating equipment. This equipment generates both electrical and heat energy using only fuel that is fossil fuel, wood waste, spent pulping liquor, municipal waste, land-fill gas, digester gas or bio-oil, or any combination of those fuels, a hydroelectric installation of a producer of hydro-electric energy, photovoltaic equipment, or wind energy conversion system. The electricity produced should also have a minimum capacity of three kilowatts.

Thus, it would seem that the list of eligible equipment disproportionately focuses on commercial electricity generation equipment. If this is the case, the measure is not horizontal in application, but rather addresses a particular group of enterprises, namely renewable electricity generators, to whom the subsidy applies. This reading of this condition in Class 43.1 leads to a determination of this as a de jure specific subsidy according to Article 2 SCM Agreement and thus also subject to examination under Part III SCM Agreement.

The possibility of an alternative interpretation, namely that the electricity generating equipment is relevant for use by many other economic actors than electricity generators and should merely be used in a commercial setting but not necessarily be the primary activity of the company, at the very least leaves the question of government discretion open. The tax authorities may thus have discretion in interpreting the scope of this phrase to either mean only commercial electricity generators or commercial operators (for example energy intensive industry) who also generate electricity (for example for their own use). Where the interpretation is left to the discretion of the tax authority, a de facto specific subsidy may still be at issue. It must thus be underlined that the wording of the Canadian accelerated depreciation provision is much more susceptible to being deemed de jure specific that the wording of the accelerated depreciation provisions in the UK, Netherlands and Ireland. The de facto specificity of this measure will also be examined below.

\subsubsection{Belgium}

In Belgium, there is no legal provision setting out the accelerated depreciation rate for energy saving equipment, nor the conditions for its application. Thus it cannot be a de jure specific subsidy. In fact, it is not a de jure subsidy at all in that there is no legislation providing for the (alleged) accelerated depreciation examined in this case study. This measure is thus not specific within the meaning of Article 2.1 of the SCM Agreement. An essential component of the establishment of a de jure specific subsidy is that the legislation limits access, or the legislation establishes objective criteria. In this case study there is no legislation to refer to. The tax authority has discretion to allow

96 Footnote 2 to Article 2.2(b). 
an accelerated depreciation rate for renewable energy investments. However, the 'granting authority' referred to in Article 2.1(a) and (b) could be considered to be the tax authority. However, since there is no documentation establishing what the tax authorities does or does not allow with respect to the accelerated depreciation provision, it cannot be easily ascertained whether the granting authority explicitly limits access or consistently follows strict objective criteria. Since there is a lack of clear and transparent, publicly available rules guiding the application of the accelerated depreciation scheme and although de jure specificity is difficult to ascertain, de facto specificity is not precluded.

\subsubsection{De Facto Specificity}

Whether the accelerated depreciation provisions are de facto specific is quite a separate question however. De facto specificity is the subject of Article 2.1(c). Here the question is whether the incentive is effectively limited to a certain group or enterprises, is predominantly only accessed by a limited number of enterprises (electricity generation companies are of particular relevance here); whether the amounts of subsidy provided are allocated disproportionately; or whether dubious discretion is exercised by the granting authority in deciding on recipients. The economic diversification of the member in question is also deemed to be relevant for this examination and the duration of the subsidy.

\subsubsection{UK, Netherlands, Ireland}

First, it shall be examined whether the accelerated depreciation provisions of the UK, the Netherlands and Ireland, which are not de jure specific, may be de facto specific to electricity generation companies. These provisions rely on the eligible assets to be included in a Ministerial List. In order for the incentive to be in any way de facto specific to electricity generation companies, the listed assets should include electricity generation assets and the depreciation provision should be disproportionately availed of by renewable electricity companies (thus have a disproportionately large listing of renewable generation equipment compared to other equipment) having purchased these electricity generation assets. Alternatively, the list should disproportionately focus on electricity generation equipment (rather than sustainable energy equipment in general), which by default would leave the accelerated depreciation provision to be disproportionately availed of by electricity generation companies.

The UK list only included one set of renewable electricity equipment - combined heat and power (CHP) equipment - subject to energy efficiency certification. The Dutch list includes wind energy equipment and solar renewable electricity equipment. The Irish list has not yet been established, however, it is clear that it will include renewable electricity equipment. Although the inclusion of renewable electricity equipment indicates that renewable electricity generators may also avail of the tax subsidy, the lists are my no means disproportionately concentrated on such equipment. In fact, renewable electricity generation equipment has an extremely small share of the number of assets that may avail of the subsidy. Furthermore, the companies eligible for the accelerated depreciation rate on renewable electricity generation equipment are not limited by a requirement that the electricity produced for commercial sale, or should be of a minimum capacity. 
It would therefore seem that the accelerated depreciation provisions in these case study countries are also not de facto specific to electricity generation companies since there is no positive evidence that the subsidy is in any way limited to use by these companies or disproportionately used by these companies or that disproportionate amounts of subsidy re granted to these companies.

\subsubsection{Canada}

The provision 'acquired by the taxpayer for use by the taxpayer for the purpose of gaining or producing income from a business carried on in Canada or a property situated in Canada' could be interpreted by the granting authority in two ways. It could be interpreted as meaning that the newly acquired equipment must be used by a commercial electricity generation enterprise in carrying out the activity of generating electricity or, alternatively, it could be interpreted as meaning that all commercial actors, regardless of their commercial activity, as long as they are engaged in some commercial activity, may avail of the subsidy. In either case, the subsidy may still be deemed to be de facto specific if the measure is disproportionately availed of by a limited number of enterprises or if the manner in which discretion has been exercised by the granting authority in the decision to grant a subsidy'. ${ }^{97}$ The Panel in US - Softwood Lumber IV stated that 'deliberate action by a government to restrict access to a subsidy that is in principle broadly available, through the use of discretion, could well be the basis for a finding of de facto specificity"..$^{8}$ Thus where the Canadian legislation is read in fact to mean that all commercial operators are eligible for the accelerated depreciation on electricity generating equipment, and the granting authority, being the tax authority, limits the interpretation of this condition to being eligible only for commercial electricity generators, there may be a case of de facto specificity by virtue of the exercise of discretion by the tax authorities.

Regardless of the above argument on the discretion of the tax authority in the interpretation of the phrase 'acquired by the taxpayer for use by the taxpayer for the purpose of gaining or producing income from a business situated in Canada', the fact that the only equipment that is listed as being eligible for the special tax treatment to only renewable electricity generation equipment provides a strong argument that the subsidy is predominantly used by a certain group of enterprises - those who produce renewable electricity. Thus there would be a finding of a de facto specific subsidy under Article 2.1(c). This view is supported by the findings of the Panel in the US Softwood Lumber IV dispute.

In US - Softwood Lumber IV, the Panel clarified that in examining specificity what the Panel is concerned with is whether there has been a distortion to the market by virtue of the provision of a subsidy (de jure or de facto) to a 'sub-set' of the industry. ${ }^{99}$ Although unlike in that dispute, the provision of particular goods or services as a financial contribution is not at issue, the eligibility for the tax incentive is product-

97 Article 2.1(c) Footnote 3 of the SCM Agreement. In examining the manner in which discretion has been exercised by the granting authority in the decision to grant a subsidy, information on the frequency with which applications are refused or approved and the reasons for those refusals or approvals should be considered. Panel Report, US - Softwood Lumber IV, para. 7.116. Ibid. 
related and the range of products creating eligibility is limited. Similar to the US Softwood Lumber IV dispute, the inherent characteristics of the goods in question limit the possible use of the subsidy to a specific sub-set of industry. Renewable electricity generation equipment can only be used for renewable electricity generation. Standing timber can only be used by the wood-product manufacturing industry.

Contrary to Canada's argument that, in order for such a subsidy to be specific, access to it should be further limited to a sub-group of those eligible to use it, the Panel stated: '[i]n the case of a good that is provided by the government ... and that has utility only for certain enterprises (because of its inherent characteristics), it is all the more likely that a subsidy conferred via the provision of that good is specifically provided to certain enterprises only'. ${ }^{100}$ I submit that although this subsidy does not concern the transfer of a particular good from the government which is useful only for a particular group of enterprises, the limitation of eligibility for the subsidy being the purchase of a particular asset, only having utility for a certain group of enterprises, amounts to the same thing.

The 'inherent characteristic' of renewable electricity generation equipment limits the possible use of the equipment and, thus, the use of the tax subsidy to a certain industry - the renewable electricity generating industry. This limitation amounts to de facto specificity.

\subsubsection{Belgium}

Since there is no legislation in Belgium establishing an accelerated depreciation provision related to investments in renewable energy assets, there is no de jure specific subsidy. However, as per Article 2.1(c) of the SCM Agreement, 'notwithstanding' the apparent non-existence of such a measure and thus 'non-specificity resulting from the application of the principles laid down in subparagraphs (a) and (b), there are reasons to believe that the subsidy may be specific'. ${ }^{101}$

In order to determine whether this 'hidden-subsidy' is de facto specific there should be an examination of how many enterprises apply for and are granted the subsidy, the value of the subsidy granted, and how the tax authority decides upon which enterprises qualify for the accelerated depreciation provision. Furthermore Article 2.4 of the SCM Agreement explicitly requires a determination of specificity (de jure or de facto) to be supported by positive evidence. As there is no documentation other than the testimony of tax practitioners in Belgium that this is 'accepted practice' of the tax authorities and the equivalent non-binding guidelines by practitioners to clients that such an accelerated depreciation scheme for energy efficient investments, including renewable energy equipment exists, this positive evidence is impossible to substantiate or evaluate to determine specificity. Therefore, it is the unfortunate result of this investigation that the information which would be necessary to establish whether the alleged de facto subsidy is de facto specific is unavailable and the collection

\begin{tabular}{ll}
\hline 100 & Ibid. \\
101 & Article 2.1(c) SCM Agreement.
\end{tabular}


of that data is also outside the scope of this thesis. ${ }^{102}$ Despite the lack of a clear answer to the question of specificity of the Belgian accelerated depreciation scheme in this thesis, it is indeed the case that in the event of the measure being challenged for WTO-consistency, the complaining Member, having suffered adverse effects (allegedly) caused by the accelerated depreciation provision, would invest in the necessary data-collection to build up the case for the specificity of the measure.

\subsection{ACCELERATED DEPRECIATION CONCLUSION}

In conclusion, only two of the case study accelerated depreciation measures are potentially specific subsidies within the meaning of Article 1 and 2 of the SCM Agreement, namely the Canadian and Belgian accelerated depreciation measures. The Canadian accelerated depreciation measure is de jure specific due to the limited wording of Class 43.1 and 43.2 and the limited product list to which the measure applies. The Belgian accelerated depreciation measure is potentially de facto specific. Although there is no legislation establishing the accelerated depreciation for energy saving assets, there is also no legislative guidance for the tax authorities so as to apply the accelerated depreciation scheme in an unbiased, horizontal way without favouring one sector over another. These subsidies are potentially specific subsidies subject to challenge under Part III of the SCM Agreement.

\section{Own INVESTMENT DEDUCTION}

In Belgium and the Netherlands tax incentives are in place which allow companies that invest in energy efficient assets, including renewable energy equipment, for their own use, to deduct a percentage of the cost of the asset as a current expense thereby lowering the tax liability for that year. In the general system of taxation, the purchase of an asset does not give rise to any current deductions, but rather the value of capital assets is increased in the company's accounts.

In Belgium the allowed deduction is $15.5 \%$ of the cost of the asset, compared to $0 \%$ in the general system of taxation and in the Netherlands (the EIA and the MIA) the percentage deduction ranges from $35 \%$ to $60 \%$ also compared to $0 \%$ in the general system. ${ }^{103}$

This differs from the approach in the Canadian case study in which it was indeed possible to investigate the de jure and/or de facto specificity of the accelerated depreciation provision since in Canada there is both legislation providing for the accelerated depreciation in addition to the limited scope of application of that tax incentive to a certain sector, namely renewable energy. In that case, it is the interpretation of the legislation which could potentially make the difference between the provision being de jure or de facto specific. See section 5.7.1 Capital Cost Allowance Class 43.1, p. 111.

103 The EIA and the MIA can be deducted alongside the VAMIL - accelerated depreciation - scheme. Also, for the purposes of this research, the general deduction related to minor own investments of up to $€ 300,000$ as per Article 3.41 WIB 2001 is disregarded. 


\section{8 .1}

To examine whether this measure is a subsidy according to Article 1.1(a)(1)(ii) of the SCM Agreement, it should be shown that there is government revenue otherwise due which is foregone. The 'but for' test remains appropriate since, contrary to the caution of the Appellate Body in US - FSC, there is a straight-forward alternative to the tax incentive available in the general system of taxation. It is straight-forward to establish the 'tax treatment of the income subject to the contested measure and the tax treatment of certain other [comparable] income'.104 The 'tax treatment of comparable income, in the hands of taxpayers in similar situations', ${ }^{105}$ namely the tax treatment of an enterprise which invests in an asset which is not listed as eligible for the investment deduction, is clearly ascertainable. An investment increases the fixed capital assets category in the enterprise's accounts, and either reduces the capital account or increases the debt account, thereby having no effect on the taxable income of the company.

The investment deduction is a clear deviation from the normal situation where the full taxable income is taxed. In the situation where the investment deduction is applied, the full taxable income is reduced by a percentage of the value of the asset in which the investment is made. This is equal to the revenue foregone, or not collected by the government and since it was originally a part of the normal taxable income it was clearly 'otherwise due'. The own investment percentage deduction is clearly a tax incentive, and therefore a deviation from the tax treatment which would apply 'but for' the measure in question. These tax incentives in the Netherlands and Belgium provide for a deduction from the normal taxable base, reducing the tax liability compared to the situation without the tax incentive. But for the tax incentive, more revenue would be due and collected. This is a clear-cut subsidy.

BE(G) Income $(100)^{106}-$ deductions (no investment deduction: asset $(10) \times 0 \%$ ) $=$ taxable income $\mathrm{x}$ tax rate $(20 \%)=$ tax due $100-0=100 \times 20 \%=20$

BE(I) Income (100) - deductions (investment deduction: asset (10) $\times 15.5 \%$ ) $=$ taxable income $x$ tax rate $(20 \%)=$ tax due.

$100-1.55=98.45 \times 20 \%=19.69$

$\mathrm{BE}(\mathrm{G}) 20>\mathrm{BE}(\mathrm{I}) 19.69$

Value of revenue foregone 0.31

$\mathbf{N L ( G ) ~ I n c o m e ~ ( 1 0 0 ) ~ - ~ d e d u c t i o n s ~ ( n o ~ i n v e s t m e n t ~ d e d u c t i o n : ~ a s s e t ~}(10) \times 0 \%$ ) $=$ taxable income $\mathrm{x}$ tax rate $(20 \%)=$ tax due

104 Appellate Body Report, US - FSC (Article 21.5 - EC), para. 90.

105 Appellate Body Report, US - FSC (Article 21.5 - EC), para. 98.

106 In the calculations demonstrating the own investment percentage deduction in the case study countries, 'income' denotes income after a depreciation deduction is already accounted for. This is the regular method of taking account of investment. For ease of calculation in the above example the depreciation deduction is deemed to already be deducted with a resultant income of 100 . 
$100-0=100 \times 20 \%=20$

NL(I-) Income (100) - deductions (investment deduction: asset (10) $\times 35 \%$ ) = taxable income $\mathrm{x}$ tax rate $(20 \%)=$ tax due.

$100-3.5=96.5 \times 20 \%=19.3$

NL(I+) Income (100) - deductions (investment deduction: asset (10) x 60\%) = taxable income $\mathrm{x}$ tax rate $(20 \%)=$ tax due.

$100-6=94 \times 20 \%=18.8$

$\mathrm{NL}(\mathrm{G}) 20>\mathrm{NL}(\mathrm{I}-)$ 16=19.7

Value of revenue foregone: 0.3

$\mathrm{NL}(\mathrm{G}) 20>\mathrm{NL}(\mathrm{I}+) \mathbf{1 6}=18.9$

Value of revenue foregone: 1.1

\subsubsection{Own Investment Deduction - a Specific Subsidy?}

Whether the own investment percentage deductions in the Netherlands and Belgium are specific subsidies depends on the conditions for eligibility.

\subsubsection{De Jure Specificity}

\subsection{Netherlands}

Like the accelerated depreciation provision, as applied in the Netherlands the UK and Ireland, eligibility for the own investment percentage deduction is open to all economic actors, regardless of their activity. It applies to the purchase of designated equipment. The condition is that the assets invested in are on a Ministerial list and are situated in the country providing the incentive. Again, the role of the purchaser - be it a renewable energy generation station or a shop - is irrelevant. The measures are not de jure specific since all businesses are eligible to have access to the incentive. The only condition is to invest in the listed asset - a condition that is economic in nature and horizontal in application. The tax subsidy applies across the board to all economic actors. With regard to this particular incentive, a shop, an office, as well as an electricity generation plant may avail of the own investment deduction.

Furthermore, the assets covered in the lists are diverse. In fact, there are two lists in the Netherlands, one for the EIA and one for the MIA. The list for the MIA is the same as that for the accelerated depreciation provision. In total the two lists cover over 600 products suitable for use to diverse sectors of the economy only including energy products in one section. ${ }^{107}$

107

This concerns the establishment of objective criteria that do not favour certain enterprises over others. The UK includes not only energy assets but also cars and water related assets. The Netherlands includes 450 assets while Ireland includes 7 broad classes. 


\subsection{Belgium}

In Belgium the list is less specific, and rather than including particular products, the general motivation for the investment is the qualifying character. For example investments to reduce loss of heat from existing buildings are covered. Investments to produce renewable electricity are also included but form only one category of 13 very broad categories of potential investments.

Despite the broad range of eligible products, an argument can be made that, although diverse, all these products have one common denominator - that they are of more value to energy intensive industry. ${ }^{108}$ However, I submit that this is not a question of de jure specificity but rather may be better examined under de facto specificity.

The legislation and lists of eligible products in these two case studies is broad enough that all sectors of the economy can invest in a listed asset and avail of the tax subsidy. The measures are thus not specific and are in compliance with Article 2.1(a) and (b). There is also no geographic criteria attached to the provisions, meaning that the measures are also not specific under Article 2.2. Thus the answer to Article 2.1(a) is indeed in the negative for these two case studies. The legislation providing the accelerated depreciation provision does not explicitly limit access to the subsidy to certain enterprises.

The answer to Article 2.1(b) is positive. The conditions for eligibility (the purchase of a listed asset) are objective, meaning neutral and economic in nature and horizontal in application.

The answer to Article 2.2 is negative.

Thus there is no de jure specificity, but de facto specificity is not ruled out.

\subsubsection{De Facto Specificity}

As shown above, the own investment percentage deductions are not de jure specific. However, whether the same measures are de facto specific is quite a separate question. Again according to Article 2.1(c) of the SCM Agreement, the question is whether the incentive is effectively limited to a certain group or enterprises, is predominantly only accessed by a limited number of enterprises (electricity generation companies are of particular relevance here); whether the amounts of subsidy provided are allocated disproportionately, or whether dubious discretion is exercised by the granting authority in deciding on recipients. The economic diversification of the member in question is also deemed to be relevant for this examination and the duration of the subsidy. 


\subsubsection{Netherlands and Belgium}

Although it is argued above that the own investment percentage deductions are not de jure specific, they may nevertheless be de facto specific to electricity generation companies. In order for the incentive to be in any way de facto specific to electricity generation companies, the listed assets should include electricity generation assets and the own investment deduction provision should be disproportionately availed of by renewable electricity companies (thus have a disproportionately large listing of renewable generation equipment compared to other equipment) having purchased these electricity generation assets. Alternatively, the list should disproportionately focus on electricity generation equipment (rather than sustainable energy equipment in general), which by default would leave the deduction provision to be disproportionately availed of by electricity generation companies.

As introduced above, although renewable electricity equipment is indeed included in the lists, it is only one minor category of eligible products. Although the inclusion of renewable electricity equipment indicates that renewable electricity generators may also avail of the tax subsidy, the lists are my no means disproportionately concentrated on such equipment. In fact, renewable electricity generation equipment has an extremely small share of the number of assets which may avail of the subsidy. Furthermore, the companies eligible for the accelerated depreciation rate on renewable electricity generation equipment are not limited by a requirement that the electricity produced for commercial sale, or should be of a minimum capacity.

It would therefore seem that the deduction provisions in these case study countries are also not de facto specific to electricity generation companies since there is no positive evidence that the subsidy is in any way limited to use by these companies or disproportionately used by these companies or that disproportionate amounts of subsidy re-granted to these companies.

\subsubsection{Own Investment Deduction Conclusion}

The own investment percentage deduction provisions, although qualifying as subsidies under Article 1.1(a)(1)(ii), are neither de facto nor de jure specific in accordance with the provisions of Article 2 and thus are not subject to the provisions of Part II, III or IV as provided by Article 1.2.

\subsection{Third-PARTy Project InVESTMENT Deduction}

In Ireland, the Netherlands and Canada, a tax incentive is provided to investors in green projects. The justification for providing the tax incentive to the investor rather than the project itself is a simple one. The incentives aim to provide financial support to start-up green energy projects so that they may become commercially competitive. Start-up companies are not, by their nature, in a position to enjoy the benefit of tax incentives. They are usually in a loss-making position for the first years of operation and thus do not have a taxable income from which a tax incentive could be deducted. The recipient of the direct tax benefit, the investor, will first be examined. 


\subsubsection{Third-Party-Project Investment Deduction - a Measure Related to Trade in Goods?}

What is important to address here is that the recipient of this type of tax incentive is an investor rather than the producer of goods. It is first necessary to consider whether such a subsidy is even covered by the SCM Agreement. ${ }^{109}$

The SCM Agreement covers subsidies related to trade in goods. As put by the Panel in Brazil - Aircraft 'the object and purpose of the SCM Agreement is to impose multilateral disciplines on subsidies which distort international trade'. ${ }^{110}$ 'In goods' can be automatically added onto the end of this sentence, which may then provide the basis for the examination of whether the investment incentives in question could be considered to be covered by the SCM Agreement. Do these incentives potentially distort international trade in goods? If so which goods do these incentives affect?

Is the provision of a tax incentive to investors in electricity generation companies a tax incentive 'related to trade in goods'? Would such a measure affect the competitive relationship of certain goods or services or both? As examined and explained in Chapter 7, there is a plausible argument that electricity would be considered to be a good within the WTO regime. Further, it is arguable that an investment incentive, albeit provided to individual investors in companies producing goods rather than the producers of the goods themselves, could affect the competitive position of the goods produced by the electricity generation companies invested in.

In support of this position, in US - Countervailing Measures on Certain EC Products, the Appellate Body considered whether natural persons (as opposed to only legal persons) can also be considered to be beneficiaries of subsidies within the meaning of the SCM Agreement. ${ }^{111}$ The Appellate Body considered that not only can a product be

Although these measures are investment-related measures, the Trade Related Investment Measures Agreement does not regulate subsidies nor in particular tax incentives. The TRIMs prohibits Members from making investment measures conditional upon local content requirements. Thus, an examination of the tax subsidies of the case study countries which are provided to investors is limited to an examination under the SCM Agreement.

110 Panel Report, Brazil-Aircraft, para. 7.26.

111 It should be noted that, although the finding of the Appellate Body is indeed relevant here, the facts of this dispute differ from the situation at hand. US - Countervailing Measures on Certain EC Products concerned a potential benefit resulting from the privatisation, at arm's length and for fair market value, of a state-owned enterprise since the government did not retain any controlling interest in the privatized enterprise. A tax concession for an investor was not in question although the Appellate Body recognised that this could be a form of benefit conferred on the investor in an enterprise (para. 113). The Appellate Body, referring to the Panel Report, also cautioned against too broad an interpretation of the relationship of an enterprise and its shareholders stating: 'finding that a firm and its owners are, for all purposes of the SCM Agreement, virtually the same, could be interpreted as entitling investigating authorities to assume, in all cases, that, for the purpose of calculating the benefit, and irrespective of the means and conditions imposed by a government for the provision of a financial contribution to owners of the firm, that firm will receive a benefit equivalent to the full financial contribution. This may or may not be so in all cases'. Para. 118. See also Gagné and Roch 2008, p. 557. 
subsidised by virtue of a 'transfer of funds' directly to the legal person that produces the good but also by virtue of a transfer of funds indirectly to the natural persons that hold shares in (or own) that enterprise producing the subsidised product. ${ }^{112}$ Furthermore, the Appellate Body went on to say: '... we note that Article VI:3 of the GATT 1994 and footnote 36 of Article 10 of the SCM Agreement contemplate this possibility by providing that a subsidy may be bestowed "indirectly" upon the manufacture, production or export of merchandise'. ${ }^{113}$ (Emphasis in original)

Furthermore, the Appellate Body highlighted that any other interpretation of the coverage other SCM Agreement 'could potentially undermine the SCM Agreement by opening a wide door enabling subsidizing governments to circumvent that Agreement's provisions by bestowing benefits on the firm's owners rather than on the firms themselves'. ${ }^{114}$

I proffer that although the investment incentives are provided to investors rather than producers, this does not preclude the measures from constituting subsidies affecting trade in goods within the meaning of the SCM Agreement, where the direct recipients of the subsidy are the shareholders or owners of (or investors in) the contested company producing the traded product.

\subsubsection{Third-Party-Project Investment Deduction - a Subsidy?}

The test that determines if a measure is a subsidy according to the SCM Agreement, Article 1.1 (a) (1) (ii), is whether government revenue that is otherwise due is foregone or not collected (e.g. tax incentives such as tax credits). ${ }^{115}$ Concerning the 'third-party-project' investment incentive, the recipient of the tax incentive is the investor rather than the project itself.

The tax incentive is provided to investors by allowing a deduction from the taxable base of the investor by the amount of the investment (in Ireland), deductions pertaining to the renewable energy project to be deducted by the shareholder (Canada) and the capital related to the project to be excluded from the calculation of income tax on investments (Netherlands). The incentives provided to the investor result in a positive financing mechanism for the start-up company. Each measure will be treated separately.

Again the 'but for' test provides an adequate benchmark. But for the investment tax incentive in Ireland, the investor would be subject to a higher tax liability. The taxable base is lowered, to the extent of the investment (up to $€ 12 \mathrm{~m}$ ). It is quite straight forward that 'but for' this incentive, more government revenue would be due which is not collected. The normative benchmark is that tax treatment of a comparable investment in a 'non green' project. For such an investment, the tax base and thus tax due would be considerably higher.

112 Appellate Body Report, US - Countervailing Measures on Certain EC Products, paras. 112113.

113 Appellate Body Report, US - Countervailing Measures on Certain EC Products, para. 113.

114 Appellate Body Report, US - Countervailing Measures on Certain EC Products, para. 115.

115 Footnote 1 in Article 1.1(ii) of SCM Agreement. 
In the Netherlands, 'but for' the Green Funds scheme, the dividends and savings deriving from the investment in the green project would be subject to taxation. ${ }^{116}$ Clearly revenue which was due is foregone and not-collected from the individuals having made the investment. ${ }^{117}$ Here again, the normative benchmark is the tax treatment of an investor in a 'non-green' project. Such an investment would normally be subject to investment tax.

In Canada, the flow-through shares allow the investor to make deductions (normally deducted by the renewable energy company) from their taxable income, which they have not incurred in carrying out their business activity. A deduction is permitted which is not permitted according to the general system of taxation. The deduction from the taxable income results in a lower tax liability and, clearly, revenue otherwise due is foregone from the government purse.

Also as discussed in detail in Chapter 7, where it is established that there is a financial contribution in the form of revenue due but foregone, Article 1.1(b) is fulfilled by default. A lower tax liability than 'otherwise due' is always going to confer a benefit.

In these three case studies the tax incentives provided to the investors, despite their being natural persons, are clearly subsidies within the meaning of Article 1.1(a)(1)(ii). The investor receives a direct tax benefit for investing in a green project which $\mathrm{s} /$ he would not receive in absence of the tax incentive. These subsidies will be examined later to determine whether they are specific subsidies within the meaning of Article 2 SCM Agreement. First, however, these subsidies should be examined for their possible pass-through effects.

\subsubsection{Indirect Beneficiary Article 1.1(a)(1)(ii)}

Although the direct tax benefit received by the investor is straightforward and clear, it is coupled with potential indirect (non-tax) benefits received by the green projects and the investment funds (in the Netherlands).

116 In the Netherlands the normal tax treatment of investments (Box 3 Income Yield Tax) is a tax of $30 \%$ on a deemed yield of $4 \%$ per annum resulting in a $1.2 \%$ tax on the value of the investments. An exemption of $€ 19,698$ is provided for.

117 At the EU level, this measure was deemed to be compatible state aid. See State aid decision NN41/05, Green Funds - The Netherlands. 'There are state resources involved. Dutch authorities, through the tax break granted to individuals who invest in the green funds, forego tax revenues'. Para. 13. 'At the first level, the measure benefits those that invest their money in green funds, i.e. the taxpayers. The measure is open to everyone and does not, at this level, favour certain undertakings within the meaning of Article 87(10) EC Treaty. Para. 16. 


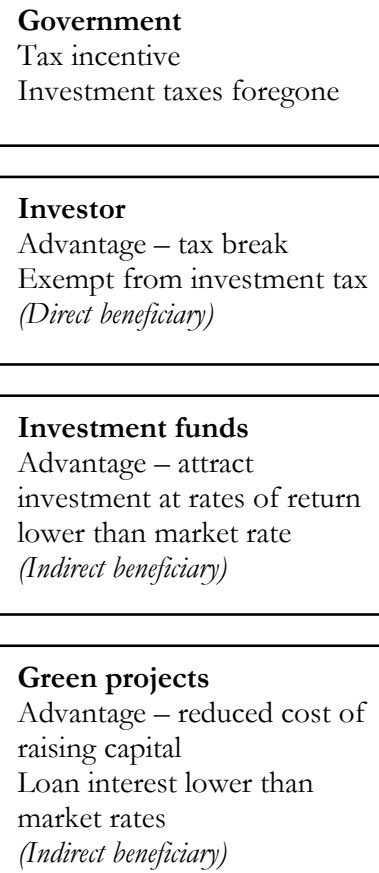

\section{Green projects}

Advantage - reduced cost of raising capital

Loan interest lower than market rates

(Indirect beneficiary)

In the first place, these potential indirect subsidies will be examined together and in general. With respect to the possibility of the direct tax incentive provided to investors in green projects conferring an indirect (non-tax) benefit on the investment funds and the green projects, the questions to be answered are: (1) is there a financial contribution (2) provided by the government (3) which confers a benefit?

As examined above in section Third-Party Project Investment Deduction - a Subsidy? dealing with the direct subsidy to the investors in green projects, it is clear that there is a financial contribution in the form of a lower tax liability which is provided by the government. ${ }^{118}$ Thus the only remaining question is whether this tax incentive actually confers an indirect benefit on the fund holder and producer of the end product (the electricity generator) as per Article 1.1(b) of the SCM Agreement.

Subsidies which confer a benefit on recipients indirectly have been examined by WTO panels and the Appellate Body on several occasions with respect to the calculation and imposition of countervailing duties. Countervailing duties may be applied to a product that is indirectly subsidised by virtue of a direct subsidy on an input product. Although an input product is not at issue here, the input of capital is.

WTO panels and the Appellate Body's interpretation of beneficiary is therefore relevant to establish whether there are indirect subsidies provided to the green 
projects through the investors and whether these potential subsidies are also subsidies within the meaning of the SCM Agreement and should be examined in turn for specificity under Article 2. Does the fund and/or the green project benefit from the tax incentive received by the investor? Since the SCM Agreement does not define the 'recipient of a benefit', 119 it should be examined as a whole in order to get a full picture of what can be considered to be a beneficiary. For example, the condition for the application of countervailing duties on downstream products is that the benefit has passed through to the end-product. ${ }^{120}$ The Panel in US - Softwood Lumber IV described the pass-through situation as follows: "[w]here the subsidies at issue are received by someone other than the producer of the investigated product, the question arises whether there is subsidization in respect of that product." 121 In this case, the subsidies are received by the investors, being someone other than the producer of the investigated product (renewable electricity), with the resulting question whether there has been indirect subsidisation of renewable electricity. Has the renewable energy project benefited from the tax subsidy provided to the investor?

In this examination, the relationship between the recipient of the subsidy and the alleged downstream beneficiary is an essential element. Therefore, the relationship between the subsidy recipient and the alleged beneficiary will now be addressed. In the case at hand the relationship concerns investors (or shareholders) and the producer of a good or the investment funds.

The Panel in US - Countervailing Measures on Certain EC Products considered the relationship between investors and the companies they invest in with the result that the Panel stated that 'for the purpose of the benefit determination under the SCM Agreement, [investigating authorities should make] no distinction ... between a company and its shareholders [because] ... [w] hen the SCM Agreement refers to the recipient of a benefit it means the company and its shareholders'. ${ }^{122}$ This clear statement would lead to the conclusion in the case at hand that it can be assumed that the benefit directly received by the shareholders in the green projects flowsthrough to the green projects since the two should be considered as one.

However, the Appellate Body overturned this 'overly broad finding' stating that such a finding 'that a firm and its owners are, for all purposes of the SCM Agreement, virtually the same, could be interpreted as entitling investigating authorities to assume, in all cases, that, for the purpose of calculating the benefit, and irrespective of the means and conditions imposed by a government for the provision of a

119 Several terms are used to refer to the 'recipient' of a 'benefit' in the Agreement. Article 2 refers to "an enterprise or industry or group of enterprises or industries"; Article 6.1(b) refers to "an industry"; footnote 36 to Article 10 refers to subsidies 'bestowed directly or indirectly upon the manufacture, production or export of any merchandise'; Article 14 refers to 'the firm'; Article 11.2(ii) refers to 'exporter or foreign producer'; Article 19.3 refers to 'sources found to be subsidized'; Annex I refers to 'a firm or an industry'; and Annex IV refers to the 'recipient firm'.

$120 \quad$ Appellate Body Report, US - Softwood Lumber IV, para. 142.

121 Panel Report, US - Softwood Lumber IV, para. 7.85. Gagné and Roch 2008, p. 557-560. In this dispute the timber harvesters received a subsidy in the form of stumpage rights, the downstream wood products lumber, and remanufactured lumber were deemed to benefit from the subsidy. Panel Report, US - Softwood Lumber IV, para. 7.54. 
financial contribution to owners of the firm, that firm will receive a benefit equivalent to the full financial contribution. This may or may not be so in all cases'. ${ }^{123}$

It is essential to note here that the Appellate Body did not wholly overturn the finding of the Panel in which case the result would have been that investors and the companies they invest in are not related and that a benefit cannot be seen to passthrough from the investors to the producer of the end product. The Appellate Body qualified the finding of the Panel limiting it to recognising that the benefit may not be passed on in full. The Appellate Body qualified the findings of the Panel recognising that there may be situations where, although a benefit is passed-on from the investors to the firm the investors invest in, not all of the benefit received by the investor is necessarily passed on. This interpretation only confirms that where a subsidy is conferred on a shareholder, a benefit passes on to the product. ${ }^{124}$ What remains to be seen is the value of that benefit in relation to the value conferred on the shareholder. What is not open for debate is that shareholders are related to the companies they invest in and are by no means operating at arm's length. ${ }^{125}$

In the same case, the Appellate Body considered that a tax incentive provided to the investors in the company could also reduce the cost of raising capital for the legal person - the company. In the words of the Appellate Body:

...it is possible to confer a "benefit" on a firm by providing a financial contribution to its owners, whether natural or legal persons, possibly holding property by means of shares. ${ }^{126}$

Furthermore, the Appellate Body stated that:

Appellate Body Report, US - Countervailing Measures on Certain EC Products, para. 118. In the same vein as the Appellate Body understood that there may be situations where not all of the benefit passes on to the end-product, it is also possible that, in exceptional circumstances, no benefit may pass on to the end-product.

Shareholders and the company they invest do not operate at arm's length. Unlike in US - Softwood Lumber IV where the Panel stated that 'where a downstream producer of subject merchandise is unrelated to the allegedly subsidized upstream producer of the input, an authority is not allowed to simply assume that a benefit has passed through', in this case the recipient and beneficiary are related. Panel Report, US - Softwood Lumber III, paras. 7.72 and 7.74. The Appellate Body Report, US - Softwood Lumber IV also supported that there can be no presumption of a flow-through of a benefit in cases of entities operating at arm's length. However for the situation at hand, this is being turned on its head where investments by shareholders are concerned. It does not hold for the case at hand as there is no at arm's length relationship. Panel Report, US Softwood Lumber III, para. 7.71; Appellate Body Report, US - Softwood Lumber IV, para. 143. Van den Bossche 2008. Panel Report, Canada - Aircraft Credits and Guarantees, para.7.80-7.81. Also in Canada - Aircraft Credits and Guarantees, the Panel stated that received a direct subsidy in the form of a tax exemption was received there could be no presumption that the benefit was passed on. In the words of the Panel: ' $[t]$ hat an entity enjoys certain tax advantages does not in and of itself prove that that entity is required to pass on those advantages to its clients in the form of subsidies within the meaning of Article 1 of the SCM Agreement'.

Appellate Body Report, US - Countervailing Measures on Certain EC Products, para. 113. 
Article VI:3 of the GATT 1994 and footnote 36 of Article 10 of the SCM Agreement contemplate this possibility by providing that a subsidy may be bestowed "indirectly" upon the manufacture, production or export of merchandise.

This is the situation at hand. A tax incentive is provided to holders of shares in a renewable electricity generation company, and an indirect benefit is derived by the company by virtue of the tax incentive - a reduced cost of raising capital.

The above analysis makes clear that there is a financial contribution, provided by the government which confers a benefit on the producer. The relationship between the recipient of the subsidy and the indirect beneficiary is not an at arm's length relationship and therefore there is a presumption of the pass-through of the benefit (albeit no presumption that all of the value of the subsidy has passed through). This is true for the three case studies with third party project incentive measures. All three measures (Ireland, Canada and the Netherlands) are subsidies conferred indirectly on the green projects within the meaning of Article 1.1 (a)(1)(ii), the benefit received by the green projects being reduced cost of raising capital. A benefit is received by the green project in the form of reduced cost of raising capital which in turn may lead to increased investment, increased share demand, increased share price, and increased sales.

In the case of the Netherlands, there is also a potential indirect benefit from this same tax incentive received by the investment fund. As examined above, there is a financial contribution in the form of revenue foregone from the government purse by virtue of the tax incentive to the investors. The benefit potentially received by the fund is the possibility to raise funds at a lower cost than market rate, due to the acceptance of the investor of lower interest rates since this loss is compensated by the tax incentive. Thus, this benefit is also a form of reduced cost of raising capital. The European Commission also considered this to be an advantage within state aid regulation. ${ }^{127}$

Therefore, as seen above, in addition to a direct subsidy ensuing from the tax incentive, two potential indirect subsidies also result from the same tax incentive as well as a potential third indirect subsidy to be examined under Article 1.1(a)(1)(iv) of the SCM Agreement below. Since the tax incentive in the Netherlands also results in the provision of low-interest loans to the green projects, the next section will examine whether the direct corporate tax incentive provided to the investors can also be deemed to be an indirect subsidy provided to the green projects through the investors in the form of low-interest loans.

\subsubsection{Indirect Beneficiary Article 1.1(a)(1)(iv)}

Before moving on to the question of specificity, the Dutch Green Funds tax incentive must be examined for its potential indirect benefits conferred on the green projects in the form of low-interest loans. The third-party project investment incentive in the Netherlands provides a benefit in addition to those discussed in the previous section (tax base reduction for investor and reduced cost of raising capital

127 State aid decision NN41/05, Green Funds - The Netherlands, para. 17. 
for the green projects). Of the total investments in the Green Funds scheme, a minimum of $70 \%$ must be used to provide loans, which end up being low interest loans, for the green projects. Not only is this a potential indirect benefit flowing through from the subsidy provided to the investors but it is also a potential direct and separate subsidy to the green projects under Article 1.1 (a)(1)(iv):

a government makes payments to a funding mechanism, or entrusts or directs a private body to carry out one or more of the type of functions illustrated in (i) to (iii) above which would normally be vested in the government and the practice, in no real sense, differs from practices normally followed by governments.

Where it can be shown that the banks participating in the Green Funds scheme are operating under the direction of the government, and acting as an agent of the government in providing low interest loans to the green projects, a separate and direct subsidy is at issue. This benefit is more easily quantified than the benefit of a reduction in the cost of raising capital. The direct financial benefit is the difference between the market interest rate and the reduced rate provided for by the 'green banks'. ${ }^{128}$

This type of measure was at issue in US - Export Restraints in which the Panel clarified that Article 1.1(a)(1) sub-paragraph (iv) aims to avoid that sub-paragraphs (i) to (iii) are circumvented by the government delegating its powers to a private body. ${ }^{129}$ However, for these Green Funds loans to fulfil Article 1.1 (a)(1)(iv), five requirements should be met. ${ }^{130}$ The government should have entrusted or directed the banks participating in the Green Funds scheme (being private bodies) ${ }^{131}$ to provide low interest loans (as described in Article 1.1 (a)(1)(i)). This practice of providing low interest loans should normally be a function 'vested in the government' and the practice of the banks does not differ from such a practice when carried out by the government. ${ }^{132}$

The Panel in US - Export Restraints examined the requirements of Article 1.1(a)(1)(iv) in detail, finding that the first requirement may concern the government executing a particular policy through a private body, in this case advancing development in renewable energy. However for there to be actual delegation, the Panel considered that there should be (1) an explicit and affirmative action, be it delegation or command; (2) addressed to a particular party; (3) the objective of which is a particular task or duty. ${ }^{133}$

In Korea-Commercial Vessels, the Panel qualified this test by limiting the requirement of an explicit affirmative act of delegation or command to a requirement of an implicit or explicit, formal or informal affirmative act of delegation of command. ${ }^{134}$ This

$128 \quad$ Benitah 2001, p. 397.

129 Panel Report, US - Export Restraints, para. 8.53.

130 Panel Report, US - Export Restraints, para. 8.25.

131 The Panel in US - Export Restraints explained that private bodies are deemed to be the 'counterpoint' to public bodies. A private body is a 'neither a government nor a public body'. Para. 8.49 .

132 Panel Report, US - Export Restraints, para. 8.25.

133 Panel Report, US - Export Restraints, para. 8.75.

134 Panel Report, Korea-Commercial Vessels, para. 7.370. 
broader interpretation was considered by the Panel to be a better reflection of the terms used in Article 1.1(a)(iv) of the SCM Agreement which nowhere refers to a requirement of an explicit act of delegation. Furthermore, the Appellate Body in US - Countervailing Duty Investigation on DRAMs took an even broader approach when interpreting the same provision by stating: “entrustment' occurs where a government gives responsibility to a private body, and 'direction' refers to situations where the government exercises its authority over a private body'. ${ }^{35}$ The Appellate Body further indicated that determining whether entrustment or delegation is at issue can only be done on a case-by-case basis, however, threat or inducement by the government to the private body could indicate a situation of entrustment or direction. ${ }^{136}$ It seems from these Reports that it is the intensity of the involvement of the government in the private body's action that will be pivotal in determining whether delegation is at issue or not. Since there is no concrete guideline provided by panels and the Appellate Body in these disputes, the result of such an examination is rather unpredictable. ${ }^{137}$

\subsection{Indirect Beneficiary Article 1.1(a)(1)(iv) Financial Contribution}

In order to determine whether the action of the Green Funds banks, providing low interest loans to the green projects, is a delegated government action the Green Funds Decree ${ }^{138}$ will be examined. This Decree lays down the conditions for financial institutions to be eligible to participate in the Green Funds scheme and the conditions for projects to be deemed green projects.

The only obligation for the financial institutions laid out in the Green Funds Decree ${ }^{139}$ is that (a) they must provide loans to the green projects ${ }^{140}$ and (b) this investment must be equal to a minimum of $70 \%$ of funds from investors under the Green Funds scheme. ${ }^{141}$ The financial institution must also ask for certification that the project being financed is a 'green project'. Once the financial institution receives this certification it may ${ }^{142}$ provide a loan to the said project. ${ }^{143}$

135 Appellate Body Report, US - Countervailing Duty Investigation on DRAMs, para. 116. Van den Bossche 2008, p. 565.

See also, Vander Schueren and Mizulin 2005, p. 199.

See also, Ibid., p. 199.

Staatscourant 11 July 2005, No. 131/p. 13, Regeling groenprojecten 2005.

Ibid.

Staatscourant 11 July 2005, No. 131/p. 13, Regeling groenprojecten 2005, p. 21, Toelichting, para. 2 .

141 Staatscourant 11 July 2005, No. 131/p. 13, Regeling groenprojecten 2005, p. 22, Toelichting, para. 2 .

142 The use of this word 'may' is relevant for the mandatory/discretionary character of the legislation with regard to the conferral of the benefit. Sim 2003, p. 53 referring to Webster's Third New International Dictionary stated: 'The dictionary meaning of 'shall' is 'used in law, regulations or directives to express what is mandatory', and 'may' is commonly understood to be permissive and not imperative. However, depending on the purpose of the legislation, the word 'may' has sometimes been interpreted as 'shall', and hence imperative rather than permissive'.

143 Staatscourant 11 July 2005, No. 131/p. 13, Regeling groenprojecten 2005, p. 22, Toelichting, para. 2 . 
Although from the wording of the Decree it would seem that indeed the financial institutions are commanded to do something (provide loans to the green projects); it is a different question whether the government is delegating a task to the bank. For delegation to be at issue, the bank should be commanded by the government to do something that usually is the mandate of the government and the government should be executing a particular government policy through the private body. Thus the next question is whether providing the loans to the green projects would normally be an activity carried out by the government.

First and foremost, in general, it would seem, by the mere existence of subparagraph (i) of Article 1.1(a)(1), providing loans can be and is an accepted activity of governments: 'a government practice involves a direct transfer of funds (e.g. grants, loans...)'. Otherwise, there would be no need to include the word 'loans' in this subparagraph as a potential subsidy. Furthermore, in general, it has been known that to fulfil some policy objectives in the past, the Dutch government has provided loans. ${ }^{144}$ Furthermore, recently the Dutch government announced its intention to set up an Energy Conservation Fund which would aim to provide for low interest loans for energy-saving investments in buildings. ${ }^{145}$

It is clear that governments, including the Dutch government, can have the mandate of providing loans and indeed carry out this activity. Providing loans is an activity that is carried out by the government to execute some specific policy objectives. Furthermore, these green loans form part of a larger environmental policy objective of the Dutch government which they also delegate to the banks. The banks, by providing loans to green projects, on the command of the government and having that task delegated to them by the government, contribute to the larger policy objective of the Dutch government that is to stimulate the development of environmentally-friendly projects.

There is an explicit and affirmative action by the Dutch government, embodied in the Green Funds Decree, which commands the financial institutions to provide loans to the green projects. The government thus delegates this task to the financial institution since it is an activity which it can have and does have the mandate for. This explicit and affirmative action is directed to a particular party (eligible financial institutions as provided for by the Green Funds Decree) and the objective is the action of providing the said loans. ${ }^{146}$

\subsection{Indirect Beneficiary Article 1.1(a)(1)(iv) Benefit}

From the foregoing, it was established that since the government commands the financial institutions to provide loans to the green projects, a potential subsidy is at issue. It is important to note that the foregoing discussion addressed loans as opposed

144 Neth. 3 of Housing and Environmental Res., Vol. 3 (1988) No. 4. In the Dutch public housing sector of the late I970s and early 1980s, loans for public housing were granted by the government. The Dutch government has also provided government loans to support the Dutch financial system. <http://www.mayerbrown.com/public_docs/ 0214fin_Netherlands.pdf $>$; last visited 24 November 2009.

$145<$ http://www.vrom.nl/pagina.html?id=39136>; last visited 24 November 2009.

146 Panel Report, US - Export Restraints, para. 8.53. 
to specifically addressing low interest loans. If the previous discussion was intended to establish whether the Dutch government delegates the activity of providing low interest loans to green projects to the financial institutions, the result would have been the opposite - that there is no such delegation by the Dutch government. In the Green Funds Decree, there is no explicit requirement for the financial institutions to provide low interest loans to the green projects, although there is indeed an explicit requirement to provide loans per se.

Article 1.1(a)(1)(iv) requires that a government delegates an action, which is listed in Article 1.1(a)(1)(i) to Article 1.1(a)(1)(iii), to a private body. In this case that refers to a government loan. Article 1.1(a)(1)(i), with reference to government loans, makes no mention of low interest loans. It is sufficient to first establish that such a loan is provided.

Whether a loan is a low interest loan or not is relevant to establish whether the potential subsidy under Article 1.1(a)(1)(iv) confers a benefit as per Article 1.1(b). Since a government loan will only be a financial contribution which confers a benefit to the extent that it is available under conditions more favourable than those available on the market. ${ }^{147}$ A benefit is conferred by a government loan (i) or by a loan provided by a private body to execute a particular government policy (iv) when that loan is provided at an interest rate lower than the market level interest rate.

In all brochures and information pertaining to the Green Funds, it is stated that the loans are provided by the participating financial institutions to the green projects at an interest rate of 1 to $2 \%$ lower than the market rates. However, in the Green Funds Decree, there is no explicit legal requirement that the loans provided by the financial institutions be provided at an interest rate lower than market rates. According to the Green Funds Decree, the banks can provide low interest loans to the green projects because of the tax incentive provided to the investors. ${ }^{148}$ The investors, by investing in green projects receive a lower than market rate return on investment and this provides the bank with the possibility to pass on this saving to the green projects in the form of lower than market rate interest rates. ${ }^{149}$ Furthermore, in the European Commission's examination of the Green Funds scheme for compatibility with the state aid rules, it stated that 'the tax relief for individual tax payers potentially enables the 'green projects' being financed at lower interest rates than otherwise would have been the case' [emphasis added]. ${ }^{150}$ In the same State aid decision, the Commission states: ' $[t]$ he funds are free to decide in which project they invest and which price they charge for their investment'. ${ }^{151}$

\footnotetext{
$147 \quad$ Van den Bossche 2008, p. 567.

148 Staatscourant 11 July 2005, No. 131/p. 13, Regeling groenprojecten 2005, p. 21, Toelichting, para. 2 .

150 State aid decision NN41/05, Green funds - The Netherlands, para. 3. In the Dutch version of this State aid decision, it is stated: 'Door de belastingkorting voor individuele belastingplichtigen kunnen de groenprojecten tegen een lagere rentevoet worden gefinancierd dan anders het geval zou zijn'.[emphasis added]

151 State aid decision NN41/05, Green funds - The Netherlands, para. 41
} 
It would seem that rather than the government delegating the task of providing low interest loans to green projects, the government provides an opportunity to the financial institutions to re-distribute gains between the investors and the borrowers, with the result that the projects receive low interest loans.

In the normal situation, an investor will only invest where the return on investment is financially viable. This also determines at what interest rate the banks can afford to loan capital to projects. In this situation, however, by providing that dividends and savings from these green projects are tax-free (foregoing tax of $1.2 \%$ on the total investment $)^{152}$ the government creates a situation where an investor can invest in the green projects, receiving a lower return on investment than normally financially viable. The whole investment becomes financially viable since the low return on investment in compensated by the reduction in tax liability compared to the tax liability for normal investments. In turn, with the surplus financial means resulting from the low return on investment, the bank is in the financial position to charge a lower loan interest to the green projects.

\section{Normal Investment Situation}

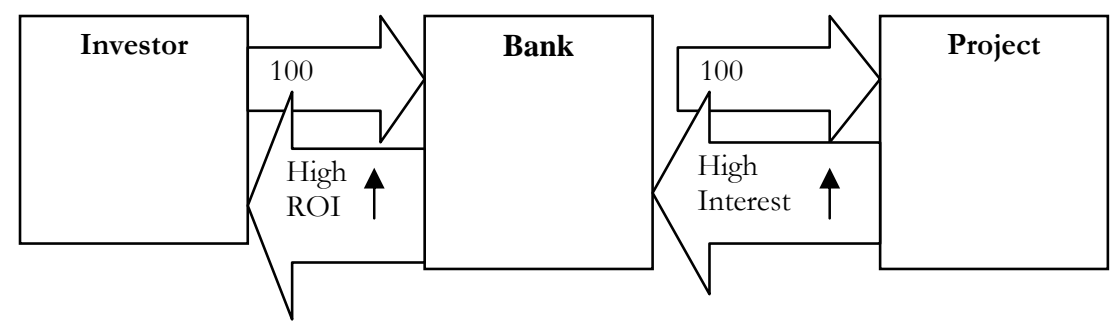
of $30 \%$ which is applied to a tax base which is equal to a fictional yield on investment of $4 \% .30 \% \times 4 \%=1.2 \%$. E.g. With an investment of $€ 100,000$, the fictional yield is $€ 4,000$ which is taxed at a rate of $30 \%$ resulting in a tax liability of $€ 1,200$ (also $1.2 \%$ of $€ 100,000)$. 


\section{Green Project Investment Situation}

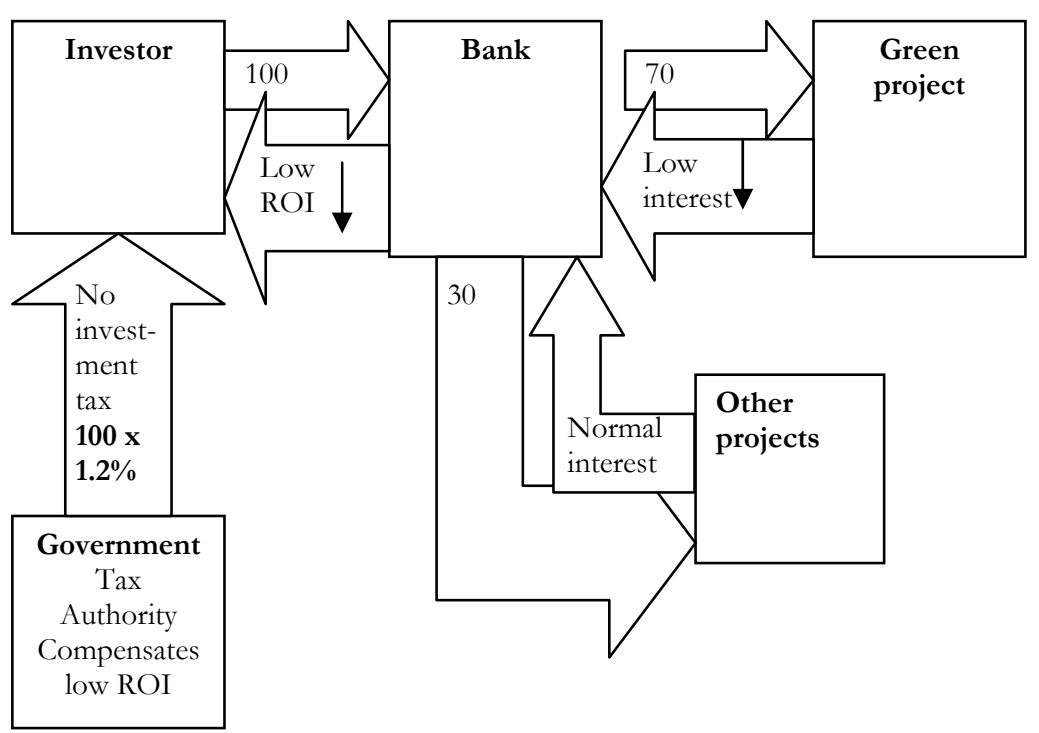

The diagrams above aim to show that there is no flow of funds from the government to the green projects, via the private banks. The low interest loans only result from a balancing of the costs of the borrower and the gains of the investors by the bank. Where there is a high return on investment for investors, there will be a high cost of capital for the borrower and vice versa.

Thus perhaps it is misleading to examine the 'confers a benefit' part of the subsidy test in isolation from the 'conferral of a financial contribution' part of the subsidy test. This is especially so when the discretion to confer a financial contribution and the discretion to confer a benefit by virtue of that financial contribution are not both in the hands of the government.

Where government loans are at issue, under Article 1.1(a)(1)(i), and those government loans are provided at low interest rates, the discretion to provide low interest rates or normal market rates is in the hands of the government. Thus, the discretion to provide a measure which falls within Article 1.1(a) and the discretion to provide this measure in a manner which confers a benefit fulfilling the conditions of Article 1.1(b) are both in the hands of the government. However, when this situation is compared to the one at hand, under Article 1.1(a)(1)(iv), the discretion to provide the measure is in the hands of the government while the discretion to provide the measure in a manner which confers a benefit fulfilling the conditions of Article 1.1(b) is in the hands of the individual private bank.

This issue, however, overlaps with the discussion whether the net cost to the government would be a relevant benchmark to determine the value or even the existence of a benefit. As the Appellate Body in Canada - Aircraft stated, 'the focus of the inquiry under Article 1.1(b) of the SCM Agreement should be on the recipient and 
not on the granting authority'. ${ }^{153}$ Furthermore, the Appellate Body stated that the cost to the government as determining benefit is 'at odds' with the ordinary meaning of Article 1.1(b) 'which focuses on the recipient and not on the government providing the "financial contribution". ${ }^{154}$ However, does this not imply that it is indeed the government which has discretion to provide the benefit, regardless whether providing that benefit or not is at any cost to the government or not. I venture to say that this rejection of the cost to the government argument does not preclude an interpretation that maintains that, regardless of cost, the discretion to provide a benefit or not should be in the hands of the government. In the case at hand, this would involve the government explicitly requiring the financial institution to provide low-interest loans as opposed to the government requiring the financial institution to provide loans and leaving it to the discretion of the bank whether those loans are at a low interest rate or not.

It is worthwhile to mention again the clarification of the Panel in Korea - Commercial $V$ essels, of the requirements for delegation as per Article 1.1(a)(1)(iv) of the SCM Agreement to be at issue. The Panel considered that even implicit and informal delegation would suffice for Article 1.1(a)(1)(iv) of the SCM Agreement to be fulfilled. ${ }^{155}$ Since determining whether entrustment or delegation is at issue can only be done on a case by case basis, ${ }^{156}$ the following section will aim to show that although there is no explicit mandatory legislation requiring the Green Funds to extend low interest loans to the green projects, this does not preclude the system falling within the ambit of Article 1.1(a)(1)(iv) of the SCM Agreement. I proffer that in addition to the developments in Korea - Commercial Vessels, a further line of argumentation bolsters the coverage of situation such as the Green Funds scheme by Article 1.1(a)(1)(iv) of the SCM Agreement. This argumentation calls upon the treatment of mandatory versus discretionary legislation in WTO law.

\subsection{Mandatory Versus Discretionary Conferral of a Benefit}

When legislation is challenged 'as such' for WTO-consistency, rather than the application of that legislation, only legislation that mandates inconsistency with the WTO agreements or precludes consistency with the WTO agreements can be found to be WTO-inconsistent. ${ }^{157}$ The objective of permitting legislation as such to be challenged was put as following by the Panel in US - Export Restraints stated that:

\footnotetext{
153 Appellate Body Report, Canada-Airraft, para. 157.

154 Ibid.

155 Panel Report, Korea-Commercial Vessels, para. 7.370.

156 See also, Vander Schueren and Mizulin 2005, p. 199.

157 Sim 2003, p. 33-34. This 'classical' mandatory/discretionary test was further clarified by the Panel in US - Section 301 Trade Act. The Panel did not overturn the classical test in which only legislation mandating WTO-inconsistency or precluding WTO-consistency can be found to be WTO-inconsistent. Rather, the Panel recognised that it is possible that, in addition to these two situations, legislation which grants discretionary powers may also be found to be WTO-inconsistent to the extent that the exercise of that discretion precludes WTO-consistency (and thereby fails the classical test). The Panel also emphasised in its further clarification of the mandatory/discretionary distinction that it is imperative that the contested measure be examined in light of the particular WTO-obligation at issue rather than 'in abstract'. Depending on the WTO obligation at
} 
'the distinction between mandatory and discretionary legislation has a rational objective in ensuring predictability of conditions for trade. It allows parties to challenge measures that will necessarily result in action inconsistent with GATT/WTO obligations, before such action is actually taken. ${ }^{158}$

To order to examine whether the Dutch Green Funds measure 'as such' would be WTO-consistent it will be examined whether the conferral of a benefit would be deemed to be mandatory or discretionary in the first place. In the Green Funds scheme, the banks are required to extend loans to the green projects, however there is no such obligation to extend low interest loans. It is this 'conferral of a benefit' which is at issue here.

In Brazil - Aircraft (Article 21.5 Canada II), the Panel considered that the programme in question allowed the lender to offer better export credit terms that it would otherwise be able to offer and as such could allow borrowers to acquire conditions better than those available otherwise on the market and could thus confer a benefit. In the words of the Panel: 'to the extent that PROEX III required Brazil, in some situations, to make PROEX III payments that would result in a benefit being conferred in respect of regional aircraft, the PROEX III programme would be mandatory legislation (in respect of the conferral of a benefit) and thus a subsidy potentially inconsistent with the SCM Agreement. ${ }^{159}$

At issue in Brazil-Aircraft was mandatory legislation (with respect to the conferral of a benefit) which was to be applied in some cases. With respect to the Green Funds scheme, the situation is so extreme as there is no legislation that mandates the conferral of a benefit. Essentially the conferral of a benefit is not covered by the legislation. Thus in this case there is no mandatory legislation addressing the conferral of a benefit.

In the words of the Panel in Canada-Aircraft and Guarantees:

[T]o satisfy the 'benefit' element of Article 1.1 of the SCM Agreement for purposes of a challenge to [the programme at issue] as such, [the complainant] must show that the programme requires conferral of a benefit, not that it could be used to do so, or even that it is used to do so.

In the same case, the Panel examined the particular situation of tax advantages. The granting of tax advantages per se does not prove that the entity is required to pass on those advantages to its clients in the form of Article 1 subsidies.

Brazil submits that ECAs benefit from a competitive advantage over their private sector competitors (because ECAs do not pay taxes, for example), and this enables them to offer more favourable terms than those available in the private sector. That an entity enjoys certain tax advantages does not in and of itself prove that that entity is

issue, it is possible that discretionary legislation may be WTO-inconsistent since the use of that discretion would inevitably go against the WTO obligation at issue. See Panel Report, US - Section 301 Trade Act, para. 7.53 and fn 675. 
required to pass on those advantages to its clients in the form of subsidies within the meaning of Article 1.160

In more recent disputes, the mandatory/discretionary distinction has been given a new lease of life. In the context of this thesis, since the legislation in question would be challenged for consistency with the SCM Agreement, it is pertinent to address a dispute where consistency with the SCM Agreement was challenged, namely US Countervailing Measures. ${ }^{161}$ The Panel held that US legislation which permitted the imposition of certain countervailing duties could not itself be found to contravene the SCM Agreement. Rather, the Panel considered that 'the aggregate effect of the legislative history, object and purpose' of the legislation and the interpretation of that legislation by the US judiciary mandated the application of the legislation in a manner inconsistent with the SCM Agreement. ${ }^{162}$ The Panel went on to state:

While only legislation that mandates a violation of WTO obligations can be WTOinconsistent, we are of the view that the existence of some form of executive discretion alone is not enough for a law to be prima facie WTO-consistent, what is important is whether the government has an effective discretion to interpret and apply its legislation in a WTO-consistent manner. ${ }^{163}$

Essentially the Panel determined that although the legislation in question was discretionary at face value, it was in effect mandatory and thus could be deemed to be inconsistent with the SCM Agreement. ${ }^{164}$

On appeal, the Appellate Body (not) addressing the mandatory/discretionary distinction only had the following to say on that matter:

We are not, by implication, precluding the possibility that a Member could violate its WTO obligations by enacting legislation granting discretion to its authorities to act in violation of its WTO obligations. We make no finding in this respect'. ${ }^{\prime 65}$

Although the Appellate Body did not consider that it was pertinent to make a bold statement on the possibility that de facto mandatory legislation could also be WTOinconsistent, the Appellate Body at least clarified, in a dispute concerning the SCM Agreement, that it is possible that de facto mandatory legislation could be found to be WTO-consistent.

It is thus clear that with respect to inconsistency with the SCM Agreement, legislation which de jure leaves discretion to the government, but de facto this discretion can only be applied in a WTO-inconsistent manner, the de jure discretionary nature of the legislation can be set aside and rather would be deemed to be de facto mandatory.

160 Panel Report, Canada-Aircraft Credits and Guarantees, para. 7.80.

161 As addressed above, in US - Section 301 Trade Act, the Panel stated that the mandatory/discretionary distinction should be examined in light of the WTO obligation at issue and not in the abstract. Supra note 157.

162 Panel Report, US - Countervailing Duties, paras. 7.156-7.157.

Panel Report, US - Countervailing Duties, para. 7.123.

Sim 2003, p. 53.

Appellate Body Report, US - Countervailing Duties, fn 334. 


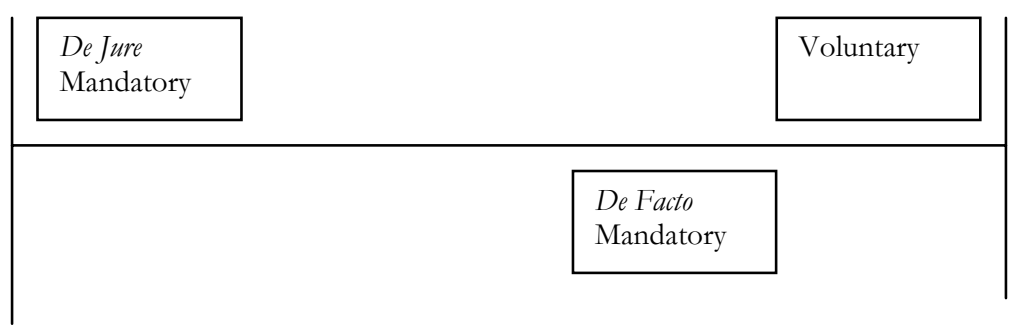

The Green Funds Decree would not be deemed mandatory legislation with respect to the conferral of a benefit since the conferral of a benefit is not addressed in the legislation. Furthermore, the government does not retain the discretion to interpret and apply the legislation in a WTO-consistent manner as the discretion to confer a benefit is in the hands of the banks. However, although the legislation is neither mandatory legislation nor legislation which de jure leaves discretion to the government, it nevertheless creates a situation in which, de facto, the discretion would be exercised in a WTO-inconsistent manner. Despite this, since the discretion (exercised in a WTO-inconsistent manner) is not exercised by the government, this measure could not be found to be WTO-inconsistent. This, one may argue, may be in line with the intention of the SCM Agreement which essentially may only attach rights and obligations to the governments of the WTO Members and not to private bodies to the extent that they act independently. Therefore, to the extent that the discretion to confer a benefit is in the hands of the private body (bank) an SCM Agreementinconsistent measure is not in question.

Although the Green Funds Decree does not provide for a de jure obligation that the banks provide low interest loans and thus, confer a benefit, it is obvious that without the government tax incentives to the investors, the banks would not give low interest loans to the green projects. In fact there is a form of a 'but for' test which emerges here. 'But for' the financial contribution provided by the government to the investors, there would be no low interest loans available for the green projects. The fact that this is not spelled out in the Decree is beside the point. The link between the two actions is, however, addressed in the Decree. There is a clear causal link between the government tax incentive and the benefit conferred on the green projects. According to the Green Funds Decree, the banks can provide low interest loans to the green projects because of the tax incentive provided to the investors. ${ }^{166}$ In the following paragraphs I will argue that this causal relationship, which is also admitted in the Decree itself results in a de facto mandatory requirement of the conferral of a benefit.

A system which results in the provision of lower than market interest rate loans and which avoids being found to be a subsidy within the meaning of the SCM Agreement because the discretion to confer a benefit is in the hands of a private bank rather than the government essentially circumvents the SCM Agreement. This is especially a

166 Staatscourant 11 July 2005, No. 131/p. 13, Regeling groenprojecten 2005, p. 21, Toelichting, para. 2 . 
problem since the low interest loans provided to green projects are incited by the provision of government tax incentives to investors in the same projects.

The existence of a de facto mandatory conferral of a benefit is also relevant and important with respect to Article 1.1(a)(1)(iv) of the SCM Agreement. The limitation of this section to measures which de jure mandates the conferral of a benefit by the private body would allow national governments to circumvent the provisions of the SCM Agreement and thereby fun afoul of the very purpose of this provision. ${ }^{167}$ The lack of a de jure mandatory requirement that the banks confer a benefit on the green projects in the form of low interest loans (thus making the conferral of a benefit also a task delegated by the government) seems to allow the same result that Article 1.1(a)(1)(iv) SCM Agreement aims to avoid - namely the circumvention of the provisions of Article 1.1(a)(1)(i) - (iii) of the SCM Agreement. This circumvention occurs since the government delegates the task of providing the financial contribution to a private body but does not mandate that the private body confer a benefit with this financial contribution. In the situation at hand, if the lack of a mandatory requirement to confer a benefit allows these low interest loans to fall outside the scope of the SCM Agreement, the current understanding of the mandatory/discretionary distinction results in a situation which runs afoul of the very purpose of Article 1.1(a)(1)(iv) SCM Agreement.

Relying only on the de jure mandatory or de facto mandatory conferral of a benefit (only where the government maintains the discretion to confer the benefit) with respect to this measure contradicts and is inconsistent with the purpose of Article 1.1(a)(1)(iv). Such an interpretation would allow the government to circumvent the SCM Agreement merely by failing to explicitly spell out in law that the private body should confer a benefit, while at the same time de facto creating a situation in the market whereby the private body will confer a benefit. For this reason, a new approach to the mandatory/discretionary distinction, with regard to the mandatory conferral of a benefit in relation to Article 1.1(a)(1)(iv) financial contributions is necessary.

WTO panels and the Appellate Body, perhaps without using the same words, have come to the same result of applying a distinction between mandatory, discretionary and de facto mandatory legislation by addressing the effects of the legislation rather than merely examining the character of the legislation in isolation. ${ }^{168}$

In the case at hand, a clear distinguishing factor is the 'system' put in place by the Dutch government (providing tax incentives to the investors), which creates the market situation in which the banks confer the benefit on the green projects by virtue of the low interest loans. The government also provides a financial benefit to the banks to give an incentive to comply with this system as only $70 \%$ of the investments related to Green Funds must be invested in those green projects, leaving 30\% of the funds being invested in 'normal interest rate' investments. ${ }^{169}$ Perhaps this can been seen as an incentive provided by the government to extend the low interest loans and

167

Panel Report, US - Export Restraints, para. 8.53.

Sim 2003, p. 53.

See diagram where the $30 \%$ of invested funds can be in projects other than green projects at normal interest rates. 
bolsters the argument that the conferral of a benefit is de facto mandatory and thus can also be deemed to be SCM Agreement-inconsistent.

In conclusion, in examining the Dutch Green Funds scheme as such, and thereby applying the mandatory/discretionary distinction, since there is no explicit requirement in the legislation to extend low interest loans, the legislation is discretionary. Furthermore, the government does not maintain the discretion to ensure that the Green Funds scheme is WTO-consistent but rather gives that discretion to the private banks by permitting the banks to decide whether the loans are low interest or not. Based on this reasoning the measure is not a subsidy (within the meaning of Article 1 SCM Agreement) since although the conferral of a financial contribution is a (de jure) task delegated by the government, there is no conferral of a benefit by the government, or (de jure) delegated by the government. This is true to the extent that the banks are not mandated to provide the loans at a low interest rate and thus there is no mandatory conferral of a benefit. However, as is my proposal, the mandatory/discretionary distinction should be read in a more broad way taking into account the very purpose of Article 1.1(a)(1)(iv) and deemed to include the de facto conferral of a benefit by the private actors which were delegated to confer the financial contribution.

This reasoning would be bolstered by the acceptance by the Panel in Korea Commercial Vessels, ${ }^{170}$ addressing Article 1.1(a)(1)(iv) of the SCM Agreement, that implicit and informal delegation also falls within its ambit. If this proposal is taken on board, I believe that this would result in the green projects being deemed to be in receipt of low interest loans which are de facto mandated by the system put in place by the government despite their not being mandated by the legislation and thus subsidies falling within the meaning of Article 1.1(a)(1)(iv) which confer a benefit.

The following section returns to the Green Funds scheme as examined above under Article 1.1(a)(1)(ii) and Article 1.1(a)(1)(iv) in order to determine whether these third party investment schemes also potentially fulfil the conditions of Article 2 of the SCM Agreement and are specific subsidies.

\subsubsection{Third-Party-Project Investment Deduction - A Specific Subsidy?}

In the sections above, one direct subsidy and three indirect subsidies were examined which stem from the third party project investment tax incentives. The three beneficiaries (investor, green funds and green projects) of these direct and indirect subsidies will be examined to determine whether the various permutations of the tax incentives are specific, thereby fulfilling Article 2 of the SCM Agreement.

Again the question is whether access to the subsidies is limited to certain enterprises by the granting authority; whether neutral and objective criteria or conditions, which are economic in nature and horizontal in application and strictly followed, determine eligibility for the subsidy and whether the subsidy is effectively only accessed by a limited number of enterprises; the amounts of subsidy provided are allocated 
disproportionately or dubious discretion is exercised by the granting authority in deciding on recipients.

\subsubsection{Specific to Investors (Ireland, Netherlands, Canada)?}

Eligibility for the third party project investment incentive is open to all economic actors, regardless of their activity. It applies once the investor invests in a designated green project. The investor should, however, be subject to taxation in the country in question (Ireland, the Netherlands, Canada) and the green project invested in should be certified and be situated in the country providing the incentive. The role of the investor - be it an individual or a company - is irrelevant. The tax incentives are not de jure specific since all individuals and businesses are eligible to have access to the incentive. The only condition is to invest in a green project - a condition which is economic in nature and horizontal in application. The tax subsidy applies across the board to all economic actors. ${ }^{171}$ This is not a specific subsidy within the meaning of Article 2 of the SCM Agreement.

\subsubsection{Specific to Investment Funds?}

Conditions for eligibility for access to the indirect benefits derived from the Green Funds tax incentive in the Netherlands are set out in the Green Funds Decree. Only investment funds may act as Green Funds. This indicates that the benefit conferred on the Green Funds themselves is specific. In the words of the European Commission 'it favours one particular branch of activity, namely investment funds' ${ }^{172}$ This indirect benefit from the tax incentive is explicitly limited to a certain group of enterprises by virtue of the conditions laid down in the Decree. The benefit is the possibility for fund, by virtue of the tax incentive, to attract money at lower rates of return than would otherwise be acceptable to investors without the tax advantage investors receive by investing.

171 At the EU level, in general, the Green Funds scheme was deemed to be compatible State aid. However, in particular with respect to the aid granted in the form of a tax incentive to the investors, the Commission considered that, at this level, this part of the aid is not State aid within the meaning of Article 87(1). See State aid decision NN41/05, Green Funds - The Netherlands, para. 16. 'At the first level, the measure benefits those that invest their money in green funds, i.e. the taxpayers. The measure is open to everyone and the tax credit available is unlimited. It is of a general character and does not, at this level, favour certain undertakings within the meaning of Article 87(1) EC Treaty'. The Commission also examined the indirect beneficiaries, the investment funds and the green projects with the conclusion that, at these levels, the second and third levels, an advantage is indeed granted and therefore 'a significant part of the aid' results in State aid within the meaning of 87(1) EC. See State aid decision NN41/05, Green Funds - The Netherlands, para. 21. However, although the aid to the indirect beneficiaries is State aid, it is compatible State aid since it is in conformity with Article 87(3)(c) EC and the Community Guidelines on State Aid for Environmental Protection.

172 State aid decision NN41/05, Green Funds - The Netherlands, para. 17. 


\subsubsection{Specific to Green Projects?}

The conditions which determine whether a project is an eligible 'green project' and therefore whether the investment in that project is eligible for the tax break are relevant to determine whether the subsidy is de jure specific. The conditions which must be fulfilled for a project to be considered a 'green project' are that the government must certify that the project meets certain sustainable energy requirements and the project should be situated in the country providing the tax incentive.

Since this thesis is concerned with renewable electricity generation, the issue to be explored is whether the tax incentive to the investors is an indirect specific subsidy to renewable energy companies. The tax incentive should be specific, and in this case, de jure or de facto specific to the renewable energy companies according to Article 2 of the SCM Agreement for a further examination of this indirect subsidy against Part III of the SCM Agreement.

Thus the conditions for eligibility should not limit the (indirect) subsidy to certain enterprises; the conditions should be neutral and objective, and be economic in nature and horizontal in application and strictly followed in order to avoid being specific. It is also relevant whether the subsidy is effectively accessed only by a limited number of enterprises; the amounts of subsidy provided are allocated disproportionately or dubious discretion is exercised by the granting authority in deciding on recipients.

These conditions will now be examined per case study separately.

\subsection{Ireland}

The company carrying out the renewable energy project must be incorporated and solely resident in Ireland and 'exists solely for the purposes of undertaking a qualifying energy project'. ${ }^{173}$ The renewable energy project must be in developing wind, solar, hydro or biomass power and the project must also be approved as a qualifying project by the Minister for Public Enterprise.

This indirect subsidy to green projects in Ireland is clearly specific. The legislation explicitly limits access to the (indirect) subsidy to certain enterprises, namely renewable energy generators. This measure, being a specific subsidy within the meaning of Article 1 and Article 2 of the SCM Agreement will therefore be examined for consistency with Part III of the SCM Agreement.

\subsection{Netherlands}

The Green Funds scheme in the Netherlands covers 11 categories of environmentally-friendly investment projects including, for example, forestation

\footnotetext{
173 Finance Act 1998, Section 486B, 'qualifying company'.
} 
projects, sustainable energy projects and environmental technology. ${ }^{174}$ The conditions attached to this incentive are also that the investment must be in new assets situated in the Netherlands for the purpose of carrying out the green project in the Netherlands. ${ }^{175}$ Furthermore, the capital of the project should be at least $€ 22,689$ and the benefit of the project to the environment should be immediate. ${ }^{176}$ Since renewable energy projects only form one category of covered green projects out of eleven, this sector is not specifically promoted by the government. Although renewable energy generators are not specifically targeted, the measure may still be specific to a larger group or sector of which renewable energy generators form a part - namely the sector 'green projects'.

This was the case in the European Commission examination of the Green Funds scheme against the State aid rules. The Commission stated: 'The measure is of selective nature as it benefits only entities exploiting green projects that are eligible under the scheme'. Furthermore, considering the approach taken to 'specificity' by panels and the Appellate Body in the Softwood Lumber dispute, it is not implausible that WTO panels and the Appellate Body would consider whether companies carrying out green projects - whether that is forestry or generation of renewable energy - would indeed constitute a specific sector or industry. However, I am convinced that the result of this examination would be negative. The sectors and industries covered by the green projects in the Green Funds scheme are even more diverse that those that were at issue in the Softwood Lumber dispute. In Softwood Lumber all of the industries in question at least had one thing in common their input was the same product: softwood lumber, regardless of the resultant end product. Here, there is no such overlap of activities and/or inputs. The only overlap is that the activities all contribute to a more sustainable environment. This includes forestation, nature reserves, agriculture, greenhouses, energy generation, housing, cycling infrastructure, rehabilitation of polluted sites and the last category leaves room for this list to be open - other innovative and high quality projects that are deemed to be in the interest of the protection of the environment, including nature and forest.

With the issue of specificity, the focus should not stray away from the free trade objective of the rules disciplining subsidisation. Subsidies are permissible as long as they do not provide an unfair trade advantage to a specific sector of industry. In view of an ever-increasing importance and interest of 'greening-up' industry, it would be a dubious move of panels and the Appellate Body to rule that 'green projects' such as those relevant for the Dutch Green Funds scheme constitute a specific group of industries within the meaning of Article 2 SCM Agreement. This is especially so considering that the only common denominator of the projects is their 'green' nature as opposed to having a particular input product as a common denominator. With an eye on the future, such a determination would open the door for a much broader

$174 \quad$ De Waard and Zom 2000, p. 372.

175 Vermeend and Van der Vaart 1998, p. 61 See also SenterNovem, Green Funds Scheme: <http://www.senternovem.nl/greenfundsscheme/finance/the_green_ certificate.asp>. Although the main rule is that the project be carried out in the Netherlands, it is also possible to carry out such a green project in the Netherlands Antilles and/or Aruba and claim the tax benefits.

176 See SenterNovem, Green Funds Scheme: <http://www.senternovem.nl/greenfunds scheme/finance/the_green_certificate.asp $>$. 
interpretation of 'specific' than has been the case to date. This is so under the assumption that, in the future, the majority of industries will be active in contributing to a sustainable environment, and thus could never constitute a specific group of limited companies.

In conclusion, I proffer that subsidies conferred on the green projects provided for in the Green Funds scheme, are not specific to a group of enterprises or industries within the meaning of Article 2 of the SCM Agreement and furthermore, renewable energy companies are not de jure specifically targeted. The scheme has a general coverage in that all companies that wish to undertake activities contributing to a sustainable environment which are within the listed activities would be eligible for Green Funds investments and eligible for requesting certification.

The de facto specificity of this indirect tax incentive is another matter. Whether the green projects involved in the Green Funds scheme are disproportionately represented by green electricity generators would indeed lead this measure to be deemed to be nevertheless specific. Here the question is whether the incentive is effectively only accessed by a limited number of economic actors; whether the amounts of subsidy provided are allocated disproportionately; or whether dubious discretion is exercised by the granting authority in deciding on recipients.

There is no evidence that the Green Funds scheme has been availed of disproportionately by one sector within the 11 categories of sustainable energy sectors covered or that the government, in awarding these declarations, has used dubious discretion.

\subsection{Canada}

The conditions relating to implementing the flow-through share option is that the (green) company is a 'principal business corporation', being a corporation whose primary activity is a combination of several specific activities which, since the introduction of the CRCE, includes generation of energy with equipment within CCA Class 43.1 and projects in which at least $50 \%$ of the capital involved falls within the scope of Class 43.1.177 This incentive was introduced specifically for renewable energy development and thus at least $50 \%$ of the capital in the company has to relate to equipment for electricity generation and heat generation - including renewable energy assets such as solar, wind, hydroelectric, heat recovery and cogeneration systems. The equipment should be situated in Canada ${ }^{178}$ and used for gaining income in a business setting.

It is clear that this indirect subsidy to the green project is explicitly set up to limit the access to the incentive (flow-through shares) to a certain group of enterprises, namely enterprises of which at least $50 \%$ of their activity is renewable energy generation. This is a specific indirect subsidy within the meaning of Article 1 and Article 2 SCM Agreement. 


\subsubsection{Third-Party-Project Investment Deduction - Conclusion}

The foregoing sections illustrated that with respect to the third-party-project investment deductions in Ireland, the Netherlands and Canada, and the various permutations of those measures as both direct and indirect subsidies, they are all three subsidies within the meaning of Article 1 SCM Agreement, including three forms of indirect subsidies ensuing from the direct tax incentive. Furthermore all three tax incentives have elements of specificity leaving them open for examination for consistency with Part II and III SCM Agreement. This examination is the substance of the following chapter. It should be borne in mind that although considered to be specific subsidies within the meaning of Article 1 and 2 of the SCM Agreement, these measures are not thereby per definition inconsistent with the SCM Agreement. ${ }^{179}$

$179 \quad$ Stilwell and Bohanes 2005, Chapter 58, p. 548. 


\section{Government}

Tax incentive

Investment taxes foregone

\section{Investor}

Advantage - tax break

Exempt from investment tax

(Direct beneficiary)

$\begin{array}{ll}\text { Subsidy } & \text { (Direct) } \\ \text { IE } & \checkmark \\ \text { NL } & \checkmark \\ \text { CA } & \checkmark\end{array}$

Subsidy (Indirect subpara ii)

NL

Advantage - attract

investment at rates of return

lower than market rate

(Indirect beneficiary)
Green projects

Advantage - reduced cost of

raising capital

Loan interest lower than

market rates

(Indirect beneficiary)
Subsidy (Indirect subpara ii)

IE

NL

CA

Subsidy (Indirect subpara iv)

NL
Specific

IE $\mathrm{X}$

NL $\quad X$

CA $\mathrm{X}$
Specific

NL

IE $\checkmark$

NL $\quad X$

CA $\checkmark$ 
This chapter has one central aim: to examine whether the tax incentives for the development of renewable energy in place in the case study countries are covered by the SCM Agreement and thus are potentially challengeable as actionable subsidies under Part III of the SCM Agreement to the extent that they potentially cause adverse effects to the interests of other Members.

This thesis has addressed three categories of tax incentives in place in five countries, namely Ireland, the UK, the Netherlands, Belgium and Canada. The examination of all these measures in their many permutations resulted in a mixed outcome, as well as dealing in technical detail with three forms of direct tax incentives, as well as indirect (beneficiaries of direct) tax incentives.

To sum up, the accelerated depreciation provision was examined to establish whether it is covered by Article 1 of the SCM Agreement with the conclusion that the result depends on the calculation method applied to the valuation or existence of a benefit. The examination addressed both Article 1.1(a)(1)(ii) and Article 1.1(a)(1)(i) of the SCM Agreement, and my conclusion was that, on a case-by-case basis, the calculation method employed should take account of both the year-by-year benefit afforded by accelerated depreciation as well as the temporal benefit. The result therefore would be that accelerated depreciation tax incentives would be deemed to be subsidies according to Article 1.1(a)(1)(i) of the SCM Agreement. Although the accelerated depreciation provisions were neither de jure specific nor de facto specific in the UK, Ireland, the Netherlands and in Belgium, it was possible that the measure could indeed be de facto specific, whereas accelerated depreciation in Canada was indeed de jure specific.

The own investment incentive in place in Belgium and the Netherlands, although both are subsidies within the meaning of Article 1.1(a)(1)(ii) of the SCM Agreement, neither measure is de jure, nor de facto specific. Therefore these measures are not covered by the SCM Agreement and are not subject to challenge for consistency with Part III of the SCM Agreement.

The third party investment deduction was somewhat more complex than the previous measures. These measures are available in Canada, the Netherlands and Ireland. These measures were complex since the beneficiaries of the tax incentives are not limited to the recipients of the incentives but rather benefits potentially flow through to other related parties. In this section the potential direct subsidy to the investors in green projects was examined against Article 1.1(a)(1)(ii) of the SCM Agreement with the result that a subsidy clearly exists. The same was true for the investigation of the potential indirect beneficiaries of the same tax incentive with Article 1.1(a)(1)(ii) and Article 1.1(a)(1)(iv) of the SCM Agreement. Three indirect subsidies were discovered and all subsidies, direct and indirect has potential to be considered specific subsidies. 


\section{Chapter 9 : Case Study Specific Subsidies WTO-Consistent?}

\subsection{INTRODUCTION}

The previous Chapters have established that the tax incentives in the case study countries are indeed subsidies within the meaning of Article 1 of the SCM Agreement and some are also specific according to Article 2 of the SCM Agreement. This being the case, these subsidies are subject to examination under Part II and III of the SCM Agreement when another Member considers that its trade has suffered from the application of these subsidies. This chapter will examine the implications for these measures of being specific subsidies and the conditions for the measures to be contested by another WTO Member.

\subsection{PROHIBITED SUBSIDIES}

Part II of the SCM Agreement deals with prohibited subsidies. ${ }^{1}$ Prohibited subsidies are presumed to create adverse effects to the interests of other Members without the need of proving this by positive evidence. ${ }^{2}$ Two types of prohibited subsidy are listed in Article 3: export subsidies and import substitution subsidies. The first concerns any subsidy, provided to a certain company or group of companies, ${ }^{3}$ which is de jure or de acto $^{4}$ conditional (possibly inter alia ${ }^{5}$ ) upon the fact that the recipient of the subsidy exports. ${ }^{6}$ However, in isolation, the fact that a company exports is not in itself sufficient to fulfil the conditions of contingency of Article 3.1(a). ${ }^{7}$

Although most of the WTO subsidies disputes concerned prohibited export subsidies, ${ }^{8}$ prohibited subsidies are not at issue in this thesis. Since the tax incentives

\section{See Van den Bossche 2008, p. 571-577.}

Appellate Body Report, Canada - Aircraft, para. 202.

Article 1.2 SCM Agreement states that if a subsidy is specific within the meaning of Article 2 SCM Agreement, it is subject to the provisions of Part II and Part III SCM Agreement, namely the provisions dealing with prohibited and actionable subsidies respectively. However, Article 2.3 states that any subsidy falling under Article 3 shall be deemed to be specific. Therefore this element, of being provided to a certain company or group of companies would not need to be proven by positive evidence where the conditions of Article 3 are fulfilled.

$4 \quad$ Footnote 4 to the SCM Agreement expands on the distinction between de jure and de facto contingency by stating that although de jure contingency is the case within which the conditions of export performance are laid out in relevant legislation, in the case of de facto conditional, the facts show that in order to obtain the subsidy there is a factual link between this fact and the actual or anticipated exportation.

5 The text of Article 3.1(a) SCM Agreement states that whether export performance is one or one of several conditions upon which granting of the subsidy is conditional is not of significance.

Article 3.1 (a) SCM Agreement.

Footnote 4 to the SCM Agreement.

Ehlermann and Goyette 2006, p. 713. The only WTO subsidies disputes in which actionable subsidies were challenged were: Indonesia - Autos, US - Upland Cotton, and Korea - Commercial Vessels. In all three disputes, the complainant alleged that the subsidies caused serious prejudice to its interests within the meaning of Article 5(c) of the SCM Agreement. Both the EC - Large Civil Aircraft and the US - Large Civil Aircraft 
discovered in the case studies are neither export subsidies as they are not contingent upon export performance, nor import substitution subsidies as they are not contingent upon the use of domestic over imported goods, ${ }^{9}$ this study will deal only with actionable subsidies. As suggested by Horlick, "[p]robably very few, if any [renewable energy subsidies], are prohibited export subsidies as governments do not usually subsidise the production of energy to be consumed in other countries'. ${ }^{10}$

\subsection{ACTIONABLE SUbSIDIES}

As stated by Zhang, subsidies with the motive or effect of reducing greenhouse gas emissions are "not likely to be "export promoting" or "domestic consumption promoting" both of which are prohibited under the SCM, it could be mostly challenged as "actionable". 11 Thus, although the subsidies are unlikely to be prohibited subsidies, they could however be challenged as actionable subsidies causing adverse effects to the interests of other Members. None of the examined case study tax incentives have conditions attached that would require export performance or the use of domestic over foreign goods. Therefore this examination will continue with the analysis of the measures as potentially actionable subsidies. Actionable

disputes concern prohibited and actionable subsidies provided to US Large Civil Aircraft (in particular to Boeing) and EC Large civil aircraft (in particular to Airbus), respectively. The Panel in the EC - Large Civil Aircraft dispute is due to complete its work in May 2010 while the interim report of the US - Large Civil Aircraft dispute is due to be issued to the parties in June 2010. See <http://www.wto.org/ english/tratop_e/dispu_e/cases_e/ds316_e.htm> and < http://www.wto.org/english/ tratop_e/dispu_e/cases_e/ds353_e.htm>; last visited 27 April 2010.

9 To give an example of an import substitution subsidy: a country acting in pursuit of Kyoto Protocol objectives provides a tax rebate to electricity generators which use national wind power as an input, whereas an electricity generation company which imports reserve electricity, also produced from wind power, may not avail of the tax incentive for the portion of electricity which is imported. Furthermore, it is also considered that were a national government to provide tax rebates to a domestic electricity generator in order for that producer to use low carbon emitting domestic products instead of foreign high-carbon emitting products, this would indeed constitute prohibited subsidisation under the SCM Agreement. Assunção and Zhang 2002, p. 3; Zhang discusses this point with respect to like products being discriminated against and thereby being GATT inconsistent. See ECJ: Outokumpu, [1998] ECR I1777, a Finnish case in which tracking the origin of electricity was also at issue. There was a Finnish tax system which favoured renewable energy, however the method of production of the electricity could not be established when the electricity had already entered into the national grid. Foreign producers of electricity, even through renewable resources were discriminated against being subject to a higher tax rate than the like producers in Finland.

Horlick 2009, p. 194.

11 Zhang 2005, p. 26; Although Zhang here refers to subsidies that promote domestic consumption as prohibited subsidies, it is import substitution subsidies that are the specific form of domestic support subsidies which promote the consumption of domestic products over the consumption of imported products which are prohibited. Not all subsidies that promote domestic consumption are import substitution subsidies and therefore not all subsidies that promote domestic consumption are prohibited subsidies. 
subsidies are in general permissible, however, they are open to challenge to the extent a Member suspects that the subsidy causes adverse effects on its interests. ${ }^{12}$

Although in the previous chapter it was possible to examine whether the tax incentives provided by the case study countries are specific subsidies within the meaning of Article 1 and 2 of the SCM Agreement, on the basis of the conditions for eligibility for such tax breaks, the examination of potential adverse effects of the same measures is more difficult. As will be illustrated in the following section, a demonstration of injury requires an analysis of economic data relating to the good at issue, electricity in this case, in both the exporting and importing countries involved in a dispute. ${ }^{13}$ Although a specific answer to the question whether the tax incentives in the case study countries have adverse effects to the interests of other Members would only serve to strengthen this thesis, it is unfortunately outside the scope of the legal analysis to source the economic data required.

It is for this reason that this section of this thesis must limit itself to providing the legal framework for the adverse effects test within Part III of the SCM Agreement. By doing this, it will be highlighted what (economic) information is necessary to be collected in order for this injury analysis to be carried out and thereby for a definitive answer to be available on the international trade implications of the case study tax incentives and their potential adverse effects.

Part III of the SCM Agreement regulates actionable subsidies. Provision of subsidies, other than export subsidies and import substitution subsidies, is not immediately inconsistent with international law. Subsidies are only inconsistent with WTO law in cases where it may be shown that such subsidies cause adverse effects on other Members. ${ }^{14}$ The provision of any subsidy, to a specific company or group of companies ${ }^{15}$ which results in adverse effects to the interests of other WTO Members will be actionable under the SCM Agreement. ${ }^{16}$ A subsidy will be considered to cause

12 Stilwell and Bohanes 2005, Chapter 58, p. 516; Benitah 2001, p. 11. Benitah refers to the requirement for adverse effects to be shown an explicit legal technique of attenuating entitlements granted to the party allegedly affected by a subsidy, namely an effect-based norm technique.

13 Sykes 1996, p. 5-26. In this paper, Sykes gives an overview or methods used in the US to establish whether there is a case for material injury. This article also provides insight to the extent of the research which would be necessary to fully carry out an injury examination for all the case study countries and all the subsidies provided. For example, in the US a computer programme CADIC to carry out generic simulation models to this effect, p. 10. Also for the economist readers of this thesis further injury calculation information can be found in Knoll 1989, p. 37-115; Murray and Rousslang 1989, p. 149-164.

14 Article 5 SCM Agreement.

15 Until 1999 (Article 31 SCM Agreement) non-specific subsidies were considered to be 'non-actionable'. However, since the failure to extend the application of this category of subsidies, subsidies which are not specific within the meaning of Article $2 S C M$ Agreement are now potentially actionable. Furthermore, Article 1.2 SCM Agreement states that if a subsidy is shown by 'positive evidence' to be specific within the meaning of Article 2 SCM Agreement, it is subject to the provisions of Part II and Part III SCM Agreement, namely the provisions dealing with prohibited and actionable subsidies respectively.

16 Article 5 SCM Agreement. Panel Report, US - Offset Act (Byrd amendment), para. 7.106. 
adverse effects to the interests of other Members should it cause injury to the domestic industry of another member, nullification or impairment of benefits accruing directly or indirectly to other Members, or serious prejudice to the interests of another Member. ${ }^{17}$ Each of these elements of adverse effects will be examined separately in the following sections.

\subsubsection{Injury}

Article 5(a) of the SCM Agreement addresses injury caused to the domestic industry of the complaining Member by specific subsidies and refers to Part V of the SCM Agreement for the determination of injury and domestic industry. ${ }^{18}$ Article 15 of the SCM Agreement primarily addresses the determination of injury to the domestic industry of a W'TO Member seeking to apply countervailing duties on another Member. In this Article, injury is deemed to include material injury or a threat thereof, ${ }^{19}$ to the domestic industry, or material retardation to the development of domestic industry (of the complaining WTO member). ${ }^{20}$ However, Article 15 does not provide a real definition of injury but rather gives a set of conditions which may (together in various combinations) ${ }^{21}$ lead to a determination of injury. ${ }^{22}$

Whether material injury is caused to another WTO Member must be based on an objective assessment ${ }^{23}$ of positive evidence ${ }^{24}$ showing: 1) the volume and price-effect of the subsidised imports on the domestic market for like products and 2) the effect these imports have on domestic producers of like products. ${ }^{25}$ According to the Panel in Mexico - Olive Oil:

Article 15.1 is an overarching provision that sets forth a Member's fundamental, substantive obligation with respect to the determination of injury. Moreover,

Article 5 (a), (b) and (c) SCM Agreement.

Footnote 11 to Article 5 SCM Agreement.

Article 15.7 SCM Agreement. Threat of material injury must be supported by factual evidence. This is shown by, inter alia, a forecast of and imminent change in circumstances in the domestic market. Factors to be taken into account include: nature and potential trade effects of contested subsidies; significant increase in subsidised imports; increase in capacity of exporter; imports having prices with the effect of depressing domestic prices; inventories of the contested alleged subsidised product.

Fotnote 45 to Article 15 SCM Agreement.

Benitah 2001, p. 14. The weight given to each factor is determined by panels and the Appellate Body on a case-by-case basis. No one factor or certain combination of factors is deemed to be decisive or the existence of injury.

22 Ibid., p. 14.

23 Clarke and Horlick 2005a, Chapter 17, p.738. An objective examination is one in which the evidence is collected, investigated and evaluated in conformity with 'the dictates of the basic principles of good faith and fundamental fairness'. Appellate Body Report, US - Hot Rolled Steel, para. 193.

24 Ibid., p. 737. Appellate Body Report, US - Hot Rolled Steel, para. 192. Positive evidence was interpreted to mean: 'that the evidence must be of an affirmative, objective and verifiable character, and that it must be credible'. Article 15.1 SCM Agreement. 
paragraph 1 informs the more specific obligations in the succeeding paragraphs of Article 15.26

The Panel in Mexico - Olive Oil went on to examine the terms 'objective examination' and 'positive evidence'. With regard to 'objective examination', the Panel quoted the Appellate Body Report in US - Hot Rolled Steel stating that the requirement to carry out an objective examination refers to the investigative process, rather than the specific facts which are deemed to be evidence of the injury. ${ }^{27}$ In particular, 'examination' refers to how the evidence is 'gathered, enquired into and subsequently evaluated'. ${ }^{28}$ That the examination must be objective requires that the examination is carried out in a manner consistent with 'the dictates of the basic principles of good faith and fundamental fairness'. ${ }^{29}$ Furthermore, the Panel in Mexico - Steel Pipes and Tubes stated that an 'objective examination' referred to is one carried out in an 'unbiased manner, without favouring the interests of any interested party, or group of interested parties, in the investigation'. ${ }^{30}$

In examining the requirement that 'positive evidence' is examined, the Appellate Body in US - Hot Rolled Steel stated that this referred to the quality of the evidence to be examined by the investigating authority. ${ }^{31}$ Essentially, according to the Appellate Body the evidence should be 'of an affirmative, objective and verifiable character, and that it must be credible'. ${ }^{32}$ Also, the positive evidence requirement requires that the data which is examined is complete, ${ }^{33}$ comprehensive and reliable. ${ }^{34}$ In order to have representative evidence, the period of investigation and, thus, for gathering relevant data is also of importance. The requirement to carry out an object examination of positive evidence limits an investigating authority in choosing the period of examination. ${ }^{35}$

The positive evidence to be examined must show: 1) the volume and price-effect of the subsidised imports on the domestic market for like products and 2) the effect these imports have on domestic producers of like products. With respect to the point of evidence related to the volume of the subsidised imports it must be examined whether there has been a significant increase in subsidised imported products. ${ }^{36}$ The Panel in EC - Countervailing Measures on DRAM Chips, referring to an alleged increase in subsidized imports stated that 'the language of Article 15.2 confers considerable

\footnotetext{
26 Panel Report, Mexico - Olive Oil, para. 7.263.

27 Panel Report, Mexico - Olive Oil, para. 7.265 referring to Appellate Body Report, US Hot Rolled Steel, para. 193.

Ibid.

Ibid.

Panel Report, Mexico - Steel Pipes and Tubes, para. 7.214.

Appellate Body Report, US - Hot Rolled Steel, para. 192.

Ibid.

Panel Report, Mexico - Anti-Dumping Measures on Rice, para. 7.77.

Panel Report, Mexico - Olive Oil, para. 7.267 referring to Panel Report, Mexico - Steel Pipes and Tubes, para. 7.249.

Panel Report, Mexico - Olive Oil, para. 7.267.

This can be an absolute increase, or an increase relative to the importing Member's production or consumption. A threat of an increase of imports is not sufficient. The increase must have already occurred. Clarke and Horlick 2005a, p. 739. GATT Panel Report, Canada - Grain Corn, paras. 5.2.4-5.2.5.
} 
latitude on an investigating authority', and 'allows an investigating authority to consider a significant increase, either in absolute terms or relative to production or consumption'. ${ }^{37}$ In US - Countervailing Duty Investigation on DRAMs, the Panel identified three ways in which it can be determined whether there has been an increase in the volume of subsidized imports, namely to consider:

1) whether there has been a significant increase in the volume of subsidized imports in absolute terms;

2) whether there has been a significant increase in the volume of subsidized imports relative to domestic production; and

3) whether there has been a significant increase in the volume of subsidized imports relative to domestic consumption. ${ }^{38}$

To determine the effect of the subsidised imports on the price of the like product in the domestic market it must be examined whether there has been a significant price undercutting by the subsidised imports or whether the imports depress prices or alternatively, prevent price increases that would have otherwise taken place. ${ }^{39}$ However, the Panel in US - Countervailing Duty Investigation on DRAMs clarified that the investigating authority 'may choose whether to examine the price effects of subsidized imports on the basis of price underselling, price depression, or price suppression'. ${ }^{40}$ The standard of comparison is the imported product compared to the 'like' domestic product. ${ }^{41}$ In determining the impact of the subsidised imports on the domestic industry, Article 15.4 of the SCM Agreement requires that 'all relevant economic factors and indices having a bearing on the state of the industry' and lists factors which must be examined cumulatively. ${ }^{42}$

The economic data which should be collected and analysed to establish injury to the domestic industry by an imported like product to the domestic product includes evidence of reduction or threat of reduction of levels of domestic output, sales, market share, profits, productivity, return on investments, change in capacity, factors affecting domestic prices, effects (actual or threatened) on cash flow, inventories, employment, wages, growth, capital/equity raising capabilities. ${ }^{43}$ Although this list of factors is not exhaustive, the examination of all these factors is obligatory. ${ }^{44}$ As stated by the Panel in Mexico - Olive Oil:

Panel Report, EC - Countervailing Measures on DRAM Chips, para. 7.282

Panel Report, US - Countervailing Measures on Certain EC Products, para. 7.233.

Article 15.2 SCM Agreement. Clarke and Horlick 2005, p. 740. These three effects of the subsidised imports are not required to be fulfilled cumulatively. Any one is sufficient.

Panel Report, US - Countervailing Measures on Certain EC Products, para. 7.250.

Article 15.6 SCM Agreement. The classification of 'like product' depends on the data available. Where data is available for the like product on the basis of the production for that like product being divided into production process, producers' sales and profits, only the production of the like product will be used to assess the effect of the subsidised imports. However, where this break down data is not available, the effects of the subsidies will be determined by examining a range of products including the like product for which such information is indeed available.

Article 15.4 SCM Agreement.

Clarke and Horlick 2005a, p. 742-743.

Article 15.4 SCM Agreement. 
...an investigating authority must examine all of the listed factors and must also evaluate any other relevant economic factors affecting the condition of the industry. However, an investigating authority may conclude that a particular factor is not probative in the circumstances of the domestic industry in a particular case, and therefore is not relevant in the actual determination. Additionally, there is no requirement that each and every injury factor, individually, must be indicative of injury. ${ }^{45}$

Thus, in order to determine injury many factors must be taken into account and such a test is cumulative as no one factor alone may be decisive. ${ }^{46}$

According to Clarke and Horlick, '[c]ausation is one of the most contentious issues with respect to injury'. ${ }^{47}$ Article 15.5 of the SCM Agreement requires that it be shown that it is the effects of the subsidies that cause the injury. There must be a clear 'genuine and substantial'48 causal link between the granting of the contested subsidy and the injury caused to the domestic industry. This is determined by reference to 'all relevant evidence' which includes taking into account factors other than the subsidies which may also result in injury to the domestic industry. There is a possible threestep test in determining the causal relationship. Step 1) distinguish sources of injury to domestic industry; step 2) attribute injury to each source; and step 3) determine the causal link between the relevant imports (a particular source) and the injury (attributed to that source) to the domestic industry. ${ }^{49}$

The Panel in Mexico - Olive Oil, examined Article 15.5 of the SCM Agreement stating that it had not previously been subject to dispute settlement. ${ }^{50}$ However, since this provision is identical to its counterpart in Article 3.5 of the Anti-Dumping Agreement, the Panel called on the panel and Appellate Body reports relating to this provision for interpretation of Article 15.5. of the SCM Agreement. ${ }^{51}$ In this dispute the Panel considered that the investigating authority:

- was required to consider other factors known to it either as a result of its own investigation or because they were raised by the interested parties;

- was required to analyze each of these factors separately and to explain the nature and extent of the injurious effects of these other factors, separating and distinguishing them from the injurious effects of the subsidized imports; and

- might also have needed to consider the collective impact of the other known factors..$^{52}$

45 Panel Report, Mexico - Olive Oil, para. 7.270 referring in footnote to Appellate Body Report, Thailand - H-Beams, paras. 121-128; Panel Report, EC - Bed Linen, paras. 6.1546.159, Panel Report, Mexico - Corn Syrup, para. 7.128; Panel Report, Egypt - Steel Rebar, para. 7.36., Panel Report, EC - Bed Linen (Article 21.5 - India), paras. 6.163, 6.213.

Article 15.2 SCM Agreement.

Clarke and Horlick 2005a, p. 743.

Appellate Body Report, US - Lamb, paras. 177-178.

Appellate Body Report, US - Lamb, para. 69.

Panel Report, Mexico - Olive Oil, para. 7.298.

Ibid.

Panel Report, Mexico - Olive Oil, para. 7.305. 
These other factors are therefore also significant in determining the level of material injury caused by the subsidised imports. ${ }^{53}$ Such factors include volumes and prices of non-subsidised imports of the like product, consumption patterns, trade restrictive practices and competition acknowledged by domestic and other competing industries, technological developments and finally the productivity and export performance of the domestic industry. According to the Panel in EC-Countervailing Measures on DRAM Chips, the investigating authority 'must make a better effort to quantify the impact of other known factors, relative to subsidized imports, preferably using elementary economic constructs or models'. ${ }^{54}$ Following on from this the Panel stated that the non-attribution language requires an investigating authority to give 'a satisfactory explanation of the nature and extent of the injurious effects of the other factors, as distinguished from the injurious effects of the subsidized imports'. ${ }^{55}$ It is clear therefore that in order to determine that the subsidies have caused material injury to the domestic industry of the complaining Member, a thorough examination must be carried out of all the relevant factors.

'Injury' in Article 5(a) of the SCM Agreement also refers to the threat of material injury and Article 15.7 states that '[a] determination of a threat of material injury shall be based on facts and not merely on allegation, conjecture or remote possibility'. ${ }^{56}$ Furthermore the change in situation which would constitute a threat of material injury should be 'foreseen and imminent'. ${ }^{57}$ The Panel in US - Softwood Lumber VI stated that the provisions of Article 15.7:

...seem to require that some 'change of circumstances' must be clearly foreseen and imminent, and that it is this change of circumstances that would create a situation in which injury would occur. ${ }^{58}$

However, the Panel further clarified that:

...while the change in circumstances must be clearly foreseen and imminent, the text does not clearly require the identification of a single event as the relevant change in circumstances..$^{59}$

Rather than considering this change in circumstances as a single event the Panel recognised that it could refer either to:

An interesting example of 'other factors' was considered in the GAT'T Panel Report, Canada - Grain Corn, paras. 5.2.9-5.2.10 when the GATT Panel considered that the US subsidies did not cause injury to the Canadian domestic industry, as the decrease in world prices for grain which was caused by the same contested US subsidies, would have effected Canada in the same way had their grain imports been from any other country.

54 Panel Report, EC-Countervailing Measures on DRAM Chips, para. 7.405.

55 Panel Report, EC - Countervailing Measures on DRAM Chips, paras. 7.404-7.405.

56 Article 15.7 SCM Agreement.

57 Ibid.

58 Panel Report, US - Softwood Lumber VI, para. 7.53.

59 Panel Report, US - Softwood Lumber VI, para. 7.55. 
... a single event, or a series of events, or developments in the situation of the industry, and/or concerning the dumped or subsidized imports, which lead to the conclusion that injury which has not yet occurred can be predicted to occur imminently. ${ }^{60}$

Article 15.7 of the SCM Agreement provides a list of factors which should be 'considered' to establish whether there is a 'threat of material injury'. Firstly, in interpreting the requirement to 'consider' the listed factors, the Panel in US - Softwood Lumber VI concluded that 'to consider' means to 'give attention to' and 'to take into account' without constituting a requirement to make a finding or determination with regard to the factors listed. ${ }^{61}$

The list of factors in Article 15.7 of the SCM Agreement is not exhaustive since they are factors which should be considered 'inter alia'. Furthermore, Article 15.7 states that ' $[\mathrm{n}] \mathrm{o}$ one of these factors by itself can necessarily give decisive guidance'. ${ }^{62}$ These factors are: the nature of the subsidy and its likely trade effects; a significant rate of increase of subsidized imports; an imminent substantial increase in the capacity of the exporter; whether imports are entering at prices that will have a significant depressing or suppressing effect on domestic prices and the inventories of the product being investigated. ${ }^{63}$

Similarly to a determination of material injury, no one factor of the factors listed in Article 15.7 of the SCM Agreement is decisive on its own but all the factors considered cumulatively should determine that 'further subsidized imports are imminent and that, unless protective action is taken, material injury would occur'. ${ }^{64}$

In addition to the factors listed in Article 15.7 of the SCM Agreement, an investigating authority should also consider the factors listed in Article 15.4, as such, indicators are also considered to be relevant factors in determining a threat of material injury. This can be deduced from a similar situation concerning an anti-dumping dispute, MexicoCorn Syrup, in which the Panel examined the counterpart to Article 15.7 of the SCM Agreement in the Anti-Dumping Agreement, namely Article 3.7.65 In this dispute, the Panel stated that it was required to examine factors listed in Article 3.4 of the AntiDumping Agreement (the counterpart of Article 15.4 of the SCM Agreement) to establish threat of material injury consistent with Article 3.1 and 3.7 of the Anti-Dumping Agreement (Articles 15.1 and 15.7 of the SCM Agreement respectively). ${ }^{66}$ From this dispute it can also be argued, by analogy, that in establishing a threat of material injury in a subsidies dispute that the factors of Article 15.4 should be considered in conjunction with the factors listed in Article 15.7 of the SCM Agreement. ${ }^{67}$

Furthermore, in establishing a threat of material injury, the Panel in US - Softwood Lumber VI considered that a threat of material injury is established in light of the

Panel Report, US - Softwood Lumber VI, para. 7.57.

Panel Report, US - Softwood Lumber VI, para. 7.67.

Article 15.7 SCM Agreement.

Article 15.7 (i)-(v) SCM Agreement.

Article 15.7 SCM Agreement.

Panel Report, Mexico - Corn Syrup, para. 7.127.

Ibid.

Van den Bossche 2008, p. 535, p. 581 and fn 344. 
examination of the condition of the industry as required by Article 15.4 of the SCM Agreement. The point here was that if Article 15.4 has been examined in the context of establishing material injury, it is not necessary to re-examine those same factors in establishing a threat of material injury as per Article 15.7 of the SCM Agreement. ${ }^{68}$

As is necessary in relation to a determination of material injury, in establishing a threat of material injury, the investigating authority must determine that there is a causal relationship between the subsidies and the threat of material injury under Article 15.5 of the SCM Agreement. Equally, the investigating authority is required to identify and examine any other known factors that potentially threaten to cause material injury to the domestic market as per Article 15.5. of the SCM Agreement.

The following sections will address the interpretation of domestic industry and like products within the meaning of Article 15 of the SCM Agreement.

\subsubsection{Domestic Industry}

For the factors listed in Article 15 of the SCM Agreement to illustrate that material injury was caused by imports of a subsidised product, or that they threaten to cause material injury, they must be examined within a context. That context is the relationship of the imports with the domestic production of the like products. An important factor is thus to establish what constitutes the domestic industry of these like products. Although the determination of domestic industry within the meaning of Article 16 of the SCM Agreement has not often been explicitly addressed by panels and the Appellate Body, ${ }^{69}$ this provides guidelines. ${ }^{70}$ Domestic industry means 'domestic producers as a whole of the like products' or alternatively 'the domestic producers whose collective output of the products constitutes a major proportion of the total domestic production of those products'. ${ }^{71}$ This latter definition excludes from this number any producers which control or are controlled by, or are in another way related to ${ }^{72}$ those producers who export the product at issue to the 'injured' Member or import the product at issue into the 'injured' Member. ${ }^{73}$ If it is not possible to determine the domestic producers of the like product, the domestic producers of the "narrowest group of goods that includes the like product for which separate data are available' would be deemed to be the domestic industry. ${ }^{74}$ This is deemed to allow only a broadening of the definition of domestic industry rather than allowing a narrow definition. ${ }^{75}$

Panel Report, US - Softwood Lumber VI, paras. 7.97-7.112; see also ibid., p. 581. Panel Report, Mexico - Olive Oil, paras. 7.177-7.217. In this dispute, the Panel examined the definition of domestic industry in Article 16.1 of the SCM Agreement.

Clarke and Horlick 2005a, p. 745. Article 15 SCM Agreement. Domestic injury is similar here to its interpretation within the Anti-dumping Agreement.

Article 16.1 SCM Agreement. Ibid., p. 746.

According to Footnote 48, related to also include a situation where the two mentioned producers are connected by a common parent company, or a common subsidiary or branch.

Article 16.1 SCM Agreement.

Clarke and Horlick 2005b, p. 717.

Panel Report, Mexico - Corn Syrup, para. 7.147. 
Applying this to the trade of electricity (or renewable electricity if such data were available so that the market for renewable electricity could be separated from the market for electricity or even energy depending on the result of the 'like products' analysis), the domestic industry of the complaining Member would be all the electricity generators in the complaining Member or those electricity generators which together produce the major proportion of electricity in the complaining Member having excluded electricity generators which are parent or daughter companies (or subsidiaries) of electricity generators supplying electricity to the complaining Member (exporting to or importing into the complaining Member).

Article 16.2 of the SCM Agreement provides that in exceptional circumstances, a Member's territory may be divided into two or more markets with the producers in each market considered to form two separate industries. This will be the case when the producers within the market sell all or almost all of their production in that market and those producers do not compete (to a great extent) with producers from outside that market. ${ }^{76}$ In such a situation, even when a large proportion of the industry does not suffer injury, injury may still exist to the extent that subsidised imports are concentrated in an isolated market within the territory. Since such subsidies may therefore cause injury to 'almost all of the production within such market', this market may be deemed to be the domestic industry for the purposes of Article 5 of the SCM Agreement. ${ }^{77}$ As far as the territory can be divided into such markets, this is the number of domestic industries which must be examined individually. The requirement to be considered a separate competitive market is that first, those producers in that market sell almost all of their production of the contested product in that particular market and second, producers of that product outside this competitive market (but still within the Member's territory) do not supply that market to any substantial level. ${ }^{78}$

Since the 'domestic market' defined in Article 16 of the SCM Agreement refers to the domestic market for like products the following section will examine the meaning of 'like products' in the context of Article 15 of the SCM Agreement.

\subsubsection{Like Products}

A significant element in the injury test is the effect of the subsidised imported product on the 'like' domestic product. Thus after examining the injury on the domestic industry for like products, it should also be established whether the products in question are like products. ${ }^{79}$ For the purposes of the SCM Agreement, products are 'like' to the extent that they are identical, meaning 'alike in all respects' or alternatively, are

\footnotetext{
76 Article 16.2 SCM Agreement.

Article 16.2 SCM Agreement.

Article 16.2 SCM Agreement. Clarke and Horlick 2005b, p. 718.

It is interesting to note here that in the WTO rules on subsidies, it is the subsidised product which is central to any investigation. This differs to the EC state aid investigations where it is the firm which is deemed to be subsidised rather than the product. See Slocock 2007, p. 250. Here Slocock humourously states that this language of examining the effects of subsidies on like products is 'novel' to EC State aid specialists and that 'products do not have bank accounts!'
} 
products whose characteristics 'closely resemble' each other. ${ }^{80}$ The examination of like products is necessary not only for injury but also for serious prejudice which is dealt with in a later section. Since the interpretation of like products is universal for all aspects of the SCM Agreement, the detailed explanation of like products will be dealt with in section Like Products following the framework of the adverse effects test. ${ }^{81}$ Also in section Like Products the examination of like products will be in the context of the tax incentives for renewable energy applied in the case study countries.

\subsubsection{Nullification or Impairment}

Where a subsidy granted by a WTO Member is suspected of causing nullification or impairment to the benefits of another WTO Member, this subsidy may be considered to be causing adverse effects and thus actionable under Article 5 SCM Agreement. The determination of nullification or impairment is derived from the same tests as applied when nullification and impairment of benefits are examined in context of the provisions of the GATT 1994. ${ }^{82}$ Article 5(b) of the SCM Agreement makes specific reference to Article II of the GATT 1994, stating that particular attention should be paid to benefits which accrue to Members pursuant to the Schedule of Concessions in which Members have bound their specific commitments to refrain from imposing higher customs duties or other charges than the agreed level on agreed products. ${ }^{83}$ Thus, the benefits at issue which must be shown to be nullified or impaired refer in particular to benefits related to reduced duties and charges deriving from Scheduled Commitments.

This was confirmed by the Panel in US - Offset Act (Byrd Amendment), referring to an old GATT dispute EEC - Oilseeds in which the GATT Panel 'considered that nonviolation nullification or impairment would arise when the effect of a tariff concession is systematically offset or counteracted by a subsidy programme'. ${ }^{84}$

Nullification or impairment, for the purposes of Article 5(b) of the SCM Agreement is established according to the definition in Article XXIII of the GATT 1994. According to Article XXIII of the GATT 1994, nullification and impairment of benefits directly or indirectly accruing to a WTO Member (or alternatively the objectives of the GATT 1994 being impeded) may occur in situations in which another WTO Member: 1) does not carry out its WTO obligations deriving from the GATT 1994; 2) applies a measure regardless of its consistency with the GATT 1994; or 3) by virtue of another situation. It is for the complaining Member to 'consider' whether its benefits are being nullified or impaired. ${ }^{85}$

As mentioned above, the benefits referred to are in particular those resulting from tariff concessions. Also, it is interesting to note the interpretation of 'nullification or impairment'. According to the Panel in Japan - Film, ' $[1]$ must be demonstrated that the competitive position of the imported products subject to and benefiting from a

Footnote 46 to Article 15.1 SCM Agreement.

See section 9.3.3.1 Like Products, p. 230.

Footnote 12 to the SCM Agreement.

Van den Bossche 2008, p. 417-418.

Panel Report, US - Offset Act (Byrd Amendment), para. 7.127.

Article XXIII:1 of the GATT 1994. 
relevant market access (tariff) concession is being upset by ('nullified or impaired ... as the result of') the application of a measure not reasonably anticipated'. 86 Thus, it can be interpreted that, similar to the examination related to injury to the domestic industry, here an imbalance between imported products and domestic products is also at issue. It is the cause of this imbalance that differs. In the case of nullification or impairment it is inextricably linked to the tariff concessions.

\subsubsection{Serious Prejudice}

The third case of subsidies which may constitute actionable subsidies under Article 5 of the SCM Agreement is where serious prejudice is caused to the interests of another Member. ${ }^{87}$ Footnote 13 to Article 5(c) of the SCM Agreement links the definition of serious prejudice in this context to its meaning in paragraph 1 of Article XVI of the GATT 1994. However, reference to Article XVI is of little assistance. As addressed previously, this Article is exactly identical to Article XVI of the GATT 1947, and considering that there is no definition of 'subsidy' to be found here, it is hardly surprising that there is also no definition of 'serious prejudice'. There is a slight clarification nevertheless, (as is also included in Footnote 13 of the SCM Agreement), that serious prejudice includes the threat of serious prejudice. One must not despair however, since the WTO Members foresaw this void and inserted a whole article in the SCM Agreement to address the concept of serious prejudice - Article 6.88 For this reason, the following section will immediately address serious prejudice within the meaning of Article 6 of the SCM Agreement.

It should first be noted that Article 6.1 of the SCM Agreement has lapsed since 1999. ${ }^{89}$ It was a provision which, according to Article 31 of the SCM Agreement only had provisional application for five years. After the five years, the Committee on

86 Panel Report, Japan - Film, para. 10.82.

87 Article 5(c) SCM Agreement.

88 Until 1999, serious prejudice could be determined by reference to one of the 4 situations described in Article 6.1 ASCM:

1) subsidisation in excess of $5 \%$ ad valorum. In Indonesia - Autos, the Panel found that the tax subsidy being equal to $35 \%$ of the sales cost of the product in question was inevitably and 'by any reasonable calculation' in excess of 5\% ad valorem. Para. 14.238;

2) subsidies eliminating operating losses of an industry;

3) subsidies eliminating operating losses of an enterprise - an exception to this case of serious prejudice was also provided, in that should such a subsidy be a once-off subsidy to an enterprise which is granted to allow that enterprise time to come up with long term solutions for its operating losses and to 'avoid acute social problems' then such a subsidy shall not be deemed to cause serious prejudice;

4) debt - forgiveness either by cancellation of a government debt or a government grant to cover another debt.

Failure by the W'TO Committee on Subsidies and Countervailing Measures to come to a consensus and agree on extending the application of this provision, which applied provisionally for five years ending December 311999 subject to Article 31 ASCM, rendered this provision no longer applicable. It is not excludable that a panel however may make reference to this article as some point of reference in determining serious prejudice and having recourse to the previous case law which addressed this provision. Zhou 2006, p. 322. 
Subsidies and Countervailing Measures could not come to consensus to extend the application of Articles 6.1, 8 and 9 of the SCM Agreement.

What is interesting to notice is that Article 6.1 of the SCM Agreement provided a list of situations in which serious prejudice was deemed to exist (e.g. the provision of subsidies covering operating losses) while Article 6.2, referring to Article 6.3, sets out a list of situations which, when they are not at issue, do not result in a subsidy causing serious prejudice. The point to note here is the existence of a double negative test (Article 6.2-3). According to some authors, the effect of this wording results in the shifting of the burden of proof from the complainant to the respondent. ${ }^{90}$ It is for the respondent to disprove that the effects of their subsidies are those listed in Article 6.3 of the SCM Agreement.

Article 6.2 and 6.3 of the SCM Agreement provides that, the burden of proof being on the respondent, there will be no case of serious prejudice should it be shown that the following effects do not ensue from provision of the subsidy in question:

1) imports of a like product of another Member (the complainant) are displaced from the market of the subsidising Member (the respondent); ${ }^{91}$

2) exports of a like product of another Member (the complainant) are displaced from the market of a third country; ${ }^{22}$

It is interesting to note, in consideration of the lack of special consideration for environmental subsidies in the SCM Agreement, that in addressing the issue of burden of proof in Environmental Disputes in the WTO, Horn and Mavroidis had no call to address the SCM Agreement. This is largely due to the lack to environmental subsidy disputes but also serves to highlight the lack of protection for Members positive environmental measures in the SCM Agreement. See Horn and Mavroidis 2009, p. 112140.

91 Article 6.3(a) SCM Agreement. The Panel in Indonesia - Autos stressed that the provisions of Article 6.4 SCM Agreement which clarifies Article 6.3(b) (see Footnote 167), is not relevant for the examination of 6.3(a). Para. 14.210. The determination of an Article 6.3(a) situation in the Indonesia - Autos dispute concerned an examination of market shares and the potential sufficient causal link between the changes to the market share and the introduction of the subsidised product. The 'close correlation in time' between the two was of significance here. Panel Report, Indonesia - Autos, para. 14.214. In addition to fulfilling the conditions of Article 6.3(a) the actual sales figures were also examined. The fact that there was no absolute decline in actual sales figures for the complaining Member, did not preclude it from being shown that sales were impeded as without the subsidisation the Complainant claimed that sales would have been higher. Panel Report, Indonesia - Autos, para. 14.218. Since such an issue is rather speculative in nature, and the requirement for proving serious prejudice is that the displaced or impeded imports must be demonstrated by positive evidence, this condition is not easily fulfilled as was the case in Indonesia - Autos. Panel Report, Indonesia - Autos, para. 14.236.

92 Article 6.3(b) SCM Agreement. Article 6.4 further clarifies the meaning of 6.3(b) by stating that included in this provision are cases in which a change in relative shares in market share to the disadvantage of the complaining Member over at least a one year period is demonstrated including 1) an increase in market share of the subsidised product; 2) despite market conditions in which the market share of the subsidised product would normally have fallen, due to the subsidy it is constant or 3) also in this case the decline in market share is not as drastic as it would have been without the subsidy. 
3) the subsidy results in significant price undercutting when comparing the subsidised product (of the respondent) with the like non-subsidised product of another Member (the complainant) in the same market; 93

4) the world market share of the subsidising Member (the respondent) has increased by virtue of the subsidy provided to a primary product or commodity, when compared with the average world market share it enjoyed in the prior three years. The increasing trend is to be concurrent with the period the subsidy has been granted.

The information relating to the relative market shares of the Members at issue in the dispute, as well as the prices of the products in question, should be compiled in the relevant Members in which serious prejudice is alleged to have occurred and provided to the parties to the dispute and to the panel in order for the serious prejudice analysis to be carried out. ${ }^{94}$ Rather than proving that a subsidy is causing serious prejudice on the domestic market, the complainant may rely on showing that the subsidy causes serious prejudice on the world market of the product at issue. ${ }^{95}$

The complainant in a subsidies dispute alleging serious prejudice need not quantify the amount of subsidy which is deemed to be conferred on the recipient product, whereas this requirement is present for countervailing duty investigations. ${ }^{96}$ And on the same note, where the serious prejudice may be due to more reasons than the subsidy alone, the complainant is also relieved of the obligation of attributing the serious prejudice to the various potential sources - a requirement which is indeed in place for both adverse effects in the form of injury to the domestic industry and also for the application of countervailing duties. ${ }^{97}$

In Article 6.3 of the SCM Agreement, the determination of serious prejudice rests, to a large extent, on a comparison of a subsidised product with a like non-subsidised product. ${ }^{98}$ However, as was the case with the injury test, likeness will be dealt with in the same way for all parts of the SCM Agreement and thus will be dealt with separately in the next section. However, with regard to Article 6.3(c) of the SCM Agreement

93 Also included here is significant price suppression, price depression and lost sales. Article 6.5 develops on Article 6.4(c), stating that this situation will be shown by a price comparison of subsidised products with like non-subsidised products in the same market, at the same times and same trade level and taking account of external factors affecting price. The comparison may also be carried out with reference to export-unit values. In this same dispute the situation under Article 6.3(c) was also addressed. The importance of the word 'significant' attached to price - undercutting was highlighted. The Panel stated that the use of this word in this context was to ensure that de minimis price-undercutting would escape this provision. Panel Report, Indonesia - Autos, para. 14.254. Furthermore the Panel commented on the terms 'the effect of the subsidy' clarifying that it, showing causal link, must demonstrate that the subsidies 'are responsible for' the price-undercutting. Panel Report, Indonesia - Autos, para. 14.255. Article 6.6 SCM Agreement, also referring to paragraph 3 of Annex V to the SCM Agreement in which information gathering in third country Members is addressed. Vander Schueren and Mizulin 2005, p. 202; Appellate Body Report, US - Upland Cotton, para. 406; Panel Report, Korea-Commercial Vessels, para. 7.566.

Ibid., p. 202.

Ibid., p. 202. Appellate Body Report, US - Upland Cotton, para. 467.

Articles 6.3(a), (b), and (c) refer to like products. 
which refers to serious prejudice due to price suppression or price depression, there is no requirement that the subsidy allegedly causing serious prejudice has been conferred on a 'like' product. ${ }^{99}$

To the extent that the displacement or impediment of imports or exports of a like product of another Member are deemed to be the cause of serious prejudice, Article 6.7 of the SCM Agreement lists six situations within which this displacement or impediment will not result in serious prejudice within the meaning of Article 6.3 of the SCM Agreement. These situations highlight in particular under what circumstances the displacement or impediment of imports or exports cannot be unequivocally the result of the subsidisation since other factors are at play. These situations are if:

1) imports from the complaining Member or exports of the complaining Member to a third-country market of the like product are prohibited or restricted;

2) imports are deflected, for non-commercial reasons, from the complaining Member to another territory by decision of an importing government involved in state trading of the product in question (or a monopoly);

3) Exports from the complaining Member are hindered due to force majeur such as natural disaster, strikes, transport failure which considerably affects production, quantities or process of the product in question;

4) Arrangements are in place which limit exports from the complaining Member;

5) The decrease in levels of the exported product in question is due to voluntary action of the exporters;

6) A reduction in exports is as a result of the complaining Member to comply with product standards or regulatory requirements in importing territories.

As is clear from the foregoing paragraphs, in order to show serious prejudice within the meaning of Article 5.1(c), highly complex factual investigations must take place involving many inter-related factors. ${ }^{100}$

\subsubsection{Like Products}

Adverse effects, including injury and serious prejudice, caused by the subsidisation of certain products rests to a large extent on the likeness of the subsidised products and with the products of the Member allegedly suffering the adverse effects.

Since in WTO law, 'like products' has no one over-arching definition and rather depends on the agreement and provision in question, ${ }^{101}$ it is important at this point to

99 Vander Schueren and Mizulin 2005, p. 202; Panel Report, Korea Commercial Vessels, para. 7.553. Vander Schueren \& Mizulin highlight the importance of this vis-à-vis challenges to subsidies on upstream products where the serious prejudice is deemed to be caused to the market for the downstream product.

100 Article 6.7 SCM Agreement.

101 Like product is discussed in the context of actionable subsidies as is the case here, but also with respect to the Most Favoured Nation obligation in Article I of the GATT 1994, the National Treatment obligation of Article III of the GATT, in determination of dumping under Article VI of the GATT 1994 and the Anti-Dumping Agreement and also relating to safeguards under Article XIX of the GATT 1994 and the Agreement on Safeguards. 
underline the meaning of like product in the context of the SCM Agreement. As stated by the Appellate Body in Japan - Alcoholic Beverages II, likeness be assessed on a caseby-case basis and involves 'an unavoidable element of individual, discretionary judgement'. ${ }^{102}$

Footnote 46 to Article 15 on the Determination of Injury in Part V of the SCM Agreement, which deals with Countervailing Measures, contains a definition of 'like product' which is intended to apply to all provisions of the SCM Agreement. It states:

Throughout this Agreement the term "like product" ("produit similaire") shall be interpreted to mean a product which is identical, i.e. alike in all respects to the product under consideration, or in the absence of such a product, another product which, although not alike in all respects, has characteristics closely resembling those of the product under consideration. ${ }^{103}$

The first WTO dispute in which 'like products' was examined within the meaning of the SCM Agreement was Indonesia - Autos and the Panel focused on the meaning of the terms 'characteristics closely resembling' since the products at issue were not identical. ${ }^{104}$ The Panel considered that the term 'closely' was not insignificant. ${ }^{105}$ The Panel listed factors which should be taken into account when determining whether products are like or not, i.e. whether products closely resemble each other. These factors included such characteristics as:

- physical characteristics; ${ }^{106}$

- brand loyalty;

- brand image/reputation;

- after-sales service; ${ }^{107}$

- status and resale value;

- product use;

- substitutability; ${ }^{108}$

102 The Panel in Indonesia - Autos; Appellate Body Report, Japan - Alcobolic Beverages II, p. 20; Appellate Body Report, EC - Asbestos, paras. 101-103. Footnote 46 to Article 15, also addressed briefly in section 9.3.1.2 Like Products, p. 225.

Panel Report, Indonesia - Autos, para. 14.172.

Ibid.

Panel Report, Indonesia - Autos, paras. 14.173-14.174.

Panel Report, Indonesia - Autos, para. 14.253.

Zarrilli 2003, p. 375-380. Zarrilli examines the likeness of 'energy products' ranging from oil and gas to renewable energy. She states that although these energy products have a competitive relationship they are not like in terms of physical characteristics or tariff classifications. However, she comes to the conclusion that despite their differences, under Article III:2, second sentence of the GATT 1994, they would be considered to be directly competitive or substitutable. Since the likeness test under this Article, with its interpretative Note, has a broader definition of likeness than the first sentence of Article III. As interesting as the examination of the likeness of different energy sources is, it should be borne in mind that in this research the energy products to be compared are electricity based on renewable inputs and electricity based on nonrenewable inputs and thus differ from this examination since their physical characteristics and tariff classification are the same. 
- price; $^{109}$

- end use; and

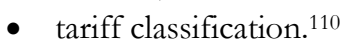

The characteristics to be compared include physical characteristics but are not limited to physical characteristics. In addition to the above list of comparative factors examined in determining whether products at issue are like, the Panel in Indonesia Autos also looked to how the industry at issue itself classified the products. ${ }^{111}$

Although the SCM Agreement interpretation of 'like products' seems to be narrower than that of the GATT $1994^{112}$ and Safeguards Agreement, ${ }^{113}$ guidance can also be drawn from interpretations of 'like products' within the meaning of these agreements for the purpose of interpreting like products within the SCM Agreement. ${ }^{114}$ In this sense it would seem reasonable that further factors would be relevant in determining whether products are like, such as consumer's tastes and preferences. However, regarding the list of factors handled by the Panel in Indonesia - Autos, brand loyalty and reputation as well as status and suitability also refer to some extent to the umbrella terms 'consumer tastes and preferences'. As examined by the Appellate Body in EC - Asbestos within the context of like in Article III:4 of the GATT 1994, essentially, the determination of products' likeness rests on an examination of the 'nature and extent of a competitive relationship between and among products'.115

In looking to interpretations of likeness, outside the SCM Agreement, the Appellate Body Report in EC - Asbestos provides further insight. In this examination of likeness, four characteristics are used as a foundation for comparison:

(i) the properties, nature and quality of the products (the physical properties of the products);

(ii) the end-uses of the products (the extent to which the products are capable of serving the same or similar end-uses);

109 Although price can be an indication of differing product characteristics, with respect to subsidised products, taking price to be a determining factor that products are unlike would lead to a situation in which complaints of price-undercutting, as referred to in Article 15.2 SCM Agreement could not be successful. The Panel in Indonesia - Autos addressed this point referring to price-undercutting referred to Article 6 SCM Agreement dealing with serious prejudice. Panel Report, Indonesia - Autos, para. 14.192.

Panel Report, Indonesia - Autos, para. 14.173. According to the Panel in Indonesia Autos, these characteristics are closely related to the physical characteristics of the products, and in fact represent the purchaser's assessment of the physical characteristics of the product. According to the Panel in Indonesia - Autos, the uses of a product 'generally arise out of, and assist in assessing the importance of, different physical characteristics of products'. Product substitutability was said to be determined partly by reference to the physical characteristics of the product and tariff classification distinguishes products with different physical characteristics according to Customs. Panel Report, Indonesia - Autos, para. 14.173. See also Zarrilli 2003, p. 375-376.

Panel Report, Indonesia - Autos, para. 14.177.

Article I:1, III:2 and III:4.

Van den Bossche 2008, p. 568.

Panel Report, Indonesia - Autos, para. 14.174.

Appellate Body Report, EC - Asbestos, paras. 98-99. 
(iii) consumers' tastes and habits in respect of the products (the extent to which consumers perceive and treat the products as alternative means of performing particular functions in order to satisfy a particular want or demand); and

(iv) the tariff classification of the products the international classification of the products for tariff purposes. ${ }^{116}$

Of these four characteristics, those that did not already appear in the examination of the Panel in Indonesia - Autos, were consumer's tastes and preferences however, to the extent that consumer's tastes and habits also refer to brand loyalty in respect of the products as well as reputation, status and suitability of the products, these qualities were re-categorised under the heading of consumer tastes and preferences. Although these lists provide guidance to future panels on what elements should be considered in the 'likeness' examination, they are not exhaustive. As also stated by the Appellate Body in EC - Asbestos, the general guidelines do 'not dissolve the duty or need to examine, in each case, all pertinent evidence'.117

The first step in the hypothetical analysis of the tax incentives for the production of renewable energy in the case study countries is to determine whether they cause adverse effects to the interests of other Members. In doing so a comparison of a subsidised product and a non-subsidised product would be undertaken. In this case the subsidised product is renewable energy. There are many possible constructions for this comparison. For example, the subsidised renewable energy could be compared to non-subsidised renewable energy. In this case it would straight forward that the products are like. They have same physical characteristics, tariff classification, end use and the consumer tastes and preferences for this product would be the same.

The problem in relation to like products occurs at the point that subsidised renewable energy is compared to non-subsidised, non-renewable energy to determine whether these products are like. The physical characteristics, tariff classification and end-use may all be the same but the consumer taste and preferences, including the reputation, status and suitability of the products as well as the brand loyalty in respect of the products may differ greatly. The awareness of consumers of the damaging effects of the consumption of fossil fuels for energy varies from country to country, and so too would the consumer tastes and preferences, (green) brand loyalty, (green) brand reputation and status and suitability of green energy products. Nevertheless, in the Kyoto Protocol-ratifying countries, at least, a high level of consumer environmental awareness has been growing and leads to the question whether green and grey electricity could not then be deemed to be 'not like' based on the appreciation of consumers of the products in question. If such a result were reached, any alleged adverse effects caused by subsidised green electricity could only be based on a comparison with the market for its like product, namely renewable energy in the complaining Member, thus limiting the extent of the reach of the SCM Agreement on the subsidisation of renewable energy.

On the other hand, if the consumer does not distinguish between green and grey electricity or between green and grey electricity brands, the subsidised renewable

116 Appellate Body Report, EC - Asbestos, paras. 101-103.

117 Appellate Body Report, EC - Asbestos, para. 85. 
electricity would be 'like' the non-subsidised non-renewable electricity, and any adverse effects created by the subsidisation would be relevant for the whole electricity market, regardless of the source of the electricity.

\subsubsection{2 (Non-product related) Processes and Production Methods}

Where a comparison of products must be made in determining likeness, and in this case where such products concern electricity which may or may not be produced from, for example, renewable energy resources, it is impossible to avoid referring to the non-product related processes and production methods debate. Since electricity produced from renewable energy resources and electricity produced from nonrenewable resources have very different environmental effects originating in their processes and production methods - ie the inputs used: renewable versus nonrenewable energy resources - it would be conceivable that such products would not be considered to be alike. However, bearing in mind the characteristics which are taken into account when determining likeness, as discussed above, processes and production methods do not feature in this list. In fact, processes and production methods have not featured in relation to determining likeness within the meaning of the SCM Agreement to date.

In order to determine the likeness of the green and grey electricity, the processes and production methods are relevant. There is a true distinction to be made between renewable and non-renewable electricity other than consumer tastes and preferences, and that is the production method (indeed this is the basis of the difference in consumer tastes and preferences). In addition, the environmental effect of that production method is also of significance. However non-product related PPMs have not been considered within the SCM Agreement. Despite this, a cue may be taken from Indonesia - Autos that inspiration can be derived from interpretations of likeness from other agreements within the GATT.

WTO panels and the Appellate Body have referred to process and production methods (PPMs) in the ambit of establishing whether trade restrictions applied based on differences in non-product-related process and production methods may be permitted within the WTO system. ${ }^{118}$ Unlike in the case studies in this thesis, in these cases the trade restrictions were challenged for consistency with the GATT 1994 and justification for those measures was sought by invoking the Article XX exception of the GATT 1994. Nevertheless, these disputes are relevant to the examination of subsidies which distinguish between products based on their process and production methods, despite the lack of an Article XX-equivalent exception in the SCM Agreement.

Although this very point was examined in the US - Tuna I (Mexico) dispute, the GATT Panel rejected a distinction between products based on their processes and production methods, ${ }^{119}$ many authors disagree with this result. ${ }^{120}$ In particular

118 See the US - Tuna, US - Shrimp, US - Gasoline, Korea - Various Measures on Beef disputes.

119 Panel Report, US - Tuna I (Mexico), para. 5.15. The Panel rejected the ban by the US on dolphin-unsafe tuna, which was based on a process and production differentiation (dolphin-safe fishing methods), as the Panel considered that the ban was a method of the US forcing trading partners to adopt the same dolphin-protection regulations. Also, 
environmentalists consider that without non-product related PPMs being addressed, the correct balance between trade interests and environmental interests will be difficult to achieve. ${ }^{121}$ The Panel in US - Shrimp, came to the same conclusion with respect to trade restrictive measures on products distinguished by their processes and production methods. ${ }^{122}$ However, the Panel, while rejecting a strict implementation of a process-based test, examined whether the measure could be provisionally justified under Article XX (g) and whether the requirements of the Chapean of Article XX of the GATT were met to determine whether the environmental protection measure, whether process-based or not, could be justified by the Article XX exception. Although the measure was provisionally justified as relating to the conservation of exhaustible natural resources the measure did not meet the requirements of the Chapean of Article XX as it was applied in a manner that constituted arbitrary and unjustifiable discrimination between WTO Members. Although this measure did not clear the hurdle of the Chapean of Article XX Peel considers that this approach has the effect to 'virtually rule out the possibility of legitimate environmental process based trade restrictions under the GATT/WTO'. ${ }^{123}$ This view purported by Peel is incorrect since it is rather the case that this dispute established that it is also possible that non-product related PPMs which result in restrictions to international trade can be justified under Article XX of the GAT'T 1994, to the extent that these measures are not applied in a manner which constituted arbitrary and unjustifiable discrimination between WTO Members.

However, to the extent that PPM-based restrictions are justifiable under Article XX of the GATT 1994, and the requirements of the Chapean are fulfilled, thereby relieving the Member applying the non-product related PPM from its obligations arising from the rest of the GATT 1994, this does not solve the 'likeness' issue relevant for this study. ${ }^{124}$ This thesis is concerned with the question of the likeness of green and grey electricity and the implications within the SCM Agreement of the result of this likeness examination. This is problematic to the extent that it is non-product related PPMs which distinguish the subsidised green electricity from the nonsubsidised grey electricity.

What these Article XX disputes did not do (in addition to not finding that the contested non-product related PPMs fulfilled the conditions of Article XX) is to include consideration of non-product related PPMs in the examination of likeness, and thereby allow non-product related PPMs to differentiate between products. As the jurisprudence of panels and the Appellate Body is at present, non-product related PPMs are relevant for the likeness debate only to the extent that they determine customer tastes and preferences. Thus with this limited permission for differentiation

the ban was considered not to be the least trade restrictive action available to the US. Bown and McCulloch 2005, Chapter 43, p. 162.

Quick and Lau 2003, p. 419-458; Hudec 2000, p. 198; Bronkers and McNelis 2000, p. 44.

Stilwell and Bohanes 2005, Chapter 58, p. 538.

Panel Report, US - Shrimp. The Appellate Body did not overturn this conclusion by the Panel referring to processes and production methods. The Appellate Body did, however, emphasise the right of WTO Members to take measures for the protection of the environment. Bown and McCulloch 2005, Chapter 43, p. 162-163.

Peel 2002, p. 243 See Kelly 2005, p. 461. 
based on non-product related PPMs there is, as of yet, no feasible way to import such a differentiation into an interpretation of the SCM Agreement examination of likeness.

Some authors maintain hope and consider that it is not inconceivable that in the future a panel may consider non-product-related PPMs while examining the likeness of products especially since the likeness guidelines to date are not a closed list but dependent on the particular product and legal provisions at issue. ${ }^{125}$ Considering that the products examined to date in cases where the PPM was rejected can be distinguished from the product at issue here (electricity) and the legal provisions also (PPMs have not been considered in a subsidies dispute), perhaps there is indeed cause for hope.

However, to the extent that PPMs would not be considered in an evaluation of the likeness of green and grey electricity within the SCM Agreement, thus rendering these two products having production methods with very different environmental effects 'like' products, an alternative safety net must be created within the SCM Agreement. Without an (operational) environmental exception built into the SCM Agreement ${ }^{126}$ it is essential that at least the interpretation of 'likeness' for the purposes of the SCM Agreement would take into account the object and purpose of the product differentiation. That is, that the environmental objective which necessitates a differentiation between green and grey electricity would be encompassed into the likeness determination precisely due to the lack of an environmental exception in the SCM Agreement.

As a background to a potential interpretation of 'likeness' which would adequately take into account the environmental objectives of renewable energy subsidies, it is pertinent to address the aim and effects test. Hudec addressed the aim and effects test in an essay 'Requiem for an Aim and Effects Test' which dealt with inconsistencies with Article III of the GATT and the availability of justification for these inconsistencies in Article XX of the GATT. ${ }^{127}$ Nevertheless this discussion sheds light on the role an aim and effects test could play within the examination of 'likeness' in the SCM Agreement.

GATT panels, ${ }^{128}$ examining alleged inconsistencies with Article III of the GATT, added an aim and effects test to the traditional likeness test. The aim and effects test was an attempt to reflect the wording of Article III, paragraph 1. It was considered that the wording of paragraph 1 referred to whether the internal taxes and regulations 'have a bona fide regulatory purpose and whether their effect on conditions of competition is to create a protective advantage in favour of domestic products'. ${ }^{129}$ However, this aim and effects test was subsequently rejected by the WTO panels and Appellate Body, first in Japan - Alcoholic Beverages II and again in EC - Bananas III,

125 Stilwell and Bohanes 2005, Chapter 58, p. 539.

126 The solutions for an environmental exception in the SCM Agreement will be addressed in section 10.1.5 Environmental Subsidy Solutions, p. 268.

Hudec 1998.

GATT Panel Report, US - Malt Beverages; US - Taxes on Automobiles. Hudec 1998. 
Canada - Periodicals and EC - Hormones. ${ }^{130}$ In reference to the (non-) existence of an aim and effects test in the WTO legal regime, Hudec states the following:

'whereas in most regulatory systems the issue of discrimination is usually addressed by asking whether a difference of treatment is rationally related to a legitimate regulatory purpose, the traditional definition of "like product" appears to have no purposeoriented criteria at all'. ${ }^{131}$

This statement points precisely to the unsatisfactory results which would ensue from applying the traditional 'likeness' test in examining the consistency of environmental subsidies with the SCM Agreement, in particular considering the lack of an environmental exception in this agreement.

In fact, to the extent that it is true that the application of an aim and effects test would essentially prove to render Article XX of the GATT redundant, ${ }^{132}$ this points to a certain equivalence of the justifications provided by Article XX of the GATT and the application of the aim and effects test in determining likeness, for example in the SCM Agreement. If this is the case, the aim and effects test has the potential to justify otherwise inconsistent measures by taking into account the bona fide policy objective behind that measure. Thus the application of an aim and effects test in the SCM Agreement could remedy the lack of an environmental exception. This is so since by virtue of an aim and effects test it could be concluded that products, otherwise like based on their physical characteristics alone, would be deemed not like based on non product related PPMs.

It could be argued therefore that such an aim and effects approach to an examination of likeness within the SCM Agreement could substitute the lack of an Article XX equivalent in the SCM Agreement. An aim and effects test would take the limited 'likeness' test in the SCM Agreement beyond the bare examination of the likeness of the physical characteristics (and consumer tastes and preferences) of the products to the regulatory objective forming the foundation of the subsidy, in this case environmental protection. Such an approach would also go as far as to delineate those legitimate environmental subsidies from those having protectionist motivations. An aim and effects test could be the tool with which panels and the Appellate Body could legitimately take environmental subsidies into account by appreciating the policy objectives which differentiate between products based on non product related PPMs. Without PPMs being considered relevant in the likeness examination, there is a risk that when Members financially support the development of renewable energy, and ensure greater environmental sustainability, those measures may be found to be actionable and must be subsequently withdrawn.

Currently, there is a lack of a clear 'yellow brick road' to a safety net for environmental subsidies within the SCM Agreement, even when inspiration for the determination of likeness is imported from the GAT'T 1994 determination of likeness. Essentially, the possibility of taking into account the environmental effects of the non-product related PPMs would depend on panels and the Appellate Body applying an aim and

$\begin{array}{ll}130 & \text { Ibid., p. 635-636. } \\ 131 & \text { Ibid., p. 626. } \\ 132 & \text { Ibid., p. 628. }\end{array}$


effects test in determining likeness for the purposes of the SCM Agreement. Without such a new approach to likeness within the SCM Agreement, the likeness examination would result in the green and grey electricity market to be considered as one market and would consider these two products to be like. In such a situation the domestic market for generic electricity would then be like the imported subsidised renewable electricity, without regard for the non-product related PPM.

\subsection{AdVERSE EFFECTS ON ELECTRICITY MARKET}

As mentioned earlier, in examining the issue of adverse effects potentially caused by the case study tax incentives for the development of renewable energy, the compilation of economic data necessary to carry out the analysis is outside the scope of this legal research and thus specific data regarding the effects of the subsidies provided by the case study countries is not available. Despite this, however, some preliminary conclusions can be proffered with regard to the potential that these subsidies cause adverse effects to the interests of other Members. The special nature of trade in renewable electricity and trade in electricity in general provides for some interesting conclusions. Furthermore, in coming to a conclusion regarding the potential effects of tax incentives for the development of renewable electricity, some more questions are automatically addressed and answered along the way, namely the consequences of adverse effects of other (not direct) tax incentives on renewable electricity, or on generic electricity, or energy in general.

1) General environmental subsidies on products and/or granted to producers may be prohibited should export or domestic input conditions be attached or otherwise may be actionable to the extent that the trade of the subsidised product causes adverse effects to the interests of another Member, making those subsidies WTOinconsistent subsidies. Since there is no environmental exception or justification for such measures, they are potentially illegal subsidies.

Furthermore, environmental subsidies on products may be inconsistent with the GATT National Treatment and Most Favoured Nation obligations. However, for these alleged inconsistencies, there is potential recourse to the environmental exceptions in Article XX of the GATT 1994.

2) Environmental tax subsidies on products and/or granted to producers may be prohibited should export or domestic input conditions be attached or otherwise may be actionable to the extent that the trade of the subsidised product causes adverse effects to the interests of another Member, making those subsidies WTOinconsistent subsidies. Since there is no environmental exception or justification for such measures, they are potentially illegal subsidies.

Furthermore, environmental tax subsidies on products may be inconsistent with the GATT National Treatment and Most Favoured Nation obligations. However, for these alleged inconsistencies, there is potential recourse to the environmental exceptions in Article XX of the GATT 1994. 
Environmental tax subsidies granted to producers fall outside the scope of the Most Favoured Nation obligation, while also being explicitly excluded from the National Treatment Obligation.

3) Environmental direct tax subsidies granted to producers (direct taxes cannot be imposed on products) may be actionable to the extent that the trade of the subsidized product causes adverse effects to the interests of another Member, making those subsidies WTO-inconsistent subsidies. Since there is no environmental exception or justification for such measures, they are potentially illegal subsidies.

4) Finally, as concerns the specific conclusion of this specific research question, namely to what extent are the direct corporate tax incentives granted to the producers of renewable electricity (or investors in producers of renewable electricity) WTOconsistent, environmental direct tax subsidies on producers of renewable electricity may be actionable to the extent that the trade of the subsidized electricity causes adverse effects to the interests of another Member. Naturally it is the right of any WTO Member alleging that these subsidies cause adverse effects to its interests to challenge these subsidies. This is true not only for the importing Member but also for third countries competing with the subsidising Member in a third country market. To the extent that adverse effects of these subsidies are experienced by another Member, that Member may challenge those subsidies.

Although the foregoing holds true, a special note is merited in reflection of the special nature of the product subject to trade in question in this thesis, electricity. As explained in section The Global Electricity Market and section Electricity Generation: Trade in Goods and/or Trade in Services, the special physical nature of the commodity electricity itself, as an un-storable, 'used-as-it-is-produced', good, which makes the treatment of subsidies to electricity different to that of most other products.

Furthermore, the developments in the structure of the electricity market in the last decade also create a peculiar interrelation of actors in the electricity market. It should be remembered in relation to the production, transmission, distribution and supply of electricity that the liberalisation of the electricity market affected each level of the chain differently. The special nature of electricity, having a public good character, a good which is deemed necessary for a basic standard of living, puts the security of supply into the hands of national governments. It is for this reason that although production and supply are liberalised, transmission and distribution remain natural monopolies. This in turn means that although there is competition between producers of electricity, including cross-border competition, it remains the task of the national government to forecast scarcity of supply and to mitigate this scarcity. One of the ways in which this scarcity (i.e. at peak times when there is insufficient national supply) can be mitigated is by the import of electricity from a neighbouring producer. These special elements particular to the electricity market mean that where the trade of electricity occurs in particular to mitigate national scarcity, the importing Member is not in the typical position of a Member importing subsidised goods and prepared to challenge those subsidies which affect the interests of national electricity producers. 
The trade of electricity, in particular in times of scarcity, is a delicate one which balances on friendly diplomatic relations between trading partners. The importation of electricity occurs under delicate negotiating conditions, with most negotiating power in the hands of the exporter - for example with regard to price. The negotiating position of the importer of electricity is a weak one as there is no choice but to import - otherwise the lights go out!

All of these circumstances, coupled with the possibility that the imported electricity is provided at a lower cost due to subsidies to producers of the electricity, lead to a situation in which the importing country, rather than perceive this reduced cost as an adverse effect on domestic production, would 'send a thank-you note' to the subsidising country to quote Paul Krugman. In a similar vein, Horlick, while referring to possible export subsidies on energy states that 'consuming countries are unlikely to complain, and competing countries are probably more likely to do the same'.133

Indeed commercial producers of electricity are likely to not be the ones sending a 'thank-you note' due to the importation of subsidised electricity, since this imported subsidised electricity would have the effect of mitigating the scarcity of electricity and thus reducing the price of electricity on the domestic market. It is the national government, responsible for ensuring the security of supply that, rather than experience a blackout during peak demand, imports subsidised electricity even if this has the effect of reducing prices gained by national electricity generators. If the choice is between importing subsidised electricity versus scarcity of electricity, the national government will be forced to maintain security of supply to keep the lights on.

This note is in particular to illustrate that due to the special nature of electricity trade in peak demand periods there is a strong likelihood that the importing Member would not challenge the subsidies on the imported electricity. At such a time, the importing Member must undertake a balancing act between protecting its interests from potential adverse effects from importing subsidised electricity and ensuring security of supply, even if this means importing subsidised electricity potentially resulting in adverse effects to the interests of domestic producers.

Notwithstanding the special circumstances in which trade in electricity frequently occurs - trade in times of scarcity - due to the nature of the product, under usual conditions of trade the subsidies would indeed be potentially subject to challenge, not only by the importing Member but also potentially by third party Members competing with the subsidising Member on the importing Member's market.

In this vein it is particularly important to reiterate the lack of a safety net in the SCM Agreement for subsidies which are in place to promote and develop sustainable and environmentally friendly electricity production, and following on from this, the international trade in sustainable and environmentally friendly renewable electricity.

$133 \quad$ Horlick 2009, fn 3, p. 194. 
Until December 1999, a special category of subsidy was considered to be nonactionable, and thus permitted within the WTO framework. ${ }^{134}$ This category was fondly referred to by Sykes as a 'green light experiment'. ${ }^{135}$ Included in the list of non-actionable subsidies was:

Assistance to promote adaptation of existing facilities ${ }^{136}$ to new environmental requirements imposed by law and/or regulations which result in greater constraints and financial burden on firms... ${ }^{137}$ [emphasis added]

In December 1999, the WTO Committee on Subsidies and Countervailing Measures failed to come to a consensus and agree on extending the application of this category of subsidy, which applied provisionally for five years ending 31 December 1999 subject to Article 31 SCM Agreement, ${ }^{138}$ thereby rendering measures previously in this category actionable.

Upon conclusion of the SCM Agreement, it was recognised that subsidies were being 'widely provided' by the Members' governments. ${ }^{139}$ Article 8 SCM Agreement aimed to provide a temporary justification for specific types of subsidies with limited motivation - such environmental protection. However, failure for a subsidy to fall within this exception to the general SCM Agreement rules did not by itself 'restrict the ability of Members to provide such assistance'. Thus, it is clear that failure to fulfil the conditions of Article 8 SCM Agreement, did not lead automatically to a subsidy being considered prohibited or actionable. For this a separate examination of the measure at issue was necessary. ${ }^{140}$

WTO Members are now in a position whereby the application of subsidies for the purposes of environmental protection may be subject to disputes before WTO panels and the Appellate Body as illustrated in this chapter and Chapter 7. Such subsidies of a type which previously would have been justified by Article 8 SCM Agreement may now be found to be actionable subsidies inconsistent with the SCM Agreement. Thus subsidies promoting Kyoto Protocol objectives lacks a safety net within the SCM Agreement, and may be subject to review under Part I, II and III of the SCM Agreement, as discussed in detail in the previous sections.

\subsection{THE SCM AGREEMENT AND THE ENVIRONMENT}

It is pertinent that the treatment of environmental subsidies in the SCM Agreement (in particular since the lapse of the category of non-actionable subsidies) be addressed. From the analysis in the Chapters of Part IV of this thesis, the difficulties in relation to the justification of environmental subsidies in WTO law have come to the fore. As

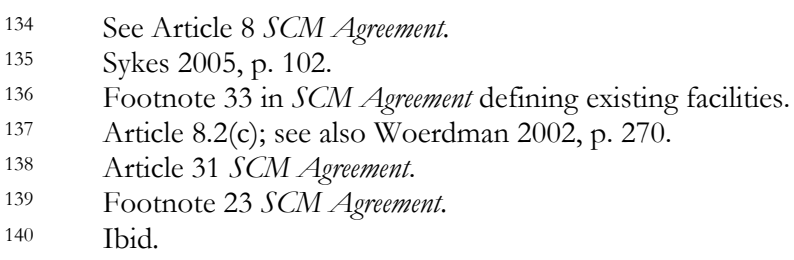


put by Zhang, the 'intricate and difficult' issue that is environmental subsidies in the WTO will be highlighted further in this section.

In international law, where environmental concerns overlap with international trade issues, conflict arises. However, it is widely recognised that trade and environment are inextricably linked. In the Preamble to the WTO Agreement, reference is made to the objectives of the Members to make 'optimal use of the world's resources' and 'to protect and preserve the environment'. ${ }^{141}$ It is this 'preambular' language that the Appellate Body referred to in the US - Shrimp (Thailand) in order to interpret Article XX of the GATT 1994. ${ }^{142}$ According to the Appellate Body in this dispute, the WTO negotiators qualified the objectives of the GATT 1947 by including an environmental perspective in the Preamble. ${ }^{143}$ Furthermore, the Panel in US - Shrimp (Article 21.5 Malasyia) stated that 'sustainable development is one of the objectives of the WTO Agreement'. ${ }^{144}$

The overlap of trade and environment has been much debated in literature ${ }^{145}$ in the context of potential conflicts between environmental protection measures and the GATT 1994 and examine the possibility of such measures being justified by the Article XX general exceptions. As mentioned in the beginning of Part IV, international trade law extends far beyond the General Agreement on Tariffs and Trade since the establishment of the WTO in 1995. However, with respect to the environment, discussions continue to be limited, to a large extent, to the provisions of Article XX of the GATT 1994.

As put by Charnovitz, 'There is a tension in environmentalism regarding subsidies'. ${ }^{146}$ There is also a tension in international trade regarding environmental subsidies. Essentially environmental subsidies are treated as any other subsidy, without any consideration for the positive motivation behind these subsidies.

Within the framework of the WTO, the Committee on Trade and Environment (hereafter CTE) was established in 1995.147 The CTE has a mandate to identify the overlap of the trade objectives pursued, on the one hand, by the WTO agreements and environmental concerns on the other hand. On the basis of the identification of these overlapping objectives, the CTE has the mandate to make recommendations for changes it deems to be merited. In this respect, as early as August 1995, it was

$141 \quad$ Stilwell and Bohanes 2005.

142 Jackson 2005, p. 40.

143 Charnovitz 2007, p. 688. Charnovitz addresses the relationship between the polluter pays principle and government subsidies. Government subsidies may either cover costs of environmental damage, eliminating the signal that that the producer would otherwise get from having to cover those costs itself. However, government subsidies may also provide funding to further develop environmentally friendly technology, in particular, where the market fails to make those developments itself.

144 Panel Report, US - Sbrimp (Article 21.5 - Malaysia), para. 5.54.

145 Doelle 2004; González-Calatayud and Marceau 2002; Green 2005, p. 143-189; Quick and Lau 2003, p. 419-458.

146 Charnovitz 1994, p. 505.

147 Uruguay Round Ministerial Decision on Trade and Environment available at: <http://www.wto.org/English/docs_e/legal_e/56-dtenv_e.htm>; last visited 24 November 2009. 
mentioned in the Trade and Environment News Bulletin that suggestions had been made for review of the SCM Agreement in light of environmental concerns. ${ }^{148}$

Furthermore, paragraphs 31 and 32 of the Doha Development Round Ministerial Declaration $^{149}$ include trade and environment in the mandate of the Doha Negotiation Round. Within this scope, the Members agreed to negotiate on the relationship between WTO rules and trade obligations in multilateral environmental agreements (MEAs), information exchange agreements between MEA secretariats and WTO committees, and on the reduction or elimination of tariff barriers on environmental goods and services. ${ }^{150}$ The Ministerial Declaration instructed the Committee on Trade and Environment to, inter alia, pay particular attention to the effect of environmental measures on market access, and in particular situations in which the elimination or reduction of trade restrictions would result in an improvement to the environment, trade and development. ${ }^{151}$ This work of the Committee on Trade and Environment should also be carried out by identifying WTO rules which would need to be clarified in this respect. The Committee on Trade and Environment, in light of its Doha mandate, addressed subsidies from an environmental protection perspective and focused on fisheries subsidies in particular. ${ }^{152}$ This work has resulted in the Ministers agreeing that clarification is necessary with respect to fisheries subsidies within the SCM Agreement. ${ }^{153}$

Furthermore, within the context of the Doha Development Round of negotiations, the Negotiation Group on Rules directly addresses the need for clarification of the SCM Agreement. Although the Trade and Environment negotiations recognise the importance of clarifying rules on subsidies in light of environmental protection and, in addition to the general negotiation mandate on subsidies in the Rules negotiations, general environmental subsidies have not been addressed. Rather, the focus has been put on subsidies to one sector which are deemed to be detrimental to the environment - fisheries subsidies.

Despite the intention indicated in the Trade and Environment News Bulletin in 1995, ${ }^{154}$ as well as in the Doha Ministerial Declaration, to review and clarify the SCM Agreement in light of environmental concerns, no agreement has been reached on positive changes made to the SCM Agreement to make room for environmental subsidies. On the contrary, as explained above, in 1999 the one environmental exception embodied in the SCM Agreement, namely Article 8.2(c), was discontinued when a consensus on its extension was not possible. Furthermore, in December 2008 the Negotiating Group on Rules circulated the new draft consolidated chair texts of the Anti-Dumping Agreement and SCM Agreement as a basis for developments to these agreements. ${ }^{155} \mathrm{In}$

Trade and Environment News Bulletin, Press/TE004/, 14 August 1995, p. 8-9. Ministerial Declaration, WT/MIN(01)/DEC/1, 20 November 2001. Ministerial Declaration, WT/MIN(01)/DEC/1, 20 November 2001, para. 31. Ministerial Declaration, WT/MIN(01)/DEC/1, 20 November 2001, para. 32(i). Ministerial Declaration, WT/MIN(01)/DEC/1, 20 November 2001, para. 28. Negotiating Group on Rules, New draft consolidated chair texts of the AD and SCM Agreements, TN/RL/W/236, 19 December 2008.

154 Trade and Environment News Bulletin, Press/TE004/, 14 August 1995, p. 8-9.

155 Negotiating Group on Rules, New draft consolidated chair texts of the AD and SCM Agreements, TN/RL/W/236, 19 December 2008.
} 
this draft document which includes proposed amendments to the antidumping agreement and the SCM Agreement, no additions have been included referring to environmental subsidies let alone an exception relating to environmental subsidies being included. Furthermore, Article 8 of the SCM Agreement was left unchanged, despite its current status. Perhaps this is a (albeit weak) sign of hope that there are still Members that hope for its reinstatement.

An interesting point arising from the consideration to reform of parts of the SCM Agreement is that the protection of the environment does feature. In the 'General Considerations' section of the same document, subsidies having negative environmental impacts are addressed. It has been proposed by Members that subsidies having damaging environmental impacts (for example subsidies which contribute to overfishing) should be prohibited subsidies. ${ }^{156}$ At no point has it been addressed that on the other side of the coin, special treatment should be given to subsidies that protect the environment. As put by Stilwell and Bohanes, 'deleterious environmental effects may arise where trade law stands in the way of subsidies that provide an efficient and effective environmental policy tool', an example of this being the subsidisation of the development of renewable energy. ${ }^{157}$ To this date, the motivation for the subsidies, as well as the effects of subsidies other than their trade effects, are left out of the equation.

With respect to the negative externalities of subsidies to fisheries, the draft document states the current examination of actionable subsidies is 'not ... designed to clearly identify any contribution that such subsidies may make to overcapacity or overfishing' ${ }^{158}$ Thus, if the proposal that, relying on the negative environmental impacts of certain subsidies, otherwise actionable subsidies would be treated as prohibited subsidies were to be accepted, then a new approach to subsidies having positive environmental impacts would also seem appropriate. That is, subsidies having positive environmental impacts, which would otherwise be actionable subsidies would be deemed to be non-actionable subsidies. In this sense, the door would be opened for the possibility to take into account factors other than trade objectives for restricting or permitting subsidies. With respect to fisheries it is recognised that natural resources are 'mobile and undomesticated', and this is also true of the positive environmental effects ensuing from an increased use of renewable energy rather than fossil fuels.

It is clear that from a trade perspective subsidies are undesirable to the extent that they cause unfair trade conditions for other Members. In other words, when subsidies of one Member unfairly strengthen the market position of their domestic producers to the detriment of competing producers from other Members, there is a

156 As stated by Bown and McCulloch, WTO rules limiting subsidies do indeed have the potential to address environmental damage, such as overfishing, however as explained above, discontinuing harmful behaviour is only one measure. Incentives for positive behaviour are equally important as disincentives for damaging behaviour, or even discontinuing incentives for damaging behaviour. Bown and McCulloch 2005, Chapter 43, p. 152.

157 Stilwell and Bohanes 2005, Chapter 58, p. 549.

158 Negotiating Group on Rules, New draft consolidated chair texts of the AD and SCM Agreements, TN/RL/W/236, 19 December 2008, p. 89. 
potential infraction of the free trade rules embodied in the WTO Agreements. In the face of possible trade distortion, it is the task of panels and the Appellate Body to examine the facts on a case-by-case basis to evaluate the extent of the unfair trade practice and the adverse effects for other Members ensuing from this practice. The focus is on the negative effects or negative externalities of the subsidisation damaging the trade interests of the other Member. ${ }^{159}$ However, as touched on above with respect to the fisheries dilemma, there is potential that in the future, not only the negative trade externalities arising from subsidisation will be relevant but also the negative environmental externalities (changing the status of a subsidy from actionable to prohibited) where such negative environmental externalities exist. ${ }^{160}$

When account is taken of the positive externalities of environmental subsidies, an interesting perspective develops. ${ }^{161}$ If a subsidy results in adverse effects to the interests of another Member, this subsidy clearly creates negative externalities for that other Member. However, where these subsidies are environmental subsidies, at the same time, that subsidising Member is creating positive environmental externalities (to the extent that these subsidies are effective and efficient in achieving the environmental goal) ${ }^{162}$ for the other Member (as well as all other countries whether WTO Members or not). In an example by Adlung this was put as follows: 'The adjacent country B benefits, as a free rider, from reduced cross border pollution'. ${ }^{163}$ This is the case since, as mentioned earlier, the natural resource, in this case the 'climate', is mobile and trans-boundary. Thus protection of the environment (or reduction of the damaging effects of climate change) by one Member is to the benefit of all. Following the approach set out above for subsidies having negative environmental externalities of up-grading the classification of the subsidy, subsidies having positive environmental externalities should be down-graded from otherwise actionable subsidies to non-actionable subsidies.

Subsidies which affect interests of other Members with the result that positive environmental externalities are created, not only for the subsidising Member and its

159 Benitah 2001, p. 7. Benitah also makes a parallel between pollution a commonly recognised environmental externality and adverse effects caused by subsidies also as negative externalities.

160 Wolf 2006, p. 113. Wolf argues that providing the possibility that hidden subsidies that essentially perpetuate Members' environmentally damaging behaviour could be countervailable would be in accordance with the polluter pays principle and force Members to internalise their environmental damage costs. Furthermore, and in this way, she sees 'the SCM Agreement as a viable mechanism for encouraging countries to internalise their environmental costs that have global effects'. Although this research in fact focuses on Members environmental protection measures, it is interesting to see that this author has also approached the SCM Agreement as a tool with which the costs of environmental damage, or protection in this case, could be fairly apportioned. Adlung 1997, p. 181-185; Bown and McCulloch 2005, p. 153. These authors refer to environmental cleanup generating positive externalities as well as the transboundary effects of positive and negative externalities in the international context.

162 Although in order for the environmental subsidies to create positive environmental externalities, they should effective and efficient subsidies which realise the goal of an improved environment, as a trans-boundary common good, it is beyond the scope of this research to examine the effectiveness and efficiency of the tax subsidies in place in the case study countries. Adlung 1997, p. 182. 
producers, but borderless positive environmental externalities merit special treatment within the SCM Agreement. ${ }^{164}$ The positive externality created by, for example, the development of renewable energy is a de facto decrease in harmful carbon emissions (by the substitution of renewable for non-renewable energy) and following on from that the positive externality of a future habitat for mankind.

Subsidies by one Member, which strengthen the market position of environmentally preferable products, which is to the benefit of all Members from a perspective of protection of natural resources, should be saved from elimination through the SCM Agreement. To do this, a more dramatic development is necessary than reinstating the already weak Article 8 SCM Agreement. This is also the case for the proposed treatment of environmentally detrimental subsidies. It is insufficient to only address environmentally harmful subsidies in the SCM Agreement, while disregarding the potential that environmental subsidies may also have positive externalities.

The foregoing section of this chapter addressed the provisions which determine whether the Member's measures are covered by the SCM Agreement in depth, highlighted the lack of an existing environmental 'non-actionable subsidy' exception, and pointed to the potential future treatment of environmental protection subsidies. Following on from this, Chapter 10, will look to the environmental exceptions embodied in Article XX of the GATT 1994 for inspiration as to how subsidies having positive externalities could be addressed in the SCM Agrement.

\subsection{REMEDIES FOR ACTIONABLE SUBSIDIES}

When a Member considers that the subsidies in the case study countries are specific subsidies within the meaning of Article 1 and 2 of the SCM Agreement and cause adverse effects to its interests, that Member has two options for action against these subsidies. The first option concerns the multilateral challenge of the contested subsidies according to the procedure set out in Article 7 of the SCM Agreement. This option for action essentially aims at the removal of the adverse effects of the subsidies or the withdrawal of the subsidies. The second option for action against subsidies concerns the unilateral imposition of countervailing duties by the affected Member on the subsidised imports in order to offset the injury to the domestic industry caused by the subsidies.

With regard to the first option for action, i.e. the multilateral challenge of the contested subsidies, such a challenge must begin with consultations, i.e. negotiations, between the complaining Member and the Member allegedly granting an actionable subsidy. ${ }^{165}$ The aim of these consultations is to reach an amicable, 'out-of-court' solution to the dispute. The complaining Member must submit available evidence to back up its request for consultations ${ }^{166}$ and the allegedly offending Member is required to enter into consultations as quickly as possible. Should a mutually agreed

164 This clearly assumes that the environmental subsidies are effective and efficient in achieving the environmental goal pursued and thereby indeed create positive environmental externalities.

165 Article 7.1 SCM Agreement.

166 Article 7.2 SCM Agreement. 
solution not be reached through consultations, a request may be made to the Dispute Settlement Body for a panel to be established. ${ }^{167}$

When it is determined that a subsidy results in adverse effects to the interests of another WTO Member, the adverse affects of the subsidy should be removed or the subsidy should be withdrawn within six months of the adoption of the report by the DSB. ${ }^{168}$ Should the offending Member fail to comply with the obligation to remove the adverse effects or to withdraw the subsidy within the time-frame provided, the complaining Member is granted authority to apply countermeasures to the trade with the subsidising Member. ${ }^{169}$ To determine the level of countermeasures which may be applied, an arbitration panel may be appointed under Article 22 of the DSU. ${ }^{170}$

As an alternative to a multilateral challenge of the subsidies provided for in Article 7 of the SCM Agreement, a Member may - as indicated above - resort to a second option for action, namely the imposition of countervailing duties on the subsidised imports according to Part V of the SCM Agreement. For countervailing duties to be justified, the Member must establish that its domestic industry for the like domestic product has suffered injury due to the subsidised imports. The analysis of injury to the domestic industry of the like products, for the purpose of applying countervailing duties, is identical to that undertaken for the multilateral remedies for actionable subsidies addressed in section Injury. ${ }^{171}$ The authorities of the Member competent to carry out the countervailing investigations must carry out the investigation transparently. The authorities must allow all interested parties to defend their interests must explain the basis for the final decisions. These decisions should be based on sufficient evidence that a subsidy exists, that there is injury to the domestic industry and that there is a causal link between the subsidised imports and that domestic industry. The competent authority may carry out such a countervailing investigation either on application by the injured domestic industry or on its own initiation.

In conclusion, the Member alleging injury to the domestic industry caused by the case study subsidies for the development of renewable energy could either challenge that subsidy multilaterally or unilaterally carry out countervailing investigations and apply countervailing duties to the subsidised imported renewable electricity. ${ }^{172}$

167

Article 7.4 SCM Agreement.

Article 7.8 SCM Agreement and Article 7.9 SCM Agreement. As put by Benitah, this option for the offending Member to remove the adverse effects of the subsidy is a reminder that actionable subsidies are not 'illegal' as such but only an issue when they cause adverse effects to the interests of other Members. Benitah 2001, p. 31.

Article 7.9 SCM Agreement.

Article 7.10 SCM Agreement.

See section 9.3.1 Injury, p. 218.

Tarasofsky suggests that it would be easier to establish causal link between the subsidisation of traded energy products (e.g. electricity) and injury caused to the like domestic product than the situation in which the subsidised energy is merely an input into traded products. Thus it is suggested subsidies on energy products are only likely to be subject to countervailing duties to the extent that the energy products are traded and that trade causes injury to the market for energy products in another Member. Tarasofsky 2008, p. 14. 
Direct tax incentives for renewable energy are both subject to WTO rules on subsidies as well as the EU State aid rules. Since in the case studies, it was demonstrated that the majority of the tax incentives in question were in line with the State aid rules (or rather were justified due to their environmental motivation) and considering that this is not the case within the WTO regime, this interrelationship will now be explored.

Both the European Communities and the Member States of the EU in their own right are WTO Members since the WTO Agreement covers subject areas which are exclusive competence of the European Communities, areas of exclusive competence of the Member States and areas where there is shared competence. However, this internal division of competence does not feature in distinguishing rights and obligations between the European Communities and the Member States for the purposes of WTO law. Despite this, it could be argued that it would be the Member State and not the European Communities which would be the respondent in a dispute concerning areas which have the exclusive competence of the Member State. The Member States, for example in relation to the case study tax incentives, have exclusive competence in relation to direct tax issues. In respect of State aid rules, the Commission has the competence to disapprove a direct tax subsidy to the extent that it is inconsistent with Article 92(1) of the EC Treaty.

In WTO subsidy disputes to date, the measures contested have been EU measures in the form of Regulations ${ }^{173}$ and the complainant was therefore also the European Communities. However, there have been no WTO subsidy disputes concerning Member State direct tax measures but there have been three such GATT disputes. In these disputes, the Member State having adopted the contested national measure was the respondent in the dispute, the Netherlands, France and Belgium. ${ }^{174}$

However, considering that the internal division of competences between the European Communities and the Member States is not part of the WTO Agreement, even in a dispute where a Member State direct tax measure would be at issue, it is not excluded that the dispute would be brought against the European Communities. ${ }^{175}$ In fact it has clearly been the case in, for example, EC - Asbestos, that although the contested measure was a Decree adopted by the French national government to ban asbestos, the European Communities was the respondent in this case. Similarly in EC - Scallops (Canada), Canada contested a French government Order determining the official names and trade descriptions of scallops. ${ }^{176}$ In both disputes, the request for consultations was addressed to the European Communities.

However, to the extent that a Member State, asserting its exclusive competence in direct taxation matters, provides direct tax subsidies, it is the responsibility of that Member State, along side the European Communities to ensure the WTO-

173 See EC - Commercial Vessels and EC - Export Subsidies on Sugar.

174 GATT Panel Report, France - Income Tax; GAT'T Panel Report, Belgium - Income Tax; GATT Panel Report, Netherlands - Income Tax.

175 Luja 2003; Luja 1999, p. 217.

176 Panel Report, EC-Scallops (Canada). 
consistency of those measures. It is for this reason that Luja states that when an investigation into possible State aid is initiated at the EU level, the WTO-consistency of that same measure should first be examined since it is the SCM Agreement which is the more extensive, or rather the more limiting, set of rules. ${ }^{177}$

Chapter 8 established that the case study tax incentives are specific subsidies within the meaning of Article 1 and 2 of the SCM Agreement. This chapter outlined the requirements that must be fulfilled in order for these subsidies to be deemed to create adverse effects to the interests of another Member. Although sourcing the economic data relevant to determine whether the trade of electricity from the case study countries indeed causes adverse effects to the interests of other Members is outside the scope of this thesis, in outlining the requirements for a determination of adverse effects, some important aspects of that examination came to the fore.

It is particularly interesting to examine the terms 'like products' and 'domestic industry' in the context of subsidised renewable electricity. The result of this examination showed that if renewable electricity is not considered to be different from generic electricity, the subsidisation of only renewable energy may be problematic. In this respect, the lack of consideration of non-product related PPMs in the appreciation of likeness limits the possibility of green electricity being considered anything other than like generic electricity. It was submitted that the use of an aim and effects test in determining likeness within the SCM Agreement, in particular in light of the lack of an environmental exception in the SCM Agreement, could prove to be a potential solution for the justification of environmental subsidies.

The case study tax incentives for renewable energy electricity generation, to the extent that they do not cause adverse effects to the interests of another Member, will be SCM Agreement - consistent. However, it is sufficient that the measures are specific subsidies within the meaning of Article 1 and 2 of the SCM Agreement to leave them open to challenge for potential adverse effects. In carrying out this research, several conclusions were reached as to the potential adverse effects of both direct and indirect tax incentives on renewable electricity as well as on generic electricity.

The conclusion here is that direct tax subsidies which cause adverse effects to the interests of other Members are liable to be challenged by the importing Member or by another electricity-exporting Member competing on the importing Member's market with the aim of having adverse effects of the subsidies removed or the subsidy withdrawn. Alternatively the Member alleging injury to the domestic industry could apply countervailing duties on the subsidised imports in order to offset the injury to the domestic industry caused by the subsidies.

It should be noted, however, that in the case of trade in electricity, a special situation arises when the trade in electricity occurs primarily in times of national scarcity of the importing Member. This is due both to the special nature of the good electricity and the special structure of the electricity market. A Member importing electricity in peak

$177 \quad$ Luja 1999, p. 218. 
demand times is required to balance its interests - those of securing the security of supply and the adverse effects on its domestic electricity producers caused by importing subsidised electricity. In such a situation it can be questioned whether the importing Member would challenge the subsidy on the imported electricity. It is likely that direct tax incentives for the development of renewable energy would not be contested since this would have to first be balanced against the obligation of the importing Member to ensure the security of supply of electricity. Since electricity transmission and distribution systems are still natural monopolies, essentially it is the State that has to determine where the balance lies between the obligation of ensuring the security of supply by importing subsidised electricity and the potential for subsidised imports of electricity to adversely affect the domestic producers of electricity. All of these circumstances, coupled with the possibility that the imported electricity is provided at a lower cost due to subsidies to producers of the electricity, lead to a situation in which the importing country, rather than contest alleged adverse effects of subsidised imports on domestic production, would appreciate the possibility of importing electricity at lower prices (due to the subsidisation) since the question to import or not, in these particular circumstances, is not at issue due to shortage and the obligation to ensure the security of supply.

Lodefalk and Storey consider that '[c]limate subsidies proper are unlikely to have action taken against them, if they are applied objectively and transparently, while paying attention to potential adverse effects'. The same authors consider, in the same vein, that 'an extension of the lapsed environmental provision, appears unnecessary...' ${ }^{178}$ Essentially it is the position of these authors that the SCM Agreement in its current state is adequate to permit 'climate subsidies' in the same way as any other subsidies are permissible: they are not prohibited subsidies and are not specific or at least do not cause adverse effects to the interests of other Members. A similar proposal is put forward by Bigdeli who states that creating a 'green energy box' in the SCM Agreement, which would exempt renewable energy subsidies from the provisions of the SCM Agreement, would be counter-productive for environmental protection. ${ }^{179}$ By subjecting actionable renewable energy subsidies to the adverse effects test, it ensures protection for the like renewable energy products produced by the more efficient green energy producers. Essentially by also subjecting renewable energy subsidies to the rigours of the SCM Agreement in its current state, this ensures that distortive renewable energy subsidies are eliminated to the benefit of efficient renewable energy producers and with the result of the promotion of renewable energy trade.

Be that as it may, the notion of a level playing field is important in international trade. Only in this way are industries in a position to compete fairly. Adverse effects can come about in cases where, for example, a policy instrument in pursuit of environmental objectives, changes the competitive relationship between competing industries. ${ }^{180}$ Subsidies may create an unfair advantage for domestic products over other products. ${ }^{181}$

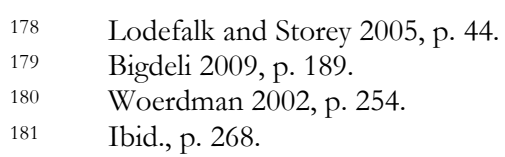


Although there has been no WTO dispute in which a Member contested an environmental subsidy challenged for consistency with the SCM Agreement to date, ${ }^{182}$ this chapter has highlighted the consequences of a potential future dispute addressing such measures. With no environmental safety net built into the SCM Agreement, environmentally motivated subsidies are at risk of being found to be actionable and causing adverse effects within the meaning of the SCM Agreement. Actionable subsidies causing adverse effects to the interests of other Members may then be required to be withdrawn, thereby eliminating their positive environmental effects. ${ }^{183}$

The foregoing chapter examined in technical detail the potential elements of the resolution of a subsidy dispute arising from the application of the environmental subsidies in the case study countries. This is important from the perspective of policy makers in order to know what the accepted limits of State intervention are. It has been shown that the SCM Agreement pays no special consideration to subsidies with environmental protection as their motivation. To the extent that there is economic evidence that these subsidies create adverse effects on the domestic market for electricity of another Member, these subsidies would be actionable and subject to a withdrawal requirement.

All of this is hypothetical however since no dispute has arisen to date. There are some views on the reasons for the lack of disputes, as explained by Herman: 'Subsidies for energy production in exporting States that might result in lower costs of imported energy goods... are typically not something that concerns governments of importing States. The importing State receives the benefit of lower energy costs to the disadvantage of the exporting State's treasury. Hence, subsidies directly related to these energy goods has not been an overwhelming international trade issue'. ${ }^{184}$ Furthermore, as put by Stilwell and Bohanes: 'the lack of disputes may mean that, among other thing, WTO Members consider environmental subsidies as legitimate, or are aware of the legal and political difficulties such challenges may cause'. ${ }^{185}$

However, if this is the case, it would seem that it would not be such a great hurdle to have the agreement of the Members that indeed these environmental subsidies are acceptable and for either a new non-actionable category to be created in the SCM Agreement, an Article XX of the GATT 1994 to be inserted into the SCM Agreement or an Understanding on the interpretation of the SCM Agreement to be concluded.

An environmental subsidy exception which applies in particular to the development of renewable energy would provide an incentive to all Members to be pro-active in the development of a sustainable energy source which has positive impacts on

182 Stilwell and Bohanes 2005, Chapter 58, p. 550.

183 As dealt with in section 10.1.4 Article XX of the GATT 1994 and the SCM Agreement, p. 259, there are arguments calling for Article XX of the GATT 1994 to be available to justify alleged inconsistencies with Agreements other than the GATT 1994, however, I maintain throughout this study, that this is not a legally available option. As also put by Condon, it seems unlikely that GATT Article XX could be invoked to preclude action under parts III and V [of the SCM Agreement]'. Condon 2009, p. 904 and p. 926. In the same vein, Bigdeli states that: 'the absence of an Article XX of the GATT provision in the ASCM should be given serious consideration'. Bigdeli 2009, p. 192.

$184 \quad$ Herman 2007, p. 55.

185 Stilwell and Bohanes 2005, Chapter 58, p. 550. 
mitigating climate change. This is also true even to the extent that Members would be reluctant to challenge subsidies which reduce the cost of imported electricity. It is after all the purpose of international legal agreements to provide legal certainty to the signatories, and in this case a clear environmental message would also be disseminated.

Such a conclusion, although almost ending the chapter on a high note, needs to be qualified. Although there have been no disputes to date concerning environmental subsidies applied to the energy sector, and it may be true that many, if not most, energy importers are only too happy for the imported energy to be subsidised and therefore cheap(er), this is obviously not true for all Members. Also, this picture while being relatively accurate at the present time when renewable energy has a miniscule share of the international energy sector, this picture will change dramatically in the future.

It is conceivable that in the future, as renewable energy technologies grow and infrastructure for trade in renewable energy improves, major traders in nonrenewable energy - namely oil and gas would not be so impressed with subsidised trade in renewable energy and despite the positive environmental externalities of such a development those Members may call the bluff of Lodefalk and Storey, Sykes, and Stilwell and Bohanes, and initiate a dispute alleging that another Member's subsidies on electricity produced from renewable energy create adverse effects on that Member's interests.

Even though it is true that there has been no dispute to date, this does not render the issue unimportant. Legal certainty and clarity must be provided for Members with respect to their environmental subsidies. 


\section{Chapter 10 : Other WTO Agreements}

\subsection{Subsidies AfFECTING Trade IN GOODS}

The previous chapters examined the GATT 1994 and SCM Agreement consequences for the tax incentives for the development of renewable energy applied in the case study countries. Although subsidies are specifically disciplined by the SCM Agreement, this does not preclude the measures from being inconsistent with the Agreement on Agriculture. The following sections will examine the case study tax incentives for possible inconsistency with this Agreement.

\subsubsection{Agreement on Agriculture}

The provisions of Part III of the SCM Agreement (actionable subsidies) examined above 'do not apply to subsidies maintained on agricultural products as provided in Article 13 of the Agreement on Agriculture'. ${ }^{1}$ In order to determine whether the subsidies examined in the case studies are subject to review within the Agreement on Agriculture, it must first be determined whether agricultural products are being subsidised. Agricultural products are those referred to in Annex 1 to the Agreement on Agriculture $^{2}$ as being products listed in the Harmonised Commodity Description and Coding System (HS) Chapters 1 to 24 (excluding fish and fish products) and an additional 13 headings. Since the tax incentives are provided to the purchasers of the listed assets, or the investors in the qualified project, in this case the generator of electricity, the subsidy is directly granted to the production of electricity - a good listed in the HS in Chapter 26.16 (industrial good). ${ }^{3}$ This is therefore not a product covered by the Agreement on Agriculture.

\subsubsection{Indirect Agricultural Subsidy}

Despite this seemingly clear cut exclusion of the Agreement on Agriculture, one step more should be taken. Although the direct subsidy arising from the tax incentives is conferred on an industrial product, it is possible that an indirect subsidy is granted to agricultural products by virtue of this same measure. Where the benefit of the subsidy on electricity flows-through to the producers of an agricultural end-product or where the inputs to the production of renewable energy are agricultural products and benefit from the same subsidy (albeit upstream) it could be argued that the producers of the inputs acquire an indirect subsidy. It has been clarified by WTO panels and the Appellate Body that for a subsidy to exist, the recipient of the financial contribution does not necessarily need to be the same as the recipient of the benefit. ${ }^{4}$ The Panel in US - Softwood Lumber IV described the pass-through situation as follows: "[w]here the subsidies at issue are received by someone other than the producer of the

$1 \quad$ Article 5 and Article 6.9 SCM Agreement. As it was shown above, in the case study countries as only actionable subsidies are at issue, prohibited subsidies are also excluded from the discussion in this section.

2 Agreement on Agriculture, Article 1.

3 Subsidies provided for growing corn which would be used as a biofuel would indeed be covered by the Agreement on Agriculture. Motaal 2008, p. 81.

$4 \quad$ Panel Report, US - Lead and Bismuth II, para. 6.77. 
investigated product, the question arises whether there is subsidization in respect of that product." 5 The question of indirect subsidies and input subsidies has been addressed and a 'pass-through' analysis developed. ${ }^{6}$

In the WTO disputes addressed to date, a direct subsidy was granted to the producers of the inputs and the indirect benefit deemed to be received by the producer of the end product - an indirect downstream subsidy. In particular the US - Softwood Lumber IV dispute sheds light on this issue, as well as being a case that also dealt with input subsidies on natural resource products. ${ }^{7}$ In the case studies examined in this thesis where renewable energy is subsidised, any agricultural product listed in Annex 1, the production of which requires electricity, and has subsidised renewable energy as an input, is potentially in receipt of a flow-through subsidy. By virtue of the flow-through indirect subsidy, the producers of the agricultural products may benefit from cheaper inputs, and thus make the production of the agricultural products much cheaper.

Furthermore, there is a possibility that where an input to the electricity generation itself is an agricultural product and the subsidy is contingent on the use of that agricultural input, that there is also an indirect subsidy to the input agricultural products in this way. To show that an indirect subsidy is granted to the agricultural inputs to renewable energy generation, an indirect upstream subsidy would be in question. ${ }^{8}$ In principle the same argumentation of downstream subsidies could be applied to potential upstream subsidies. By providing a subsidy contingent on use of the upstream products, an indirect subsidy may be granted to the producers of the input since the market for the inputs will be affected by increased demand. It is therefore possible that such an upstream indirect subsidy would be inconsistent with the Agreement on Agriculture, to the extent that the upstream inputs are 'agricultural products'.

Without further delving into the upstream/downstream differentiation, as mentioned above, in order for any subsidy, be it direct or indirect, to be examined for consistency with the Agreement on Agriculture, the products should be covered by

Panel Report, US - Softtwood Lumber IV, para. 7.85. Gagné and Roch 2008, p. 557. Appellate Body Report, US - Softwood Lumber IV, paras. 139-143; Appellate Body Report, US - Upland Cotton, paras. 471-472; Appellate Body Report, US - Countervailing Measures on Certain EC Products, paras. 112-113.

Gagné and Roch 2008, p. 557; Davidson, Bergsma, Backes and Van den Bossche 1999, p. 80. In this report, a similar situation is explored in relation to subsidies on sustainably produced wood products, both conferred directly to processed products and indirectly to the unprocessed inputs upstream. Van den Bossche states that if subsidies are conferred on sustainably-produced processed wood products (such as paper, carton, pulp and furniture), only an indirect benefit could be deemed to be conferred on the producers of sustainably-produced unprocessed input wood products (such as wood chips, sawdust) - as explained above, an upstream indirect subsidy. Although the direct benefit is clearly conferred on the processed sustainably-produced wood products, this does not preclude that the subsidy may also benefit (directly or indirectly) the processed or unprocessed sustainably-produced input wood products. Another example of a downstream subsidy would be a subsidy provided to airline companies, which in turn increases the demand for aircraft and by virtue of this downstream subsidy and indirect subsidy is provided to aircraft manufacturers. 
Annex 1 to the Agreement on Agriculture. In the first example given, any agricultural product which has subsidised electricity as an input could thus be subject to review. As for the second example in which the agricultural products are inputs to the renewable energy itself, a more detailed examination is necessary.

In only one of the case study counties are 'agricultural products' required as inputs to the production of renewable energy. Only the Canadian accelerated depreciation provision requires that the generation of renewable electricity be based on inputs of some 'agricultural products', namely: bio-oil, ${ }^{9}$ and digester gas. ${ }^{10}$ Although bio-oil and digester gas are 'agricultural products' or agricultural by-products, they are not necessarily classified as such for the purpose of the Agreement on Agriculture.

These 'new agricultural products' - second-generation biofuels made from waste materials of biological origin (as opposed to traditional agricultural products used for first generation biofuels $)^{11}$ - are neither classified as industrial products nor agricultural products for the purposes of the WTO agreements. ${ }^{12}$ Even the most common biofuels on the market - biodiesel and ethanol, which are made from traditional agricultural products, are not classified in a consistent way at the international level. Ethanol is listed as an agricultural product (HS 2207) while biodiesel is listed as an industrial product (HS 382490). ${ }^{13}$ By listing ethanol as an agricultural product, no distinction is made between ethanol as alcohol and ethanol as a biofuel.

Despite the fact that ethanol and biodiesel are both biofuels, their different classification in the Harmonised Coding System leads to very different treatment within the WTO - ethanol being subject to the rules in the Agreement on Agriculture and biodiesel not. ${ }^{14}$ Furthermore, a possible re-classification of all biofuels - ethanol and biodiesel - in one HS Heading Chapter 27 has been rejected to date by the HS Review Sub-Committee of the World Customs Organisation. ${ }^{15}$ A reclassification

9 'Liquid fuel that is created from wood waste or plant residues using a thermo-chemical conversion process that takes place in the absence of oxygen'. '[A] mixture of gases that are produced from the decomposition of organic waste in a digester and that are extracted from an eligible sewage treatment facility for that organic waste'.

11 First generation biofuels (ethanol) may be produced from traditional agricultural products such as corn and sugar beets which are indeed 'agricultural products' within the meaning of the Agreement on Agriculture. See for example Van den Bossche, Schrijver and Gerrit 2007, p. 158.

12 Harmonized System Review Sub-Committee, 36th Session, Brussels 21 May 2008, Doc No. NR0722E1a, available at: <http://www.biological-arms-control.org/projects_ trademonitoring/States $\% 20$ parties $\% 20$ adjourning $\% 20$ the $\% 20$ process $\% 20$ for $\% 20$ proce dural $\% 20$ reasons $\% 20(21 \% 20 \mathrm{May} \% 202008)$.pdf $>$, last visited 4 February 2010 . The Sub Committee decided not to include second-generation biodiesel in the classification since new second-generation biofuels do not have a defined chemical composition yet. Machado-Filho 2008, p. 67-88; Motaal 2008, p. 61-86. Motaal 2008, p. 76-77.

Harmonized System Review Sub-Committee, 36 th Session, Brussels 27 November 2007, Doc. No. NR0751E1b, available at: <http://www.biological-armscontrol.org/projects_trademonitoring/States $\% 20$ parties $\% 20$ instructing $\% 20$ the $\% 20 \mathrm{~W}$ CO $\% 20$ Secretariat $\% 20$ to $\% 20$ become $\% 20$ engaged $\% 20$ in $\% 20$ the $\% 20$ matter $\% 20(27 \% 2$ 0November,\%202007).pdf> and Harmonized System Review Sub-Committee, 36 $6^{\text {th }}$ 
would have involved moving (bio)ethanol from Chapter 22 (agricultural product) to Chapter 27 (industrial product including fossil fuels) and also including biodiesel in Chapter 27 rather than Chapter 38. Such a re-classification would call for two products - e.g. ethanol alcohol and ethanol biofuel - to be distinguished on the basis of their end-use. With regard to biodiesel, in order to avoid establishing such an enduse criterion, the Sub-Committee decided to removed the term 'fuel' from the biodiesel classification. ${ }^{16}$ This went further to also justify the classification of biodiesel in Chapter 38 rather than in Chapter 27 where fossil fuels are classified. ${ }^{17}$ There is a reluctance to classify products based on their end use and rather to rely on the chemical make up of the products - thereby classifying ethanol, biodiesel and other fossil fuels all in different chapters. It seems to be reasonable therefore to consider that the consistent classification of all biofuels is not to be expected in the near future.

Since these more traditional biofuels are not consistently classified, it is sure that second-generation biofuels (those produced from feedstock or agricultural byproducts) also have no clear classification yet. This is even more so the case since, unlike first generation biofuels, second-generation biofuels are only in a developmental stage and are not yet widely commercially available.

The biofuels covered by the Canadian accelerated depreciation measure are secondgeneration biofuels, derived from wood waste, plant residues and organic waste. What is clear at this point is that the Chapters of the HS covered by the Agreement on Agriculture do not cover these inputs. ${ }^{18}$ Therefore I submit that, since the Agreement on Agriculture currently does not cover inputs to second-generation biofuels, indirect input subsidies for the production of second-generation ethanol are not covered by the Agreement on Agriculture. Since the case study country tax incentives refer only to second-generation biofuels, they are therefore not inconsistent with the Agreement on Agriculture. Naturally, however, unlike in the case studies at hand, direct subsidies to ethanol producers are covered by the Agreement on Agriculture since ethanol itself is an agricultural product.

Although a strong case cannot be made for an indirect agricultural subsidy flowing upstream to the suppliers of (second-generation) agricultural inputs for the production of (second-generation) biofuels, the first example given, an indirect

Session, Brussels 21 May 2008, Doc. No. NR0722E1a, available at: $<$ http://www.biological-arms-control.org/projects_trademonitoring/States\%20parties $\% 20$ adjourning $\% 20$ the $\% 20$ process $\% 20$ for $\% 20$ procedural $\% 20$ reasons $\% 20(21 \% 20$ May \%202008).pdf>; last visited 4 February 2010.

16 Harmonized System Review Sub-Committee, 36 th Session, Brussels 21 May 2008, Doc. No. NR0722E1a, available at: <http://www.biological-arms-control.org/projects_ trademonitoring/States $\% 20$ parties $\% 20$ adjourning $\% 20$ the $\% 20$ process $\% 20$ for $\% 20$ proce dural $\% 20$ reasons $\% 20(21 \% 20$ May\%202008).pdf $>$; last visited 4 February 2010.

17 See also Motaal 2008, p. 77-78. NR0722 (27 November 2007): Report of the $36^{\text {th }}$ Session of the Harmonized System Review Subcommittee.

18 However, to the extent that the second-generation biofuel produced from the plant residues and organic waste is a second-generation ethanol (agricultural product) or, for example bio-hydrofined diesel (industrial product), the classification problem will remain in respect of the direct subsidies to the producers of these biofuels. 
subsidy to agricultural producers using subsidised electricity as an input, is a situation with more potential legal consequences.

For example, if in the Netherlands, tomatoes are produced in 24-hour greenhouses with the use of electric heat and light, an input used includes low-cost renewable energy, which has received subsidies in the form of the MIA/EIA/Vamil or Green Funds. There is a financial contribution, which confers an indirect benefit on the agricultural producer in the form of reduced renewable energy electricity costs. The tomatoes are the indirect benefiting product, and are naturally an agricultural product within the ambit of the Agreement on Agriculture. However, as stated earlier, the tax incentives discovered in the case studies are neither export subsidies as they are not contingent upon export performance, nor import substitution subsidies as they are not contingent upon the use of domestic over imported goods. ${ }^{19}$ This leaves the question of how the Agreement on Agriculture deals with subsidies that would otherwise be actionable under the SCM Agreement.

Before answering the question how the Agreement on Agriculture deals with subsidies that would otherwise be actionable under the SCM Agreement it is appropriate to outline what the ambit of the Agreement on Agriculture is in general. The Agreement on Agriculture aims to reduce trade restrictions on agricultural products by requiring Members to reduce tariffs on agricultural products and to reduce subsidies on agricultural products. ${ }^{20}$ However, the rules pertaining to subsidies granted to agricultural products are less strict than the provisions of the SCM Agreement. Firstly, the Agreement on Agriculture primarily addresses agricultural export subsidies and domestic agricultural support subsidies. ${ }^{21}$ Agricultural export subsidies are defined in the same way as export subsidies for the purposes of the SCM Agreement.22 In this way, since export subsidies (within the meaning of the SCM Agreement) were not considered to be at issue with respect to the case study tax incentives, this would also be the case concerning agricultural export subsidies.

Domestic support measures, within the context of the Agreement on Agriculture, refer to measures which support domestic prices or support the cost of production directly. Article 6 of the Agreement on Agriculture requires Members to reduce domestic support measures and those commitments form part of the GATT Schedule of Concessions. ${ }^{23}$ Members are restricted to providing domestic agricultural support within the limits of their commitments. The Agreement on Agriculture exempts certain domestic support measures from the reduction requirement. Included in these exempted measures, within the 'Green Box' category, are payments under environmental programmes. ${ }^{24}$ Thus, to the extent that the case study tax incentives

19 See section 9.2 Prohibited Subsidies, p. 215.

20 McMahon 2005, p. 202. It is interesting to note that Annex 2, 12(a) of the Agreement on Agriculture exempts environmental programmes from Members obligations to make reduction commitments for subsidies - Green Box subsidies. Bown and McCulloch 2005, Chapter 43, p. 152. Of course as explained above, these commitments only refer to export and import substitution subsidies and not the type of subsidies covered in this book.

McMahon 2005, Chapter 6, p. 207-214.

Appellate Body Report, US - FSC, para. 141.

Article 6 Agreement on Agriculture.

Annex 2 to the Agreement on Agriculture. 
indeed operate to support the production of renewable energy, Members may be justifiably exempted from the requirement to commit to reduce this domestic support since the tax incentives may be deemed to form part of an environmental programme. The environmental programme should be one which is funded by the government without having the effect of a price-support for producers. This government-funded programme may also include payments made through 'revenue foregone'. ${ }^{25}$

Article 21 of the Agreement on Agriculture provides that the provisions of the SCM Agreement apply subject to the provisions of the Agreement on Agriculture. Furthermore, until 2004, ${ }^{26}$ Article 13 of the Agreement on Agriculture, the 'Peace Clause', saved agricultural export subsidies and domestic agricultural support subsidies from scrutiny of consistency with the SCM Agreement to the extent that those subsidies conformed to the requirements of the Agreement on Agriculture. Moreover, Article 13, also called Members to exercise due restraint in commencing countervailing duty investigations under the SCM Agreement until after the end of the implementation period (until 2004). ${ }^{27}$ This due restraint referred again only to agricultural export subsidies and domestic agricultural support subsidies. Although since 2004 and the expiration of the 'Peace Clause' both agricultural export subsidies and domestic agricultural support subsidies can both be challenged under the Agreement on Agriculture and the SCM Agreement.

Articles 5 and 6 of the SCM Agreement state that: '[t]his Article does not apply to subsidies maintained on agricultural products as provided in Article 13 of the Agreement on Agriculture' and Article 13 of the Agreement on Agriculture refers only to agricultural export subsidies and domestic agricultural support measures.

Thus, in conclusion, the tax incentives in place in the case study countries would only be subject to the provisions of the Agreement on Agriculture to the extent that they potentially provide flow-through benefits to agricultural products and should they be deemed to be agricultural export subsidies or domestic agricultural support measures. However, even if considered to be domestic agricultural support measures, these tax incentives would be exempted from the reduction commitment requirement since they are payments under environmental programmes. The Agreement on Agriculture allows for domestic support measures to be environmentally justified even if they confer indirect benefits on agricultural products. Lastly, however, even if exempted from reduction commitments under the Agreement on Agriculture the same measures would nevertheless have to be examined for consistency with the SCM Agreement.28

Although the Agreement on Agriculture does not have legal consequences for the tax incentives in the case study countries, it can be looked upon for inspiration for an environmental safety net for the SCM Agreement. The Agreement on Agriculture, also disciplining subsidies like the SCM Agreement, has an environmental exception built into the Agreement. Article 7 of the Agreement on Agriculture addresses 'green box' subsidies that include payments under environmental programmes. According to this

25

Van den Bossche, Schrijver and Gerrit 2007, p. 162.

The Peace Clause lapsed in the end of 2003.

McMahon 2005, Chapter 6, p. 214-215.

Benitah 2001, p. 34. 
Article, in conjunction with Annex 2, payments under environmental programmes which would otherwise be considered to be import substitution subsidies (and if not on agricultural products potentially prohibited subsidies under the SCM Agreement) are exempted from reduction commitment requirements. ${ }^{29}$ In other words, the subsidies could be conferred 'freely' and were exempt from reduction commitments. ${ }^{30}$ Although these subsidies are now challengeable under the SCM Agreement since the lapse of the Peace Clause, it is interesting to notice that there is special treatment of environmental subsidies in the Agreement on Agriculture.

Again this treatment of the Agreement on Agriculture of environmental subsidies is an example of where, within the W'TO Agreements, the positive motivation of the subsidy programme is considered sufficient to counterbalance the potential negative trade effects. This will become more apparent in the later section which deals with another essential example of an environmental safety net in the WTO Agreements, namely the Article XX exception in the GATT 1994.

\subsubsection{GATT 1994}

Although in Chapter 7 the consistency of the case study tax incentives with the nondiscrimination provisions of the GATT 1994 was addressed, in this section, the GATT 1994 will be called upon for inspiration for the treatment of environmental subsidies within the SCM Agreement. It will be explored whether and to what end an Article XX exception may be invoked in defence of an alleged inconsistency with the SCM Agreement and more generally, the Article XX exception will be addressed with a view to gaining inspiration for a future environmental subsidy exception in the SCM Agreement itself.

\subsubsection{Article XX of the GATT 1994 and the SCM Agreement}

Since the only SCM Agreement exception for environmentally motivated measures expired in 1999, a lacuna clearly exists. Despite the lack of an environmental exception in the SCM Agreement, there is such a provision available to justify measures that are allegedly inconsistent with obligations in the GATT 1994, namely Article XX.

The environmental exception embodied in the WTO Agreement is enshrined in Article XX of the GATT 1994. Where an inconsistency with another provision of the GATT 1994 is contested, general exceptions to the GATT obligations are provided in this Article. In order to fulfil the Article XX exception, at least two conditions must be met. Firstly, to be provisionally justified by Article XX, the measure at issue must be relating to, or necessary for, one of the objectives listed in sub paragraphs (a) to (j) of Article XX. Thereafter, the application of these measures must also meet the requirements of the Chapeau of Article XX.

Article XX of the GATT 1994 lists a set of policy objectives which may permit the maintenance of a measure which would otherwise be considered GATT-inconsistent. Paragraphs (a) to (j) include two provisions which relate to the protection of the

$29 \quad$ Charnovitz 2007, p. 688; Benitah 2001, p. 33.

$30 \quad$ Stilwell and Bohanes 2005, Chapter 58, p. 517. 
environment by combating climate change as is the objective of the Kyoto Protocol, and also of particular interest with respect to energy products, ${ }^{31}$ namely paragraph (b) and paragraph (g). Article XX provides that:

Nothing in this Agreement shall be construed to prevent the adoption or enforcement by any contracting party of measures: ...

(b) necessary to protect human, animal or plant life or health; ...

(g) relating to the conservation of exhaustible natural resources if such measures are made effective in conjunction with restrictions on domestic production or consumption; [emphasis added] ${ }^{32}$

These two exceptions have been referred to as the 'environmental window' of international trade law. ${ }^{33}$ However, what they perhaps are is an 'environmental window' of GATT 1994 law only. As stated in the Chapeau, 'nothing in this Agreement...' This phrase delineates the application of Article XX as a defence for alleged inconsistencies with obligations enshrined in the GATT 1994 only. I will return to this point of the (non-) application of Article XX to the SCM Agreement after a primary introduction to the requirements of the article itself.

In order to be an exception consistent with these provisions, the measure must have one of the policy objectives as listed, and it must be shown that such a measure is necessary to this effect ${ }^{34}$ or related to the achievement of this objective. ${ }^{35}$ In US Gasoline it was determined that where no other reasonably available measures which could have been implemented which would have been consistent or at least lessinconsistent or, in other words, if no more reasonable measure was available then the measure could be deemed to be necessary. ${ }^{36}$ Although the necessity test and within it a 'weighing and balancing test' of the contested measures and the available alternatives has gradually developed by the interpretations in, for example in the Korea - Various Measures on Beef and EC - Asbestos, it has been considered that the more recent dispute Brazil - Retreaded Tyres, may constitute a positive 'turning point' in the jurisprudence. ${ }^{37}$ This is so since, in its examination, the Panel and the Appellate Body both emphasised the importance of the characterisation of the regulatory goal pursued in determining the necessity of the measures. ${ }^{38}$ However, in China Publications and Audiovisual Products, the Appellate Body confirmed that, although the Appellate Body in Brazil - Retreaded Tyres ${ }^{39}$ emphasised the importance of considering the interests and values at stake, the necessity test in Brazil-Retreaded Tyres was not different from the test applied in the US - Gambling and Korea - Various Measures on Beef..$^{40}$ Therefore, although the evaluation of the regulatory goal pursued is recognised

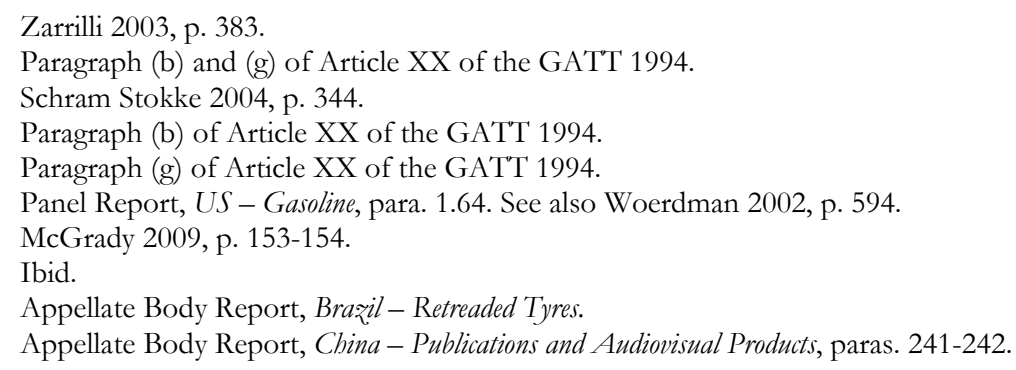


as important element in the necessity test it forms part and parcel of the traditional 'weighing and balancing' required in the necessity test.

Where a Member can show that the contested measure falls within (b) or (g), and that that measure is necessary to protect human, animal or plant life or health or relating to the conservation of exhaustible natural resources the additional requirements of the Chapeau must also be fulfilled in order for the measure to be justified by Article XX.

The Chapean of Article XX of the GATT 1994 requires that:

...such measures are not applied in a manner which would constitute a means of arbitrary or unjustifiable discrimination between countries where the same conditions prevail, or a disguised restriction on international trade... [emphasis added] ${ }^{41}$

Within the WTO Agreement it is important to note that the treatment of a measure having environmental protection as a policy objective will differ greatly depending on the form of that measure. A measure in the form of internal taxation which distinguishes between products based on their environmental impact and which operates with the effect of affording protection to domestic products and which is contested for example under Article III of the GATT 1994 may be saved by Article $\mathrm{XX}$. However, a subsidy promoting renewable energy, contested as an actionable subsidy under the SCM Agreement would have no such safety net. An environmental exception that only justifies some types of action by Members (for environmental protection) to the exclusion of others, for example subsidies, and without any clear justification, is by no means satisfactory. The result is that a Member, in choosing a policy measure in pursuit of environmental protection, may be influenced to choose a measure which may otherwise be justified by Article XX as opposed to a subsidy which may be contested for consistency with the SCM Agreement and thus left without an environmental justification should that measure create negative externalities for other Members. The provision of a 'safety net' for Members ensuring environmental protection using subsidies is an issue which must now be addressed, seven years after the expiry of the non-actionable subsidies provision.

Since an environmental exception is lacking in the SCM Agreement it may be proffered that potential inspiration could be drawn from Article XX of the GATT 1994 for a similar provision to be inserted into the SCM Agreement. This would provide a safety net for Member's environmental protection measures and also put measures contested for inconsistency with the GATT 1994 and subsidies contested for inconsistency with the SCM Agreement on equal footing with respect to their equal environmental motivation and positive, borderless, environmental externalities.

In the current discussions relating to pro-Kyoto Protocol action pursued by WTO Members and their potential legal implications, recourse is had mainly to measures potentially inconsistent with the GATT 1994. The Article XX exception and the 'liberal view' of panels and the Appellate Body in the application of Article XX, are paraded out each time in defence of the WTO regime's concern for environmental issues and tolerance of environmental measures adversely affecting trade. This 
argument, highlighting the availability of Article XX in justification of environmentally motivated action, does not address Members' measures falling within the ambit of other WTO agreements, in this case the SCM Agreement. The GATT 1994 provides a clear and available answer to the question: what is the stance of the WTO on environmental protection? The answer is: environmental protection measures are tolerated despite their trade distorting effects. It is for this reason that Article XX becomes relevant in searching for a solution with respect to the SCM Agreement.

Article XX provides for general exceptions for inconsistencies with the obligations embodied in the Articles of the GATT 1994. Since in the first sentence of Article XX it states that 'nothing in this Agreement shall be construed to prevent the adoption' of the measures listed in that Article, the majority view is that an Article XX defence is not available for inconsistencies with provisions of the other WTO Agreements. ${ }^{42}$ Therefore, in relation to subsidies, Article XX may only be invoked when an inconsistency with Article XVI of the GATT 1994 is claimed and may only be invoked as a justification for failing to act consistently with the obligation embodied in Article XVI of the GATT 1994. The respondent may only attempt to avail of the Article XX exception in response to a claim of inconsistency with an Article of the GATT 1994 by the complainant. Therefore, a complainant, unwilling to allow the respondent to avail of this exception and thus justification for its action, would content itself in bringing its claims under the SCM Agreement. ${ }^{43}$ From previous case law, it is clear that by not making any claims under the GATT 1994, Members have been able to settle disputes adequately with reference only to the SCM Agreement. A claim under the GATT 1994 is not necessary as the SCM Agreement provides sufficient clarification on the WTO rules on subsidies.

As discussed in Chapter 7, the only obligation in Article XVI of the GATT 1994 is that when a subsidy is suspected to distort trade, the subsidising Member is requested to discuss the possibility of limiting the subsidisation as well as to avoid providing export subsidies. Prior to 1995 when Article XVI, along with the Tokyo Round

42 Nevertheless, there is a minority view that argues that Article XX would be available to justify alleged inconsistencies with agreements other than the GATT 1994. In CbinaPublications and Audiovisual Products, the Appellate Body explored the availability of Article XX to justify an alleged inconsistency with the Accession Protocol. To the extent that the obligations in the agreement with which there is an alleged inconsistency (in this case the Accession Protocol) are explicitly subject to the rights and obligations of the Member under the WTO Agreement, then it would follow that all the provisions of the WTO Agreement would be at the disposal of that Member to justify its measure. The agreement with which inconsistency is alleged would in this case operate subject to the provisions of Article XX of the GATT 1994 making this defence indeed available. Although this echoes the minority view on the availability of Article XX, it was only confirmed by the Appellate Body for a very narrow and special set of circumstances, fulfilled in this case with respect to the Accession Protocol. Appellate Body Report, China - Publications and Audiovisual Products, paras. 233-336. See below p. 366 for further elaboration.

43 For the GATT 1994 to be within the terms of reference of a panel, the complainant must list the GATT 1994 and the articles of the GATT 1994 with which inconsistency is claimed in the request for the establishment of the panel. Where the complainant only lists the Articles of the SCM Agreement in the request for the establishment of the panel, review of the GATT 1994 is outside the terms of reference of the panel. 
Subsidies Code from 1979, were the only provisions dealing with subsidies, this was also even then not much of an obligation to require recourse to Article XX. It would seem clear also that for this reason no subsidy case to date has come before GATT panels or WTO panels whereby a subsidising Member claimed that the alleged inconsistency with Article XVI of the GATT (1947 or 1994) could be justified by virtue of the general exception provision of Article XX.

Of all subsidies disputes to have come before panels and the Appellate Body to date, Article XVI of the GATT 1994 was included in the terms of reference of the panel in US - Upland Cotton. ${ }^{44}$ In that case, Brazil contested the measures maintained by the US and claimed their inconsistency with, inter alia, Article XVI:1 and XVI:3 of the GATT 1994 and SCM Agreement Articles 3.1(a), 3.1(b), 3.2, 5, 6. However, the US did not attempt to invoke Article XX as a justification for its measures with respect to the allegation of inconsistency with Article XVI of the GATT 1994. This only makes sense, since any such justification would only go so far as to relieving the US of the obligation to have considered limiting the subsidy in question.

Since the Uruguay Round, and the conclusion of the SCM Agreement, it is the latter, the SCM Agreement which disciplines the provision of subsidies by WTO Members in detail and the agreement to which a complainant will refer in its request for a panel. This is not to say that the existence of the SCM Agreement excludes the application of Article XVI of the GATT. The two co-exist. In fact, it is only in a situation where a provision of the GATT 1994 conflicts with a provision of the SCM Agreement that the SCM Agreement prevails. ${ }^{45}$ Although, without a conflict between the terms of the two agreements, both are available to the complainant, the exception provided by Article XX relieves a Member of only a very minor obligation with respect to subsidies.

In US - Upland Cotton, the Panel clarified that since in Article XVI no definition of a subsidy was provided and also more specifically no definition of export subsidy was provided, whereas both have since been defined in the SCM Agreement, it would be inappropriate 'to apply a separate or different definition of 'export subsidies' under Article XVI:3 than that which is now applicable for the purposes of ... Article 3.1(a) of the SCM Agreement'. However, rather than conclude that such a situation constituted a conflict between the agreements, thus making only the SCM Agreement prevail, the Panel simply read the SCM Agreement and Article XVI of the GATT 1994 together.

Although far-fetched, it is worth mentioning that perhaps it could be argued that the SCM Agreement simply clarifies and expands on Article XVI of the GATT 1994, in the same, or a similar fashion as, for example, the Understanding on the Interpretation of Article II:1(b) of the General Agreement on Tariffs and Trade 1994, thereby making possibility to invoke Article XX a reality. Despite mentioning this for the sake of discussion, counter arguments are much stronger which decline to see the SCM Agreement as an Understanding since it is clear that when the Members intended to negotiate a new Understanding it was called an Understanding, while when the Members intended for a new and somewhat independent Agreement to be negotiated it was therefore called an Agreement - the Agreement on Subsidies and Countervailing

44 Panel Report, US - Upland Cotton, p. 13.

45 Annex $1 \mathrm{~A}$ of the WTO Agreement. 
Measures. As stated by the Appellate Body in Brazil Desiccated Coconut: 'the question for consideration is not whether the SCM Agreement supersedes Article VI of the GATT. But it creates rules which are separate and distinct from those of the SCM Agreement, and can be applied without reference to that agreement'. ${ }^{46}$

Although a solution in which Article XX could be read into applying to the SCM Agreement via Article XVI of the GATT 1994 would be very desirable considering the possible desirable environmental results, it is not legally feasible. It would seem clear also that for this reason no complainant in a subsidy dispute to date has invoked the Article XX exception for alleged inconsistency with Article XVI of the GATT 1994 or the SCM Agreement. As put by Marceau and Trachtman extending the application of Article XX of the GATT to justify an alleged inconsistency with another agreement of Annex 1A would require 'a heroic approach to interpretation'. ${ }^{4}$

Despite this, there have been instances where panels and the Appellate Body have toyed with the idea of permitting an Article XX exception for an alleged inconsistency with a WTO Agreement other than the GATT 1994. In US - Customs Bond Directive, the Appellate Body re-examined the Panel's deliberation on the Article XX exception as invoked by the US to justify its alleged inconsistency with $A d$ Note to Article VI:2 and 3 of the GATT 1994 and Article 18.1 of the Anti-Dumping Agreement. ${ }^{48}$ Furthermore in the Panel Report China - Publications and Audiovisual Products, ${ }^{49}$ the Panel, referring to the Appellate Body Report above, also examined Article XX as a possible exception to China's alleged inconsistency with paragraph 5.1 of the Accession Protocol and/or paragraphs 83(d), 84(a) and/or 84(b) of the Working Party Report (and thus with paragraph 1.2 of the Accession Protocol).

In US - Customs Bond Directive the Appellant (rightly in my opinion) raised the question whether Article XX was even an available defence for the alleged inconsistencies and appealed against the Panel's examination of Article XX stating that 'the Panel erred' in examining this defence by the US. ${ }^{50}$ Despite the appeal by the complainant, the Appellate Body did not express any view at all on the availability of an Article XX defence and rather examined whether indeed the measure by the US was 'necessary' as required under Article XX(d). ${ }^{51}$ The Appellate Body first made a full evaluation ('assuming arguendo, that such a defence is available') 52 of whether the measure by the US fulfilled the conditions of Article XX. In conclusion the Appellate Body deemed the measure by the US not necessary within the meaning of Article XX(d) of the GAT'T 1994 and rounded up the legal analysis on the 'systemic issue' of whether the Article XX exception was available to the US at all by stating: 'we do not

46

47

48
Zhou 2006, p. 324. Appellate Body Report, Brazil-Desiccated Coconut.

Marceau and Trachtman 2002, p. 874.

Appellate Body Report, US - Shrimp (Thailand), US - Customs Bond Directive, paras. 304319.

Panel Report, China - Publications and Audiovisual Products, paras. 7.708-7.917. The findings of the Appellate Body in this dispute are discussed in the following paragraphs.

Appellate Body Report, US - Shrimp (Thailand), US - Customs Bond Directive, para. 306. Appellate Body Report, US - Shrimp (Thailand), US - Customs Bond Directive, para. 310. Ibid. 
express a view on the question of whether a defence under Article $\mathrm{XX}(\mathrm{d})$ of the GAT'T 1994 was available to the United States'. ${ }^{53}$

Likewise in China - Publications and Audiovisual Products, the Panel followed the line of reasoning by the Appellate Body in US - Customs Bond Directive, while recognising that this 'systemic issue' raised 'complex legal issues'. ${ }^{54}$ The Panel even stated that Article XX of the GATT 1994 explicitly 'contains the phrase "nothing in this Agreement" with the term "Agreement" referring to the GATT 1994, not other agreements like the Accession Protocol'. ${ }^{5}$ Therefore, it is clear that the Panel was aware that the possibility to raise an Article XX exception to justify alleged inconsistencies with agreements other than the GATT 1994 was indeed dubious. Despite this however, the Panel continued in what could be termed a 'blinkered fashion' following the reasoning (or perhaps the lack of reasoning) of the Appellate Body in US - Customs Bond Directive.

In the same way as the Appellate Body proceeded US - Customs Bond Directive, the Panel in China - Publications and Audiovisual Products, examined whether China's measures fulfilled the conditions of Article XX(a) on the assumption that the defence was available to justify the alleged inconsistency with the Accession Protocol. ${ }^{56}$ The result of this examination was also that the measures were deemed unnecessary within the meaning of Article XX(a) and thus, in any case could not be justified.57 The final nail in the coffin of this (or rather these two) empty analysis (analyses) of the application of Article XX to obligations arising out of an agreement other than the GATT 1994, in the words of the Panel is: 'we need not, and hence do not, revert to the issue whether Article $\mathrm{XX}(\mathrm{a})$ is in fact applicable as a direct defence to breaches of China's trading rights commitments. We thus take no position on this issue'. ${ }^{58}$

Considering the legal conundrum that is the availability of the Article XX exception to Members whose measures are contested for alleged inconsistency with one of the WTO agreements, other than the GATT 1994 it was unfortunate that, until the Appellate Body Report in China - Publications and Audiovisual Products, no statement was made by the panels and the Appellate Body on the issue in these previous disputes. It seems unnecessary that the panels and Appellate Body in these previous disputes went to so much effort in humouring the parties to the disputes above and engaging in or at least bordering on judicial activism, while at the same time making no concrete statement on the availability of an Article XX defence. ${ }^{59}$

\footnotetext{
53 Appellate Body Report, US - Shrimp (Thailand), US - Customs Bond Directive, para. 319.

54 Panel Report, China - Publications and Audiovisual Products, paras. 7.743-7.744.

55 Ibid.

$56 \quad$ Ibid.

57 Panel Report, China - Publications and Audiovisual Products, para. 7.913.

$58 \quad$ Panel Report, China - Publications and Audiovisual Products, para. 7.914.

59 Bartels 2004, p. 868. Charges of judicial activism in the past have also attached to the decisions of panels and the Appellate Body in highly sensitive cases involving environmental protection, for example, US - Shrimp. Although as Bartels points out, in these cases, as in the argument here, the dissatisfaction attaches to the legal reasoning of panels and the Appellate Body rather than to the more fundamental issue of whether panels and the Appellate Body are the appropriate bodies to decide the disputes.
} 
Nevertheless, more light has been shed on the issue following the Appellate Body Report in China - Publications and Audiovisual Products. Although the Appellate Body did not make a statement as to the availability, in general, of the Article XX defence to alleged inconsistencies with agreements other than the GATT 1994, it nevertheless addressed the issue head-on with respect to China's claim of invoking Article XX(a) to justify alleged inconsistencies with the Accession Protocol. From this Appellate Body Report, few sweeping statements can be made. Neither does it follow from this Report that an Article XX defence is available for alleged inconsistencies with agreements other than the GATT 1994 in general, nor does it follow that an Article XX defence is not available. Be this as it may, the Appellate Body Report in ChinaPublications and Audiovisual Products has shed further light on this issue and will be elaborated on here.

The Appellate Body addressed the Panel's approach of 'assuming arguendo that China can invoke Article XX(a)' and concluded that this approach could pose problems in ensuring the legal certainty and predictability. For this reason, the Appellate Body undertook to examine the availability of Article $\mathrm{XX}(\mathrm{a})$ in China's defence in its entirety.

Central to the conclusion by the Appellate Body in China - Publications and Audiovisual Products was the wording of the introductory clause of Accession Protocol with which China was allegedly inconsistent, which stated: '[w]ithout prejudice to China's right to regulate trade in a manner consistent with the WTO Agreement'. China relied on this wording to invoke the Article XX(a) defence. The Appellate Body examined this phrase in detail and in the context of China's Accession Protocol's trading rights commitments and determined that its meaning was that China's obligation 'to undertake[s] a commitment in respect of traders, in the form of a commitment to grant to all enterprises in China the right to import and export goods', under the Accession Protocol was subject to 'China's right to regulate trade in a manner consistent with the WTO Agreement. ${ }^{60}$ Since, in this sense, China was entitled to pursue measures which otherwise would be permitted within the WTO Agreement, although consistency with the WTO Agreement and specifically the GATT 1994 was not being challenged, this both encompassed pursuing measures which do 'not contravene any WTO obligation' as well as measures which 'even if they contravene a WTO obligation, they may be justified under an applicable exception'. ${ }^{61}$ This overall right enshrined in the Accession Protocol, to pursue measures within the boundaries of the WTO Agreement 'as a whole, including its Annexes' ${ }^{62}$ conferred on China the right, to rely on this introductory phrase to justify its measures within the meaning of Article XX(a) of the GATT 1994. ${ }^{63}$ According to the Appellate Body, in this case, due to the particular wording of the Accession Protocol, China was entitled to invoke Article XX(a) of the GATT 1994 to justify the alleged inconsistencies with the Accession Protocol. ${ }^{64}$

\footnotetext{
Appellate Body Report, China - Publications and Audiovisual Products, para. 226. Appellate Body Report, China - Publications and Audiovisual Products, para. 223. Appellate Body Report, China - Publications and Audiovisual Products, para. 222. Appellate Body Report, China - Publications and Audiovisual Products, para. 233. Appellate Body Report, China - Publications and Audiovisual Products, para. 336.
} 
Although in the end, in China - Publications and Audiovisual Products, the Appellate Body, having examined the issue in great depth came to the conclusion that China was entitled to invoke the Article XX exception for an alleged inconsistency with its Accession Protocol, this was solely due to the specific wording of the Protocol which made the commitments made under the Protocol subject to all the rights and obligations embodied in the WTO Agreement, including Article XX of the GATT 1994. Thus to the extent that in the future WTO panels or the Appellate Body examine alleged inconsistencies with agreements other than the GATT 1994, it is proffered that Article XX may only be invoked to the extent that the wording of that agreement limits its status to one subsidiary to the GATT 1994 (or the WTO Agreement as a whole).

As explained above, the SCM Agreement applies concurrently with the GATT 1994 and is not a subsidiary agreement and in this sense it is not likely that, in the manner of China - Publications and Audiovisual Products, the provisions of Article XX of the GATT 1994 will be available to justify otherwise SCM Agreement-inconsistent measures.

It is worth mentioning, to the extent that Article XX may ever be available to Members whose environmental subsidies are contested for consistency with the SCM Agreement or otherwise if an Article XX equivalent were to be developed within the SCM Agreement itself, a point which was examined in previous Article XX disputes concerned the territorial relationship between the protected value being pursued by the contested measure and the Member applying the measure. In US - Shrimp, the Appellate Body considered the nexus between the environmental endangerment and the territory of the Member invoking the Article XX exception. In that case, the Appellate Body considered that there was a sufficient nexus between the endangered turtles and the waters within the US jurisdiction for the US to be entitled to take (environmental) protective measures.

Similarly, in EC - Tariff Preferences, the Panel examined whether the European Communities' Drug Arrangements was a measure whose objective was the protection of human life or health within the meaning of Article XX(b) of the GATT 1994. The Panel examined the objectives listed in the Drug Arrangements and in its Explanatory Memorandum which referred to 'the eradication of poverty and the promotion of sustainable development in the developing countries' including 'combatting drug production and trafficking'. ${ }^{65}$ In order to achieve this objective, the Drug Arrangements provided for improved market access for the twelve participating developing countries. The Panel held that the objective of the Drug Arrangements was not the protection of human life or health and thus did not fall within Article XX(b). Furthermore, according to the Panel, 'there was no evidence presented before the Panel to suggest that providing improved market access is aimed at protecting human life or health in drug importing countries'. ${ }^{66}$ [emphasis added] Therefore, even if the objectives of the Drugs Arrangements did include the protection of human life or health, there was no evidence that the measures pursued protected life and health in the drug importing Member - the European Communities. Therefore, in any case,

65 Panel Report, EC - Tariff Preferences, paras. 7.200-7.201.

66 Panel Report, EC - Tariff Preferences, para. 7.202. 
there would be lack of a sufficient nexus between the objectives pursued and the territory of the Member invoking the Article XX exception.

In relation to the risks posed by climate change and the measures taken by Members to mitigate the damage, it is unknown whether in the future the nexus between the territory of a Member and the environmental risk would be sufficiently close to permit the Member to rely on an Article XX justification for that measure. ${ }^{67}$

I would argue that since climate change is truly a trans-boundary issue, all Members as well as non-Members could claim a sufficiently clear nexus between their territory and the risk at issue. ${ }^{68}$ Perhaps however, the most significant nexus could be demonstrated by countries which have been suffering from extreme weather conditions which have been considered to be caused by climate change. ${ }^{69}$ Although, since there is no environmental exception in the SCM Agreement, and therefore such a nexus between an environmental protection subsidy and the environmental risk being protected against is not relevant at the present time, it is worth highlighting this issue as it has arisen within the GATT 1994 context.

Despite the fact that the Article XX environmental exceptions are not (yet) available for contested environmental subsidies, Article XX may provide for inspiration in the development of an equivalent safety net for subsidies having positive environmental externalities.

\subsubsection{Environmental Subsidy Solutions}

The dilemma posed by the lack of consideration within the SCM Agreement for the environmental protection motivation behind some Members subsidies will find its solutions only to the extent that drastic measures are taken within the WTO framework. These drastic measures could take the form of inserting an Article XX equivalent into the SCM Agreement, as mentioned above, or reinstating Article 8 of the SCM Agreement (albeit a limited exception). If the environmental subsidy solution of choice would be the insertion of an Article XX equivalent into the SCM Agreement, it would only be reasonable that it would also mirror the Chapean of Article XX of the GATT and furthermore mirror the necessity test embodied in Article XX(b). ${ }^{70}$ With these safety clauses in place, as put by Cottier et al this would help to ensure that the environmental exceptions would not 'be hijacked by domestic interest groups to the detriment of both trade and the environment'. ${ }^{71}$ Indeed it should also be recognised that the SCM Agreement, which incorporates the possibility for Members to sanction

$67 \quad$ Peel 2002, p. 242

68 Condon agrees with this argument stating: 'The effects of climate change are global. Therefore, there should be a sufficient jurisdictional nexus between all WTO Members and climate change'. Condon 2009, p. 912.

69 UN International Strategy for Disaster Reduction, up to 236,000 people lost their lives in 2008 in 300 disasters which can be closely linked to climate change, with damages over \$180billion.

70 Cottier, Malumfaschi et al. 2009, p. 11, available at: <http://www.nccrtrade.org/images/stories/projects/ip6/IP6_synthesis_report_with\%20biblio.pdf>, last visited 24 November 2009.

71 Ibid. 
the use of subsidies with countervailing measures, would require an interpretation of an Article XX equivalent specific to weed out protectionist subsidies disguised as environmental subsidies and to provide for a balance between allowing environmental subsidies while also allowing Members to continue to impose countervailing duties where necessary.

Article XX, since it only applies to inconsistencies with the GATT 1994, includes an environmental exception which only justifies some types of measures by Members but excludes the justification of other measures which are covered by Agreements other than the GATT 1994: namely subsidies. This different treatment of environmental subsidies and general environmental protection measures is by no means satisfactory. The result is that a Member, in choosing a policy measure in pursuit of environmental protection, may be influenced to choose a measure which may otherwise be justified by Article XX as opposed to a subsidy which may be contested for consistency with the SCM Agreement and thus left without an environmental justification should that measure create negative trade externalities for other Members.

Zhang also suggests that the actionable subsidy definition could be amended to allow environmental subsidies and exempt such subsidies from the imposition of countervailing duties or challenges for SCM Agreement-inconsistency. ${ }^{72}$ Indeed this solution could be covered by the development of (or the reinstatement of) a category of 'non-actionable subsidies' thereby freeing environmental subsidies from challenge and from the application of countervailing duties in the same way as subsidies falling within Article 8 of the SCM Agreement were free from challenge and from the application of countervailing duties.

A further solution proposed by Zhang is that (a non-binding) 'Understanding' on the interpretation of the SCM Agreement be developed in which it would be clarified for panels which subsidies are non-actionable. ${ }^{73}$ Considering the possibilities available in the WTO Agreement, the possibility relating to an 'authoritative interpretation' is provided for in Article IX:2. However, such an 'authoritative interpretation' would be binding, as a non-binding authoritative interpretation would render it ineffective entirely. ${ }^{74}$ There are, however, more serious issues with this possibility of an authoritative interpretation and the role it could play in rendering environmental subsidies non-actionable within the SCM Agreement. The suggestion by Zhang that a binding authoritative interpretation would clarify 'for dispute resolution panels that when subsidies are not actionable 75 is not an available solution. An authoritative interpretation to the SCM Agreement which would (re-)establish a category of nonactionable subsidies would go beyond interpreting the SCM Agreement and rather would amend this Agreement to create new rights and obligations for the Members. Authoritative interpretations are limited in scope to creating an instrument by which existing WTO provisions 'shall be understood to mean' or 'shall be interpreted (or applied) as follows', thereby providing clarifications on existing ambiguous rules. ${ }^{76}$

Zhang 2005, p. 30.

Ibid.

Ehlermann and Ehring 2005, p. 807.

Zhang 2005, p. 30.

Ehlermann and Ehring 2005, p. 811. 
Essentially they are intended to fine-tune and 'refine' existing provisions. ${ }^{77}$ The last sentence of Article IX:2 of the WTO Agreement which states: 'This paragraph shall not be used in a manner that would undermine the amendment provisions in Article X', prohibits such an interpretation or understanding which goes beyond clarification to encompass changing the law. ${ }^{78}$

However, the authoritative interpretation provision of Article IX:2 of the WTO Agreement has never been availed of. ${ }^{79}$ Therefore, although it may be fanciful to imagine the possibility of developing interpretations or understandings which would not be subject to the lengthy and burdensome (and improbable) procedure of amending the SCM Agreement, this possibility is unlikely to be availed of. Decision making by consensus applies (de facto) both to authoritative interpretations ${ }^{80}$ as well as amendments. Considering the limited scope of the authoritative interpretations to provide that environmental subsidies be considered to be non-actionable subsidies, a hefty amendment procedure would seem to be the only legally available option.

What constitutes a subsidy and which subsidies should be permitted (good subsidies) and which subsidies should be prohibited (bad subsidies) is not agreed upon by commentators on subsidies. ${ }^{81}$ As put forward by Sykes, economically speaking, subsidies are not necessarily problematic. Subsidies, to the extent that they confer a benefit on the recipient, along with the behaviour for which it provides an incentive may be 'socially desirable'. ${ }^{82}$ Furthermore, considering the extent of the 'conceptual and practical difficulties in determining what constitutes an undesirable "subsidy" the examination of actionable subsidies is quite problematic'. ${ }^{83}$ In fact, from an economist's point of view, Sykes even states that there is a strong argument that the W'TO system should abandon its general rules disciplining actionable subsidies and rather only discipline a certain number of actionable subsidies in certain problematic sectors.

In the sense of this research, subsidies which advance the development of energy sources which are environmentally friendly could fall within this category of 'socially desirable' subsidies. The fact that the subsidies at issue in this thesis are potentially actionable subsidies, and perhaps 'socially desirable' subsidies, leaves the categorisation of these subsidies as 'good' or 'bad' subsidies in the hands of panels and the Appellate Body. However, as highlighted by Sykes, this is not an easy task to undertake. It is difficult for panels and the Appellate Body to assess the impact of subsidies on competing industry, and to establish whether this impact is justified. ${ }^{84}$

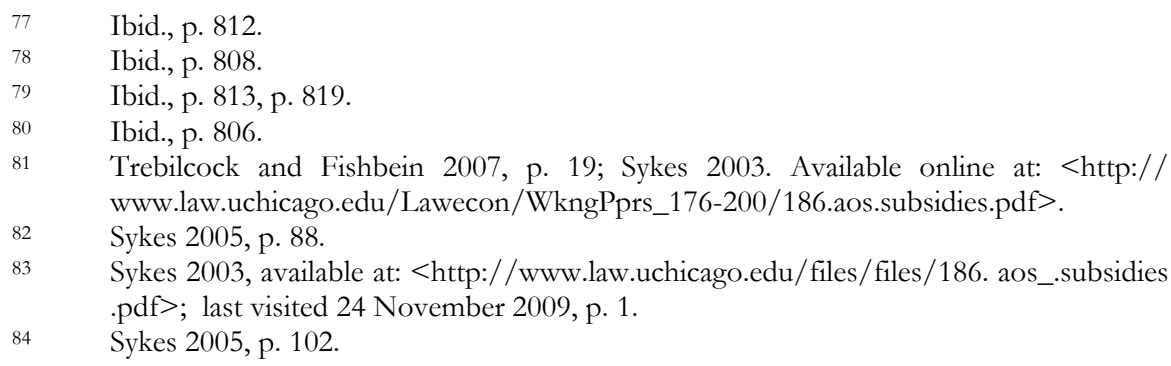


In section Like Products, ${ }^{85}$ the use of an 'aim and effects' test was explored. Such a test with the SCM Agreement would also provide an environmental solution for environmentally motivated subsidies. If used within the SCM Agreement, the aim and effects test has the potential to justify otherwise inconsistent measures by taking into account the bona fide policy objective behind that measure. Thus the application of an aim and effects test in the SCM Agreement could remedy the lack of an environmental exception. This is so since by virtue of an aim and effects test it could be concluded that products, otherwise alike based on their physical characteristics alone, would be deemed not to be alike based on non-product-related PPMs.

An aim and effects test could be the tool with which panels and the Appellate Body could legitimately take environmental subsidies into account by appreciating the policy objectives which differentiate between products based on non-product-related PPMs. Without PPMs being considered relevant in the likeness examination, there is a risk that when Members financially support the development of renewable energy, and ensure greater environmental sustainability, those measures may be found to be actionable and must be subsequently withdrawn.

Of the solutions proposed, I proffer that the most likely and the solution requiring the least drastic developments in terms of having the agreement of the Members and amending the SCM Agreement, is a move towards the use of an 'aim and effects test' in establishing likeness within the SCM Agreement. This is especially so since it is recognised that negotiating the insertion of a new provision in the SCM Agreement, such as an Article XX of the GATT 1994 equivalent, or reinstating Article 8 of the SCM Agreement, is an extremely burdensome procedure, if not unlikely in the foreseeable future. Although in an ideal world an Article XX equivalent in the SCM Agreement could automatically provide Members with the possibility of justifying their environmental subsidies, it is unrealistic to expect that such a drastic amendment to the SCM Agreement could be achieved considering that even an agreement to continue the Article 8 SCM Agreement non-actionable subsidy category was impossible to reach.

For the same reason, it is also unlikely that now, more than ten years after the lack of an agreement to extend the application of Article 8 of the SCM Agreement, as it was originally drafted or in a modified form, that such an agreement would be reached. Furthermore, even to the extent that such an agreement would be reached, in an ideal world, it would be desirable that a new modified Article 8 would be introduced. The original Article 8, as it applies to environmental subsidies is limited only to providing assistance to promote the adaptation of existing facilities to new environmental requirements imposed by law and/or regulations and is limited to $20 \%$ of cost of adaptation. Such a limitation of the environmental subsidies would be better represented by a more general Article XX-like test which is less prescriptive and detailed and would thus also be more adaptable to the change in perception of environmental subsidies over time. It must be reiterated however, as desirable such drastic changes may be, they are unlikely to be achieved.

My recommended solution is to resort to an 'aim and effects' test in establishing likeness within the SCM Agreement. I submit that this is a more feasible option than the two alternatives addressed above. This solution would be possible to implement

85 See section 9.3.3.1 Like Products, p. 230. 
through the interpretation of likeness in the SCM Agreement by WTO panels and the Appellate Body by reference to the recognition of the importance of the objectives of sustainable development and the protection and preservation of the environment in the Preamble to the WTO Agreement.

\subsubsection{Article 3 of the TRIMs and the SCM Agreement}

Although the Agreement on Trade Related Investment Measures is essentially an explanation on how trade related investment measures can be inconsistent with the basic provisions of the GATT and thus do not form any new rights or obligations for Members as would a new Agreement, there is a provision in Article 3 of TRIMs which, if inserted into the SCM Agreement upon agreement of the Members would solve the environmental exception lacuna. Article 3 of the TRIMs states: 'All exceptions under GAT'T 1994 shall apply, as appropriate, to the provisions of this agreement'. If this wording were to be inserted into the SCM Agreement, it would make the Article XX exception available to Members to justify otherwise potentially actionable subsidies due to their positive environmental effects. Although inserting any new provisions into any WTO agreement is a very heavy process, and recognising that this is particularly so in relation to subsidies due to fears of Members taking advantage of environmental exceptions to introduce hidden protectionist subsidies, it is my view that such a simple provision referring to Article XX would put subsidies on equal footing with other policy measures with environmental motivation.

\subsection{Subsidies AFFECTING TRADE IN SERVICES}

Chapter 7 proffered argumentation for why the production of electricity would be classified as a good within the WTO system, rather than a service. It is thus clear that subsidies granted directly to producers of electricity are granted to producers of goods, not suppliers of services. Despite this however, the tax incentives may still fall within the ambit of the GATS, since the same tax incentives may affect the subsequent supply of services in connection with the good electricity. For example, electricity (the good) is produced, but then it is transmitted, distributed and supplied, all activities that may fall within the classification of the supply of services. If the production of the good electricity is subsidised, it is not inconceivable that an indirect subsidy may thus flow from the producer of the electricity through to the supplier of the service related to the electricity. Therefore, the following section will examine whether, if this were to be found to be the case in relation to the tax incentives in place in the case study countries, there would be significant consequences for the Members arising from GATS obligations with regard to subsidies.

\subsection{THE GATS}

The Panel on EC - Bananas III defined the scope of application of the GATS in the following terms:

" $[\mathrm{N}] \mathrm{o}$ measures are excluded a priori from the scope of the GATS as defined by its provisions. The scope of the GATS encompasses any measure of a Member to the extent it affects the supply of a service regardless of whether such measure directly 
governs the supply of a service or whether it regulates other matters but nevertheless affects trade in services". 86

As discussed above, although the generation of electricity may be classified as the production of a good within the WTO regime, ${ }^{87}$ a measure subsidising the production of electricity from renewable resources does not necessarily only have a potential to affect trade in goods (trade in electricity) but may also affect trade in services (the transmission, distribution and supply of electricity).

The unfair trade practice of subsidisation in the supply of services is dealt with in Article XV of the GATS. As with trade in goods, subsidies may also have trade distorting effects affecting trade in services. ${ }^{88}$ Until the conclusion of the GATS in 1994, there were no existing rules disciplining the provision of subsidies in services. Therefore, the aim of Article XV of the GATS was to initiate some momentum in developing rules on subsidies and countervailing measures disciplining subsidies affecting trade in services. Article XV calls for WTO Members to commence negotiations to this end. The first step Members were to take, according to Article XV of the GATS, was to commence sharing information on subsidies affecting trade in services provided to domestic service suppliers. The negotiations were to take place on the basis of a 'future work programme' which would outline the time-frame and the aims of the negotiations. ${ }^{89}$

Article XV:2 of the GATS provides that should a Member suspect that another Member's subsidy adversely affects the trade in services of that complaining Member, it may request consultations. ${ }^{90}$

Unlike the cases of subsidies affecting trade in goods, where Members are required to enter into consultations as quickly as possible, a WTO Member maintaining subsidies allegedly causing adverse effects on the trade in services of another Member, is required only to give a request for consultations by the complaining Member sympathetic consideration. ${ }^{91}$

The Working Party on GATS Rules, established on 30 March 1995 by the Council for Trade in Services, was given the mandate to facilitate negotiations on subsidies in trade in services in order to fulfil the objectives of Article XV of the GATS.92

Despite a lack of specific rules dealing with subsidies in the GATS, subsidies causing adverse effects to the interests of another Member may be inconsistent with the National Treatment obligation enshrined in Article XVII of the GATS. This is so

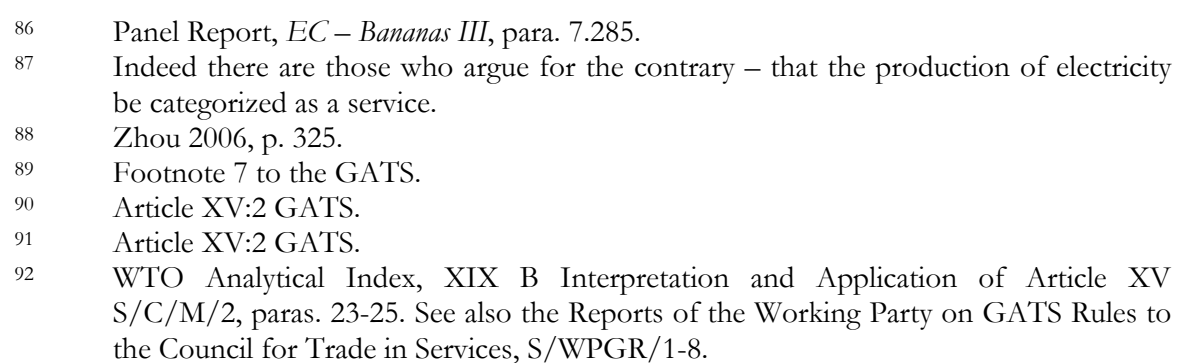


only to the extent that the Member has made specific commitments regarding the liberalisation of trade in that particular service sector. ${ }^{93}$ If a domestic energy service supplier derives a benefit from a national subsidy granted to electricity generators and the same benefit is not available or extended to foreign service suppliers and that Member has committed itself to granting national treatment in that sector of trade in services in its Schedule of Commitments, the subsidy may be contested for inconsistency with the National Treatment obligation. Essentially, if a member has made a commitment, that Member must extend treatment no less favourable to service suppliers and services of other WTO members within that service sector. Where a Member has made commitments, the scope of the National Treatment obligation of Article XVII of the GATS will be determined by the commitments themselves along with the conditions, qualifications and limitations attached to those commitments. However, if the subsidising WTO Member made no commitments in this regard the subsidy will be saved from scrutiny. Unlike the National Treatment obligation of Article III of the GATT 1994, the National Treatment obligation of Article XVII of the GATS does not apply to all services and all service suppliers but only to the services and service suppliers for which the Member has made commitments. It is important to note however, with regard to ongoing subsidies negotiations that subsidies granted by the government to government services, as long as they are 'supplied neither on a commercial basis nor in competition with one or more service suppliers', will still fall outside the scope of the GATS. ${ }^{94}$ This 'carve out' is provided for in Article I:3 of the GATS and aims to keep the public funding of services such as health care and education, to the extent that they are supplied in the exercise of governmental authority, outside its scope. ${ }^{95}$

Services related to trade in electricity are covered by the WTO Services Sectoral Classification List in section 1) Business Services (F) Other Business Services (j) services incidental to energy distribution (887). Upon examination of the Services Schedule of Commitments of the case study countries, there have been no commitments made by these Members to liberalise trade in services incidental to energy distribution. ${ }^{96}$ For this reason any indirect benefit received by the energy service suppliers ensuing from the tax incentives for the development of renewable energy would not be found to be inconsistent with GATS obligations.

The rules disciplining subsidies affecting service suppliers are much less developed than the rules relating to subsidies affecting trade in goods. To the extent that no commitments are made to liberalise services incidental to energy distribution by the case study Members, any remedies for trade distortions caused by subsidies affecting trade in services are left to the discretion and cooperation of the Members involved. There is no recourse to panels or Appellate Body for potential adverse effects on services caused by subsidies or for an alleged inconsistency with Article XVII of the GATS. Until such a moment as these Members make GATS commitments relating

$93 \quad$ Meggiolaro and Vergano 2005, p. 98.

94 GATS Fact and Fiction, The GATS and Public Funding, WTO, 2001, p. 8.

95 Chanda, p. 2004.

96 The USA has listed 'services incidental to energy distribution' in its Schedule of Commitments and has listed no limitations to the liberalisation of trade in this sector, with the exception of Mode 4 being unbound to the extent that no limitations are made in the Horizontal Commitments that apply to all service sectors across the board. 
to electricity distribution, these measures are not covered by the GATS. The current status of subsidy (non) disciplining in the GATS recalls the subsidy situation relating to goods prior to the Uruguay Round and the conclusion of the SCM Agreement and even prior to the conclusion of the Tokyo Round Subsidies Code. Furthermore, even if it would be possible to frame the effects of the indirect subsidies as being incompliant with the National Treatment obligation, any recourse for adverse effects to the interests of other Members relies first on the particular sector of trade in services to have been voluntarily liberalised by the Member in question and commitments in their schedules to be made to that effect. Where energy related services are concerned, this is not the case.

The tax incentives in place in the case study countries, even if potentially indirectly benefiting energy service suppliers, have no ramifications ensuing from application of the GATS. Even to the extent that the Doha Development Round would make significant progress with the GATS, development of the subsidies provisions may not be at the top of the list of priorities within those negotiations. ${ }^{97}$

\subsection{CONCLUSION}

This chapter examined the Agreement on Agriculture, the GATT 1994 (Article XX), the GATS with a view to giving a complete picture of the WTO consequences for the case study Members applying the examined tax incentives. It was clarified that, although no direct agricultural subsidies are at issue, there is potential that agricultural products may be the beneficiaries of indirect subsidies. However, although agricultural products may indeed be affected, the WTO examination is limited to an examination for consistency with Part III of the SCM Agreement.

Article XX of the GATT 1994 was examined for its possible application as an exception provision relating to obligations arising in the SCM Agreement as well as inspiration for the development of an environmental subsidy exception within the SCM Agreement itself. To the same end, Article 3 of the TRIMs was also discussed.

Some solutions are proffered to ease these tensions and to provide for room for Members to pursue environmentally motivated subsidies within the limits of international trade law. Three solutions are proffered: a new non-actionable category to be created in the SCM Agreement, an Article XX of the GATT 1994 to be inserted into the SCM Agreement or, finally, at least an 'aim and effects test' should be applied in examining likeness within the SCM Agreement. Since this research concluded that Article XX of the GATT 1994 is not available to Members whose measures are contested for alleged inconsistency with the SCM Agreement, even in light of the Appellate Body Report in China - Publications and Audiovisual Products, one such development such as one of the solutions listed above would seem to be necessary to overcome the lacuna in the SCM Agreement in relation to environmental subsidies.

Of the three solutions, I proffer that the most likely and the solution requiring the least drastic developments in terms of having the agreement of the Members and amending the SCM Agreement, is the third solution put forward - a move towards the

$97 \quad$ Adlung 2007, p. 262. 
use of an 'aim and effects test' in establishing likeness within the SCM Agreement. This is especially so since it is recognised that negotiating the insertion of a new provision in the SCM Agreement, such as an Article XX of the GATT 1994 equivalent, or reinstating Article 8 of the SCM Agreement, is an extremely burdensome procedure, if not unlikely in the foreseeable future. Although in an ideal world an Article XX equivalent in the SCM Agreement could automatically provide Members with the possibility of justifying their environmental subsidies, it is unrealistic to expect that such a drastic amendment to the SCM Agreement could be achieved considering that even an agreement to continue the Article 8 SCM Agreement non-actionable subsidy category was impossible to reach.

For the same reason, it is also unlikely that now, more than ten years after the lack of an agreement to extend the application of Article 8 of the SCM Agreement, as it was originally drafted or in a modified form, that such an agreement would be reached. Furthermore, even to the extent that such an agreement would be reached, in an ideal world, it would be desirable that a new modified Article 8 would be introduced. The original Article 8, as it applies to environmental subsidies is limited only to providing assistance to promote the adaptation of existing facilities to new environmental requirements imposed by law and/or regulations and is limited to $20 \%$ of the cost of adaptation. Such a limitation of the environmental subsidies would be better represented by a more general Article XX-like test which is less prescriptive and detailed and would thus also be more adaptable to the change in perception of environmental subsidies over time. It must be reiterated however, as desirable such drastic changes may be, they are unlikely to be achieved.

It has become clear from the examination of environmentally motivated subsidies for consistency with the SCM Agreement, that currently there is no regard for the motivation of a subsidy when examining whether it is WTO-consistent or not. My recommended solution is to resort to an 'aim and effects' test in establishing likeness within the SCM Agreement. I submit that this is a more feasible option than the two alternatives addressed above. This solution would be possible to implement through the interpretation of likeness in the SCM Agreement by WTO panels and the Appellate Body by reference to the recognition of the importance of the objectives of sustainable development and the protection and preservation of the environment in the Preamble to the WTO Agreement.

The consistency of the case study tax incentives with the GATS was also examined with the conclusion that since the case study countries have made no commitments related to services incidental to energy distribution, subsidies affecting services incidental to electricity distribution are saved from scrutiny under Article XVII of GATS. Furthermore, the subsidies disciplines in the GATS are less developed than their counterpart in the GATT 1994 and the SCM Agreement, with the result that a WTO Member maintaining subsidies allegedly causing adverse effects on the trade in services of another Member, is required only to give a request for consultations by the complaining Member sympathetic consideration.

This final paragraph provides a 'final word', bringing the starting point of this thesis, namely the Kyoto Protocol, to meet this end point. Since there is no list incorporated 
into the Kyoto Protocol of the types of measures to be pursued by ratifying States, the choice is left up to national governments' discretion. ${ }^{98}$ Tax incentives are measures pursued for environmental protection. This fact coupled with the fact that not all WTO Members have ratified the Kyoto Protocol, potential adverse effects to the interests of other Members of pro-Kyoto Protocol measures cannot be ruled out. ${ }^{99}$ In light of this, it is important to review the WTO rules relating to some of the potential pro-Kyoto Protocol measures being pursued by the ratifying states and examine the potential adverse effects to the interests of other Members that may result from these measures. The obligation to keep international trade in mind not only derives from the Parties' independent obligations as WTO Members but also derives from their legally binding obligations in Article 2 of the Kyoto Protocol to 'strive to implement policies and measures... in such a way as to minimise adverse effects... on international trade'.

As put forward by Zhang, the importance of 'scrutinising' WTO rules with respect to pro-Kyoto Protocol measures is significant not only for ensuring compliance with WTO law, but also to ensure that environmental objectives pursued do not come to a standstill due to trade disputes. The aim is to avoid conflict through consultation at an early stage. ${ }^{100}$ Since the category of non-actionable subsidies is no longer available to national governments seeking to provide pro-Kyoto Protocol subsidies, one way of avoiding this looming trade versus environment conflict would be to have such a category reintroduced through the Doha Development Round negotiations on subsidies. However, re-implementing Article 8.2(c) SCM Agreement would still leave Members in a position where only a very specific type of aid would be permitted. ${ }^{101}$ Alternatively, the introduction of a reference to Article XX of the GATT 1994 could be envisaged. However, it must be also borne in mind when discussing possible solutions to the trade environment tension that amending the WTO agreements does not seem a likely possibility or in any way an efficient solution considering the immense difficulties experienced in trying to achieve consensus.

Many hurdles must be overcome for environmental subsidies to be afforded special consideration within the SCM Agreement and, as such, to date there has been practically no forward movement. In 2003, in relation to natural resource subsidies, (not even environmental subsidies), the US addressed the need for work on the SCM Agreement in relation to natural resources and energy pricing. However, despite this, no other Members have responded to this call for improvements. ${ }^{102}$

There is an environmental exception built into the GATT 1994, ${ }^{103}$ the Agreement on Agriculture, the SPS Agreement, ${ }^{104}$ TBT Agreement, ${ }^{105}$ TRIPS, ${ }^{106}$ and even the

\footnotetext{
$98 \quad$ Assunção and Zhang 2002, p. 1.

$99 \quad$ See ibid. Faure, Gupta and Nentjes 2003, p. 362.

$100 \quad$ Assunção and Zhang 2002.

101 See ibid.

102 Subsidies Disciplines Requiring clarification and improvement, Communication from the United States, TN/RL/W/78, 19 March, p. 3; Gagné and Roch 2008, p. 565.

103 Article XX of the GATT 1994.

104 The SPS Agreement requires Members to take into account ecological and environmental conditions in its risk assessments and to consider ecosystems in qualifying pest or disease free areas. Articles 5.2, 6.2 SPS Agreement. See Charnovitz 2007, p. 688.
} 
GATS. ${ }^{107}$ The lapse of the environmental exception in the SCM Agreement makes it the 'Odd Agreement Out'. In order to acknowledge the existence of environmental subsidies and therefore provide room for such subsidies to be justified within the W'TO, it is essential that some form of environmental exception or environmental justification be built into the SCM Agreement.

106 TRIPS provides an environmental exception to patentability. TRIPS Agreement, Article 27.2. See ibid., p. 689.

107 Article XIV(b) provides an exception for measures which are necessary for the protection of human, animal or plant life or health, similarly to Article XX of the GATT. See ibid., p. 689. 
Part V: Conclusions and Summary 



\section{Chapter 11 : Conclusions and Summary}

\subsection{Kyoto Protocol: Not the Catalyst For the EnVIRONMENTAL TAX SUBSIDIES}

At the starting point of the research for this thesis the Kyoto Protocol was the context within which the intertwining issues of the research could be addressed. The Kyoto Protocol calls upon ratifying States to develop national strategies to reduce the damaging effects of climate change by, inter alia, promoting the development of renewable energy. It also addresses tax measures from the perspective of reducing support to greenhouse gas-emitting sectors through tax incentives. Lastly the Kyoto Protocol also refers to the obligation of ratifying States to minimise adverse effects on trade while implementing national climate change measures. As national measures to address climate change and pursue Kyoto Protocol objectives, tax incentives for the development of renewable energy were chosen as the measures to be examined.

At the time of the ratification of the Kyoto Protocol, the development of national indirect tax measures (such as carbon taxes) to address climate change was a hot topic'. Most discourse which addressed the interface of tax policy and environmental protection examined only indirect tax measures. Therefore, it was appropriate for the purpose of innovative research, to direct the focus of the research for this thesis rather to direct tax incentives as a tool for fulfilling the Kyoto Protocol goal of developing renewable energy.

At the start of my research, it was my expectation that direct tax measures would be frequently implemented to pursue the Kyoto Protocol goal of developing and increasing the use of renewable energy resources. This was and is not the case. Direct corporate tax incentives for renewable energy generation are not important 'KyotoProtocol tools'. The direct corporate tax incentives in place in the case study countries were mainly already in place prior to the ratification of the Kyoto Protocol. New direct corporate tax incentives were not heavily used as a national pro-Kyoto Protocol tool. This calls into question the role of national tax measures pursued in fulfilling Kyoto Protocol objectives considering that, since the ratification of the Kyoto Protocol, indirect tax measures such as carbon taxes and energy taxes have been in the lime light, to the exclusion of direct tax measures.

By a close examination of the direct tax incentives for the development of renewable energy in the case study countries, the research leading up to this thesis unveiled that, despite the existence of such environmentally motivated tax incentives for the development of renewable energy, they were not motivated by the need to fulfil the Kyoto Protocol obligations. The direct corporate tax incentives for renewable energy which have been uncovered in the case study countries, to a large extent, were introduced earlier than and independently of the ratification of the Kyoto Protocol, and in some cases as early as the 1960s. Prior to the application of the tax incentives, the Kyoto Protocol was not the starting point in justifying these economic instruments, which actually do fall within the ambit of pursuing Kyoto Protocol goals. Contrary to my expectations, direct tax incentives for the development of renewable energy were not instigated by the ratification of the Kyoto Protocol. 
A culprit for the lack of connection between the UNFCCC and the Kyoto Protocol with the implementation of direct corporate tax incentives for the development of renewable energy generation is partly a simple and practical matter of division of tasks in national governments. Post-Kyoto Protocol 'Climate Change Action Plans' are developed and run by the departments and ministries for the environment. Tax incentives, on the other hand, are naturally the business of the departments/ ministries of finance. Overlapping mandates between these two areas is not evident. In fact, in the Climate Change Action Plans developed by departments/ministries for the environment, only very little reference, and of an exceptionally general nature, is made to the role of taxation or tax incentives in meeting Kyoto Protocol goals.

Despite this finding, that the Kyoto Protocol did not instigate the implementation of direct tax incentives for the development of renewable energy in the case study countries, these tax incentives are in place, and aim at a Kyoto Protocol goal - the development of renewable energy.

A further insight into the distance between pro-Kyoto Protocol policies and the environmental tax incentives discussed in this thesis stems from the basic nature of climate change and the basic principles of taxation. It is widely recognised that climate change is an issue without borders, a tragedy of the commons, and thus the solutions to this problem should also be trans-boundary and intergovernmental. The Kyoto Protocol is testimony to this. However, although the Kyoto Protocol introduced three new market-based mechanisms to combat climate change, emission trading, clean development mechanism and Joint Implementation, achieving Kyoto Protocol targets and finding a solution for this dilemma is primarily left to unilateral national measures. Yet, unilateral national tax measures cannot but operate with national restrictions, due to the very nature of the tax system. The sovereignty of national tax systems ensures that tax policies are always, at least in some ways, limited by national boundaries. This is particularly true in relation to direct tax matters. Indirect tax issues have given way to some extent and allowed for balancing of international legal objectives with sovereign objectives.

Therefore, taking into account the innate national nature of direct corporate tax measures, their application in the resolution of a trans-boundary problem, such as climate change as a 'tragedy of the commons', can be questioned. In fact, I am of the opinion that policy measures implemented through national tax systems, and in particular with direct tax measures, are clearly at odds with the international nature of the climate change problem. It is perhaps also for this reason that the introduction of the tax incentives for the development of renewable energy is not directly coupled with the Kyoto Protocol objectives and obligations.

\subsection{EU POSITIVE LEGAL ENVIRONMENT FOR ENVIRONMENTAL TAX INCENTIVES}

Part II concerning the EU legal environment served as a prelude to the examination of the tax incentives in place in the case study countries, and in particular in the EU case studies countries which are subject to the EU State aid rules. The conclusion from this investigation was that the EU Member States' tax incentives were not deemed to be incompatible with the EU State aid rules. 
A special legal regime has been created in the EU to provide for a broad justification of measures having environmental protection as their motivation and thus saving these measures from being deemed to be unlawful State aid. The Renewable Energy Directive, the Community Guidelines on State Aid for Environmental Protection and the new General Block Exemption Regulation provide a legal environment within which (tax) incentives, such as those in place in the case study countries for the development of renewable energy, are provided with a safety net and thus are not considered to be unlawful State aid. The results of this examination present a legal environment for environmental tax incentives that contrasts strongly to that embodied in the WTO subsidies rules. Perhaps this legal environment may provide timely inspiration for the WTO legal regime with respect to the treatment of environmental subsidies.

\subsection{CASE STUdies}

The case study countries examined included six countries, namely Ireland, the United Kingdom, Belgium, the Netherlands, Canada and New Zealand. Outside the EU the only Annex I countries having ratified the Kyoto Protocol at the time this research was undertaken were Canada, New Zealand, Iceland, Japan, the Russian Federation, the Ukraine and Norway. Considering the focus of the research was to rest on the examination of the consistency of the tax incentives with WTO rules on subsidies, the Ukraine was eliminated as it was not yet a WTO Member as well as the Russian Federation, which is still not a WTO Member. Finally, the last determining factor in the choice of non-EU case study countries rested on the neighbouring countries, and trading partners of the most important non- Kyoto Protocol-ratifying States, the USA and Australia, namely Canada and New Zealand.

The choice of case study countries also provided a broad geographical coverage, covering three continents from Europe to North America and Oceania.

From the examination of direct corporate tax incentives for the development of renewable energy in the case study countries, only one country sets itself apart by not having implemented any direct tax incentives to this end, namely New Zealand. In New Zealand, electricity generation is a relatively innocent party in the climate change saga as agriculture and transport are the sectors which account for the greatest share of greenhouse gas emissions. Furthermore, despite the absolute lack of tax incentives, there is an exponential growth of wind energy and renewable energy resources in general are the dominant energy resource.

As for the other case study countries, all five have direct corporate tax incentives for the development of renewable energy. These various measures can be divided into three categories: accelerated depreciation, own investment deductions and third-party investment deductions. Although the various measures in the five countries can be delineated into three categories, there is no discernible framework of tax incentives nor of the conditions for eligibility which is recognisable as common to all the case study countries. Different tax incentives are used in each of these five countries, to different extents, incentivising different actions and with different budgets. Each of the case study countries concerned introduced their tax incentives independently - a testimony to sovereignty in direct tax matters. 
One common denominator for all the direct tax incentives investigated was that they do not form a direct part of a real pro-Kyoto Protocol drive. Most of the measures were introduced many years prior to the ratification of the Kyoto Protocol, some as early as forty years before. I submit that with regard to the introduction of environmental subsidies for the development of renewable energy, the Kyoto Protocol was not an explicit driving force for these measures and that these measures would have anyway been put in place (or were already in place).

A further common denominator of the direct tax incentives which emerged from the case studies (in the EU and Canada) was that the economic benefit of the incentive created by the measures was called into question. However, despite their questionable economic benefit, the tax incentives provide a 'moral' signal to investors and developers to invest in the development of renewable energy. The choice of tax measures over other policy measures in particular provides the national governments with an annual opportunity for positive 'propaganda' through the tax acts and annual budgets. The introduction and/or the extension of environmentally motivated tax incentives provides a platform for national governments to exhibit their commitment to the protection of the environment as well as their support (including financial support) for corporations which are also pursuing renewable energy strategies. This function of tax incentives has been termed an 'educational and transformative function'.

Although these weighty conclusions may be proffered, it is not for this thesis to address the functioning of the Kyoto Protocol nor the effectiveness of the tax measures pursued for environmental goals in general, but rather to examine the W'TO-consistency of the case study direct tax incentives for the development of renewable energy.

\subsection{Subsidy TeST FOR TAX INCENTIVES}

It was examined in this thesis whether the generation of electricity is the production of a good and thus covered by the multilateral agreements on trade in goods. Thereafter, WTO provisions addressing tax subsidies in the SCM Agreement were examined. It was explained that in order for a subsidy to exist within the meaning of the SCM Agreement, there should be a financial contribution provided by the government that confers a benefit. In particular when a financial contribution is in the form of a tax measure, this financial contribution is examined against Article 1.1(a)(1)(ii) of the SCM Agreement, which refers to government revenue foregone that is otherwise due. If such a financial contribution is deemed to exist, and it confers a benefit as per Article 1.1(b) of the SCM Agreement, it is a subsidy within the meaning of Article 1 of the SCM Agreement. Thereafter the subsidy is examined for specificity within the meaning of Article 2 of the SCM Agreement as only specific subsidies are subject to the rules of the SCM Agreement.

A clarification was proffered in this thesis with regard to the steps of the subsidy test of Article 1.1(a)(1)(ii) of the SCM Agreement - the subsidy test when tax incentives are at issue. The subsidy test requires three separate elements of the test to be examined: the existence of a financial contribution, that the financial contribution was provided by the government and that the contribution confers a benefit. A practical approach 
for examining the three prongs of the subsidy test where tax incentives are concerned was put forward. In this approach it is argued that the third prong (a benefit is thereby conferred) in Article 1.1(b) is also recognised and indirectly addressed in the wording of sub-paragraph Article 1.1(a)(1)(ii). The separate benefit examination of Article 1.1(b) is, for all practical purposes, already carried out in establishing whether a tax incentive is a financial contribution within the meaning of Article 1.1(a)(1)(ii) of the SCM Agreement. Revenue foregone, which is otherwise due, inevitably confers a benefit on the recipient since a lower tax liability is at issue than would be without the financial contribution.

\subsection{Case Study Tax InCENTIVES - SPeCIFIC SubSIDIES Within THE MEANING OF THE SCM AGREEMENT?}

This thesis addressed three categories of tax incentives, accelerated depreciation, own investment deductions and third-party investment deductions in place in five countries, namely Ireland, the UK, the Netherlands, Belgium and Canada. The examination of the WTO-consistency of all these measures in their many permutations (direct/indirect) resulted in a mixed outcome.

The accelerated depreciation measures were examined to establish whether they are covered by Article 1 of the SCM Agreement. Whether the accelerated depreciation provision is a financial contribution within the meaning of Article 1.1(a)(1)(ii) and/or Article 1.1(a)(1)(i) of the SCM Agreement depends on the calculation method applied to the valuation of the potential benefit. The examination addressed both Article 1.1(a)(1)(ii) and Article 1.1(a)(1)(i) of the SCM Agreement and my conclusion is that the calculation method employed should take account of both the year-by-year benefit afforded by accelerated depreciation as well as the temporal benefit, together. The result therefore is that the accelerated depreciation tax incentives are financial contributions within the meaning of Article 1.1(a)(1)(i) of the SCM Agreement. The accelerated depreciation provisions are neither de jure specific nor de facto specific in the UK, Ireland, and in the Netherlands. The accelerated depreciation measure applied in Canada is a de jure specific subsidy while in Belgium, although the measure is not de jure specific, it is possible that the accelerated depreciation measure could be de facto specific.

The own investment incentive in place in Belgium and the Netherlands, are both subsidies within the meaning of Article 1.1(a)(1)(ii) of the SCM Agreement. They are, however, neither de jure, nor de facto specific. Therefore, these measures are not subject to challenge for consistency with Part III of the SCM Agreement.

The third party investment deduction was somewhat more complex than the previous measures. These measures are available in Canada, the Netherlands and Ireland. These measures are more complex since the beneficiaries of the tax incentives are not limited to the recipients of the tax incentives but rather benefits potentially flow through to other related parties. The direct subsidies to the investors in green projects in Ireland, the Netherlands and Canada were examined against Article 1.1(a)(1)(ii) of the SCM Agreement with the result that a subsidy clearly exists in all cases. The same was true for the investigation of the potential subsidies to indirect beneficiaries of the same tax incentives with Article 1.1(a)(1)(ii) and Article 
1.1(a)(1)(iv) of the SCM Agreement. Three subsidies to indirect beneficiaries potentially flow through from the application of the direct incentive provided to the investors. Although the subsidies granted directly to the investors are not specific subsidies, the indirect subsidies to the investment funds in the Netherlands was deemed to be a specific subsidy while the indirect subsidy to the green projects in the Netherlands, although a subsidy, was not specific. In Ireland and Canada the indirect subsidies to the green projects were deemed to be specific subsidies within the meaning of Articles 1 and 2 of the SCM Agreement.

\subsection{ACTIONABLE SUbSIDIES}

By outlining the information that must be gathered to assess whether the case study specific subsidies create adverse effects to the interests of other Members, some important conclusions about the potential consistency of tax incentives for the development of renewable energy with WTO law could be drawn.

This thesis examined the interpretation of 'like products' addressed in establishing whether a subsidy creates adverse effects to the interest of other Members within the meaning of the SCM Agreement. This examination drew on the interpretation of 'like product' in the GATT 1994 for inspiration. If renewable electricity is deemed to be a 'like product' with generic electricity, subsidies granted only to renewable energy may be problematic. Based on the considerations to determine likeness in the SCM Agreement used to date, the likeness of renewable electricity and generic electricity would rely to a large extent on the consumer's tastes and preferences in relation to renewable versus generic electricity.

The lack of consideration of non-product related PPMs in the appreciation of likeness greatly limits the possibility of green electricity being considered anything other than like generic electricity. It was submitted that the use of an aim and effects test in determining likeness within the SCM Agreement, in particular in light of the lack of an environmental exception in the SCM Agreement, could prove to be a potential solution for the justification of environmental subsidies.

The case study tax incentives for renewable energy electricity generation, to the extent that they do not cause adverse effects to the interests of another Member, will be SCM Agreement-consistent. However, it is sufficient that the measures are specific subsidies within the meaning of Articles 1 and 2 of the SCM Agreement to leave them open to challenge for adverse effects. Furthermore, as there is neither an environmental exception nor justification currently available within the SCM Agreement the environmental motivation of these subsidies does not save them from potential SCM Agreement-inconsistency. Irrespective of the potential outcome of the individual examination of the environmental subsidies in this study, it is proposed that it is essential that environmental subsidies are specifically addressed by the SCM Agreement and the motivation for environmental subsidies be taken into account in determining the SCM Agreement-consistency.

Although this thesis specifically addresses the question of WTO-consistency of tax incentives for the development of renewable electricity, the conclusions drawn from the research for this study provide some further answers on the W'TO-consistency of 
subsidies other than direct tax subsidies (such as indirect tax incentives) for renewable electricity and also insights into the WTO-consistency of incentives for environmentally friendly products other than renewable electricity. The conclusion here is that direct tax subsidies which cause adverse effects to the interests of other Members are liable to be challenged by the importing Member or by another electricity-exporting Member competing on the importing Member's market.

A special situation arises when the trade in electricity occurs primarily in times of national scarcity in the importing Member. This special situation is due both to the special nature of the good electricity and the special structure of the electricity market. A Member importing electricity in peak demand times is required to balance its interests - those of securing the security of supply and the adverse effects on its domestic electricity producers caused by importing subsidised electricity. In such a situation it can be questioned whether the importing Member would challenge the subsidy on the imported electricity. It is likely that direct tax incentives for the development of renewable energy would not be contested since this would first have to be balanced against the interest of the importing Member to ensure the security of supply of electricity.

Since electricity transmission and distribution systems are still natural monopolies, essentially it is the State which has to determine where the balance lies between the interest of ensuring the security of supply by importing subsidised electricity and the potential that subsidised imports of electricity adversely affect the domestic producers of electricity. All of these circumstances lead to a situation in which the importing country, rather than contest alleged adverse effects of subsidised imports on domestic production, would appreciate the possibility of importing electricity at lower prices. The question whether to import or not, in these particular circumstances, is not at issue due to shortage and the obligation to ensure the security of supply.

Although doubt is cast on the case study tax incentives being challenged by an importing Member experiencing electricity shortages, it must nevertheless be underlined that absent this special situation, WTO Members employing specific environmental subsidies which cause adverse effects to the interests of other Members are subject to challenge for WTO-consistency.

\subsection{POSITIVE ENVIRONMENTAL EXTERNALITIES}

This study explored the concept of positive and negative externalities and explored a line of argument advocating that the negative trade externalities created by the environmental tax incentives are potentially counterbalanced by the positive (transboundary) environmental externalities created by the same measures. The transboundary nature of climate change could create a natural justification for mitigating measures, even if they have international trade implications, to the extent that those mitigating measures result in positive trans-boundary environmental externalities.

This thesis highlighted that since no environmental safety net is built into the SCM Agreement, environmentally motivated subsidies are at risk of being found to be 
actionable and causing adverse effects within the meaning of the SCM Agreement. It also follows from this that those actionable subsidies causing adverse effects would be required to be withdrawn, thereby eliminating their positive environmental effects. The SCM Agreement pays no special consideration (other than in the lapsed Article 8.2) to subsidies with environmental protection as their motivation. To the extent that there is economic evidence that these subsidies create adverse effects, environmental subsidies would be actionable and subject to a withdrawal requirement.

Despite the risk of the above, no dispute concerning environmental tax incentives has been brought to the WTO to date. This may, however, be due to reasons other than the lack of the existence of tax incentives affecting trade. As put by Stilwell and Bohanes, 'the lack of disputes may mean that, among other things, WTO Members consider environmental subsidies as legitimate, or are aware of the legal and political difficulties such challenges may cause'. This view is important for environmental subsidies with special consideration for the positive trans-boundary environmental effects counterbalancing potential adverse effects to the interests of other Members.

Be that as it may, the lack of trade disputes to date addressing the issue of environmental subsidies in the WTO forum is not a guarantee that this will remain so and for that reason the exploration of alternative solutions to address the environmental lacuna in the SCM Agreement is necessary.

\subsection{ENVIRONMENTAL SOLUTIONS IN THE SCM AGREEMENT}

The tensions between the pursuit of environmental objectives and international trade obligations came to the fore in this study. Some solutions are proffered to ease these tensions and to provide for room for Members to pursue environmentally motivated subsidies within the limits of international trade law. Three solutions are proffered: a new 'non-actionable subsidies' category to be created in the SCM Agreement, an 'Article XX of the GATT 1994' type of provision to be inserted into the SCM Agreement or, finally, the application of an 'aim and effects test' in determining likeness in the context of the SCM Agreement. Since this research concluded that Article XX of the GATT 1994 is not available to Members whose measures are contested for alleged inconsistency with the SCM Agreement, one of these three solutions listed above would seem to be necessary to overcome the lacuna in the SCM Agreement in relation to environmental subsidies.

Of the three solutions, I proffer that the most likely and the solution requiring the least drastic developments is the third solution put forward - a move towards the use of an 'aim and effects test' in establishing likeness in the context of the SCM Agreement. This is especially so since it is recognised that negotiating the insertion of a new provision in the SCM Agreement, such as an 'Article XX of the GATT 1994' type of provision or reinstating Article 8 of the SCM Agreement regarding non-actionable subsidies, is an extremely burdensome procedure, and unlikely in the foreseeable future. Although in an ideal world an Article XX equivalent in the SCM Agreement would automatically provide Members with the possibility of justifying their environmental subsidies, it is unrealistic to expect that such a radical amendment to 
the SCM Agreement could be achieved considering that even an agreement to extend the application of Article 8 of the SCM Agreement was impossible to reach.

For the same reason, it is also unlikely that now, more than ten years after the failure to reach an agreement to extend the application of Article 8 of the SCM Agreement, it would be possible to reach such an agreement. Furthermore, even to the extent that such an agreement would be reached, in an ideal world, it would be desirable that a new modified Article 8 would be introduced. The original Article 8, as it applies to environmental subsidies, is limited to providing assistance to promote the adaptation of existing facilities to new environmental requirements imposed by law and/or regulations. Limiting environmental subsidies would be better addressed by a more general 'Article XX of the GAT'T 1994'-like test which is less prescriptive and detailed and would thus also be more adaptable to the change in perception of the role and effectiveness of environmental subsidies over time. It must be reiterated, however, that as desirable as such drastic changes may be, they are unlikely to be achieved.

It is clear from the examination of environmentally motivated subsidies for consistency with the SCM Agreement that currently there is no regard for the motivation of a subsidy when examining whether it is WTO-consistent or not. My recommended solution is to resort to an 'aim and effects' test in establishing likeness in the context of the SCM Agreement. I submit that this is a more feasible option than the two alternatives addressed above. This solution would be possible to implement through the interpretation of likeness in the SCM Agreement by WTO panels and the Appellate Body by reference to the recognition of the importance of the objectives of sustainable development and the protection and preservation of the environment in the Preamble to the WTO Agreement. This solution would provide room for the environmental motivation of environmental subsidies to be taken into account by addressing the environmental impact of the products to which the measures are attached.

There is an environmental exception built into the GATT 1994, the Agreement on Agriculture, TRIPS, and even the GATS, while the SPS Agreement and the TBT Agreement explicitly allow Members to pursue environmental measures. The lapse of the environmental exception in the SCM Agreement makes it the 'Odd Agreement Out' and until this lapse or lacuna is rectified, environmental subsidies are at the mercy of the SCM Agreement or rather WTO Members' silent acceptance of the value of environmental subsidies irrespective of potential adverse effects to their interests.

Finally, the importance of examining the WTO rules with respect to environmental subsidies should not be underestimated, not only for ensuring compliance with WTO law, but also to ensure that the environmental objectives pursued by those same measures are not impeded due to trade disputes concerning the environmental protection measures. The tension between environmental protection and trade can be lessened to the extent that a solution could be provided, and room could be made for the consideration of the environmental motivation of environmental subsidies within the SCM Agreement. This thesis has aimed to address this lacuna and to increase awareness for the tension that exists in the overlap of pursuing trade objectives and the protection of the environment. As fisheries subsidies have gained attention in the context of readdressing subsidies with negative environmental effects, so too should 
positive environmental subsidies be addressed with a view to reducing and resolving this tension.

\subsection{FINAL WORD}

One would have expected that alongside indirect tax measures pursued to achieve the Kyoto Protocol commitments, direct corporate tax incentives would also play a significant role. Unfortunately, this is not the case. However, this is not due to a lack of usage of this economic tool for the development of renewable energy in general (albeit dating from pre-Kyoto Protocol times), but rather is due to a lack of acknowledgement that direct tax policy may also play a role in pursuing Kyoto Protocol objectives. This lack of acknowledgement stems, to some extent, from a lack of legal, political and academic discourse addressing environmental direct tax incentives and also a disproportionate concentration on indirect tax measures, such as carbon taxes.

This study attempts to open the doors to debate relating to the use of direct tax incentives for the development of renewable energy and to address the lacuna in academic discourse on environmental direct tax incentives. At the same time, for the development of environmental direct tax incentives, the international legal regime must be acknowledged and the measures must be developed within the boundaries of these rules. In the same way, the international legal regime must also react to the increased international environmental conscience and bend and adapt to the need for increased environmental protection. Environmental protection measures must be afforded consideration appropriate to the positive environmental externalities created by them. The development of leeway for environmental subsidies within the 'Odd Agreement Out', the SCM Agreement, is thus pertinent. 


\section{Chapter 12 Samenvatting en Conclusies}

\section{Kyoto Protocol Geen Katalysator voor Fiscale Milieuprikkels}

Het startpunt van dit onderzoek was het Kyoto Protocol als de algemene context waarin de onderling verweven vraagstukken van dit onderzoek konden worden geduid. Het Kyoto Protocol roept de verdragspartijen op om nationale strategieën te ontwikkelen met als doel de schadelijke gevolgen van klimaatverandering te reduceren door, onder andere, de ontwikkeling van hernieuwbare energiebronnen te stimuleren. Ook noemt het Protocol belastingmaatregelen in de samenhang van het verminderen van steun aan de uitstoot van broeikasgassen door middel van fiscale prikkels. Tenslotte verwijst het Kyoto Protocol naar de verplichting van de vedragspartijen om negatieve handelseffecten tot een minimum te beperken bij de verwezenlijking van nationale klimaatveranderingsmaatregelen. De nationale maat-regelingen die beantwoorden aan de doelstellingen van het Kyoto Protocol en in het kader van dit onderzoek aan de orde worden gesteld, zijn de fiscale prikkels die de ontwikkeling van hernieuwbare energiebronnen beogen te stimuleren.

De invoering van nationale indirecte belastingmaatregelen om klimaatverandering tegen te gaan, zoals $\mathrm{CO}_{2}$-heffingen, was een 'bot topic' toen het Kyoto Protocol werd bekrachtigd. Regelingen in de sfeer van de indirecte belastingen overheersten het academische debat over de wisselwerking tussen fiscaal beleid en milieubescherming. Om deze reden was het passend, mede in het streven naar vernieuwend onderzoek, om de nadruk van deze studie te leggen op fiscale prikkels in de sfeer van de directe belastingen, die als instrument dienen om de doelstellingen van het Kyoto Protocol betreffende de ontwikkeling van hernieuwbare energie te verwezenlijken.

Bij aanvang van mijn onderzoek was mijn verwachting dat directe belastingmaatregelen veelvuldig zouden worden toegepast om de ontwikkeling en het gebruik van hernieuwbare energie te stimuleren in het kader van de Kyoto-doelstellingen. Dit was en is nog steeds niet het geval. De meeste prikkels die de onderzochte staten in hun wetgeving hadden opgenomen waren reeds van kracht, vaak lang voordat het het Kyoto Protocol werd bekrachtigd, sommige reeds in de zestiger jaren van de twintigste eeuw. Hoewel ook nieuwe prikkels in de sfeer van directe belastingen werden ingevoerd, was de reden voor hun introductie niet onmiddelijk naar de bekrachtiging van het Kyoto Protocol terug te leiden. Hoezeer de bestaande en nieuwe directe belastingmaatregelen ook als doel hebben om de ontwikkeling en het gebruik van hernieuwbare energie te stimuleren, was hun introductie dus niet direct gemotiveerd door een beleidsbehoefte om de Kyoto-doelstellingen te verwezenlijken. In tegenstelling tot mijn verwachtingen spoorde de bekrachtiging van het Kyoto Protocal het gebruik van directe belastingmaatregelen als positieve stimuli voor hernieuwbare energie niet aan.

Een verklaring voor de ontbrekende aansluiting tussen aan de ene kant de UNFCCC en het Kyoto Protocol en aan de andere kant de directe belastingmaatregelen gericht op de ontwikkeling van hernieuwbare energie, kan deels eenvoudig gevonden worden in de praktische verdeling van beleidstaken in nationale overheden. Post-Kyoto Protocol 'Climate Change Action Plans' worden opgesteld en uitgevoerd door de ministeries en departementen van milieu. Fiscale prikkels zijn daarentegen doorgaans de bevoegdheid van de ministeries en departementen van financiën. Een overlappend 
mandaat tussen beide beleidsterreinen is niet vanzelfsprekend. In werkelijkheid wordt in de Climate Change Action Plans van de ministeries/departementen van milieu sporadisch verwezen - en de gevonden verwijzingen zijn van zeer algemene aard naar de rol van belastingheffing en fiscale prikkels in de verwezenlijking van de Kyoto-doelstellingen.

Niettegenstaande de vaststelling dat het Kyoto Protocol als zodanig het gebruik van directe belastingmaatregelen als positieve stimuli voor hernieuwbare energie niet aanzwengelde, bestaan deze fiscale prikkels thans en beantwoorden ze aan een Kyoto-doelstelling; de ontwikkeling van hernieuwbare energie.

Nader inzicht in de afstand tussen pro-Kyoto Protocol beleid en de fiscale milieuprikkels die onderwerp van studie zijn in deze dissertatie kan worden afgeleid uit de fundamentele aard van klimaatverandering en de grondbeginselen van belastingheffing. Het is algemeen bekend dat klimaatverandering een vraagstuk zonder grenzen is; een tragedy of the commons. De oplossingen voor dit probleem moeten daarom ook transnationaal en intergouvernmenteel gezocht worden. Het Kyoto Protocol is hiervan het bewijsstuk. Maar, hoewel het Kyoto Protocol drie nieuwe marktgebaseerde instrumenten introduceerde teneinde klimaatverandering tegen te gaan - de handel in emissierechten, Clean Development Mechanism en Joint Implementation - is de verwezenlijking van de Kyoto-doelstellingen en het zoeken naar een oplossing voor dit dilemma een opdracht die primair zal moeten vervuld door middel van unilaterale nationale maatregelen. Nochtans kunnen unilaterale nationale belastingmaatregelen niet anders dan enkel binnen nationale kaders werken vanwege de grondstructuur van het belastingstelsel. De publiekrechtelijke aard van nationale belastingstelsels leidt ertoe dat fiscaal beleid altijd, op een bepaalde manier, door nationale grenzen wordt beperkt. Dit geldt in het bijzonder voor de directe belastingen. In de sfeer van de indirecte belastingen bestaat een zekere ruimte om internationale juridische doelstellingen te wegen met nationale belangen (en doelstellingen).

Mede gelet op de inherent nationale aard van de directe belastingen kunnen om vorenstaande reden vraagtekens worden gezet bij de geschiktheid van deze voor de aanpak van een transnationaal probleem zoals klimaatverandering, zijnde een tragedy of the commons. Naar mijn mening staan beleidsmaatregelen die worden doorgevoerd via nationale belastingstelsels, in het bijzonder via de directe belastingen, haaks op de internationale aard van het probleem van klimaatverandering. Wellicht is het daarom dat geen direct verband wordt gelegd tussen de introductie van nieuwe fiscale prikkels voor de ontwikkeling van hernieuwbare energie en de doelstellingen en verplichtingen van het Kyoto Protocol.

\section{Het Rechtskader in de EU ten Aanzien van Fiscale Milieuprikkels}

Deel II over het rechtskader in de EU diende als inleiding tot de analyse van de fiscale prikkels die in de onderzochte staten van kracht waren, in het bijzonder in de EU lidstaten waar de EU staatssteunregels gelden. De conclusie van deze analyse was dat de fiscale prikkels van EU lidstaten niet onverenigbaar werden geacht met de EU staatssteunregels.

In de EU is een bijzonder rechtskader van kracht dat een ruime rechtvaardigingsruimte geeft aan regelingen die gericht zijn op milieubescherming, waardoor deze 
regelingen niet aanmerkt worden als onwettige staatsteun. De Richtlijn ter bevordering van energie uit hernieuwbare bronnen, de Richtsnoeren inzake staatssteun voor milieubescherming en de Nieuwe Algemene Groepsvrijstellings-verordening geven een rechtskader waarin (fiscale) stimuleringsmaatregelen, zoals deze in de onderzochte staten gelden ten aanzien van hernieuwbare energie, van een vangnet zijn voorzien, zodat zij niet worden aangemerkt als onwettige staatsteun. Uit de resultaten van deze analyse volgt een juridisch raamwerk voor fiscale milieuprikkels dat zich duidelijk onderscheidt van de WTO subsidieregelingen. Wellicht dat dit raamwerk een geschikte bron van inspiratie kan zijn voor het juridische kader van de WTO met betrekking tot de behandeling van milieusubsidies.

\section{Casestudy's}

Zes staten zijn als casestudy's in het onderzoek betrokken, namelijk Ierland, het Verenigd Koninkrijk, België, Nederland, Canada en Nieuw-Zeeland. De enige Annex I staten, afgezien van de EU lidstaten, die het Kyoto Protocol hadden bekrachtigd ten tijde van dit onderzoek waren Canada, Nieuw-Zeeland, IJsland, Japan, de Rusland, Oekraïne en Noorwegen. Aangezien het zwaartepunt van dit onderzoek bij de analyse van de vernigbaarheid van fiscale prikkels met de WTO subsidieregelingen ligt, moest Oekraïne buiten beschouwing blijven omdat deze staat pas in 2008 is toegetreden tot de WTO. Hetzelfde geldt voor Rusland dat nog steeds niet tot de WTO is toegetreden. De laatste omstandigheid ter bepaling van de keuze van de staten die als casestudy zijn gebruikt is gelegen in de buurlanden en handelspartners van de belangrijkste staten die het Kyoto Protocol niet hebben bekrachtigd, de VS en Australië, namelijk Canada en Nieuw-Zeeland.

De gekozen casestudy's lieten ook een brede geografische spreiding van staten over drie continenten toe; Europa, Noord-Amerika en Oceanië.

De electriciteitsopwekking is in Nieuw-Zeeland een relatief onschuldige partij in de klimaatveranderingsaga. De landbouw- en transportsector zijn verantwoordelijk voor het grootste aandeel in de uitstoot van broeikasgassen. Ondanks de afwezigheid van fiscale milieuprikkels, groeit het aandeel van windenergie bovendien exponentieel en zijn hernieuwbare energiebronnen de voornaamste energiebronnen in NieuwZeeland.

Wat betreft de overige onderzochte staten, hebben de andere vijf staten fiscale prikkels ter stimulering van de ontwikkeling van hernieuwbare energie in hun wetgeving opgenomen. De verschillende maatregelen kunnen in drie categorieen worden ingedeeld: versnelde afschrijving, investeringsaftrek voor eigen investeringen en investeringsaftrek voor investeringen in derden. Hoewel de verschillende maatregelen in deze categorieën kunnen worden geplaatst, kunnen echter gemeenschappelijke toepassingsvoorwaarden noch een algemeen kader worden onderscheiden voor deze maatregelen. De vijf staten passen verschillende fiscale prikkels toe, in uiteenlopende mate van stimulering, ten aanzien van verscheidene activiteiten en met afwijkende begrotingen. Elk van de onderzochte staten heeft zijn maatregelen onafhankelijk van de andere ingevoerd - een getuigenis van hun soevereiniteit in de sfeer van directe belastingen.

Een gemeenschappelijke noemer van alle onderzochte fiscale prikkels is dat zij niet rechtsreeks onderdeel zijn van een werkelijke ambitie om de Kyoto-doelstellingen te 
verwezenlijken. De meeste maatregelen zijn ingevoerd voordat het Kyoto Protocal was bekrachtigd, sommige zelfs veertig jaar eerder. Mjins inziens was het Kyoto Protool niet een expliciete aandrijvende kracht voor de invoering van de deze fiscale prikkels gericht op de stimulering van de ontwikkeling van hernieuwbare energie en zouden zij onafhankelijk van het Protocol zijn ingevoerd (of waren al ingevoerd).

Een andere gemeenschappelijke noemer van de fiscale prikkels in de onderzochte staten (EU en Canada in dit verband) is dat het economische voordeel van de maatregelen in twijfel werd getrokken. Ondanks deze twijfel geven deze prikkels een 'moreel' signaal af naar investeerders en ontwikkelaars om te investeren in hernieuwbare energie. De keuze voor belastingmaatregelen boven andere beleidsmaatregelen verschaft de nationale overheden in het bijzonder de gelegenheid om elk jaar positieve 'propaganda' te voeren met hun belastingplannen en staatsbegrotingen. De invoering en/of uitbreiding van fiscale milieuprikkels geeft nationale overheden een kans om hun vastberadenheid het milieu te beschermen ten tonele te voeren en tevens hun (financiële) steun te geven aan initiatieven van het bedrijfsleven met betrekking tot hernieuwbare energie. Deze functie van fiscale prikkels is de 'educatieve en transformatieve functie' genoemd.

Hoewel deze belangrijke conclusies kunnen worden getrokken, heeft deze dissertatie niet tot doel om het functioneren van het Kyoto Protocol te beschouwen of de effectiviteit van de belastingmaatregelen gericht op milieudoelen te beoordelen, maar om de verenigbaarheid van de in de casestudy's onderzochte fiscale prikkels met WTO-recht te analyseren.

\section{Subsidietest voor Fiscale Prikkels}

In deze dissertatie werd onderzocht of electriciteitsopwekking gelijk staat aan de productie van een goed en om deze reden binnen het toepassingbereik valt van de multilaterale verdragen inzake de handel in goederen. Vervolgens werden de W'TOregelingen ten aanzien van belastinguitgaven in de SCM Agreement geanalyseerd. Uit deze beschouwing volgde dat een subsidie in de zin van de SCM Agreement aanwezig is als de overheid door middel van een financiële bijdrage een voordeel toekent. Indien de financiële bijdrage vanwege een belastingmaatregel wordt toegekend, zal deze maatregel aan artikel 1.1(a)(1)(ii) SCM Agreement moeten worden getoetst, dat verwijst naar misgelopen belastingopbrengsten die overigens zouden zijn geheven. Indien een dergelijke financiële bijdrage geacht wordt te bestaan en deze tevens een voordeel in de zin van artikel 1.1(b) SCM Agreement meebrengt, dan is sprake van een subsidie zoals bedoeld in artikel 1 SCM Agreement. Vervolgens zal moeten worden getoetst of de subsidie een specifiek karakter heeft in de zin van artikel 2 SCM Agreement, omdat enkel specifieke subsidies onderworpen zijn aan de SCM Agreement.

Deze dissertatie biedt ook een verheldering ten aanzien van de stappen van de subsidietest van artikel 1.1(a)(1)(ii) SCM Agreement - de subsidietest ten aanzien van fiscale prikkels. Deze test vereist een analyse van drie onderscheidenlijke elementen: het bestaan van een financiële bijdrage, de toekenning door de overheid van deze bijdrage en dat deze financiële bijdrage een voordeel is. Een pragmatische benadering van deze drie stappen van de subsidietest werd gevolgd in het geval van fiscale prikkels. Deze benadering gaat ervan uit dat de derde stap (het voordeelvereiste) van artikel 1.1(b) ook wordt erkend en reeds besloten ligt in de tekst van artikel 1.1(a)(1)(ii). Het zelfstandige voordeelvereiste van artikel 1.1(b) wordt feitelijk al 
getoetst door vast te stellen of een fiscale prikkel een bijdrage is in de zin van artikel 1.1(a)(1)(ii) SCM Agreement. Misgelopen belastingopbrengsten, die overigens zouden zijn geheven, vormen per definitie voordelen voor de belastingplichtige die gebruikt maakt van de fiscale prikkel, omdat deze tot een lagere belastingschuld leidt in vergelijking tot de situatie waarbij de prikkel afwezig is.

\section{Fiscale Prikkels in de Casestudy's - Specifieke Subsidies in de Zin van de SCM Agreement?}

Deze dissertatie heeft drie categorieën fiscale prikkels aan de orde gesteld: versnelde afschrijving, investeringsaftrek voor eigen investeringen en investeringsaftrek voor investeringen in derden. Het onderzoek beperkte zich tot vijf staten, namelijk Ierland, het VK, Nederland, België en Canada. De toetsing van de verenigbaarheid met WTO-recht van deze maatregelen in hun verschillende omzettingen (direct/indirect) resulteerde in een gemengd beeld.

De versnelde afschrijvingsregelingen zijn onderzocht om vast te stellen of zij binnen het bereik van artikel 1 SCM Agreement vallen. Het antwoord op de vraag of deze versnelde afschrijvingsregelingen financiële bijdragen vormen, zoals bedoeld in artikelen 1.1(a)(1)(ii) en/of 1.1(a)(1)(i) ACM Agreement, hangt af van de rekenmethode die wordt toegepast om het mogelijke voordeel te waarderen. Zowel artikel 1.1(a)(1)(ii) als artikel 1.1(a)(1)(i) SCM Agreement zijn in het onderzoek betrokken en mijn conclusie is, dat de rekenmethode zowel het voordeel genoten over de hele periode, alsook het jaarlijkse voordeel in aanmerking dient te nemen. Desgevolg vormen de versnelde afschrijvingsregelingen financiële bijdragen zoals bedoeld in artikel 1.1(a)(1)(i) ACM Agreement. De versnelde afschrijvingsregelingen in het VK, Ierland en Nederland zijn noch de jure specifiek, noch de facto specifiek. De regeling die in Canada wordt toegepast is de jure, maar niet de facto, specifiek, terwijl de Belgische versnelde afschrijvingsregeling potentieel de facto specifiek is, zonder de jure specifiek te zijn.

De investeringsaftrek voor eigen investeringen in België en Nederland zijn beide subsidies in de zin van artikel 1.1(a)(1)(ii) SCM Agreement. Echter, ze zijn niet specifiek, de jure, noch de facto. Om deze reden kunnen deze regelingen niet worden aangevochten vanwege onverenigbaarheid met Part III van de SCM Agreement.

De analyse van de investeringsaftrek voor investeringen in derden was enigszins meer complex dan de analyse van de andere twee typen maatregelen. Maatregelen van het derde type zijn van kracht in Canada, Nederland en Ierland. De complexiteit van de regeling ligt besloten in het feit dat dat de kring van personen die het voordeel van de fiscale prikkel genieten zich niet beperkt tot de ontvangers van de belastingreductie, maar zich potentieel uitstrekt naar aan deze ontvangers verbonden partijen. De directe subsidies aan de investeerders in groene projecten in Nederland, Ierland en Canada zijn getoetst aan artikel 1.1(a)(1)(ii) SCM Agreement met als resultaat dat zij ook rechtens een subsidie vormden. Dezelfde conclusie werd bereikt ten aanzien van de toetsing van potentiële subsidies aan indirect gerechtigden aan artikelen 1.1(a)(1)(ii) en 1.1(a)(1)(iv) SCM Agreement. Hoewel de subsidies die rechtstreeks worden toegekend aan de investeerders niet als specifiek waren aan te merken, werd de indirecte subsidie aan investeringsfondsen (investment funds) in Nederland specifiek geacht, terwijl dat niet gold voor de indirecte subsidie aan groene projecten 
in Nederland. In Ierland en Canada werden de indirecte subsidies voor groene projecten specifiek geacht in de zin van artikel 1 en 2 van de SCM Agreement.

\section{Aanvechtbare Subsidies}

Door een uiteenzetting van de gegevens die verzameld moeten worden om te beoordelen of een specifieke subsidie uit de casestudy's nadelige effecten voor andere WTO-lidstaten sorteert, konden enkele belangrijke conclusies worden getrokken over de potentiële verenigbaarheid van de fiscale prikkels gericht op de ontwikkeling van hernieuwbare energie met WTO-recht.

Deze dissertatie onderzocht de uitleg van 'gelijksoortige producten' (like products) met het doel om vast te stellen of een subsidie nadelige effecten sorteert die indruisen tegen de belangen van andere WTO-lidstaten zoals bedoeld in de SCM Agreement. De analyse zocht ter inspiratie aansluiting bij de uitleg van de term in de GATT 1994. Als hernieuwbare energie een gelijksoortig product is als generieke energie, dan kan het verstrekken van subsidies enkel aan hernieuwbare energie problematisch zijn. Op basis van de criteria die thans worden gehanteerd zal de gelijksoortigheid van hernieuwbare en generieke energie sterk afhangen van de voorkeuren van de consument ten aanzien van beide producten.

Het gebrek aan aandacht voor niet-product gerelateerde PPM's in de beoordeling van gelijksoortigheid beperkt in hoge mate de mogelijkheid dat groene stroom als andersoortig van grijze stroom wordt aangemerkt. Een 'aim and effects test' ter bepaling van gelijksoortigheid voor toepassing van de SCM Agreement werd voorgesteld, in het bijzonder vanwege de ontstentenis van een milieuexceptie in de SCM Agreement, als potentiële oplossing voor de rechtvaardiging van milieusubsidies.

De fiscale prikkels gericht op de stimulering van de ontwikkeling van hernieuwbare energie in de casestudy's zullen verenigbaar zijn met de SCM Agreement voor zover deze geen nadelige effecten sorteren die indruisen tegen de belangen van een andere WTO-lidstaat. Niettemin zijn zij aanvechtbaar vanwege mogelijke nadelige effecten als zij specifieke subsidies zijn in de zin van artikelen 1 en 2 SCM Agreement. Bovendien kunnen de milieugronden waarop de maatregelen berusten de mogelijke onverenigbaarheid van deze met de SCM Agreement niet wegnemen, nu er geen uitzondering of rechtvaardigingsgrond is opgenomen met betrekking tot milieudoelen in de SCM Agreement. Onafhankelijk van de individuele conclusies met betrekking tot de onderscheidenlijke fiscale prikkels in de casestudy's is het noodzakelijk dat milieusubsidies een bijzondere behandeling krijgen in de SCM Agreement en dat de doelstellingen van milieusubsidies kunnen worden meegewogen ter beoordeling van de verenigbaarheid van deze met de SCM Agreement.

Hoewel deze dissertatie in het bijzonder de verenigbaarheid van fiscale prikkels gericht op de stimulering van de ontwikkeling van hernieuwbare energie met WTOrecht behenadelde, kunnen de conclusies van dit onderzoek een aanzet tot nadere antwoorden geven ten aanzien van de verenigbaarheid van andere subsidies voor hernieuwbare energie dan directe belastingmaatregelen, zoals maatregelen in de sfeer van de indirecte belastingen. Daarnaast kan dit onderzoek ook tot nadere inzichten leiden in de verenigbaarheid van financiële stimuleringsmaatregelen gericht op andere milieuvriendelijke producten dan hernieuwbare energie. De conclusie van het voorliggende onderzoek is dat subsidies in de sfeer van directe belastingen die nadelige 
effecten sorteren en indruisen tegen de belangen van andere WTO-lidstaten aangevochten kunnen worden door de importerende WTO-lidstaat, of door andere exportstaten voor electriciteit die concurreren op de markt van dezelfde importstaat.

Een bijzondere situatie in de handel in electriciteit treedt met name in tijden van schaarste van de importerende lidstaat in. De bijzondere aard van deze situatie houdt enerzijds verband met de bijzondere aard van het goed electriciteit en anderzijds met de bijzondere structuur van de electriciteitsmarkt. Een importerende lidstaat zal in tijden van grote vraag naar electriciteit genoodzaakt zijn om zijn belangen af te wegen - enerzijds het verzekeren van het electriciteitsaanbod en anderzijds de nadelige effecten op de binnenlandse productie vanwege de import van gesubsidieerde energie. In een dergelijke situatie kan worden betwist of de importerende lidstaat de subsidie op de geïmporteerde energie zal willen aanvechten. Waarschijnlijk zullen fiscale prikkels gericht op de stimulering van de ontwikkeling van hernieuwbare energie niet worden aangevochten, aangezien een dergelijke actie zal moeten worden afgewogen tegen het belang van een verzekerd electriciteitsaanbod.

$\mathrm{Nu}$ de transmissie- en distributiesystemen voor electriciteit nog steeds natuurlijke monopolies zijn, ligt het feitelijk op de weg van de staat om te beoordelen welk evenwicht zal worden gevonden in de belangenafweging van een verzekerd electriciteitsaanbod en de mogelijke nadelige effecten die een import van gesubsidieerde energie kan hebben op de binnenlandse productie. Het samenstel van omstandigheiden kan leiden tot een situatie waarin de importstaat de mogelijkheid tot import van energie tegen lagere prijzen zal aanvaarden, in plaats van de maatregelen aan te vechten vanwege vermeende nadelige effecten. De vraag om wel of niet te importeren is in deze bijzondere situatie niet van toepassing gelet op een electriciteitstekort en de verplichting om het aanbod van electriciteit veilig te stellen.

Hoewel betwijfeld kan worden of de fiscale prikkels in de casestudy's zullen worden aangevochten door een importerende WTO-lidstaat die lijdt onder een electriciteitstekort, moet worden benadrukt, dat, afgezien van deze bijzondere situatie, WTOlidstaten die specifieke milieusubsidies verstrekken met nadelige effecten gedaagd kunnen worden om de verenigbaarheid van hun maatregelen met WTO-recht te verdedigen.

\section{Positieve Externaliteitseffecten op het Milieu}

Deze studie beschouwde de begrippen positieve en negatieve externaliteiten en onderzocht een argumentatielijn betogende dat de negatieve externaliteitseffecten op de handel door fiscale milieuprikkels mogelijk kunnen worden gecompenseerd door positieve (grensoverschrijdende) externaliteitseffecten op het milieu door diezelfde maatregelen. De grensoverschrijdende aard van klimaatverandering kan een natuurlijke rechtvaardiging vormen voor verzachtende maatregelen, zelfs als deze gevolgen hebben voor de internationale handel, voor zover deze verzachtende maatregelen in positieve grensoverschrijdende externaliteitseffecten op het milieu resulteren.

Deze dissertatie benadrukte dat, aangezien de SCM Agreement niet voorziet in een vangnet voor milieusubsidies, deze milieusubsidies aangevochten kunnen worden en mogelijkerwijs negatieve effecten kunnen hebben zoals bedoeld in de SCM Agreement. Indien deze subsidies succesvol zouden worden aangevochten vanwege hun negatieve effecten, zouden zij moeten worden ingetrokken. Daarmee verdwijnen ook 
de mogelijke positieve externaliteitseffecten van deze subsidies op het milieu. De SCM Agreement besteedt geen bijzondere aandacht (behalve in het oude artikel 8.2) aan subsidies met milieubescherming als doelstelling. Voor zover economisch bewijs aantoont dat deze subsidies negatieve effecten hebben, zouden deze milieusubsidies aanvechtbaar zijn en moeten worden ingetrokken.

Niettegenstaande het bovengeschetste risico zijn tot op heden nog geen geschillen bij de WTO aanhangig gemaakt ten aanzien van fiscale milieuprikkels. De oorzaak kan in andere gronden zijn gelegen dan een gebrek aan het bestaan van dergelijke fiscale prikkels die de handel kunnen beïnvloeden. In de woorden van Stilwel en Bohanes: 'the lack of disputes may mean that, among other things, WTO Members consider environmental subsidies as legitimate, or are aware of the legal and political difficulties such challenges may cause'. Deze gedachtegang is vooral van belang voor milieusubsidies met bijzondere aandacht voor de positieve grensoverschrijdende externaliteitseffecten op het milieu die de potentiële negatieve gevolgen voor andere WTO-lidstaten kunnen compenseren.

Hoe het ook zij, het gemis aan geschillen ten aanzien van milieusubsidies bij het WTO-forum tot op heden is geen garantie dat dit zo blijft. Om deze reden is een verkenning van alternatieve oplossingen noodzakelijk om de leemte met betrekking tot milieumaatregelen in de SCM Agreement aan te pakken.

\section{Oplossingen voor Milieumaatregelen in de SCM Agreement}

De spanning tussen het nastreven van milieudoelen en het vervullen van internationale handelsverplichtigen trad in dit onderzoek op de voorgrond. Om deze spanning te verlichten en om WTO-lidstaten ruimte te bieden in het internationale handelsrecht om milieudoelen na te streven worden enkele voorstellen gedaan. Drie oplossingen worden voorgedragen: een nieuwe categorie 'niet-aanvechtbare subsidies' in de SCM Agreement, de invoeging van een bepaling langs de lijn van artikel XX GATT 1994 in de SCM Agreement, of tenslotte, de toepassing van een 'aim and effects test' om gelijksoortigheid te beoordelen in de context van de SMC Agreement. Aangezien het voorliggende onderzoek concludeerde dat artikel XX GATT 1994 niet kan worden ingeroepen door WTO-lidstaten van wie de maatregelen worden aangevochten vanwege vermeende onverenigbaarheid met de SCM Agreement, lijkt een van de drie bovengenoemde oplossingen noodzakelijk om de leemte ten aanzien van milieusubsidies in de SCM Agreement te vullen.

Van deze drie oplossingen zal m.i. de derde oplossing met de grootste waarschijnlijkheid en met de minst verregaande aanapassingen kunnen worden ingevoerd - een 'aim and effects test' om gelijksoortigheid te beoordelen in het kader van de SCM Agreement. Dit is met name zo, omdat invoeging van een nieuwe bepaling in de SCM Agreement, zoals artikel XX GATT 1994, of herinvoering van artikel 8 SCM Agreement over niet-aanvechtbare subsidies zeer moeilijk zal zijn op de korte termijn. Hoewel idealiter een equivalent van artikel XX in de SCM Agreement de WTO-lidstaten een weg kan bieden om hun milieusubsidies te rechtvaardigen, is het onrealistisch om te verwachten, dat een dergelijk ingrijpende wijziging in de SCM Agreement bereikt zou kunnen worden, gegeven dat het zelfs onmogelijk is gebleken om overeenstemming te bereiken tot een verlenging van artikel 8 SCM Agreement. 
Om diezelfde reden is het nu, tien jaar na het mislukte besluit over artikel 8 SCM Agreement, nog steeds onwaarschijnlijk dat overeenstemming zal worden bereikt over verlenging van artikel 8 SCM Agreement. En zelfs indien die zou kunnen worden bereikt is het wenselijk dat artikel 8 wordt gewijzigd. Het oude artikel 8 , zoals het van toepassing was op milieusubsidies, was beperkt tot het ondersteunen en bevorderen van een aanpassing van bestaande faciliteiten aan nieuwe milieueisen die door wet- en regelgeving worden gesteld. Een beperking van milieusubsidies zou beter kunnen worden aangepakt door een algemenere toets zoals artikel XX GATT 1994. Deze bepaling is minder voorschrijvend en gedetailleerd van opzet en kan daarom beter beantwoorden aan veranderende zienswijzen over de rol en effectiviteit van milieusubsidies in de tijd. Zoals eerder gesteld, moet worden benadrukt dat het onwaarschijnlijk is, dat tot dergelijke ingrijpende wijzigingen zal worden besloten, ook al zijn deze wijzigingen wenselijk.

Uit het onderzoek naar de verenigbaarheid van milieusubsidies met de SCM Agreement kwam naar voren, dat er thans geen ruimte is om het doel van de subsidie in de analyse te betrekken. De benadering die ik voorsta is de toepassing van een 'aim and effects test' om gelijksoortigheid te bepalen in het kader van de SCM Agreement. Mijns inziens is deze oplossing eenvoudiger te bereiken dan de twee vorengenoemde alternatieven. Deze oplossing kan worden bereikt door een wijziging in de interpretatie van 'gelijksoortigheid' in de SCM Agreement door de WTO-panels en de Appellate Body, met verwijzing naar de erkenning van het belang van duurzame ontwikkeling en de bescherming en het behoud van het milieu in de preambule van de WTO Agreement. Deze benadering biedt ruimte om de milieudoelstelling van milieusubsidies in aanmerking te nemen door rekening te houden met de milieu-impact van de producten waarop deze maatregelen van toepassing zijn.

Een uitzondering voor het milieu is opgenomen in de GATT 1994, de TRIPS en zelfs de GATS. Ook de SPS Agreement en de TBT Agreement staan de WTO-lidstaten uitdrukkelijk toe om milieumaatregelen te hebben. Het vervallen van de uitzondering in de SCM Agreement makkt het de 'Odd Agreement Out'. Totdat deze leemte is gevuld, blijven milieusubsidies onderworpen aan de stille aanvaarding door de SCM Agreement, of beter gezegd de WTO-lidstaten van de waarde die deze milieusubsidies hebben, onafhankelijk van de mogelijke nadelige effecten die kunnen indruisen tegen hun belangen.

Tenslotte, het belang van een onderzoek naar de WTO-regelingen ten aanzien van milieusubsidies moet niet worden onderschat, niet enkel om de naleving van het WTO-recht te verzekeren, maar ook om veilig te stellen dat de milieudoelen die deze maatregelen nastreven niet worden doorkruist door handelsgeschillen over milieubeschermingsmaatregelen. Het spanningsveld tussen milieubescherming en handel kan worden verkleind voor zover een oplossing hiervoor bestaat en ruimte kan worden geschapen in de SCM Agreement om de milieudoelstellingen van milieusubsidies te laten meewegen. Deze dissertatie had tot doel deze lacune aan te pakken en het bewustzijn te verhogen van de spanning tussen het vervullen van handelsdoelstellingen en het streven naar milieubescherming. Zoals visserijsubsidies aandacht hebben gekregen bij de heroverweging van subsidies met negatieve gevolgen voor het milieu, zo zouden ook positieve milieusubsidies moeten worden beschouwd teneinde deze spanning te verkleinen en op te lossen. 


\section{Besluit}

De verwachting was, dat, naast maatregelen in de sfeer van de indirecte belastingen, ook prikkels in de directe belastingen een significante rol zouden spelen om de verplichtingen van het Kyoto Protocol na te komen. Dit is helaas niet het geval. Echter, dit is niet vanwege een beperkte toepassing van dit economische instrument om de ontwikkeling van duurzame energie in het algemeen te bevorderen. Het is eerder te wijten aan een beperkt bewustzijn dat het directe belastingbeleid een rol kan spelen in het halen van de doelstellingen die het Kyoto Protocol stelt. Dit beperkte bewustzijn heeft gedeeltelijk te maken met een onvolledig juridisch, politiek en academisch debat over milieuprikkels in de sfeer van directe belastingen, maar ook met een disproportionele aandacht voor indirecte belastingmaatregelen, zoals $\mathrm{CO}_{2-}$ heffingen.

Dit onderzoek poogt om het debat te openen over de toepassing van fiscale prikkels gericht op de ontwikkeling van hernieuwbare energie en de leemte in het wetenschappelijk onderzoek naar fiscale milieuprikkels te dichten. Desalniettemin zal bij het ontwerp van fiscale milieuprikkels het internationale juridische kader in acht moeten worden genomen en zullen de maaregelen binnen de grenzen van deze rechtsregels moeten blijven. Tevens zal het internationale rechtskader moeten reageren op een toegenomen internationaal milieubewustzijn. Het kader zal moeten worden gebogen en aangepast aan de noodzaak het milieu beter te beschermen. Milieubeschermingsmaatregelen zullen de aandacht moeten kijgen die passend is aan de positieve externaliteitseffecten die ze hebben op het milieu. De ontwikkeling van speelruimte voor milieusubsidies in de 'Odd Agreement Out', de SCM Agreement, is daarom noodzakelijk. 


\section{Table of Cases}

\section{Gatt Panel Reports}

Australia-Ammonium Sulphate

Canada - Grain Corn

France-Income Tax

Belgium - Income Tax

Netherlands - Income Tax

France - Wheat Exports

$U S-C V D$ (India)

$U S-D I S C$

US - Malt Beverages

US - Taxes on Automobiles

US - Tuna I (Mexico)
GATT Working Party Report, The Australian Subsidy on Ammonium Sulphate, adopted 3 April 1950, BISD II/188

GATT Panel Report, Canadian Countervailing Duties on Grain Corn from the United States, adopted 26 March 1992, BISD 39S/411

GATT Panel Report, Income Tax Practices Maintained by France, adopted 7 December 1981, BISD 23S/114 and $28 \mathrm{~S} / 114$

GATT Panel Report, Income Tax Practices Maintained by Belgium, adopted 7 December 1981, BISD 23S/127 and $28 \mathrm{~S} / 114$

GATT Panel Report, Income Tax Practices Maintained by the Netherlands, adopted 7 December 1981, BISD 23S/137 and 28S/114

GATT Panel Report, French Assistance to Exports of Wheat and Wheat Flour, adopted 21 November 1958, BISD 7S/46

GATT Panel Report, Panel on United States Countervailing Duties, adopted 3 November 1981 , BISD 28S/113

GATT Panel Report, United States Tax Legislation (DISC), adopted 7 December 1981, BISD 23S/98 and $28 \mathrm{~S} / 114$

GATT Panel Report, United States - Measures Affecting Alcoholic Beverages, adopted 19 June 1992, BISD $39 S / 206$

GATT Panel Report, US - Taxes on Automobiles, 11 October 1994, unadopted

GATT Panel Report, United States - Restriction on Imports of Tuna, 3 September 1991, unadopted, BISD $39 \mathrm{~S} / 155$ 


\section{WTO Panel Reports}

Brazil-Aircraft (Article 21.5 Canada II)

Canada-Aircraft

Canada-Aircraft Credits and

Guarantees

Canada-Autos

China - Publications and Audiovisual Products

Dominican Republic - Import and Sale of Cigarettes

EC-Bananas III

EC-BedLinen

EC-Bed Linen (Article 21.5 - India)
Panel Report, Brazil - Export Financing Programme for Aircraft - Second Recourse by Canada to Article 21.5 of the DSU, WT/DS46/RW/2, adopted 23 August 2001, DSR 2001:X, 5481

Panel Report, Canada - Measures Affecting the Export of Civilian Aircraft, WT/DS70/R, adopted 20 August 1999, as upheld by the Appellate Body Report, WT/DS70/AB/R, DSR 1999/IV, 1443

Panel Report, Canada - Export Credits and Loan Guarantees for Regional Aircraft, WT/DS222/R and Corr. 1, adopted 19 February 2002, DSR 2002:III, 849

Panel Report, Canada - Certain Measures Affecting the Automotive Industry, WT/DS139/R, WT/DS42/R, adopted 19 June 2000, as modified by the Appellate Body Report, WT/DS139, AB/R WT/DS142/AB/R, DSR 2000:VII, 3043

Panel Report, China - Measures Affecting Trading Rights and Distribution Services for Certain Publications and Audiovisual Entertainment Products, WT/DS363/R, adopted 19 January 2010, as modified by Appellate Body Report, WT/DS363/AB/R

Panel Report, Dominican Republic - Measures Affecting the Importation and Internal Sale of Cigarettes, WT/DS291/R, WT/DS292/R, WTDS293/R, Corr.1 and Add. 1, 2, 3, 4, 5, 6, 7, 8 and 9, adopted 21 November 2006

Panel Report, European Communities - Regime for the Importation, Sale and Distribution of Bananas, WT/DS27/R/USA, WT/DS27/R/ECU adopted 25 September 1997, as modified by Appellate Body Report, WT/DS27/AB/R, DSR 1997:II, 695, 803, 943; DSR 1997:III, 1085

Panel Report, European Communities - Anti-Dumping Duties on Imports of Cotton-Type Bed Linen from India, WT/DS141/R, adopted 12 March 2001, as modified by Appellate Body Report, WT/DS141/AB/R, DSR 2001:VI, 2077

Panel Report, European Communities - Anti-Dumping Duties on Imports of Cotton-Type Bed Linen from India, EC - Commercial Vessels - Recourse to Article 21.5 of the DSU by India, WT/DS141/RW, adopted 24 April 2003, as modified by Appellate Body Report, WT/DS141/AB/RW, DSR 2003:IV, 1269 
EC-Countervailing Measures on DRAM Chips

EC - Scallops (Canada)

EC - Export Subsidies on Sugar (Australia)

EC - Export Subsidies on Sugar (Brazil)

EC - Export Subsidies on Sugar (Thailand)

EC - Tariff Preferences

Egypt-Steel Rebar

Indonesia - Autos

Japan - Alcobolic Beverages II

Japan - Film

Korea-Commercial Vessels
Panel Report, European Communities - Countervailing Measures on Dynamic Random Access Memory Chips from Korea, WT/DS299/R, adopted 3 August 2005, DSR 2005:XVIII, 8671

Panel Report, European Communities - Trade Description of Scallops, Request by Canada, WT/DS7/R, circulated 5 August 1996, DSR 1996:I, 93

Panel Report, European Communities - Export Subsidies on Sugar, Complaint by Australia, WT/DS265/R, adopted 19 May 2005, as modified by the Appellate Body Report, WT/DS265/AB/R, WT/DS266/AB/R, WT/DS283/AB/R, DSR 2005:XIII, 6499

Panel Report, European Communities - Export Subsidies on Sugar, Complaint by Brazil, WT/DS266/R, adopted 19 May 2005, as modified by the Appellate Body Report, WT/DS265/AB/R, WT/DS266/AB/R, WT/DS283/AB/R, DSR 2005:XIIV, 6793

Panel Report, European Communities - Export Subsidies on Sugar, Complaint by Thailand, WT/DS283/R, adopted 19 May 2005, as modified by the Appellate Body Report, WT/DS265/AB/R, WT/DS266/AB/R, WT/DS283/AB/R, DSR 2005:XIV, 7071

Panel Report, European Communities - Conditions for the Granting of Tariff Preferences to Developing countries, WT/DS246/R, adopted 20 April 2004, as modified by Appellate Body Report, WT/DS246/AB/R, DSR 2004:III, 1009

Panel Report, Egypt-Definitive Anti-Dumping Measures on Steel Rebar from Turkey, WT/DS211/R, adopted 1 October 2002, DSR 2002:VII, 2667

Panel Report, Indonesia - Certain Measures Affecting the Automobile Industry, WT/DS54/R, WT/DS55/R, WT/DS59/R, WT/DS64/R and Corr.1, 2, 3 and 4, adopted 23 July 1998, DSR 1998:VI, 2201

Panel Report, Japan - Taxes on Alcoholic Beverages, WT/DS8/R, WT/DS10/R, WT/DS11/R, adopted 1 November 1996, as modified by Appellate Body Report, WT/DS245/AB/R, DSR 2003:IX, 4481

Panel Report, Japan - Measures Affecting Consumer Photographic Film and Paper, WT/DS44/R, adopted 22 April 1998, DSR 1998:IV, 1179

Panel Report, Korea - Measures Affecting Trade in Commercial Vessels, WT/DS273?R, adopted 11 April 2005, DSR 2005:VII, 2749 
Korea - Various Measures on Beef

Mexico - Anti-Dumping Measures on Rice

Mexico - Corn Syrup

Mexico-Olive Oil

Mexico - Steel Pipes and Tubes

US - Countervailing Measures on Certain EC Products

US - Export Restraints

US - FSC

US - FSC (Article 21.5 - EC II)

US - Lead and Bismuth II
Panel Report, Korea - Measures Affecting Imports of Fresh, Chilled and Frozen Beef, WT/DS161/R, WT/DS169/R, adopted 10 January 2001, as modified by the Appellate Body Report, WT/DS161/AB/R, WT/DS169/AB/R, DSR 2001:I, 59

Panel Report, Mexico - Definitive Anti-Dumping Measures on Beef and Rice, Complaint with Respect to Rice, WT/DS295/R, adopted 20 December 2005, as modified by the Appellate Body Report, WT/DS295/AB/R, DSR 2005:XXIII, 11007

Panel Report, Mexico - Anti-Dumping Investigation of High Fructose Corn Syrup (HFCS) from the United States, WT/DS132/R, adopted 24 March 2006, as modified by Appellate Body Report, WT/DS320/AB/R

Panel Report, Mexico - Definitive Countervailing Measures on Olive Oil from the European Communities,

WT/DS341/R, adopted 21 October 2008

Panel Report, Mexico - Anti-Dumping Duties on Steel Pipes and Tubes from Guatemala, WT/DS331/R, adopted 24 July 2007, 252

Panel Report, United States - Countervailing Measures Concerning Certain Products from the European Communities, WT/DS212/R, adopted 8 January 2003, as modified by the Appellate Body Report, WT/DS212/AB/R, DSR 2003:I

Panel Report, United States - Measures Treating Export Restraints as Subsidies, WT/DS194/R and Corr. 2, adopted 23 August 2001, DSR 2001:XI, 5777

Panel Report, United States - Tax Treatment for "Foreign Sales Corporations", WT/DS108/R, adopted 20 March 2000, as modified by the Appellate Body Report, WT/DS108/AB/R, DSR 2000:IV, 1675

Panel Report, United States - Tax Treatment for Foreign Sales Corporations' - Second Recourse to Article 21.5 of the DSU by the European Communities, WT/DS108/RW2, adopted 14 march 2006, upheld by the Appellate Body Report, WT/DS108/AB/RW2, 242

Panel Report, United States - Imposition of Countervailing Duties on Certain Hot-Rolled Lead and Bismuth Carbon Steel Products Originating in the United Kingdom,

WT/DS/138/R and Corr. 2, adopted 7 June 2000, as upheld by the Appellate Body Report,

WT/DS138/AB/R, DSR 2000:VI, 2623 
US - Offset Act (Byrd Amendment)

US - Section 301 Trade Act

US - Shrimp (Article 21.5 - Malaysia)

US - Softwood Lumber III

US - Softwood Lumber IV

US - Softwood Lumber VI

US - Upland Cotton
Panel Report, United States - Continued Dumping and Subsidy Offset Act of 2000, WT/DS217/R,

WT/DS234/R, adopted 27 January 2003, as modified by the Appellate Body Report, WT/DS217/AB/R, WT/DS234/AB/R, DSR 2003:II, 489

Panel Report, United States - Section 301-310 of the Trade Act of 1974, WT/DS152/R, adopted 27 January 2000, DSR 2000:II, 815

Panel Report, United States - Import Probibition of Certain Shrimp and Shrimp Products, Recourse to Article 21.5 of the DSU by Malaysia, WTDS58/RW, adopted 21 November 2001, as upheld by the Appellate Body Report, WT/DS58/AB/RW, DSR 2001:XIII, 6539

Panel Report - United States - Preliminary Determinations with Respect to Certain Softwood Lumber from Canada, W'T/DS236/R, adopted 1 November 2002, DSR 2002:IX, 3597

Panel Report, United States - Final Countervailing Duty Determination with Respect to Certain Softwood Lumber from Canada

Panel Report, WT/DS257/R and Corr. 1, adopted 17 February 2004, modified by the Appellate Body Report, WT/DS257/AB/R, DSR 2004:II

Panel Report, United States - Investigation of the International Trade Commission in Softwood Lumber from Canada, WT/DS277/R, adopted 26 April 2004, DSR 2004:VI, 2485

Panel Report, United States - Subsidies on Upland Cotton, WT/DS267/R and Corr. 1, adopted 21 March 2005, as modified by the Appellate Body Report, WT/DS267/AB/R, DSR 2005:II-VI, 299

Appellate Body Report, Brazil-Export Financing Programme for Aircraft, WT/DS46/AB/R, adopted 20 August 1999, DSR 1999:III, 1161

Appellate Body Report, Brazil-Measures Affecting Desiccated Coconut, WT/DS22/AB/R, adopted 20 March 1997, DSR 1997:1, 167

Appellate Body Report, Brazil-Measures Affecting Imports of Retreaded Tyres, WT/DS322/AB/R, adopted 17 December 2007 
Canada-Aircraft

Canada-Periodicals

China - Publications and Audiovisual Products

EC-Asbestos

Korea - Various Measures on Beef

Thailand-H-Beams

US - Countervailing Duty Investigation on DRAMs

US - Countervailing Measures on Certain EC Products

US - Hot Rolled Steel

$U S-F S C$ (Article 21.5-EC)

US - Gambling
Appellate Body Report, Canada-Measures Affecting the Export of Civilian Aircraft, WT/DS70/AB/R, adopted 20 August 1999, DSR 1999:III, 1377

Appellate Body Report, Canada - Certain Measures Concerning Periodicals, WT/DS31/AB/R, adopted 30 July 1997, DSR 1997:1, 449

Appellate Body Report, China - Measures Affecting Trading Rights and Distribution Services for Certain Publications and Audiovisual Entertainment Products, WT/DS363/AB/R, adopted 21 December 2009, 19 January 2010

Appellate Body Report, European Communities Measures Affecting Asbestos and Asbestos-Containing Products, WT/DS135/AB/R, adopted 5 April 2001, DSR 2001:VII, 3243

Appellate Body Report, Korea - Measures Affecting Imports of Fresh, Chilled and Frozen Beef,

WT/DS161/AB/R and Corr. 1, adopted 10 January 2001, DSR 2001:I, 5

Appellate Body Report, Thailand - Anti-Dumping Duties on Angles, Shapes and Sections of Iron or Non-Alloy Steel and H-Beams from Poland, WT/DS122/AB/R, adopted 5 April 2001, DSR 2001:VII, 2701

Appellate Body Report, United States - Countervailing Duty Investigation on Dynamic Random Access Memory Semiconductors (DRAMS) from Korea,

WT/DS296/AB/R, adopted 20 July 2005, DSR296

Appellate Body Report, United States - Countervailing Measures Concerning Certain Products from the European Communities, WT/DS212/AB/R, adopted 9 December 2002, DSR 2003:I, 5

Appellate Body Report, United States - Anti-Dumping Measures on Certain Hot-Rolled Steel Products from Japan, WT/DS184/AB/R, adopted 23 August 2001, DSR 2001:X, 4697

Appellate Body Report, United States - Tax Treatment for "Foreign Sales Corporations", - Recourse to Article 21.5 of the DSU by the European Communities,

WT/DS108/AB/RW, adopted 29 January 2002, DSR 2002:I, 55

Appellate Body Report, United States - Measures Affecting the Cross-Border Supply of Gambling and Betting Services, WT/DS285/AB/R and Corr. 1, adopted 20 April 2005, DSR 2005:XII, 5663 


US - Gasoline
US - Lamb
US - Customs Bond Directive
US - Shrimp (Thailand)
US - Softwood Lumber IV
US - Upland Cotton

US - Upland Cotton
Appellate Body Report, United States - Standards for Reformulated and Conventional Gasoline,

WT/DS2/AB/R, adopted 20 May 1996, DSR 1996:I, 3

Appellate Body Report, United States - Safeguard Measures on Imports of Fresh, Chilled or Frozen lamb Meat from New Zealand and Australia, WT/DS177/AB/R, WT/DS178/AB/R, adopted 16 May 2001, DSR 2001:IX, 4501

Appellate Body Report, United States - Custons Bond Directive for Merchandise Subject to AntiDumping/Countervailing Duties, WT/DS345/AB/R, adopted 1 August 2008

Appellate Body Report, United States - Measures Relating to Shrimp from Thailand, WT/DS343/AB/R, adopted 1 August 2008

Appellate Body Report, United States - Final Countervailing Duty Determination with Respect to Certain Softwood Lumber from Canada, WT/DS257/AB/R, adopted 17 February 2004, DSR 2004:II, 571

Appellate Body Report, United States - Subsidies on Upland Cotton, WT/DS267/AB/R, adopted 21 March 2005, DSR 2005:II-VI, 299

\section{ECJ Cases}

C-6/64

C-173/73

C-91/79

C-393/92

C-213/96

\section{State aid decisions}

N262/94

N353/98

N247/99

N648/1999
VAMIL [1994] OJ C267

Tax relief for corporate equity investment in renewable energy projects [1999] OJC151/04

Environmental investment deduction [2000] OJ C175/06

Environmental investment deduction [2000] OJ C284/04 
N555/2000

N797/2000

$\mathrm{N} 79 / 2001$

N634/2001

N266/2003

N447/2003

NN24/2005

NN41/2005

N643/2005
Temporary tax exemption for certain combined cycle power plants in the context of the continuation of the ecological tax reform in Germany [2001] OJ C37/09

Enhanced capital allowances for energy efficient investments [2001] OJC160/08

Amendment to environmental investment deduction [2001] OJ C117/09

Environmental investment deductions 2002 [2002] OJ C018/03

Q7 Offshore windpark [2003] OJ C266/02

Tax relief for corporate equity investment in renewable energy projects [2005] OJ C265/03

Environmental investment deduction [2005] OJ C230/04

Green funds [2007] OJ C14/01

Budget increase environmental investment tax deduction - the Netherlands [2006] OJ C291/06 


\section{Bibliography}

Adlung 2007

R. Adlung, "Negotiations on Safeguards and Subsidies in Services: a Never-Ending Story?', (2007) 10 Journal of International Economic Law, 235-265.

\section{Adlung 2007}

R. Adlung, "Trade Policies and the Environment - Subsidies, Taxes and Border Adjustments", (1997) Intereconomics, 181-185.

\section{Albath 2004}

L. Albath, Trade and Energy: Investment in the Gas and Electricity Sectors, (London 2004).

\section{Andrews 1972}

W.D. Andrews, "Personal Deductions in an ideal income tax", (1972) 86(2) Harvard Law Review, 309-385.

\section{Assunção and Zhang 2002}

L. Assunção and Z. Zhang, Domestic Climate Policies and the WTO, UNCTAD Discussion Paper Series, (2002).

\section{Ault and Arnold 2004}

H. J. Ault and B. J. Arnold, Comparative Income Taxation, (The Hague 2004).

\section{Bartels 2004}

L. Bartels, "The Separation of Powers in the WTO: How to Avoid Judicial Activism”, (2004) 53 International and Comparative Law Quarterly, 861-895.

\section{Barton 1998a}

B. Barton, "From Public Service to Market Commodity: Electricity and Gas Law in New Zealand”, (1998) 16 Journal of Energy and Natural Resources Law, 351-388.

\section{Barton 1998b}

B. Barton, "Developments in Electricity Law and Policy in Europe", (1998) 2 New Zealand Journal of Environmental Law, 187-208.

\section{Barton 2005}

B. Barton, "Renewable Energy in New Zealand", (2005) 23 Journal of Energy and Natural Resources Law, 141-155.

\section{Benitah 2001}

M. Benitah, The Law of Subsidies under the GATT/WTO System, (The Hague 2001).

\section{Bentley 2000}

P. Bentley, "Challenging Fiscal Subsidies under WTO Law: The Example of the US Foreign Sales Corporation", (2000) 4 The EC Tax Journal, 81-104. 


\section{Berghofer 2009}

M. Berghofer, "The General Block Exemption Regulation: A Giant on Feet of Clay", (2009) European State Aid Law Quarterly, 323-336.

\section{Bielecki and Ervik 2004}

J. Bielecki and L.K. Ervik, "Electricity Trade and Trade Related Measures", in J. Bielecki and M. Desta (eds.), Electricity Trade in Europe Review of the Economic and Regulatory Changes, (The Hague 2004), 265-284.

\section{Bigdeli 2009}

S.Z. Bigdeli, "Incentive Schemes to Promote Renewables and the WTO Law of Subsidies", in T. Cottier, O. Nartova and S.Z. Bigdeli (eds.), International Trade Regulation and the Mitigation of Climate Change, (Cambridge 2009), 155-192.

\section{Borgsmidt 1999}

K. Borgsmidt, "Eco-taxes in the Framework of Community Law", (1999) 4 EC Tax Review, 228-240.

\section{Bown and McCulloch 2005}

C.P. Bown and R. McCulloch, "Environmental Issues", in P.F.J. Macrory, A.E. Appleton and M.G. Plummer (eds.), The World Trade Organization: Legal, Economic and Political Analysis Volume II, (New York 2005), 137-170.

\section{Bradbrook 2001}

A.J. Bradbrook, "The Development of a Protocol on Energy Efficiency and Renewable Energy to the United Nations Framework Convention on Climate Change", (2001) 5 New Zealand Journal of Environmental Law, 55-90.

\section{Bradbrook 1997}

A.J. Bradbrook, "A Legislative Framework for Renewable Energy and Energy Conservation”, (1997) 15 Journal of Energy and Natural Resources Law, 313-337.

\section{Bronkers and McNelis 2000}

M. Bronkers and N. McNelis, "Rethinking the Like Product Definition in GATT 1994: Anti-dumping and Environmental Protection", in M. Bronkers (ed.), A Cross Section of WTO Law, (London 2000), 345-385.

\section{Brooks 2004}

K. Brooks, "Delimiting the Concept of Income: The Taxations of In-Kind Benefits", (2004) 49(2) McGill Law Journal, 255-307.

\section{Bruggeman 2005}

V. Bruggeman, "Legal Aspects of Wind Energy in Belgium and the Netherlands", in G. van Calster and K. Deketelaere (eds.), Energy and Environmental Law, (Leuven 2005), 506-540.

\section{Bruins Slot 1998}

W. Bruins Slot, "De Greenpeacelease”, (1998) Weekblad Fiscaal Recht, 669-670. 


\section{Cameron 2000}

P. Cameron, "From Principles to Practice: The Kyoto Protocol”, (2000) 18 Journal of Energy and Natural Resources Law, 1-18.

\section{Casamento 2005}

R. Casamento, "Accounting for and Taxation of Emission Allowances and Credits", in D. Freestone and C. Streck (eds.), Legal Aspects of Implementing the Kyoto Protocol Mechanisms, (Oxford 2005), 55-70.

\section{Chanda 2003}

R. Chanda, "Social Services and The GATS: Key Issues and Concerns", (2003) 31 World Development, 1997-2011.

\section{Chapman 2003}

R. Chapman, "A Policy Mix for Environmentally Sustainable Development Learning from the Dutch Experience”, (2003) 7 New Zealand Journal of Environmental Law, 29-51.

\section{Charnovitz 2007}

S. Charnovitz, “The W'TO's Environmental Progress”, (2007) 10 Journal of International Economic Law, 685-706.

\section{Charnovitz 1994}

S. Charnovitz, "Free Trade, Fair Trade, Green Trade: Defogging the Debate", (1994) 27 Cornell International Law Journal, 459-525.

\section{Clarke and Horlick 2005a}

P.A. Clarke and G.N. Horlick, "Injury Determinations in Antidumping and Countervailing Duty Investigations", in P.F.J. Macrory, A.E. Appleton and M.G. Plummer (eds.), The World Trade Organization: Legal, Economic and Political Analysis, vol. I, (New York 2005), 735-748.

\section{Clarke and Horlick 2005b}

P.A. Clarke and G.N. Horlick, "The Agreement on Subsidies and Countervailing Measures", in P.F.J. Macrory, A.E. Appleton and M.G. Plummer (eds.), The World Trade Organization: Legal, Economic and Political Analysis, vol. II, (New York 2005), 679734.

Clement, Lehman, Hamrin and Wiser 2005

D. Clement, M. Lehman, J. Hamrin and J. Wiser, International Tax Incentives for Renewable Energy: Lessons for Public Policy, (San Francisco 2005) available at: $<$ http://www.resource-solutions.org/lib/librarypdfs/IntPolicy-Renewable_Tax_ Incentives.pdf $>$.

\section{Collins 2201-2002}

N. Collins, "European Environmental Policy and Its Effects on Free Trade", (20012002) 26 William and Mary Environmental Law and Policy Review, 185-214. 


\section{Condon 2009}

B.J. Condon, "Climate Change and Unresolved Issues in WTO Law", (2009) 12 Journal of International Economic Law, 895-926.

Cottier, Malumfaschi et al. 2009

T. Cottier, G. Malumfaschi et al., Energy in WTO Law and Policy', Working Paper No. 2009/25, May 2009, NCCR, Bern University, available at: <http://www.nccrtrade.org/images/stories/projects/ip6/IP6_synthesis_report_with\%20biblio.pdf $>$

\section{Cramer 2005}

V. Cramer, "Fiscal Instruments to Promote Renewable Energy in the Netherlands and Why They Were Not Continued", in H. Ashiabor, K. Deketelaere, L. Kreiser and J. Milne (eds.), Critical Issues in Environmental Taxation Volume II, (Richmond 2005), 201-214.

Daly 2005

M. Daly, The WTO and Direct Taxation, (2005) June WTO Discussion paper.

\section{Davidson, Bergsma, Backes and Van den Bossche 1999}

M.D. Davidson, G.C. Bergsma, C. Backes and P. Van den Bossche, Economische instrumenten voor duurzaam geproduceerd hout. Een verkenning, (Delft 1999).

\section{De Búrca and Craig 2003}

G. De Búrca and P. Craig, EU Law; Text, Cases and Materials, $3^{\text {rd }}$ ed., (Oxford 2003).

\section{De Leeuw and Van Ierland 2000}

R. de Leeuw and E.C. van Ierland, "CDM in Climate Policies in the Netherlands: A Promising Tool?”, in M. Faure, J. Gupta and A. Nentjes (eds.), Climate Change and the Kyoto Protocol, (Cheltenham 2000), 171-194.

\section{De Vries and Ouwehand 2004}

R.J. de Vries and W.P.A. Ouwehand, "De Aanstaande Handel in Broeikasgasemissierechten: een eerste fiscale inventarisatie", (2004) Weekblad Fiscaal Recht, 18991906.

\section{De Waard and Zom 2000}

J.C. de Waard and A.B.J.M. Zom, "Vergroening van het belastingstel in Nederland, groene vergezichten of groene grenzen?”, (2000) Fiscale Actualiteit, 369-376.

\section{Deiverova and Nyssens 2009}

K. Deiverova and H. Nyssens, "The new General Block Exemption Regulation (GBER): What changed?”, (2009) European State aid Law Quarterly, 27-38.

\section{Deketelaere 1999}

K. Deketelaere, "The Use of Fiscal Instruments in the European Environmental Policy: A Review Essay”, (1999) Energy \& Environment, 181-207.

\section{Deketelaere 1994}

K. Deketelaere, Naar Een Europese Milieufiscaliteit, (Leuven 1994). 
Deketelaere and Faure 1999

K. Deketelaere and M. Faure, Environmental Law in the United Kingdom and Belgium from a Comparative Analysis, (Antwerp 1999).

Del Rio and Gual 2004

P. del Rio and M. Gual, "The Promotion of Green Electricity in Europe: Present and Future”, (2004) 14 European Environment, 219-234.

\section{Delimatsis 2009}

P. Delimatsis, "Financial innovation and climate change: the case of renewable energy certificates and the role of the GATS", (2009) 8 World Trade Review, 439-460.

Delvaux 2003

B. Delvaux, "EC State Aid Regime on Renewables", (2003) European Environmental Law Review, 103-112.

Doelle 2004

M. Doelle, "Climate Change and the WTO: Opportunities to Motivate State Action on Climate Change Through the World Trade Organization", (2004) 13 Review of European Community \& International Environmental Law, 85-103.

\section{Duff 2003}

D.G. Duff, “Tax Policy and Global Warming”, (2003) 51 Canadian Tax Journal, 2063 2118.

\section{Duff and Green 2006}

D.G. Duff and A. Green, "Wind Power in Canada", in H. Ashiabor, K. Deketelaere, L. Kreiser, and J. Milne (eds.), Critical Issues in Environmental Taxation, vol. IV, (Oxford 2006), 3-38.

\section{Duff, Alarie, Brooks and Philipps 2006}

D.G. Duff, B. Alarie, K. Brooks and L. Philipps, Canadian Income Tax Law, 2nd ed., (Toronto 2006).

\section{Duggan 2002}

A. Duggan, Tax Guide 2002 (corporation tax), (Dublin 2002).

\section{Duggan 2000}

A. Duggan, Tax Guide 2000-2001 (corporation tax), (Dublin 2000).

\section{Egan 2002}

B. Egan, "Taxation Environment for Renewable Energy", (2002) 15 Irish Tax Review, 373-377.

\section{Ehlermann and Ehring 2005}

C.-D. Ehlermann and L. Ehring, "The Authoritative Interpretation Under Article IX:2 of the Agreement Establishing the World Trade Organization: Current Law, Practice and Possible Improvements", (2005) 8 Journal of International Economic Law, 803-824. 
Ehlermann and Goyette 2006

C.-D. Ehlermann and M. Goyette, "The Interface between EU State Aid Control and the WTO Diciplines on Subsidies”, (2006) 5 European State Aid Law Quarterly, 695718.

\section{Essers, Flutsch and Ultee 2000}

P.H.J. Essers, P.A. Flutsch and M.A. Ultee, Environmental Policy and Direct Taxation in Europe, (London 2000).

\section{Etherington 2006}

J. Etherington, Wind Power Subsidy in the UK (2006), available at: <http://www.sswfag.org.uk/docs/Wind $\% 20$ power $\% 20$ subsidy $\% 20$ in $\% 20$ the $\% 20 \mathrm{U}$ K.doc $>$.

\section{Faure, Gupta and Nentjes 2003}

M. Faure, J. Gupta and A. Nentjes (eds.), Climate Change and the Kyoto Protocol, (Massachusetts 2003).

\section{Faure and Ubachs 2005}

M. Faure and S. Ubachs, "Harmful Tax Measures and Greying of Taxation in the Netherlands: What Went Wrong?”, in H. Ashiabor, K. Deketelaere, L. Kreiser and J. Milne (eds.), Critical Issues in Environmental Taxation, vol. II, (Richmond 2005), 521531.

\section{Fernández Armenteros 2005}

M. Fernández Armenteros, "State Aid Issues Raised by the Implementation of Climate Change Policy Instruments", in M. Bothe and E. Rehbinder (eds.), Climate Change Policy, (Utrecht 2005), 219-257.

\section{Fisher 2005}

R.M. Fisher, "Wind Energy in New Zealand: Regulatory and Policy Lessons to Date", (2005) 9 New Zealand Journal of Environmental Law, 307-335.

\section{Fowler 2009}

R. Fowler, An Initial Assessment of the Copenhagen Outcomes (2009), available at: $<$ http://www.law.uoregon.edu/academics/docs/first_S10/copenhagen.pdf>.

\section{Franco and Herrera 2005}

Y.G. Franco and P.M. Herrera, "New Economic Instruments to Foster Renewable Sources of Energy: An EC Law Approach", in H. Ashiabor, K. Deketelaere, L. Kreiser and J. Milne (eds.), Critical Issues in Environmental Taxation, vol. II, (Richmond 2005), 177-189.

\section{Gagné and Roch 2008}

G. Gagné and F. Roch, "The US-Canada Softwood Lumber Dispute and the WTO Definition of Subsidy", (2008) 7 World Trade Review, 547-572. 


\section{Gassler 1997}

Y.E. Gassler, "Integrale invoering van vennotschapsbelasting voor de energiesector", (1997) Weekblad Fiscaal Recht, 1632-1639.

\section{Gibbs 2003}

M. Gibbs, "Energy Services, Energy Policies and the Doha Agenda", in UNCTAD, Energy and Environment Services: Negotiating Objectives and Development Priorities, (Geneva 2003), 3-22, available at: <http://www.unctad.org/en/docs/ditctncd20033p1 _en.pdf $>$.

\section{Gillespie 1997}

A. Gillespie, "Burning Follies: The Creation and Failure of the New Zealand Response to Climate Change", (1997) 1 New Zealand Journal of Environmental Law, 4366.

\section{Gonzáles-Calatayud and Marceau 2002}

A. González-Calatayud and G. Marceau, "The Relationship between DisputeSettlement Mechanisms of MEAs and those of the WTO", (2002) 11 Review of European Community \& International Environmental Law, 275-286.

\section{Green 2006a}

A. Green, "Trade Rules and Climate Change Subsidies", (2006) 5 World Trade Review, 377-414.

\section{Green 2006b}

A. Green, "You Can’t Pay Them Enough: Subsidies, Environmental Law and Social Norms", (2006) The Harvard Environmental Law Review, 407-440.

\section{Green 2005}

A. Green, "Climate Change, Regulatory Policy and the WTO", (2005) 8 Journal of International Economic Law, 143-189.

\section{Hancher 2004}

L. Hancher, "Trade-Neutral Policies for the Promotion of Electricity from Renewables", in M. Desta and J. Bielecki (eds.), Electricity Trade in Europe Review of the Economic and Regulatory Changes, (The Hague 2004), 285-320.

\section{Hawke 2002}

N. Hawke, "Canadian Federalism and Environmental Protection", (2002) 14 Journal of Environmental Law, 185-196.

\section{Herman 2007}

L.L. Herman, Rules on Energy Trade, a Report to the World Energy Council, WEC/FINAL/6Sept/07 (Toronto 2007).

\section{Hernández-López 2001}

E. Hernández-López, "Trade in Electronic Commerce Services Under the WTO. The Need to Clearly Classify Electronic Transmissions as Services and not Tariff Liable", (2001) 4 The Journal of World Intellectual Property, 557-580. 


\section{Herreveld 1998}

F.R. Herreveld, "Vergroening van het belastingstelsel; de haute cuisine van de fiscale politiek", (1998) Weekblad Fiscaal Recht, 1715-1716.

\section{Hoffmann 2006}

L. Hoffmann, "The Role of Economic Instruments to Reduce Carbon Emissions and their Implementation: A Comparison of Environmental Policies in New Zealand and Germany", (2006) 10 New Zealand Journal of Environmental Law, 129-168.

\section{Horlick 2009}

G. Horlick, "The WTO and Climate Change 'Incentives", in T. Cottier, O. Nartova and S.Z. Bigdeli (eds.), International Trade Regulation and the Mitigation of Climate Change, (Cambridge 2009), 193-196.

\section{Horn and Mavroidis 2009}

H. Horn and P.C. Mavroidis, "Burden of Proof in Environmental Disputes in the WTO: Legal Aspects”, (2009) European Energy and Environmental Law Review, 112-140.

\section{Hudec 1998}

R.E. Hudec, "GATT/WTO Constraints on National Regulation: Requiem for an 'Aim and Effects' Test”, (1998) 32 The International Lawyer, 619-650.

\section{Hudec 2000}

R.E. Hudec, "The Product-Process Doctrine in GATT/WTO Jurisprudence", in M. Bronkers and R. Quick (eds.), New Directions in International Economic Law, Essays in Honour of John H. Jackson, (The Hague 2000), 187-217.

\section{Jackson 2005}

J.H. Jackson, "Justice Feliciano and the WTO Environmental Cases: Laying the Foundations of a Constitutional Jurisprudence with Implications for Developing Countries", in S. Charnovitz, D. Steger and P. Van den Bossche (eds.), Law in the service of human dignity, essays in honour of Florentino Feliciano, (Cambridge 2005), 29-43.

\section{Jackson 1969}

J.H. Jackson, World Trade and the Law of GATT, (Indianapolis 1969).

\section{Jog, Lenjosek and McKenzie 1996}

V.M. Jog, G.J. Lenjosek and K.J. McKenzie, "Flowthrough Shares: Premium-Sharing and Cost-Effectiveness", (1996) 44 Canadian Tax Journal, 1016-1051.

\section{Johnson 2008}

D.L. Johnson, "Electricity and the Environment - Current Trends and Future Directions", (2008) New Zealand Journal of Environmental Law, 195-232.

\section{Johnston et al. 2008}

A. Johnston, et al., “The Proposed New EU Renewables Directive”, (2008) European Energy and Environmental Law Review, 126-145. 
Judge, Bradley and Scully 1998

N.E. Judge, J.A. Bradley and M. Scully, FINAK 1998: Commentary on Both Finance Acts 1998, (Dublin 1998).

\section{Kamminga 1996}

C. Kamminga, "Environmental and Financial Implications of an Energy Tax-Subsidy Scheme: An Illustration for the Netherlands", (1996) 1 Environmental Tax \& Accounting, 53-61.

\section{Kelly 2005}

P.J. Kelly, "The Seduction of the Appellate Body: Shrimp/Sea Turtle I and II and the Proper Role of States in WTO Governance", (2005) 38 Cornell International Law Journal, 459-491.

\section{Klom 1997}

A.M. Klom, "Effects of Deregulation Policies on Electricity Competition in the EU", (1997) 15 Journal of Energy and Natural Resources Law, 1-22.

\section{Knoll 1989}

M.S. Knoll, "An Economic Approach to the Determination of Injury under United States Antidumping and Countervailing Duty Law", (1989) 22 N.Y.U. Journal of International Law and Politics, 37-115.

\section{Kramer and Sumner 1999}

S.M. Kramer and B.A. Sumner, "Electric Reliability in North America: Cross-Border Implications", (1999) 13 Natural Resources \& Environment, 81-86.

\section{Krishna 2006}

V. Krishna, The Fundamentals of Canadian Income Tax, $9^{\text {th }}$ ed., (Toronto 2006).

\section{Lakatos 2004}

A. Lakatos, "Overview of the Regulatory Environment for Trade in Electricity", in M. Desta and J. Bielecki (eds.), Electricity Trade in Europe Review of the Economic Changes, (The Hague 2004), 119-154.

\section{Lodefalk and Storey 2005}

M. Lodefalk and M. Storey, "Climate Measures and WTO Rules on Subsidies", (2005) 39 Journal of World Trade, 23-44.

\section{Lucas 1996}

A.R. Lucas, "Impact of Privatisation and Deregulation of Energy Industries on Canadian Environmental Law and Policy", (1996) 14 Journal of Energy and Natural Resources Law, 68-75.

\section{Luja 2003}

R.H.C. Luja, Assessment and Recovery of Tax incentives in the EC and the WTO: a View on State Aids, Trade Subsidies and Direct Taxation, (Antwerp 2003). 


\section{Luja 1999}

R.H.C. Luja, "WTO Agreements versus the EC Fiscal Aid Regime: Impact on Direct Taxation”, (1999) 27 Intertax, 207-225.

\section{Machado-Filho 2008}

H. Machado-Filho, "Climate Change and the International Trade of Biofuels", (2008) 2 Carbon \& Climate Law Review, 67-88.

\section{Macrory 2003}

R. Macrory, I. Havercroft and R. Purdy (eds.), Principles of EuropeanEnvironmental Law, (Groeningen 2004).

\section{Manning 2005}

D.J. Manning, "Session 7: Canada and U.S. Approaches to the Evolving North American Energy Relationship in the Aftermath of the 2003 Electricity Blackout: Market Forces vs. Government Regulation; U.S Speaker", (2005) 31 Canada-United States Law Journal, 227-236.

\section{Marceau and Trachtman 2002}

G. Marceau and J.P. Trachtman, "The Technical Barriers to Trade Agreement, the Sanitary and Phytosanitary Measures Agreement, and the General Agreement on Tariffs and Trade", (2002) 36 Journal of World Trade, 811-881.

\section{Margalioth 2007}

Y. Margalioth, "Not a Panacea for Economic Growth: The Case of Accelerated Depreciation", (2007) 26 Virginia Tax Review, 493-517.

\section{McGrady 2009}

B. McGrady, "Necessity Exceptions in WTO Law: Retreaded Tyres, Regulatory Purpose and Cumulative Regulatory Measures", (2009) 12 Journal of International Economic Law, 153-173.

\section{McKeever 2005}

G. McKeever, "Session 7: Canada and U.S. Approaches to the Evolving North American Energy Relationship in the Aftermath of the 2003 Electricity Blackout: Market Forces vs. Government Regulation; Canadian Speaker", (2005) 31 Canada-US Law Journal, 217-226.

\section{McMahon 2005}

J.A. McMahon, "The Agreement on Agriculture", in P.F.J. Macrory, A.E. Appleton and M.G. Plummer (eds.), The World Trade Organization: Legal, Economic and Political Analysis, vol. I, (New York 2005), 187-230.

\section{Meggiolaro and Vergano 2005}

F. Meggiolaro and P.R. Vergano, "Energy Services in the Current Round of WTO Negotiations", (2005) International Trade Law Report, 97-108. 


\section{Milne 2005}

J.E. Milne, "Harnessing the Wind: The Role of Tax Incentives as a Strand in the Reins", in H. Ashiabor, K. Deketelaere, L. Kreiser and J. Milne (eds.), Critical Issues in Environmental Taxation, vol. II, (Richmond 2005), 215-241.

\section{Mitchell and Tran 2009}

A. Mitchell and C. Tran, The Consistency of the EU Renewable Energy Directive with the WTO Agreements, Georgetown Law Faculty Working Papers, October 2009, available at: <http://scholarship.law.georgetown.edu/fwps_papers/119/>.

\section{Motaal 2008}

D.A. Motaal, “The Biofuels Landscape: Is There a Role for the WTO?”, (2008) 42 Journal of World Trade, 61-86.

\section{Murphy 2005}

G. Murphy, “Tax Reliefs: The Government's Review”, (2005) 37 Accountancy Ireland, 40-41.

\section{Murray and Rousslang 1989}

T. Murray and D.J. Rousslang, "A Method for Estimating Injury Caused by Unfair Trade Practices", (1989) 9 International Review of Law and Economics, 149-164.

\section{Ní Ghiollarnáth 2009}

C. Ní Ghiollarnáth, "Direct Fiscal Aid for Renewable Energy Development: A Positive Cue from the Commission?", in H. Ashiabor, K. Deketelaere, L. Kreiser and J. Milne (eds.), Critical Issues in Environmental Taxation, vol. VI, (Oxford 2009), 377-392.

O'Brien, Carey, Hoj and Woergoetter 2001

P. O'Brien, D. Carey, J. Hoj and A. Woergoetter, Encouraging Environmentally Sustainable Growth in Belgium, (2001) No. 300 OECD Economics Department Working Papers.

O'Connor and Forde 2003

J. O'Connor and E. Forde, "Why Ireland Remains Tax-Attractive", (2003) 14 International Tax Review, 39-42.

Ó'Gallachóir, Bazilian and McKeogh 2005

B.P. Ó'Gallachóir, M. Bazilian and E.J. McKeogh, "Wind Energy Policy Development in Ireland - A Critical Analysis', (2005) Proc. 11th Annual International Sustainable Development Research Conference.

\section{O’Mahony 2002}

G. O’Mahony, "Ireland Continues to Woo International Business", (2002) 13 International Tax Review, 43-44.

\section{O’Mahony 2001}

G. O’Mahony, "Ireland Maintains its Charm”, (2001) 12 International Tax Review, 3639. 
Ottinger and Jayne 2001-2002

R.L. Ottinger and M. Jayne, "Global Climate Change Kyoto Protocol Implementation: Legal Frameworks for Implementing Clean Energy Solutions", (2001-2002) 18 Pace Environmental Law Review, 19-86.

\section{Pardy 1998}

P. Pardy, "Answer is Blowing in the Wind", (1998) 30 Accountancy Ireland, 14-15.

\section{Paredis 2000}

E. Paredis, "De Ecologische belastinghervorming: achtergronden, mogelijkheden, beperkingen", (2000) Fiscale Actualiteit, 409-418.

\section{Parr 2000}

R. Parr, "Equity and the New Zealand Government Climate Change Domestic Policy Options Statement", (2000) 4 New Zealand Journal of Environmental Law, 49-79.

\section{Peel 2002}

J. Peel, "Confusing Product with Process: A Critique of the Application of ProductBased Tests to Environmental Process Standards in the WTO”, (2002) 10 New York University Environmental Law Journal, 217-342.

\section{Petersen 2009}

M. Petersen, "Restructuring the Electricity Sector in the EU and in Russia", (2009) European Energy and Environmental Law Review, 171-179.

\section{Piddington and Scrimgeour 2005}

K. Piddington and F. Scrimgeour, "Environmental Tax Reform in New Zealand: The Agenda", in H. Ashiabor, K. Deketelaere, L. Kreiser and J. Milne (eds.), Critical Issues in Environmental Taxation, vol. II, (Richmond 2005), 533-541.

\section{Prinsen 1998}

D.J. Prinsen, "De energie-investeringsaftrek: een wassen neus?", (1998) Weekblad Fiscaal Recht, 212-214.

\section{Quick and Lau 2003}

R. Quick and C. Lau, "The European Commission's Green Paper on Integrated Product Policy in Light of the 'Like Product'- and 'PPM'-Debates", (2003) 6 Journal of International Economic Law, 419-458.

\section{Rajamani 2008}

L. Rajamani, "From Berlin to Bali and Beyond: Killing Kyoto Softly", (2008) 57 International and Comparative Law Quarterly, 909-939.

\section{Redmond 2004}

M. Redmond, "Who is Really Exploiting Our Tax System?", (2004) 17 Irish Tax Review, 443-444. 


\section{Redmond and Thornton 2004}

M. Redmond and B. Thornton, FINAK 2004: Commentary on Finance Act 2004, (Dublin 2004).

\section{Richardson 1998}

B.J. Richardson, "Legislation and Treaty Notes Kyoto Protocol to the United Nations Framework Convention on Climate Change", (1998) 2 New Zealand Journal of Environmental Law, 249-262.

\section{Rubini 2009}

L. Rubini, The Definition of Subsidy and State Aid: WTO and EC Law in Comparative Perspective, (Oxford 2009).

\section{Sagemuller 2006}

I. Sagemuller, "Legislative and Policy Regime Governing the Generation of Wind Energy in New Zealand", (2006) 24 Journal of Energy and Natural Resources Law, 165208.

\section{Sanderson 1995}

C. Sanderson, "Reciprocity as a Condition Precedent to Canada-US Trade in Electricity”, (1995) 13 Journal of Energy and Natural Resources Law, 1-13.

\section{Schram Stokke 2004}

O. Schram Stokke, "Trade Measures and Compliance: Institutional Interplay Between WTO and the Marrakesh Accords", (2004) 4 International Environmental Agreements: Politics, Law and Economics, 339-357.

\section{Seinen 2005}

A.T. Seinen, "Staatssteun voor milieubescherming: uit-zondering op het verbod", (2005) 32 Milieu \& Recht, 66-71.

\section{Sereda 2000}

L. Sereda, "Renewable Energy - Tax Developments and Opportunities", (2000) 13 Canadian Petroleum Tax Journal, 105-122.

\section{Sim 2003}

K.K. Sim, "Rethinking the mandatory/discretionary legislation distinction in WTO jurisprudence", (2003) 2 World Trade Review, 33-64.

\section{Slemrod and Avi-Yonah 2001}

J. Slemrod and R. Avi-Yonah, "(How) Should Trade Agreements Deal with Income Tax Issues?”, (2001) 55 Tax Law Review, 533-554.

\section{Slocock 2007}

B. Slocock, "EC and WTO Subsidy Control Systems - Some Reflections", (2007) European State Aid Law Quarterly, 249-256. 


\section{Steiner 2000}

F. Steiner, Regulation, Industry Structure and Performance in the Electricity Supply Industry, OECD Economics Department Working Papers No. 238 (2000).

\section{Stevens and Pon 2002}

D.E. Stevens and J. Pon, "Taxes and the Environment: Tax Consequences of Emission-Reduction Regulations", in C.T. Foundation (ed.), Proceedings of the 54th Tax Conference, (Toronto 2002), 1-18.

\section{Stilwell and Bohanes 2005}

M. Stilwell and J. Bohanes, "Trade and the Environment", in P.F.J. Macrory, A.E. Appleton and M.G. Plummer (eds.), The World Trade Organization: Legal, Economic and Political Analysis, vol. II, (New York 2005), 511-570.

\section{Sykes 2005}

A.O. Sykes, "Subsidies and Countervailing Measures", in P.F.J. Macrory, A.E. Appleton and M.G. Plummer (eds.), The World Trade Organization: Legal, Economic and Political Analysis, vol. II, (New York 2005), 83-108.

\section{Sykes 2003}

A.O. Sykes, The Economics of WTO Rules on Subsidies and Countervailing Measures, (2003) John M. Olin Law \& Economics Working Paper No. 86 (2 $2^{\text {nd }}$ Series), available at: $<$ http://www.law.uchicago.edu/files/files/186.aos_ subsidies.pdf $>$.

\section{Sykes 1996}

A.O. Sykes, "The Economics of Injury in Antidumping and Countervailing Duty Cases", (1996) 16 International Review of Law and Economics, 5-26.

\section{Tarasofsky 2008}

R. Tarasofsky, "Heating up International Trade Law: Challenges and Opportunities Posed by Efforts to Combat Climate Change", (2008) 1 Carbon \& Climate Law Review, 7-17.

\section{Thorndike and Ventry 2002}

J.J. Thorndike and D.J. Ventry, Tax Justice: The Ongoing Debate, (Washington 2002).

\section{Trebilcock and Fishbein 2007}

M. Trebilcock and M. Fishbein, "International Trade: Barriers to Trade", in A.T. Guzman and A.O. Sykes (eds.), Research Handbook in International Economic Law, (Cheltenham 2007), 1-61.

\section{Ubachs 2004}

S. Ubachs, "Milieuvriendelijker kunnen we het niet maken", (2004) 31 Milieu \& Recht, 150-154.

\section{Van den Bossche 2008}

P. Van den Bossche, The Law and Policy of the World Trade Organization, 2 ${ }^{\text {nd }}$ ed., (Cambridge 2008). 
Van den Bossche, Schrijver and Gerrit 2007

P. Van den Bossche, N. Schrijver and F. Gerrit, Unilateral Measures Addressing NonTrade Concerns (The Hague 2007).

Vander Schueren and Mizulin 2005

P. Vander Schueren and N. Mizulin, "WTO Jurisprudence on Non-Agricultural Subsidies: New Developments", (2005) International Trade Law Report, 197-204.

\section{Van Hoorn 2009}

V. van Hoorn, "WTO Consistency and Border Implications for Europe 'Unbundling', 'Reciprocity' and the European Internal Energy Market: WTO Consistency and Broader Implications for Europe", (2009) European Energy and Environmental Law Review, 51-76.

\section{Vedder 2010}

H. Vedder, "The Treaty of Lisbon and European Environmental Law and Policy", (2010) Journal of Environmental Law, 285-299.

\section{Vermeend and Van der Vaart 1998}

W. Vermeend and J. van der Vaart, Greening Taxes: The Dutch Model, (The Hague 1998).

\section{Vermulst and Graafsma 2002}

E. Vermulst and V. Graafsma, WTO Disputes Anti-dumping Subsidies and Safeguards, (London 2002).

\section{Wälde and Gunst 2004}

T. Wälde and A. Gunst, "International Energy Trade and Access to Networks: the Case of Electricity", in M. Desta and J. Bielecki (eds.), Electricity Trade in Europe Review of the Economic and Regulatory Changes, (The Hague 2004), 179-212.

Wang and Liu 2006

X. Wang and J. Liu, "Some Considerations on Electricity in GATS", (2006) 3 USChina Law Review, 30-33.

\section{Woerdman 2002}

E. Woerdman, Implementing the Kyoto Mechanisms: Political Barriers and Path Dependence, (Groningen 2002).

\section{Wolf 2006}

L.G.T. Wolf, "Countervailing a Hidden Subsidy: The U.S. Failure to Require Greenhouse Gas Emission Reductions", (2006) 19 The Georgetown International Environmental Law Review, 83-115.

Ya Qin 2004

J. Ya Qin, "WTO Regulation of Subsidies to State-Owned Enterprises (SOEs) - A Critical Appraisal of the China Accession Protocol", (2004) 7 Journal of International Economic Law, 863-919. 


\section{Zarrilli 2004}

S. Zarrilli, "Multilateral Rules and Trade in Energy Goods and Services: the case of Electricity", in M. Desta and J. Bielecki (eds.), Electricity Trade in Europe Review of the Economic and Regulatory Changes, (The Hague 2004), 235-264.

\section{Zarrilli 2003}

S. Zarrilli, "Domestic Taxation of Energy Products and Multilateral Trade Rules: Is This a Case of Unlawful Discrimination?”, (2003) 37 Journal of World Trade, 359-394.

\section{Zhang 2005}

S. Zhang, "The Kyoto Protocol and International Trade Law", in G. van Calster and

K. Deketelaere (eds.), Energy and Environmental Law, (Leuven 2005), 24-40.

\section{Zhang and Line Carpentier 2007}

Z. Zhang and C. Line Carpentier, "Trade and the Environment in North America", (2007) 7 International Environmental Agreements: Politics, Law and Economics, 105-107.

\section{Zhou 2006}

Z. Zhou, "The Definition of Subsidies under the SCM Agreement", in M. Lang, J. Herdin and I. Hofbauer (eds.), The Relevance of WTO Law for Tax Matters, (Vienna 2006), 313-331.

\section{Zwemmer 1998}

J.W. Zwemmer, "Verschuiving door vergroening", (1998) Weekblad Fiscaal Recht, 1757-1758. 


\section{Curriculum Vitae}

Carol Ní Ghiollarnáth (Forde) was born in Galway, Ireland on 05 December 1980. Carol graduated with a Bachelor of Corporate Law from the National University of Ireland, Galway in 2003. In 2004, Carol graduated with an LL.M in International and European Law with a specialisation in European Law and Tax Regulation from the MIC Programme in Maastricht University. During her LL.M, Carol also worked as research assistant to Prof. dr. Peter Van den Bossche and participated in the Maastricht University team for the ELSA WTO Moot Court Competition which achieved the WTI award for the Best Written Pleading. Following her LL.M, Carol worked in the International and European Law Department of Maastricht University under the supervision of Prof. dr. Ellen Vos as a junior researcher on the European Commission $6^{\text {th }}$ Framework Project, SAFEFOODS. From September 2005 until March 2010, Carol worked as PhD researcher in the Tax Law Department of Maastricht University conducting research towards her $\mathrm{PhD}$, teaching Comparative Income Taxation at the Faculty of Economics and coaching award-winning moot court teams for the European Tax College International and European Tax Law Moot Court Competition and the ELSA WTO Moot Court Competition. 